\title{
MANUAL of GARDENING
}

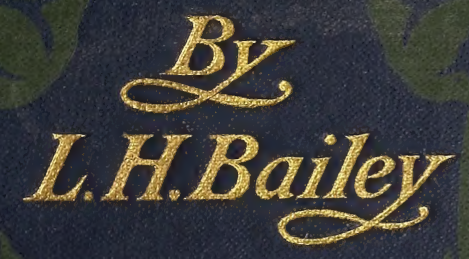


\% 
TU20. I. Arnos 

A MANUAL OF GARDENING 


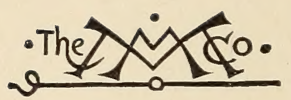

THE MACMILLAN COMPANY

NEW YORK - BOSTON - CHICAGO SAN FRANCISCO

MACMILLAN \& CO, Limited

LONDON - BOMBAY - CALCUTTA MELBOURNE

THE MACMILLAN CO. OF CANADA, LtD. TORONTO 


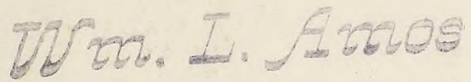




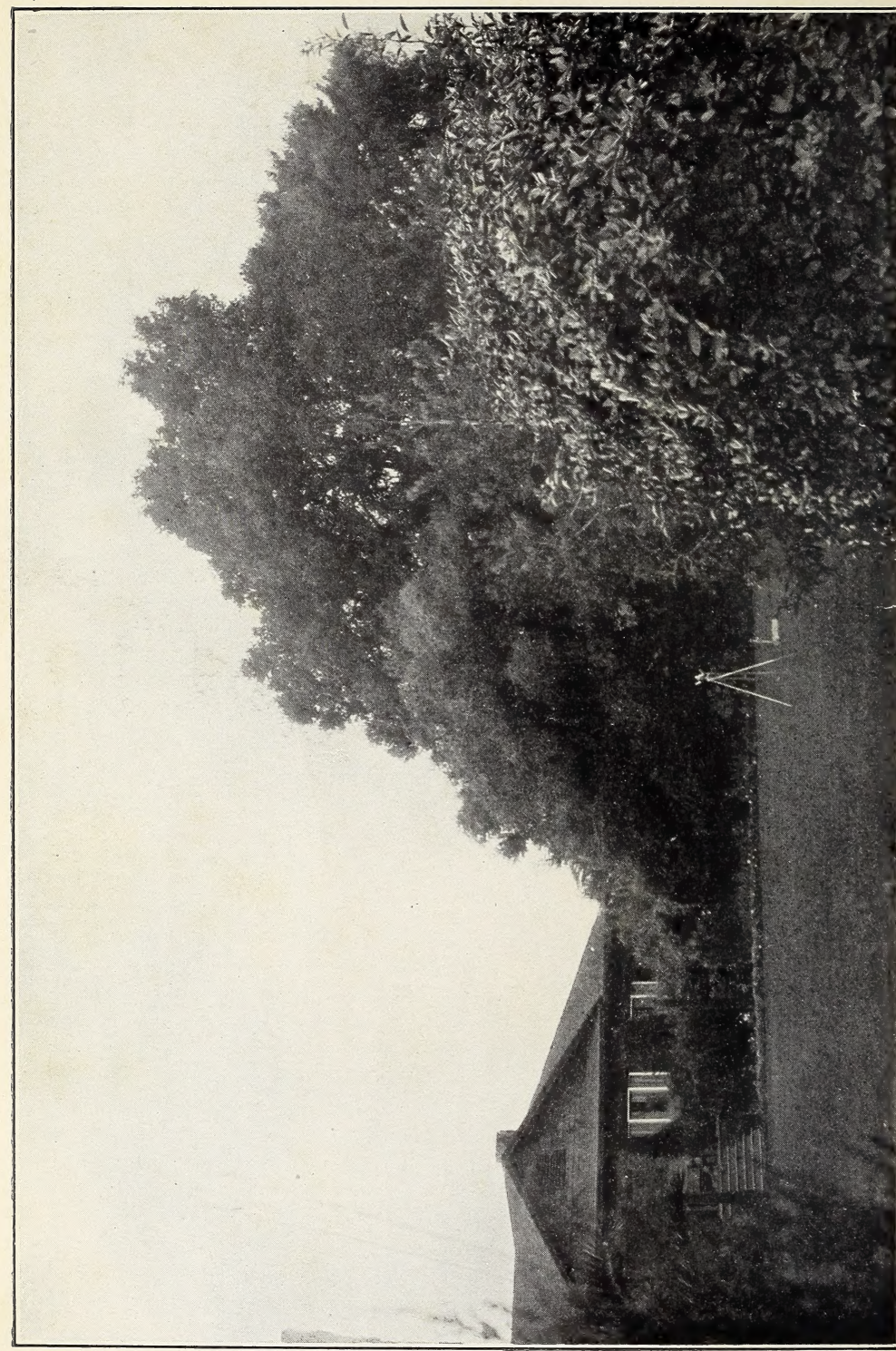

E 


\section{MANUAL OF GARDENING}

A PRACTICAL GUIDE

TO THE MAKING OF HOME GROUNDS AND THE GROWING OF FLOWERS, FRUITS, AND VEGETABLES FOR HOME USE

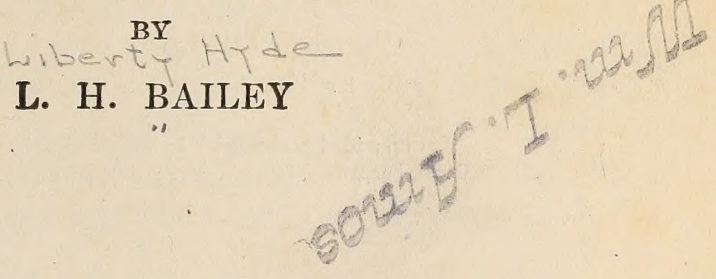

SECOND EDITION

Now Wark

THE MACMILLAN COMPANY

1912

All rights reserved 


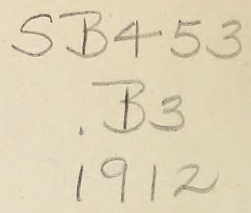

Copyright, 1910, BY THE MACMILLAN COMPANY.

Set up and electrotyped. Published March, Igro. Reprinted December, I9ıо ; March, IgII ; September, IgI2.

\section{in ischange \\ Uni of Macylard MAR I 31942}

Normoon 租ress

J. S. Cushing Co. - Berwick \& Smith Co. Norwood, Mass., U.S.A. 


\section{EXPLANATION}

IT has been my desire to reconstruct the two books, "GardenMaking" and "Practical Garden-Book"; but inasmuch as these books have found a constituency in their present form, it has seemed best to let them stand as they are and to continue their publication as long as the demand maintains itself, and to prepare a new work on gardening. This new work I now offer as "A Manual of Gardening." It is a combination and revision of the main parts of the other two books, together with much new material and the results of the experience of ten added years.

A book of this kind cannot be drawn wholly from one's own practice, unless it is designed to have a very restricted and local application. Many of the best suggestions in such a book will have come from correspondents, questioners, and those who enjoy talking about gardens; and my situation has been such that these communications have come to me freely. I have always tried, however, to test all such suggestions by experience and to make them my own before offering them to my reader. I must express my special obligation to those persons who collaborated in the preparation of the other two books, and whose contributions have been freely used in this one: to C. E. Hunn, a gardener of long experience; Professor Ernest Walker, reared as a commercial florist; Professor L. R. Taft and Professor F. A. Waugh, well known for their studies and writings in horticultural subjects. 
In making this book, I have had constantly in mind the home-maker himself or herself rather than the professional gardener. It is of the greatest importance that we attach many persons to the land; and I am convinced that an interest in gardening will naturally take the place of many desires that are much more difficult to gratify, and that lie beyond the reach of the average man or woman.

It has been my good fortune to have seen amateur and commercial gardening in all parts of the United States, and I have tried to express something of this generality in the book; yet my experience, as well as that of my original collaborators, is of the northeastern states, and the book is therefore necessarily written from this region as a base. One gardening book cannot be made to apply in its practice in all parts of the United States and Canada unless its instructions are so general as to be practically useless; but the principles and points of view may have wider application. While I have tried to give only the soundest and most tested advice, I cannot hope to have escaped errors and shortcomings, and I shall be grateful to my reader if he will advise me of mistakes or faults that he may discover. I shall expect to use such information in the making of subsequent editions.

Of course an author cannot hold himself responsible for failures that his reader may suffer. The statements in a book of this kind are in the nature of advice, and it may or it may not apply in particular conditions, and the success or failure is the result mostly of the judgment and carefulness of the operator. I hope that no reader of a gardening book will ever conceive the idea that reading a book and following it literally will make him a gardener. He must always assume his own risks, and this will be the first step in his personal progress.

I should explain that the botanical nomenclature of this book is that of the "Cyclopedia of American Horticulture," unless otherwise stated. The exceptions are the "trade 
names," or those used by nurserymen and seedsmen in the sale of their stock.

I should further explain the reason for omitting ligatures and using such words as peony, spirea, dracena, cobea. As technical Latin formularies, the compounds must of course be retained, as in Pceonia officinalis, Spircea Thunbergi, Draccena fragrans, Cobcea scandens; but as Anglicized words of common speech it is time to follow the custom of general literature, in which the combinations $æ$ and $œ$ have disappeared. This simplification was begun in the "Cyclopedia of American Horticulture" and has been continued in other writings.

ITHACA, NeW YoRK,

L. H. BAILEY.

January 20, 1910. 



\section{CONTENTS}

CHAPTER I

The Point of View

What a garden is

\section{CHAPTER II}

The General Plan or Theory of the Place • • • • . 6-60

The plan of the grounds . . . . . . • • • • 8

The picture in the landscape .. . . . . . . . . . . . 12

Birds; and cats . . . . . . . . . . 16

The planting is part of the design or picture . . . . . . 19

The flower-growing should be part of the design . . . . $\quad 27$

Defects in flower-growing . • . . . . . . 28

Lawn flower-beds . . . . . . . . . 29

Flower-borders . . . . . . . . . . 31

The old-fashioned garden . . . . . . . . 34

Contents of the flower-borders . . . . . . . 34

The value of plants may lie in foliage and form rather than in bloom . . . . . . . . . . . 37

Odd and formal trees . . . . . . . . 40

Poplars and the like . . . . . . . . 41

Plant-forms . . . . . . . . . . 43

Various specific examples..$\quad$. . . . . . . . 44

An example . . . . . . . . . . 45

Another example, . . . . . . . . . 47

A third example . . . . . . . . . 48

A small back yard . $. \quad . \quad . \quad . \quad . \quad . \quad .49$

A city lot . . . . . . . . . . 50

General remarks . . . . . . . . 54

Review . . . . . . . . . . . . 58

CHAPTER III

Execution of Sone of the Laxdscape Featcres • • . 61-86

The grading . . . . . . . . . . 61 
The terrace

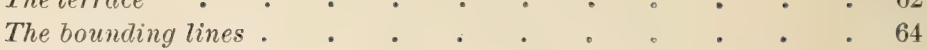

Walks and drives . . . . . . . . . . . . . 67

The question of drainage, curbing, and gutters $\quad$ • $\quad$. $\quad$. 69

The materials . . . . . . . . . 73

Making the borders . . . . . . . . . . . . . . 74

Making the lawn . . . . . . . . . . . . . . 77

Preparing the ground . . . . . . . . . 77

The kind of grass . . . . . . . . . . 78

When and how to sow the seed . . . . . 80

Securing a firm sod . . . . . . . . . 81

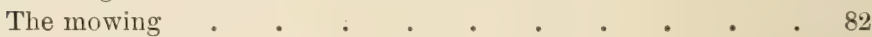

Fall treatment . . . . . . . . . . . . 82

Spring treatment . . . . . . . . . . . 83

Watering lawns . . . . . . . . . . . . . 83

Sodding the lawn . . . . . . . . . . 84

A combination of sodding and seeding . . . . . $\quad$. 85

Sowing with sod . . . . . . . . . . 86

Other ground covers . . . . . . . . . . . . . 86

CHAPTER IV

The Handling of the Land . . . . . . . 87-114

The draining of the land . . . . . . . . . . . . . . 88

Trenching and subsoiling . . . . . . . . . . . . 90

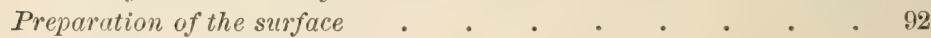

The saving of moisture . . . . . . . . . . . . . 97

Hand tools for weeding and subsequent tillage and other hand work 101

The hoe . . . . . . . . . . . 101

Scarifiers . . . . . . . . . . . 105

Hand-weeders . . . . . . . . . . . 106

Trowels and their kind . . . . . . . 106

Rollers . . . . . . . . 108

Markers . . . . . . . . . . 108

Enriching the land . . . . . . . . . 110

\section{CHAPTER V}

The Handling of the Plants . . . . . . . 115-177

Sowing the seeds . . . . . . . . . . . . 116

Propagating by cuttings . . . . . . . . . 118

Dormant stem-cuttings . . . . . . . . 118 
Cuttings of roots

Green cuttings .

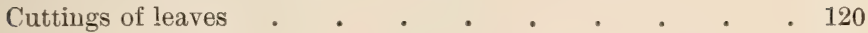

General treatment . . . . . . . . . . 121

Transplanting young seedlings . . . . . . . . . 122

Transplanting established plants and trees . . . . . . 124

Tub-plants . . . . . . . . . . 125

When to transplant . . . . . . . . . . . 126

Depth to transplant . . . . . . . . . 127

Making the rows straight . . . . . . . . . 127

Cutting-back ; filling. . . . . . . . . 129

Removing very large trees . . . . . . 130

Winter protection of plants . . . . . . . 135

Pruning . . . . . . . . . . . . 139

Tree surgery and protection . . . . . . . . . . 142

Tree guards . . . . . . . . . 143

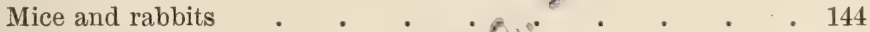

Girdled trees . . . . . . . 144

Repairing street trees . . . . . . . 145

The grafting of plants . . . . . . . . . . . 151

Keeping records of the plantation . . . . . . . . . 154

The storing of fruits and vegetables . . . . . . . 158

The forcing of plants .

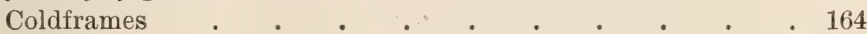

Hotbeds . . . . . . . . . . . . . 168

Management of hotbeds . . . . . . . . 175

\section{CHAPTER VI}

Protecting Plants from Things that Prey on Them

Screens and covers . . . . . . . . . . 186

Fumigating . . . . . . . . . . . . 188

Soaking tubers and seeds. . . . . . . . . . . . 190

Spraying . . . . . . . . . . . . 190

Insecticide spraying formulas . . . . . • • • . . 193

Fungicide spraying formulas . . . . . . . . . . 196

Treatment for some of the common insects . . . . . . . . 198

Treatment for some of the common plant diseases . . . . 207 


\section{CHAPTER VII}

The Growing of the Ornamental Plants - The Classes of Plants, and Lists . . . . . . . . 214-349 Planting for immediate effect . . . . . . . . . 215 The use of "foliage" trees and shrubs . . . . . . . 218 Windbreaks and screens . . . . . . . . . 219

The making of hedges . . • . . . . . . 220

The borders . . . . . . . . . . . 222

The flower-beds . . . . . . . . . . . 225

Bedding effects . . . . . . . . . . . . . 228

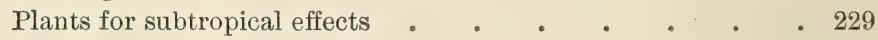
Aquatic and bog plants . . . . . . . . . . 230 Rockeries and alpine plants . . . . . . . . . 232

1. Plants for Carpet-beds . . . . . . . . . 234 Lists for carpet-beds . . . . . . . . . . 235

2. The Annual Plants . . . . . . . . . . 241 List of annuals by color of flowers . . . . . . . . . . 246 Useful annuals for edgings of beds and walks, and for ribbon-beds 248 Annuals that continue to bloom after frost . . . . . 248 List of annuals suitable for bedding (that is, for "mass-effects" of color) . . . . . . . . . . . . 249 List of annuals by height. . . . . . . . . 251 Distances for planting annuals . . . • • • • . 256

3. Hardy Herbaceous Perennials. . . . . . . 260 Perennial herbs suitable for lawn and "planting" effects . . 262 A brief seasonal flower-garden or border list of herbaceous perennials

One hundred extra-hardy perennial herbs

- 264

4. Bulbs and Tubers . . . . . . . . . . 281

Fall-planted bulbs. . . . . . . . . . . . . 281

List of outdoor fall-planted bulbs for the North . . . . . 288

Winter bulbs . . . . • • . • • • • . 289

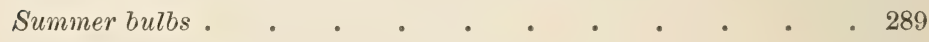

5. The Shrubbery . . . . . . . . . . 290

List of shrubbery plants for the North . . . . . . . 292

Shrubs for the South . . . . . . . . 305 
6. Climbing Plants . • . • • • . . 307 Annual herbaceous climbers . . . . . . . . . 310 Perennial herbaceous climbers . . . . . . 311 Woody perennial climbers . . . . . . . . . . 314 Climbing roses. . . . . . . . . . . . . 318

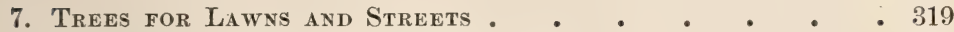
List of hardy deciduous trees for the North • • • • • 322 Non-coniferous trees for the South . • . . . . 330

8. Coniferous Evergreen Shrubs and Trees . • . 331 List of shrubby conifers . . . . . . . . . . 333 Arboreous conifers . . . . . . . . . . . 334

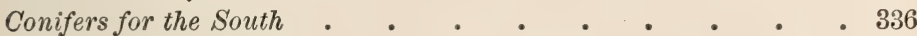

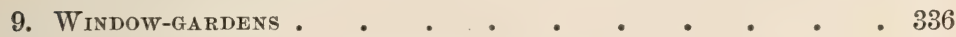
The window-box for outside effect . • . . . . 337 The inside window-garden, or "house plants" . . . . . 341 Bulbs in the windov-garden . . . . . . . . . 345 Watering house plants . . . . . . . . . 347 Hanging baskets . . . . . . . . . . . 348 Aquarium . . . . . . . . . . . 348

\section{CHAPTER VIII}

The Growing of the Ornamental Plants - Instructions on ParTICULAR KINDS • • . . . . . . . 350-407

Abutilons, 351; agapanthus, 351 ; alstremeria, 352 ; amaryllis, 352 ; anemone, 353 ; aralia, 354 ; araucaria, 354 ; auricula, 354; azaleas, 355 ; begonias, 356 ; cactus, 358 ; caladium, 359 ; calceolaria, 360 ; calla, 360 ; camellias, 361 ; cannas, 361 ; carnations, 363 ; century plants, 364 ; chrysanthemums, 365 ; cineraria, 367 ; clematis, 367.; coleus, 368 ; crocus, 368 ; croton, 369 ; cyclamen, 370 ; dahlia, 370 ; ferns, 372 ; freesia, 373 ; fuchsia, 373 ; geranium, 374 ; gladiolus, 374 ; gloxinia, 375 ; grevillea, 376 ; hollyhocks, 376 ; hyacinths, 377 ; iris, 378 ; lily, 378 ; lily-of-the-valley, 381 ; mignonette, 381 ; moon-flowers, 381 ; narcissus, 382 ; oleander, 383 ; oxalis, 384 ; palms, 384 ; pandanus, 385 ; pansy, 386 ; pelargonium, 386 ; peony, 387 ; phlox, 388 ; primulas, 389 ; rhododendrons, 390 ; rose, 391 ; smilax, 401 ; stocks, 402 ; sweet pea, 403 ; swainsona, 403; tuberose, 404; tulips, 405; violet, 406; wax plant, 407. 


\section{CHAPTER IX}

The Growing of the Fruit Plants . . . . . . 408-450

Dwarf fruit-trees . . . . . . . . . . 409

Age and size of trees . . . . . . . . . . 410

Pruning . . . . . . . . . . . . 411

Thinning the fruit . . . . . . . . . . . . 412

Washing and scrubbing the trees . . . . . . . 414

Gathering and keeping fruit . . . . . . . . 414

Almond, 415; apples, 416; apricot, 420 ; blackberry, 421; cherry, 422 ; cranberry, 424 ; currant, 425 ; dewberry, 426 ; fig, 426 ; gooseberry, 427 ; grape, 428; mulberry, 432 ; nuts, 433 ; orange, 433 ; peach, 435 ; pear, 437 ; plum, 439 ; quince, 442 ; raspberry, 443 ; strawberry, 445.

\section{CHAPTER $\mathrm{X}$}

The Growing of the Vegetable Plants .

The culture of the leading vegetables . . . . . . 461

Asparagus, 461; artichoke, 462; artichoke, Jerusalem, 463; bean, 463 ; beet, 466 ; broccoli, 467 ; brussels sprouts, 467 ; cabbage, 468 ; carrot, 471 ; cauliflower, 471 ; celeriac, 472 ; celery, 472 ; chard, 475 ; chicory , 476 ; chervil, 476 ; collards, 476 ; cives, 477 ; corn salad, 477 ; corn, 477 ; cress, 478 ; cucumber, 478 ; dandelion, 479 ; egg-plant, 480 ; endive, 481 ; garlic, 481 ; horseradish, 481 ; kale, 482 ; kohlrabi, 483 ; leek, 483 ; lettuce, 483 ; mushroom, 484 ; mustard, 487 ; muskmelon, 487 ; okra, 488 ; onion, 488 ; parsley, 490 ; parsnip, 490 ; pea, 490 ; pepper, 491 ; potato, 492 ; radish, 493 ; rhubarb, 493 ; salsify, 494 ; sea-kale, 495 ; sorrel, 495 ; spearmint, 495 ; spinach, 495 ; squash, 496 ; sweet-potato, 496 ; tomato, 497 ; turnips and rutabagas, 498 ; watermelon, 499.

\section{CHAPTER XI}

Seasonal Reminders For the North . For the South. 


\section{LIST OF PLATES}

PLATE

I. The open center . . . . . . . . Frontispiece

FACIYG PAGE

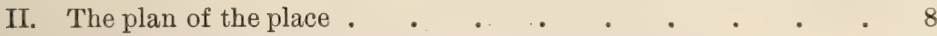

III. Open-center treatment in a semi-tropical country . . 18

IV. Subtropical bedding against a building. Caladiums, cannas, abutilons, permanent rhododendrons, and other large stuff, with tuberous begonias and balsams between . . . .

V. A subtropical bed. Center of cannas, with border of Pennisetum longistylum (a grass) started in late February or early March

VI. A tree that gives character to a place . $\quad . \quad . \quad . \quad . \quad$.

VII. Bedding with palms. If a bricked-up pit is made about the porch, pot palms may be plunged in it in spring and tub conifers in winter; and fall bulbs in tin cans (so that the receptacles will not split with frost) may be plunged among the evergreens

VIII. A well-planted entrance. Common trees and bushes, with Boston ivy on the post, and Berberis Thunbergii in front .

IX. A rocky bank covered with permanent informal planting . .

X. A shallow lawn pond, containing water-lilies, rariegated sweet flag, iris, and subtropical bedding at the rear; fountain covered with parrot's feather (Myriophyllum proserpinacoides)

XI. A back yard with summer house, and gardens beyond . .

XII. A back yard with heavy flower-garden planting . . . 271

XIII. The pageant of summer. Gardens of C. W. Dowdeswell, England, from a painting by Miss Parsons . . . . .

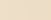

290

XIV. Virginia creeper screen, on an old fence, with wall-flowers and hollyhocks in front . . . . . . .

XV. Scuppernong grape, the arbor vine of the South. This plate shows the noted scuppernongs on Roanoke Island, of which the origin is unknown, but which were of great size more than one hundred years ago 
PLATE FACING PAGE

XVI. A flower-garden of China asters, with border of one of the dusty millers (Centaurea).

- 330

XVII. The peony. One of the most steadfast of garden flowers . 350

XVIII. Cornflower or bachelor's button. Centaurea Cyanus . . 370

XIX. Pyracantha in fruit. One of the best ornamental-fruited plants for the middle and milder latitudes . $\quad . \quad \therefore 390$

XX. A simple but effective window-box, containing geraniums, petunias, verbenas, heliotrope, and vines . . . 405

XXI. The king of fruits. Newtown as grown in the Pacific country 416

XXII. Wall-training of a pear tree . . . . . . . 4430

XXIII. Cherry currant . . . . . . . . . . 445

XXIV. Golden Bantam sweet corn . . . . . . . 477

XXV. The garden radish, grown in fall, of the usual spring sorts . 493 
A MANUAL OF GARDENING 



\section{MANUAL OF GARDENING}

\section{CHAPTER I}

\section{THE POINT OF VIEW}

Wherever there is soil, plants grow and produce their kind, and all plants are interesting; when a person makes a choice as to what plants he shall grow in any given place, he becomes a gardener or a farmer; and if the conditions are such that he cannot make a choice, he may adopt the plants that grow there by nature, and by making the most of them may still be a gardener or a farmer in some degree.

Every family, therefore, may have a garden. If there is not a foot of land, there are porches or windows. Wherever there is sunlight, plants may be made to grow; and one plant in a tin-can may be a more helpful and inspiring garden to some mind than a whole acre of lawn and flowers may be to another.

The satisfaction of a garden does not depend on the area, nor, happily, on the cost or rarity of the plants. It depends on the temper of the person. One must first seek to love plants and nature, and then to cultivate the happy peace of mind that is satisfied with little.

In the vast majority of cases a person will be happier if he has no rigid and arbitrary notions, for gardens are moodish, particularly with the novice. If plants grow and thrive, he should be happy; and if the plants that thrive chance not to be the ones that he planted, they are plants nevertheless, and nature is satisfied with them. 
We are wont to covet the things that we cannot have; but we are happier when we love the things that grow because they must. A patch of lusty pigweeds, growing and crowding in luxuriant abandon, may be a better and more worthy object of affection than a bed of coleuses in which every spark of life and spirit and individuality has been sheared out and suppressed. The man who worries morning and night about the dandelions in the lawn will find great relief in loving the dandelions. Each blossom is worth more than a gold coin, as it shines in the exuberant sunlight of the growing spring, and attracts the insects to its bosom. Little children like the dandelions: why may not we? Love the things nearest at hand; and love intensely. If I were to write a motto over the gate of a garden, I should choose the remark that Socrates is said to have made as he saw the luxuries in the market, "How much there is in the world that I do not want!"

I verily believe that this paragraph I have just written is worth more than all the advice with which I intend to cram the succeeding pages, notwithstanding the fact that I have most assiduously extracted this advice from various worthy but, happily, long-forgotten authors. Happiness is a quality of a person, not of a plant or a garden; and the anticipation of joy in the writing of a book may be the reason why so many books on garden-making have been written. Of course, all these books have been good and useful. It would be ungrateful, at the least, for the present writer to say otherwise; but books grow old, and the advice becomes too familiar. The sentences need to be transposed and the order of the chapters varied, now and then, or interest lags. Or, to speak plainly, a new book of advice on handicraft is needed in every decade, or perhaps oftener in these days of many publishers. There has been a long and worthy procession of these handbooks, Gardiner \& Hepburn, M'Mahon, Cobbett - original, pungent, versatile Cobbett! - Fessenden, Squibb, Bridgeman, Sayers, 
Buist, and a dozen more, each one a little richer because the others had been written. But even the fact that all books pass into oblivion does not deter another hand from making still another venture.

I expect, then, that every person who reads this book will make a garden, or will try to make one; but if only tares grow where roses are desired, I must remind the reader that at the outset I advised pigweeds. The book, therefore, will suit

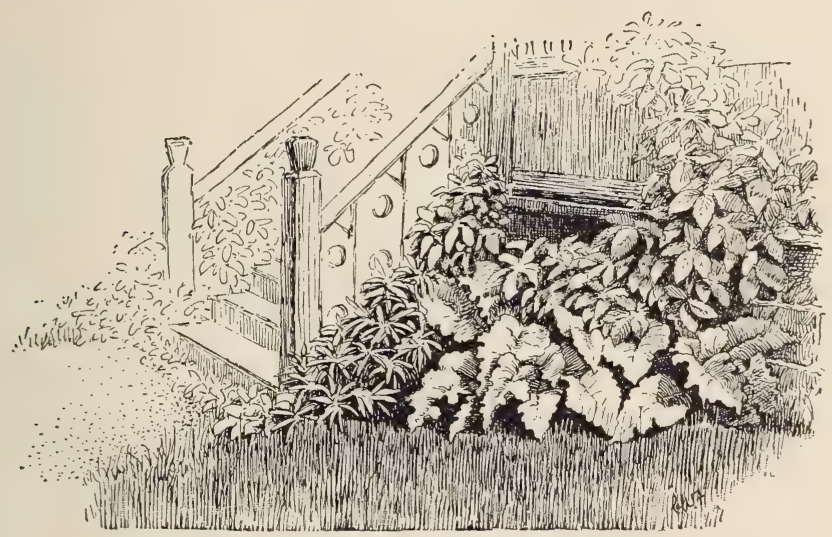

1. The ornamental burdock.

everybody, - the experienced gardener, because it will be a repetition of what he already knows; and the novice, because it will apply as well to a garden of burdocks as of onions.

What a garden is.

A garden is the personal part of an estate, the area that is most intimately associated with the private life of the home. Originally, the garden was the area inside the inclosure or lines of fortification, in distinction from the unprotected area or fields that lay beyond; and this latter area was the particular domain of agriculture. This book understands the garden to 
be that part of the personal or home premises devoted to ornament, and to the growing of vegetables and fruits. The garden, therefore, is an ill-defined demesne; but the reader must not make the mistake of defining it by dimensions, for one may have a garden in a flower-pot or on a thousand acres. In other words, this book declares that every bit of land that is not used for buildings, walks, drives, and fences, should be planted. What we shall plant - whether sward, lilacs, thistles, cabbages, pears, chrysanthemums, or tomatoes - we shall talk about as we proceed.

The only way to keep land perfectly unproductive is to keep it moving. The moment the owner lets it alone, the planting has begun. In my own garden, this first planting is of pigweeds. These may be followed, the next year, by ragweeds, then by docks and thistles, with here and there a start of clover and grass; and it all ends in June-grass and dandelions.

Nature does not allow the land to remain bare and idle. Even the banks where plaster and lath were dumped two or three years ago are now luxuriant with burdocks and sweet clover; and yet persons who pass those dumps every day say that they can grow nothing in their own yard because the soil is so poor! Yet I venture that those same persons furnish most of the pigweed seed that I use on my garden.

The lesson is that there is no soil - where a house would be built - so poor that something worth while cannot be grown on it. If burdocks will grow, something else will grow; or if nothing else will grow, then I prefer burdocks to sand and rubbish.

The burdock is one of the most striking and decorative of plants, and a good piece of it against a building or on a rough bank is just as useful as many plants that cost money and are difficult to grow. I had a good clump of burdock under my study window, and it was a great comfort; but the man would persist in wanting to cut it down when he mowed the lawn. When I 
remonstrated, he declared that it was nothing but burdock; but I insisted that, so far from being burdock, it was really Lappa major, since which time the plant and its offspring have enjoyed his utmost respect. And I find that most of my friends reserve their appreciation of a plant until they have learned its name and its family connections.

The dump-place that I mentioned has a surface area of nearly one hundred and fifty square feet, and I find that it has grown over two hundred good plants of one kind or another this year. This is more than my gardener accomplished on an equal area, with manure and water and a man to help. The difference was that the plants on the dump wanted to grow, and the imported plants in the garden did not want to grow. It was the difference between a willing horse and a balky horse. If a person wants to show his skill, he may choose the balky plant; but if he wants fun and comfort in gardening, he would better choose the willing one.

I have never been able to find out when the burdocks and mustard were planted on the dump; and I am sure that they were never hoed or watered. Nature practices a wonderfully rigid economy. For nearly half the summer she even refused rain to the plants, but still they thrived; yet I staid home from a vacation one summer that I might keep my plants from dying. I have since learned that if the plants in my hardy borders cannot take care of themselves for a time, they are little comfort to me.

The joy of garden-making lies in the mental attitude and in the sentiments. 


\section{CHAPTER II}

THE GENERAL PLAN OR THEORY OF THE PLACE

Having now discussed the most essential elements of gardening, we may give attention to such minor features as the actual way in which a satisfying garden is to be planned and executed.

Speaking broadly, a person will get from a garden what he puts into it; and it is of the first importance, therefore, that a clear conception of the work be formulated at the outset. I do not mean to say that the garden will always turn out what it was desired that it should be; but the failure to turn out properly is usually some fault in the first plan or some neglect in execution.

Sometimes the disappointment in an ornamental garden is a result of confusion of ideas as to what a garden is for. One of my friends was greatly disappointed on returning to his garden early in September to find that it was not so full and floriferous as when he left it in July. He had not learned the simple lesson that even a flower-garden should exhibit the natural progress of the season. If the garden begins to show ragged places and to decline in late August or early September, it is what occurs in all surrounding vegetation. The year is maturing. The garden ought to express the feeling of the different months. The failing leaves and expended plants are therefore to be looked on, to some extent at least, as the natural order and destiny of a good garden.

These attributes are well exhibited in the vegetable-garden. In the spring, the vegetable-garden is a model of neatness and 
precision. The rows are straight. There are no missing plants. The earth is mellow and fresh. Weeds are absent. One takes his friends to the garden, and he makes pictures of it. By late June or early July, the plants have begun to sprawl and to get out of shape. The bugs have taken some of them. The rows are no longer trim and precise. The earth is hot and dry. The weeds are making headway. By August and September, the garden has lost its early regularity and freshness. The camera is put aside. The visitors are not taken to it: the gardener prefers to go alone to find the melon or the tomatoes, and he comes away as soon as he has secured his product. Now, as a matter of fact, the garden has been going through its regular seasonal growth. It is natural that it become ragged. It is not necessary that weeds conquer it; but I suspect that it would be a very poor garden, and certainly an uninteresting one, if it retained the dress of childhood at the time when it should develop the personalities of age.

There are two types of outdoor gardening in which the progress of the season is not definitely expressed, - in the carpetbedding kind, and in the subtropical kind. I hope that my reader will get a clear distinction in these matters, for it is exceedingly important. The carpet-bedding gardening is the making of figure-beds in house-leeks and achyranthes and coleus and sanitalia, and other things that can be grown in compact masses and possibly sheared to keep them within place and bounds; the reader sees these beds in perfection in some of the parks and about florists' establishments; he will understand at once that they are not meant in any way to express the season, for the difference between them in September and June is only that they may be more perfect in September. The subtropical gardening (plates IV and V) is the planting out of house-grown stuff, in order to produce given effects, of such plants as palms, dracenas, crotons, caladiums, papyrus, together with such luxuriant things as dahlias and cannas and large 
ornamental grasses and castor beans; these plants are to produce effects quite foreign to the expression of a northern landscape, and they are usually at their best and are most luxuriant when overtaken by the fall frosts.

Now, the home gardener usually relies on plants that more or less come and go with the seasons. He pieces out and extends the season, to be sure; but a garden with pansies, pinks, sweet william, roses, sweet peas, petunias, marigolds, salpiglossis, sweet sultan, poppies, zinnias, asters, cosmos, and the rest, is a progress-of-the-season garden, nevertheless; and if it is a garden of herbaceous perennials, it still more completely expresses the time-of-year.

My reader will now consider, perhaps, whether he would have his garden accent and heighten his natural year from spring to fall, or whether he desires to thrust into his year a feeling of another order of vegetation. Either is allowable; but the gardener should distinguish at the outset.

I wish to suggest to my reader, also, that it is possible for the garden to retain some interest even in the winter months. I sometimes question whether it is altogether wise to clear out the old garden stems too completely and too smoothly in the fall, and thereby obliterate every mark of it for the winter months; but however this may be, there are two ways by which the garden year may be extended: by planting things that bloom very late in fall and others that bloom very early in spring; by using freely, in the backgrounds, of bushes and trees that have interesting winter characters.

\section{The plan of the grounds (see Plate II).}

One cannot expect satisfaction in the planting and developing of a home area unless he has a clear conception of what is to be done. This necessarily follows, since the pleasure that one derives from any enterprise depends chiefly on the definiteness of his ideals and his ability to develop them. The home- 


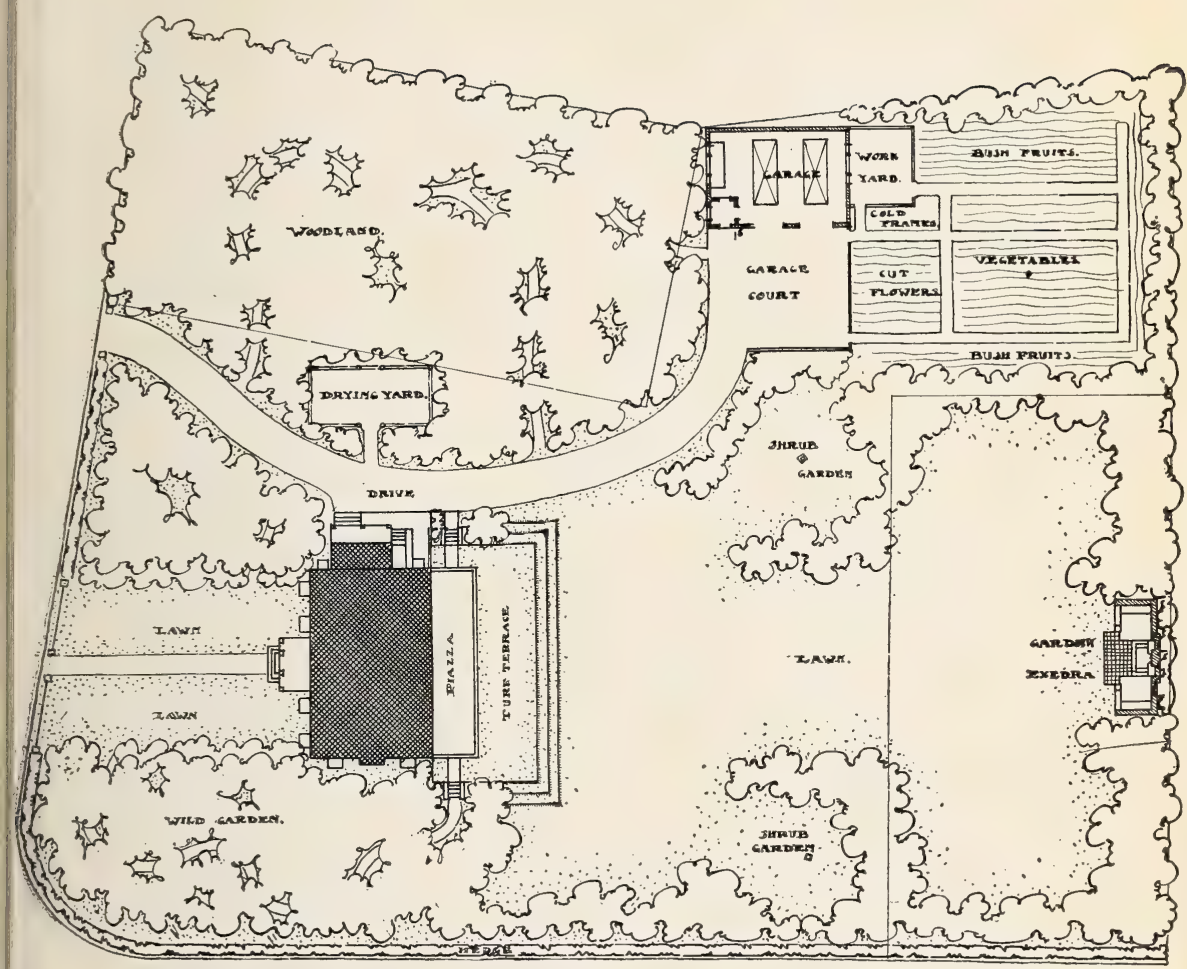

II. The plan of the place. The arrangement of the property (which is in New York) is determined by an existing woodland to the left or southeast of the house and a natural opening to the southwest of the house. The house is colonial, and the entire treatment is one of considerable simplicity. Wild or woodland gardens have been developed to the right and left of the entrance, the latter or entrance lawns being left severely simple and plain in their treatment. To the rear of the house a turf terrace raised three steps above the general grade of the lawn leads to a general lawn terminated by a small garden exedra or teahouse with a fountain in its center, and to two shrub gardens forming interesting and closed pockets of lawn. The stable and vegetable gardens are located to the south of the house in a natural opening in the woodland. The design is made by a professional landscape architect. 

maker should develop his plan before he attempts to develop his place. He must study the various subdivisions in order that the premises may meet all his needs. He should determine the locations of the leading features of the place and the relative importance to be given to the various parts of it, - as of the landscape parts, the ornamental areas, the vegetablegarden, and the fruit plantation.

The details of the planting may be determined in part as the place develops; it is only the structural features and purposes that need to be determined beforehand in most small properties. The incidental modifications that may be made in the planting from time to time keep the interest alive and allow the planter to gratify his desire to experiment with new plants and. new methods.

It must be understood that I am now speaking of ordinary home grounds which the home-maker desires to improve by himself. If the area is large enough to present distinct landscape features, it is always best to employ a landscape architect of recognized merit, in the same spirit that one would employ an architect. The details, however, may even then be filled in by the owner, if he is so inclined, following out the plan that the landscape architect makes.

It is desirable to have a definite plan on paper (drawn to scale) for the location of the leading features of the place. These features are the residence, the out-houses, the walks and drives, the service areas (as clothes yards), the border planting, flower-garden, vegetable-garden, and fruit-garden. It should not be expected that the map plan can be followed in every detail, but it will serve as a general guide; and if it is made on a large enough scale, the different kinds of plants can be located in their proper positions, and a record of the place be kept. It is nearly always unsatisfactory, for both owner and designer, if a plan of the place is made without a personal inspection of the area. Lines that look well on a map may not 
adjust themselves readily to the varying contours of the place itself, and the location of the features inside the grounds will depend also in a very large measure on the objects that lie

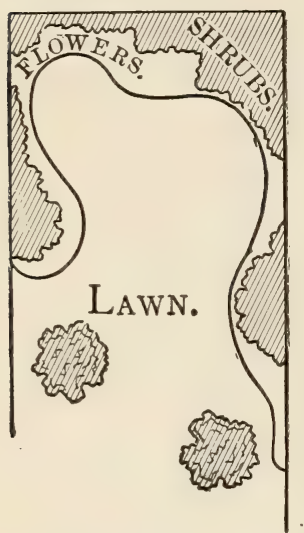

2. Diagram of a back yard.

outside it. For example, all interesting and bold views should be brought into the place, and all unsightly objects in the immediate vicinity should be planted out.

A plan of a back yard of a narrow city lot is given in Fig. 2, showing the heavy border planting of trees and shrubs, with the skirting border of flowers. In the front are two large trees, that are desired for shade. It will readily be seen from this plan how extensive the area for flowers becomes when they are placed along such a devious border. More color effect can be got from such an arrangement of the flowers than could be secured if the whole area were planted to flower-beds.

A contour map plan of a very rough piece of ground is shown in Fig. 3. The sides of the place are high, and it becomes necessary to carry a walk through the middle area; and on either side of the front, it skirts the banks. Such a plan is usually unsightly on paper, but may nevertheless fit special cases very well. The plan is inserted here for the purpose of illustrating the fact that a plan that will work on the ground does not necessarily work on a map.

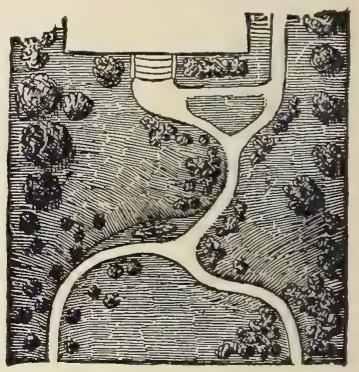

3. Plan of a rough area.

In charting a place, it is important to locate the points from which the walks are to start, and at which they are to emerge from the grounds. These two points are then joined by direct 
and simple curves; and alongside the walks, especially in angles or bold curves, planting may be inserted.

A suggestion for school premises on a four-corners, and which the pupils enter from three directions, is made in Fig. 4. The two playgrounds are separated by a broken group of bushes extending from the building to the rear boundary; but, in general, the spaces are kept open, and the heavy border-masses clothe the place and make it home-like. The lineal extent of the group margins is astonishingly large, and along all these margins flowers may be planted, if desired.

If there is only six feet between a schoolhouse and the fence, there is still room for a border of shrubs. This border should be between the walk and the
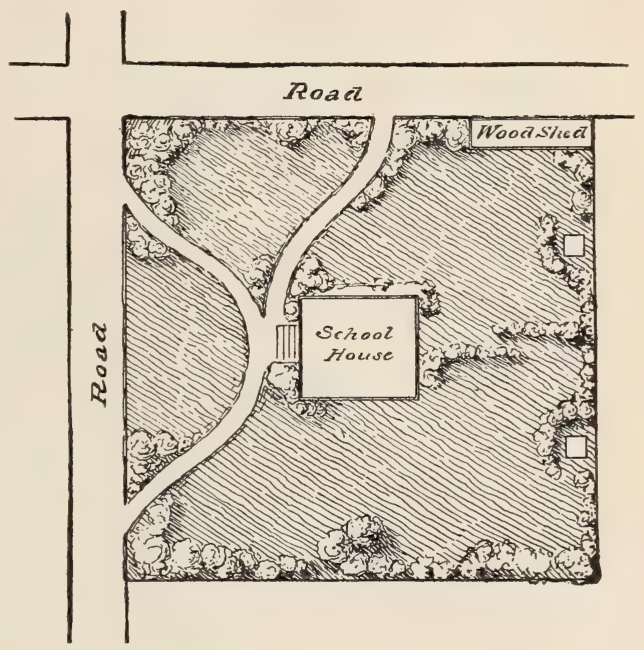

4. Suggestion for a school-ground on a fourcorners.

fence, - on the very boundary, - not between the walk and the building, for in the latter case the planting divides the premises and weakens the effect. A space two feet wide wibl allow of an irregular wall of bushes, if tall buildings do not cut out the light; and if the area is one hundred feet long, thirty to fifty kinds of shrubs and flowers can be grown to perfection, and the school-grounds will be practically no smaller for the plantation.

One eannot make a plan of a place until he knows what he 
wants to do with the property; and therefore we may devote the remainder of this chapter to developing the idea in the layout of the premises rather than to the details of map-making and planting.

Because I speak of the free treatment of garden spaces in this book it must not be inferred that any reflection is intended on the "formal" garden. There are many places in which the formal or "architect's garden" is much to be desired; but each of these cases should be treated wholly by itself and be made a part of the architectural setting of the place. These questions are outside the sphere of this book. All formal gardens are properly individual studies.

All very special types of garden design are naturally excluded from a book of this kind, such types, for example, as Japanese gardening. Persons who desire to develop these specialties will secure the services of persons who are skilled in them; and there are also books and magazine articles to which they may go.

\section{The picture in the landscape.}

The deficiency in most home grounds is not so much that there is too little planting of trees and shrubs as that this planting is meaningless. Every yard should be a picture. That is, the area should be set off from other areas, and it should have such a character that the observer catches its entire effect and purpose without stopping to analyze its parts. The yard should be one thing, one area, with every feature contributing its part to one strong and homogeneous effect.

These remarks will become concrete if the reader turns his eye to Figs. 5 and 6. The former represents a common type of planting of front yards. The bushes and trees are scattered promiscuously over the area. Such a yard has no purpose, no central idea. It shows plainly that the planter had no constructive conception, no grasp of any design, and no apprecia- 
tion of the fundamental elements of the beauty of landscape. Its only merit is the fact that trees and shrubs have been planted; and this, to most minds, comprises the essence and sum of the ornamentation of grounds. Every tree and bush is an individual alone, unattended, disconnected from its environments, and, therefore, meaningless. Such a yard is only a nursery.

The other plan (Fig. 6) is a picture. The eye catches its meaning at once. The central idea is
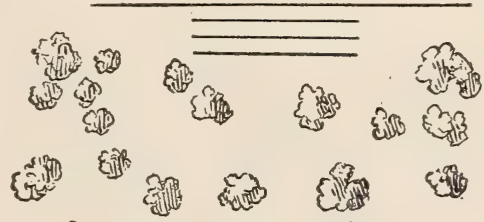
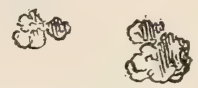

5. The common or nursery way of planting.

the residence, with a free and open greensward in front of it. The same trees and bushes that were scattered haphazard over Fig. 5 are massed into a framework to give effectiveness to the picture of home and comfort. This style of planting makes a landscape, even though the area be no larger than a parlor. The other style is only a collection of curious plants. The one

6. The proper or pictorial type of planting.

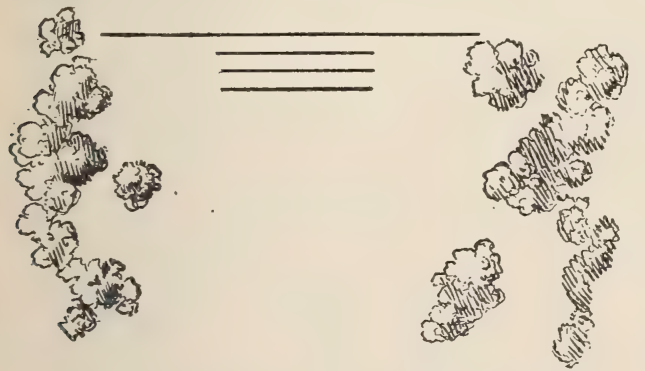

has an instant and abiding pictorial effect, which is restful and satisfying: the observer exclaims, "What a beautiful home this is!" The other piques one's curiosity, obscures the residence, divides and distracts the attention: the observer exclaims, "What excellent lilac bushes are these !"

An inquiry into the causes of the unlike impressions that one receives from a given landscape and from a painting of it 
explains the subject admirably. One reason why the picture appeals to us more than the landscape is because the picture is condensed, and the mind becomes acquainted with its entire purpose at once, while the landscape is so broad that the individual objects at first fix the attention, and it is only by a process of synthesis that the unity of the landscape finally becomes apparent. This is admirably illustrated in photographs. One of the first surprises that the novice experiences in the use of the camera is the discovery that very tame scenes become interesting and often even spirited in the photograph. But there is something more than mere condensation in this vitalizing and beautifying effect of the photograph or the painting: individual objects are so much reduced that they no longer appeal to us as distinct subjects, and however uncouth they may be in the reality, they make no impression in the picture; the thin and sere sward may appear rather like a closely shaven lawn or a new-mown meadow. And again, the picture sets a limit to the scene; it frames it, and thereby cuts off all extraneous and confusing or irrelevant landscapes.

These remarks are illustrated in the æsthetics of landscape gardening. It is the artist's one desire to make pictures in the landscape. This is done in two ways: by the form of plantations, and by the use of vistas. He will throw his plantations into such positions that open and yet more or less confined areas of greensward are presented to the observer at various points. This picture-like opening is nearly or quite devoid of small or individual objects, which usually destroy the unity of such areas and are meaningless in themselves. A vista is a narrow opening or view between plantations to a distant landscape. It cuts up the broad horizon into portions that are readily cognizable. It frames parts of the country-side. The verdurous sides of the planting are the sides of the frame; the foreground is the bottom, and the sky is the top. It is of the utmost importance that good views be left or secured from the best windows of the house 
(not forgetting the kitchen window); in fact, the placing of the house may often be determined by the views that may be appropriated.

If a landscape is a picture, it must have a canvas. This canvas is the greensward. Upon this, the artist paints with tree and bush and flower as the painter does upon his canvas with brush and pigments. The opportunity for artistic composition and design is nowhere so great as in the landscape garden, because no other art has such a limitless field for the expression of its emotions. It is not strange, if this be true, that there have been few great landscape gardeners, and that, falling short of art, the landscape gardener too often works in the sphere of the artisan. There can be no rules for landscape gardening, any more than there can be for painting or sculpture. The operator may be taught how to hold the brush or strike the chisel or plant the tree, but he remains an operator; the art is intellectual and emotional and will not confine itself in precepts.

The making of a good and spacious lawn, then, is the very first practical consideration in a landscape garden.

The lawn provided, the gardener conceives what is the dominant and central feature in the place, and then throws the entire premises into subordination to this feature. In home grounds this central feature is the house. To scatter trees and bushes over the area defeats the fundamental purpose of the place, the purpose to make every part of the grounds lead up to the home and to accentuate its homelikeness.

A house must have a background if it is to become a home. A house that stands on a bare plain or hill is a part of the universe, not a part of a home. Recall the cozy little farm-house that is backed by a wood or an orchard; then compare some pretentious structure that stands apart from all planting. Yet how many are the farm-houses that stand as stark and cold against the sky as if they were competing with the moon! We would not believeit possible for a man to live in a house twenty-five years and 
not, by accident, allow some tree to grow, were it not that it is so!

Of course these remarks about the lawn are meant for those countries where greensward is the natural ground cover. In the South and in arid countries, greensward is not the prevailing feature of the landscape, and in these regions the landscape design may take on a wholly different character, if the work is to be nature-like. We have not yet developed other conceptions of landscape work to any perfect extent, and we inject the

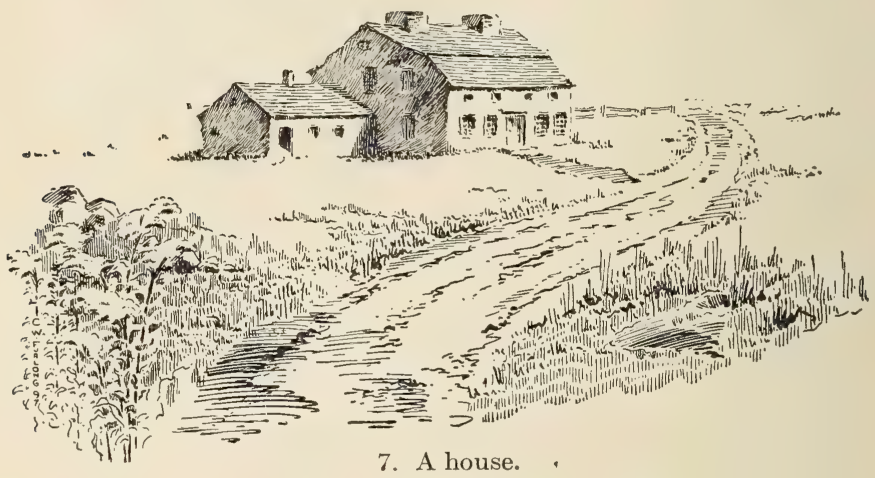

English greensward treatment even into deserts. $\mathrm{W}$ e may look for the time when a brown landscape garden may be made in a brown country; and it may be good art not to attempt a broad open center in regions in which undergrowth rather than sod is the natural ground cover. In parts of the United States we are developing a good Spanish-American architecture; perhaps we may develop a recognized comparable landscape treatment as an artistic expression.

Birds; and cats.

The picture in the landscape is not complete without birds, and the birds should comprise more species than English 
sparrows. If one is to have birds on his premises, he must (1) attract them and (2) protect them.

One attracts birds by providing places in which they may nest. The free border plantings have distinct advantages in attracting chipping sparrows, catbirds, and other species. The bluebirds, house wrens, and martins may be attracted by boxes in which they can build.

One may attract birds by feeding them and supplying water. Suet for woodpeckers and others, grain and crumbs for other

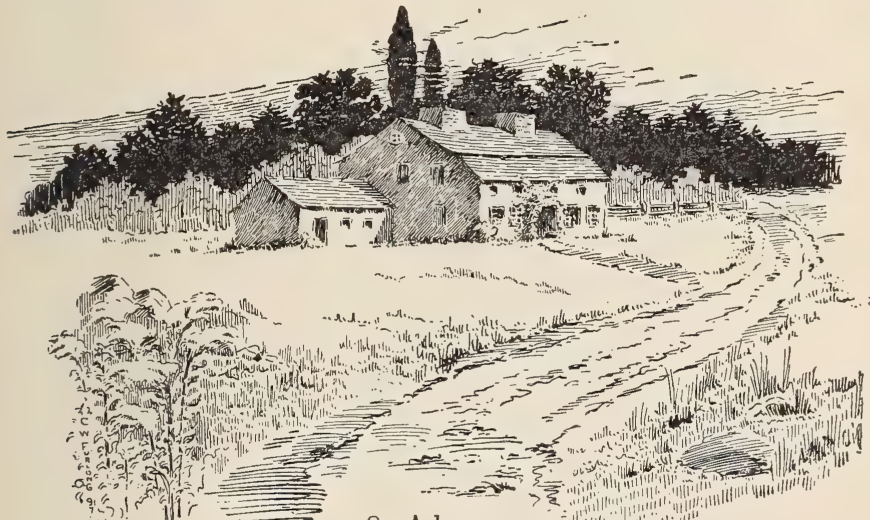

8. A home.

kinds, and taking care not to frighten or molest them, will soon win the confidence of the birds. A slowly running or dripping fountain, with a good rim on which they may perch, will also attract them; and it is no mean enjoyment to watch the birds at bathing. Or, if one does not care to go to the expense of a bird fountain, he may supply their wants by means of a shallow dish of water set on the lawn.

The birds will need protection from cats. There is no more reason why cats should roam at will and uncontrolled than that dogs or horses or poultry should be allowed unlimited license. A cat away from home is a trespasser and should be so treated. 
A person has no more right to inflict a cat on a neighborhood than to inflict a goat or rabbits or any other nuisance. All persons who keep cats should feel the same responsibility for them that they feel for other property; and they should be willing to forfeit their property right when they forfeit their control. The cats not only destroy birds, but they break the peace. The caterwauling at night will not be permitted in well-governed communities any more than the shooting of fire-arms or vicious talking will be allowed: all night-roaming cats should be gathered in, just as stray dogs and tramps are provided for.

I do not dislike cats, but I desire to see them kept at home and within control. If persons say that they cannot keep them on their own premises, then these persons should not be allowed to have them. A bell on the cat will prevent it from capturing old birds, and this may answer a good purpose late in the season; but it will not stop the robbing of nests or the taking of young birds, and here is where the greatest havoc is wrought.

It is often asserted that cats must roam in order that rats and mice may be reduced; but probably few house mice and few rats are got by wandering cats ; and, again, many cats are not mousers. There are other ways of controlling rats and mice; or if cats are employed for this purpose, see that they are restricted to the places where the house rats and mice are to be found.

Many persons like squirrels about the place, but they cannot expect to have both birds and squirrels unless very special precautions are taken.

The English or house sparrow drives away the native birds, although he is himself an attractive inhabitant in winter, particularly where native birds are not resident. If one desires to keep English sparrows in reduced numbers, it can be easily accomplished by poisoning them in winter (when other birds are not endangered) with wheat soaked in strychnine water. The contents of one of the eighth-ounce vials of strych- 


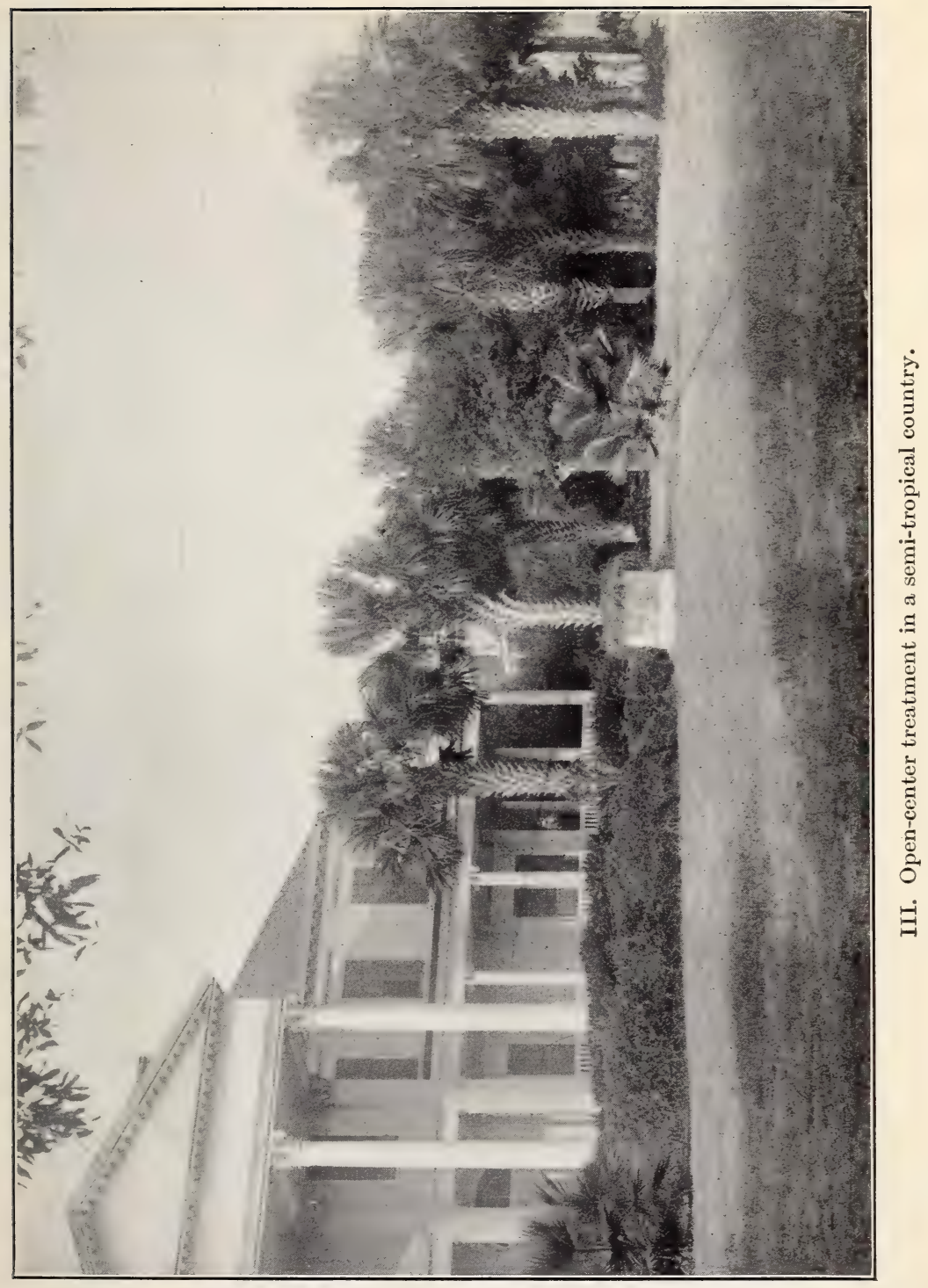



nine that may be secured at a drug store is added to sufficient water to cover a quart of wheat. Let the wheat stand in the poison water twenty-four to forty-eight hours (but not long enough for the grains to sprout), then dry the wheat thoroughly. It cannot be distinguished from ordinary wheat, and sparrows usually eat it freely, particularly if they are in the habit of eating scattered grain and crumbs. Of course, the greatest caution must be exercised that in the use of such highly poisonous materials, accidents do not occur with other animals or with human beings.

The planting is part of the design or picture.

If the reader catches the full meaning of these pages, he has acquired some of the primary conceptions in landscape gardening. Thesuggestion will grow upon him day by day; and if he is of an observing turn of mind, he will find that this simple lesson will revolutionize his habit of thought respecting the planting of grounds and the beauty of landscapes. He will see that a bush or flower-bed that is no part of any general purpose or design that is, which does not contribute to the making of a picture - might better never have been planted. For myself, I would rather have a bare and open pasture than such a yard as that shown in Fig. 9, even though it contained the choicest plants of every land. The pasture would at least be plain and restful and unpretentious; but the yard would be full of effort and fidget.

Reduced to a single expression, all this means that the greatest artistic value in planting lies in the effect of the mass, and not in the individual plant. A mass has the greater value because it presents a much greater range and variety of forms, colors, shades, and textures, because it has sufficient extent or dimensions to add structural character to a place, and because its features are so continuous and so well blended that the mind is not distracted by incidental and irrelevant ideas. Two 


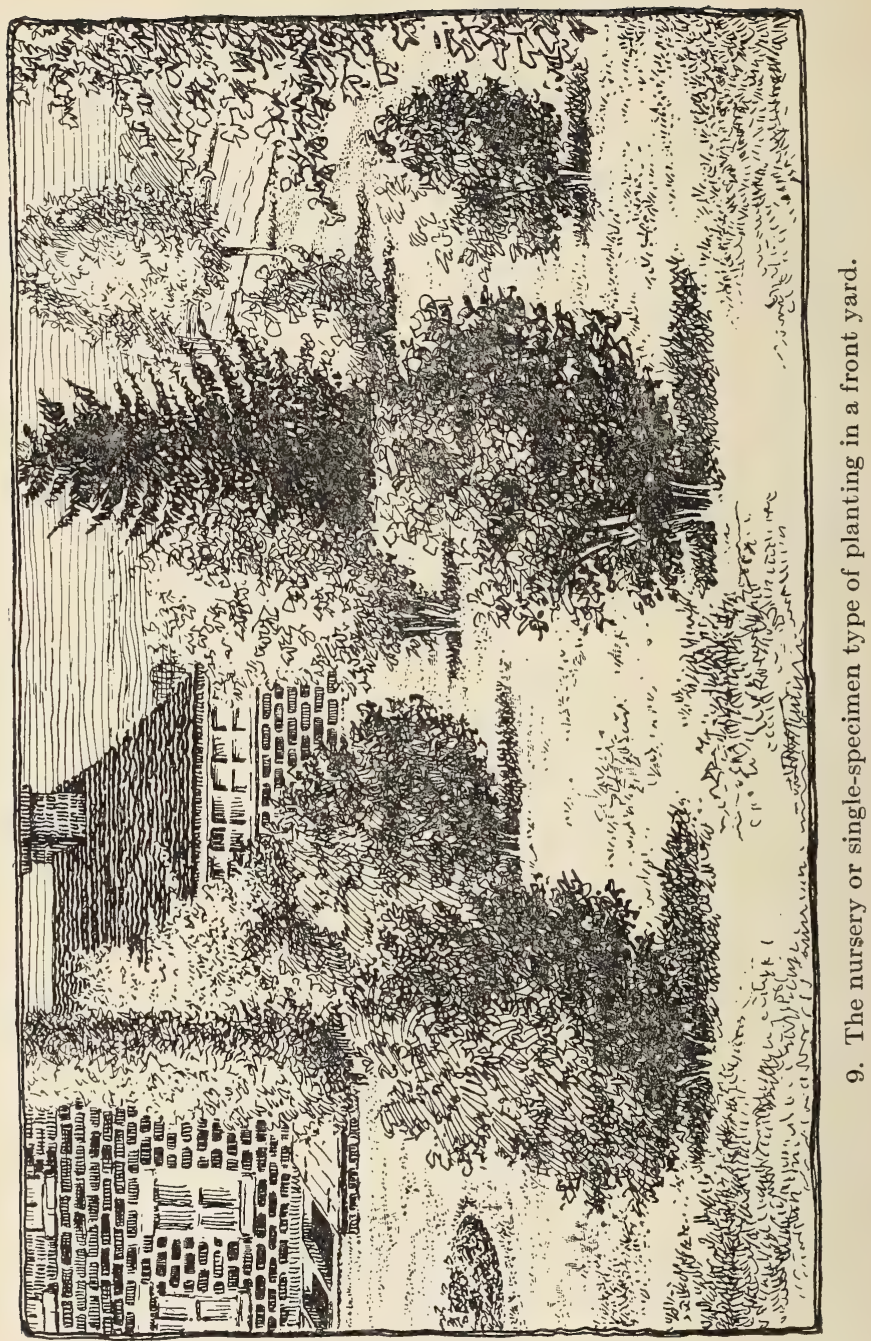


pictures will illustrate all this. Figures 10, 11 are pictures of natural copses. The former stretches along a field and makes a

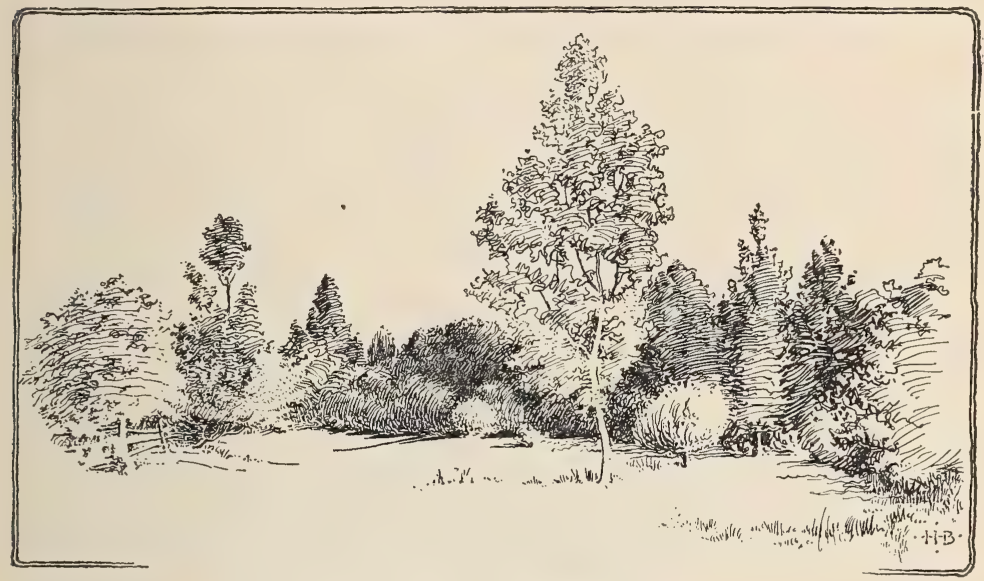

10. A native fence-row.

lawn of a bit of meadow which lies in front of it. The landscape has become so small and so well defined by this bank of verdure that it has a familiar and personal feeling. The great, bare, open meadows are too ill-defined and too extended to give any domestic feeling; but here is a part of the meadow set off into an area that one can compass with his affections.

These masses in Figs. 10, 11, and 12 have their own intrin-

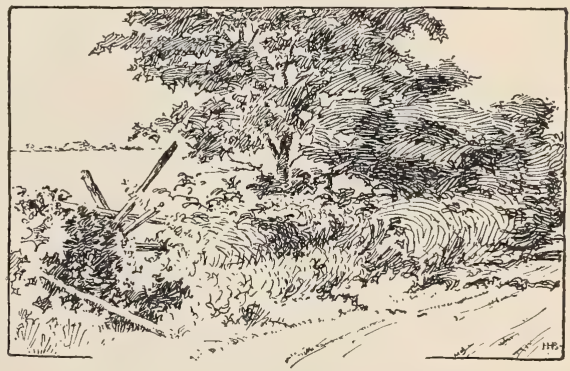

11. Birds build their nests here. sic merits, as well as their office in defining a bit of nature. One is attracted by the freedom of arrangement, the irregularity of 


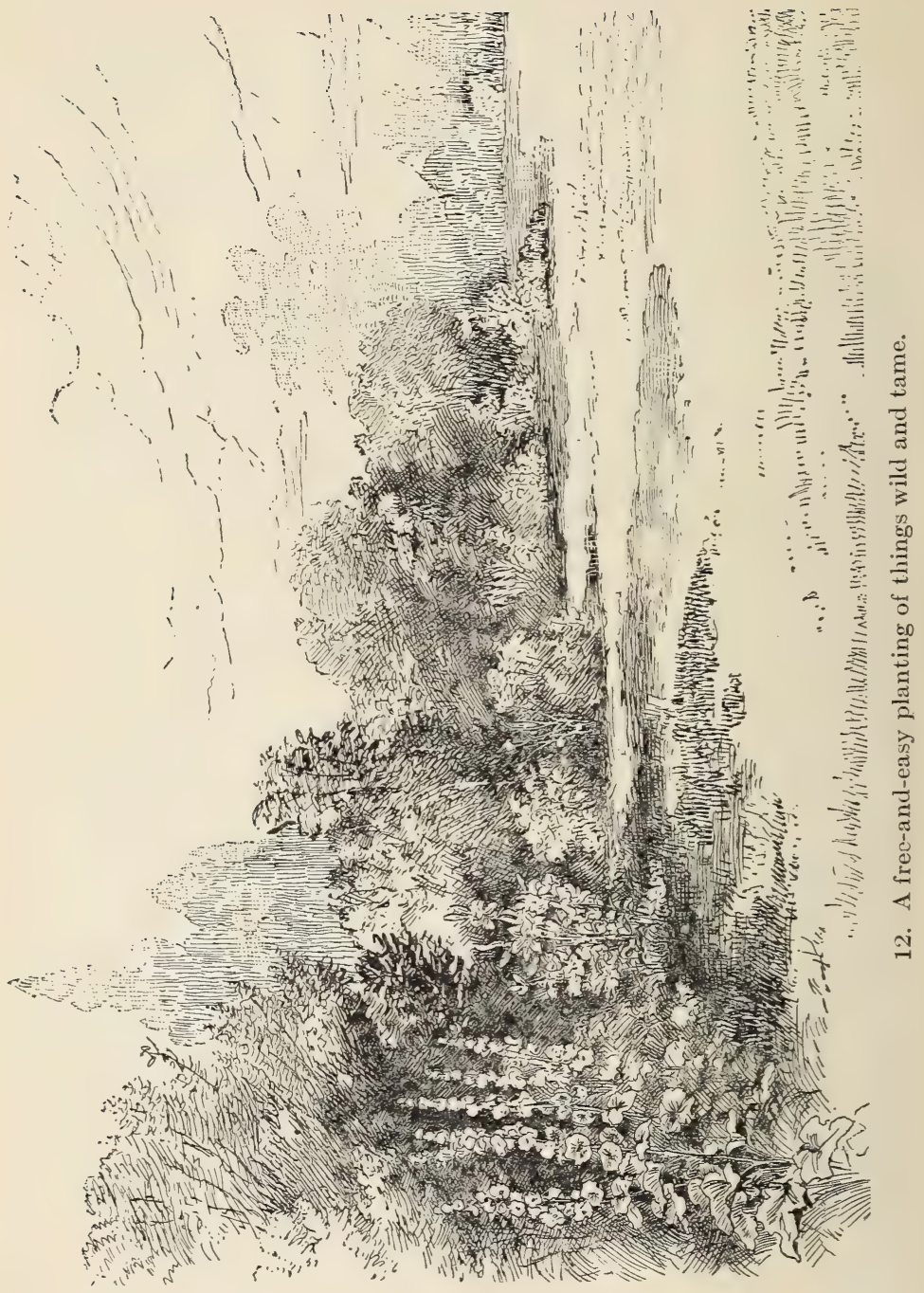


sky-line, the bold bays and promontories, and the infinite play of light and shade. The observer is interested in each because it has character, or features, that no other mass in all the world possesses. He knows that the birds build their nests in the tangle and the rabbits find it a covert.

Now let the reader turn to Fig. 9, which is a picture oî an "improved" city yard. Here there is no structural outline to the planting, no defining of the area, no continuous flow of the

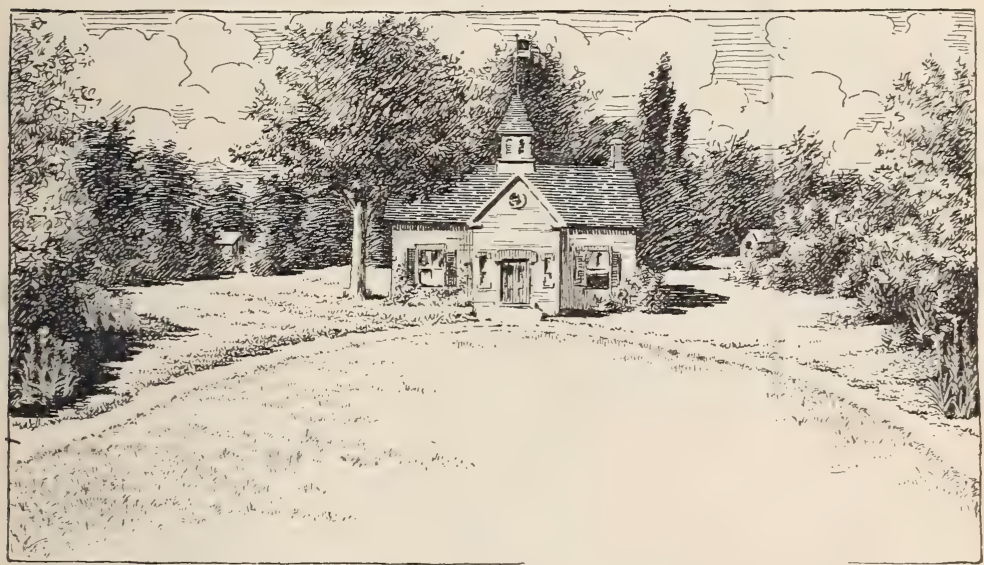

13. An open treatment of a school-ground. More trees might be placed in the area, if desired.

form and color. Every bush is what every other one is or may be, and there are hundreds like them in the same town. The birds shun them. Only the bugs find any happiness in them. The place has no fundamental design or idea, no lawn upon which a picture may be constructed. This yard is like a sentence or a conversation in which every word is equally emphasized.

In bold contrast with this yard is the open-center treatment in Fig. 13. Here there is pictorial effect; and there is opportu- 
nity along the borders to distribute trees and shrubs that may be desired as individual specimens.

The motive that shears the trees also razes the copse, in order that the gardener or "improver" may show his art. Compare

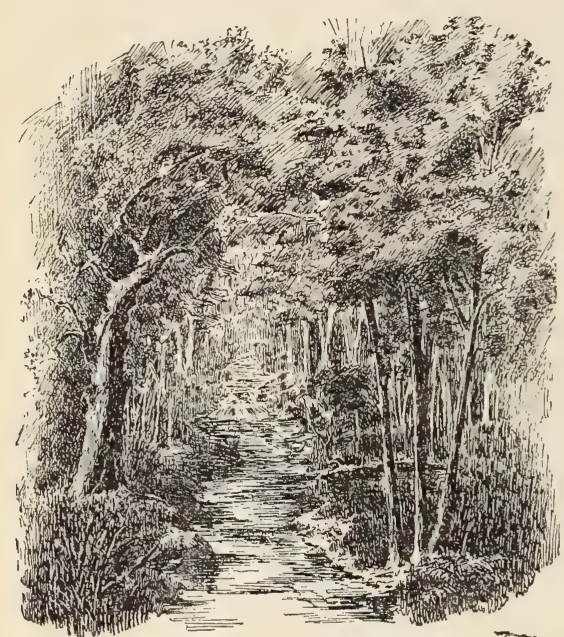

Figs. 14 and 15. Many persons seem to fear that they will never be known to the world unless they expend a great amount of muscle or do something emphatic or spectacular; and their fears are usually well founded.

It is not enough that trees and bushes be planted in masses. They must be kept in masses by letting

14. A rill much as nature made it.

them grow freely in a natural way. The pruningknife is the most inveterate enemy of shrubbery. Pictures 16 and 17 illustrate what I mean. The former represents a good group of bushes so far as arrangement is concerned, but it has been ruined by the shears. The attention of

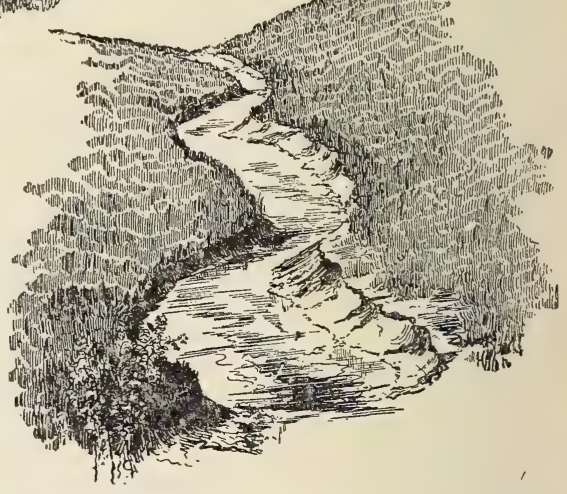

15. A rill "improved," so that it will not look "ragged" and unkempt. the observer is instantly arrested by the individual bushes. Instead of one free and expressive object, there are several stiff 
and expressionless ones. If the observer stops to consider his own thoughts when he comes upon such a collection, he will

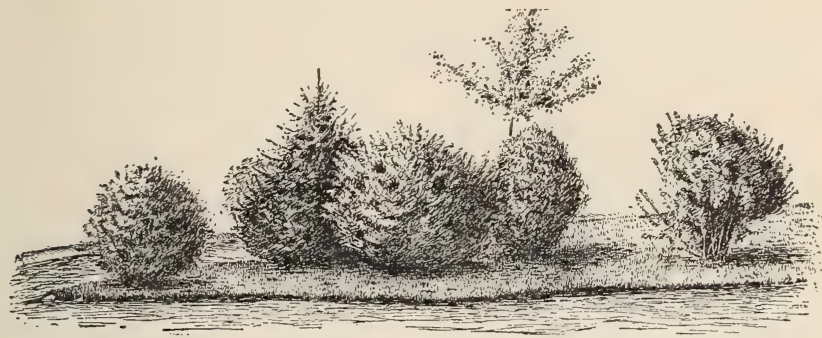

16. The making of a good group, but spoiled by the pruning shears.

likely find himself counting the bushes; or, at least, he will be making mental comparisons of the various bushes, and

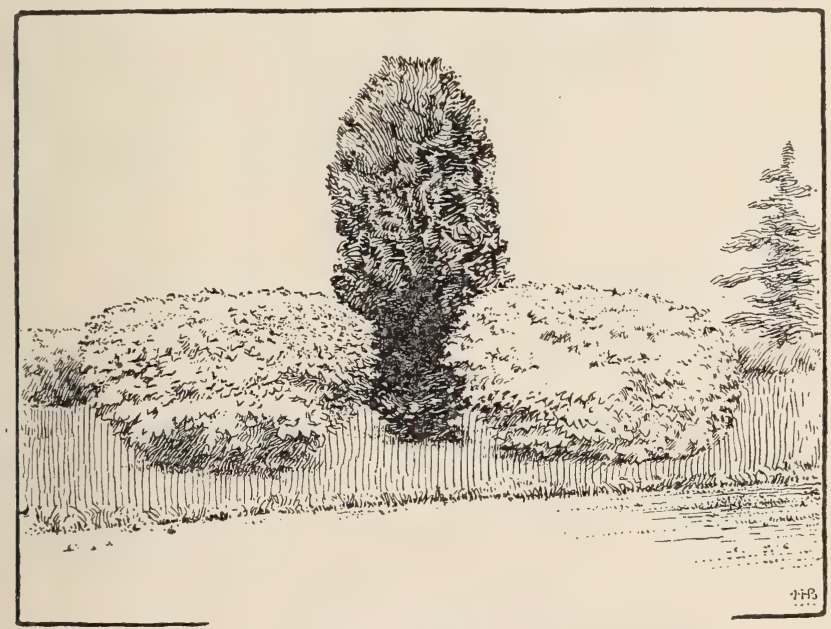

17. The three guardsmen.

wondering why they are not all sheared to be exactly alike. Figure 17 shows how the same "artist" has treated two deut- 
zias and a juniper. Much the same effect could have been secured, and with much less trouble, by laying two flour barrels end to end and standing a third one between them.

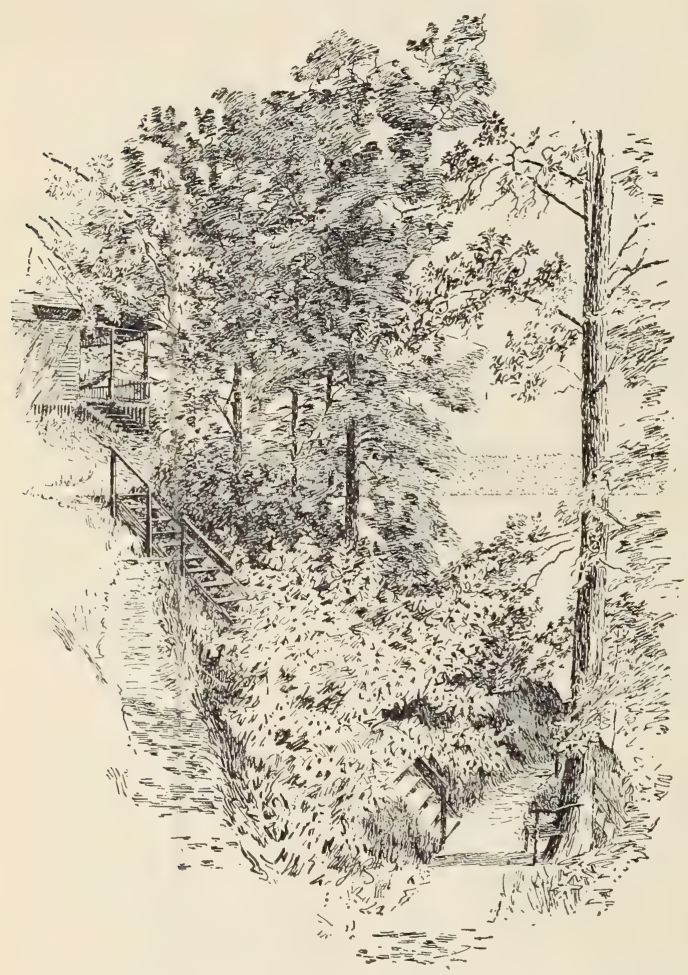

18. A bit of semi-rustic work built into a native growth.

I must hasten to say that I have not the slightest objection to the shearing of trees. The only trouble is in calling the practice art and in putting the trees where people must see them (unless they are part of a recognized formal-garden design). If the operator simply calls the business shearing, and puts the things where he and others who like them may see them, objection could not be raised. Some persons like painted stones, others iron bulldogs in the front yard and the word "welcome" worked into the door-mat, and others like barbered trees. So long as these likes are purely personal, it would seem to be better taste to put such curiosities in the back yard, where the owner may admire them without molestation. 
There is a persistent desire among workmen to shear and to trim: it displays their industry. It is a great thing to be able to allow the freedom of nature to remain. The artist often builds his structures into a native planting (as in Fig. 18) rather than to trust himself to produce a good result by planting on razed surfaces.

In this discussion, I have tried to enforce the importance of the open center in non-formal home grounds in greensward regions. Of course this does not mean that there may not be central planting in particular cases where the conditions distinctly call for it nor that there may not be trees on the lawn. If one has the placing of the trees, he may see that they are not scattered aimlessly; but if good trees are already growing on the place, it would be folly to think of removing them merely because they are not in the best ideal positions; in such case, it may be very necessary to adapt the treatment of the area to the trees. The home-maker should always consider, also, the planting of a few trees in such places as to shade and protect the residence: the more closely they can be made a part of the general design or handling of the place, the better the results will be.

\section{The flower-growing should be part of the design.}

I do not mean to discourage the use of brilliant flowers and bright foliage and striking forms of vegetation; but these things are never primary considerations in a good domain. The structural elements of the place are designed first. The flanking and bordering masses are then planted. Finally the flowers and accessories are put in, as a house is painted after it is built. Flowers appear to best advantage when seen against a background of foliage, and they are then, also, an integral part of the picture. The flower-garden, as such, should be at the rear or side of a place, as all other personal appurtenances are; but flowers and bright leaves may be freely scattered along the borders and near the foliage masses. 
It is a common saying that many persons have no love or appreciation of flowers, but it is probably nearer to the truth to say that no person is wholly lacking in this respect. Even those persons who declare that they care nothing for flowers are generally deceived by their dislike of flower-beds and the conventional methods of flower-growing. I know many persons who stoutly deny any liking for flowers, but who, nevertheless, are rejoiced with the blossoming of the orchards and the purpling of the clover fields. The fault may not lie so much with the persons themselves as with the methods of growing and displaying the flowers.

\section{Defects in flower-growing.}

The greatest defect with our flower-growing is the stinginess of it. We grow our flowers as if they were the choicest rarities, to be coddled in a hotbed or under a bell-jar, and then to be exhibited as single specimens in some little pinched and ridiculous hole cut in the turf, or perched upon an ant-hill that some gardener has laboriously heaped on a lawn. Nature, on the other hand, grows many of her flowers in the most luxurious abandon, and one can pick an armful without offense. She grows her flowers in earnest, as a man grows a crop of corn. One can revel in the color and the fragrance and be satisfied.

The next defect with our flower-growing is the flower-bed. Nature has no time to make flower-bed designs: she is busy growing flowers. And, then, if she were given to flower-beds, the whole effect would be lost, for she could no longer be luxurious and wanton, and if a flower were picked her whole scheme might be upset. Imagine a geranium-bed or a coleusbed, with its wonderful "design," set out into a wood or in a free and open landscape! Even the birds would laugh at it!

What I want to say is that we should grow flowers freely when we make a flower-garden. We should have enough of them to make the effort worth the while. I sympathize with the 
man who likes sunflowers. There are enough of them to be worth looking at. They fill the eye. Now show this man ten feet square of pinks or asters, or daisies, all growing free and easy and he will tell you that he likes them. All this has a particular application to the farmer, who is often said to dislike flowers. He grows potatoes and buckwheat and weeds by the acre: two or three unhappy pinks or geraniums are not enough to make an impression.

Lawn flower-beds.

The easiest way to spoil a good lawn is to put a flower-bed in it; and the most effective way in which to show off flowers to the

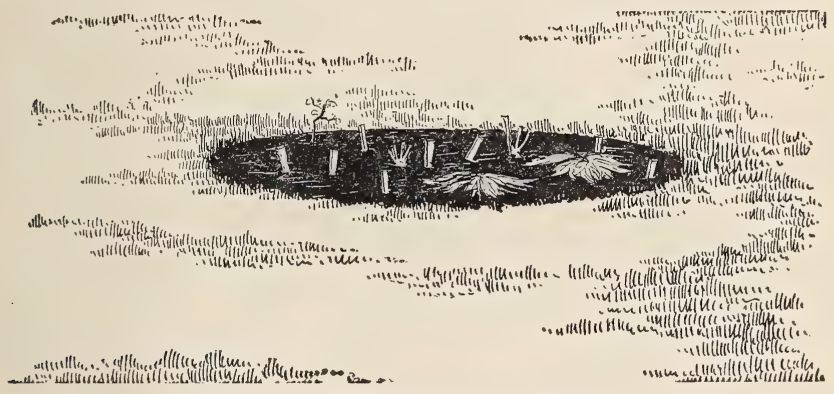

19. Hole-in-the-ground gardening.

least advantage is to plant them in a bed in the greensward. Flowers need a background. We do not hang our pictures on fence-posts. If flowers are to be grown on a lawn, let them be of the hardy kind, which can be naturalized in the sod and which grow freely in the tall unmown grass; or else perennials of such nature that they make attractive clumps by themselves. Lawns should be free and generous, but the more they are cut up and worried with trivial effects, the smaller and meaner they look.

But even if we consider these lawn flower-beds wholly apart from their surroundings, we must admit that they are at best 
unsatisfactory. It generally amounts to this, that we have four months of sparse and downcast vegetation, one month of limp and frost-bitten plants, and seven months of bare earth (Fig. 19). I am not now opposing the carpet-beds which professional gardeners make in parks and other museums. I like museums, and some of the carpet-beds and set pieces are "fearfully and wonderfully made" (see Fig. 20). I am directing my remarks

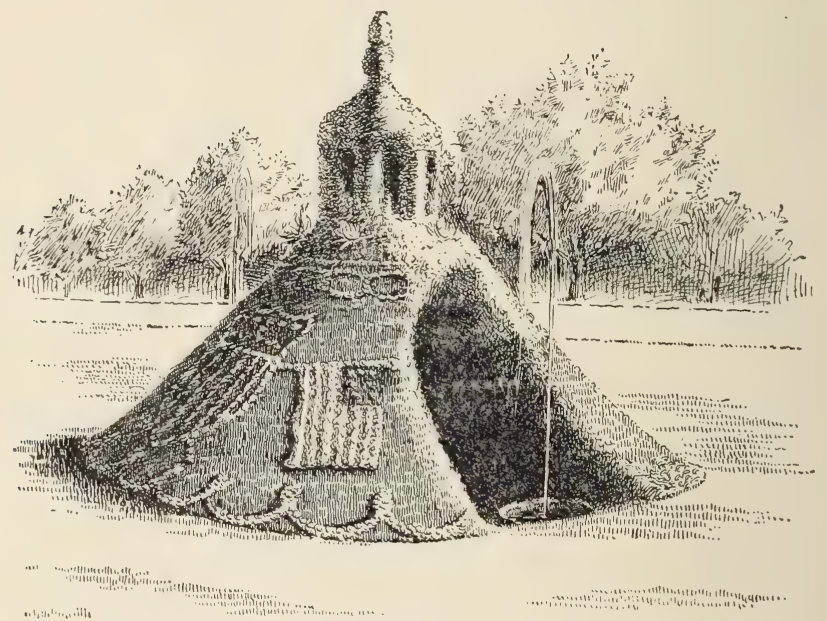

20. Worth paying admittance price to see!

to those humble home-made flower-beds that are so common in lawns of country and city homes alike. These beds are cut from the good fresh turf, often in the most fantastic designs, and are filled with such plants as the women of the place may be able to carry over in cellars or in the window. The plants themselves may look very well in pots, but when they are turned out of doors, they have a sorry time for a month adapting themselves to the sun and winds, and it is generally well on towards midsummer before they begin to cover the earth. During all these weeks they have demanded more time and 
labor than would have been needed to care for a plantation of much greater size and which would have given flowers every day from the time the birds began to nest in the spring until the last robin had flown in November.

\section{Flower-borders.}

We should acquire the flower-border. The border spoken sets bounds one's own. The peron it. Along these by the corners of the residence or in front of porches these are places for flowers. Ten flowers against
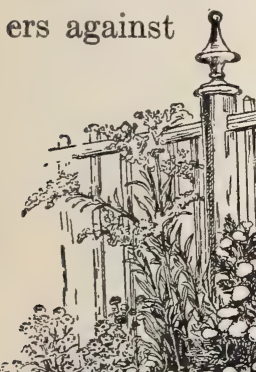

(2) planting of which we have so to the place, and makes it son lives inside his place, not borders, against groups, often 
It is a border, - a strip of land two or three feet wide along a fence. This is the place where pigweeds usually grow. Here

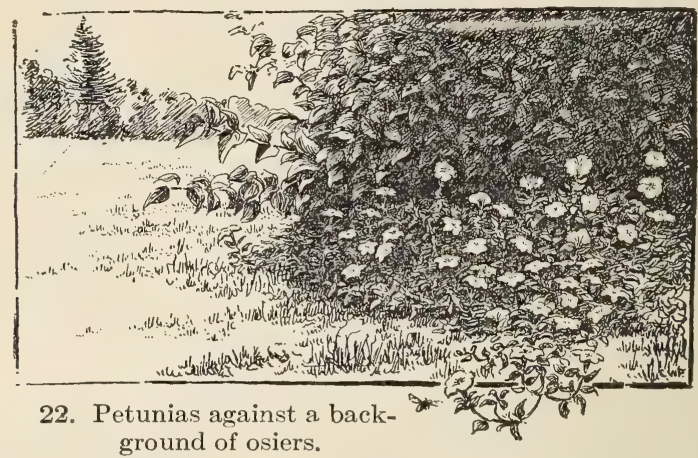

he has planted marigolds, gladiolus, golden rod, wild asters, China asters, and - best of all - hollyhocks. Any one would

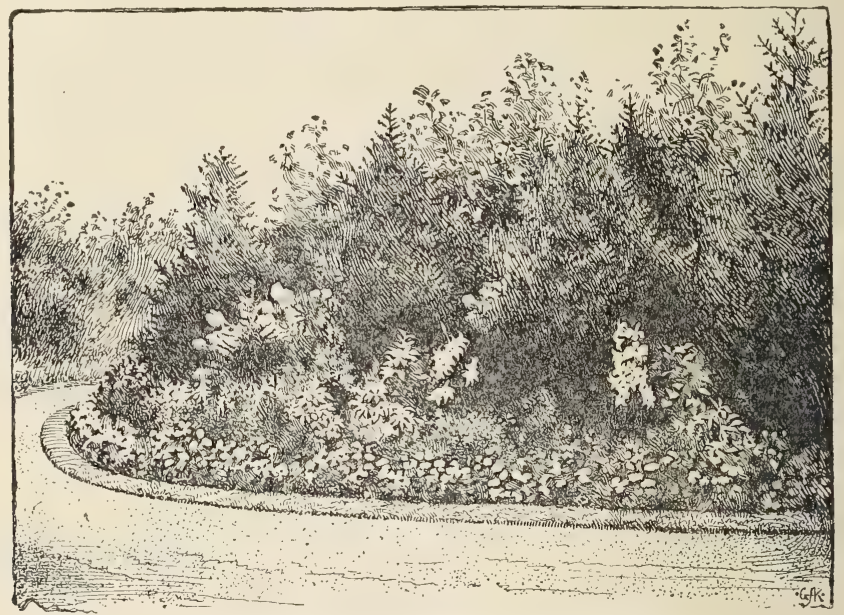

23. A sowing of flowers along a marginal planting.

like that flower-garden. It has some of that local and indefinable charm that always attaches to an "old-fashioned garden" 
with its medley of form and color. Nearly every yard has some such strip of land along a rear walk or fence or against a building. It is the easiest thing to plant it, - ever so much easier

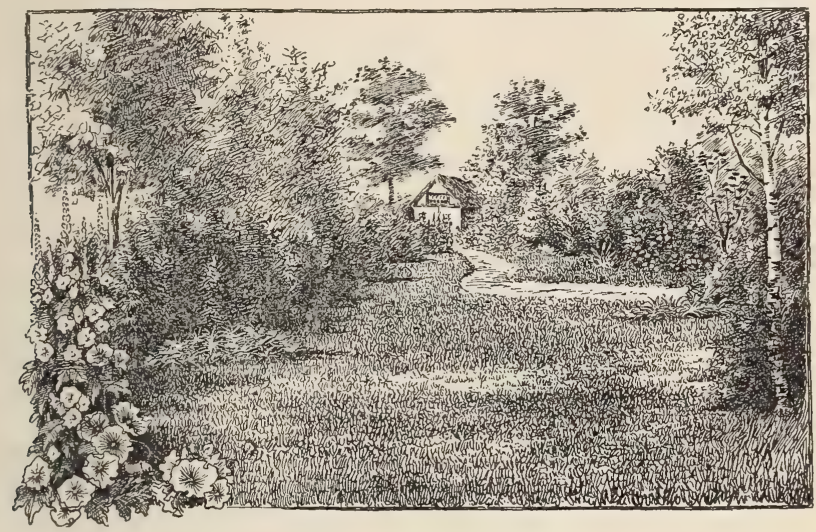

24. An open back yard. Flowers may be thrown in freely along the borders, but they would spoil the lawn if placed in its center.

than digging the characterless geranium bed into the center of an inoffensive lawn. The suggestions are carried further in Figs. 22 to 25.

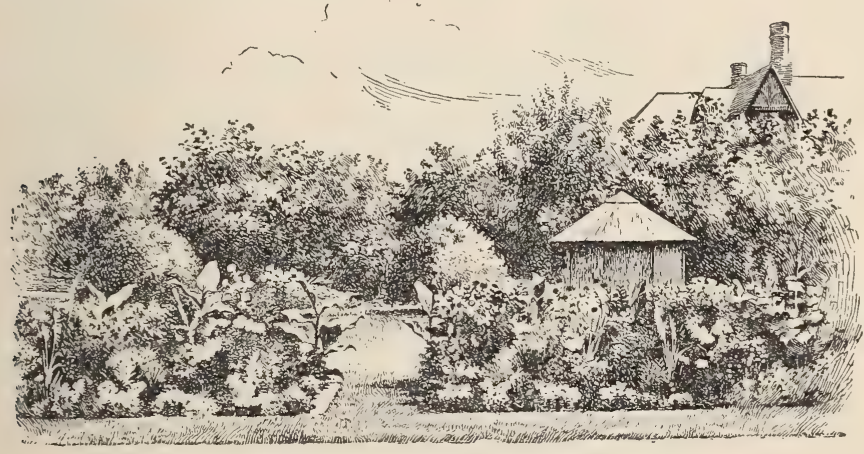

25. A flower-garden at the rear or one side of the place. 


\section{The old-fashioned garden.}

Speaking of the old-fashioned garden recalls one of William Falconer's excellent paragraphs ("Gardening," November 15, 1897, p. 75): "We tried it in Schenley Park this year. We needed a handy dumping ground, and hit on the head of a deep ravine between two woods; into it we dumped hundreds upon hundreds of wagon loads of rock and clay, filling it near to the top, then surfaced it with good soil. Here we planted some shrubs, and broadcast among them set out scarlet poppies, eschscholzias, dwarf nasturtiums, snapdragons, pansies, marigolds, and all manner of hardy herbaceous plants, having enough of each sort to make a mass of its kind and color, and the effect was fine. In the middle was a plantation of hundreds of clumps of Japan and German irises interplanted, thence succeeded by thousands of gladioli, and banded with montbretias, from which we had flowers till frost. The steep face of this hill was graded a little and a series of winding stone steps set into it, making the descent into the hollow quite easy; the stones were the rough uneven slabs secured in blasting the rocks when grading in other parts of the park, and both along outer edges of the steps and the sides of the upper walk a wide belt of moss pink was planted; and the banks all about were planted with shrubs, vines, wild roses, columbines, and other plants. More cameras and kodaks were leveled by visitors at this piece of gardening than at any other spot in the park, and still we had acres of painted summer beds."

\section{Contents of the flower-borders.}

There is no prescribed rule as to what one should put into these informal flower-borders. Put in them the plants you like. Perhaps the greater part of them should be perennials that come up of themselves every spring, and that are hardy and reliable. Wild flowers are particularly effective. Every one knows that 
many of the native herbs of woods and glades are more attractive than some of the most prized garden flowers. The greater part of these native flowers grow readily in cultivation, sometimes even in places which, in soil and exposure, are much unlike their native haunts. Many of them make thickened roots, and they may be safely transplanted at any time after the flowers have passed. To most persons the wild flowers are less known than many exotics that have smaller merit, and the extension of cultivation is constantly tending to annihilate them. Here, then, in the informal flower-border, is an opportunity to rescue them. Then one may sow in freely of easygrowing annuals, as marigolds, China asters, petunias and phloxes, and sweet peas.

One of the advantages of these borders lying at the boundary is that they are always ready to receive more plants, unless they are full. That is, their symmetry is not marred if some plants are pulled out and others are put in. And if the weeds now and then get a start, very little harm is done. Such a border half full of weeds is handsomer than the average hole-inthe-lawn geranium bed. An ample border may receive wild plants every month in the year when the frost is out of the ground. Plants are dug in the woods or fields, whenever one is on an excursion, even if in July. The tops are cut off, the roots kept moist until they are placed in the border; most of these much-abused plants will grow. To be sure, one will secure some weeds; but then, the weeds are a part of the collection! Of course, some plants will resent this treatment, but the border may be a happy family, and be all the better and more personal because it is the result of moments of relaxation. Such a border has something new and interesting every month of the growing season; and even in the winter the tall clumps of grasses and aster-stems hold their banners above the snow and are a source of delight to every frolicsome bevy of snowbirds.

I have spoken of a weedland to suggest how simple and easy 
a thing it is to make an attractive mass-plantation. One may make the most of a rock (Fig. 26) or bank, or other undesirable feature of the place. Dig up the ground and make it rich, and then set plants in it. You will not get it to suit you the first year, and perhaps not the second or the third; you can always pull out plants and put more in. I should not want a lawngarden so perfect that I could not change it in some character each year; I should lose interest in it.

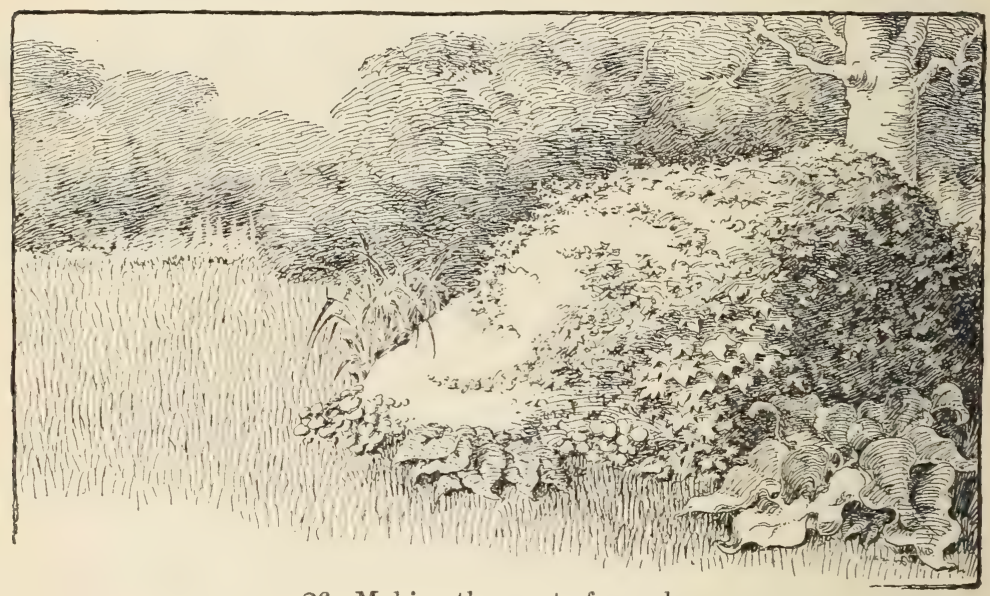

26. Making the most of a rock.

It must not be understood that I am speaking only for mixed borders. On the contrary, it is much better in most cases that each border or bed be dominated by the expression of one kind of flower or bush. In one place a person may desire a wild aster effect, or a petunia effect, or a larkspur effect, or a rhododendron effect; or it may be desirable to run heavily to strong foliage effects in one direction and to light flower effects in another. The mixed border is rather more a flower-garden idea than a landscape idea; when it shall be desirable to emphasize the one and when the other, cannot be set down in a book. 
The value of plants may lie in foliage and form rather than in bloom.

What kinds of shrubs and flowers to plant is a wholly secondary and largely a personal consideration. The main plantings are made up of hardy and vigorous species; then the things that you like are added. There is endless choice in the species, but the arrangement or disposition of the plants is far more important than the kinds; and the foliage and form of the plant are usually of more importance than its bloom.

The appreciation of foliage effects in the landscape is a higher type of feeling than the desire for mere eolor. Flowers are transitory, but foliage and plant forms are abiding. The common roses have very little value for landscape planting because the foliage and habit of the rose-bush are not attractive, the leaves are inveterately attacked by bugs, and the blossoms are fleeting. Some of the wild roses and the Japanese Rosa rugosa, however, have distinct merit for mass effects.

Even the common flowers, as marigold, zinnias, and gaillardias, . are interesting as plant-forms long before they come into bloom. To many persons the most satisfying epoch in the garden is that preceding the bloom, for the habits and stature of the plants are then unobscured. The early stages of lilies; daffodils, and all perennials are most interesting; and one never appreciates a garden until he realizes that this is so.

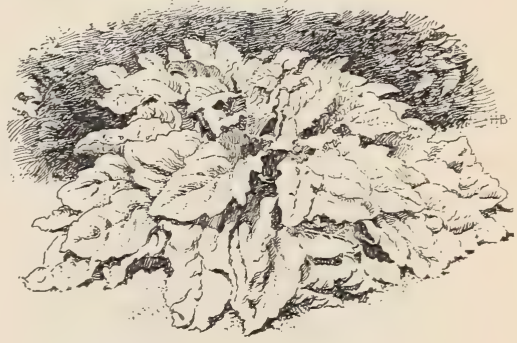

27. The plant-form in a perennial salvia.

Now let the reader, with these suggestions in mind, observe for one week the plant-forms in the humble herbs that he meets, whether these herbs are strong garden plants or the 
striking sculpturing of mulleins, burdocks, and jimson-weed. Figures 27 to 31 will be suggestive.

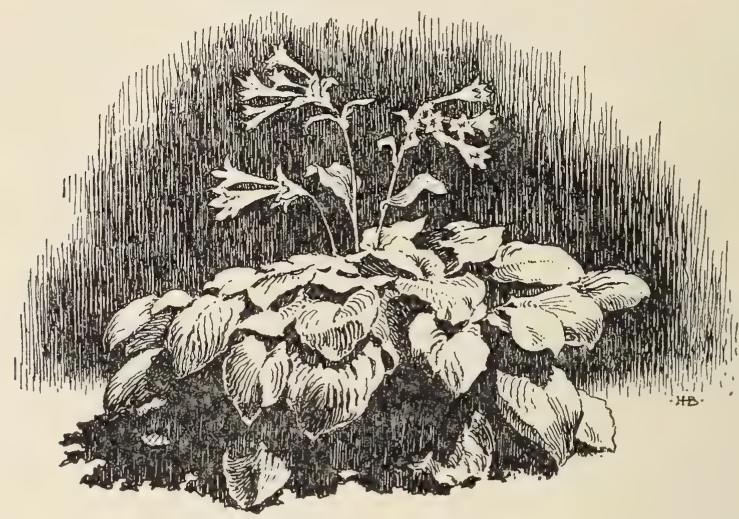

28. Funkia, or day-lily. Where lies the chief interest, - in the plant-form or in the bloom?

Wild bushes are nearly always attractive in form and habit when planted in borders and groups. They improve in appearance under cultivation because they are

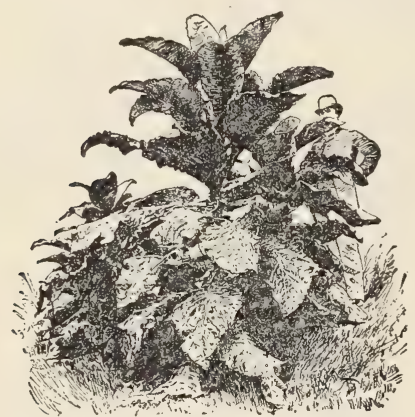

29. A large-leaved nicotiana.

given a better chance to grow. In wild nature there is such fierce struggle for existence that plants usually

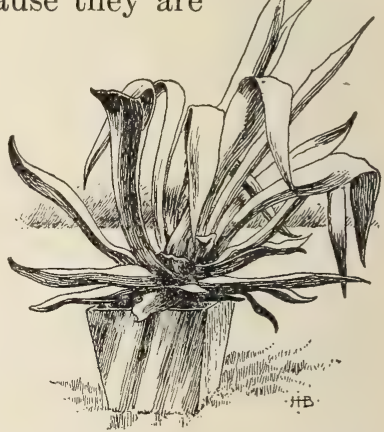

30. The awkward century plant that has been laboriously carried over winter year by year in the cellar: compare with other plants here shown as to its value as a lawn subject. 
grow to few or single stems, and they are sparse and scraggly in form; but once given all the room they want and a good soil, they become luxurious, full, and comely. In most home grounds in the country the body of the planting may be very effectively composed of bushes taken from the adjacent woods and fields. The masses may then be enlivened by the addition here and there of cultivated bushes, and the planting of

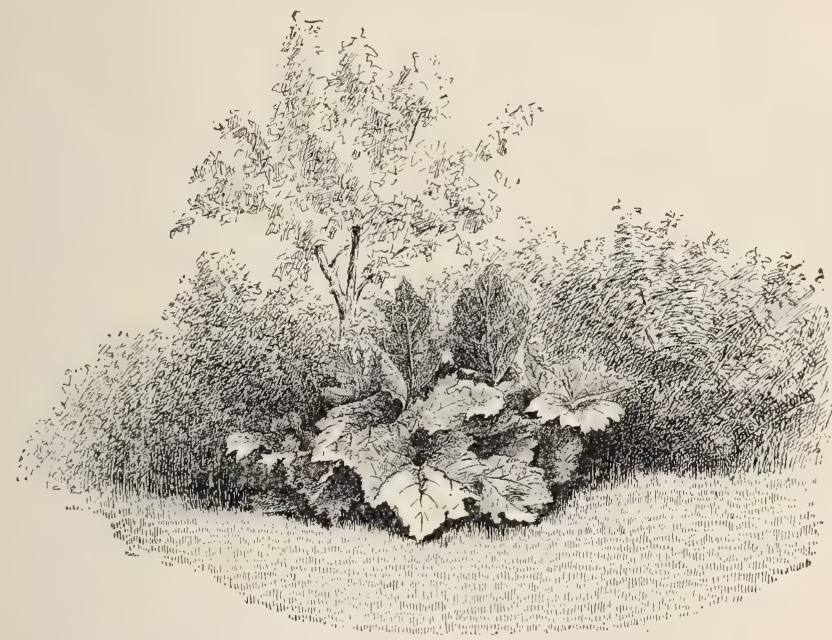

31. Making a picture with rhubarb.

flowers and herbs about the borders. It is not essential that one know the names of these wild bushes, although a knowledge of their botanical kinships will add greatly to the pleasure of growing them. Neither will they look common when transferred to the lawn. There are not many persons who know even the commonest wild bushes intimately, and the things change so much in looks when removed to rich ground that few home-makers recognize them. 


\section{Odd and formal trees. .}

It is but a corollary of this discussion to say that plants which are simply odd or grotesque or unusual should be used with the greatest caution, for they introduce extraneous and jarring effects. They are little in sympathy with a landscape garden. An artist would not care to paint an evergreen that is sheared into some grotesque shape. It is only curious, and shows what

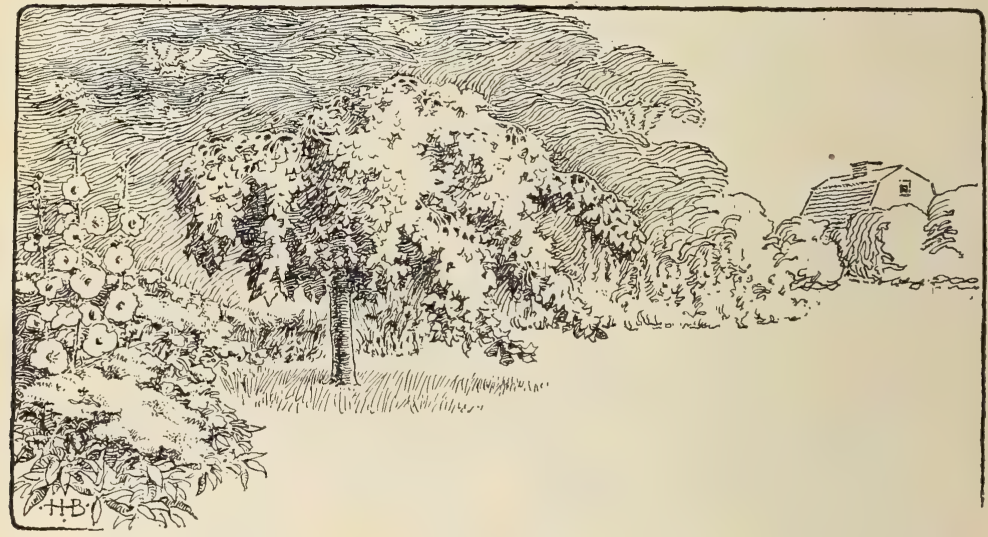

32. A weeping tree at one side of the grounds and supported by a background.

a man with plenty of time and long pruning shears can accomplish. A weeping tree (particularly of a small-growing species) is usually seen to best advantage when it stands against a group or mass of foliage (Fig. 32), as a promontory, adding zest and spirit to the border; it then has relation with the place.

This leads me to speak of the planting of the Lombardy poplar, which may be taken as a type of the formal tree, and as an illustration of what I mean to express. Its chief merits to the average planter are the quickness of its growth and the readiness with which it multiplies by sprouts. But in the North it is likely to be a short-lived tree, it suffers from storms, and it has 


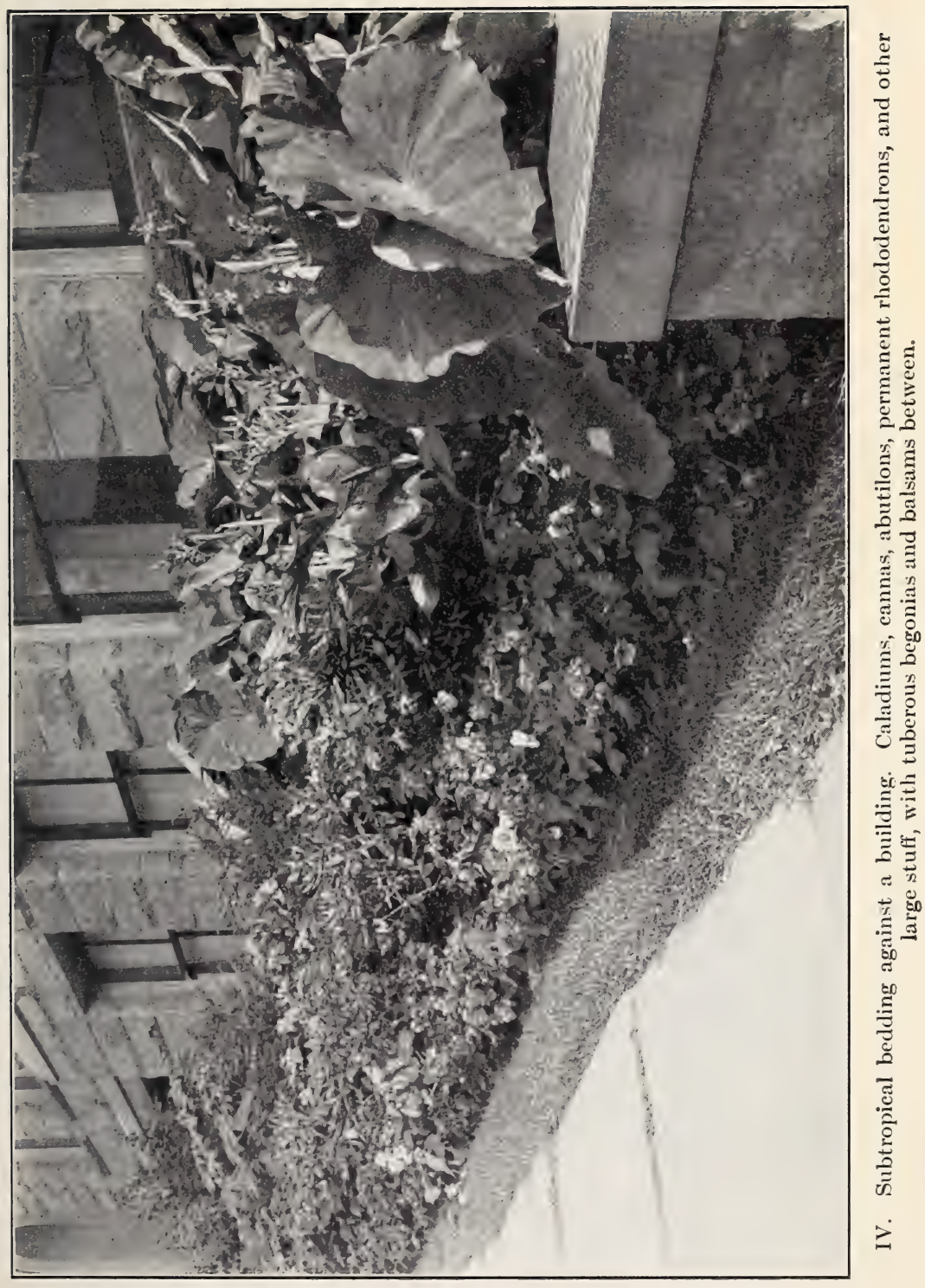



few really useful qualities. It may be used to some advantage in wincibreaks for peach orchards and other short-lived plantations; but after a few years a screen of Lombardies begins to fail, and the habit of suckering from the root adds to its undesirable features. For shade it has little merit, and for timber none. Persons like it because it is striking, and this, in an artistic sense, is its gravest fault. It is unlike anything else in our landscape, and does not fit into our scenery well. A row of Lombardies along a roadside is like a row of exclamation points!

But the Lombardy can often be used to good effect as one factor in a group of trees, where its spire-like shape, towering above the surrounding foliage, may lend a spirited charm to the landscape. It combines well in such groups if it stands in visual nearness to chimneys or other tall formal objects. Then it gives a sort of architectural finish and spirit to a group; but the effect is generally lessened, if not altogether spoiled, in small places, if more than one Lombardy is in view. One or two specimens may often be used to give vigor to heavy plantations about low buildings, and the effect is generally best if they are seen beyond or at the rear of the building. Note the use that the artist has made of them in the backgrounds in Figs. 12, 13, and 43 .

\section{Poplars and the like.}

Another defect in common ornamental planting, which is well illustrated in the use of poplars, is the desire for plants merely because they grow rapidly. A very rapid-growing tree nearly always produces cheap effects. This is well illustrated in the common planting of willows and poplars about summer places or lake shores. Their effect is almost wholly one of thinness and temporariness. There is little that suggests strength or durability in willows and poplars, and for this reason they should usually be employed as minor or secondary features in ornamental or home grounds. When quick results are de- 
sired, nothing is better to plant than these trees; but better trees, as maples, oaks, or elms, should be planted with them, and the poplars and willows should be removed as rapidly as the other species begin to afford protection. When the plantation finally assumes its permanent characters, a few of the remaining

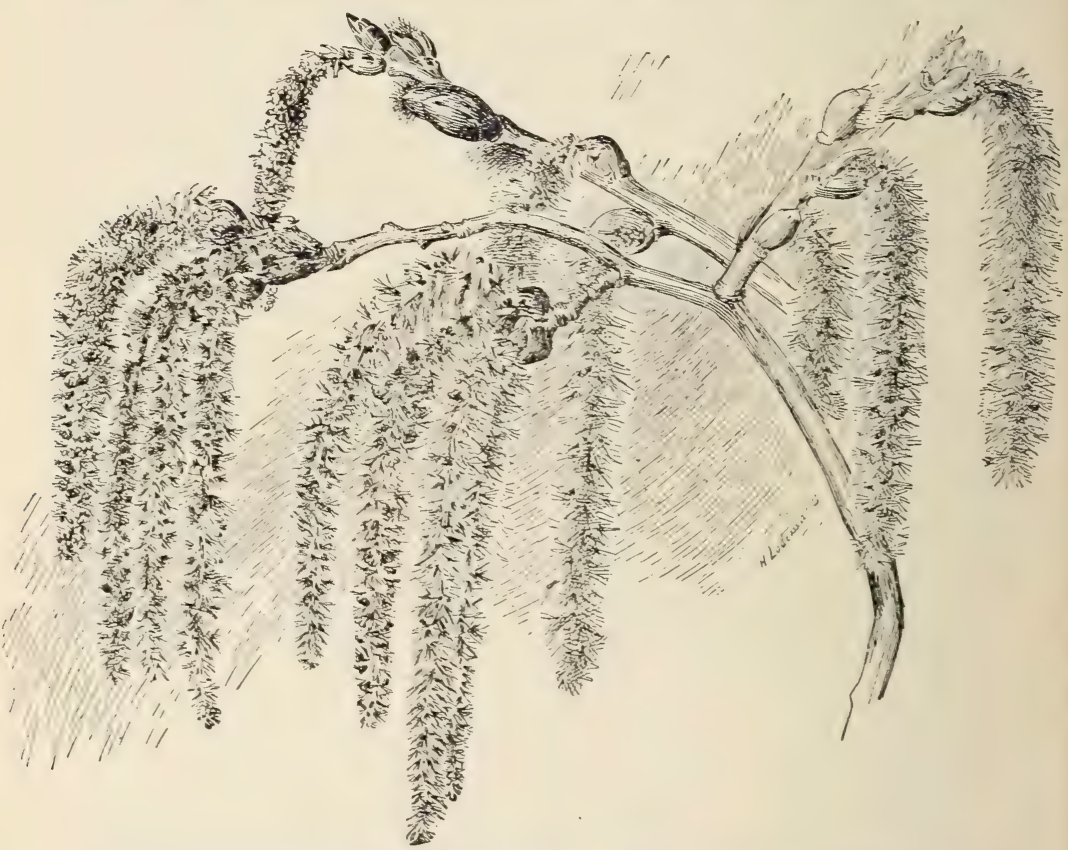

33. A spring expression worth securing. Catkins of the small poplar.

poplars and willows, judiciously left, may afford very excellent effects; but no one who has an artist's feeling would be content to construct the framework of his place of these rapidgrowing and soft-wooded trees.

I have said that the legitimate use of poplars in ornamental grounds is in the production of minor or secondary effects. As a rule, they are less adapted to isolated planting as speci- 
men trees than to using in composition, - that is, as parts of general groups of trees, where their characters serve to break the monotony of heavier forms and heavier foliage. The poplars are gay trees, as a rule, especially those, like the aspens, that have a trembling foliage. Their leaves are bright and the tree-tops are thin. The common aspen or "popple," Populus tremuloides, of our woods, is a meritorious little tree for certain effects. Its dangling catkins (Fig. 33), light, dancing foliage, and silver-gray limbs, are always cheering, and its autumn color is one of the purest golden-yellows of our landscape. It is good to see a tree of it standing out in front of a group of maples or evergreens.

\section{Plant-forms.}

Before one attains to great sensitiveness

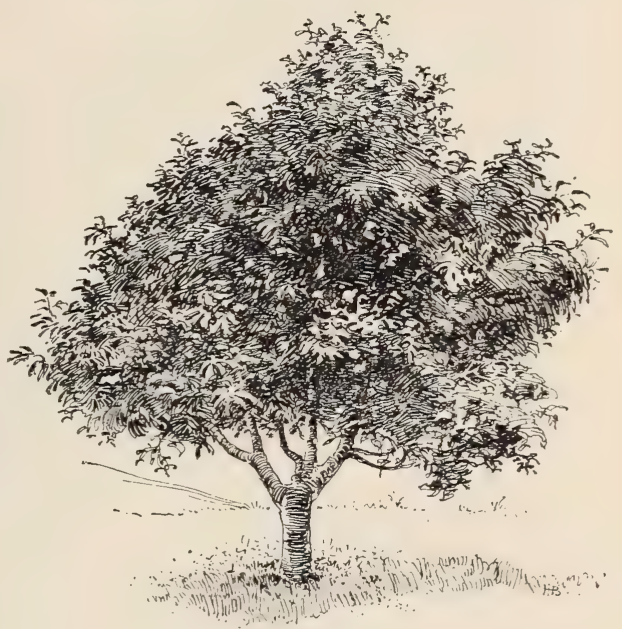

34. Plant-form in cherries. - Reine Hortense. in the appreciation of gardens, he learns to distinguish plants by their forms. This is particularly true for trees and shrubs. Each species has its own "expression," which is determined by the size that is natural to it, mode of branching, form of top, twig characters, bark characters, foliage characters, and to some extent its flower and fruit characters. It is a useful practice for one to train his eye by learning the difference in expression of the trees of different varieties of cherries or pears or apples or other fruits, if he has access to a plantation of them. The differences in cherries and pears are very marked (Figs. 34-36). He may 
also contrast and compare carefully the kinds of any tree or shrub of which there are two or three species in the neighbor-

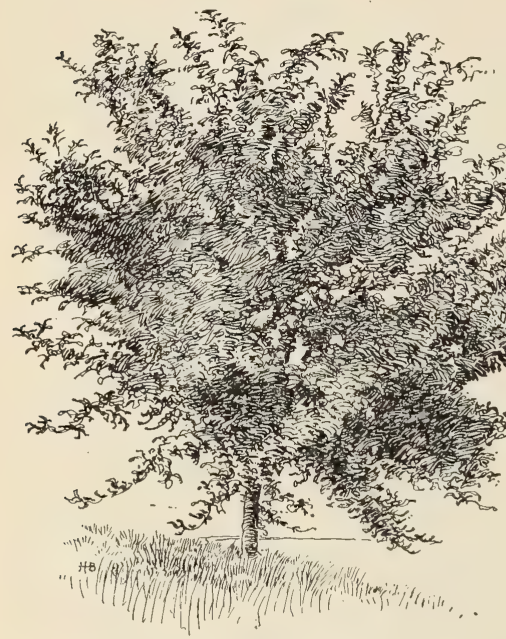

35. Morello cherry.

elms; the aspen, large-toothed poplar, cottonwood, balm of gilead, Carolina poplar, Lombardy poplar; the main species of oaks; the hickories; and the like.

It will not be long before the observer learns that many of the tree and shrub characters are most marked in winter ; and he will begin unconsciously to add the winter to his year.

Various specific examples. hood, learning to distinguish them without close examination; as the sugar maple, red maple, soft maple, and Norway maple (if it is planted); the white or American elm, the cork elm, the slippery elm, the planted European

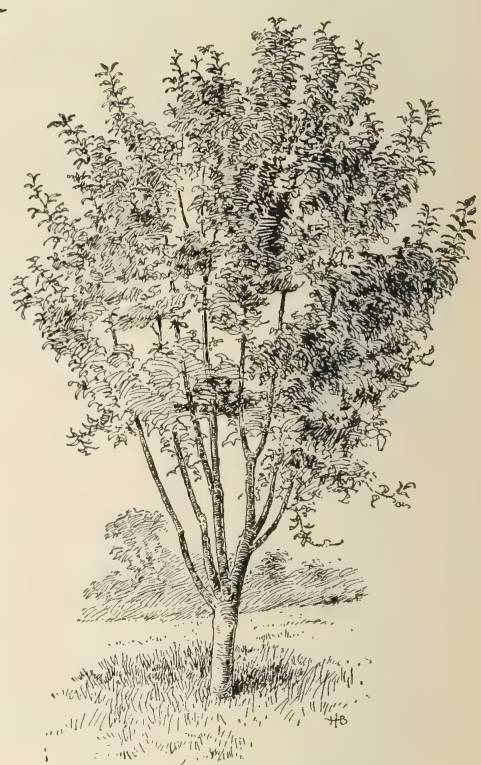

36. May Duke cherry.

The foregoing remarks will mean more if the reader is shown some concrete examples. I have chosen a few cases, not because 
they are the best, or even because they are always good enough for models, but because they lie in my way and illustrate what I desire to teach.

\section{A front yard example.}

We will first look at a very ordinary front yard. It contained no plants, except a pear tree standing near the corner

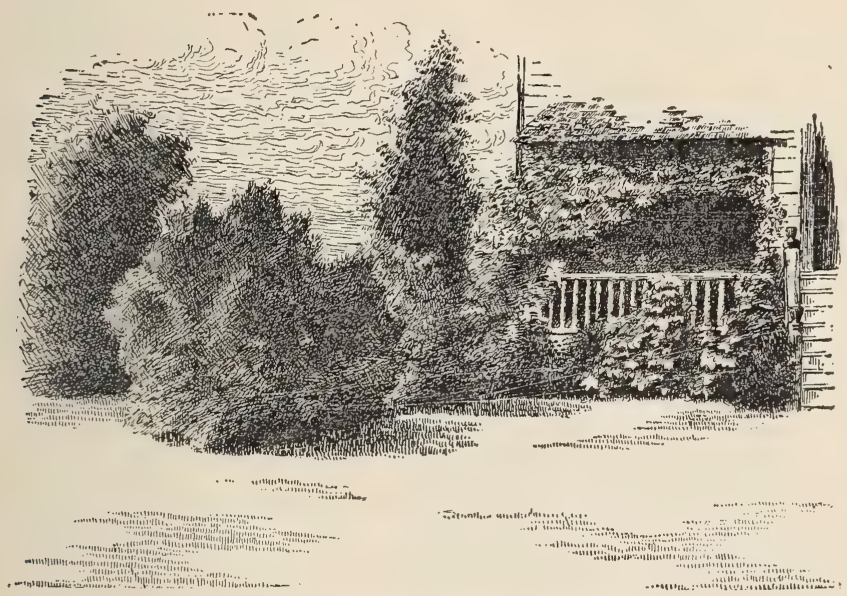

37. The planting in a simple front yard.

of the house. Four years later sees the yard as shown in Fig. 37. An exochorda is the large bush in the very foreground, and the porch foundation is screened and a border is thereby given to the lawn. The length of this planting from end to end is about fourteen feet, with a projection towards the front on the left of ten feet. In the bay at the base of this projection the planting is only two feet wide or deep, and from here it gradually swings out to the steps, eight feet wide. The prominent large-leaved plant near the steps is a bramble, Rubus odoratus, very common in the neighborhood, and it is a choice 
plant for decorative planting, when it is kept under control. The plants in this border in front of the porch are all from the wild, and comprise a prickly ash, several plants of two wild osiers or dogwoods, a spice bush, rose, wild sunflowers and asters and golden-rods. The promontory at the left is a more ambitious but less effective mass. It contains an exochorda, a reed, variegated elder, sacaline, variegated dogwood, tansy, and a young tree of wild crab. At the rear of the plantation,

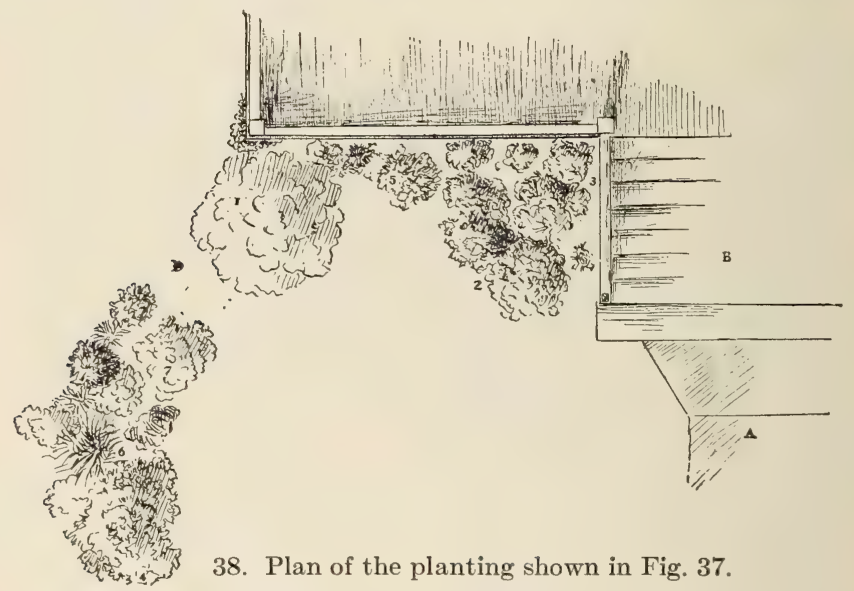

next the house, one sees the pear tree. The best single part of the planting is the reed (Arundo Donax) overtopping the exochorda. The photograph was taken early in summer, before the reed had become conspicuous.

A ground plan of this planting is shown in Fig. 38. At A is the walk and B the steps. An opening at D serves as a passage. The main planting, in front of the porch, fourteen feet long, received twelve plants, some of which have now spread into large clumps. At 1 is a large bush of osier, Cornus Baileyi, one of the best red-stemmed bushes. At 2 is a mass of Rubus odoratus; at 5 asters and golden-rods; at 3 a clump of wild 
sunflowers. The projecting planting on the left comprises about ten plants, of which 4 is exochorda, 6 is arundo or reed, at the back of which is a large clump of sacaline, and 7 is a variegated-leaved elder.

\section{Another example.}

A back yard is shown in Fig. 39. The owner wanted a tennis court, and the yard is so small as not to allow of wide planting at the borders. However, something could be done. On the left is a weedland border, which formed the basis of the discussion of wild plants on page 35 . In the first place, a good lawn was made. In the second place, no walks or drives were laid in the area. [The drive for grocers' wagons and coal is seen in the rear, ninety feet from the house. From I to $\mathrm{J}$ is the weedland, separating the area from the neighbor's premises. Near I is a clump of roses. At $K$ is a large

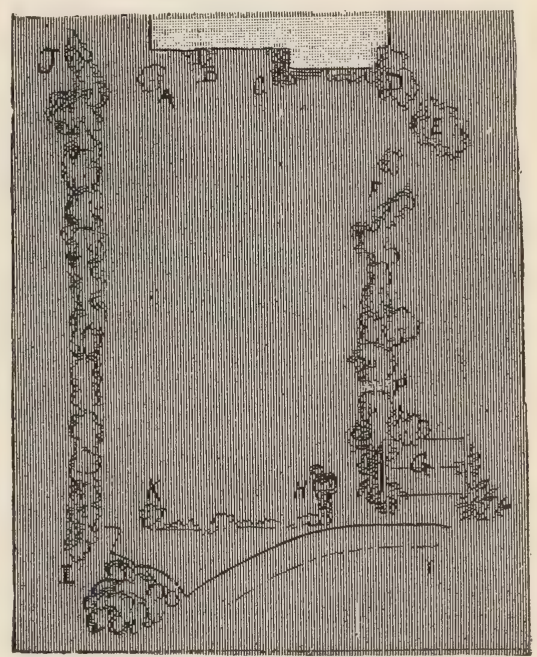

39. Diagram of a back-yard planting. $50 \times 90$ feet.

bunch of golden-rods. H marks a clump of yucca. $G$ is a cabin, covered with vines on the front. From $\mathrm{G}$ to $\mathrm{F}$ is an irregular border, about six feet wide, containing barberries, forsythias, wild elder, and other bushes. D E is a screen of Russian mulberry, setting off the clothes yard from the front lawn. Near the back porch, at the end of the screen, is an arbor covered with wild grapes, making a play-house for the children. A clump of lilacs stands at A. At B is a vine- 
covered screen, serving as a hammock support. The lawn made and the planting done, it was next necessary to lay the walks. These are wholly informal affairs, made by sinking a plank ten inches wide into the ground to a level with the sod. The border plantings of this yard are too straight and regular for the most artistic results, but such was necessary in order not to

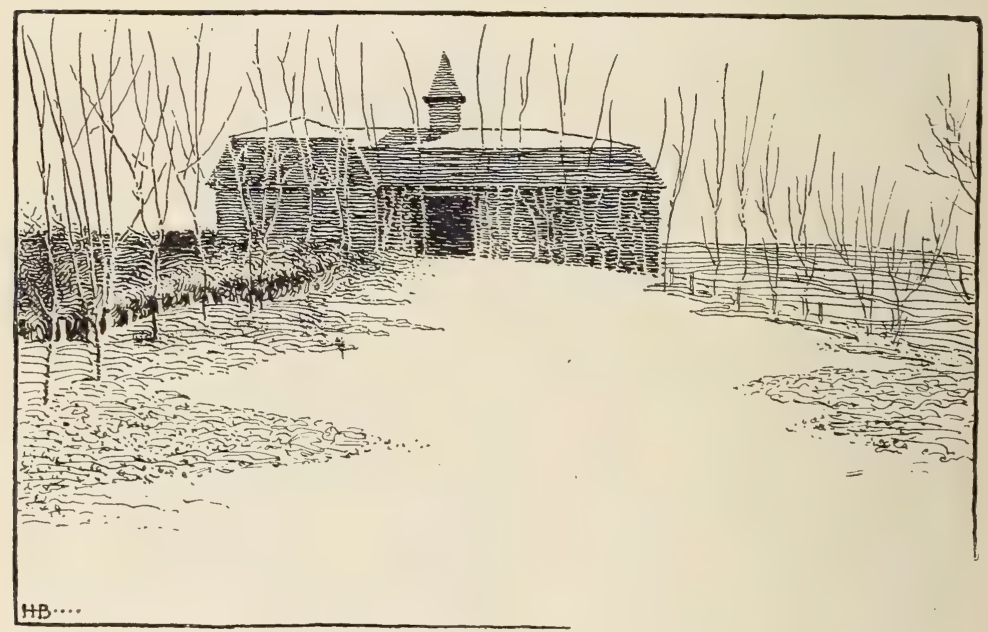

40. The beginning of a landscape garden.

encroach upon the central space. Yet the reader will no doubt agree that this yard is much better than it could be made by any system of scattered and spotted planting. Let him imagine how a glowing carpet-bed would look set down in the center of this lawn!

\section{A third example.}

The making of a landscape picture is well illustrated in Figs. 40, 41. The former shows a small clay field (seventyfive feet wide, and three hundred feet deep), with a barn at 
the rear. In front of the barn is a screen of willows. The observer is looking from the dwelling-house. The area has been plowed and seeded for a lawn. The operator has then marked out a devious line upon either border with a hoe handle, and all the space between these borders has been gone over with a garden roller to mark the area of the desired greensward.

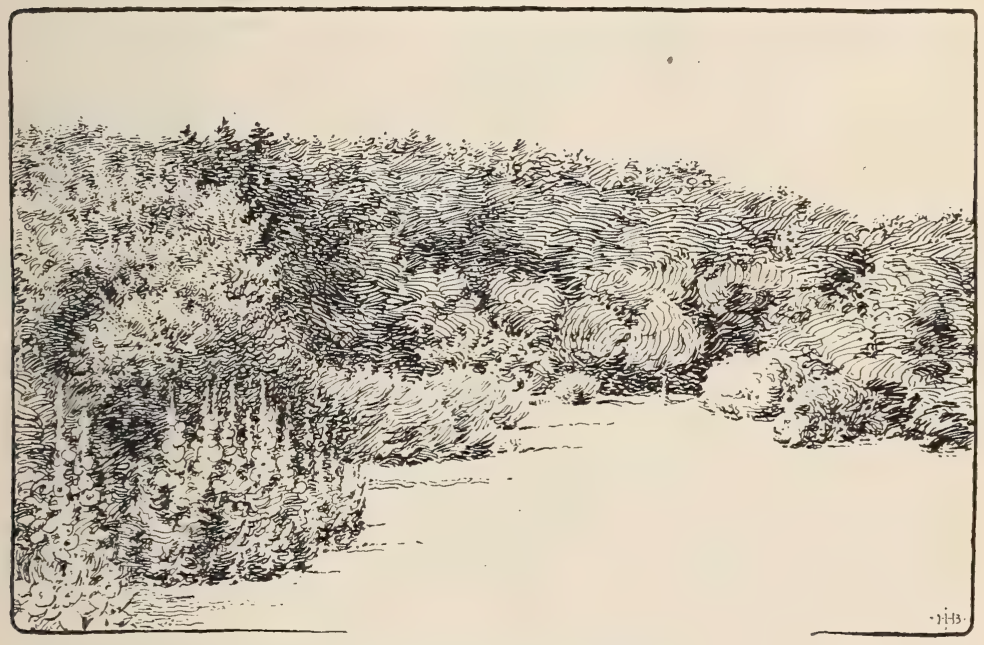

41. The result in five years.

The borders are now planted with a variety of small trees, bushes, and herbs. Five years later the view shown in Fig. 41 was taken.

\section{A small back yard.}

A back yard is shown in Fig. 42. It is approximately sixty feet square. At present it contains a drive, which is unnecessary, expensive to keep in repair, and destructive of any attempt to make a picture of the area. The place could be improved by planting it somewhat after the manner of Fig. 43. 


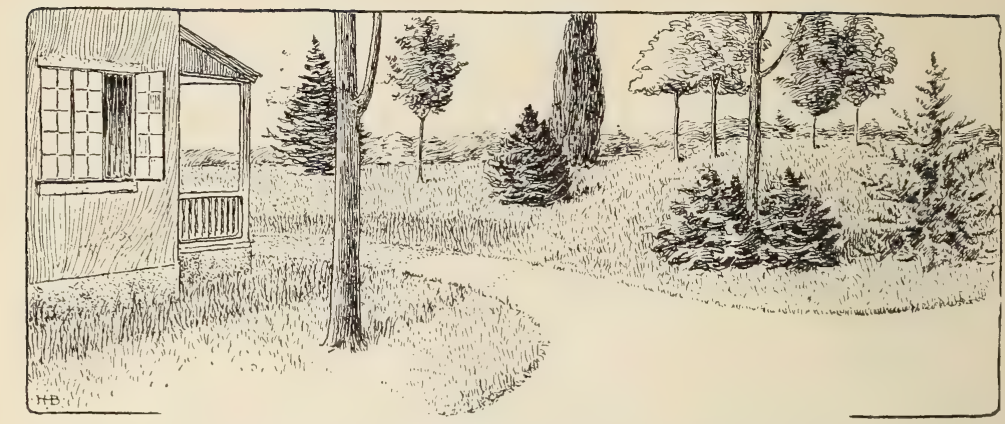

42. A meaningless back-yard planting, and an unnecessary drive.

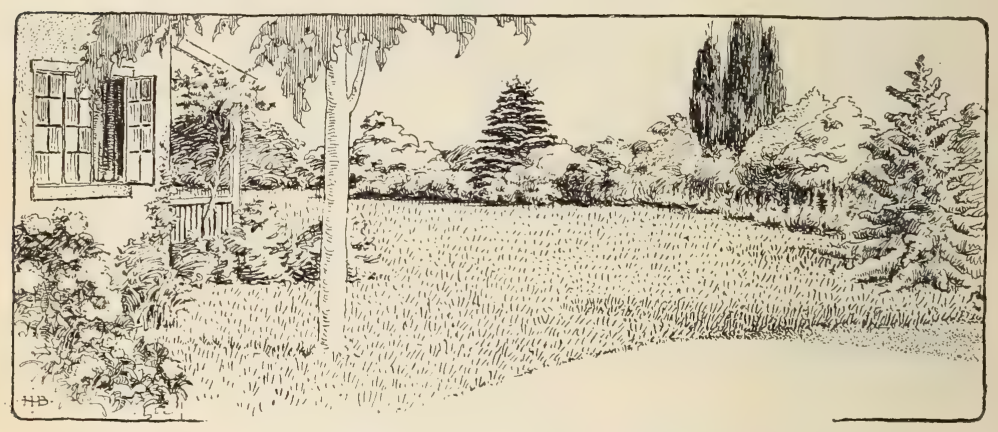

43. Suggestions for improving Fig. 42.

\section{A city lot.}

A plan of a city lot is given in Fig. 44. The area is fifty by one hundred, and the house occupies the greater part of the width. It is level, but the surrounding land is higher, resulting in a sharp terrace, three or four feet high, on the rear, E D. This terrace vanishes at $\mathrm{C}$ on the right, but extends nearly the whole length of the other side, gradually diminishing as it approaches A. There is a terrace two feet high extending from A to $\mathrm{B}$, along the front. Beyond the line $\mathrm{E} \mathrm{D}$ is the rear of an establishment which it is desired to hide. Since the terraces 
set definite borders to this little place, it is desirable to plant the boundaries rather heavily. If the adjoining lawns were on the same level, or if the neighbors would allow one area to be merged into the other by pleasant slopes, the three yards might be made into one picture; but the place must remain isolated.

There are three problems of structural planting in the place: to provide a cover or screen at the rear; to provide lower border masses on the side terraces; to plant next the foundations of the house. Aside from these problems, the grower is entitled to have a certain number of specimen plants, if he has particular liking for given types, but these specimens must be planted in some relation to the structural masses, and not in the middle of the lawn.

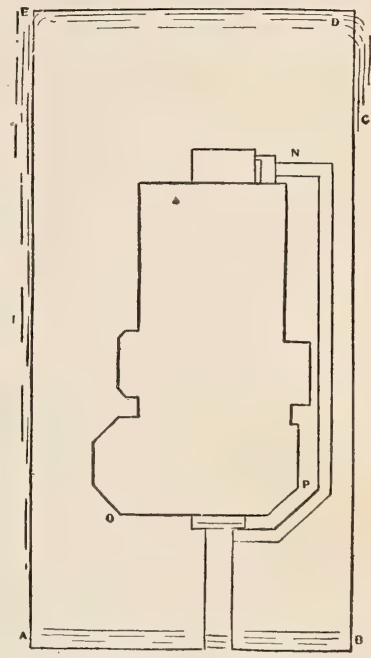

44. Present outline of a city back yard, desired to be planted.

The owner desired a mixed planting, for variety. The following shrubs were actually selected and planted. The place is in central New York:-

\section{Shrubs for the tall background}

2 Barberry, Berberis vulgaris and var. purpurea.

1 Cornus Mas.

2 Tall deutzias.

3 Lilacs.

2 Mock oranges, Philadelphus grandiflorus and $P$. coronarius.

2 Variegated elders.

2 Eleagnus, Elœagnus hortensis and E. longipes.

1 Exochorda.

2 Hibiscuses. 
1 Privet.

3 Viburnums.

1 Snowball.

1 Tartarian honeysuckle.

1 Silver Bell, Halesia tetraptera.

These were planted on the sloping bank of the terrace, from E to D. The terrace has an incline, or width, of about three feet. Figure 45 shows this terrace after the planting was completed, looking from the point C.

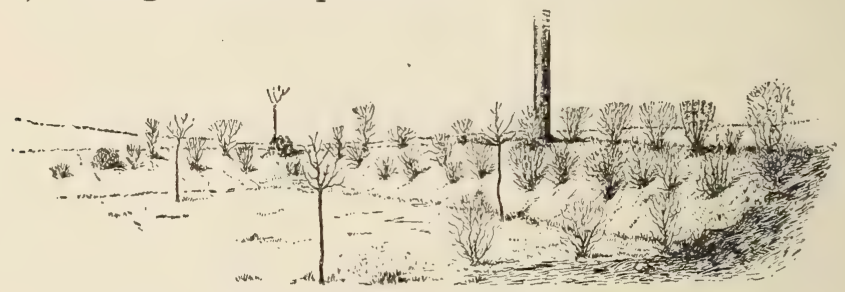

45. The planting of the terrace in Fig. 44 .

Shrubs of medium size, suitable for side plantings and groups in the foregoing example

3 Barberries, Berberis Thunbergii.

3 Osier dogwoods, variegated.

2 Japanese quinces, Cydonia Japonica and C. Maulei.

4 Tall deutzias.

1 Variegated elder.

7 Weigelas, assorted colors.

1 Rhodotypos.

9 Spireas of medium growth, assorted.

1 Rubus odoratus.

1 Lonicera fragrantissima.

Most of these shrubs were planted in a border two feet wide, extending from $\mathrm{B}$ to $\mathrm{C} \mathrm{D}$, the planting beginning about ten feet back from the street. Some of them were placed on the terrace at the left, extending from $\mathrm{E}$ one-fourth of the distance 
to A. The plants were set about two feet apart. A strong clump was placed at $\mathrm{N}$ to screen the back yard. In this back yard a few small fruit trees and a strawberry bed were planted.

Low informal shrubs for front of porch and banking against house

3 Deutzia gracilis.

6 Kerrias, green and variegated.

3 Daphne Mezereum.

3 Lonicera Halliana.

3 Rubus phœnicolasius.

3 Symphoricarpus vulgaris.

4 Mahonias.

1 Ribes aureum.

1 Ribes sanguineum.

1 Rubus cratægifolius.

1 Rubus fruticosus var. laciniatus.

These bushes were planted against the front of the house (a porch on a high foundation extends to the right from $\mathrm{O}$ ), from the walk around to $\mathrm{P}$, and a few of them were placed at the rear of the house.

Specimen shrubs for mere ornament, for this place

Azalea.

Rhododendron.

Rose.

2 Hydrangeas.

1 Snowball.

1 each Forsythia suspensa and F. viridissima.

2 Flowering almonds.

These were planted in conspicuous places here and there against the other masses.

Here are one hundred excellent and interesting bushes planted in a yard only fifty feet wide and one hundred feet deep, and yet the place has as much room in it as it had before. There 
is abundant opportunity along the borders for dropping in cannas, dahlias, hollyhocks, asters, geraniums, coleuses, and other brilliant plants. The bushes will soon begin to crowd, to be sure, but a mass is wanted, and the narrowness of the

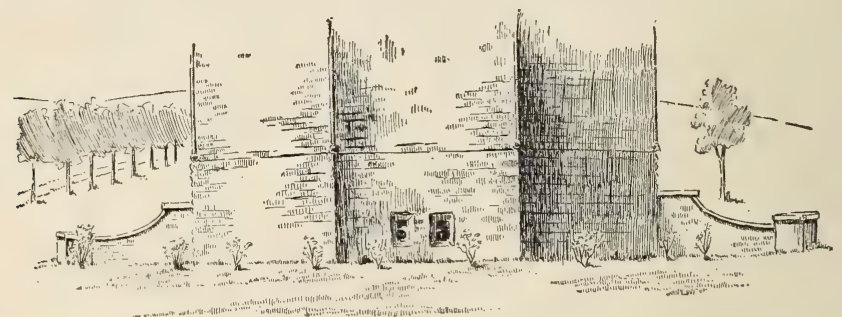

46. Said to have been planted.

plantations will allow each bush to develop itself laterally to perfection. If the borders become too thick, however, it is an easy matter to remove some of the bushes; but they probably will not. Picture the color and variety and life in that little yard. And if a pigweed now and then gets a start in the border, it would do no harm to let it alone: it belongs there! Then picture the same area filled with disconnected, spotty, dyspeptic, and unspirited flower-beds and rose bushes!

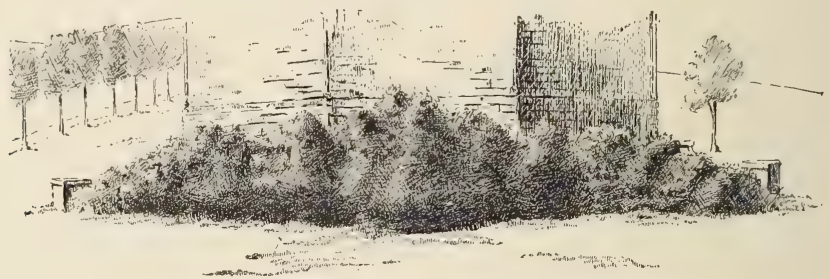

47. An area well filled. Compare Fig. 46.

Various examples.

Strong and bare foundations should be relieved by heavy planting. Fill the corners with snow-drifts of foliage. Plant with a free hand, as if you meant it (compare Figs. 46 and 47). 
The corner by the steps is a perennial source of bad temper. The lawn-mower will not touch it, and the grass has to be cut with a butcher-knife. If nothing else comes to hand, let a burdock grow in it (Fig. 1).

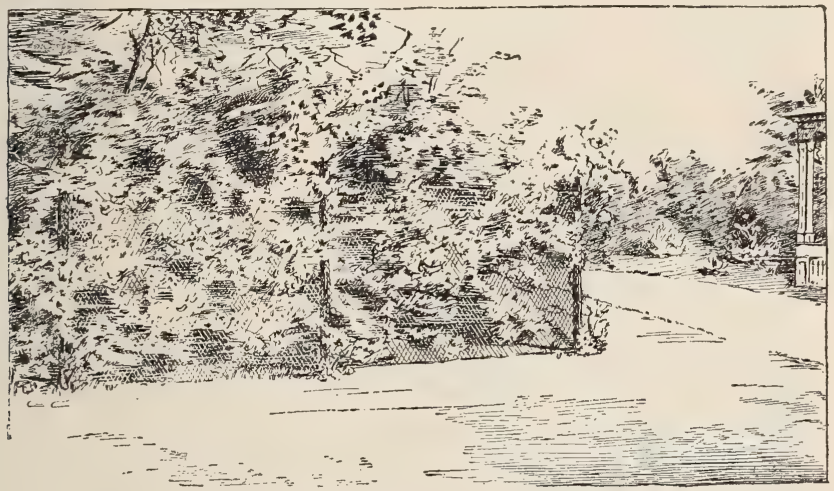

48. The screening of the tennis-screen.

The tennis-screen may be relieved by a background (Fig. 48 ), and a clump of ribbon-grass or something else is out of the way against a post (Fig. 49).

Excellent mass effects may be secured by cutting wellestablished plants of sumac, ailanthus, basswood, and other strong-growing things, to the ground each year, for the purpose of securing the stout shoots. Figure 50 will give the hint.

But if one has no area

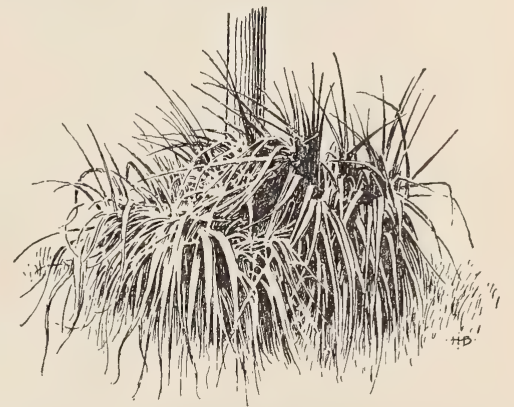

49. At the bottom of the clothes-post. which he can make into a lawn and upon which he can plant such verdurous masses, what then may he do? Even then 
there may be opportunity for a little neat and artistic planting. Even if one lives in a rented house, he may bring in a bush or an herb from the woods, and paint a picture with it. Plant it in the corner by the steps, in front of the porch, at the corner of the house, - almost anywhere except in the center of the lawn. Make the ground rich, secure a strong root, and plant it with care; then wait. The little clump will not only have a beauty and interest of its own, but it may add immensely to the furniture of the yard.

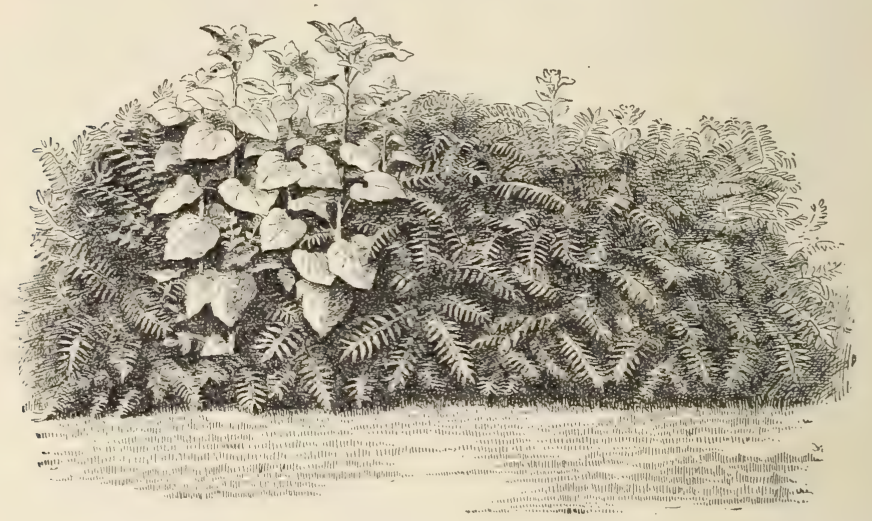

50. Young shoots of ailanthus (and sunflowers for variety).

About these clumps one may plant bulbs of glowing tulips or dainty snowdrops and lilies-of-the-valley; and these may be followed with pansies and phlox and other simple folk. Very soon one finds himself deeply interested in these random and detached pictures, and almost before he is aware he finds that he has rounded off the corners of the house, made snug little arbors of wild grapes and clematis, covered the rear fence and the outhouse with actinidia and bitter-sweet, and has thrown in dashes of color with hollyhocks, cannas, and lilies, and has tied the foundations of the buildings to the greensward by low 
strands of vines or deft bits of planting. He soon comes to feel that flowers are most expressive of the best emotions when they are daintily dropped in here and there against a background of foliage, or else made a side-piece in the place. There is no limit to the adaptations; Figs. 51 to 58 suggest some of the backyard possibilities.

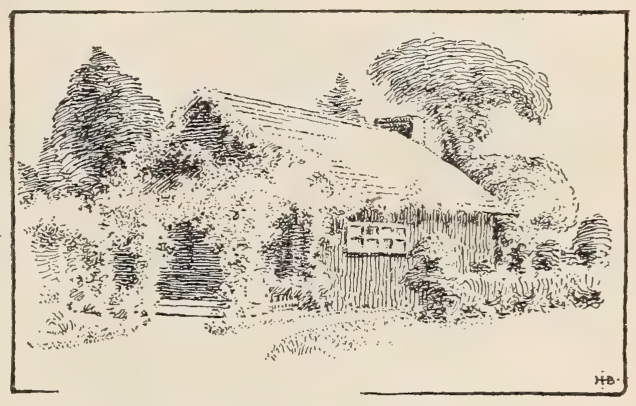

51. A back-yaird cabin.

Presently he rebels at the bold, harsh, and impudent de-

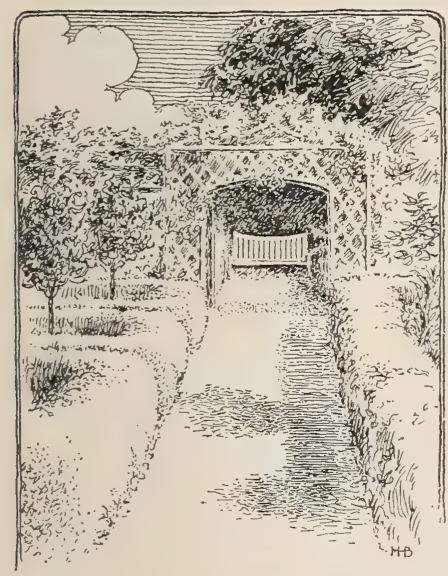

52. A garden path with hedgerows, trellis, and bench, in formal treatment. signs of some of the gardeners, and grows into a resourceful love of plant forms and verdure. He may still like the weeping and cut-leaved and party-colored trees of the horticulturist, but he sees that their best effects are to be had when they are planted sparingly, as borders or promontories of the structural masses.

The best planting, as the best painting and the best music, is possible only with the best and tenderest feeling and the closest living with nature. One's place grows to be a reflection of himself, changing as he changes, and expressing his life and sympathies to the last. 


\section{Review}

We have now discussed some of the principles and applications of landscape architecture or landscape gardening, par-

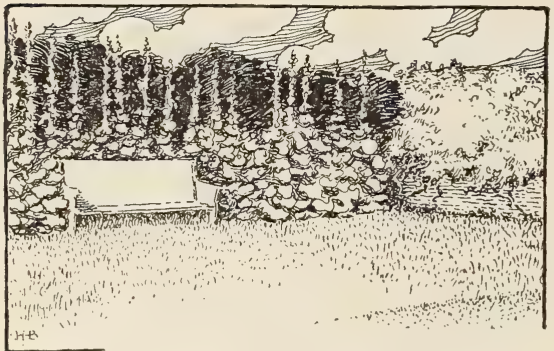

53. An enclosure for lawn games.

central figure, the planting completes the composition and adds the color.

The second conception is the principle that the picture should have a landscape effect. That is, it should be nature-like. Carpet-beds are masses of color, not pictures. They are the little garnishings and reliefs that are to be used very cautiously, as little eccentricities and conventionalisms in a building should never be more than very minor features.

Every other concept in landscape gardening is subordinate to these two. Some of the most important of these secondary yet underlying considerations are as follows:-

The place is to be conceived of as a unit. If a building is not pleasing, ask an architect to improve it. The real architect the planting. The object of landscape gardening is to make a picture. All the grading, seeding, planting, are incidental and supplemental to this one central idea. The greensward is the canvas, the house or some other prominent point is the

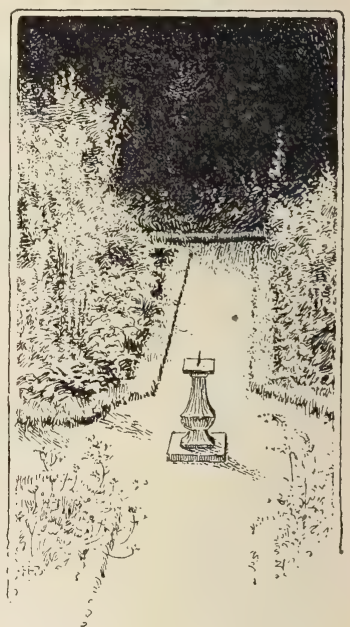

54. Sunlight and shadow. ticularly in reference to 
will study the building as a whole, grasp its design and meaning, and suggest improvements that will add to the forcefulness of the entire structure. A dabbler would add a chimney here, a window there, and apply various daubs of paint to the building. Each of these features might be good in itself. The paints might be the best of ochre, ultramarine, or paris green, but they might have no relation to the building as a whole and would be only ludicrous. These two examples illustrate the difference between landscape gardening and

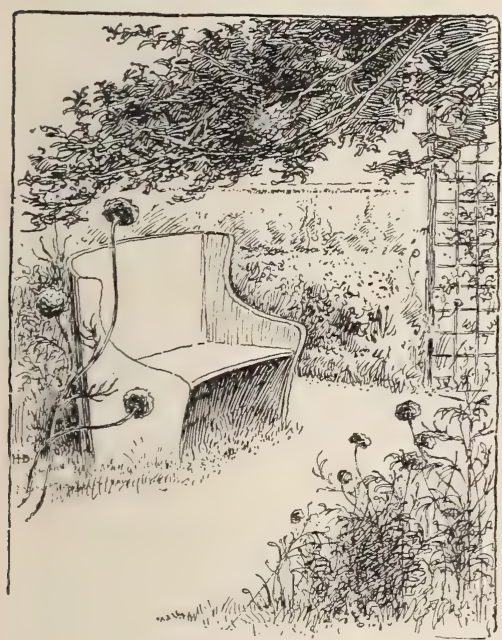

56. A garden corner.

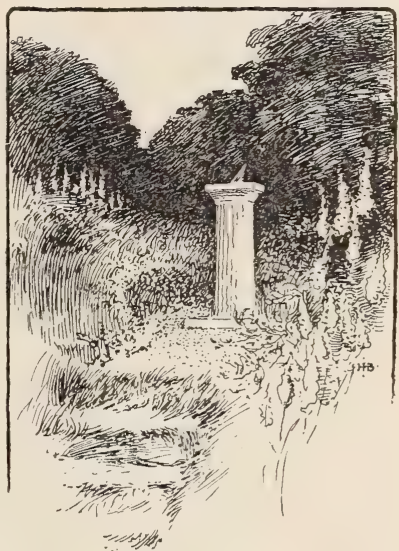

55. An upland garden, with grass-grown steps, sundial, and edge of foxgloves.

the scattering over the place of mere ornamental features.

There should be one central and emphatic point in the picture. A picture of a battle draws its interest from the action of a central figure or group. The moment the incidental and lateral figures are made as prominent as the central figures, the picture loses emphasis, life, and meaning. The borders of a place are of less importance than its center. Therefore Keep the center of the place open; Frame and mass the sides; Avoid scattered effects. 


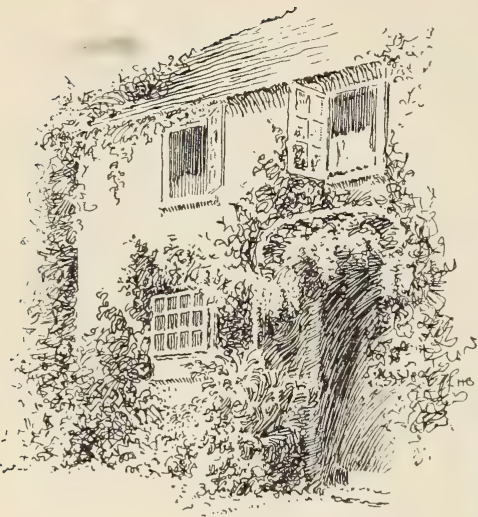

57. An old-fashioned doorway.

effective than twenty flowers in the center of the lawn.

More depends on the positions that plants occupy with reference to each other and to the structural design of the place, than on the intrinsic merits of the plants themselves.

Landscape gardening, then, is the embellishment of grounds in such a way that they will have a nature-like or landscape effect: The flowers and accessories may heighten and accelerate the effect, but they should not contradict it.

In a landscape picture flowers are incidents. They add emphasis, supply color, give variety and finish; they are the ornaments, but the lawn and the mass-plantings make the framework. One flower in the border, and made an incident of the picture, is more

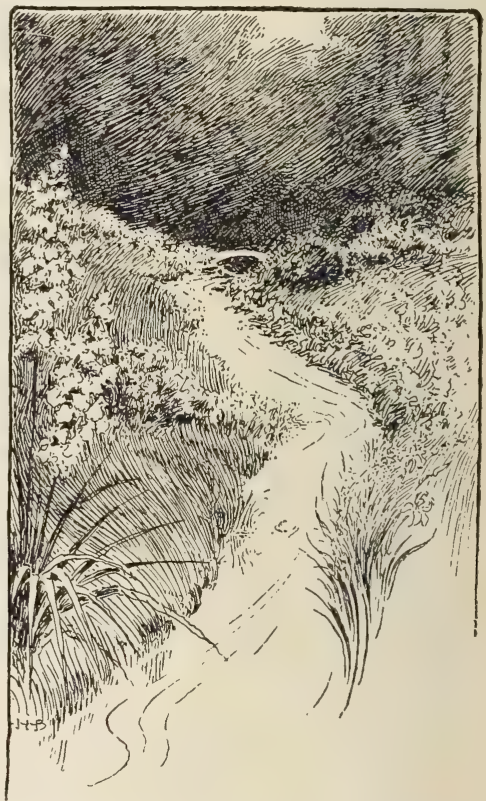

58. An informally treated stream. 


\section{CHAPTER III}

\section{EXECUTION OF SOME OF THE LANDSCAPE FEATURES}

THE general lay-out of a small home property having now been considered, we may discuss the practical operations of executing the plan. It is not intended in this chapter to discuss the general question of how to handle the soil: that discussion comes in Chapter IV; nor in detail how to handle plants: that occurs in Chapters $\mathrm{V}$ to $\mathrm{X}$; but the subjects of grading, laying out of walks and drives, executing the border plantings, and the making of lawns, may be briefly considered.

Of course the instructions given in a book, however complete, are very inadequate and unsatisfactory as compared with the advice of a good experienced person. It is not always possible to find such a person, however; and it is no little satisfaction to the homemaker if he can feel that he can handle the work himself, even at the expense of some mistakes.

\section{The grading.}

The first consideration is to grade the land. Grading is very expensive, especially if performed at a season when the soil is heavy with water. Every effort should be made, therefore, to reduce the grading to a minimum and still secure a pleasing contour. A good time to grade, if one has the time, is in the fall before the heavy rains come, and then allow the surface to settle until spring, when the finish may be made. All filling will settle in time unless thoroughly tamped as it proceeds.

The smaller the area the more pains must be taken with the grading; but in any plat that is one hundred feet or more square, 
very considerable undulations may be left in the surface with excellent effect. In lawns of this size, or even half this size, it is rarely advisable to have them perfectly flat and level. They should slope gradually away from the house; and when the lawn is seventy-five feet or more in width, it may be slightly crowning with good effect. A lawn should never be hollow, - that is, lower in the center than at the borders, - and broad lawns that are perfectly flat and level often appear to be hollow. A slope of one foot in twenty or thirty is none too much for a pleasant grade in lawns of some extent.

In small places, the grading may be done by the eye, unless there are very particular conditions to meet. In large or difficult areas, it is well to have the place contoured by instruments: This is particularly desirable if the grading is to be done on contract. A basal or datum line is established, above or below which all surfaces are to be shaped at measured distances. Even in small yards, such a datum line is desirable for the best kind of work.

\section{The terrace.}

In places in which the natural slope is very perceptible, there is a tendency to terrace the lawn for the purpose of making the various parts or sections of it more or less level and plane. In nearly all cases, however, a terrace in a main lawn is objectionable. It cuts the lawn into two or more portions, and thereby makes it look smaller and spoils the effect of the picture. A terrace always obtrudes a hard and rigid line, and fastens the attention upon itself rather than upon the landscape. Terraces are also expensive to make and to keep in order; and a shabby terrace is always distracting.

When formal effects are desired, their success depends, however, very largely on the rigidity of the lines and the care with which they are maintained. If a terrace is necessary, it should be in the form of a retaining wall next the street, or else it 


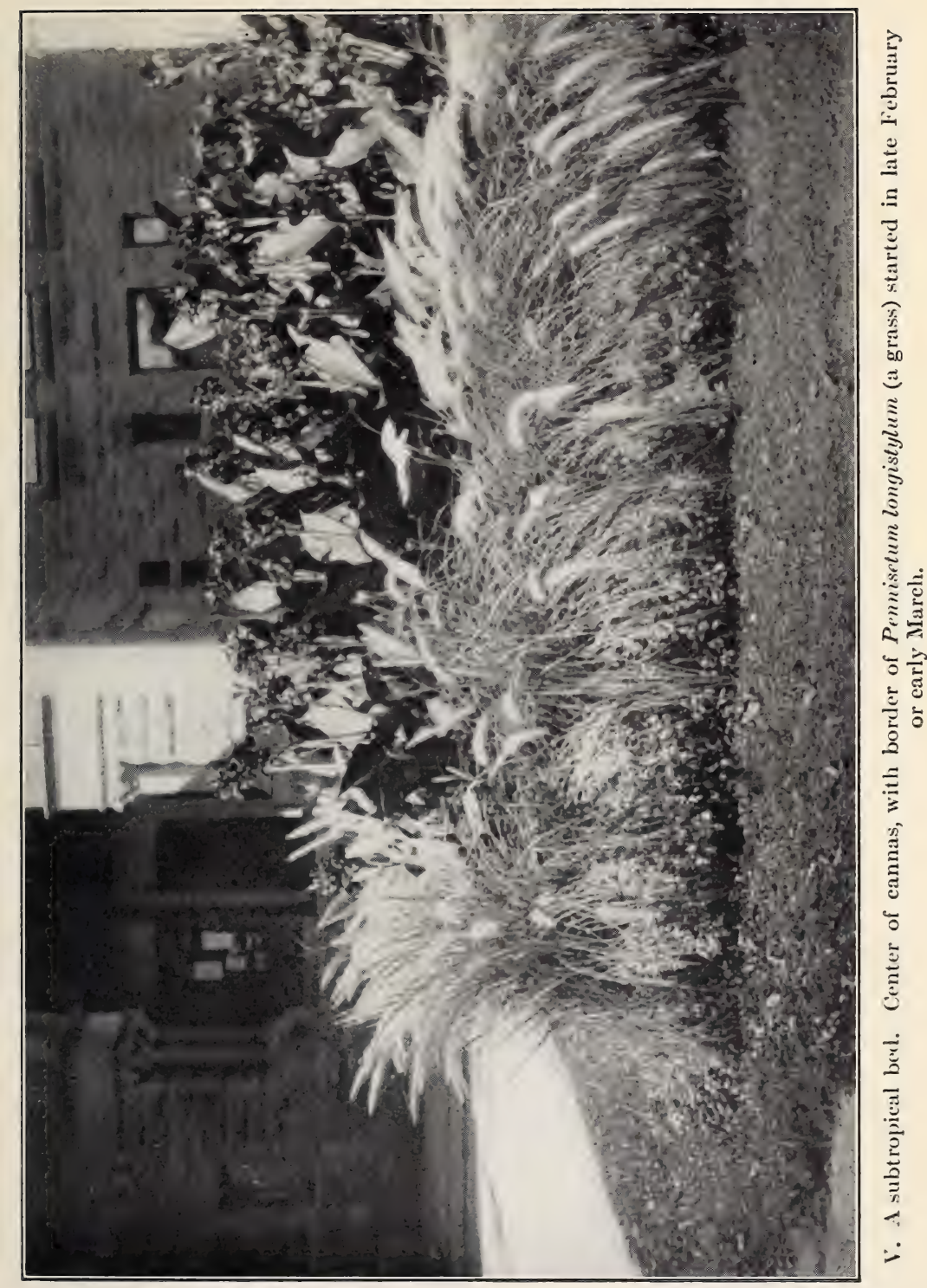



should lie next the building, giving as broad and continuous a lawn as possible. It should be remembered, however, that a terrace next a building should not be a part of the landscape, but a part of the architecture; that is, it should serve as a base to the building. It will at once be seen, therefore, that terraces are most in place against those buildings that have strong horizontal lines, and they are little suitable against buildings with very broken lines and mixed or gothic features. In order to join the terrace to the building, it is usually advisable to place some architectural feature upon its crown, as a balustrade, and to ascend it by means of architectural steps. The terrace elevation, therefore, becomes a part of the base of the building, and the top of it is an esplanade.

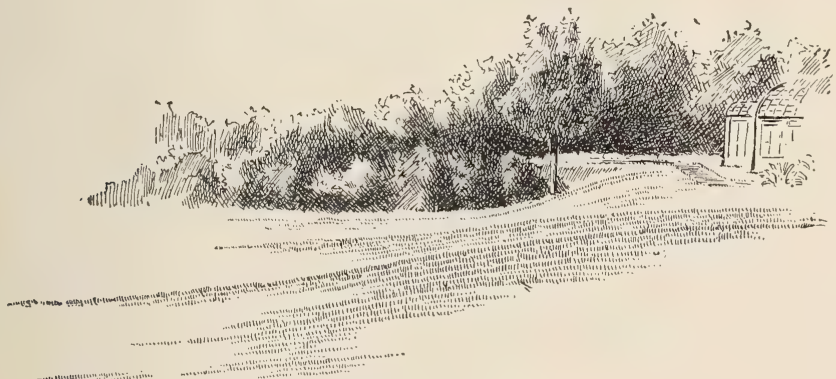

59. A terrace in the distance; in the foreground an ideal "running out" of the bank.

A simple and gradually sloping bank can nearly always be made to take the place of a terrace. For example, let the operator make a terrace, with sharp angles above and below, in the fall of the year; in the spring, he will find (if he has not sodded it heavily) that nature has taken the matter in hand and the upper angle of the terrace has been washed away and deposited in the lower angle, and the result is the beginning of a good series of curves. Figure 59 shows an ideal slope, with its double curve, comprising a convex curve on the top of the bank, 
and a concave curve at the lower part. This is a slope that would ordinarily be terraced, but in its present condition it is a part of the landscape picture. It may be mown as readily as any other part of the lawn, and it takes care of itself.

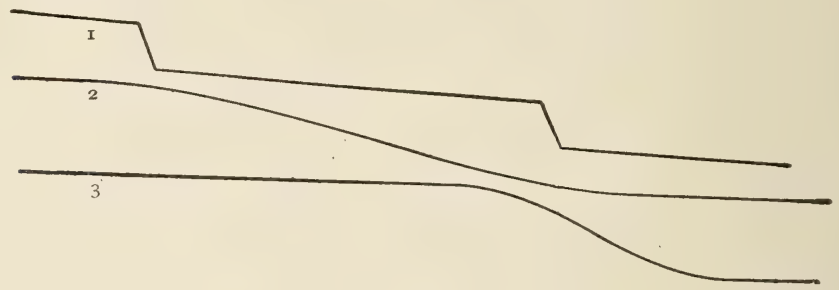

60. Treatment of a sloping lawn.

The diagrams in Fig. 60 indicate poor and good treatment of a lawn. The terraces are not needed in this case; or if they are, they should never be made as at 1 . The same dip could be taken up in a single curved bank, as at 3 , but the better way, in general, is to give the treatment shown in 2 .

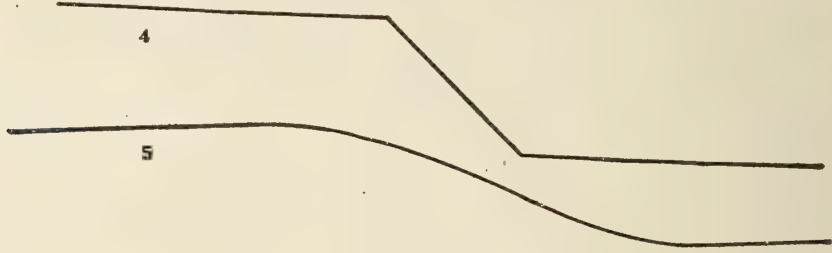

61. Treatment of a very steep bank.

Figure 61 shows how a very high terrace, 4, can be supplaced by a sloping bank 5 . Figure 62 shows a terrace that falls away too suddenly from the house.

\section{The bounding lines.}

In grading to the borders of the place, it is not always necessary, nor even desirable, that a continuous contour should be maintained, especially if the border is higher or lower than the 
1 lawn. A somewhat irrregular line of grade will appear to be most natural, and lend itself best to effective planting. This is specially true in the grade to watercourses, which, as a rule, should be more or less devious or winding; and the adjacent land should, therefore, present various heights and contours. It is not always necessary, however, to make distinct banks along water-courses, particu-

62. A terrace or slope that falls too suddenly away from a building. There should be a level place or esplanade next the building, if possible.

larly if the place is small and the natural lay of the land is more or less plane or flat. A very slight depression, as shown in Fig. 63, may answer all the purposes of a water grade in such places.

If it is desirable that the lawn be as large and spacious as possible, then the boundary of it should be removed. Take

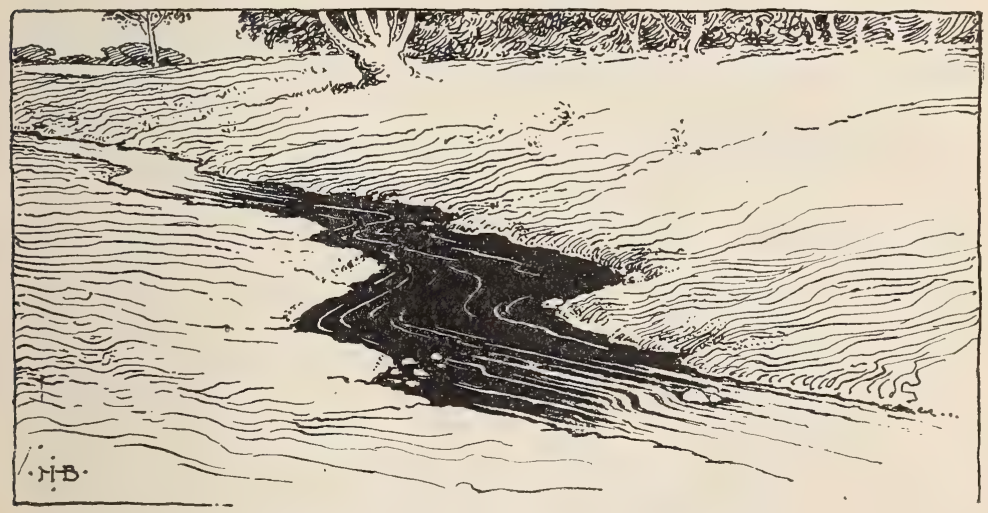

63. Shaping the land down to a water-course.

away the fences, curbing, and other right lines. In rural places, a sunken fence may sometimes be placed athwart the 
lawn at its farther edge for the purpose of keeping cattle off the place, and thereby bring in the adjacent landscape. Figure 64 suggests how this may be done. The depression near the foot of the lawn, which is really a ditch and scarcely visible from the

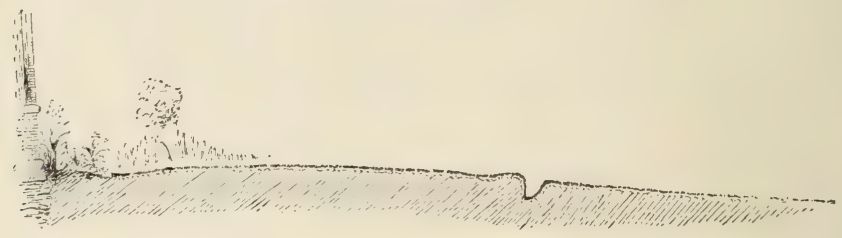

64. A sunken fence athwart a foreground.

upper part of the place because of the slight elevation on its inner rim, answers all the purposes of a fence.

Nearly all trees are injured if the dirt is filled about the base to the depth of a foot or more. The natural base of the plant should be exposed so far as possible, not only for protection of the tree, but because the base of a tree trunk is one of its most distinctive features. Oaks, maples, and in fact most

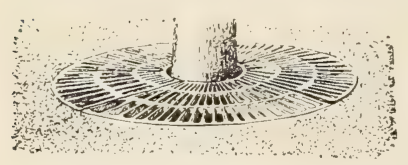

A good grating about a tree.
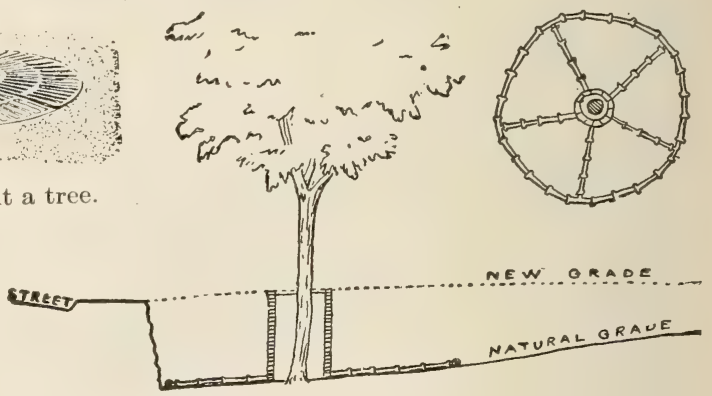

65. Protecting a tree in filled land.

trees will lose their bark near the crown if the dirt is piled against them; and this is especially true if the water tends to settle about the trunks. Figure 65 shows how this difficulty may be obviated. A well is stoned up, allowing a space of a 
foot or two on all sides, and tile drains are laid about the base of the well, as shown in the diagram at the right. A grating to cover a well is also shown. It is often possible to make a sloping bank just above the tree, and to allow the ground to fall away from the roots on the lower side, so that there is no well or hole; but this is practicable only when the land below the tree is considerably lower than that above it.

If much of the surface is to be removed, the good top earth should be saved, and placed back on the area, in which to sow the grass seed and to make the plantings. This top soil may be piled at one side out of the way while the grading is proceeding.

\section{Walks and drives.}

So far as the picture in the landscape is concerned, walks and drives are blemishes. Since they are necessary, however, they must form a part of the landscape design. They should be as few as possible, not only because they interfere with the artistic composition, but also because they are expensive to make and to maintain.

Most places have too many, rather than too few, walks and drives. Small city areas rarely need a driveway entrance, not even to the back door. The back yard in Fig. 39 illustrates this point. The distance from the house to the street on the back is about ninety feet, yet there is no driveway in the place. The coal and provisions are carried in; and, although the deliverymen may complain at first, they very soon accept the inevitable. It is not worth the while to maintain a drive in such a place for the convenience of truckmen and grocers. Neither is it often necessary to have a drive in the front yard if the house is within seventy-five or one hundred feet of the street. When a drive is necessary, it should enter, if possible, at the side of the residence, and not make a circle in the front lawn. This remark may not apply to areas of a half acre or more. 
The drives and walks should be direct. They should go where they appear to go, and should be practically the shortest distances between the points to be reached. Figure 66 illustrates some of the problems connected with walks to the front door. A common type of walk is $a$, and it is a nuisance. The time that one loses in going around the cameo-set in the center would be sufficient, if conserved, to lengthen a man's life by several months or a year. Such a device has no merit in art or convenience. Walk $b$ is better, but still is not ideal, inasmuch as it makes too much of a right-angled curve, and the

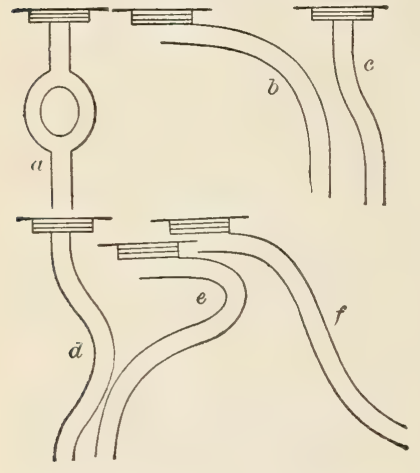

66. Forms of front walks. pedestrian desires to cut across the corner. Such a walk, also, usually extendis too far beyond the corner of the house to make it appear to be direct. It has the merit, however, of leaving the center of the lawn practically untouched. The curve in walk $d$ is ordinarily unnecessary unless the ground is rolling. In small places, like this, it is better to have a straight walk directly from the sidewalk to the house. In fact, this is true in nearly all cases in which the lawn is not more than forty to seventy-five feet deep. Plan $c$ is also inexcusable. A straight walk would answer every purpose better. Any walk that passes the house, and returns to it, $e$, is inexcusable unless it is necessary to make a very steep ascent. If most of the traveling is in one direction from the house, a walk like $f$ may be the most direct and efficient. It is known as a direct curve, and is a compound of a concave and a convex curve.

It is essential that any service walk or drive, however long, should be continuous in direction and désign from end to end. Figure 67 illustrates a long drive that contradicts this principle. 
It is a series of meaningless curves. The reason for these curves is the fact that the drive was extended from time to time as new houses were added to the villa. The reader will easily perceive how all the kinks might be taken out of this drive and one direct and bold curve be substituted.

\section{The question of} drainage, cürbing, and gutters.

Thorough drainage, natural or artificial, is essential to hard and permanent walks and drives. This point is too often neglected. On the draining and grading of residence streets a well-known landscape gardener, O. C. Simonds, writes as follows in "Park and Cemetery":

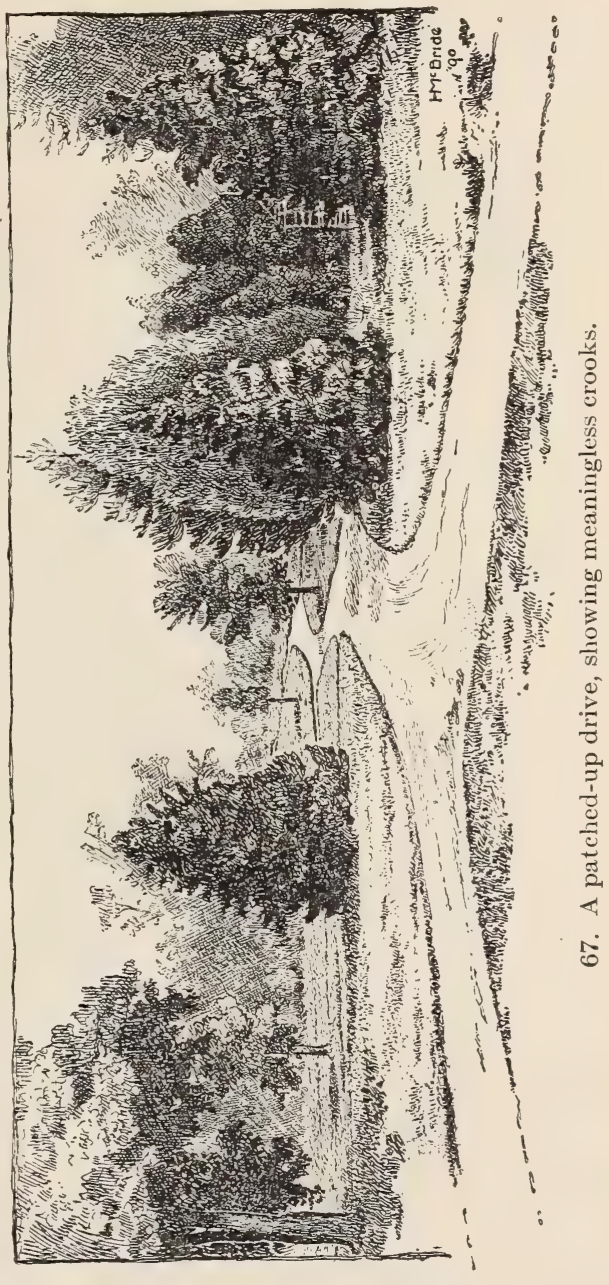

"The surface drainage is something that interests us whenever it rains or when the snow melts. It has been customary to locate catch-basins for receiving the surface water at street 
intersections. This arrangement causes most of the surface water from both streets to run past the crossings, making it necessary to depress the pavement, so that one must step down

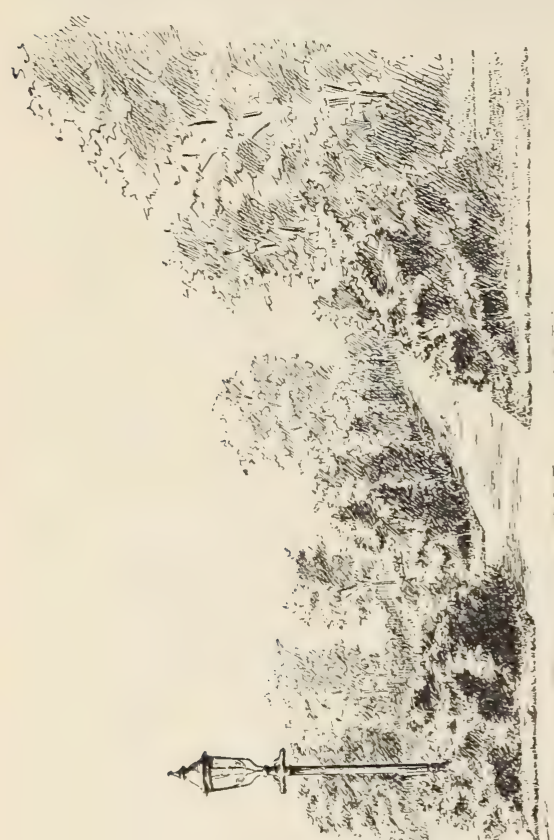
and up in going from one side of a street to the other, or else a passageway for $\cong$ the water must be made through the crossing. It ब) may be said that a step down to the pavement and up again to the sidewalk at the street intersections is of no consequence,but it is really more elegant and satisfactory to have the walk practically continuous (Fig. 68). With the catch-basin at the corner, the stoppage of the inlet, or a great fall of rain, sometimes covers the crossing with water, so that one must 
either wade or go out of his way. With catch-basins placed in the center of the blocks, or, if the blocks are long, at some distance from the crossing, the intersections can be kept relatively high and dry. Roadways are generally made crowning in the center so that water runs to the sides, but frequently the fall lengthwise of the roadway is less than it should be. City engineers are usually inclined to make the grade along the length of a street as nearly level as possible. Authorities who have given the subject of roads considerable study recommend a fall lengthwise of not less than one foot in one hundred and twenty-five, nor more than six feet in one hundred. Such grades are not always feasible, but a certain amount of varia-

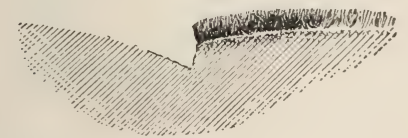

69. A common form of edge for walk or drive.

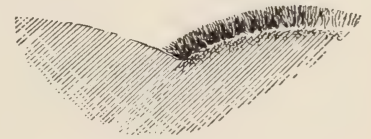

70. A better form.

tion in level can usually be made in a residence street which will make it much more pleasing in appearance, and have certain practical advantages in keeping the street dry. The water is usually confined to the edge of the pavement by curbing, which may rise anywhere from four to fourteen inches above the surface. This causes all the water falling on the roadway to seek the catch-basin and be wasted, excepting for its use in flushing the sewer. If the curbing, which is really unnecessary in most cases, were omitted, much of the surface water would soak into the ground between the sidewalk and the pavement, doing much good to trees, shrubs, and grass. The roots of the trees naturally extend as far, or farther, than their branches, and for their good the ground under the pavement and sidewalk should be supplied with a certain amount of moisture.

"The arrangement made for the removal of surface water from the street must also take care of the surplus water from 
adjacent lots, so there is a practical advantage in having the level of the street lower than that of the ground adjoining. The appearance of houses and home grounds is also much better when they are higher than the street, and for this reason it is usually desirable to keep the latter as low as possible and give the underground pipes sufficient covering to protect them from frost. Where the ground is high and the sewers very deep, the grades should, of course, be determined with reference to surface conditions only. It sometimes happens that this general arrangement of the grades of home grounds, which is desirable on most accounts, causes water from melting snow to flow over the sidewalk in the winter time, where it may freeze and be dangerous to pedestrians. A slight depression of the lot away from the sidewalk and then an ascent toward the house would usually remedy this difficulty, and also make the house appear higher. Sometimes, however, a pipe should be placed underneath the sidewalk to allow water to reach the street from inside of the lot line. The aim in surface drainage should always be to keep the traveled portions of the street in the most perfect condition for use. The quick removal of surplus water from sidewalks, crossings, and roadways will help insure this result."

These remarks concerning the curbings and hard edges of city streets may also be applied to walks and drives in small grounds. Figure 69, for example, shows the common method of treating the edge of a walk, by making a sharp and sheer elevation. This edge needs constant trimming, else it becomes unshapely; and this trimming tends to widen the walk. For general purposes, a border, like that shown in Fig. 70, is better. The sod rolls over until it meets the walk, and the lawn-mower is able to keep it in condition. If it becomes more or less rough and irregular, it is pounded down.

If it is thought necessary to trim the edges of walks and drives, then one of the various kinds of sod-cutters that are sold by 


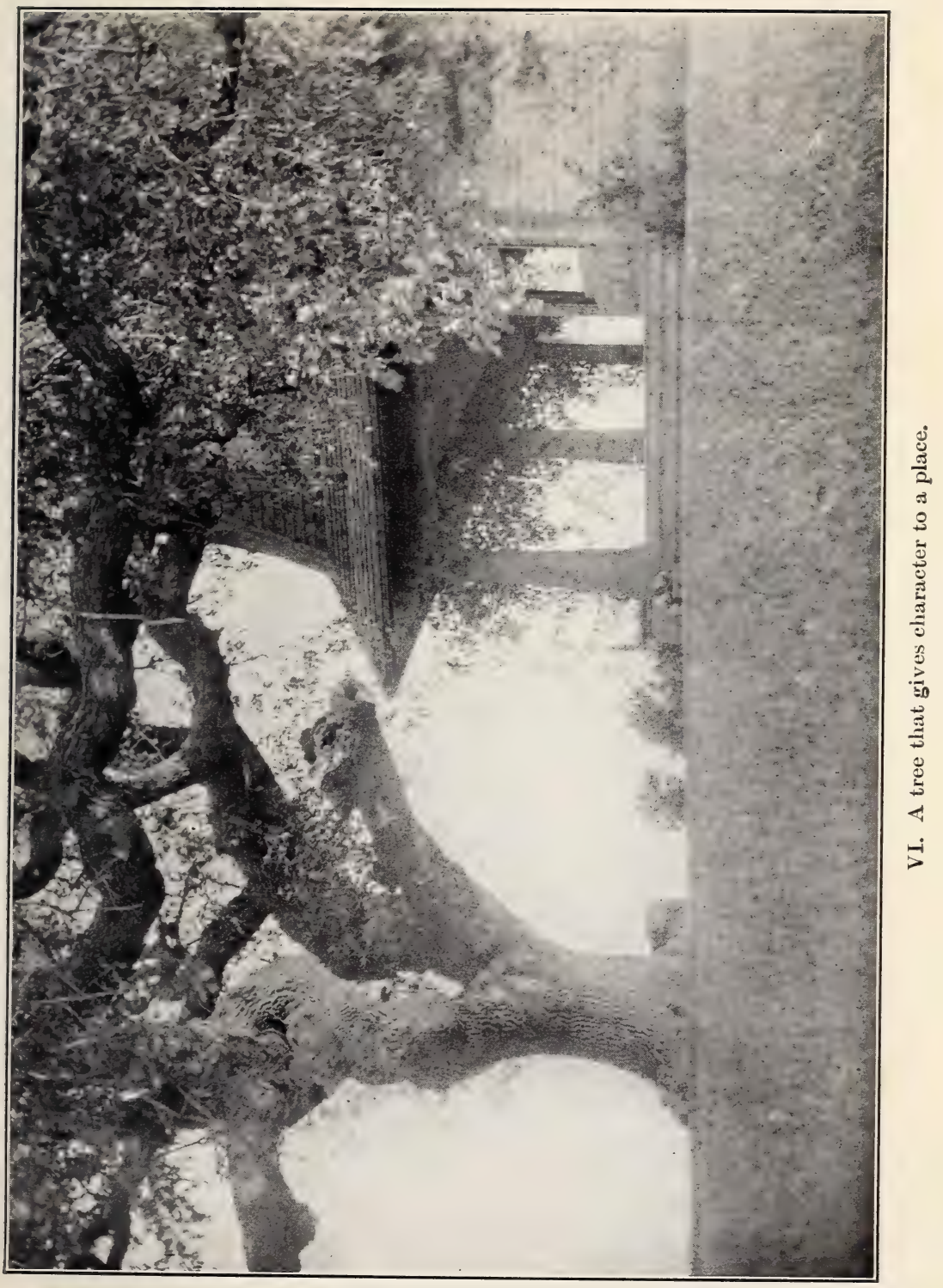



dealers may be used for the purpose, or an old hoe may have its shank straightened and the corners of the blade rounded off, as shown in Fig. 71, and this will answer all purposes of the common sod-cutter; or, a sharp, straight-edged spade may sometimes be used. The loose overhanging grass on these edges is ordinarily cut by large shears made for the purpose.

Walks and drives should be laid in such direction that they will tend to drain themselves; but if it is necessary to have gutters, these should be deep and sharp at the bottom, for the water then draws together and tends to keep the gutter clean. A shallow and rounded brick or cobble gutter does not clean itself; it is very likely to fill with weeds, and vehicles often drive in it.

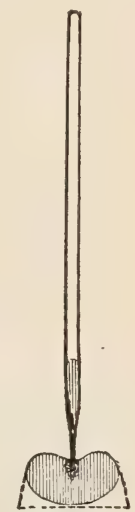

71. Sod cutter.

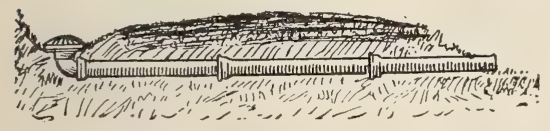

72. Draining the gutter and the drive.

underneath for the purpose of carrying away the surface water.

\section{The materials.}

The best materials for the main walks are cement and stone flagging. In many soils, however, there is enough binding material in the land to make a good walk without the addition of any other material. Gravel, cinders, ashes, and the like, are nearly always inadvisable, for they are liable to be loose in dry weather and sticky in wet weather. In the laying of cement it is important that the walk be well drained by a layer of a foot or two of broken stone or brickbats, unless the walk is on loose and leachy land or in a frostless country. 
In back yards it is often best not to have any well-defined walk. A ramble across the sod may be as good. For a back walk, over which delivery men are to travel, one of the very best means is to sink a foot-wide plank into the earth on a level with the surface of the sod; and it is not necessary that the walk be perfectly straight. These walks do not interfere with the work of the lawn-mower, and they take care of themselves.

When the plank rots, ten years, the plank is dropped in its place.

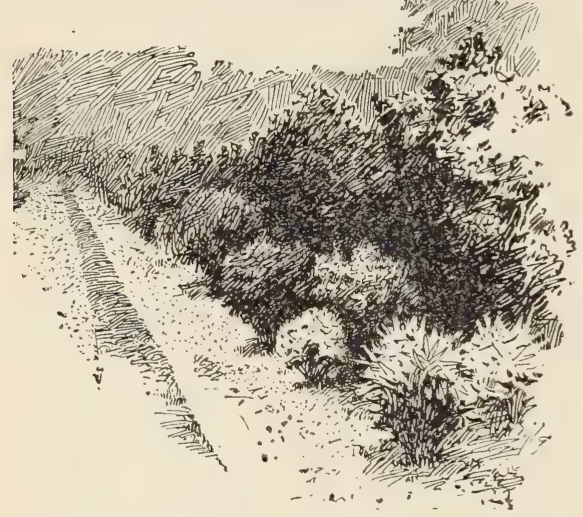

73. Planting alongside a walk. at the expiration of five to taken up and another one This ordinarily makes the best kind of a walk alongside a rear border. (Plate XI.) In gardens, nothing is better for a walk than tanbark.

The sides of walks and drives may often be planted with shrubbery. It is not necessary that they always have prim and definite borders. Figure 73 illustrates a bank of foliage which breaks up the hard line of a walk, and serves also as a border for the growing of flowers and interesting specimens. This walk is also characterized by the absence of high and hard borders. Figure 68 illustrates this fact, and also shows how the parking between the walk and the street may be effectively planted.

\section{Making the borders.}

The borders and groups of planting are laid out on the paper plan. There are several ways of transferring them to the ground. Sometimes they are not made until after the lawn is 
established, when the inexperienced operator may more readily lay them out. Usually, however, the planting and lawn-making proceed more or less simultaneously. After the shaping of the ground has been completed, the areas are marked off by stakes, by a limp rope laid on the surface, or by a mark made with a rake handle. The margin once determined, the lawn may be seeded and rolled (Fig. 40), and the planting allowed to proceed as it may; or the planting may all be done inside the borders, and the seeding then be applied to the lawn. If the main dimensions of the borders and beds are carefully measured and marked by stakes, it is an easy

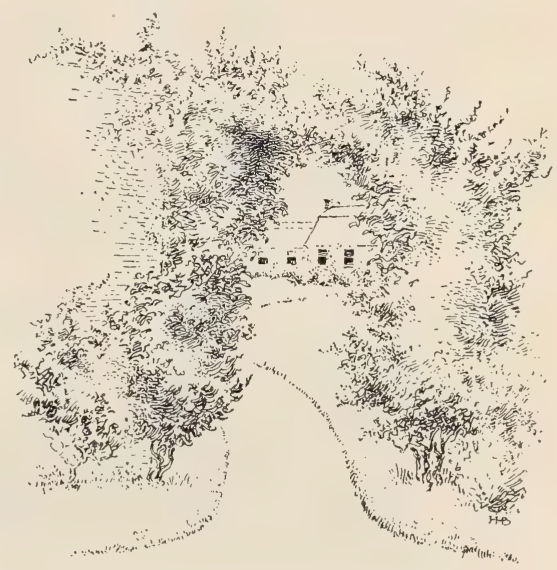

74. A bowered pathway. matter to complete the outline by making a mark with a stick or rakestale.

The planting may be done in spring or fall, - in fall preferably if the stock is ready (and of hardy species) and the land

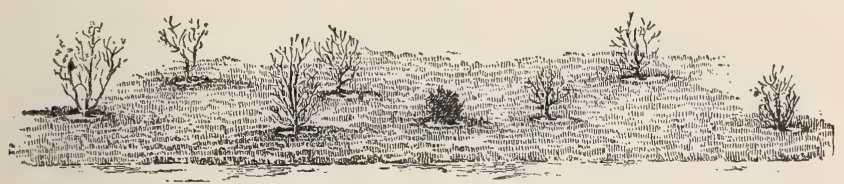

75. Objects for pity.

in perfect condition of drainage; usually, however, things are not ready early enough in the fall for any extended planting, and the work is commonly done as soon as the ground settles in spring (see Chapter V). Head the bushes back. Dig up the 
entire area. Spade up the ground, set the bushes thick, hoe them at intervals, and then let them go. If you do not like the bare earth between them, sow in the seeds of hardy annual flowers, like phlox, petunia, alyssum, and pinks. Never set the bushes in holes dug in the old sod (Fig. 75). The person who plants his shrubs in holes in the sward does not seriously mean to make any foliage mass, and it is likely that he does not know what relation the border mass has to artistic planting. The illustration, Fig. 76, shows the office that a shrubbery may perform in relation to a building; this particular building was erected in an open field.

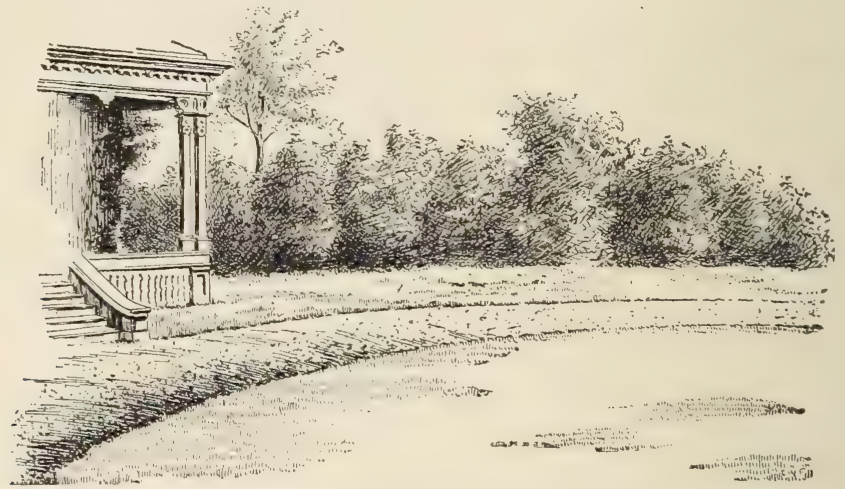

76. A border group, limiting the space next the residence and separating it from the fields and the clothes-yards.

I have said to plant the bushes thick. This is for quick effect. It is an easy matter to thin the plantation if it becomes too thick. All common bushes may usually be planted as close as two to three feet apart each way, especially if one gets many of them from the fields, so that he does not have to buy them. If there are not sufficient of the permanent bushes for thick planting, the spaces may be filled temporarily by cheaper or commoner bushes; but do not forget to remove the fillers as rapidly as the others need the room. 


\section{Making the lawn.}

The first thing to be done in the making of a lawn is to establish the proper grade. This should be worked out with the greatest care, from the fact that when a lawn is once made, it should not be necessary to change its level and contour.

\section{Preparing the ground.}

The next important step is to prepare the ground deeply and thoroughly. The permanence of the sod will depend very largely on the fertility and preparation of the soil in the beginning. The soil should be deep and porous, so that the roots will strike far into it, and be enabled thereby to withstand droughts and cold winters. The best means of deepening the soil, as explained in Chapter IV, is by tile-draining; but it can also be accomplished to some extent by the use of the subsoil plow and by trenching. Since the lawn cannot be refitted, however, the subsoil is likely to fall back into a hard-pan in a few years if it has been subsoiled or trenched, whereas a good tile-drain affords a permanent amelioration of the under soil. Soils that are naturally loose and porous may not need this extra attention. In fact, lands that are very loose and sandy may require to be packed or cemented rather than loosened.' One of the best means of doing this is to fill them with humus, so that the water will not leach through them rapidly. Nearly all lands that are designed for lawns are greatly benefited by heavy dressings of manure thoroughly worked into them in the beginning, although it is possible to get the ground too rich on the surface at first; it is not necessary that all the added plant-food be immediately available.

The lawn will profit by an annual application of good chemical fertilizer. Ground bone is one of the best materials to apply, at the rate of three hundred to four hundred pounds to the acre. It is usually sown broadcast, early in spring. Dis- 
solved South Carolina rock may be used instead, but the application will need to be heavier if similar results are expected. Yellow and poor grass may often be reinvigorated by an application of two hundred to three hundred pounds to the acre of nitrate of soda. Wood ashes are often good, particularly on soils that tend to be acid. Muriate of potash is not so often used, although it may produce excellent results in some cases. There is no invariable rule. The best plan is for the lawn-maker to try the different treatments on a little piece or corner of the lawn; in this way, he should secure more valuable information than can be got otherwise.

The first operation after draining and grading is the plowing or spading of the surface. If the area is large enough to admit a team, the surface is worked down by means of harrows of various kinds. Afterwards it is leveled by means of shovels and hoes, and finally by garden rakes. The more finely and completely the soil is pulverized, the quicker the lawn may be secured, and the more permanent are the results.

\section{The kind of grass.}

The best grass for the body or foundation of lawns in the North is June-grass or Kentucky blue-grass (Poa pratensis), not Canada blue-grass (Poa compressa).

Whether white clover or other seed should be sown with the grass seed is very largely a personal question. Some persons like it, and others do not. If it is desired, it may be sown directly after the grass seed is sown, at the rate of one to four quarts or more to the acre.

For special purposes, other grasses may be used for lawns. Various kinds of lawn mixtures are on the market, for particular uses, and some of them are very good.

A superintendent of parks in one of the Eastern cities gives the following experience on kinds of grass: "For the meadows on the large parks we generally use extra recleaned Kentucky 
blue-grass, red-top, and white clover, in the proportion of thirty pounds of blue-grass, thirty pounds of red-top, and ten pounds of white clover to the acre. Sometimes we use for smaller lawns the blue-grass and red-top without the white clover. We have used blue-grass, red-top, and Rhode Island bent in the proportion of twenty pounds each, and ten pounds of white clover to the acre, but the Rhode Island bent is so expensive that we rarely buy it. For grass in shady places, as in a grove, we use Kentucky blue-grass and rough-stalked meadow-grass (Poa trivialis) in equal parts at the rate of seventy pounds to the acre. On the golf links we use blue-grass without any mixture on some of the putting greens; sometimes we use Rhode Island bent, and on sandy greens we use red-top. We always buy each kind of seed separately and mix them, and are particular to get the best extra recleaned of each kind. Frequently we get the seed of three different dealers to secure the best."

In most cases, the June-grass germinates and grows somewhat slowly, and it is usually advisable to sow four or five quarts of timothy grass to the acre with the June-grass seed. The timothy comes on quickly and makes a green the first year, and the June-grass soon crowds it out. It is not advisable to sow grain in the lawn as a nurse to the grass. If the land is well prepared and the seed is sown in the cool part of the year, the grass ought to grow much better without the other crops than with them. Lands that are hard and lacking in nitrogen may.be benefited if crimson clover (four or five quarts) is sown with the grass seed. This will make a green the first year, and will break up the subsoil by its deep roots and supply nitrogen, and being an annual plant it does not become troublesome, if mown frequently enough to prevent seeding.

In the southern states, where June-grass does not thrive, Bermuda-grass is the leading species used for lawns; although there are two or three others, as the goose-grass of Florida, that may be used in special localities. Bermuda-grass is usually 
propagated by roots, but imported seed (said to be from Australia) is now available. The Bermuda-grass becomes reddish after frost; and English rye-grass may be sown on the Bermuda sod in August or September far south for winter green; in spring the Bermuda crowds it out.

When and how to sow the seed.

The lawn should be seeded when the land is moist and the weather comparatively cool. It is ordinarily most advisable to grade the lawn in late summer or early fall, because the land is then comparatively dry and can be moved cheaply. The surface can also be got in condition, perhaps, for sowing late in September or early in October in the North; or, if the surface has required much filling, it is well to leave it in a somewhat unfinished state until spring, in order that the soft places may settle and then be refilled before the seeding is done. If the seed can be sown early in the fall, before the rains come, the grass should be large enough, except in northernmost localities, to withstand the winter; but it is generally most desirable to sow in very early spring. If the land has been thoroughly prepared in the fall, the seed may be sown on one of the late light snows in spring and as the snow melts the seed is carried into the land, and germinates very quickly. If the seed is sown when the land is loose and workable, it should be raked in; and if the weather promises to be dry or the sowing is late, the surface should be rolled.

The seeding is usually done broadcast by hand on all small areas, the sower going both ways (at right angles) across the area to lessen the likelihood of missing any part. Steep banks are sometimes sown with seed that is mixed in mold or earth to which water is added until the material will just run through the spout of a watering-can; the material is then poured on the surface, which is first made loose.

Inasmuch as we desire to secure many very fine stalks of grass rather than a few large ones, it is essential that the seed 
be sown very thick. Three to five bushels to the acre is the ordinary application of grass seed (page 79).

\section{Securing a firm sod.}

The lawn will ordinarily produce a heavy crop of weeds the first year, especially if much stable manure has been used. The weeds need not be pulled, unless such vicious intruders as docks or other perennial plants gain a foothold; but the area should be mown frequently with a lawn-mower. The annual weeds die at the approach of cold, and they are kept down by the use of the lawn-mower, while the grass is not injured.

It rarely happens that every part of the lawn will have an equal catch of grass. The bare or sparsely seeded places should be sown again every fall and spring until the lawn is finally complete. In fact, it requires constant attention to keep a lawn in good sod, and it must be continuously in the process of making. It is not every lawn area, or every part of the area, that is adapted to grass; and it may require long study to find out why it is not. Bare or poor places should be hetcheled up strongly with an iron-toothed rake, perhaps fertilized again, and then reseeded. It is unusual that a lawn does not need repairing every year. Lawns of several acres which become thin and mossy may be treated in essentially the same way by dragging them with a spike-tooth harrow in early spring as soon as the land is dry enough to hold a team. Chemical fertilizers and grass seed are now sown liberally, and the area is perhaps dragged again, although this is not always essential; and then the roller is applied to bring the surface into a smooth condition. To plow up these poor lawns is to renew all the battle with weeds, and really to make no progress ; for, so long as the contour is correct, the lawn may be repaired by these surface applications.

The stronger the sward, the less the trouble with weeds; yet it is practically impossible to keep dandelions and some other weeds out of lawns except by cutting them out with a knife 
thrust underground (there are good spuds manufactured for this purpose, Figs. 108 to 111). If the sod is very thin after the weeds are removed, sow more grass seed.

\section{The mowing.}

The mowing of the lawn should begin as soon as the grass is tall enough in the spring and continue at the necessary intervals throughout the summer. The most frequent mowings are needed early in the season, when the grass is growing rapidly. If it is mown frequently - say once or twice a week - in the periods of most vigorous growth, it will not be necessary to rake off the mowings. In fact, it is preferable to leave the grass on the lawn, to be driven into the surface by the rains and to afford a mulch. It is only when the lawn has been neglected and the grass has got so high that it becomes unsightly on the lawn, or when the growth is unusually luxurious, that it is necessary to take it off. In dry weather care should be taken not to mow the lawn any more than absolutely necessary. The grass should be rather long when it goes into the winter. In the last two months of open weather the grass makes small growth, and it tends to lop down and to cover the surface densely, which it should be allowed to do.

\section{Fall treatment.}

As a rule, it is not necessary to rake all the leaves off lawns in the fall. They afford an excellent mulch, and in the autumn months the leaves on the lawn are among the most attractive features of the landscape. The leaves generally blow off after a time, and if the place has been constructed with an open center and heavily planted sides, the leaves will be caught in these masses of trees and shrubs and there afford an excellent mulch. The ideal landscape planting, therefore, takes care of itself to a very large extent. It is bad economy to burn the leaves, 
especially if one has herbaceous borders, roses, and other plants that need a mulch. When the leaves are taken off the borders in the spring, they should be piled with the manure or other refuse and there allowed to pass into compost (pages 110, 111).

If the land has been well prepared in the beginning, and its life is not sapped by large trees, it is ordinarily unnecessary to cover the lawn with manure in the fall. The common practice of covering grass with raw manure should be discouraged because the material is unsightly and unsavory, and the same results can be got with the use of commercial fertilizers combined with dressings of very fine and well-rotted compost or manure, and by not raking the lawn too clean of the mowings of the grass.

\section{Spring treatment.}

Every spring the lawn should be firmed by means of a roller, or, if the area is small, by means of a pounder, or the back of a spade in the hands of a vigorous man. The lawn-mower itself tends to pack the surface. If there are little irregularities in the surface, caused by depressions of an inch or so, and the highest places are not above the contour-line of the lawn, the surface may be brought to level by spreading fine, mellow soil over it, thereby filling up the depressions. The grass will quickly grow through this soil. Little hummocks may be cut off, some of the earth removed, and the sod replaced.

\section{Watering lawns.}

The common watering of lawns by means of lawn sprinklers usually does more harm than good. This results from the fact that the watering is generally done in clear weather, and the water is thrown through the air in very fine spray, so that a considerable part of it is lost in vapor. The ground is also hot, and the water does not pass deep into the soil. If the lawn is watered at all, it should be soaked; turn on the hose at nightfall and let it run until the land is wet as deep as it is dry, then 
move the hose to another place. A thorough soaking like this, a few times in a dry summer, will do more good than sprinkling every day. If the land is deeply prepared in the first place, so that the roots strike far into the soil, there is rarely need of watering unless the place is arid, the season unusually dry; or the moisture sucked out by trees. The surface sprinkling engenders a tendency of roots to start near the surface, and therefore the more the lawn is lightly watered, the greater is the necessity for watering it.

Sodding the lawn.

Persons who desire to secure a lawn very quickly may sod the area rather than seed it, although the most permanent results are usually secured by seeding. Sodding, however, is expensive, and is to be used only about the borders of the place, near buildings, or in areas in which the owner can afford to expend considerable money. The best sod is that which is secured from an old pasture, and for two or three reasons. In

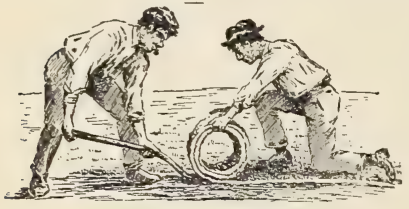

77. Cutting sod for a lawn. the first place, it is the right kind of grass, the June-grass (in the North) being the species that oftenest runs into pastures and crowds out other plants. Again, it has been so closely eaten down, especially if it has been pastured by sheep, that it has made a very dense and well-filled sod, which can be rolled up in thin layers. In the third place, the soil in old pastures is likely to be rich from the droppings of animals.

In taking sod, it is important that it be cut very thin. An inch and a half thick is usually ample. It is ordinarily rolled up in strips a foot wide and of any length that will allow the rolls to be handled by one or two men. A foot-wide board is laid upon the turf, and the sod cut along either edge of it. One person then stands upon the strip of sod and rolls it towards 
himself, while another cuts it loose with a spade, as shown in Fig. 77. When the sod is laid, it is unrolled on the land and then firmly beaten down. Land that is to be sodded should be soft on top, so that the sod can be well pounded into it. If the sod is not well pounded down, it will settle unevenly and present a bad surface, and will also dry out and perhaps not live through a dry spell. It is almost impossible to pound down sod too firm. If the land is freshly plowed, it is important that the borders that are sodded be an inch or two lower than the adjacent land, because the land will settle in the course of a few weeks. In a dry time, the sod may be covered from a half inch to an inch with fine, mellow soil as a mulch. The grass should grow through this soil without difficulty. Upon terraces and steep banks, the sod may be held in place by driving wooden pegs through it.

\section{A combination of}

sodding and seeding.

An "economical sodding" is described in "American Garden" (Fig. 78): "To obtain sufficient sod of suitable quality for covering terrace-slopes or small blocks that for any reason cannot well be seeded is often a difficult matter. In the accompanying illustration we show how a surface of sod may be used to good advantage over a larger area than its real measurement represents. This is done by laying the sods, cut in strips from

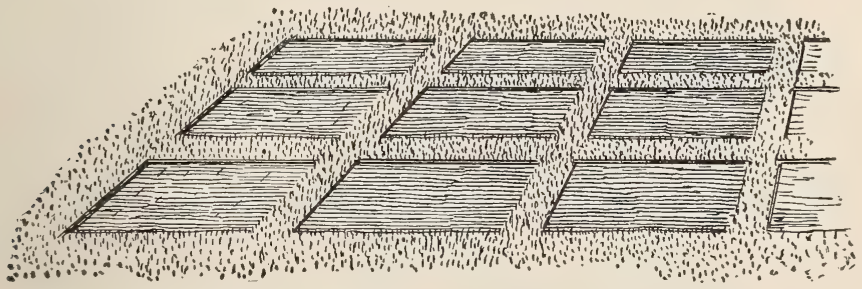

78. Economical sodding, the spaces being seeded. 
six to ten inches wide, in lines and cross-lines, and after filling the spaces with good soil, sowing these spaces with grass-seed. Should the catch of seed for any reason be poor, the sod of the strips will tend to spread over the spaces between them, and failure to obtain a good sward within a reasonable time is almost out of the question. Also, if one needs sod and has no place from which to cut it except the lawn, by taking up blocks of sod, leaving strips and cross-strips, and treating the surface as described, the bare places are soon covered with green."

\section{Sowing with sod.}

Lawns may be sown with pieces of sods rather than with seeds. Sods may be cut up into bits an inch or two square, and these may be scattered broadcast over the area and rolled into the land. While it is preferable that the pieces should lie right side up, this is not necessary if they are cut thin, and sown when the weather is cool and moist. Sowing pieces of sod is good practice when it is difficult to secure a catch from seed.

If one were to maintain a permanent sod garden, at one side, for the selecting and growing of the very best sod (as he would grow a stock seed of corn or beans), this method should be the most rational of all procedures, at least until the time that we produce strains of lawn grass that come true from seeds.

\section{Other ground covers.}

Under trees, and in other shady places, it may be necessary to cover the ground with something else than grass. Good plants for such uses are periwinkle (Vinca minor, an evergreen trailer, often called "running myrtle"), moneywort (Lysimachia nummularia), lily-of-the-valley, and various kinds of sedge or carex. In some dark or shady places, and under some kinds of trees, it is practically impossible to secure a good lawn, and one may be obliged to resort to decumbent bushes or other forms of planting. 


\section{CHAPTER IV}

\section{THE HANDLING OF THE LAND}

ALmost any land contains enough food for the growing of good crops, but the food elements may be chemically unavailable, or there may be insufficient water to dissolve them. It is too long a story to explain at this place, - the philosophy of tillage and of enriching the land, - and the reader who desires to make excursions into this delightful subject should consult King on "The Soil," Roberts on "The Fertility of the Land," and recent writings of many kinds. The reader must accept my word for it that tilling the land renders it productive.

I must call my reader's attention to the fact that this book is on the making of gardens, - on the planning and the doing of the work from the year's end to end, - not on the appreciation of a completed garden. I want the reader to know that a garden is not worth having unless he makes it with his own hands or helps to make it. He must work himself into it. He must know the pleasure of preparing the land, of contending with bugs and all other difficulties, for it is only thereby that he comes into appreciation of the real value of a garden.

I am saying this to prepare the reader for the work that I lay out in this chapter. I want him to know the real joy that there is in the simple processes of breaking the earth and fitting it for the seed. The more pains he takes with these processes, naturally the keener will be his enjoyment of them. No one can have any other satisfaction than that of mere manual exercise if he does not know the reasons for what he does with his soil. I am sure that my keenest delight in a garden com?s in the one month of the opening season and the other month of 
the closing season. These are the months when I work hardest and when I am nearest the soil. To feel the thrust of the spade, to smell the sweet earth, to prepare for the young plants and then to prepare for the closing year, to handle the tools with discrimination, to guard against frost, to be close with the rain and wind, to see the young things start into life and then to see them go down into winter, - these are some of the best of the joys of gardening. In this spirit we should take up the work of handling the land.

\section{The draining of the land.}

The first step in the preparation of land, after it has been thoroughly cleared and subdued of forest or previous vegetation,

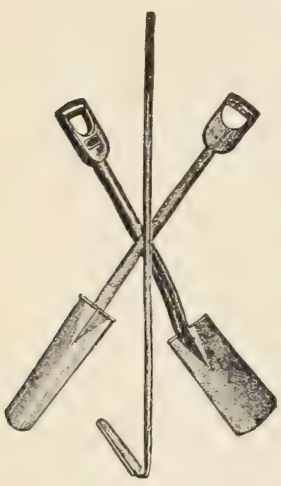

79. Ditching tools. is to attend to the drainage. All land that is springy, low, and "sour," or that holds the water in puddles for a day or two following heavy rains, should be thoroughly underdrained. Draining also improves the physical condition of the soil even when the land does not need the removal of superfluous water. In hard lands, it lowers the water-table, or tends to loosen and aerate the soil to a greater depth, and thereby enables it to hold more water without injury to plants. Drainage is particularly useful in dry but hard garden lands, because these lands are often in sod or permanently planted, and the soil cannot be broken up by deep tillage. Tile drainage is permanent subsoiling.

Hard-baked cylindrical tiles make the best and most permanent drains. The ditches usually should not be less than two and one-half feet deep, and three or three and one-half feet is often better. In most garden areas, drains may be laid with profit as often as every thirty feet. Give all drains 
a good and continuous fall. For single drains and for laterals not over four hundred or five hundred feet long, a two and onehalf inch tile is sufficient, unless much water must be carried from swales or springs. In stony countries, flat stones may be used in place of tiles, and persons who are skillful in laying them make drains as good and permanent as those constructed of tiles. The tiles or stones are covered with sods, straw, or paper, and the earth is then filled in. This temporary cover

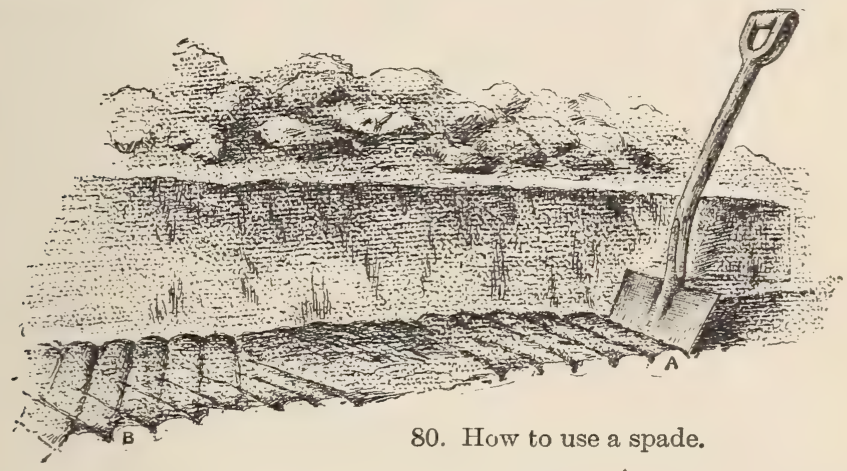

keeps the loose dirt out of the tiles, and by the time it is rotted the earth has settled into place.

In small places, ditching must ordinarily be done wholly with hand tools. A common spade and pick are the implements usually employed, although a spade with a long handle and narrow blade, as shown in Fig. 79, is very useful for excavating the bottom of the ditch.

In most cases, much time and muscle are wasted in the use of the pick. If the digging is properly done, a spade can be used to cut the soil, even in fairly hard clay land, with no great difficulty. The essential point in the easy use of the spade is to manage so that one edge of the spade always cuts a free or exposed surface. The illustration (Fig. 80) will explain the method. When the operator endeavors to cut the soil in the 
method shown at $\mathrm{A}$, he is obliged to break both edges at every thrust of the tool; but when he cuts the slice diagonally, first throwing his spade to the right and then to the left, as shown at $\mathrm{B}$, he cuts only one side and is able to make progress without the expenditure of useless effort. These remarks will apply to any spading of the land.

In large areas, horses may be used to facilitate the work of ditching. There are ditching plows and machines, which, however, need not be discussed here; but three or four furrows may be thrown out in either direction with a strong plow, and a subsoil plow be run behind to break up the hard-pan, and this may reduce the labor of digging as much as one-half. When the excavating is completed, the bottom of the ditch is evened up by means of a line or level, and the bed for the tiles is prepared by the use of a goose-neck scoop, shown in Fig. 79. It is very important that the outlets of drains be kept free of weeds and litter. If the outlet is built up with mason work, to hold the end of the tile intact, very much will be added to the permanency of the drain.

Trenching and subsoiling.

Although underdraining is the most important means of increasing the depth of the soil, it is not always practicable
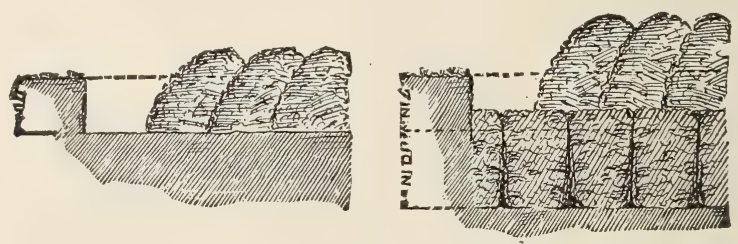

- $\quad$ 81. Trenching with a spade.

to lay drains through garden lands. In such cases, recourse is had to very deep preparation of the land, either every year or every two or three years. 
In small garden areas, this deep preparation will ordinarily be done by trenching with a spade. This operation of trenching consists in breaking up the earth two spades deep. Figure 81 explains the operation. The section at the left shows a single spading, the earth being thrown over to the right, leaving the subsoil exposed the whole width of the bed. The section at the right shows a similar operation, so far as the surface spading is concerned, but the subsoil has also been cut as fast as it has been exposed. This under soil is not thrown out on the surface,

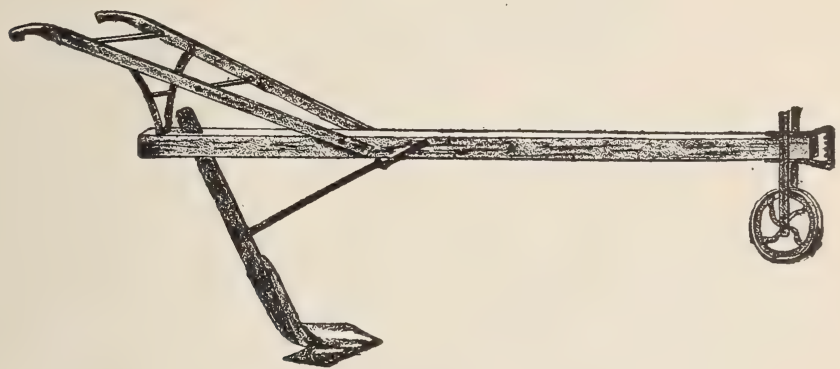

82. Home-made subsoil plow.

and usually it is not inverted; but a spadeful is lifted and then allowed to drop so that it is thoroughly broken and pulverized in the manipulation.

In all lands that have a hard and high subsoil, it is usually essential to practice trenching if the best results are to be secured; this is especially true when deep-rooted plants, as beets, parsnips, and other root-crops, are to be grown; it prepares the soil to hold moisture; and it allows the water of heavy rainfall to pass to greater depths rather than to be held as puddles and in mud on the surface.

In places that can be entered with a team, deep and heavy plowing to the depth of seven to ten inches may be desirable on hard lands, especially if such lands cannot be plowed very 
often; and the depth of the pulverization is often extended by means of the subsoil plow. This subsoil plow does not turn a furrow, but a second team draws the implement behind the ordinary plow, and the bottom of the furrow is loosened and

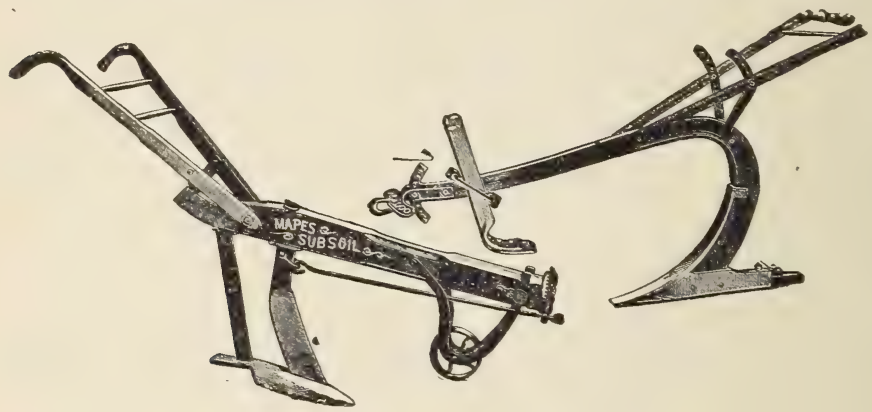

83. Forms of subsoil plows.

broken. Figure 82 shows a home-made subsoil plow, and Fig. 83 two types of commercial tools. It must be remembered that it is the hardest lands that need subsoiling and that, therefore, the subsoil plow should be exceedingly strong.

\section{Preparation of the surface.}

Every pains should be taken to prevent the surface of the land from becoming crusty or baked, for the hard surface establishes a capillary connection with the moist soil beneath, and is a means of passing off the water into the atmosphere. Loose and mellow soil also has more free plant-food, and provides the most congenial conditions for the growth of plants. The tools that one may use in preparing the surface soil are now so many and so well adapted to the work that the gardener should find special satisfaction in handling them.

If the soil is a stiff clay, it is often advisable to plow it or dig it in the fall, allowing it to lie rough and loose all winter, so that the weathering may pulverize and slake it. If the clay is very 
tenacious, it may be necessary to throw leafmold or litter over the surface before the spading is done, to prevent the soil from running together or cementing before spring. With mellow and loamy lands, however, it is ordinarily best to leave the preparation of the surface until spring.

In the preparation of the surface, the ordinary hand tools, or spades and shovels, may be used. If, however, the soil is mellow, a fork is a better tool than a spade, from the fact that it does not slice the soil, but tends to break it up into smaller and more irregular masses. The ordinary spadingfork, with strong flat tines, is a most serviceable tool; a spading-fork for soft ground may be made from an old manure fork by cutting down the tines, as shown in Fig. 84.

It is important that the soil should not be sticky when it is prepared, as it is likely to become hard and baked and the physical condition be greatly injured. However, land that is too wet for the 84. Improvisreception of seeds may still be thrown up loose with a spade or fork and allowed to dry, and after

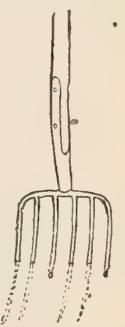
two or three days the surface preparation may be completed with the hoe and the rake. In ordinary soils the hoe is the tool to follow the spading-fork or the spade, but for the final preparation of the surface a steel garden-rake is the ideal implement.

In areas, large enough to admit horse tools, the land can be fitted more economically by means of the various types of plows, harrows, and cultivators that are to be had of any dealer in agricultural implements. Figure 85 shows various types of model surface plows. The one shown at the upper left-hand is considered by Roberts, in his "Fertility of the Land," to be the ideal general-purpose plow, as respects shape and method of construction.

The type of machine to be used must be determined wholly 
by the character of the land and the purposes for which it is to be fitted. Lands that are hard and cloddy may be reduced by the use of the disk or Acme harrows, shown in Fig. 86; but

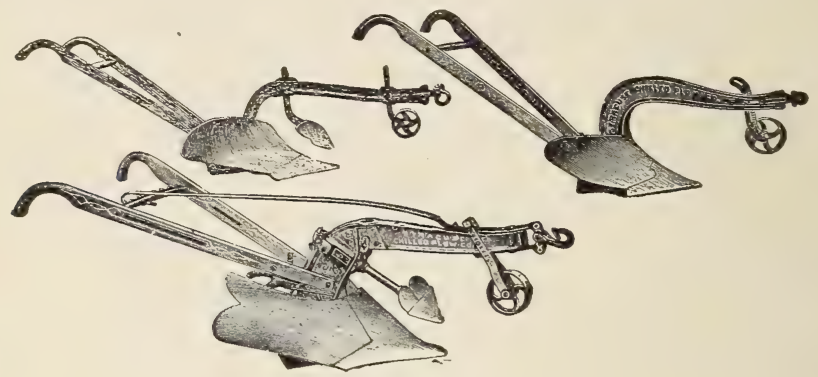

85. Excellent types of surface plows.

those that are friable and mellow may not need such heavy and vigorous tools. On these mellower lands, the spring-tooth

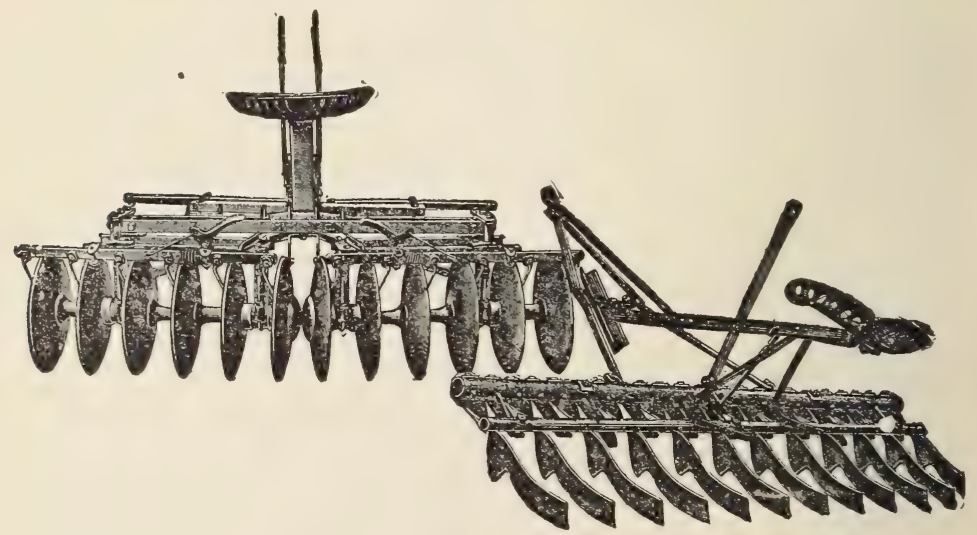

86. Disk and Acme harrows, for the first working of hard or cloddy land.

harrow, types of which are shown in Fig. 87, may follow the plow. On very hard lands, these spring-tooth harrows may follow the disk and Acme types. The final preparation of the 
land is accomplished by light implements of the pattern shown in Fig. 88. These spike-tooth smoothing-harrows do for the field what the hand-rake does for the garden-bed. If it is desired to put a very fine finish on the surface of the ground by means of horse tools, implements like the Breed or Wiard weeder may be used. These are con- structed on the principle of a spring-tooth horse hay-rake, and are most excellent, not only for fitting loose land for ordinary seeding, but also for subsequent tillage.

In areas that cannot be entered with a team,

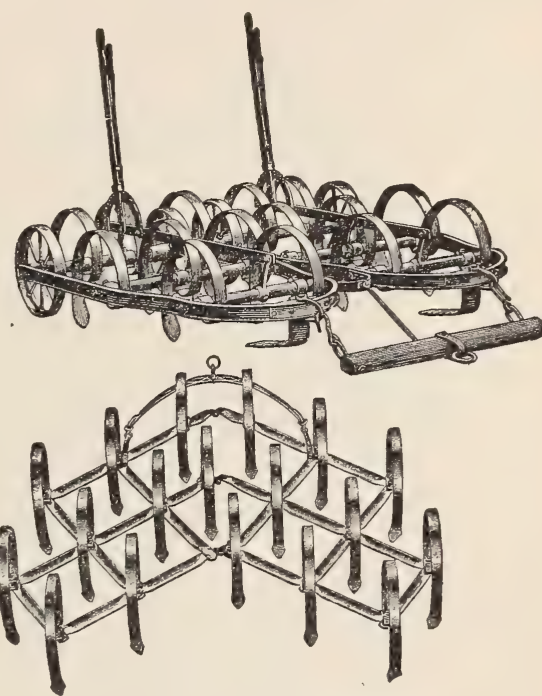

87. Spring-tooth harrows. various one-horse implements may do the work that is accomplished by heavier tools in the field. The spring-tooth cultivator, shown at the right in Fig. 89, may do the kind of work

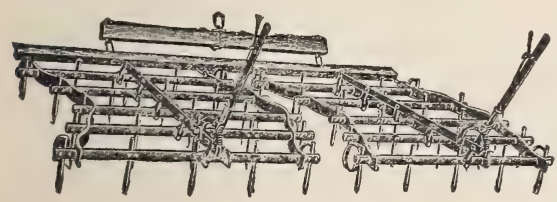

88. Spike-tooth harrow. that the spring-tooth harrows are expected to do on larger areas; and. various adjustable spiketooth cultivators, two of which are shown in Fig. 89 , are useful for putting a finish on the land. These tools are also available for the tilling of the surface when crops are growing. The spring-tooth cultivator is a most useful tool for cultivating raspberries and blackberries, and other strong-rooted crops. 


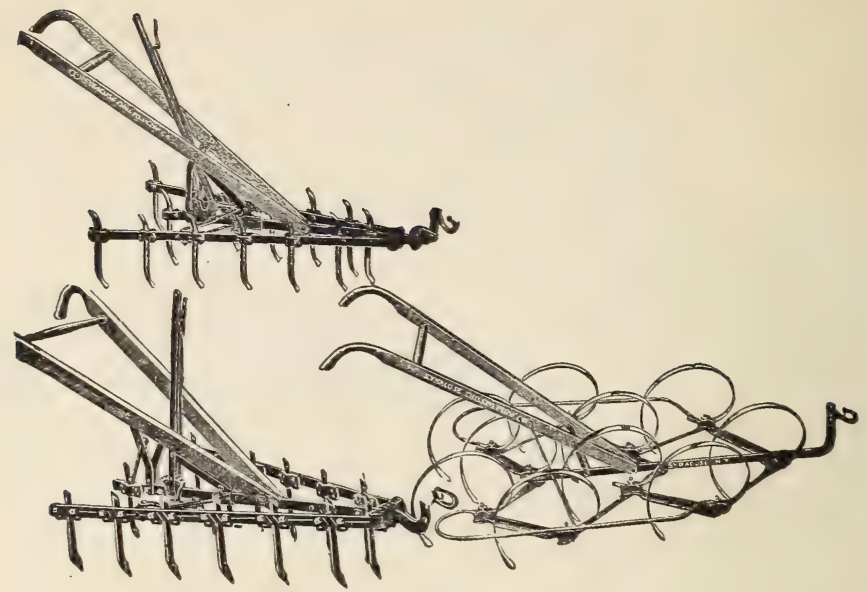

89. Spike-tooth and spring-tooth cultivators.

For still smaller areas, in which horses cannot be used and which are still too large for tilling wholly by means of hoes

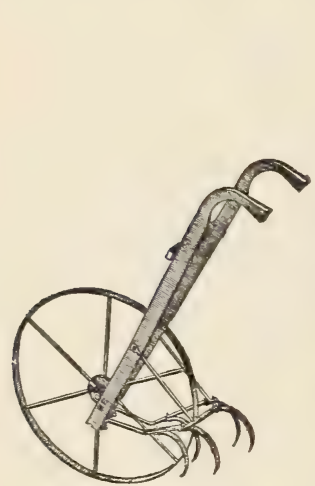

90. Good type of wheel-hoe.

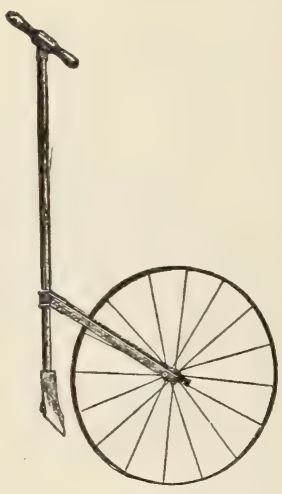

91. A single-blade wheel-hoe.

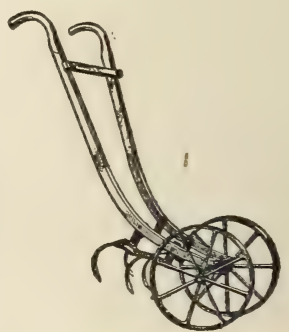

92. Double wheelhoe, useful.in straddling the row.

and rakes, various types of wheel-hoes may be used. These implements are now made in great variety of patterns, to 
suit any taste and almost any kind of tillage. For the best results, it is essential that the wheel should be large and with a broad tire, that it may override obstacles. Figure 90 shows an excellent type of wheel-hoe with five blades, and Fig. 91 shows one with a single blade and that may be used in very narrow rows. Two-wheeled hoes (Fig. 92) are often used, particularly when it is necessary to have the implement very steady, and the wheels may straddle the rows of low plants. Many of these wheel-hoes are provided with various shapes of blades, so that the implement may be adjusted to many kinds of work. Nearly all the weeding of beds of onions and like plants can be done by means of these wheel-hoes, if the ground is well prepared in the beginning; but it must be remembered that they are of comparatively small use on very hard and cloddy and stony lands.

\section{The saving of moisture.}

The garden must have a liberal supply of moisture. The first effort toward securing this supply should be the saving of the rainfall water.

Proper preparation and tillage put the land in such condition that it holds the water of rainfall. Land that is very hard and compact may shed the rainfall, particularly if it is sloping and if the surface is bare of vegetation. If the hard-pan is near the surface, the land cannot hold much water, and any ordinary rainfall may fill it so full that it overflows, or puddles stand on the surface. On land in good tilth, the water of rainfall sinks away, and is not visible as free water.

As soon as the moisture begins to pass from the superincumbent atmosphere, evaporation begins from the surface of the land. Any body interposed between the land and the air checks this evaporation; this is why there is moisture underneath a board. It is impracticable, however, to floor over the garden with boards, but any covering will have similar effect, 
but in different degree. A covering of sawdust or leaves or dry ashes will prevent the loss of moisture. So will a covering of dry earth. Now, inasmuch as the land is already covered with earth, it only remains to loosen up a layer or, stratum on top in order to secure the mulch.

All this is only a roundabout way of saying that frequent shallow surface tillage conserves moisture. The comparatively dry and loose mulch breaks up the capillary connection between the surface soil and the under soil, and while the mulch itself may be useless as a foraging ground for roots, it more than pays its keep by its preventing of the loss of moisture; and its own soluble plant-foods are washed down into the lower soil by the rains.

As often as the surface becomes compact, the mulch should be renewed or repaired by the use of the rake or cultivator or harrow. Persons are deceived by supposing that so long as the surface remains moist, the land is in the best possible condition; a moist surface may mean that water is rapidly passing off into the atmosphere. A dry surface may mean that less evaporation is taking place, and there may be moister earth beneath it; and moisture is needed below the surface rather than on top. A finely raked bed is dry on top; but the footprints of the cat remain moist, for the animal packed the soil wherever it stepped and a capillary connection was established with the water reservoir beneath. Gardeners advise firming the earth over newly planted seeds to hasten germination. This is essential in dry times; but what we gain in hastening germination we lose in the more rapid evaporation of moisture. The lesson is that we should loosen the soil as soon as the seeds have germinated, to reduce evaporation to the minimum. Large seeds, as beans and peas, may be planted deep and have the earth firmed about them, and then the rake may be applied to the surface to stop the rise of moisture before it reaches the air.

Two illustrations, adapted from Roberts's "Fertility," show 


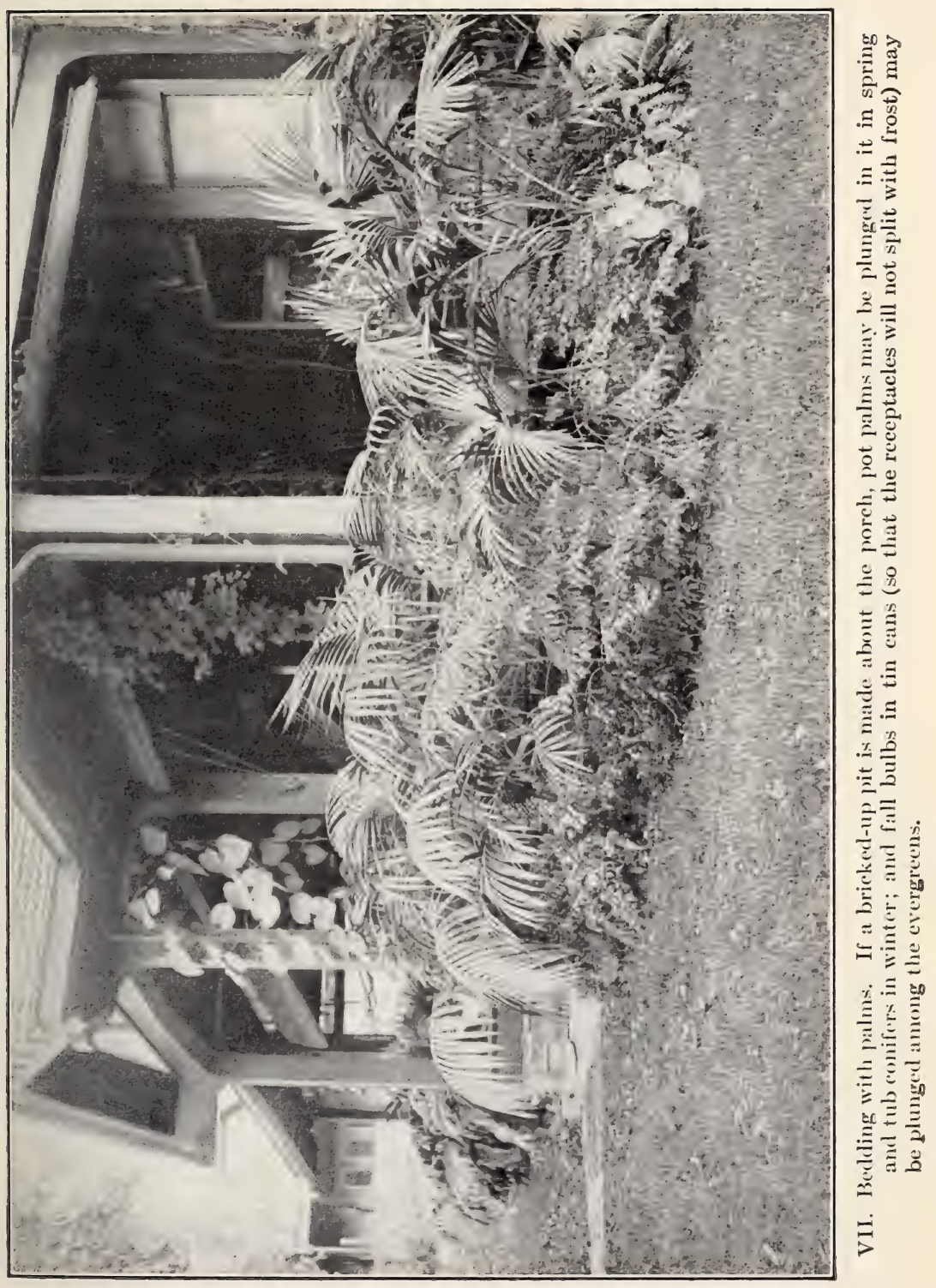



good and poor preparation of the land. Figure 93 is a section of land twelve inches deep. The under soil has been finely broken and pulverized and then compacted. It is mellow but firm, and is an excellent water reservoir. Three inches of the surface is a mulch of loose and dry earth. Figure 94 shows an earth-

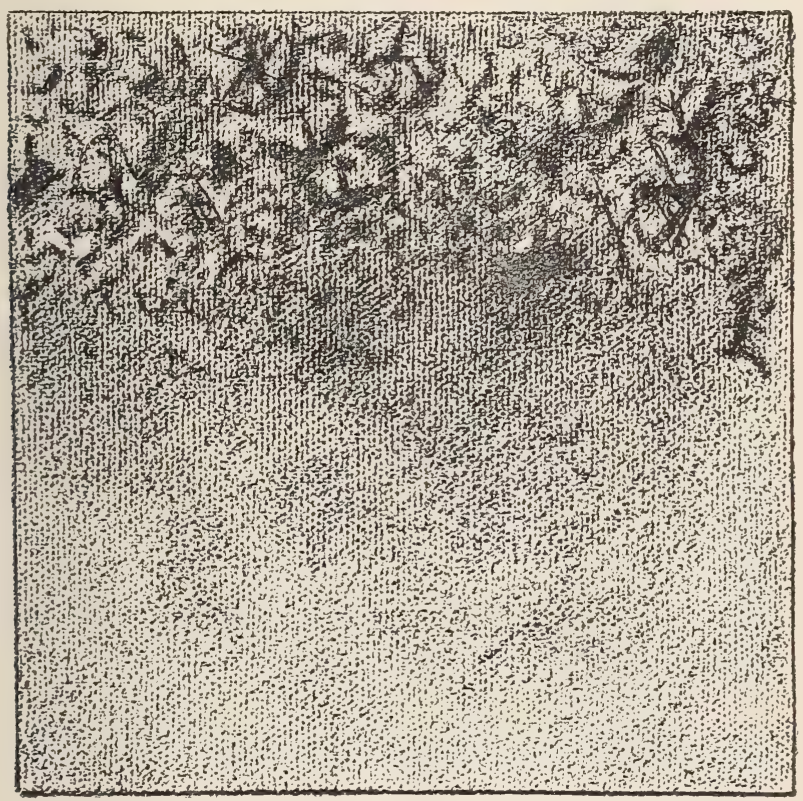

93. To illustrate good preparation of ground.

mulch, but it is too shallow; and the under soil is so open and cloddy that the water runs through it.

When the land is once properly prepared, the soil-mulch is maintained by surface-working tools. In field practice, these tools are harrows and horse cultivators of various kinds; in home garden practice they are wheel-hoes, rakes, and many patterns of hand hoes and scarifiers, with finger-weeders and other small implements for work directly among the plants. 
A garden soil is not in good condition when it is hard and crusted on top. The crust may be the cause of wasting water, it keeps out the air, and in general it is an uncongenial physical condition; but its evaporation of water is probably its chief defect. Instead of pouring water on the land, therefore, we

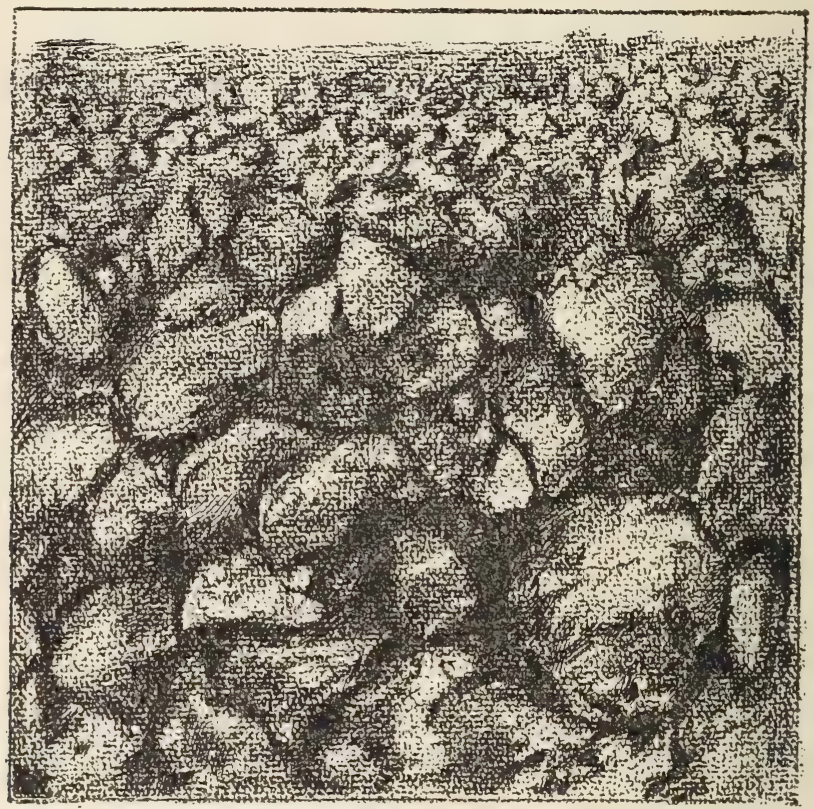

94. To illustrate poor preparation of ground.

first attempt to keep the moisture in the land. If, however, the soil becomes so dry in spite of you that the plants do not thrive, then water the bed. Do not sprinkle it, but water it. Wet it clear through at evening. Then in the morning, when the earth begins to dry, loosen the surface again to keep the water from getting away. Sprinkling the plants every day or two is one of the surest ways of spoiling them. We may water the ground with a garden-rake. 
Hand tools for weeding and subsequent tillage and other hand work.

Any of the cultivators and wheel-hoes are as useful for the subsequent tilling of the crop as for the initial preparation of the land, but there are other tools also that greatly facilitate the keeping of the plantation in order. Yet wholly aside from the value of a tool as an implement of tillage and as a weapon for the pursuit of weeds, is its merit merely as a shapely and interesting instrument. A man will take infinite pains to choose a gun or a fishing-rod to his liking, and a woman gives her best attention to the selecting of an umbrella; but a hoe is only a hoe and a rake only a rake. If one puts his personal choice into the securing of plants for a garden, so should he discriminate in the choice of hand tools, to secure those that are light, trim, well made, and precisely adapted to the work to be accomplished. A case of neat garden tools ought to be a great joy to a joyful gardener. So I am willing to enlarge on the subject of hoes and their kind.

\section{The hoe.}

The common rectangular-bladed hoe is so thoroughly established in the popular mind that it is very difficult to introduce new patterns, even though they may be intrinsically superior. As a general-purpose tool, it is no doubt true that a common hoe is better than any of its modifications, but there are various patterns of hoe-blades that are greatly superior for special uses, and

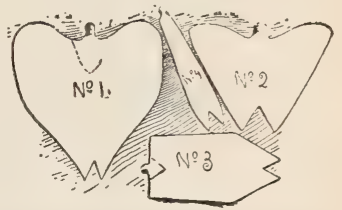

95. Lseful forms of hoeblades. which ought to appeal to any quiet soul who loves a garden.

The great width of the common blade does not admit of its being used in very narrow rows or very close to delicate plants, and it does not allow of the deep stirring of the soil in narrow 
spaces. It is also difficult to enter hard ground with such a broad face. Various pointed blades have been introduced from

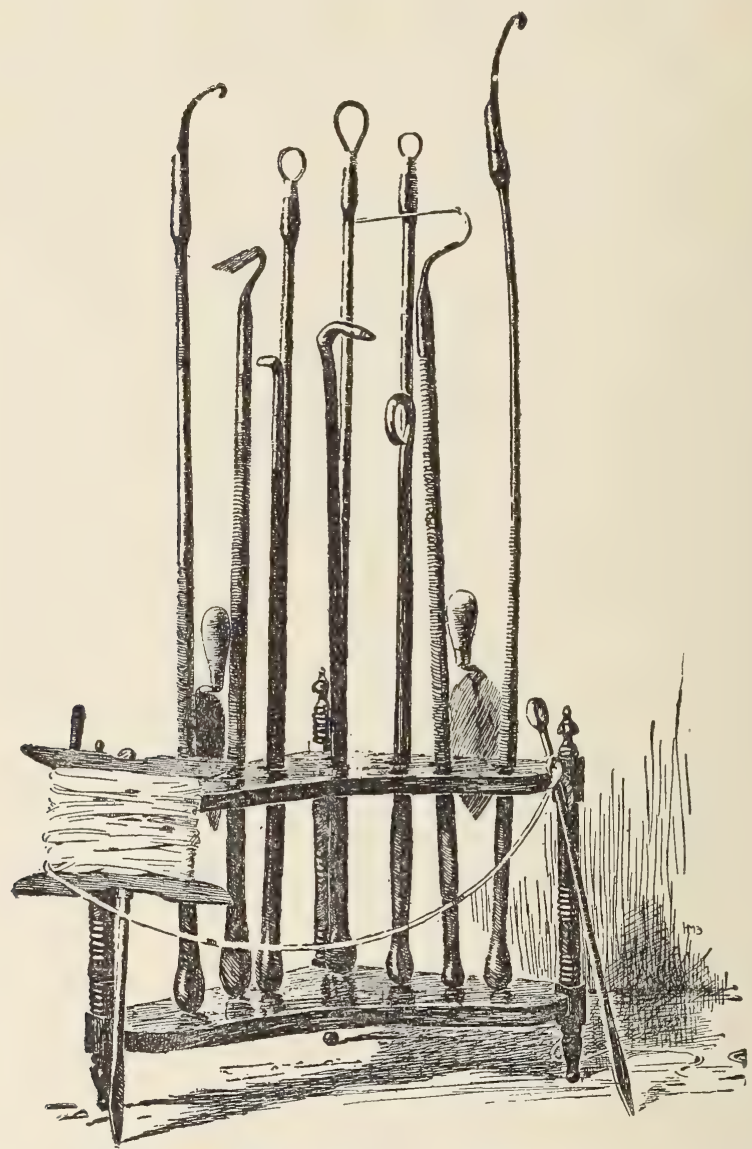

96. A stack of gardening weapons, comprising some of Tarryer's weeding spuds and thimbles.

time to time, and most of them have merit. Some persons prefer two points to the hoe, as shown in Marvin's blades, in 
Fig. 95. These interesting shapes represent the suggestions of gardeners who will not be bound by what the market affords, but who have blades cut and fitted for their own satisfaction.

Persons who followed the entertaining writings of one who called himself Mr. A. B. Tarryer, in "American Garden," a few years back, will recall the great variety of implements that he advised for the purpose of extirpating his hereditary foes, the weeds. A variety of these blades and tools is shown in Figs. 96 and 97 . I shall let Mr. Tarryer tell his story at some length in order to lead my reader painlessly into a new field of gardening pleasures.

Mr.Tarryer contends that the wheel-hoe is much too clumsy an affair to allow of the pursuit of an individual weed. While the operator is busy adjusting his machine and manipulating it about the corners of the garden, the quack-grass has escaped over the fence or has

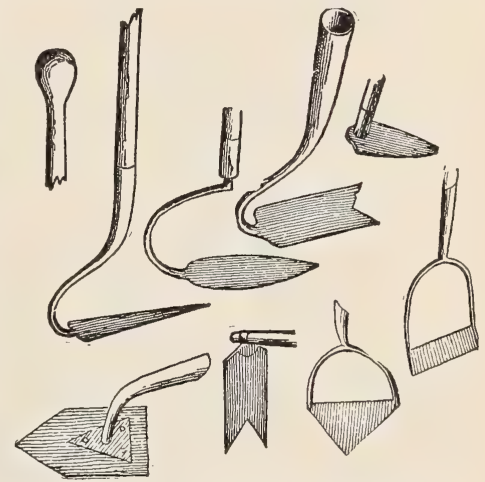

97. Some of the details of the Tarryer tools. gone to seed at the other end of the plantation. He devised an expeditious tool for each little work to be performed on the garden, - for hard ground and soft, for old weeds and young (one of his implements was denominated "infantdamnation").

"Scores of times during the season," Mr. Tarryer writes, "the ten or fifteen minutes one has to enjoy in the flower, fruit, and vegetable garden - and that would suffice for the needful weeding with the hoes we are celebrating - would be lost in harnessing horses or adjusting and oiling squeaky wheel-hoes, even if everybody had them. The 'American Garden' is not big enough, nor my patience long enough, to 
give more than an inkling of the unspeakable merits of these weapons of society and civilization. When Mrs. Tarryer was showing twelve or fifteen acres of garden with never a weed to be seen, she valued her dozen or more of these light implements at five or ten dollars daily; whether they were in actual use or adorning the front hall, like a hunter's or angler's furniture, made no difference. But where are these millennial tools made and sold? Nowhere. They are as unknown as the Bible was in the dark ages, and we must give a few hints towards manufacturing them.

"First, about the handles. The ordinary dealer or workman may say these knobs can be formed on any handles by winding them with leather; but just fancy a young maiden setting up her hoe meditatively and resting her hands and chin upon an old leather knob to reflect upon something that has been said to her in the garden, and we shall perceive that a knob by some other name would smell far sweeter. Moreover, trees grow large enough at the butt to furnish all the knobs we wanteven for broom-sticks - though sawyers, turners, dealers, and the public seem not to be aware of it; yet it must be confessed we are so far gone in depravity that there will be trouble in getting those handles.

"In a broadcast prayer of this public nature, absolute specifications would not be polite. Black walnut and butternut are fragrant as well as beautiful timber. Cherry is stiff, heavy, durable, and, like maple, takes a slippery polish. For fine, light handles, that the palm will stick to, butt cuts of poplar or cottonwood cannot be excelled, yet straight-grained ash will bear more careless usage.

"The handles of Mrs. Tarryer's hoes are never perfectly straight. All the bayonet class bend downward in use half an inch or more; all the thrust-hoe handles bend up in a regular curve (like a fiddle-bow turned over) two or three inches. Unless they are hung right, these hoes are very awk- 
ward things. When perfectly fit for one, they may not fit another; that is, a tall, keen-sighted person cannot use the hoe that is just fit for a very short one. . . C Curves in the handles throw centers of gravity where they belong. Good timber generally warps in a handle about right, only implement makers and
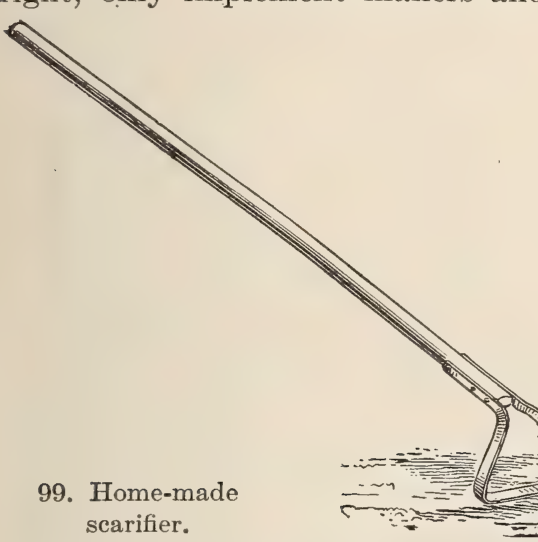

scarifier.

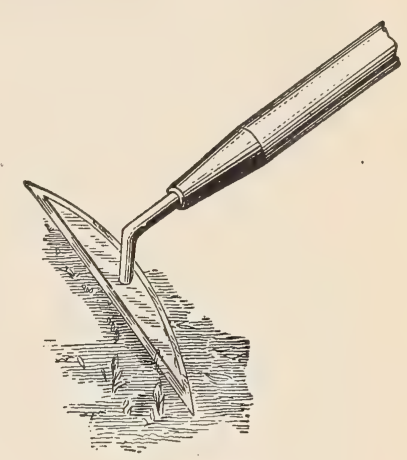

98. A scarifier.

babes in weeding may not know when it is made fast right side up in the hoe.

"There are plenty of thrust-hoes in market, such as they are. Some have malleable iron sockets and bows - heavier to the buyer and cheaper to the dealer - instead of wroughtiron and steel, such as is required for true worth."

\section{Scarifiers.}

For many purposes, tools that scrape or scarify the surface are preferable to hoes that

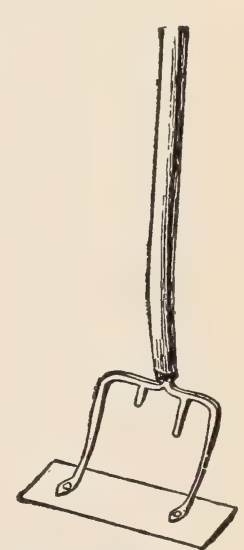

100. Home-made scarifier or scraper. dig up the ground. Weeds may be kept down by cutting them off, as in walks and often in flower-beds, rather than 


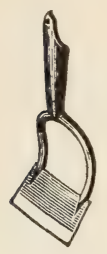

101. The common scarifier.

by rooting them out. Figure 98 shows such a tool, and a home-made implement answering the same purpose is illustrated in Fig. 99. This latter tool is easily made from strong band-iron. Another type is suggested in Fig. 100, representing a slicing-hoe made by fastening a sheet of good metal to the tines of a broken fork. The kind chiefly in the market is shown in Fig. 101.

\section{Hand-weeders.}

For small beds of flowers or vegetables, handweeders of various patterns are essential to easy

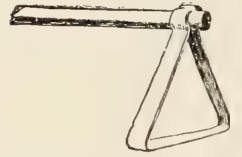

103. A handweeder.

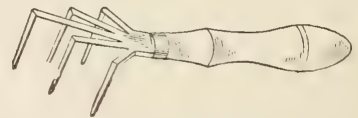

104. A finger-weeder.

and efficient work. One of the best patterns, with long and short handles, is shown in Fig. 102. Another style, that may be

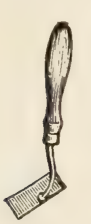

105. A small hand-weeder. made at home of hoop-iron, is drawn 102. Good
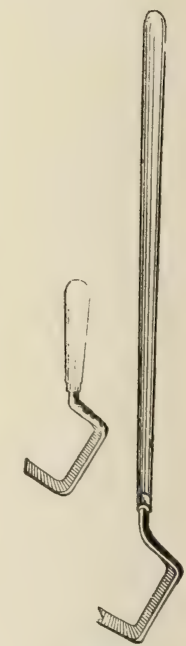

hand-weeders. in Fig. 103. A finger-weeder is illustrated in Fig. 104. In Fig. 105 a common form is shown. Many patterns of hand-weeders are in the market, and other forms will suggest themselves to the operator.

Trowels and their kind.

Small hand-tools for digging, as trowels, dibbers, and spuds, may be had of dealers. In buying a trowel it is economy to pay an extra price and secure a steel blade with a strong shank that runs through the entire length of the handle. One of these 


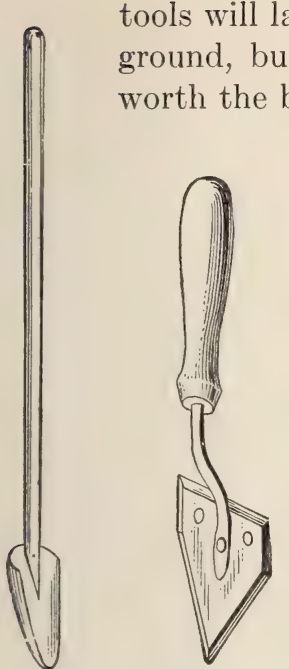

106. Long- 107. Improvised handled trowel.

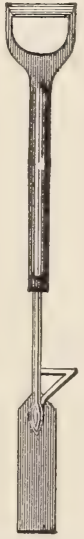

trowel.
108. Weedspud.

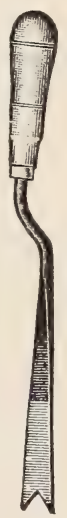

109. A good weed-spud.

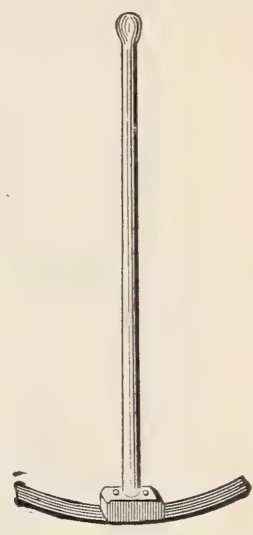

110. Weed-cutter.

one piece is also manufactured, and is the most durable pattern. A steel trowel may be secured to a long handle; or the blade of a broken trowel may be utilized in the same way (Fig. 106). A very good trowel may also be made from a discarded blade of a mowing machine (Fig. 107), and it answers the purpose of a hand-weeder.

Weed-spuds are shown in Figs. 108 to 111. The first is particularly serviceable in cutting docks and other strong weeds from lawns and pastures. It is provided with a brace to allow it to be thrust into the ground with the foot. It is seldom necessary to dig out perennial weeds to the tips of their deep roots, if the crown is severed a short distance below the surface.

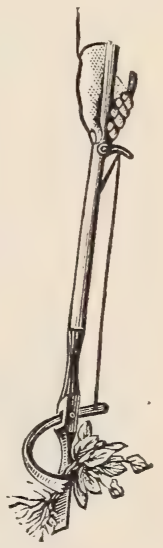

111. A weedspud that lifts the weed. 
Rollers.

It is often essential that the land be compacted after it has been spaded or hoed, and some kind of hand-roller is then use-

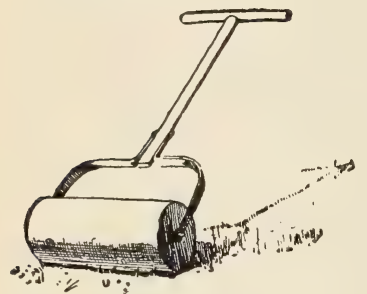

112. Hand-roller. ful. Very efficient iron rollers are in the market, but a good one can be made from a hard chestnut or oak log, as shown in Fig. 112. (It should be remembered that when the surface is hard and compact, water escapes from it rapidly, and plants may suffer for moisture on arrival of warm weather.) The roller is useful in two ways - to compact the under-surface, in which case the surface should be again loosened as soon as the rolling is done; and to firm the earth about seeds (page 98 ) or the roots of newly set plants.

\section{Markers.}

A marker may often be combined with the roller to good advantage, as in Fig. 113. Ropes

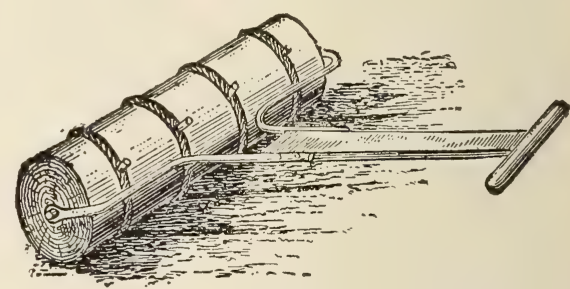

113. Roller and marker. are secured about the cylinder at proper intervals, and these

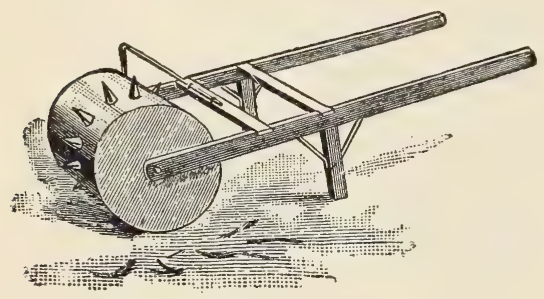

114. Roller and marker. mark the rows. Knots may be placed in the ropes to indicate the

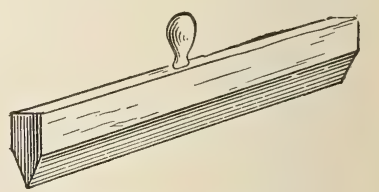

115. Marking-stick. 
places where plants are to be set or seeds dropped. An extension of the same idea is seen in Fig. 114, which shows iron or wooden pegs that make holes in which very small plants

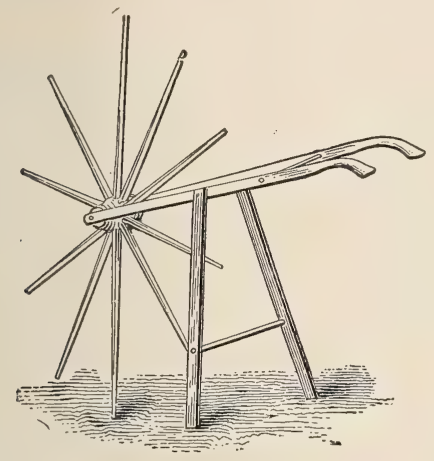

116. Tool for spacing plants.

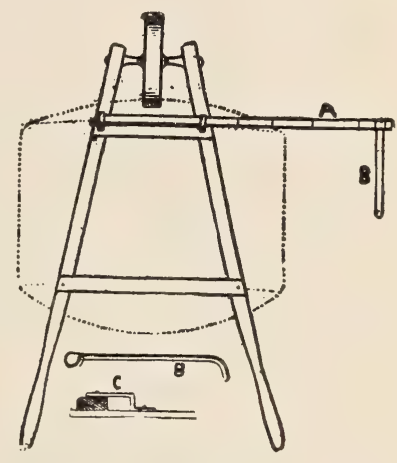

117. Barrow rigged with a marker.

may be set. An L-shaped rod projects at one side to mark the place of the next row.

In most cases the best and most expeditious method of mark-

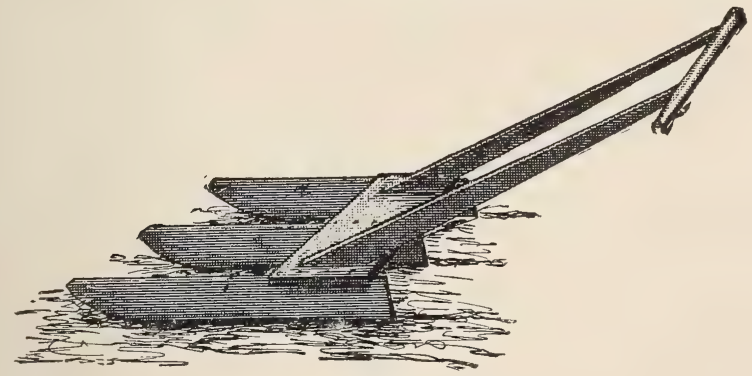

118. Hand sled-marker.

ing out the garden is by the use of the garden line, which is secured to a reel (Fig. 96), but various other devices are often useful. For very small beds, drills or furrows may be made by a simple marking-stick (Fig. 115). A handy marker is shown 
in Fig. 116. A marker can be rigged to a wheel-barrow, as in Fig. 117. A rod is secured underneath the front truss, and

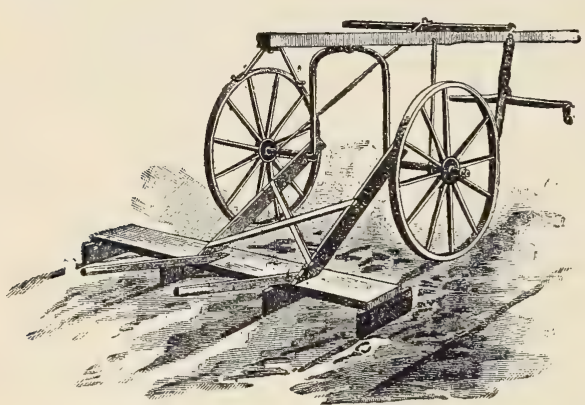

119. Trailing sled-marker. from its end an adjustable trailer, B, is hung. The wheel of the barrow marks the row, and the trailer indicates the place of the next row, thereby keeping the rows parallel. A hand sled-marker is shown in Fig. 118, and a similar device may be secured to the frame of a sulky cultivator (Fig. 119) or other wheel tool. A good adjustable sled-marker is outlined in Fig. 120.

\section{Enriching the land.}

Two problems are involved in the fertilizing of the land: the direct addition of plant-food, and the improvement of the physical structure of the soil. The latter office is often the more important.

Lands that, on the one hand, are very hard and solid, with a tendency to bake, and, on the other, that are loose and leachy, are very greatly benefited

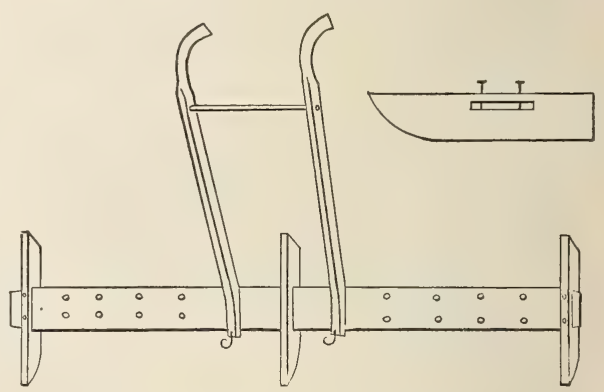

120. Adjustable sled-marker. by the addition of organic matter. When this organic matteras animal and plant remains - decays and becomes thoroughly incorporated with the soil, it forms what is called humus. The 
addition of this humus makes the land mellow, friable, retentive of moisture, and promotes the general chemical activities of the soil. It also puts the soil in the best physical condition for the comfort and well-being of the plants. Very many of the lands that are said to be exhausted of plant-food still contain enough potash, phosphoric acid, and lime, and other fertilizing elements, to produce good crops; but they have been greatly injured in their physical condition by long-continued cropping, injudicious tillage, and the withholding of vegetable matter. A part of the marked results secured from the plowing under of clover is due to the incorporation of vegetable matter, wholly aside from the addition of fertilizing material ; and this is emphatically true of clover because its deep-growing roots penetrate and break up the subsoil.

Muck and leafmold are often very useful in ameliorating either very hard or very loose lands. Excellent humous material may be constantly at hand if the leaves, garden refuse, and some of the manure are piled and composted (p. 114). If the pile is turned several times a year, the material becomes fine and uniform in texture.

The various questions associated with the fertilizing of the land are too large to be considered in detail here. Persons who desire to familiarize themselves with the subject should consult recent books. It may be said, however, that, as a rule, most lands contain all the elements of plant-food in sufficient quantities except potash, phosphoric acid, and nitrogen. In many cases, lime is very beneficial to land, usually because it corrects acidity and has a mechanical effect in pulverizing and flocculating clay and in cementing sands.

The chief sources of commercial potash are muriate of potash, sulfate of potash, and wood ashes. For general purposes, the muriate of potash is now recommended, because it is comparatively cheap and the composition is uniform. A normal application of muriate of potash is 200 to 300 pounds to the 
acre; but on some lands, where the greatest results are demanded, sometimes as much as twice this application may be made.

Phosphoric acid is got in dissolved South Carolina and Florida rock and in various bone preparations. These materials are applied at the rate of 200 to 400 pounds to the acre.

Commercial nitrogen is secured chiefly in the form of animal refuse, as blood and tankage, and in nitrate of soda. It is more likely to be lost by leaching through the land than the mineral substances are, especially if the land lacks humus. Nitrate of soda is very soluble, and should be applied in small quantities at intervals. Nitrogen, being the element which is mostly conducive to vegetative growth, tends to delay the season of maturity if applied heavily or late in the season. From 100 to 300 pounds of nitrate of soda may be applied to the acre, but it is ordinarily better to make two or three applications at intervals of three to six weeks. Fertilizing materials may be applied either in fall or spring; but in the case of nitrate of soda it is usually better not to apply in the fall unless the land has plenty of humus to prevent leaching, or on plants that start very early in the spring.

Fertilizing material is sown broadcast, or it may be scattered lightly in furrows underneath the seeds, and then covered with earth. If sown broadcast, it may be applied either after the seeds are sown or before. It is usually better to apply it before, for although the rains carry it down, nevertheless the upward movement of water during the dry weather of the summer tends to bring it back to the surface. It is important that large lumps of fertilizer, especially muriate of potash and nitrate of soda, do not fall near the crowns of the plants; otherwise the plants may be seriously injured. It is a general principle, also, that it is best to use more sparingly of fertilizers than of tillage. The tendency is to make fertilizers do penance for the sins of neglect, but the results do not often meet one's expectations. 
If one has only a small garden or a home yard, it ordinarily will not pay him to buy the chemicals separately, as suggested above, but he may purchase a complete fertilizer that is sold under a trademark or brand, and has a guaranteed analysis. If one is raising plants chiefly for their foliage, as rhubarb and ornamental bushes, he should choose a fertilizer comparatively rich in nitrogen; but if he desires chiefly fruit and flowers, the mineral elements, as potash and phosphoric acid, should usually be high. If one uses the chemicals, it is not necessary that they be mixed before application; in fact, it is usually better not to mix them, because some plants and some soils need more of one element than of another. Just what materials, and how much, different soils and plants require must be determined by the grower himself by observation and experiment; and it is one of the satisfactions of gardening to arrive at discrimination in such matters.

Muriate of potash costs $\$ 40$ and upwards per ton, sulfate about $\$ 48$, dissolved boneblack about $\$ 24$, ground bone about $\$ 30$, kainit about $\$ 13$, and nitrate of soda about $2 \frac{1}{4}$ cents per pound. These prices vary, of course, with the composition or mechanical condition of materials, and with the state of the market. The average composition of unleached wood ashes in the market is about as follows: Potash, 5.2 per cent; phosphoric acid, 1.70 per cent; lime, 34 per cent; magnesia, 3.40 per cent. The average composition of kainit is 13.54 per cent potash, 1.15 per cent lime.

The fact that the soil itself is the greatest storehouse of plantfood is shown by the following average of thirty-five analyses of the total content of the first eight inches of surface soils, per acre: 3521 pounds of nitrogen, 4400 pounds of phosphoric acid, 19,836 pounds of potash. Much of this is unavailable, but good tillage, green-manuring, and proper management tend to unlock it and at the same time to save it from waste.

Every careful gardener will take satisfaction in saving leaves 
and trimmings and stable refuse and making compost of it to supplement the native supplies in the soil. Some out-of-theway corner will be found for a permanent pile, with room for piling it over from time to time. The pile will be screened by his garden planting. (Figure 121 suggests a useful cart for collecting such materials.) He will also save the power of his

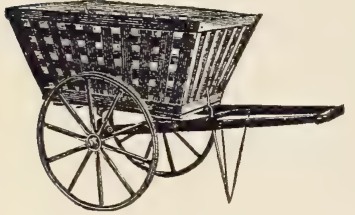

121. A good cart for collecting leaves and other materials. land by changing his crops to other parts of the garden, year by year, not growing his China asters or his snapdragons or his potatoes or strawberries continuously on the same area; and thus, also, will his garden have a new face every year.

Lest the reader may get the idea that there is no limit to be placed on the enriching of the soil, I will caution him at the end of my discussion that he may easily make the place so rich that some plants will overgrow and will not come into flowering or fruiting before frost, and flowers may lack brilliancy. On very rich land, scarlet sage will grow to great size but will not bloom in the northern season; sweet peas will run to vine; gaillardias and some other plants will break down; tomatoes and melons and peppers may be so late that the fruit will not ripen. Only experience and good judgment will safeguard the gardener as to how far he should or should not go. 


\section{CHAPTER V}

\section{THE HANDLING OF THE PLANTS}

There is a knack in the successful handling of plants that it is impossible to describe in print. All persons can improve their practice through diligent reading of useful gardening literature, but no amount of reading and advice will make a good gardener of a person who does not love to dig in a garden or who does not have a care for plants just because they are plants.

To grow a plant well, one must learn its natural habits. Some persons learn this as if by intuition, acquiring the knowledge from close discrimination of the behavior of the plant. Often they are themselves unconscious of this knack of knowing what will make the plant to thrive; but it is not at all necessary to have such an intuitive judgment to enable one to be even more than a fairly good gardener. Diligent attention to the plant's habits and requirements, and a real regard for the plant's welfare, will make any person a successful plant-grower.

Some of the things that a person should know about any plant he would grow are these:-

Whether the plant matures in the first, second, third, or subsequent years; and when it naturally begins to fail. The time of the year or season in which it normally grows, blooms, or fruits; and whether it can be forced at other seasons.

Whether it prefers a situation dry or moist or wet, hot or cool, sunny or shady.

Its preferences as to soil, whether very rich or only moderately rich, sand or loam, or peat or clay.

Its hardiness as to frost, wind, drought, heat. 
Whether it has any special requirements as to germination, and whether it transplants well.

Whether it is specially liable to attack by insects or disease.

Whether it has a special inability to grow two years in succession on the same land.

Having suited the situation to the plant, and having prepared the ground well and made a resolution to keep it well, special attention must be given to such matters as these:-

Guarding from all insects and diseases; and also from cats and chickens and dogs; and likewise from rabbits and mice.

Protecting from weeds.

Pruning, in the case of fruit trees and bushes, and also of ornamental woody plants on occasion, and sometimes even of annual herbs.

Staking and tying, particularly of sprawly garden flowers. Persistent picking of seed pods or dead flowers from flower plants, in order to conserve the strength of the plant and to prolong its season of bloom.

Watering in dry weather (but not sprinkling or dribbling). Thorough winter protecting of plants that need it.

Removing dead leaves, broken branches, weak and sickly plants, and otherwise keeping the place tidy and trim.

\section{Sowing the seeds.}

Prepare the surface earth well, to make a good seed-bed. Plant when the ground is moist, if possible, and preferably just before a rain if the soil is of such character that it will not bake. For shallow-planted seeds, firm the earth above them by walking over the row or by patting it down with a hoe. Special care should be exercised not to sow very small and slow-germinating seeds, as celery, carrot, onion, in poorly prepared suil 
or in ground that bakes. With such seeds it is well to sow seeds of radish or turnip, for these germinate quickly and break the crust, and also mark the row so that tillage may be begun before the regular-crop seeds are up.

Land may be prevented from baking over the seeds by scattering a very thin layer of fine litter, as chaff, or of sifted moss or mold, over the row. A board is sometimes laid on the row to retain the moisture, but it must be lifted gradually just as soon as the plants begin.to break the ground, or the plants will be greatly injured. Whenever practicable, seed-beds of celery and other slow-germinating seeds should be shaded. If the beds are watered, be careful that the soil is not packed by the force of the water or baked by the sun. In thickly sown seedbeds, thin or transplant the plants as soon as they have made their first true leaves.

For most home-grounds, seeds may be sown by hand, but for large areas of one crop, one of the many kinds of seed-sowers may be used. The particular methods of sowing seeds are usually specified in the seed catalogues, if other than ordinary treatment is required. The sled-markers (already described, p. 109) open a furrow of sufficient depth for the planting of most seeds. If marker furrows are not available, a furrow may be opened with a hoe for such deep-planted seeds as peas and sweet peas, or by a trowel or end of a rakestale for smaller seeds. In narrow beds or boxes, a stick or ruler (Fig. 115) may be used for opening creases to receive the seeds.

The depth at which seeds are to be planted varies with the kind, the soil and its preparation, the season, and whether they are planted in the open or in the house. In boxes and under glass, it is a good rule that the seed be sown at a depth equal to twice its own diameter, but deeper sowing is usually necessary out of doors, particularly in hot and dry weather. Strong and hardy seeds, as peas, sweet peas, large fruit-tree seeds, may be planted three to six inches deep. Tender seeds, that are injured 
by cold and wet, may be planted after the ground is settled and warm at a greater depth than before that season. As a rule, nothing is gained by sowing tender seeds before the weather is thoroughly settled and the ground warm.

\section{Propagating by cuttings.}

Many common plants are propagated by cuttings rather than by seeds, particularly when it is desired to increase a particular variety.

Cuttings are parts of plants inserted in soil or water with the intention that they shall grow and make new plants. They are of various kinds. They may be classified, with reference to the age of the wood or tissue, into two classes; viz. those made from perfectly hard or dormant wood (taken from the winter twigs of trees and bushes), and those made from more or less immature or growing wood. They may be classified again in respect to the part of the plants from which they are taken, as root-cuttings, tuber-cuttings (as the ordinary "seed" planted for potatoes), stem-cuttings, and leaf-cuttings.

\section{Dormant stem-cuttings.}

Dormant-wood cuttings are used for grapes (Fig. 122), currants, gooseberries, willows, poplars, and many other kinds of soft-wooded trees and shrubs. Such cuttings are ordinarily

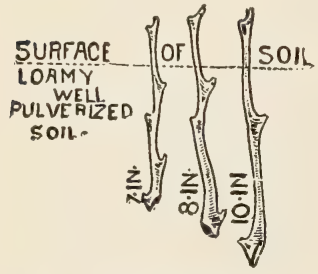

122. The planting of the dormant-wood cuttings. taken in fall or winter, but cut into the proper lengths and then buried in sand or moss where they do not freeze, in order that the lower end may heal over or callous. In the spring these cuttings are set in the ground, preferably in a rather sandy and welldrained place.

Usually, hardwood cuttings are made with two to four joints or buds, and when they are 
planted, only the upper bud projects above the ground. They may be planted erect, as Fig. 122 shows, or somewhat slanting. In order that the cutting may reach down to moist earth, it is desirable that it should not be less than 6 in. long; and it is sometimes better if it is 8 to $12 \mathrm{in.}$ If the wood is short-jointed, there may be several buds on a cutting of this length; and in order to prevent too many shoots from arising from these buds the lowermost buds are often cut out. Roots will start as readily if the lower buds are removed, since the buds grow into shoots and not into roots.

Cuttings of currants, grapes, gooseberries, and the like may be set in rows that are far enough apart to admit of easy tillage either with horse or hand tools, and the cuttings may be placed 3 to 8 in. apart in the row. The

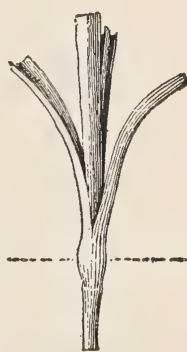

123. Carnation cutting.

English varieties of gooseberries, considerably grown in this country, do not propagate readily from cuttings.

After the cuttings have grown one season, the plants are usually transplanted and given more room for the second year's growth, after which time they are ready to be set in permanent plantations. In some cases, the plants are set at the end of the first year; but two-year plants are stronger and usually preferable.

\section{Cuttings of roots.}

Root-cuttings are used for blackberries, raspberries, and a few other things. They are ordinarily made of roots from the size of a lead pencil to one's little finger, and are cut in lengths from 3 to 5 in. long. The cuttings are stored the same as stem-cuttings and allowed to callous. In the spring they are planted in a horizontal or nearly horizontal position in moist sandy soil, being entirely covered to a depth of 1 or 2 in. 


\section{Green cuttings.}

Softwood or greenwood cuttings are usually made of wood that is mature enough to break when it is bent sharply. When the wood is so soft that it will bend and not break, it is too immature, in the majority of plants, for the making of good cuttings.

One to two joints is the proper length of a greenwood utting.

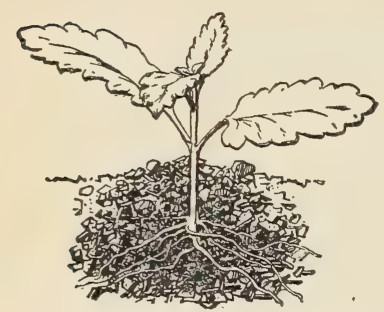

124. Verbena cutting. If of two joints, the lower leaves should be cut off and the upper leaves cut in two so that they do not present their entire surface to the air and thereby evaporate the plant juices too rapidly. If the cutting is of only one joint, the lower end is usually cut just above a joint. In either case, the cuttings are usually inserted in sand or well-washed gravel, nearly or quite up to the leaves. Keep the bed uniformly moist throughout its depth, but avoid any soil which holds so much moisture that it becomes muddy and sour. These cuttings should be shaded until they begin to emit their roots. Coleus, geraniums, fuchsias, carnations, and nearly all the common greenhouse and house plants, are propagated by these cuttings or slips (Figs. 123, 124).

\section{Cuttings of leaves.}

Leaf-cuttings are often used for the fancy-leaved begonias, gloxinias, and a few other plants. The young plant usually arises most readily from the leaf-stalk or petiole. The leaf, therefore, is inserted into the ground much as a green cutting is. Begonia leaves will throw out young plants from the main ribs when these veins or ribs are cut. Therefore, well-grown and firm begonia leaves are sometimes laid flat on the sand and 


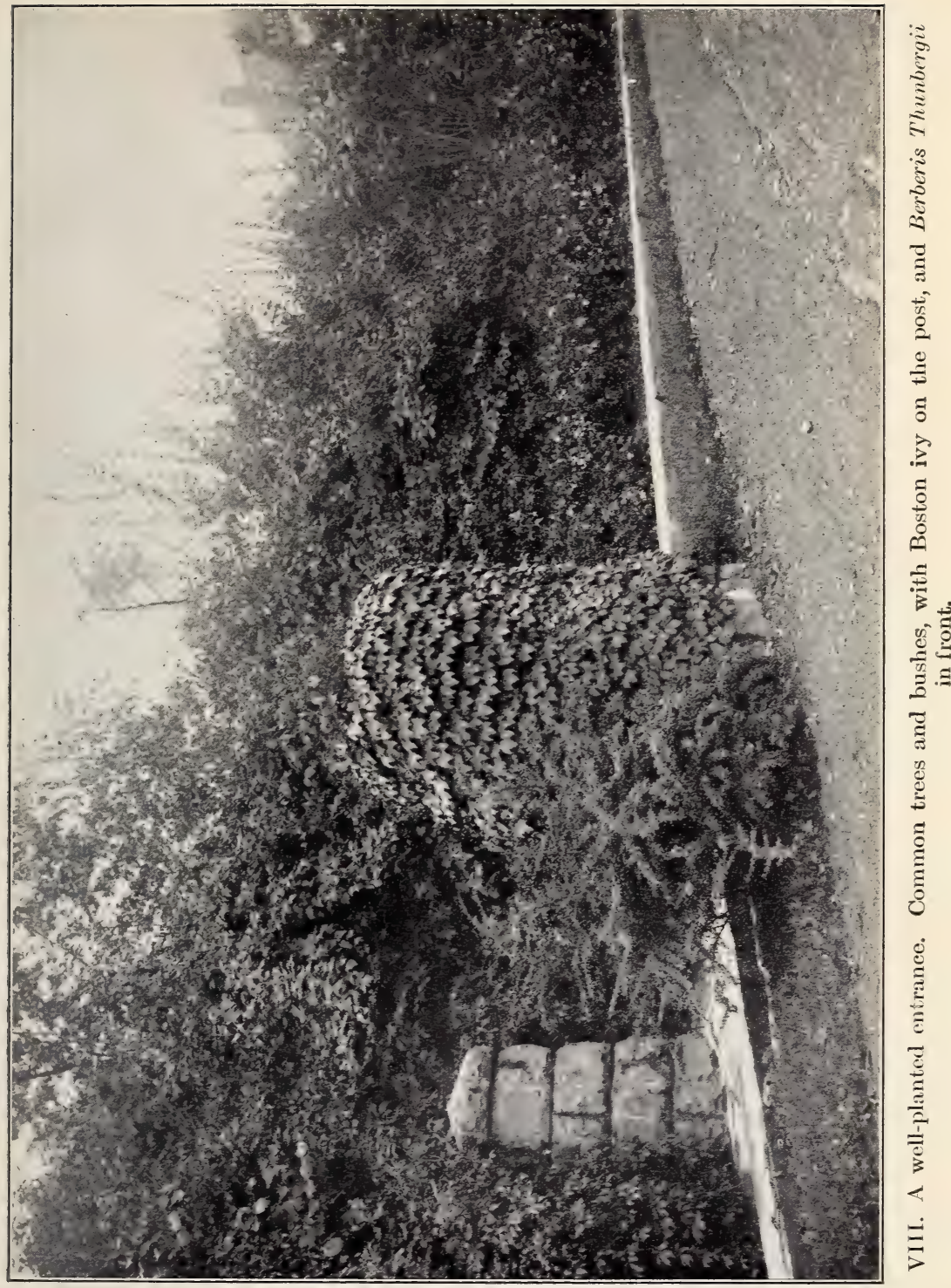



the main veins cut; then the leaf is weighted down with pebbles or pegs so that these cut surfaces come into intimate contact with the soil beneath. The usual way, however, is to cut a triangular piece of the leaf (Fig. 125) and insert the tip in sand. So long as the cutting is alive, do not be discouraged, even if it do not start.

General treatment of cuttings.

In the growing of all greenwood and leaf-cuttings, it is well to remember that they should have a gentle bottom heat; the soil should be such that it will hold moisture and yet not remain wet; the air about the tops should not become

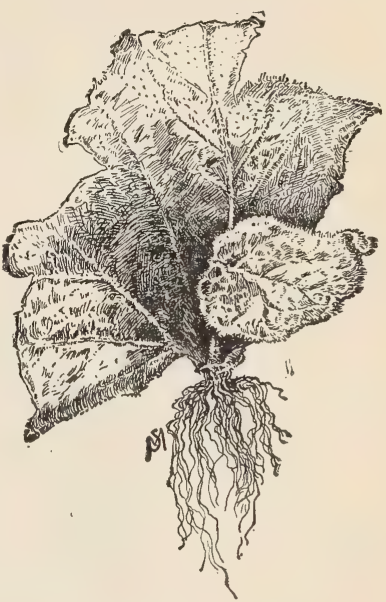

125. Leaf-cutting. close and stagnant, else the plants will damp off; and the tops should be shaded for a time. In order to control all the conditions, such cuttings are grown under

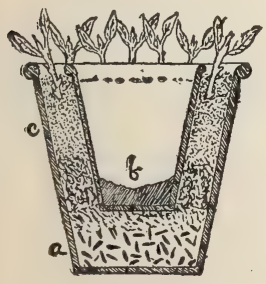

126. Cuttings inserted in a double pot. cover, as in a greenhouse, coldframe, or a box in the residence window.

An excellent method of starting cuttings in the living room is to make a double pot, as shown in Fig. 126. Inside a 6-in. pot set a 4-in. pot. Fill the bottom, $a$, with gravel or bits of brick, for drainage. Plug the hole in the inside pot. Fill the spaces between, $c$, with earth, and in this set the cuttings. Water may be poured into the inner pot, $b$, to supply the moisture. 


\section{Transplanting young seedlings.}

In the transplanting of cabbages, tomatoes, flowers, and all plants recently started from seeds, it is important that the

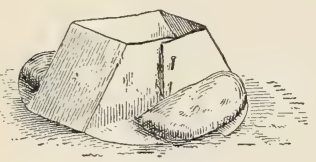

127. To check evaporation at transplanting. ground be thoroughly fined and compacted. Plants usually live better if transplanted into ground that has been freshly turned. If possible, transplant in cloudy or rainy weather, particularly if late in the season. Firm the earth snugly about the roots with the hands or feet, in order to bring up the soil moisture; but it is generally best to rake the surface in order to reëstablish the earth-mulch, unless the plants are so small that their roots cannot reach through the mulch (p. 98).

If the plants are taken from pots, water the pots some time in advance, and the ball of earth will fall out when the pot is inverted and tapped lightly. In taking up plants from the ground, it is advisable, also, to water them well some time before removing; the earth may then be held on the roots. See that the watering is done far enough in advance to allow the water
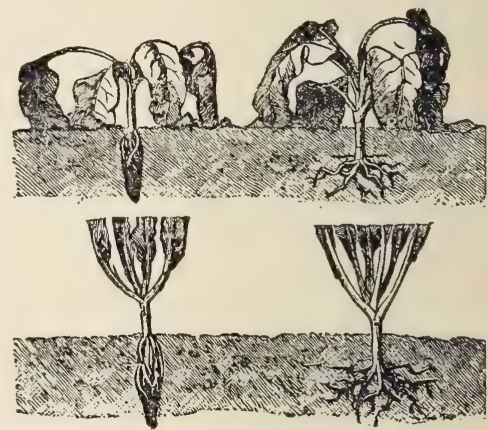

128. Plants sheared and not sheared when transplanted.

to settle away and distribute itself; the earth should not be muddy when the plants are removed.

In order to reduce the evaporation from the plant, shingles may be stuck into the ground to shade the plant; or a screen may be improvised with pieces of paper (Fig. 122), tin cans, inverted flower-pots, coverings of brush, or other means.

It is nearly always advisable to remove some of the foliage, 
particularly if the plant has several leaves and if it has not been grown in a pot, and also if the transplanting is done in warm weather. Figure 128 shows a good treatment for transplanted plants. With the foliage all left on, the plants are likely to behave as in the upper row; but with most of it cut off, as in the lower row, there is little wilting, and new leaves soon start. Figure 129 also shows what part of the leaves may be cut off on transplanting. If the ground is freshly turned and the transplanting is well done, it rarely will be necessary to water the

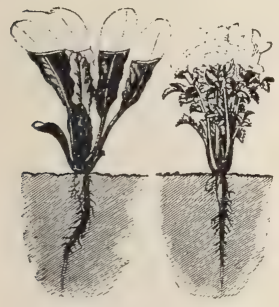

129. Where to shear the tops of young plants.

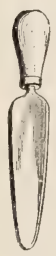

130. Trowel dibber.

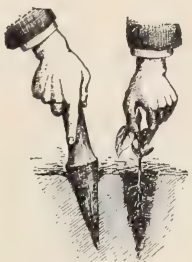

131. The dibber.

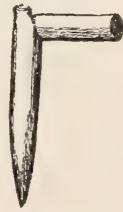

132. Homemade padded dibber.

plants; but if watering is necessary, it should be done at nightfall, and the surface should be loosened the next morning or as soon as it becomes dry.

In the transplanting of young plants, some kind of a dibber should be used to make the holes. Dibbers make holes without removing any of the earth. A good form of dibber is shown in Fig. 130, which is like a flat or plane trowel. Many persons prefer a cylindrical and conical dibber, like that shown in Fig. 131. For hard soils and larger plants, a strong dibber may be made from a limb that has a right-angled branch to serve as a handle. This handle may be softened by slipping a piece of rubber hose on it (Fig. 132). A long iron dibber, which may also be used as a crow-bar, is shown in Fig. 133. In transplanting with the dibber, a hole is first made by a thrust of the tool, and the earth 


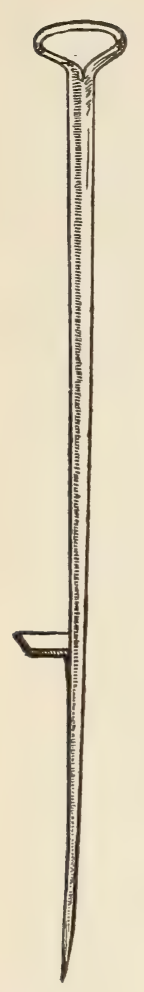

133. Dibber and crow-bar combined.

is then pressed against the root by means of the foot, hand, or the dibber itself (as in Fig. 131). The hole is not filled by putting in dirt at the top.

For large plants, a broader dibber may be used. An implement like that shown in Fig. 134 is useful for setting strawberries and other plants with large roots. It is made of twoinch plank, with a block on top to act

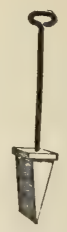

134. Strawberry planter. as foot-rest and to prevent the blade from going too deep. In order to provide space for the foot and easily to direct the thrust, the handle may be placed at one side of the middle. For plunging pots, a dibber like that shown in Fig. 135 is useful, particularly when the soil is so hard that a longpointed tool is necessary. The bottom of the hole may be filled with earth before the pot is inserted; but it is often advisable to leave the vacant space below (as in $b$ ) to provide drainage, to keep the plant from rooting, and to prevent earth-worms from entering the hole in the bottom of the pot. For smaller pots, the tool may be inserted a less depth (as at $c$ ).

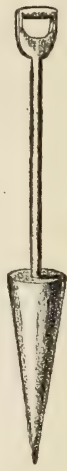

135. The plunging of pots.

\section{Transplanting established plants and trees.}

In setting potted plants out of doors, it is nearly always advisable to plunge them, - that is to set the pots into the earth, unless the place is very wet. The pots are then watered by the rainfall, and demand little care. If the plants are to be 
returned to the house in the fall, they should not be allowed to root through the hole in the pot, and the rooting may be prevented by turning the pot around every few days. Large decorative plants may be made to look as if growing naturaily in the lawn by sinking the pot or box just below the surface and rolling the sod over it, as suggested in Fig. 136. A space around and below the tub may be provided to insure drainage.

\section{Tub-plants.}

For the shifting of very large tub-plants, a box or tub with movable sides, as in Fig.

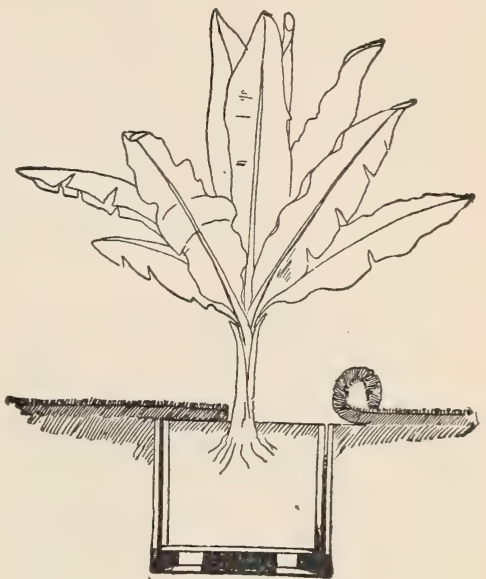

136. Setting large tub-plants in the lawn. 137, is handy and efficient. The plant-box recommended to parties who grew plants for exhibition at the World's Fair is shown in Fig. 138. It is made of strong boards or planks.

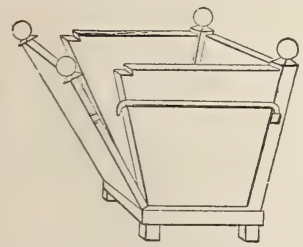

137. Plant-box with a movable side. At $\mathrm{A}$ is shown the inside of one of two opposite sections or sides, four feet wide at top, three feet wide at bottom, and three feet high. The cleats are two-byfour scantlings, through which holes are bored to admit the bolts with which the box is to be held together. B is an outside view of one of the alternating sections, three feet four inches wide at top, two feet four inches at bottom, and three feet deep. A one-by-six strip is nailed through the center to give strength. $\mathrm{C}$ is an end view of $\mathrm{A}$, showing the bolts and also a two-by-four cleat to which the bottom is to be nailed. This box was used mostly for trans- 

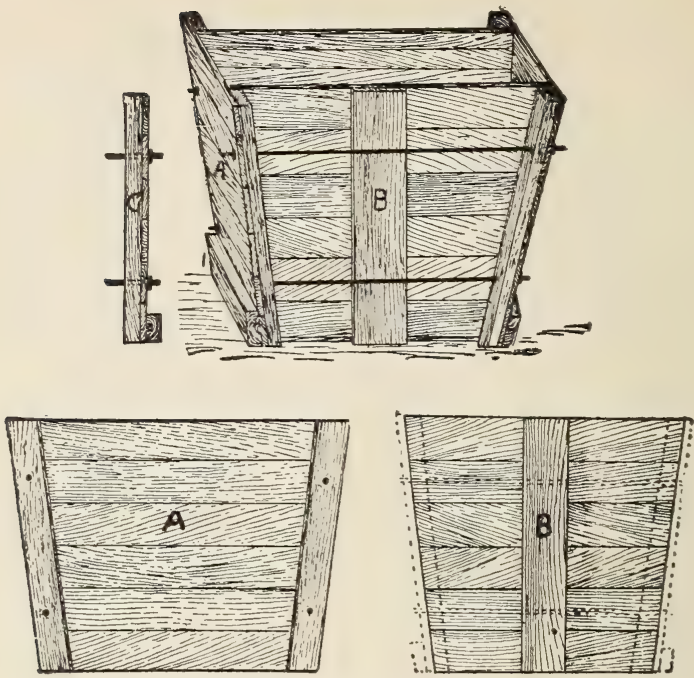

138. Box-for transporting large transplanted stock.

porting large growing stock to the exposition, the stock having been dug from the open and the box secured around the ball of earth.

When to transplant.

In general, it is best to set hardy plants in the fall, particularly if the ground is fairly dry and the exposure is not too bleak. To this class belong most of the fruit trees and ornamental trees and shrubs; also hardy herbs, as columbines, peonies, lilies, bleeding-hearts, and the like. They should be planted as soon as they are thoroughly mature, so that the leaves begin to fall naturally. If any leaves remain on the tree or bush at planting time, strip them off, unless the plant is an evergreen. It is generally best not to cut back fall-planted trees to the full extent desired, but to shorten them three-fourths of the required amount in the fall, and take off the remaining fourth in 
the spring, so that no dead or dry tips are left on the plant. Evergreens, as pines and spruces, are not headed-in much, and usually not at all.

All tender and very small plants should be set in the spring, in which case very early planting is desirable; and spring planting is always to be advised when the ground is not thoroughly drained and well prepared.

\section{Depth to transplant.}

In well-compacted land, trees and shrubs should be set at about the same depth as they stood in the nursery, but if the land has been deeply trenched or if it is loose from other causes, the plants should be set deeper, because the earth will probably settle. The hole should be filled with fine surface earth. It is generally not advisable to place manure in the hole, but if it is used, it should be of small amount and very thoroughly mixed with the earth, else it will cause the soil to dry out. In lawns and other places where surface tillage cannot be given, a light mulch of litter or manure may be placed about the plants; but the earth-mulch (page 98), when it can be secured, is much the best conserver of moisture.

\section{Making the rows straight.}

In order to set trees in rows, it is necessary to use a garden line (Fig. 96), or to mark out the ground with some of the

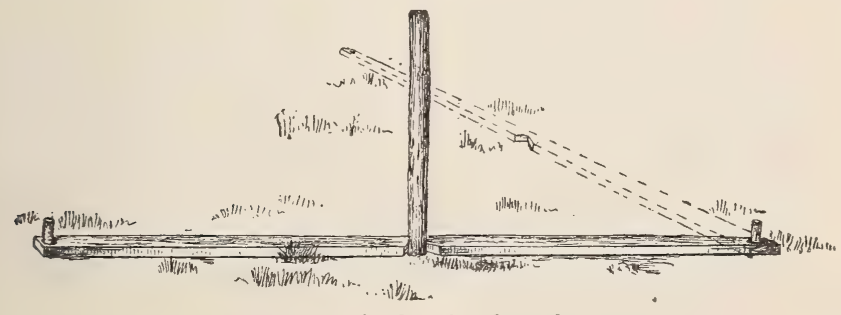

139. A planting board. 
devices already described (Figs. 113-120); or in large areas, the place may be staked out. In planting orchards, the area is laid out (preferably by a surveyor) with two or more rows of stakes so placed that a man may sight from one fixed point to

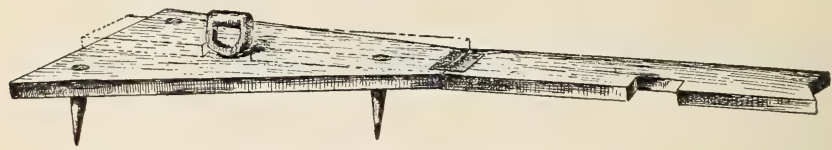

140. Device for placing the tree.

another. Two or three men work to best advantage in such planting.

There are various devices for locating the place of the stake after the stake has been removed and the hole dug, in case the

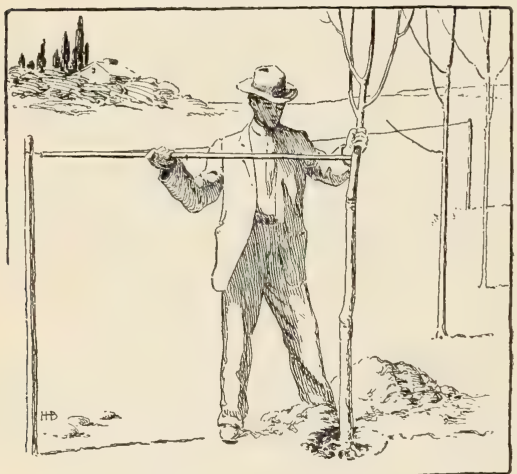

141. Lining a tree from a stake. area is not regularly staked out in such a way that sighting across the area may be employed. One of the simplest is shown in Fig. 139. It is a narrow and thin board with a notch in the center and a peg in either end, one of the pegs being stationary. The implement is so placed that the notch meets the stake, then one end of it is thrown out of the way until the hole is dug. When the implement is brought again to its original position, the notch marks the place of the stake and the tree. Figure 140 is a device with a lid, in the end of which is a notch to mark the place of the stake. This lid is thrown back, as shown by the dotted lines, when the hole is being dug. Figure 141 shows a method of bringing trees in row by measuring from a line. 
Cutting-back ; filling.

In the planting of any tree or bush, the roots should be cut back beyond all breaks and serious bruises, and fine earth should be thoroughly filled in and firmed about them, as in Fig. 142. No implement is so good as the fingers for working the soil about

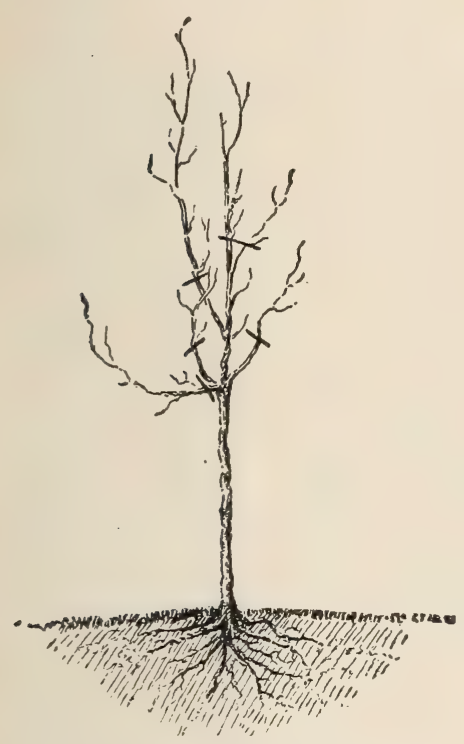

142. Proper planting of a tree.

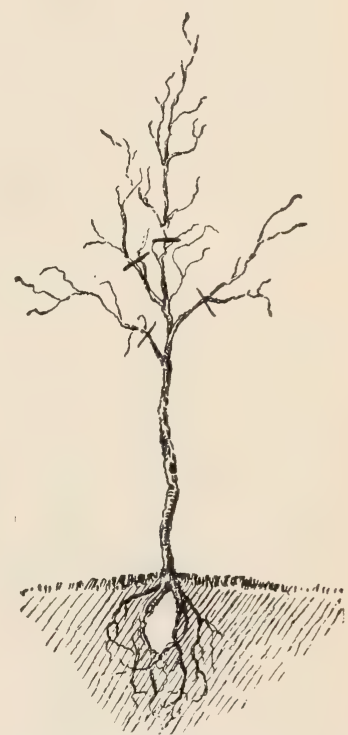

143. Careless planting of a tree.

the roots. If the tree has many roots, work it up and down slightly several times during the filling of the hole, to settle the earth in place. When the earth is thrown in carelessly, the roots are jammed together, and often an empty place is left beneath the crown, as in Fig. 143, which causes the roots to dry out.

The marks on the tops of these trees in Figs.142 and 143 show where the branches may be cut. See also Fig. 152. Figures 144 
and 145 show the tops of trees after pruning. Strong branchy trees, as apples, pears, and ornamental trees, are usually headed

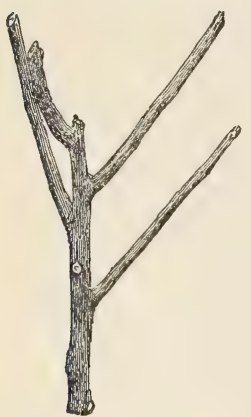

144. Pruned young tree,

back in this way, upon planting. If the tree has one straight leader and many or several slender branches (Fig. 146), it is usually pruned, as in Fig. 147, each branch being cut back to one or two buds. If there are no branches, or very few of them, - in which case there will be good buds upon the main stem, - the leader may be cut back a third or half its length, to a mere whip. Ornamental bushes with long tops are usually cut back a third or a half when set, as shown in Fig. 45.

Always leave a little of the small bud-making growth. The practice of cutting back shade trees to mere long clubs, or poles, with no small twigs, is to be discouraged. The tree in such case is obliged to force out adventitious buds from the old wood, and it may not have vigor enough to do this; and the process may be so long delayed as to allow the tree to be overtaken by drought before it gets a start.

Removing very large trees.

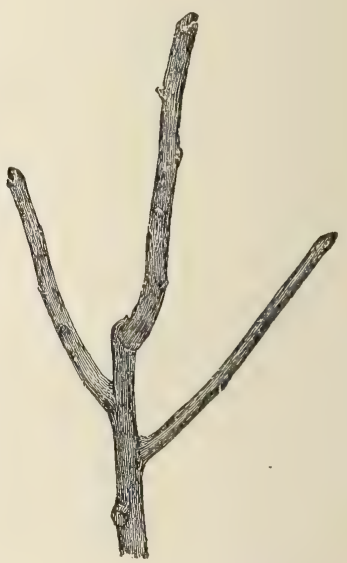

145. Pruned young tree.

Very large trees can often be moved with safety. It is essential that the transplanting be done when the trees are perfectly dormant, - winter being preferable, - that a large mass of earth and roots be taken with the tree, and that the top be vigorously cut back. Large trees are often moved in winter on a stone-boat, by securing a large ball of earth frozen about 
the roots. This frozen ball is secured by digging about the tree for several days in succession, so that the freezing progresses with the excavation. A good device for moving such trees is shown in Fig. 148. The trunk of the tree is securely

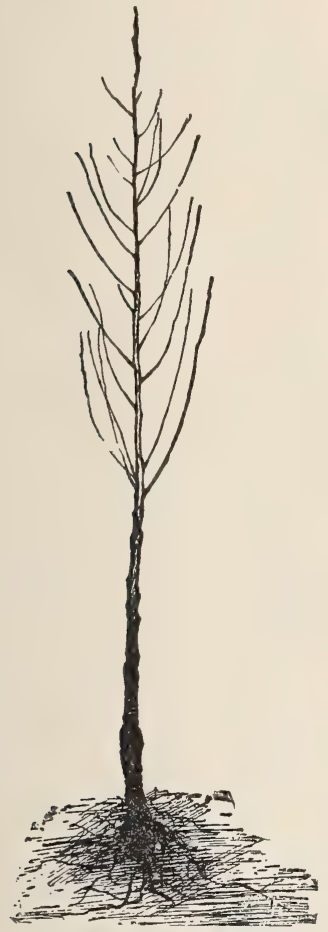

146. Peach tree.

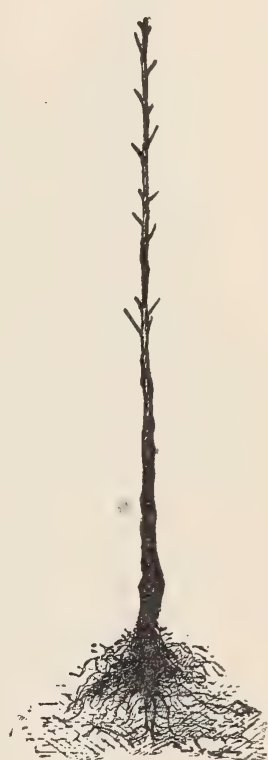

147. Peach tree pruned for planting.

wrapped with burlaps or other soft material, and a ring or chain is then secured about it. A long pole, $b$, is run over the truck of a wagon and the end of it is secured to the chain or ring upon the tree. This pole is a lever for raising the tree out of the ground. A team is hitched at $a$, and a man holds the pole $b$. 
Other and more elaborate devices are in use, but this explains the idea and is therefore sufficient for the present purpose; for when a person desires to remove a very large tree he should secure the services of an expert.

The following more explicit directions for moving large trees are by Edward Hicks, who has had much experience in the business, and who made this report to the press a few years ago:

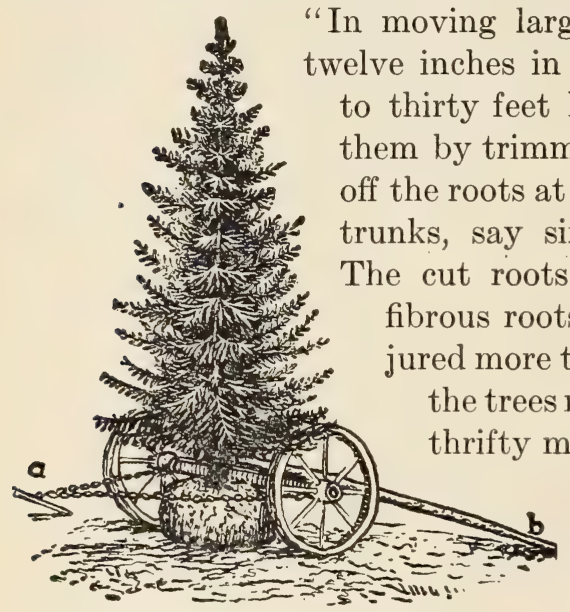

148. Moving a large tree.

"In moving large trees, say those ten to to thirty feet high, it is well to prepare to thirty feet high, it is well to prepare them by trimming and cutting or sawing off the roots at a proper distance from the trunks, say six to eight feet, in June. The cut roots heal over and send out fibrous roots, which should not be inured more than is necessary in moving the trees next fall or spring. Young, thrifty maples and elms, originally from the nursery, do not need such preparation nearly as much as other and older trees. In moving a tree, we begin by digging a wide trench six to eight feet from it, leaving all possible roots fast to it. By digging under the tree in the wide trench, and working the soil out of the roots by means of round or dullpointed sticks, the soil falls into the cavity made under the tree. Three or four men in as many hours could get so much of the soil away from the roots that it would be safe to attach a rope and tackle to the upper part of the trunk and to some adjoining post or tree for the purpose of pulling the tree over. A good quantity of bagging must be put around the tree under the rope to prevent injury, and care should be taken that the pulling of the rope does not split off or break a limb. A team is hitched to 
the end of the draft rope, and slowly driven in the proper direction to pull the tree over. If the tree does not readily tip over, dig. under and cut off any fast root. While it is tipped over, work out more of the soil with the sticks. Now pass a large rope, double, around a few large roots close to the tree, leaving the ends of the rope turned up by the trunk to be used in lifting the tree at the proper time. Tip the tree in the opposite direction and put another large rope around the large roots close to the trunk; remove more soil and see that no roots are fast to the ground. Four guy-ropes attached to the upper parts of the tree, as shown in the cut (Fig. 149), should be put on properly and used to prevent the tree from tipping over too far as well as to keep it upright. A good deal of the soil can

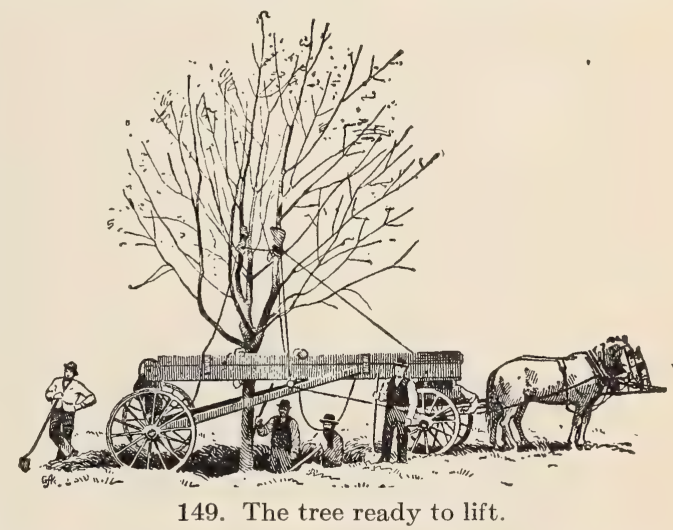
be put back in the hole without covering the roots to get it out of the way of the machine. The latter can now be placed about the tree by removing the front part, fastened by four bolts, placing the frame with the hind wheels around the tree and replacing the front parts. Two timbers, three-by-nine inches, and twenty feet long, are now placed on the ground under the hind wheels, and in front of them, parallel to each other for the purpose of keeping the hind wheels up out of the big hole when drawing the tree away; and they are also used while backing the hind wheels across the new hole in which the tree is to be planted. The machine (Figs. 149, 150) consists of a hind axle twelve feet long, and broad-tired wheels. The frame is made of spruce 
three-by-eight inches and twenty feet long. The braces are three-by-five inches and ten feet long, and upright three-by-nine inches and three feet high; these are bolted to the hind axle and main frame. The front axle has a set of blocks bolted together and of sufficient height to support the front end of the frame. Into the top timbers, three-by-six inches, hollows are cut at the proper distances to receive the ends of two locust rollers. A windlass or winch is put at each end of the frame,

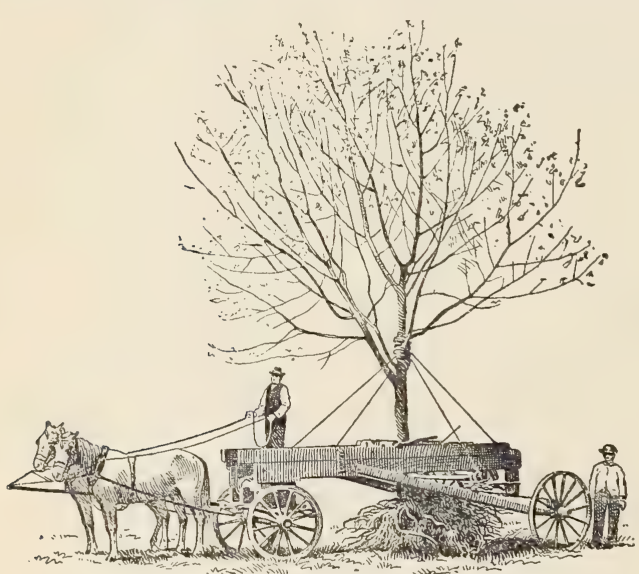

150. The tree ready to move.

by which trees can easily and steadily be lifted and lowered, the large double ropes passing over the rollers to the windlasses. A locust boom is put across the machine under the frame and above the braces; iron pins hold it in place. The side guy-ropes are made fast to the ends of this boom. The other guy-ropes are made fast to the front and rear parts of the machine. Four rope loops are made fast inside of the frame, and are so placed that by passing a rope around the trunk of the tree and through the loops two or three times, a rope ring is made around the tree that will keep the trunk in the middle of the frame and not allow it to hit either the edges or the rollers - a very necessary safeguard. As the tree is slowly lifted by the windlasses, the guy-ropes are loosened, as needed. The tree will pass obstructions, such as trees by the roadside, but in doing so it is better to lean the tree backward. When the tree has arrived at its new place, the two timbers are placed along the opposite edges 
of the hole so that the hind wheels can be backed over it. The tree is then lowered to the proper depth, and made plumb by the guy-ropes, and good, mellow soil is thrown in and packed well into all the cavities under the roots. When the hole is half filled, several barrels of water should be poured in; this will wash the soil into the cavities under the center of the tree much better. When the water has settled away, fill in and pack the soil till the hole is little more than full. Leave a depression, so that all the rain that may fall will be retained. The tree should now be judiciously trimmed and the machine removed. Five men can take up, move, and plant a tree in a day, if the distance is short and the digging not too hard. The tree should be properly wired to stakes to prevent the wind from blowing it over. The front part of the machine is a part of our platform spring market-wagon, while the hind wheels are from a wood-axle wagon. A tree ten inches in diameter, with some dirt adhering to its roots, will weigh a ton or more."

\section{Winter protection of plants.}

If the ground is not ready for planting in the fall, or if it is desired for any reason to delay until spring, the trees or bushes may be heeled-in, as illustrated in Fig. 151. The roots are laid in a furrow or trench, and are covered with wellfirmed earth. Straw or manure may be thrown over the earth still further to protect the roots, but if it is thrown over the tops, mice

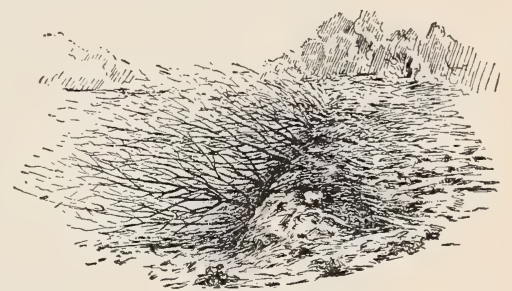

151. Trees heeled-in for winter. may be attracted by it and the trees be girdled. Tender trees or bushes may be lightly covered to the tips with earth. Plants should be heeled-in only in loose, warm, loamy or sandy ground and in a well-drained place. 
Fall-planted trees should generally be mounded up, sometimes even as high as shown in Fig. 152. This hilling holds the plant in position, carries off the water, prevents too deep freezing, and holds the earth from heaving. The mound is taken away in the spring. It is sometimes advisable to mound-up established trees in the fall, but on well-drained land the practice is usually not necessary. In hilling trees, pains should be taken not to

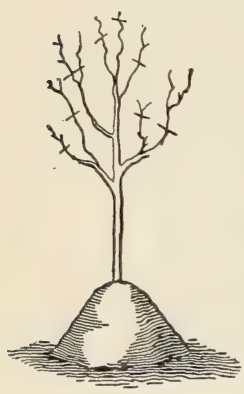

152. Tree earthed up for winter. leave deep holes, from which the earth was dug, close to the tree, for water collects in them. Roses and many other bushes may be mounded in the fall with profit.

It is always advisable to mulch plants that are set in the fall. Any loose and dry material - as straw, manure, leaves, leafmold, litter from yards and stables, pine boughs may be used for this purpose. Very strong or compact manures, as those in which there is little straw or litter, should be avoided. The ground may be covered to a depth of five or six inches, or even a foot or more if the material is loose. Avoid throwing strong manure directly on the crown of the plants, especially of herbs, for the materials that leach from the manure sometimes injure the crown buds and the roots.

This protection may also be given to established plants, particularly to those which, like roses and herbaceous plants, are expected to give a profusion of bloom the following year. This mulch affords not only winter protection, but is an efficient means of fertilizing the land. A large part of the plant-food materials have leached out of the mulch by spring, and have become incorporated in the soil, where the plant makes ready use of them.

Mulches also serve a most useful purpose in preventing the ground from packing and baking by the weight of snows and rains, and the cementing action of too much water in the surface 
soil. In the spring, the coarser parts of the mulch may be removed, and the finer parts spaded or hoed into the ground.

Tender bushes and small trees may be wrapped with straw, hay, burlaps, or pieces of matting or carpet. Even rather large trees, as bearing peach trees, are often baled up in this

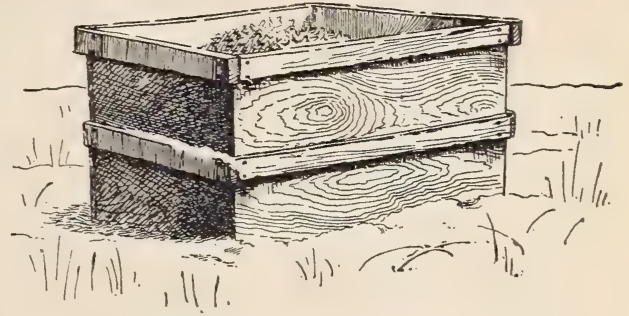

153. Covering plants in a box. way, or sometimes with corn fodder, although the results in the protection of fruit-buds are not often very satisfactory. It is important that no grain is left in the baling material, else mice may be attracted to it.

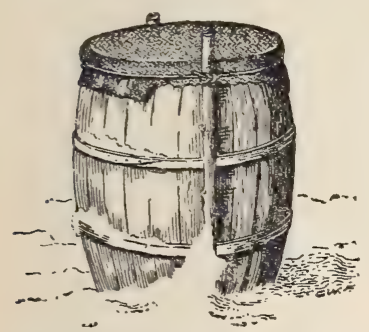

154. Covering plants in a barrel.
(The danger of gnáwing by mice that nest in winter coverings is always to be anticipated.) It should be known, too, that the object in tying up or baling plants is not so much to protect from direct cold as to mitigate the effects of alternate freezing and thawing, and to protect from drying winds. Plants may be wrapped so thick and tight as to injure them.

The labor of protecting large plants is often great and the results uncertain, and in most cases it is a question whether more satisfaction could not be attained by growing only hardy trees and shrubs.

The objection to covering tender woody plants cannot be urged with equal force against tender herbs or very low bushes, for these are protected with ease. Even the ordinary mulch may afford sufficient protection; and if the tops kill back, the plant quickly renews itself from near the base, and in many plants - as in most hybrid perpetual roses - the best bloom is 
on these new growths of the season. Old boxes or barrels may be used to protect tender low plants (Figs. 153, 154). The box is filled with leaves or dry straw and either left open on top or covered with boards, boughs, or even with burlaps (Fig. 154).

Connoisseurs of tender roses and other plants sometimes go to the pains of erecting a collapsible shed over the bush, and filling with leaves or straw. Whether this is worth while de-

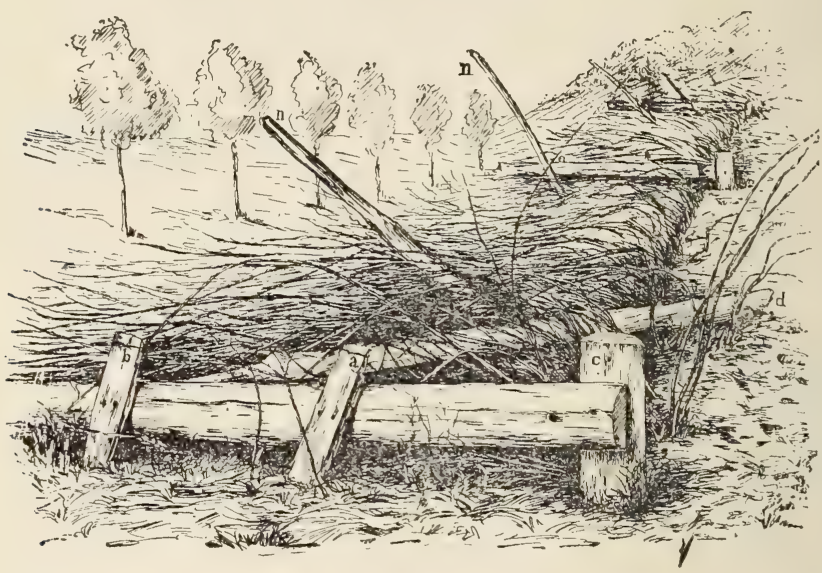

155. Laying down of trellis-grown blackberries.

pends wholly on the degree of satisfaction that one derives from the growing of choice plants (see Roses, in Chap. VIII).

The tops of plants may be laid down for the winter. Figure 155 shows a method of laying down blackberries, as practiced in the Hudson River valley. The plants were tied to a trellis, as the method is in that country, two wires $(a, b)$ having been run on either side of the row. The posts are hinged on a pivot to a short post $(c)$, and are held in position by a brace $(d)$. The entire trellis is then laid down on the approach of winter, as shown in the illustration. The blackberry tops are so strong that they hold the wires up from the ground, even when the trellis is laid 
down. To hold the wires close to the earth, stakes are thrust over them in a slanting position, as shown at $n n$. The snow that drifts through the plants ordinarily affords sufficient protection for plants which are as hardy as grapes and berries. In fact, the species may be uninjured even without cover, since, in their prostrate position, they escape the cold and drying winds.

In severe climates, or in the case of tender plants, the tops should be covered with straw, boughs, or litter, as recommended for regular mulch-covers. Sometimes a V-shaped trough made from two boards is placed over the stems of long or vine-like plants that have been laid down. All plants with slender or more or less pliant stems can be laid down with ease. With such protection, figs can be grown in the northern states. Peach and other fruit trees may be so trained as to be tipped over and covered.

Laid-down plants are often injured if the covering remains too late in the spring. The ground warms up early, and may start the buds on parts of the buried plants, and these tender buds may be broken when the plants are raised, or injured by sun, wind, or frost. The plants should be raised while the wood and buds are still hard and dormant.

\section{Pruning.}

Pruning is necessary to keep plants in shape, to make them more floriferous and fruitful, and to hold them within bounds.

Even annual plants often may be pruned to advantage. This is true of tomatoes, from which the superfluous or crowding shoots may be removed, especially if the land is so rich that they grow very luxuriantly; sometimes they are trained to a single stem and most of the side shoots are taken away as they appear. If plants of marigold, gaillardia, or other strong and spreading growers are held by stakes or wire-holders (a good practice), it may be advisable to remove the weak and sprawling shoots. Balsams give better results when side shoots are 
taken off. The removing of the old flowers, which is to be advised with flower-garden plants (page 116), is also a species of pruning.

Distinction should be made between pruning and shearing. Plants are sheared into given shapes. This may be necessary in bedding-plants, and occasionally when a formal effect is desired in shrubs and trees; but the best taste is displayed, in the vast majority of cases, in allowing the plants to assume their natural habits, merely keeping them shapely, cutting out old or dead wood, and, in some cases, preventing such crowding of shoots as will reduce the size of the bloom. The common practice of shearing shrubbery is very much to be reprehended; this subject is discussed from another point of view on page 24 .

The pruner should know the flower-bearing habit of the plant that he prunes, - whether the bloom is on the shoots of last season or on the new wood of the present season, and whether the flower-buds of spring-blooming plants are separate from the leaf-buds. A very little careful observation will determine these points for any plant. (1) The spring-blooming woody plants usually produce their flowers from buds perfected the fall before and remaining dormant over winter. This is true of most fruit-trees, and such shrubs as lilac, forsythia, tree peony, wistaria, some spireas and viburnums, weigela, deutzia. Cutting back the shoots of these plants early in spring or late in fall, therefore, removes the bloom. The proper time to prune such plants (unless one intends to reduce or thin the bloom) is just after the flowering season. (2) The summerblooming woody plants usually produce their flowers on shoots that grow early in the same season. This is true of grapes, quince, hybrid perpetual roses, shrubby hibiscus, crape myrtle, mock orange, hydrangea (paniculata), and others. Pruning in winter or early spring to secure strong new shoots is, therefore, the proper procedure in these cases.

Remarks on pruning may be found under the discussion of 
roses and other plants in subsequent chapters, when the plants need any special or peculiar attention.

Fruit-trees and shade-trees are usually pruned in winter, preferably late in winter, or in very early spring. However, there is usually no objection to moderate pruning at any time of the year; and moderate pruning every year, rather than violent pruning in occasional years, is to be advised. It is an old idea that summer pruning tends to favor the production of fruit-buds and therefore to make for fruitfulness; there is undoubtedly truth in this, but it must be remembered that fruitfulness is not the result of one treatment or condition, but of all the conditions under which the plant lives.

All limbs should be removed close to the branch or trunk from which they arise, and the surface of the wound should be practically parallel with such branch or trunk, rather than to be cut back to stubs. The stubs do not heal readily.

All wounds much above an inch across may be protected by a coat of good linseed-oil paint; but smaller wounds, if the tree is vigorous, usually require no protection. The object of the paint is to protect the wound from cracking and decay until the healing tissue covers it.

Superfluous and interfering branches should be removed from fruit-trees, so that the top will be fairly open to sun and to the pickers. Well-pruned trees allow of an even distribution and uniform development of the fruit. Watersprouts and suckers should be removed as soon as they are discovered. How open the top may be, will depend on the climate. In the West, open trees suffer from sun-scald.

The fruit-bearing habit of the fruit-tree must be considered in the pruning. The pruner should be able to distinguish fruitbuds from leaf-buds in such species as cherries, plums, apricot, peach, pear, apple, and so prune as to spare these buds or to thin them understandingly. The fruit-buds are distinguished by their position on the tree and by their size and shape. They 
may be on distinct "spurs" or short branches, in all the above fruits; or, as in the peach, they may be chiefly lateral on the new shoots (in the peach, the fruit-buds are usually two at a node and with a leaf-bud between them), or, as sometimes in apples and pears, they may be at the ends of last year's growths. Fruit-buds are usually thicker, or "fatter," than leaf-buds, and often fuzzy. Heading-back the tree of course tends to concentrate the fruit-buds and to keep them nearer the center of the tree-top; but heading-back must be combined with intelligent saving and thinning of the interior shoots. Headingback of pears and peaches and plums is usually a very desirable practice.

\section{Tree surgery and protection.}

Aside from the regular pruning to develop the tree into its best form to enable it to do its best work, there are wounds and malformations to be treated. Recently, the treating of injured and decayed trees has received much attention, and "tree doctors" and "tree surgeons" have engaged in the business. If there are quacks among these people, there are also competent and reliable men who are doing useful service in saving and prolonging the life of trees; one should choose a tree doctor with the same care that he would choose any other doctor. The liability of injury to street trees in the modern city and the increasing regard for trees, render the services of good experts increasingly necessary.

Street trees are injured by many causes: as, starving because of poor soil and lack of water under pavements; smoke and dust; leakage from gas mains and from electric installation; gnawing by horses; butchering by persons stringing wires; carelessness of contractors and builders; wind and ice storms; overcrowding; and the blundering work of persons who think that they know how to prune. Well-enforced municipal regulations should be able to control most of these troubles. 


\section{Tree guards.}

Along roadsides and other exposed places it is often necessary to protect newly set trees from horses, boys, and vehicles. There are various kinds of tree guards for this purpose. The best types are those that are more or less open, so as to allow the free passage of air and which are so far removed from the body of the tree that its trunk may expand without difficulty. If the guards are very tight, they may shade the trunk so much that the tree may suffer when the guard is removed, and they prevent the discovery of insects and injuries. It is important that the guard does not fill with litter in which insects may harbor. As soon as the tree is old enough to escape injury, the guards should be removed. A very good guard, made of laths held together with three strips of band-iron, and secured to iron posts, is shown in Fig. 156. Figure 157 shows a guard made by winding fencing wire upon three posts or stakes. When there is likely to be elanger from too great shading of the

156. Lath tree guard.

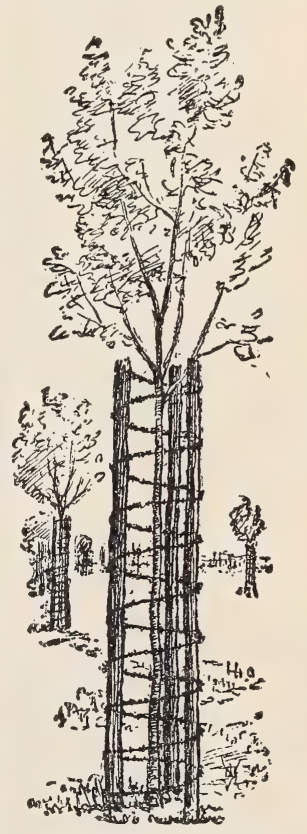

157. Wire-and-post tree guard. 


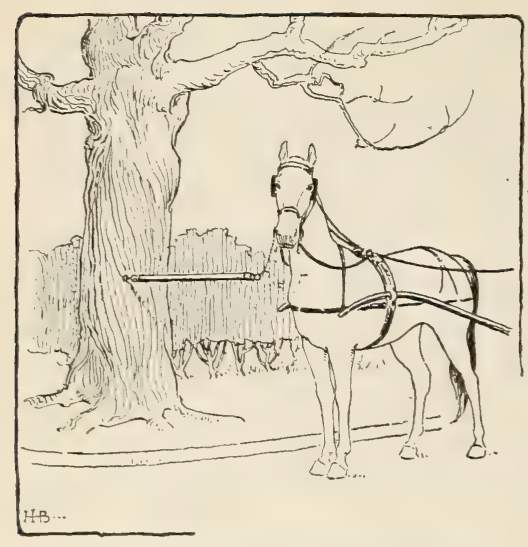

158. How a horse may be hitched to a tree.

guard is one of the best. There are good forms of tree guards on the market.

Of course hitching-posts should be provided, wherever horses are to stand, to remove the temptation of hitching to trees. Figure 158 , however, shows a very good device when a hitching post is not wanted. A strong stick, four or five feet long, is secured to the tree by a staple and at the lower end of the stick is a short chain with a snap in the end. The snap is secured to the bridle, and the horse is not able to reach the tree.

\section{Mice and rabbits.}

Trees and bushes are often seriously injured by the gnawing of mice and rabbits. The best preventive is not to have the vermin. If there are no places in which rabbits and mice can burrow and breed, there will be little difficulty. At the approach of winter, if mice are feared, the dry litter should be removed from about the trees, or it should be packed down very firm, so that the mice cannot nest in it. If the rodents are very abundant, it may be advisable to wrap fine wire netting about the base of the tree. A boy who is fond of trapping or hunting will ordinarily solve the rabbit difficulty. Rags tied on sticks which are placed at intervals about the plantation will often frighten rabbits away.

\section{Girdled trees.}

Trees that are girdled by mice should be wrapped up as soon as discovered, so that the wood shall not become too dry. When 
warm weather approaches, shave off the edges of the girdle so that the healing tissue may grow freely, smear the whole surface with grafting-wax, or with clay, and bind the whole wound with strong cloths. Even though the tree is completely girdled for a distance of three or four inches, it usually may be saved by this treatment, unless the injury extends into the wood. The water from the roots rises through the soft wood and not between the bark and the wood, as commonly supposed. When this sap water has reached the foliage, it takes part in the elaboration of plant-food, and this food is distributed throughout the plant, the path of transfer being in the inner layers of bark. This food material, being distributed back to the girdle, will generally heal over the wound if the wood is not allowed to become dry.

In some cases, however, it is necessary to join the bark above and below the girdle by means

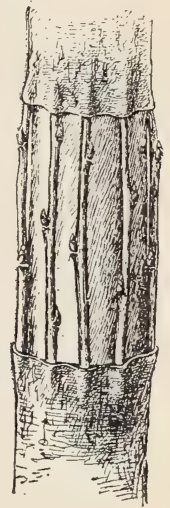

159. Bridge-grafting a girdle. of cions, which are whittled to a wedge-shape on either end, and inserted underneath the two edges of the bark (Fig. 159). The ends of the cions and the edges of the wound are held by a bandage of cloth, and the whole work is protected by melted grafting-wax poured upon it. ${ }^{1}$

Repairing street trees.

The following advice on "tree surgery" is by A. D. Taylor (Bulletin 256, Cornell University, from which the accompanying illustrations are adapted):

1 A good grafting-wax is made as follows: Into a kettle place one part by weight of tallow, two parts of beeswax, four parts of rosin. When completely melted, pour into a tub or pail of cold water, then work it with the hands (which should be greased) until it develops a grain and becomes the color of taffy candy. The whole question of the propagation of plants is discussed in "The Nursery-Book." 
"Tree surgery includes the intelligent protection of all mechanical injuries and cavities. Pruning requires a previous intimate knowledge of the habits of growth of trees; surgery, on the other hand, requires in addition a knowledge of the best methods for making cavities air-tight and preventing decay. The filling of cavities in trees has not been practiced sufficiently long to warrant making a definite statement as to the permanent success or failure of the operation; the work is still in

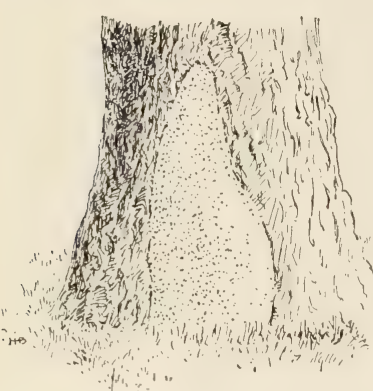

160. A cement-filled cavity at the base of a tree. an experimental stage. The caring for cavities in trees must be urged as the only means of preserving affected specimens, and the preservation of many noble specimens has been at least temporarily assured through the efforts of those practicing this kind of work.

"Successful operation depends on two important factors: first, that all decayed parts of the cavity be wholly removed and the exposed surface thoroughly washed with an antiseptic; second, that the cavity, when filled, must be air tight and hermetically sealed if possible. Trees are treated as follows: The cavity is thoroughly cleaned by removing all decayed wood and washing the interior surface with a solution of copper sulfate and lime, in order to destroy any fungi that may remain. The edges of the cavity are cut smooth in order to allow free growth of the cambium after the cavity is filled. Any antiseptic, such as corrosive sublimate, creosote, or even paint, may answer the purpose; creosote, however, possesses the most penetrating powers of any. The method of filling the cavities depends to a great extent on their size and form. Very large cavities with great openings are generally bricked on the outside, over the 
opening, and filled on the inside with concrete, the brick serving the purpose of a retaining wall to hold the concrete in place. Concrete used for the main filling is usually made in the proportion of one part good portland cement, two parts sand, and four parts crushed stone, the consistency of the mixture being such that it may be poured into the cavity and require little or no tamping to make the mass solid. (Fig. 160.)

"Fillings thus made are considered by expert tree surgeons to be a permanent preventive of decay. The outside of the filling is always coated with a thin covering of concrete, consisting of one part cement to two parts fine sand. Cavities resulting from freezing, and which, though large on the inside, show only a long narrow crack on the outside, are most easily filled by placing a form against the entire length of the opening, having a space at the top through which the cement may be poured (Fig. 161). Another method of retaining the concrete is to reinforce it from the outside by driving rows of spikes along the inner surface of either side of the cavity and lacing a stout wire across the face of the cavity. For best results, all fillings must come flush with the inner bark when finished. During the first year, this growing tissue will spread over the outer edge of the filling, thus forming an hermetically sealed cavity. In the course of time, the outside of small or narrow openings should be completely covered with tissue, which buries the filling from view.

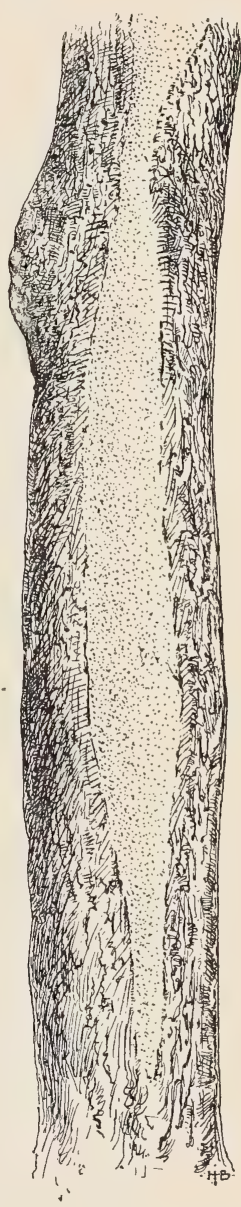

161. A wound, made by freezing, trimmed out and filled with cement. 
"It has been found that there is a tendency for portland cement to contract from the wood after it dries, leaving a space between the wood and the cement through which water and

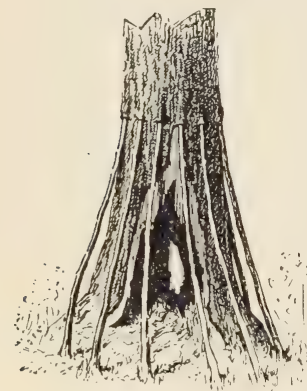

162. Bridge-grafting or inarching from saplings planted about the tree. heavy storms, and should not occur if the filling is correctly done.

"In addition to the preservation of decayed specimens by filling the cavities, as above outlined, it has been proposed to strengthen the tree by treating it as shown in Fig. 162. Young saplings of the same species, after having become established as shown, are grafted by approach to the mature specimen.

"Injury frequently results from error in the method of attempting to save broken, or to strengthen and support weak branches that are otherwise healthy. The means used for supporting cracked, wind-racked, and overladen branches which show a tendency to split at the forks are bolting and chaining. The practice of placing iron bands around large branches in order to protect them has resulted in much harm; as the tree grows and expands, such bands tighten, causing the bark to be broken and resulting after a few years in a partial girdling (Fig. 163). 
"To bolt a tree correctly is comparatively inexpensive. The safest method consists in passing a strong bolt through a

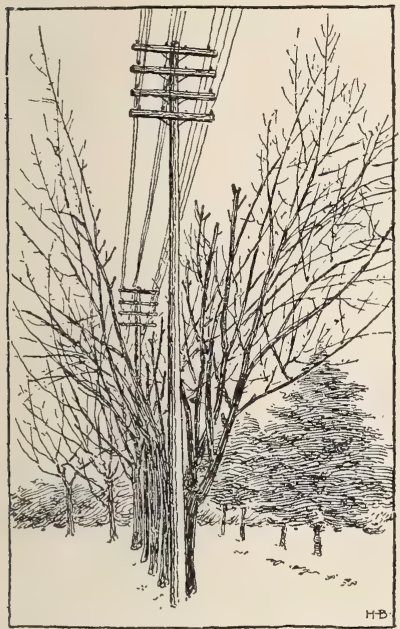

164. Trees ruined to allow of the passage of wires. hole bored in the branch for this purpose, and fastening it on the

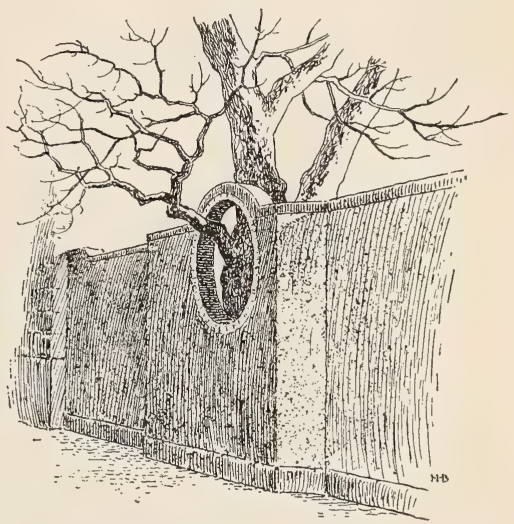

165. Accommodating a wall to a valuable tree.

outside by means of a washer and a nut. Generally the washer has been placed against the bark and the nut then holds it

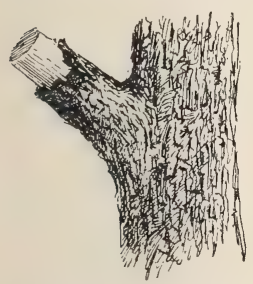

166. The death of a long stub. in place. A better method of bolting, and one which insures a neat appearance of the branch in addition to serving as the most certain safeguard against the entrance of disease, is to counter-sink the nut in the bark and imbed it in portland cement. The hole for the sinking of

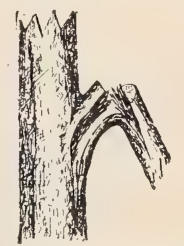

167. Bungling pruning.

the nut and washer is thickly coated with lead paint and then with a layer of cement, on which are placed the nut and washer, both of which are then imbedded in cement. If the outer 
surface of the nut be flush with the plane of the bark, within a few years it will be covered by the growing tissue.

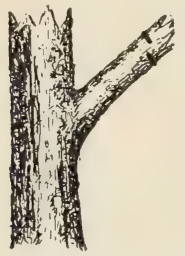

168. The proper way to saw off a large limb. A cut is first made on the under side to prevent splitting down; then it is cut on the upper side. Then the entire "stub" is removed close to the trunk.

"The inner ends of the rods in the two branches may be connected by a rod or chain. The preference for the chain over the rod attachment is based on the compressive and tensile stresses which come on the connection during wind storms. Rod connections are preferred, however, when rigidity is required, as in unions made close to the crotch; but for tying two branches together before they have shown signs of weakening at the fork, the chain may best be used, as the point of attachment may

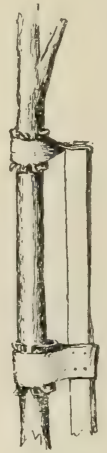

169. A weak-bodied young tree well supported; padding is placed under the bandages.

be placed some distance from the crotch, where the flexibility factor will be important and the strain comparatively small. Elms in an advanced stage of maturity, if subjected to severe climatic conditions, often show this tendency to split. These

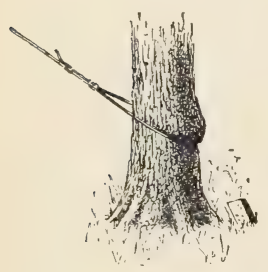

170. The wrong way of attaching a guy rope.

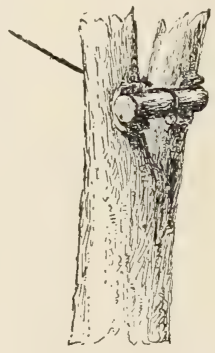

171. An allowable way of attaching a guy rope.

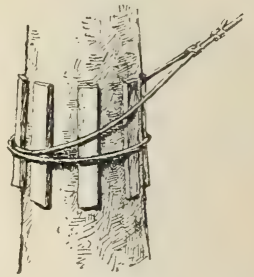

172. The best way of attaching a guy rope, if a tree must be used as support. 


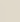




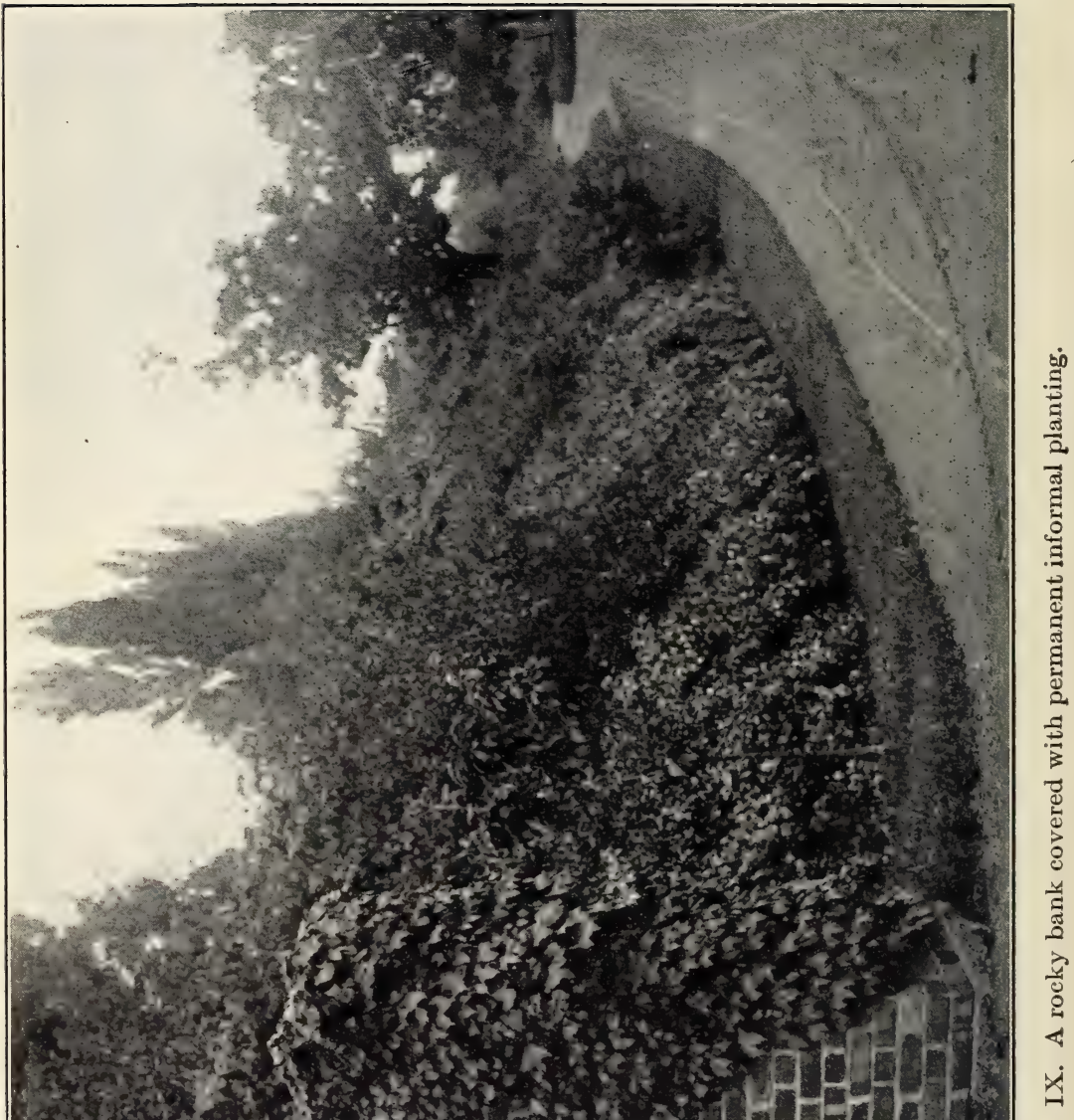


trees, especially, should be carefully inspected and means taken to preserve them, by bolting if necessary,"

The illustrations, Figs. 164-173, are self-explanatory, and show poor

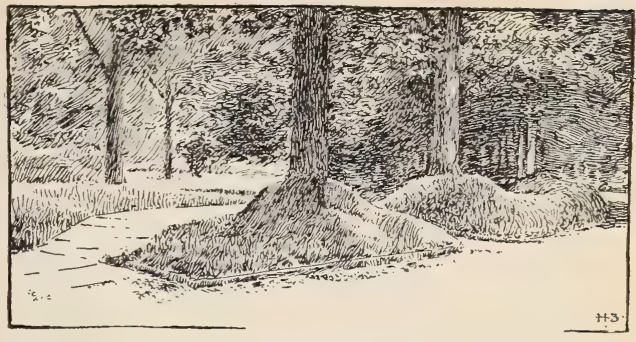

173. A method of saving valuable trees along streets on which heavy lowering of grade has been made. practice and good practice in the care of trees.

The grafting of plants.

Grafting is the operation of inserting a piece of a plant into another plant with the intention that it shall grow. It differs from the making of cuttings in the fact that the severed part grows in another plant rather than in the soil.

There are two general kinds of grafting - one of which inserts a piece of branch in the stock (grafting proper), and one which inserts only a bud with little or no wood attached (budding). In both cases the success of the operation depends on the growing together of the cambium of the cion (or cutting) and that of the stock. The cambium is the new and growing tissue lying underneath the bark and on the outside of the growing wood. Therefore, the line of demarcation between the bark and the wood should coincide when the cion and stock are joined.

The plant on which the severed piece is set is called the stock. The part which is removed and set into the stock is called a cion if it is a piece of a branch, or a "bud" if it is only a single bud with a bit of tissue attached.

The greater part of grafting and budding is performed when the cion or bud is nearly or quite dormant. That is, grafting is usually done late in winter and early in spring, and budding 
may be performed then, or late in summer, when the buds have nearly or quite matured.

The chief object of grafting is to perpetuate
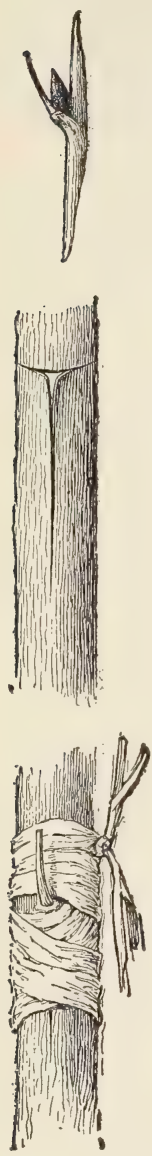

174. Budding. The "bud"; the opening to receive it; the bud tied. a kind of plant which will not reproduce itself from seed, or of which seed is very difficult to obtain. Cions or buds are therefore taken from this plant and set into whatever kind of plant is obtainable on which they will grow. Thus, if one wants to propagate the Baldwin apple, he does not for that purpose sow seeds thereof, but takes cions or buds from a Baldwin tree and grafts them into some other apple tree. The stocks are usually obtained from seeds. In the case of the apple, young plants are raised from seeds which are secured mostly from cider factories. without reference to the variety from which they came. When the seedlings have grown to a certain age, they are budded or grafted, the grafted part making the entire top of the tree; and the top bears fruit like that of the tree from which the cions were taken.

There are many ways in which the union between cion and stock is made. Budding may be first discussed. It consists in inserting a bud underneath the bark of the stock, and the commonest practice is that which is shown in the illustrations. Budding is mostly performed in July, August, and early September, when the bark is still loose or in condition to peel. Twigs are cut from the tree which it is desired to propagate, and the buds are cut off with a sharp knife, a shield-shaped bit of bark (with possibly a little wood) being left with them (Fig. 174). The bud is then shoved into a slit made in the 
stock, and it is held in place by tying with a soft strand. In two or three weeks the bud will have "stuck" (that is, it will have grown fast to the stock), and the strand is cut to prevent its strangling the stock. Ordinarily the bud does not grow until the following spring, at which time the entire stock or branch in which the bud is inserted is cut off an inch above the bud; and the bud thereby receives all the energy of the stock. Budding is the commonest grafting operation in nurseries. Seeds of peaches may be sown in spring, and the plants which result will be ready for budding that same August. The following spring, or a year from the planting of the seed, the stock is cut off just above the bud (which is inserted near the ground), and in the fall of that year the tree is ready for sale; that is, the top is one season old and the root is two seasons old, but in the trade it is known as a one-year-old tree. In the Souvh, the peach stock may be budded in June or early July of the year in which the seed is planted, and the bud grows into a saleable tree the same year: this is known as June budding. In apples and pears the stock is usually two years old before

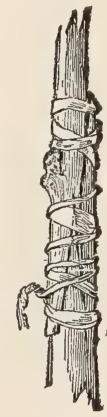

175. Whipgraft. it is budded, and the tree is not sold until the top has grown two or three years. Budding may be performed also in the spring, in which case the bud will grow the same season. Budding is always done on young growths, preferably on those not more than one year old.

Grafting is the insertion of a small branch (or cion), usually bearing more than one bud. If grafting is employed on small stocks, it is customary to employ the whip-graft (Fig. 175). Both stock and cion are cut across diagonally, and a split made in each, so that one fits into the other. The graft is tied securely with a string, and then, if it is above ground, it is also waxed carefully.

In larger limbs or stocks, the common method is to employ 
the cleft-graft (Fig. 176). This consists in cutting off the stock, splitting it, and inserting a wedge-shaped cion in one or both sides of the split, taking care that the cambium layer of the cion matches that of the stock. The exposed surfaces are then securely covered with wax.

Grafting is usually performed early in the spring, just before the buds swell. The cions should have been cut before this time, when they were perfectly dormant. Cions may be stored

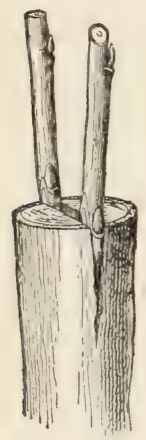

176. Cleft-graft

before waxing. in sand in the cellar or in the ice-house, or they may be buried in the field. The object is to keep them fresh and dormant until they are wanted.

If it is desired to change the top of an old plum, apple, or pear tree to some other variety, it is usually accomplished by means of the cleft-graft. If the tree is very young, budding or whip-grafting may be employed. On an old top the cions should begin to bear when three to four years old. All the main limbs should be grafted. It is important to keep down the suckers or watersprouts from around the grafts, and part of the remaining top should be cut away each year until the top is entirely changed over (which will result in two to four years).

A good wax for covering the exposed parts is described in the footnote on page 145 .

\section{Keeping records of the plantation.}

If one has a large and valuable collection of fruit or ornamental plants, it is desirable that he have some permanent record of them. The most satisfactory method is to label the plants, and then to make a chart or map on which the various plants are indicated in their proper positions. The labels are always liable to be lost and to become illegible, and they are often misplaced by careless workmen or mischievous boys. 
For vegetables, annuals, and other temporary plants, the best labels are simple stakes, like that shown in Fig. 177. Garden stakes a foot long, an inch wide, and three-eighths inch thick may be bought of label manufacturers for three to five dollars a thousand. These take a soft pencil very readily, and if the labels are taken up in the fall and stored in a dry place, they will last two or three years.

For more permanent herbaceous plants, as rhubarb and asparagus, or even for bushes, a stake that is sawed from clear pine or cypress, eighteen inches long, three inches wide, and an inch or more thick, affords a most excellent label. The lower end of the stake is sawed to a point, and is dipped in coal tar or creosote,

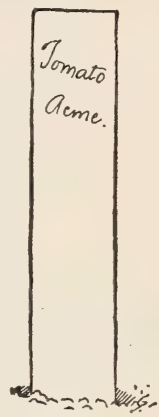

177. The common stake label. or other preservative. The top of the stake is painted white, and the legend is written with a large and soft pencil. When the writing becomes illegible or the stake is needed for other

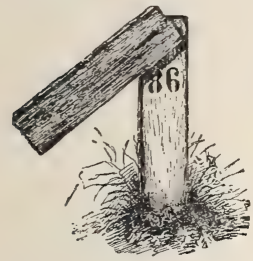

178. A good stake label, with the legend covered. plants, a shaving is taken off the face of the label with a plane, a fresh coat of paint added, and the label is as good as ever. These labels are strong enough to withstand shocks from whiffletrees and tools, and should last ten years.

Whenever a legend is written with a lead pencil, it is advisable to use the pencil when the paint (which should be white lead) is still fresh or soft. Figure 178 shows a very good device for preserving the writing on the face of the label. A block of wood is secured to the label by means of a screw, covering the legend completely and protecting it from the weather.

If more ornamental stake labels are desired, various types can be bought in the market, or one can be made after the fashion of Fig. 179. This is a zinc plate that can be painted black, on 
which the name is written with white paint. Many persons, however, prefer to paint the zinc white, and write or stamp the label with black ink or black type. Two strong wire legs are soldered to the label, and these prevent it from turning around. These labels are, of course, much more expensive than the ordinary stake labels, and are usually not so satisfactory, although more attractive.

For labeling trees, various kinds of zinc tallies are in common use, as shown in Figs. 180 and 181. Fresh zinc takes a lead pencil

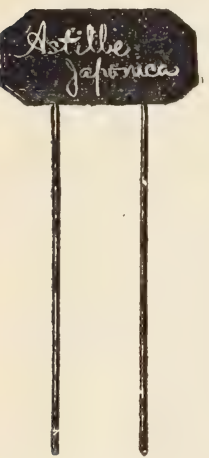

179. Metal stake label. readily, and the writing often becomes more legible as it becomes older, and it will usually

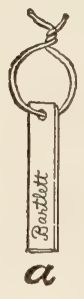

180. Zinc tallies.
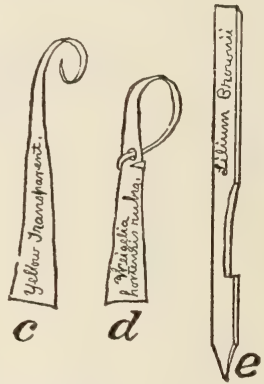

181. Common zinc tally.

remain three or four years. These labels are attached either by wires, as $a, b$, Fig. 180, or they are wound about the limb as shown in $c, d$, and $e$, in Fig. 180. The type of zinc label most in use is a simple strip of zinc, as shown in Fig. 181, wrapped about the limb. The metal is so flexible that it expands readily with the growth of the branch. While these zinc labels are durable, they are very inconspicuous because of their neutral color, and it is often difficult to find them in dense masses of foliage.

The common wooden label of the nurserymen (Fig. 182) is perhaps as useful as any for general purposes. If the label has had a light coat of thin white lead, and the legend has been made 
with a soft lead pencil, the writing should remain legible four or five years. Fig. 183 shows another type of label that is more

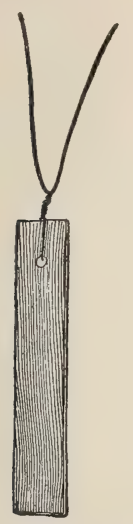

182. A common

nursery label. durable, since the wire is stiff and large, and is secured around the limb by means of pincers. The large loop allows the limb to expand, and the stiff wire prevents the misplacing of the label by winds and workmen. The tally itself is what is known as the "package label " of the nurserymen, being six inches long, one and one-fourth inches wide, and costing (painted) less than one and one-half dollars a thousand. The legend is made with a lead pencil when the paint is fresh,

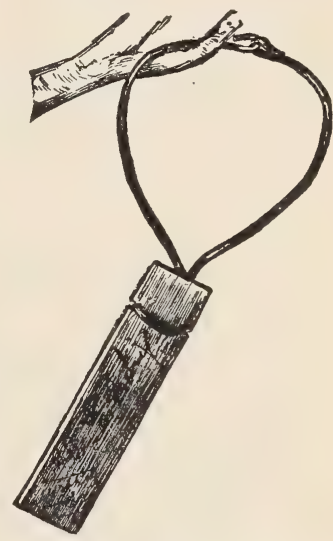

183. Cornell tree label.

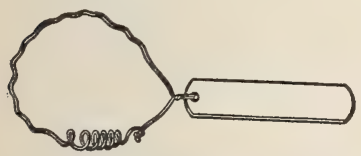

184. Serviceable large-loop tree label.

and sometimes the label is dipped in thin white lead after the writing is made, so that the paint covers the writing with a very thin protecting coat. A similar label is shown in Fig. 184, which has a large wire loop, with a coil, to allow the expansion of the limb.

The tallies of this type are often made of glass, or porcelain with the name indelibly printed in them. Figure 185 shows a zinc tally, which is secured to the tree by means of a sharp and pointed wire driven into

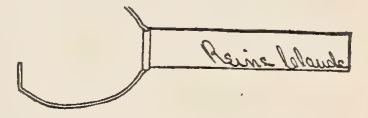

185. Zine tree label. the wood. Some prefer to have two arms to this wire, driving one point on either side of the tree. If galvanized wire is used, these labels will last for many years. 
It is very important, when adjusting labels to trees, to be sure that the wire is not twisted tight against the wood. Figure 186

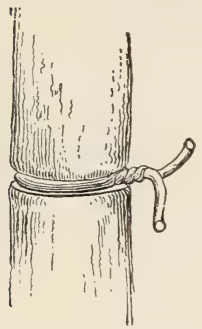

186. Injury by a tight label wire. shows the injury that is likely to result from label wires. When a tree is constricted or girdled, it is very liable to be broken off by winds. It should be a rule to attach the label to a limb of minor importance, so that if the wire should injure the part, the loss will not be serious. When the label, Fig. 182, is applied, only the tips of the wire should be twisted together, leaving a large loop for the expansion of the limb.

The storing of fruits and vegetables.

The principles involved in the storing of perishable products, as fruits and vegetables, differ with the different commodities. All the root-crops, and most fruits, need to be kept in a cool, moist, and uniform temperature if they are to be preserved a great length of time. Squashes, sweet-potatoes, and some other things need to be kept in an intermediate and what might be called a high

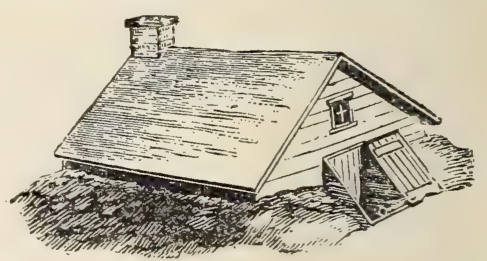

187. The old-fashioned "outdoor cellar," still a very useful and convenient storage place. temperature; and the atmosphere should be drier than for most other products. The low temperature has the effect of arresting decomposition and the work of fungi and bacteria. The moist atmosphere has the effect of "preventing too great evaporation and the consequent shriveling.

In the storing of any commodity, it is very important that the product is in proper condition for keeping. Discard all specimens that are bruised or are likely to decay. Much of the decay of fruits and vegetables in storage is not the fault of 
the storage process, but is really the work of diseases with which the materials are infected before they are put into storage. For example, if potatoes and cabbages are affected with the rot, it is practically impossible to keep them any length of time.

Apples, winter pears, and all roots, should be kept at a temperature somewhat near the freezing point. It should not rise above $40^{\circ} \mathrm{F}$. for best results. Apples can be kept even at one or two degrees below the freezing point if the temperature is uniform. Cellars in which there are heaters are likely to be too dry and the temperature too high. In such places it is well to keep fresh vegetables and fruits in tight receptacles, and pack the roots in sand or moss in order to prevent shriveling. In these places, apples usuallykeep better if headed up in barrels than if kept on racks or

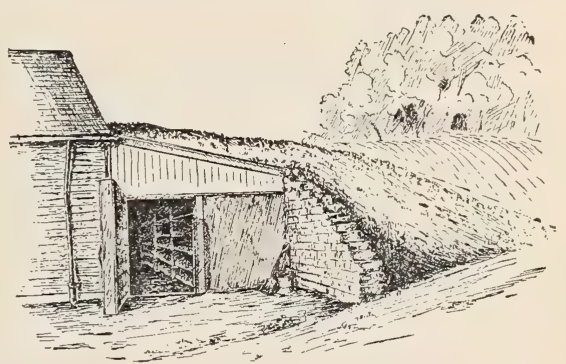

188. Lean-to fruit cellar, covered with earth. The roof should be of cement or stone slabs. Provide a ventilator.

shelves. In moist and cool cellars, however, it is preferable for the home supply to place them on shelves, not piling them more than five or six inches deep, for then they can be sorted over as occasion requires. In case of fruits, be sure that the specimens are not over-ripe when placed in storage. If apples are allowed to lie in the sun for a few days before being packed, they will ripen so much that it is very difficult to keep them.

Cabbages should be kept at a low and uniform temperature, and water should be drained away from them. They are stored in many ways in the field, but success depends so much on the season, particular variety, ripeness, and the freedom from injuries by fungi and insects, that uniform results are rarely secured by any one method. The best results are to be 
expected when they can be kept in a house built for the purpose, in which the temperature is uniform and the air fairly moist. When stored out of doors, they are likely to freeze and thaw alternately; and if the water runs into the heads, mischief results. Sometimes they are easily stored by being piled into a conical heap on well-drained soil and covered with dry straw,

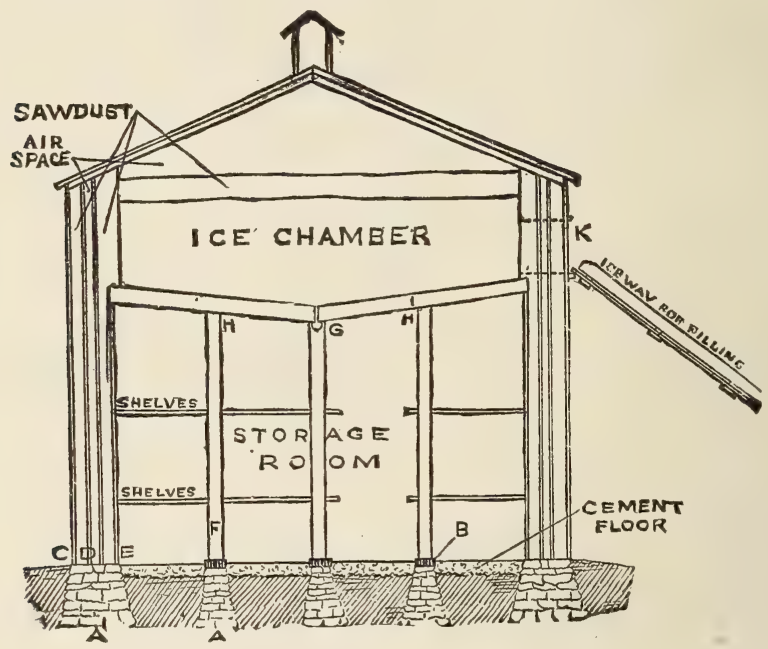

189. A fruit storage house cooled by ice.

and the straw covered with boards. It does not matter if they are frosted, provided they do not thaw out frequently. Sometimes cabbages are laid head down in a shallow furrow plowed in well-drained land, and over them is thrown straw, the stumps being allowed to project through the cover. It is only in winters of rather uniform temperature that good results are to be expected from such methods. These are some of the main considerations involved in the storing of such things as cabbage; the subject is mentioned again in the discussion of cabbage on page 470 ; also pages 513,515 . 
In the storing of all products, especially those which have soft and green matter, as cabbages, it is well to provide against the heating of the produce. If the things are buried out of doors, it is important to put on a very light cover at first so that the heat may escape. Cover them gradually as the cold weather comes on. This is important with all vegetables that are placed in pits, as potatoes, beets, and the like. If covered deeply at once, they are likely to heat and rot. All pits made out of doors should be on well-drained and preferably sandy land.

When vegetables are wanted at intervals during the winter from pits, it is well to make compartment pits, each compartment holding a wagon load or whatever quantity will be likely to be wanted at each time. These pits are sunk in well-drained land, and between each of the two pits is left a wall of earth about a foot thick. One pit can then be emptied in cold weather without interfering with the others.

An outside cellar is better than a house cellar in which there is a heater, but it is not so handy. If it is near the house, it need not be inconvenient, however. A house is usually healthier if the cellar is not used for storage. House cellars used for storage should have a ventilating shaft.

Some of the principles involved in an ice-cooled storage house are explained in the diagram, Fig. 189. If the reader desires to make a careful study of storage and storage structures, he should consult cyclopedias and special articles.

\section{The forcing of plants.}

There are three general means (aside from greenhouses) of forcing plants ahead of their season in the early spring - by means of forcing-hills and hand-boxès, by coldframes, and by hotbeds.

The forcing-hill is an arrangement by means of which a single plant or a single "hill" of plants may be forced where it per. 
manently stands. This type of forcing may be applied to perennial plants, as rhubarb and asparagus, or to annuals, as melons and cucumbers.

In Fig. 190 is illustrated a common method of hastening the growth of rhubarb in the spring. A box with four removable

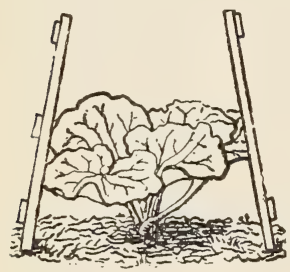

190. Forcing-hill for rhubarb. sides, two of which are shown in end section in the figure, is placed around the plant in the fall. The inside of the box is filled with straw or litter, and the outside is banked thoroughly with any refuse, to prevent the ground from freezing. When it is desired to start the plants, the covering is removed from both the inside and outside of the box and hot manure is piled around the box to its top. If the weather is yet cold, dry light leaves or straw may be placed inside the box; or a pane or sash of glass may be placed on top of the box, when it will become a coldframe. Rhubarb, asparagus, sea-kale, and similar plants may be advanced two or four weeks by means of this method

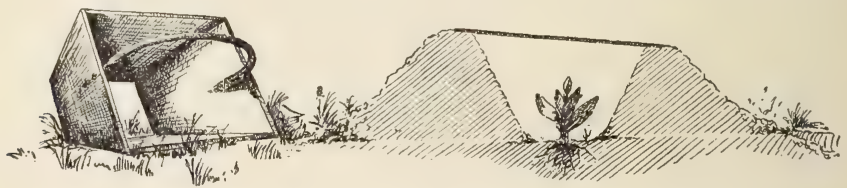

191. Forcing-hill, and the mold or frame for making it.

of forcing. Some gardeners use old barrels or half-barrels in place of the box. The box, however, is better and handier, and the sides can be stored for future use.

Plants that require a long season in which to mature, and which do not transplant readily, as melons and cucumbers, may be planted in forcing-hills in the field. One of these hills is shown in Fig. 191. The frame or mold is shown at the left. This mold is a box with flaring sides and no top or bottom, and 
provided with a handle. This frame is placed with the small end down at the point where the seeds are to be planted, and the earth is hilled up about it and firmly packed with the feet. The mold is then withdrawn, and a pane of glass is laid upon the top of the mound to concentrate the sun's rays, and to prevent the bank from washing down with the rains. A clod of earth or a stone may be placed upon the pane to hold it down. Sometimes a brick is used as a mold. This type of forcing-hill is not much used, because the bank of earth is liable to be washed away, and heavy rain coming when the glass is off will fill the hill with water and drown the plant. However, it can be used to very good advantage when the gardener can give it close attention.

A forcing-hill is sometimes made by digging a hole in the ground and planting the seeds in the bottom of it, placing the pane of glass upon a slight ridge or mound which is made on the sur-

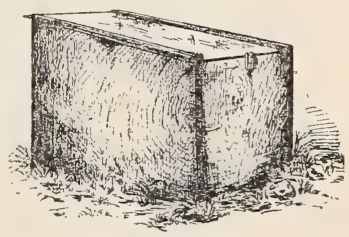

192. Hand-box. face of the ground. This method is less desirable than the other, because the seeds are placed in the poorest and coldest soil, and the hole is very likely to fill with water in the early days of spring.

An excellent type of forcing-hill is made by the use of the hand-box, as shown in Fig. 192. This is a rectangular box, without top or bottom, and a pane of glass is slipped into a groove at the top. It is really a miniature coldframe. The earth is banked up slightly about the box, in order to hold it against winds and to prevent the water from running into it. If these boxes are made of good lumber and painted, they will last for many years. Any size of glass may be used which is desired, but a ten-by-twelve pane is as good as any for general purposes.

After the plants are thoroughly established in these forcinghills, and the weather is settled, the protection is wholly removed, and the plants grow normally in the open. 
A very good temporary protection may be given to tender plants by using four panes of glass, as explained in Fig. 193, the two inner panes being held together at the top by a block of wood through which four nails are driven. Plants are more likely to burn in these glass frames than in the hand-boxes, and such frames are not so well adapted to the protection of plants

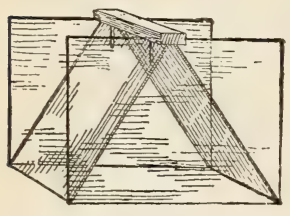

193. Glass forcing-hill. in very early spring; but they are often useful for special purposes.

In all forcing-hills, as in coldframes and hotbeds, it is exceedingly important that the plants receive plenty of air on bright days. Plants that are kept too close become weak or "drawn," and lose the ability to withstand changes of weather when the protection is removed. Even though the wind is cold and raw, the plants inside the frames ordinarily will not suffer if the glass is taken off when the sun is shining.

\section{Coldframes.}

A coldframe is nothing more than an enlarged hand-box; that is, instead of protecting but a single plant or a single hill with a single pane of glass, the frame is covered with sash, and is large enough to accommodate many plants.

There are three general purposes for which a coldframe is used: For the starting of plants early in spring; for receiving partially hardened plants that have been started earlier in hotbeds and forcing-houses; for wintering young cabbages, lettuce, and other hardy plants that are sown in the fall.

Coldframes are ordinarily placed near the buildings, and the plants are transplanted into the field when settled weather comes. Sometimes, however, they are made directly in the field where the plants are to remain, and the frames, and not the plants, are removed. When used for this latter purpose, the frames are made very cheap by running two rows of parallel 
planks through the field at a distance apart of six feet. The plank on the north is ordinarily ten to twelve inches wide, and that on the south eight to ten inches. These planks are held

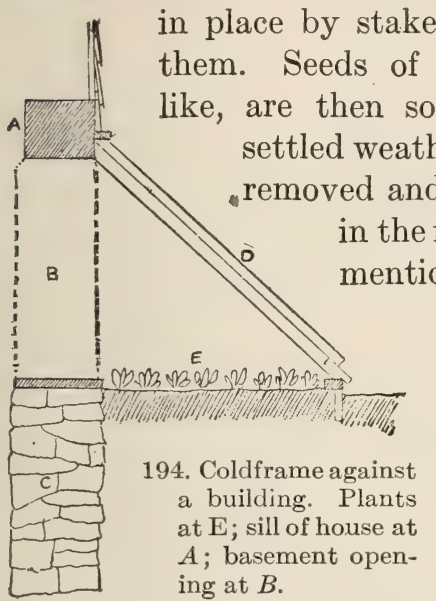

$D$, are laid on rafters which run from this sill to the sill of the house, A. If this frame is on the south side of the building, plants may be started even as early as a month before the opening of the season. Such lean-to frames are sometimes made against greenhouses or warm cellars, and heat is supplied to them by the opening of a door in the wall, as at $B$. In frames that are in such sunny positions as these, it is exceedingly important that care be

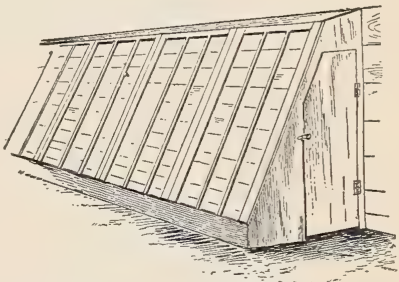

195. Weather screen, or coldframe, against a building. taken to remove the sash, or at least to give ample ventilation, in all sunny days.

A different type of lean-to structure is shown in Fig. 195. This may be either a temporary or permanent building, and 


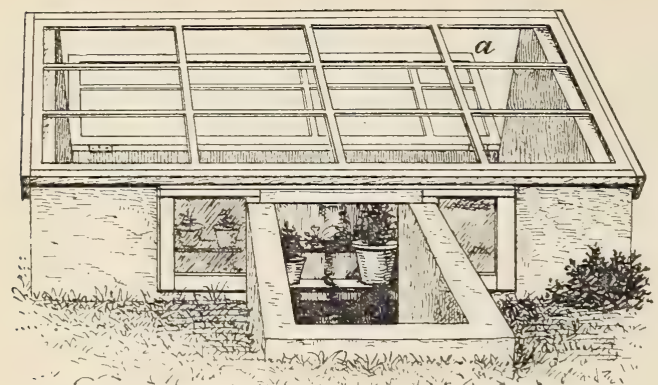

196. A pit or coldframe on permanent walls, and a useful adjunct to a garden. The rear cover is open $(a)$.

it is generally used for the protection of half-hardy plants that are grown in pots and tubs. It may be used, however, for the purpose of forwarding pot-plants early in the spring and for the protection of peaches, grapes, oranges, or other fruits in tubs or boxes. If it is desired merely to protect the plants through the winter, it is best

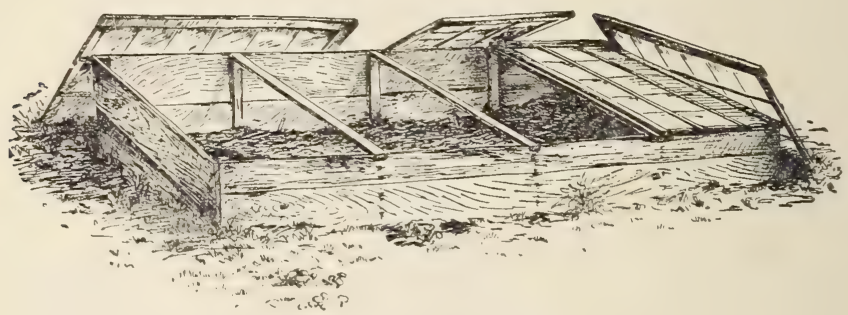

197. The usual form of coldframe.

to have the structure on the north side of the building, in order that the sun may not force the plants into activity.

Another structure that may be used both to carry half-hardy plants over winter and for starting plants early in spring is shown in Fig. 196. It is really a miniature greenhouse without heat. It is well adapted for mild climates. The

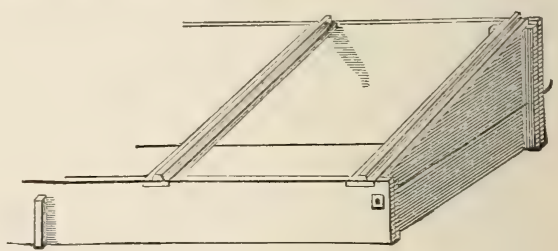

198. A strong and durable frame. 
picture was made from a structure in the coast region of North Carolina.

The common type of coldframe is shown in Fig. 197. It is

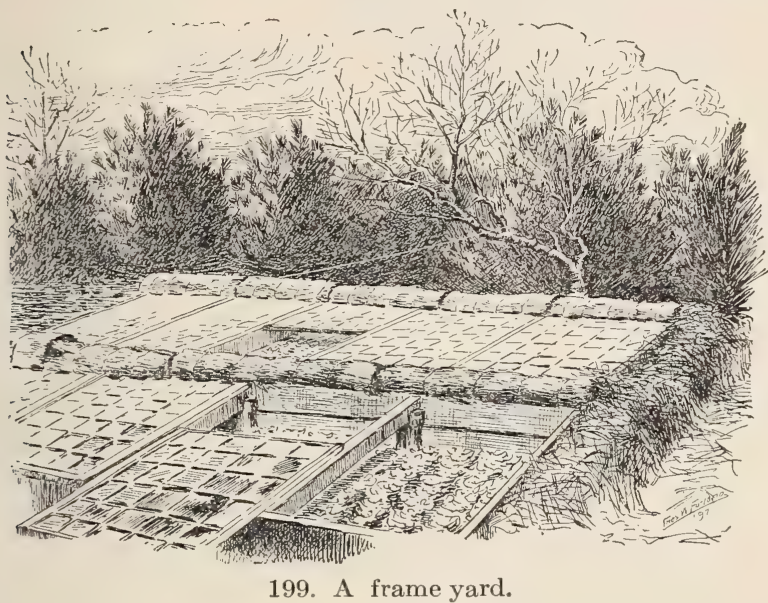

twelve feet long and six feet wide, and is covered with four three-by-six sash. It is made of ordinary lumber loosely nailed together. If one expects to use coldframes or hotbeds every year, however, it is advisable to make the frames of two-inch stuff, well painted, and to join the parts by bolts and tenons, so that they may be taken apart and stored until needed for the next year's crop. Figure 198 suggests a method of making frames so that they may be taken apart.

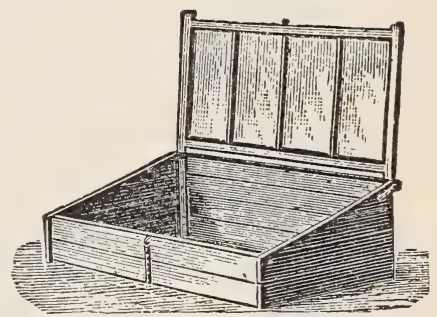

200. Portable coldframe.

It is always advisable to place coldframes and hotbeds in a protected place, and particularly to protect them from cold north winds. Buildings afford excellent protection, but the sun is 


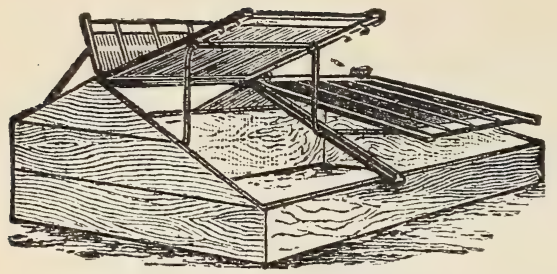

201. A larger portable coldframe.

sometimes too hot on the south side of large and light-colored buildings. One of the best means of protection is to plant a hedge of evergreens, as shown in Fig. 199. It is always desirable, also, to place all the coldframes and hotbeds close together, for the purpose of economizing time and labor. A regular area or yard may be set aside for this purpose.

Various small and portable coldframes may be used about the garden for the protection of tender plants or to start them early in

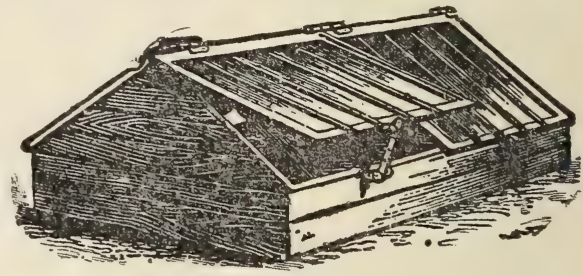

202. A commodious portable frame. the spring. Pansies, daisies, and border carnations, for example, may be brought on very early by setting such frames

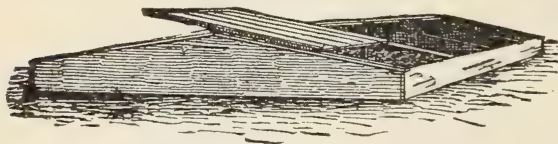

203. A low coldframe. over them or by planting them under the frames in the fall. These frames may be of any size desired, and the sash may be either removable, or, in case of small frames, they may be hinged at the top. Figs. 200-203 illustrate various types.

\section{Hotbeds.}

A hotbed differs from a coldframe in being provided with bottom heat. This heat is ordinarily supplied by means of fermenting manure, but it may be obtained from other fermenting material, as tanbark or leaves, or from artificial heat, as flues; steam pipes, or water pipes. 
The hotbed is used for the very early starting of plants; and when the plants have outgrown the bed, or have become too thick, they are transplanted into cooler hotbeds or into coldframes. There are some crops, however, that are carried to full maturity in the hotbed itself, as radishes and lettuce.

The date at which the hotbed may be started with safety depends almost entirely on the means at command of heating it and on the skill of the operator. In the northern states, where outdoor gardening does not begin until the first or the last of May, hotbeds are sometimes started as early as January; but they are ordinarily delayed until early in March.

The heat for hotbeds is commonly supplied by the fermentation of horse manure. It is important that the manure be as uniform as possible in composition and texture, that it come from highly fed horses, and is practically of the same age. The best results are usually secured with manure from livery stables, from which it can be obtained in large quantities in a short space of time. Perhaps as much as one half of the whole material should be of litter or straw that has been used in the bedding.

The manure is placed in a long and shallow square-topped pile, not more than four or six feet high, as a rule, and is then allowed to ferment. Better results are generally obtained if the manure is piled under cover. If the weather is cold and fermentation does not start readily, wetting the pile with hot water may start it. The first fermentation is nearly always irregular; that is, it begins unequally in several places in the pile. In order to make the fermentation uniform, the pile must be turned occasionally, taking care to break up all hard lumps and to distribute the hot manure throughout the mass. It is sometimes necessary to turn the pile five or six times before it is finally used, although half this number of turnings is ordinarily sufficient. When the pile is steaming uniformly throughout, it is 
placed in the hotbed, and is covered with the earth in which the plants are to be grown.

Hotbed frames are sometimes set on top of the pile of fermenting manure, as shown in Fig. 204. The manure should extend some distance beyond the edges of the frame; otherwise the frame will become too cold about the outside, and the plants will suffer.

It is preferable, however, to have a pit beneath the frame in which the manure is placed. If the bed is to be started in

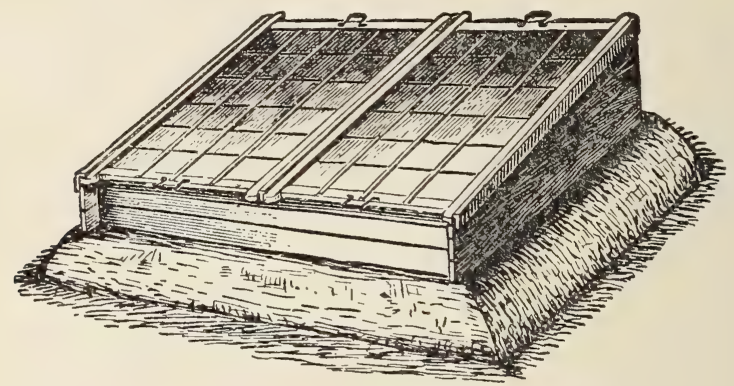

204. Hotbed with manure on top of the ground.

midwinter or very early in the spring, it is advisable to make this pit in the fall and to fill it with straw or other litter to prevent the earth from freezing deep. When it is time to make the bed, the litter is thrown out, and the ground is warm and ready to receive the fermenting manure. The pit should be a foot wider on either side than the width of the frame. Fig. 205 is a cross-section of such a hotbed pit. Upon the ground a layer of an inch or two of any coarse material is placed to keep the manure off the cold earth. Upon this, from twelve to thirty inches of manure is placed. Above the manure is a thin layer of leafmold or some porous material, that will serve as a distributor of the heat, and above this is four or five inches of soft garden loam, in which the plants are to be grown. 
It is advisable to place the manure in the pit in layers, each stratum to be thoroughly trodden down before another one is put in. These layers should be four to eight inches in thickness. By this means the mass is easily made uniform in consistency. Manure that has too much straw for the best results, and which will therefore soon part with its heat, will spring up quickly when the pressure of the feet is removed. Manure that has

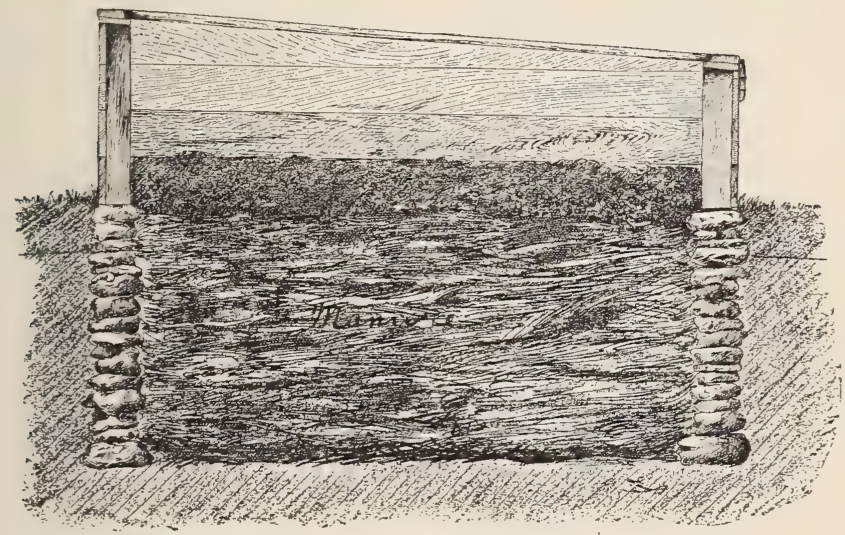

205. Section of a hotbed built with a pit.

too little straw, and which therefore will not heat well or will spend its heat quickly, will pack down into a soggy mass underneath the feet. When the manure has sufficient litter, it will give a springy feeling to the feet as a person walks over it, but will not fluff up when the pressure is removed. The quantity of manure to be used will depend on its quality, and also on the season in which the hotbed is made. The earlier the bed is made, the larger should be the quantity of manure. Hotbeds that are intended to hold for two months should have about two feet of manure, as a rule.

The manure will ordinarily heat very vigorously for a few days after it is placed in the bed. A soil thermometer should be 
thrust through the earth down to the manure, and the frame kept tightly closed. When the temperature is passing below $90^{\circ}$, seeds of the warm plants, like tomatoes, may be sown, and when it passes below $80^{\circ}$ or $70^{\circ}$, the seeds of cooler plants may be sown.

If hotbeds are to be used every year, permanent pits should be provided for them. Pits are made from two to three feet deep, preferably the former depth, and are walled up with stone or brick. It is important that they be given good drainage from below. In the summer-time, after the sash are stripped, the

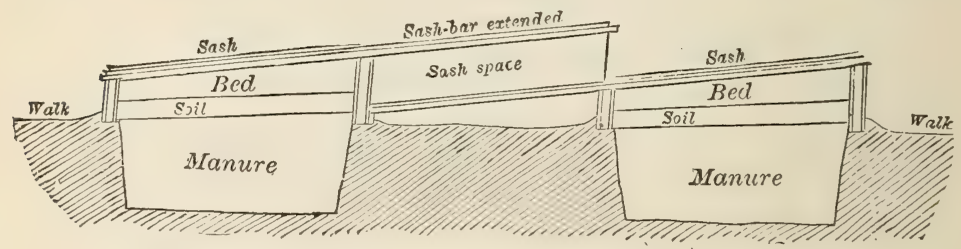

206. Parallel runs of hotbeds with racks for holding sashes.

old beds may be used for the growing of various delicate crops, as melons or half-hardy flowers. In this position, the plants can be protected in the fall. As already suggested, the pits should be cleaned out in the fall and filled with litter to facilitate the work of making the new bed in the winter or spring .

Various modifications of the common type of hotbed will suggest themselves to the operator. The frames should ordinarily run in parallel rows, so that a man walking between them can attend to the ventilation of two rows of sash at once. Fig. 206 shows a different arrangement. There are two parallel runs, with walks on the outside, and between them are racks to receive the sash from the adjacent frames. The sash from the left-hand bed are run to the right, and those from the right-hand bed are run to the left. Running on racks, the operator does not need to handle them, and the breakage of glass is therefore less; but this system is little used because 
of the difficulty of reaching the farther side of the bed from the single walk.

If the hotbed were high enough and broad enough to allow a man to work inside, we should have a forcing-house. Such a structure is shown in Fig. 207, upon one side of which the manure and soil are already in place. These manureheated houses are often very efficient, and are a good make-shift until such time as the gardener can afford to put in flue or pipe heat.

Hotbeds may be heated by means of

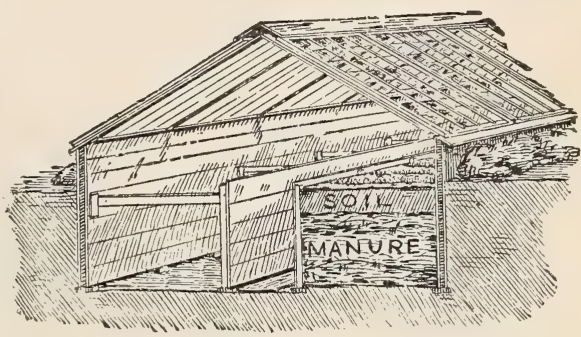

207. Manure-heated greenhouse.

steam or hot water. They can be piped from the heater in a dwelling-house or greenhouse. Fig. 208 shows a hotbed with two pipes, in the positions 7, 7 beneath the bed. The earth is shown at 4 , and the plants (which, in this case, are vines)

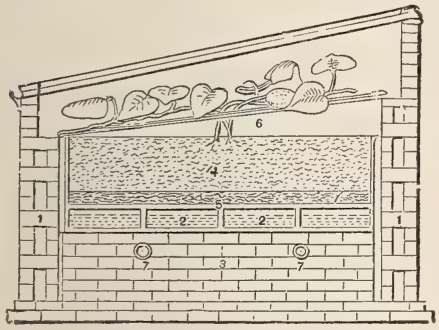

208. Pipe-heated hotbed. are growing upon a rack, at 6 . There are doors in the end of the house, shown in 2, 2, which may be used for ventilation or for admitting air underneath the beds. The pipes should not be surrounded by earth, but should run through a free air space.

It would scarcely pay to put in a hot water or steam heater for the express purpose of heating hotbeds, for if such an expense were incurred, it would be better to make a forcing-house. Hotbeds may be heated, however, with hot-air flues with very good results. A home-made brick furnace may be constructed in a pit at one end of the run and underneath a shed, and the 
smoke and hot air, instead of being carried directly upwards, is carried through a slightly rising horizontal pipe that runs underneath the beds. For some distance from the furnace, this flue may be made of brick or unvitrified server pipe, but stove-pipe may be used for the greater part of the run. The chimney is ordinarily at the farther end of the run of beds. It should be high, in order to provide a good draft. If the run of beds is long, there should be a rise in the underlying pipe of at least one foot in twenty-five. The greater the rise in this pipe,

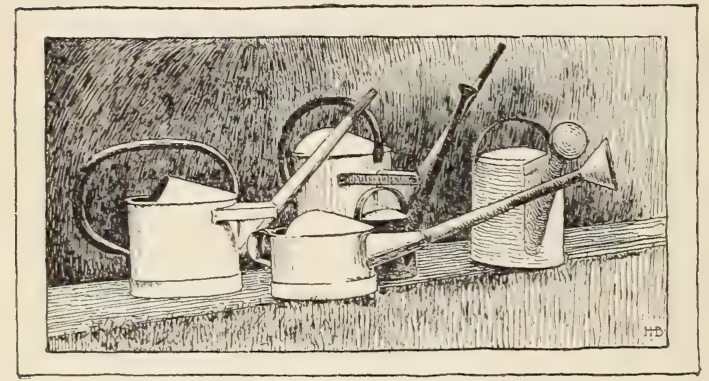

209. Useful kinds of watering-pots. These are adapted to different uses, as are different forms of hoes or pruning tools. the more perfect will be the draft. If the runs are not too long, the underlying pipe may return underneath the beds and enter a chimney directly over the back end of the furnace, and such a chimney, being warmed from the furnace, will ordinarily have an excellent draft. The underlying pipe should occupy a free space or pit beneath the beds, and whenever it lies near to the floor of the bed or is very hot, it should be covered with asbestos cloth. While such flue-heated hotbeds may be eminently successful with a grower or builder of experience, it may nevertheless be said, as a general statement, that whenever such trouble and expense are incurred, it is better to make a forcing-house. The subject of forcing-houses and greenhouses is not discussed in this book.

The most satisfactory material for use in hotbed and coldframe sash is double-thick, second-quality glass; and panes 
twelve inches wide are ordinarily broad enough, and they suffer comparatively little in breakage. For coldframes, however, various oiled papers and waterproof cloths may be used, particularly for plants that are started little in advance of the opening of the season. When these materials are used, it is not necessary to have expensive sash, but rectangular frames are made from strips of pine seven-eighths inch thick and two and one-half inches wide, halved together at the corners and each corner reënforced by a square carriage-corner, such as is used by carriage-makers to secure the corners of buggy boxes. These corners can be bought by the pound at hardware stores.

Management of hotbeds.

Close attention is required in the management of hotbeds, to insure that they do not become too hot when the sun comes out suddenly, and to give plenty of fresh air.

Ventilation is usually effected by raising the sash at the upper end and letting it rest upon a block. Whenever the temperature is above freezing point, it is generally advisable to take the sash off part way, as shown in the central part of Fig. 199, or even to strip it off entirely, as shown in Fig. 197.

Care should be taken not to water the plants at nightfall, especially in dull and cold weather, but to give them water in the morning, when the sun will soon bring the temperature up to its normal state. Skill and judgment in watering are of the greatest importance in the management of hotbeds; but this skill comes only from thoughtful practice. The satisfaction and effectiveness of the work are greatly increased by good hose connections and good watering-pots (Fig. 209).

Some protection, other than the glass, must be given to hotbeds. They need covering on every cold night, and sometimes during the entire day in very severe weather. Very good material for covering the sash is matting, such as is used for cov- 
ering floors. Old pieces of carpet may also be used. Various hotbed mattings are sold by dealers in gardeners' supplies.

Gardeners often make mats of rye straw, although the price of good straw and the excellence of manufactured materials make this home-made matting less desirable than formerly. Such mats are thick and durable, and are rolled up in the morning, as shown in Fig. 199. There are various methods of making these straw mats, but Fig. 210 illustrates one of the best. A frame is made after the manner of a saw-horse, with a double

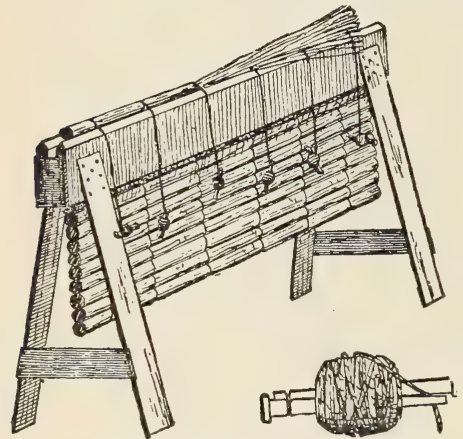

210. The making of straw mats. top, and tarred or marline twine is used for securing the strands of straw. It is customary to use six runs of this warp. Twelve spools of string are provided, six hanging on either side. Some persons wind the cord upon two twenty-penny nails, as shown in the figure, these nails being held together at one end by wire which is secured in notches filed into them. The other ends of the spikes are free, and allow the string to be caught between them, thus preventing the balls from unwinding as they hang upon the frame. Two wisps of straight rye straw are secured and laid upon the frame, with the butt ends outward and the heads overlapping. Two opposite spools are then brought up, and a hard knot is tied at each point. The projecting butts of the straw are then cut off with a hatchet, and the mat is allowed to drop through to receive the next pair of wisps. In making these mats, it is essential that the rye contains no ripe grain; otherwise it attracts the mice. It is best to grow rye for this especial purpose, and to cut it before the grain is in the milk, so that the straw does not need to be threshed. 
In addition to these coverings of straw or matting, it is sometimes necessary to provide board shutters to protect the beds, particularly if the plants are started very early in the season. These shutters are made of half-inch or five-eighths-inch pine lumber, and are the same size as the sash - three by six feet. They may be placed upon the sash underneath the matting, or they may be used above the matting. In some cases they are used without any matting.

In the growing of plants in hotbeds, every effort should be made to prevent the plants from growing spindling, or becoming "drawn." To make stocky plants, it is necessary to give room to each plant, to be sure that the distance from the plants to the glass is not great, to provide not too much water in dull and cold weather, and particularly to give abundance of air. 


\section{CHAPTER VI}

\section{PROTECTING PLANTS FROM THINGS THAT PREY ON THEM}

Plants are preyed on by insects and fungi; and they are subject to various kinds of disease that, for the most part, are not yet understood. They are often injured also by mice and rabbits (p. 144), by moles, dogs, cats, and chickens; and fruit is eaten by birds. Moles may be troublesome on sandy land; they heave the ground by their burrowing and may often be killed by stamping when the burrow is being raised; there are mole traps that are more or less successful. Dogs and cats work injury mostly by walking across newly made gardens or lying in them. These animals, as well as chickens, should be kept within their proper place (p. 16); or if they roam at will, the garden must be inclosed in a tight wire fence or the beds protected by brush laid closely over them.

The insects and diseases that attack garden plants are legion; and yet, for the most part, they are not very difficult to combat if one is timely and thorough in his operations. These difficulties may be divided into three great categories: the injuries wrought by insects; the injuries of parasitic fungi; the various types of so-called constitutional diseases, some of which are caused by germs or bacteria, and many of which have not yet been worked out by investigators.

The diseases caused by parasitic fungi are usually distinguished by distinct marks, spots or blisters on the leaves or stems, and the gradual weakening or death of the part; and, in many cases, the leaves drop bodily. For the most part, these spots on the leaves or stems sooner or later exhibit a mildew-like or 
rusty appearance, due to the development of the spores or fruiting bodies. Fig. 211 illustrates the ravages of one of the parasitic fungi, the shothole fungus of the plum. Each spot probably represents a distinct attack of the fungus, and in this particular disease these injured parts of tissue are liable to fall out, leaving

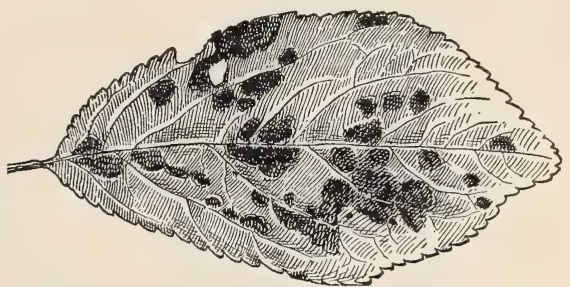

211. Shot-hole disease of plum. holes in the leaf. Plum leaves that are attacked early in the sea-

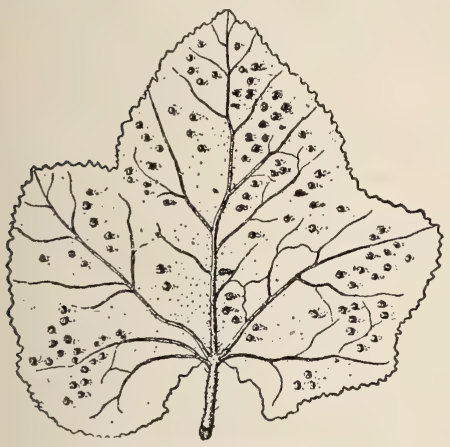

212. Hollyhock rust. son by this disease usually drop prematurely; but sometimes the leaves persist, being riddled by holes at the close of the season. Fig. 212 is the rust of the hollyhock. In this case the pustules of the fungus are very definite on the under side of the leaf. The blisters of leaf-curl are shown in Fig. 213. The ragged work of apple-scab fungus is shown in Fig. 214.

The constitutional and bacterial diseases usually affect the whole plant, or at least large portions of it; and the seat of

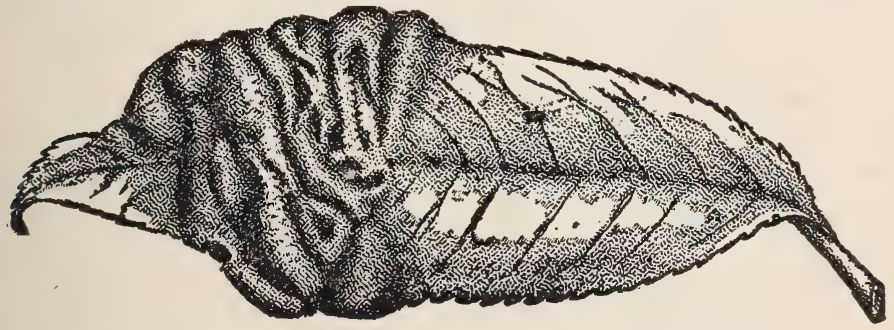

213. Leaf-curl of peach, due to a fungus. 
attack is commonly not so much in the individual leaves as in the stems, the sources of food supply being thereby cut off from the foliage. The symptoms of this class of diseases are general weakening of plant when the disease affects the plant as a whole or when it attacks large branches; or sometimes the leaves shrivel and die about the edges or in large irregular discolored spots, but without the distinct pustular marks of the parasitic fungi.

There is a gen- 214. Leaves and fruits injured by fungi, chiefly appleeral tendency

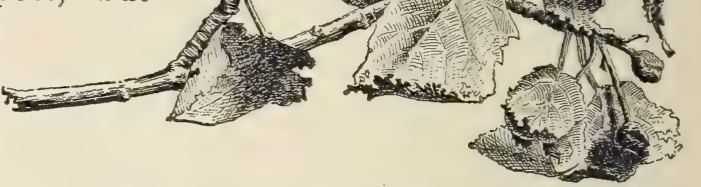
for the foliage on plants affected with such diseases to shrivel and to hang on the stem for a time. One of the bèst illustrations of this type of disease is the pear-blight. Sometimes the plant gives rise to abnormal growths, as in the "willow. shoots" of peaches affected with yellows (Fig. 215).

Another class of diseases are the root-galls. They are of various kinds. The root-gall of raspberries, crown-gall of peaches, apples, and other trees, is the most popularly recognized of this class of troubles (Fig. 216). It has long been known as a disease of nursery stock. Many states have laws against the sale of trees showing this disease. Its cause was unknown, until in 1907 Smith and Townsend, of the Bureau of Plant Industry, United States Department of Agriculture, undertook an investigation. They proved that it is a bacterial disease (caused by Bacterium tumefaciens); but just how the bacteria gain entrance to the root is not known. The same bacterium may cause galls on the stems of other plants, as, for example, on certain of the daisies. The "hairy-root" of apples, and 
certain galls that often appear on the limbs of large apple-trees, are also known to be caused by this same bacterium. The disease seems to be most serious and destructive on the raspberry, particularly the Cuthbert variety. The best thing to be done when the raspberry patch becomes infested is to root out the plants and destroy them, planting a new patch with clean stock on land that has not grown berries for some time. Notwithstanding the laws that have been made against the distribution of root-gall from nurseries, the evidence seems to show that it is not a serious disease of apples or peaches, at least not

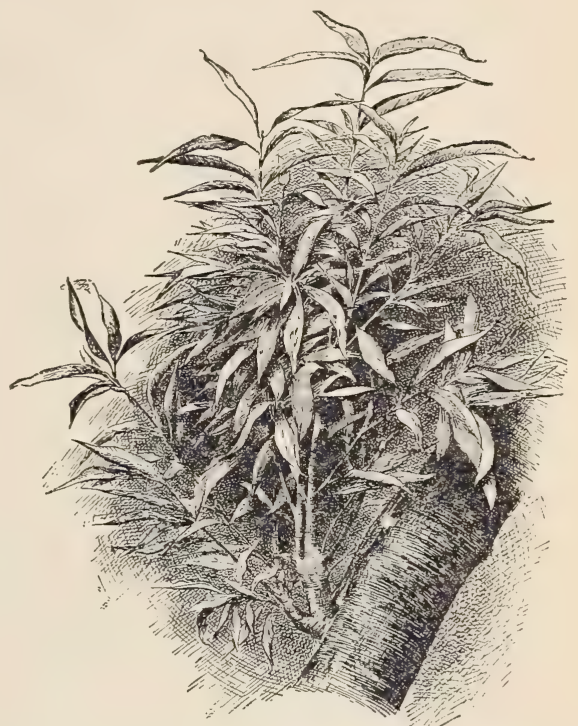

215. The slender tufted growth indicating peach yellows. The cause of this disease is undetermined.

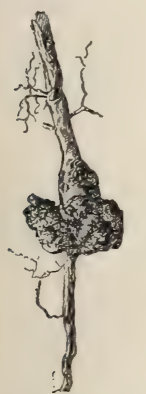

216. Gall on a raspberry root.

in the northeastern United States. It is not determined how far it may injure such trees.

Of obvious insect injuries, there are two general types, - those wrought by insects that bite or chew their food, as the ordinary beetles and worms, and those wrought by insects that puncture the surface of the plant and derive their food by sucking the juices, as scale-insects and plant-lice. The canker-worm (Fig. 217) is a notable example of the former class; and many of these insects may be dispatched by the appli- 
cation of poison to the parts that they eat. It is apparent, however, that insects which suck the juice of the plant are not poisoned by any liquid that may be applied to the surface. They may be killed by various materials that act upon them externally, as the soap washes, miscible oils, kerosene emulsions, lime-and-sulfur sprays, and the like.

There has been much activity in recent years in the identification and study of insects, fungi, and microorganisms that injure plants; and great numbers of bulletins and monographs have been published; and yet the gardener who has tried assiduously to follow these investigations is likely to go to his garden any morning and find troubles that he cannot identify and which perhaps even an investigator himself might not understand. It is important, therefore, that the gardener inform himself not only on particular kinds of insects and diseases, but that he develop a resourcefulness of his own. He should be able to do something, even if he does not know a complete remedy or specific. Some of the procedure, preventive and remedial, that needs always to be considered, is as follows:-

Keep the place clean, and free from infection. Next to keeping the plants vigorous and strong, this is the first and best means of averting trouble from insects and fungi. Rubbish and all places in which the insects can hibernate and the fungi can propagate should be done away with. All fallen leaves from plants that 
have been attacked by fungi should be raked up and burned, and in the fall all diseased wood should be cut out and destroyed. It is important that diseased plants are not thrown on the manure heap, to be distributed through the garden the following season.

Practice a rotation or alternation of crops (p.114). Some of the diseases remain in the soil and attack the plant year after year. Whenever any

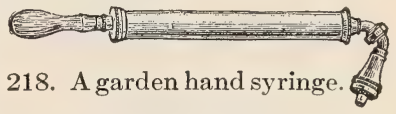
crop shows signs of root disease, or soil disease, it is particularly important that another crop be grown on the place. See that the disease or insect is not bred on weeds or other plants that are botanically related to the crop you grow. If the wild mallow, or plant known to children as "cheeses" (Malva rotundifolia), is destroyed, there will

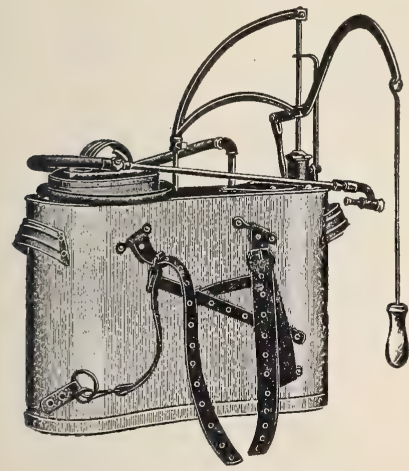

219. A knapsack pump.

be much less difficulty with hollyhock rust. Do not let the cabbage club-root disease breed on wild turnips and other mustards, or blackknot on plum sprouts and wild cherries, or tent-caterpillars on wild cherries and other trees.

Always be ready to resort to hand-picking. We have grown so accustomed to killing insects by other means that we have almost forgotten that hand-picking is often the surest and sometimes even the most expeditious means of checking an invasion in a home garden. Many insects can be jarred off early in the morning. Eggmasses on leaves and stems may be removed. Cutworms may be dug out. Diseased leaves may be picked 
off and burned; this will do much to combat the hollyhock rust, aster rust, and other infections.

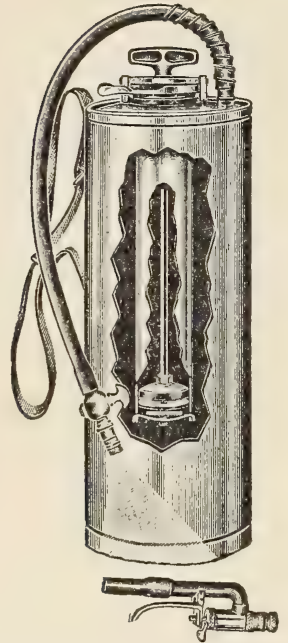

220. A compressed-air hand pump for garden work.

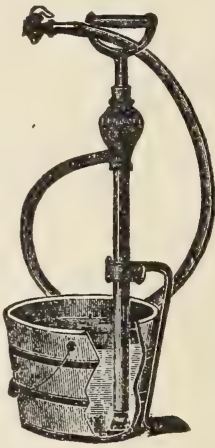

221. A bucket pump.

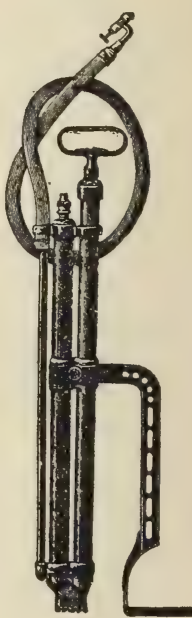

222. A bucket pump.

Keep close watch on the plants, and be prepared to strike quickly. It should be a matter of pride to a gardener to have in his workhouse a supply of the common insecticides and fungicides (Paris green or arsenate of lead, some of the tobacco preparations, white hellebore, whale-vil soap, bordeaux mixture, flowers of sulfur, carbonate of copper for solution in

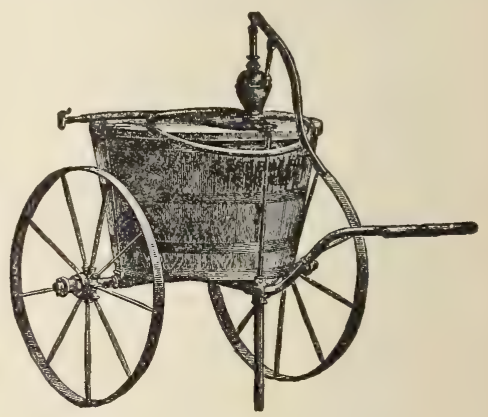

223. A cart-mounted pump. 
ammonia), and also a good hand syringe (Fig. 218), a knapsack pump (Figs. 219, 220), a bucket pump (Figs. $221,222)$, a hand bellows or powder gun, perhaps a barrow outfit (Figs. 223, 224, 225), and if the plantation is large enough, some kind of a force pump (Figs. $226,227,228$ ). If one is always ready, there is little

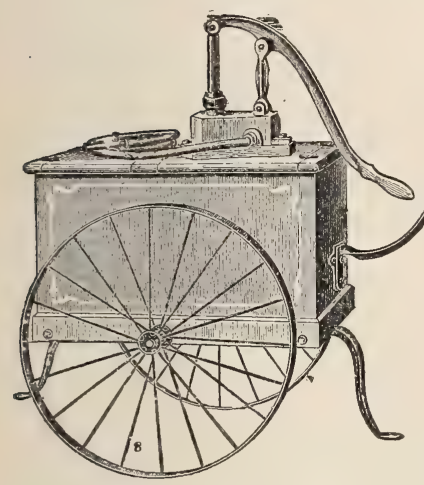

224. A garden outfit.

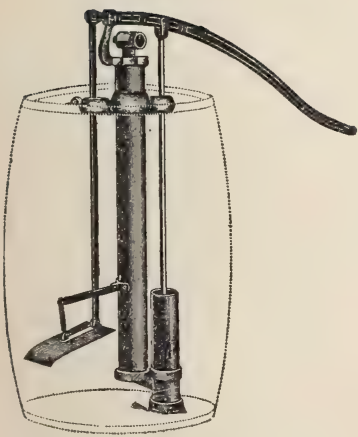

226. A barrel hand pump.

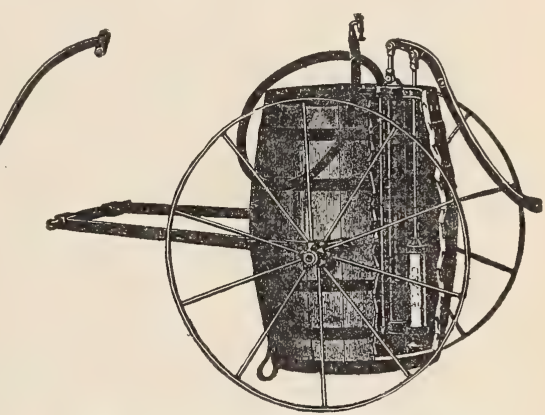

225. A cart-mounted barrel pump.

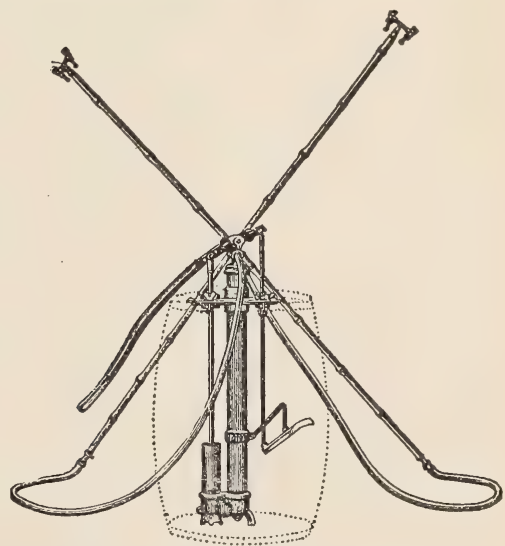

227. A barrel outfit, showing nozzles on extension rods for trees. 
danger from any insect or disease that is controllable by spraying.

\section{Screens and covers.}

There are various ways of keeping insects away from plants. One of the best is to cover the plants with fine mosquito-netting

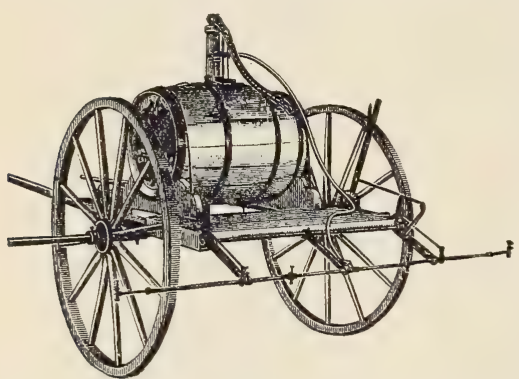

228. A truck-mounted barrel hand spray soil, these boxes, by keeping pump. or to grow them in handframes, or to use a wirecovered box like that shown in Fig. 229. In growing plants under such covers, care must be taken that the plants are not kept too close or confined; and in cases in which the insects hibernate in the the soil warm, may cause the insects to hatch all the sooner. In most cases, however, these covers are very efficient, especially for keeping the striped bugs off young plants of melons and cucumbers.

Cut-worms may be kept away from plants by placing sheets of tin or of heavy glazed paper about the stem of the plant, as shown in Fig. 230. Climbing cut-worms are kept off young trees by the means shown in Fig. 231. Or a roll of cotton may be placed about the trunk of the tree, a string being tied on the lower edge of the roll

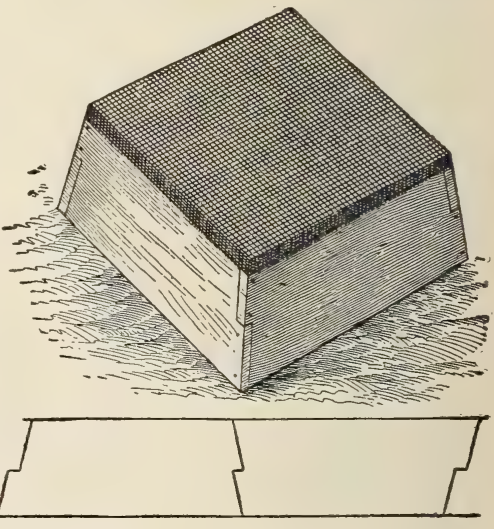

229. Wire-covered box for protecting plants from insects. 
and the upper edge of the cotton turned down like the top of a boot; the insects cannot crawl over this obstruction (p. 203).

The maggots that attack the roots of cabbages and cauliflowers may be kept from the plant by pieces of tarred paper, which are placed close about the stem upon the surface of the ground. Fig. 232 illustrates a hexagon of paper, and also shows a tool used for cutting it. This means of preventing the attacks of the cabbage maggot is described in detail by the late

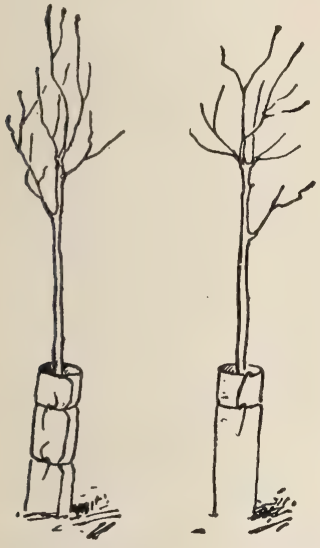

231. Protecting trees from cut-worms.
Professor Goff (for another method of

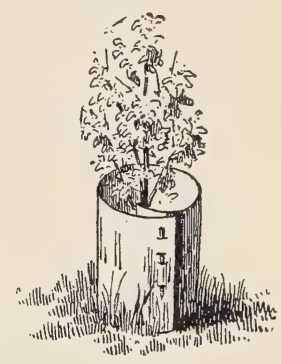

230. Protecting from cut-worms. controlling cabbage maggot see p. 201) :"The cards are cut in a hexagonal form, in order better to economize the material, and a thinner grade of tarred paper than the ordinary roofing felt is used, as it is not only cheaper, but being more flexible, the cards made from it are more readily placed about the plant without being torn. The blade of the tool, which should be made by an expert blacksmith, is formed from a band of steel, bent in the form of a half hexagon, and then taking an acute angle, reaches

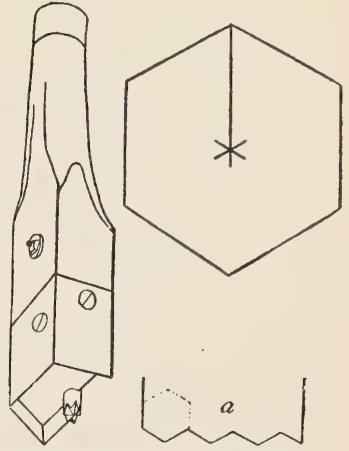

232. Showing how paper is cut for protecting cabbages from maggots. The Goff device. nearly to the center, as shown in Fig. 232. The part making the star-shaped cut is formed from a separate piece of steel, so 
attached to the handle as to make a close joint with the blade. The latter is beveled from the outside all round, so that by removing the part making the star-shaped cut, the edge may be ground on a grindstone. It is important that the angles in the blade be made perfect, and that its outline represents an exact half hexagon. To use the tool, place the tarred paper on the end of a section of a log or piece of timber and first cut the lower edge into notches, as indicated at $a$, Fig. 232, using only one angle of the tool. ' Then commence at the left side and place the blade as indicated by the dotted lines, and strike at the end of the handle with a light mallet, and a complete card is made. Continue in this manner across the paper. The first cut of every alternate course will make an imperfect card, and the last cut in any course may be imperfect, but the other cuts will make perfect cards if the tool is correctly made, and properly used. The cards should be placed about the plants at the time of transplanting. To place the card, bend it slightly to open the slit, then slip it on to the center, the stem entering the slit, after which spread the card out flat, and press the points formed by the star-shaped cut snugly around the stem."

\section{Fumigating.}

An effective means of destroying insects in glass houses is by fumigating with various kinds of smoke or vapors. The best material to use for general purposes is some form of tobacco or tobacco compounds. The old method of fumigating with tobacco is to burn slowly slightly dampened tobacco stems in a kettle or scuttle, allowing the house to be filled with the pungent smoke. Lately, however, fluid extracts and other preparations of tobacco have been brought into use, and these are so effective that the tobacco-stem method is becoming obsolete. The use of hydrocyanic acid gas in greenhouses is now coming to be common, for plant-lice, white-fly, and other insects. It is also used to fumigate nursery stock for San José scale, and mills 
and dwellings for such pests and vermin as become established in them. The following directions are from Cornell Bulletin 283 (from which the formulas in the succeeding pages, and most of the advice, are also taken):-

"No general formula can be given for fumigating the different kinds of plants grown in greenhouses, as the species and varieties differ greatly in their ability to withstand the effects of the gas. Ferns and roses are very susceptible to injury, and fumigation if attempted at all should be performed with great caution. Fumigation will not kill insect eggs and thus must be repeated when the new brood appears. Fumigate only at night when there is no wind. Have the house as dry as possible and the temperature as near $60^{\circ}$ as practicable.

"Hydrocyanic acid gas is a deadly poison, and the greatest care is required in its use. Always use 98 to 100 per cent pure potassium cyanide and a good grade of commercial sulfuric acid. The chemicals are always combined in the following proportion: Potassium cyanide, $1 \mathrm{oz}$.; sulfuric acid, 1 fluid oz.; water, 4 fluid oz. Always use an earthen dish, pour in the water first, and add the sulfuric acid to it. Put the required amount of cyanide in a thin paper bag and when all is ready, drop it into the liquid and leave the room immediately. For mills and dwellings, use $1 \mathrm{oz}$. of cyanide for every $100 \mathrm{cu}$. $\mathrm{ft}$. of space. Make the doors and windows as tight as possible by pasting strips of paper over the cracks. Remove the silverware and food, and if brass and nickel work cannot be removed, cover with vaseline or cloths. Plece proper amount acid and water for every room in 2 -gal. jars. Use two or more in large rooms or halls. Weigh out the potassium cyanide in paper bags, and place them near the jars. When all is ready, drop the cyanide into the jars, beginning on the top floors, since the fumes are lighter than air. In large buildings, it is frequently necessary to suspend the bags of cyanide over the jars by cords running through screw eyes and all leading to a 
place near the door. By cutting all the cords at once the cyanide will be lowered into the jars and the operator may escape without injury. Let the fumigation continue all night, locking all outside doors and placing danger signs on the house."

In greenhouses, the white-fly on cucumbers and tomatoes may be killed by overnight fumigation with $1 \mathrm{oz}$. of potassium cyanide to every $1000 \mathrm{cu}$. ft. of space; or with a kerosene emulsion spray or whale-oil soap, on plants not injured by these materials.

The green aphis is dispatched in houses by fumigation with any of the tobacco preparations; on violets, by fumigation with $\frac{1}{2}$ to $\frac{3}{4} \mathrm{oz}$. potassium cyanide for every $1000 \mathrm{cu}$. ft. of space, leaving the gas in from $\frac{1}{2}$ to $1 \mathrm{hr}$.

The black aphis is more difficult to kill than the green aphis, but may be controlled by the same methods thoroughly used.

\section{Soaking tubers and seeds.}

Potato scab may be prevented, so far as planting infected "seed" is concerned, by soaking the seed tubers for two hours in 30 gal. of water containing 1 pt. of commercial (about 40 per cent) formalin. Oats and wheat, when attacked by certain kinds of smut, may be rendered safe to sow by soaking or mixing with similar or weaker solutions. It is probable that some other tubers and seeds can be similarly treated with good results.

Potatoes may also be soaked (for scab) one and one-half hours in a solution of corrosive sublimate, $1 \mathrm{oz}$. to $7 \mathrm{gal}$. of water:

\section{Spraying.}

The most effective means of destroying insects and fungi however, in any general or large way, is by the use of various sprays. The two general types of insecticides have already been mentioned - those that kill by poisoning, and those that 
kill by destroying the body of the insect. Of the former, there are three materials in common use - Paris green, arsenate of lead, and hellebore. Of the latter, the most usual at present are kerosene emulsion, miscible oils, and the lime-sulfur wash. In the last year or two, the lime-sulfur preparations have been greatly perfected, and they are now becoming popular in commercial work not only for insects but for certain fungi.

Sprays for fungi usually depend for their efficiency on some form of copper or sulfur, or both. For surface mildews, as grape mildew, dusting flowers of sulfur on the foliage is a protection. In most cases, however, it is necessary to apply materials in liquid form, because they can be more thoroughly and economically distributed, and they adhere to the foliage better. The best general fungicide is the bordeaux mixture. It is generally, however, not advisable to use the bordeaux mixture on ornamental plants, because it discolors the foliage and makes the plants look very untidy. In such cases it is best to use the ammoniacal copper solution, which leaves no stain.

In all spraying operations it is especially important that the applications be made the very moment the insect or disease is discovered, or in the case of fungous diseases, if one is expecting an attack, it is well to make an application of bordeaux mixture or lime-sulfur even before the disease appears. When the fungus once gets inside the plant tissue, it is very difficult to destroy it. For ordinary conditions, from two to four sprayings are necessary to dispatch the enemy. In spraying for insects in home gardens, it is often advisable to make a second application the day following the first one in order to destroy the remaining insects before they recover from the first treatment.

There are many kinds of machines and devices for the application of sprays to plants. For a few individual specimens, the spray may be applied with a whisk, or with a common garden syringe. If one has a few trees to treat, however, it is best to 
have some kind of bucket pump like those shown in Figs. 221, 222. On a lawn or in a small garden a tank on wheels (Figs. $223,224,225)$ is handy and efficient. In such cases, or even for larger areas, some of the knapsack pumps (Figs. 219, 220) are very desirable. These machines are always serviceable, because the operator stands so near to his work; but as they carry a comparatively small quantity of liquid and do not

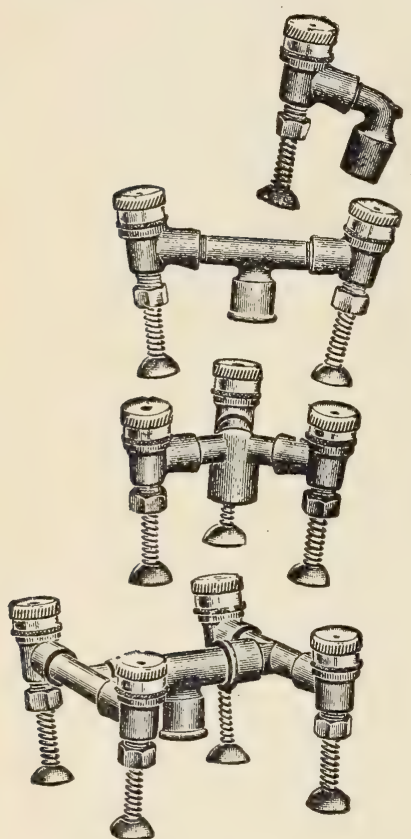

233. Cyclone or vermorel type of nozzle, single and multiple. throw it rapidly, they are expensive when much work is to be done. Yet, in ordinary home grounds, the knapsack pump or compressed-air pump is one of the most efficient and practicable of all the spraying devices.

For large areas, as for small orchards and fields, a barrel pump mounted on a wagon is best. Common types of barrel pumps are shown in Figs. 226, 227, 228. Commercial plantations are now sprayed by power machines. There are many good patterns of spraying machines, and the intending purchaser should send for catalogues to the various manufacturers. The addresses may be found in the advertising pages of rural papers.

As to nozzles for spraying it may be said that there is no one pattern that is best for all purposes. For most uses in home grounds the cyclone or vermorel type (Fig. 233) will give best satisfaction. The pump manufacturers supply special nozzles for their machines. 


\section{Insecticide spraying formulas.}

The two classes of insecticides are here described, - the poisons (arsenites and white hellebore) for chewing insects, as the beetles and all kinds of worms; the contact insecticides, as kerosene, oils, soap, tobacco, lime-sulfur, for plant-lice, scale, and insects in such position that the material cannot be fed to them (as maggots in the underground parts).

Paris green. - The standard insecticidal poison. This is used in varying strengths, depending on the insect to be controlled and the kind of plant treated. Mix the Paris green into a paste and then add to the water. Keep the mixture thoroughly agitated while spraying. If for use on fruit trees, add $1 \mathrm{lb}$. of quick lime for every pound of Paris green to prevent burning the foliage. For potatoes it is frequently used alone, but it is much safer to use the lime. Paris green and bordeaux mixture may be combined without lessening the value of either, and the caustic action of the arsenic is prevented. The proportion of the poison to use is given under the various insects discussed in the succeeding pages.

Arsenate of lead. - This can be applied in a stronger mixture than other arsenical poisons without injuring the foliage. It is, therefore, much used against beetles and other insects that are hard to poison, as elm-leaf beetle and canker-worm. It comes in the form of a paste and should be mixed thoroughly with a small quantity of water before placing in the sprayer, else the nozzles will clog. Arsenate of lead and bordeaux mixture or lime-sulfur can be combined without lessening the value of either. It is used in strengths varying from 4 to $10 \mathrm{lb}$. per 100 gal., depending on the kind of insect to be killed.

Arsenite of soda and arsenite of lime are sometimes used with bordeaux mixture.

White Hellebore. - For wet application, use fresh white hellebore, 4 oz.; water, 2 or 3 gal. For dry application, use hellebore, $1 \mathrm{lb}$; flour or air-slaked lime, $5 \mathrm{lb}$. This is a yellowish white powder made from the roots of the white hellebore plant. It loses its strength after a time and should be used fresh. It is used as a substitute for the 
arsenical poisons on plants or fruits soon to be eaten, as on currants and gooseberries for the currant-worm.

Tobacco. - This is a valuable insecticide and is used in several forms. As a dust it is used extensively in greenhouses for plant-lice, and in nurseries and about apple trees for the woolly aphis. Tobacco decoction is made by steeping or soaking the stems in water. It is often used as a spray against plant-lice. Tobacco in the form of $e x-$ tracts, punks, and powders is sold under various trade names for use in fumigating greenhouses. (See page 188.)

Kerosene emulsion. - Hard, soft, or whale-oil soap, $\frac{1}{2} \mathrm{lb}$; water, 1 gal.; kerosene, 2 gal. Dissolve the soap in hot water; remove from the fire and while still hot add the kerosene. Pump the liquid back into itself for five or ten minutes or until it becomes a creamy mass. If properly made, the oil will not separate out on cooling.

For use on dormant trees, dilute with 5 to 7 parts of water. For killing plant-lice on foliage dilute with 10 to 15 parts of water. Crude oil emulsion is made in the same way by substituting crude oil in place of kerosene. The strength of oil emulsions is frequently indicated by the percentage of oil in the diluted liquid:-

For a $10 \%$ emulsion add 17 gal. of water to 3 gal. stock emulsion. For a $15 \%$ emulsion add $10 \frac{1}{3}$ gal. of water to 3 gal. stock emulsion. For a $20 \%$ emulsion add 7 gal. of water to 3 gal. stock emulsion. For a $25 \%$ emulsion add 5 gal. of water to 3 gal. stock emulsion.

Carbolic acid emulsion. - Soap, 1 lb. ; water, 1 gal.; crude carbolic acid, 1 pt. Dissolve the soap in hot water, add the carbolic acid, and agitate into an emulsion. For use against root-maggots, dilute with 30 parts of water.

Soaps. - An effective insecticide for plant-lice is whale-oil soap. Dissolve in hot water and dilute so as to obtain one pound of soap to every five or seven gallons of water. This strength is effective against plant-lice. It should be applied in stronger solutions, however, for scale insects. Home-made soaps and good laundry soaps, like Ivory soap, are often as effective as whale-oil soap.

Miscible oils. - There are now on the market a number of preparations of petroleum and other oils intended primarily for use against the San José scale. They mix readily with cold water and are immedi- 
ately ready for use. While quickly prepared, easily applied, and generally effective, they cost considerably more than lime-sulfur wash. They are, however, less corrosive to the pumps and more agreeable to use. They are especially valuable to the man with only a few trees or shrubs who would not care to go to the trouble and expense to make up the lime-sulfur wash. They should be diluted with not more than 10 or 12 parts of water. Use only on dormant trees.

Lime and sulfur wash. - Quicklime, $20 \mathrm{lb}$.; flowers of sulfur, $15 \mathrm{lb}$.; water, 50 gal. The lime and sulfur must be thoroughly boiled. An iron kettle is often convenient for the work. Proceed as follows: Place the lime in the kettle. Add hot water gradually in sufficient quantity to produce the most rapid slaking of the lime. When the lime begins to slake, add the sulfur and stir together. If convenient, keep the mixture covered with burlap to save the heat. After slaking has ceased, add more water and boil the mixture one hour. As the sulfur goes into solution, a rich orange-red or dark green color will appear. After boiling sufficiently, add water to the required amount and strain into the spray tank. The wash is most effective when applied warm, but may be applied cold. If one has access to a steam boiler, boiling with steam is more convenient and satisfactory. Barrels may be used for holding the mixture, and the steam applied by running a pipe or rubber hose into the mixture. Proceed in the same way until the lime is slaked, when the steam may be turned on. Continue boiling for $45 \mathrm{~min}$. to an hour, or until sulfur is dissolved.

This strength can be applied safely only when the trees are dormant. It has been mainly an insecticide for use on San José scale, for which it affords a standard treatment; but recently it has been modified for use against other insects and certain fungi (as peach leaf-curl, apple-scab, brown-rot).

Four kinds of lime-sulfur preparation are now recognized: (1) the ordinary home-made wash for winter use (given above); (2) concentrated commercial solutions, now on the market under various names; (3) home-made concentrated solution; (4) self-boiled lime-sulfur. The commercial concentrates differ much in strength; and these, as well as the home-made concentrate, should be tested by a hydrometer before use, and then they should be diluted with water to a definite strength. The formulas for these washes are discussed on pages 539-541. 


\section{Fungicide spraying formulas.}

The standard fungicide is bordeaux mixture, made in several forms. The second most important fungicide for the home gardener is ammoniacal copper carbonate. Sulfur dust (flowers of sulfur) and liver of sulfur (potassium sulfide) are also useful in dry or wet sprays for surface mildews. The lime-sulfur wash, primarily an insecticide, also has fungicidal property (p. 195).

Bordeaux mixture. - Copper sulfate, $4 \mathrm{lb}$; stone lime or quicklime (unslaked), $4 \mathrm{lb}$; water, 50 gal. This formula is the strength usually recommended. Stock mixtures of copper sulfate and lime are desirable. They are prepared in the following way:-

(1) Dissolve the required amount of copper sulfate in water in the proportion of one pound to one gallon several hours before the solution is needed, the copper sulfate crystals being suspended in a sack near the top of the water. A solution of copper sulfate is heavier than water. As soon then, as the crystals begin to dissolve the solution will sink, keeping water in contact with the crystals. In this way, the crystals will dissolve much sooner than if placed in the bottom of the barrel of water. In case large quantities of stock solution are needed, two pounds of copper sulfate may be dissolved in one gallon of water.

(2) Slake the required amount of lime in a tub or trough. Add the water slowly at first, so that the lime crumbles into a fine powder. If small quantities of lime are used, hot water is preferred. When completely slaked, or entirely powdered, add more water. When the lime has slaked sufficiently, add water to bring it to a thick milk, or to a certain number of gallons. The amount required for each tank of spray mixture can be secured approximately from this stock mixture, which should not be allowed to dry out.

(3) Use five gallons of stock solution of copper sulfate for every fifty gallons of bordeaux required. Pour this into the tank. Add water until the tank is about two-thirds full. From the stock lime mixture take the required amount. Knowing the number of pounds of lime in the stock mixture and the volume of that mixture, one can take out approximately the number of pounds required. Dilute this a little by adding water, and strain into the tank. Stir the mixture, 
and add water to make the required amount. Experiment stations often recommend the diluting of both the copper sulfate solution and the lime mixture to one-half the required amount before pouring together. This is not necessary, and is often impracticable for commercial work. It is preferable to dilute the copper sulfate solution. Never pour together the strong stock mixtures and dilute afterward. Bordeaux mixture of other strengths, as recommended, is made in the same way, except that the amounts of copper sulfate and lime are varied.

(4) It is not necessary to weigh the lime in making bordeaux mixture, for a simple test can be used to determine when enough of a stock lime mixture has been added. Dissolve an ounce of yellow prussiate of potash in a pint of water and label it "poison." Cut a V-shaped slit in one side of the cork so that the liquid may be poured out in drops. Add the lime mixture to the diluted copper sulfate solution until the ferro-cyanide (or prussiate) test solution will not turn brown when dropped from the bottle into the mixture. It is always best to add a considerable excess of lime.

"Sticker" or adhesive for bordeaux mixture. - Resin, 2 lb.; sal soda (crystals), 1 lb.; water, 1 gal. Boil until of a clear brown color - one to one and one-half hours. Cook in iron kettle in the open. Add this amount to each fifty gallons of bordeaux for onions and cabbage. For other plants difficult to wet, add this amount to every one hundred gallons of the mixture. This mixture will prevent the bordeaux from being washed off by the heaviest rains.

Ammoniacal copper carbonate. - Copper carbonate, 5 oz.; ammonia, 3 pt.; water, 50 gal. Dilute the ammonia in seven or eight parts of water. Make a paste of the copper carbonate with a little water. Add the paste to the diluted ammonia, and stir until dissolved. Add enough water to make fifty gallons. This mixture loses strength on standing, and therefore should be made as required. It is used in place of bordeaux when one wishes to avoid the coloring of maturing fruits or ornamental plants. Not as effective as bordeaux.

Potassium sulfide. - Potassium sulfide (liver of sulfur), $3 \mathrm{oz}$. ; water, 10 gal. As this mixture loses strength on standing, it should be made just before using. It is particularly valuable for the powdery mildew of many plants, especially gooseberry, carnation rust, rose mildew, etc. Sulfur. - Sulfur has been found to possess considerable value as a 
fungicide. The flowers of sulfur may be sprinkled orer the plants, particularly when they are wet. It is most effective in hot, dry weather. In rose houses it is mixed with half its bulk of lime, and made into a paste with water. This is painted on the steam pipes. The fumes destroy mildew on the roses. Mixed with lime, it has proved effective in the control of onion smut when drilled into the rows with the seed. Sulfur is not effective against black-rot of grapes.

\section{Treatment for some of the common insects.}

The most approved preventive and remedial treatments for such insect pests as are most likely to menace home grounds and plantations are here briefly discussed. In case of any unusual difficulty that he cannot control, the home-maker should take it up with the agricultural experiment station in the state, sending good specimens of the insect for identification. $\mathrm{He}$ should also have the publications of the station.

The statements that are here made are intended as advice rather than as directions. They are chosen from good authorities (mostly from Slingerland and Crosby in this case); but the reader must, of course, assume his own risk in applying them. The effectiveness of any recommended treatment depends very largely on the care, thoroughness, and timeliness with which the work is done; and new methods and practices are constantly appearing as the result of new investigations. The dates given in these directions are for New York.

A phis or plant-louse. - The stock remedies for aphides or plantlice are kerosene emulsion and the tobacco preparations. Whale-oil soap is also good. The tobacco may be applied as a spray, or in the house as fumigation; the commercial forms of nicotine are excellent. (See page 194.) Be sure to apply the remedy before the leaves have curled and afford protection for the lice; be sure, also, to hit the underside of the leaves, where the lice usually are. The presence of lice on trees is sometimes first discovered from the honey-dew that drops on walks. 
Usually the emulsion is diluted with 10-15 parts of water for plantlice (see formula, page 194); but some of the species (as the dark brown cherry-leaf louse) require a stronger emulsion, about 6 parts of water.

The lady-birds (one of which is shown in Fig. 234) destroy great numbers of plant-lice, and their presence should therefore be encouraged.

Apple-maggot or "railroad-worm." - The small white maggots make brownish winding burrows in the flesh of the fruit, particularly in summer and early fall varieties. This insect cannot be reached by a spray as the parent fly inserts her eggs under the skin of the apple. When full-grown, the maggot leaves the fruit, passes into the ground, and there transforms inside a tough, leathery case. Tillage has been found to be of no value as a means of control.. The only

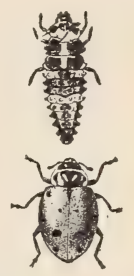

234. Lady-bird beetle; larva above. effective treatment is to pick up all windfalls every two or three days, and either to feed them out or to bury them deeply, thus killing the maggots.

Asparagus beetle. - Clean cultural methods are usually sufficient to prevent the asparagus beetle's seriously injuring well-established beds. Young plants require more or less protection. A good grade of arsenate of lead, $1 \mathrm{lb}$. to $25 \mathrm{gal}$. of water, will quickly destroy the grubs on the foliage of either young or old plants. Apply it wih an ordinary sprinkling can, or better, use one of the numerous spraying devices now on the market. The necessity for treatment must be determined by the abundance of the pests. They should not be permitted to become abundant in midsummer or the over-wintering beetles may injure the shoots in the spring.

Blister-mite on apple and pear. - The presence of this minute mite is indicated by small irregular brownish blisters on the leaves. Spray in late fall or early spring with the home-made lime-sulfur or with the concentrated preparations, 1 gal. to 10 gal. water. Recent experiments show this treatment to be effective.

Borers. - The only certain remedy for borers is to dig them out, or to punch them out with a wire. Keep the space about the base of the tree clean, and watch closely for any sign of borers. The flat-headed borer of the apple works under the bark on the trunk and larger 
branches, particularly where much exposed to sun. The dead and sunken appearance of the bark indicates its presence. The roundheaded borer works in the wood of apples, quinces, and other trees; it should be hunted for every spring and fall. On hard land, it is well to dig the earth away from the base of the tree and fill the space with coal ashes; this will make the work of examination much easier.

The peach and apricot borer is the larva of a clear-wing moth. The larva burrows just under the bark near or beneath the surface of the ground; its presence is indicated by a gummy mass at the base of the tree. Dig out the borers in June and mound up the trees. At the same time, apply gas-tar or coal-tar to the trunk from. the roots to a foot or more above the surface of the ground.

The bronze birch borer is destroying many fine white birch trees in some parts of the country. Its presence is known by the dying of the top of the tree. There yet is no known way of preventing this borer from attacking white birches, and the only practicable and effective method so far found for checking its ravages is promptly to cut and burn the infested trees in autumn, in winter, or before May 1. There is no probability of saving a tree when the top branches are dead, although cutting out the dead parts may stay the trouble temporarily. Cut and burn such trees at once and thus prevent the spread of the insect.

Bud-moth on apple. - The small brown caterpillars with black heads devour the tender leaves and flowers of the opening apple buds in early spring. Make two applications of either $1 \mathrm{lb}$. Paris green or $4 \mathrm{lb}$. arsenate of lead in $100 \mathrm{gal}$. of water; the first when the leaf-tips appear and the second just before the blossoms open. If necessary, spray again after the blossoms fall.

Cabbage and cauliflower insects. - The green caterpillars that eat cabbage leaves and heads hatch from eggs laid by the common white butterfly(Fig. 295). There are several broods every season. If plants are not heading, spray with kerosene emulsion or with Paris green to which the sticker has been added. If heading, apply hellebore.

The cabbage aphides, small mealy plant-lice, are especially troublesome during cool, dry seasons when their natural enemies are less active. Before the plants begin to head, spray with kerosene emulsion diluted with 6 parts of water, or whale-oil soap, 1 lb. in 6 gal. of water. 
The white maggots that feed on the roots hatch from eggs laid near the plant at the surface of the ground by a small fly somewhat resembling the common house fly. Hollow out the earth slightly around every plant and freely apply carbolic acid emulsion diluted with 30 parts of water. Begin the treatment early, a day or two after the plants are up or the next day after they are set out. Repeat the application every 7 to 10 days until the latter part of May. It has also been found to be practicable to protect the plants by the use of tightly fitting cards cut from tarred paper. (See page 187.)

Canker-worms. - These caterpillars are small measuring-worms or loopers that defoliate apple trees in May and June (Fig. 217). The female moths are wingless, and in late fall or early spring crawl up the trunks of the trees to lay their eggs on the branches. Spray thoroughly once or twice, before the blossoms open, with $1 \mathrm{lb}$. Paris green or $4 \mathrm{lb}$. arsenate of lead in 100 gal. of water. Repeat the application after the blossoms fall. Prevent the ascent of the wingless females by means of sticky bands or wire-screen traps.

Case-bearers on apple. - The small caterpillars live in pistol-shaped or cigar-shaped cases, about $\frac{1}{4}$ in. long. They appear in spring on the opening buds at the same time as the bud-moth and may be controlled by the same means.

Codlin-moth. - The codlin-moth lays the eggs that produce the pinkish caterpillar which causes a large proportion of wormy apples and pears. The minute eggs are laid on both the leaves and on the skin of the fruit. Most of the caterpillars enter the apple at the blossom end. When the petals fall, the calyx is open and this is the time to spray. The calyx soon closes and keeps the poison inside ready for the young caterpillar's first meal. After the calyx has closed, it is too late to spray effectively. The caterpillars become full grown in July and August, leave the fruit, crawl down on the trunk, and there most of them spin cocoons under the loose bark. In most parts of the country there are two broods annually. Immediately after the blossoms fall, spray with $1 \mathrm{lb}$. Paris green or $4 \mathrm{lb}$. arsenate of lead in 100 gal. of water. Repeat the application about 3 wk. later. Use burlap bands on trunks, killing all caterpillars under them every ten days from July 1 to August 1, and once later before winter.

Cucurbit (cucumber, melon, and squash) insects. - Yellow, black- 
striped beetles appear in numbers and attack the plants as soon as they are up. Plant early squashes as a trap-crop around the field. Protect the vines with screens (Fig. 229) until they begin to run, or keep them covered with bordeaux mixture, thus making them distasteful to the beetles.

Squash vines are frequently killed by a white caterpillar that burrows in the stem near the base of the plant. Plant a few early squashes between the rows of the late varieties as a trap-crop. As soon as the early crop is harvested, remove and burn the vines. When the vines are long enough, cover them at the joints with earth in order to develop secondary root systems for the plant in case the main stem is injured.

Dark green plant-lice feed on the under sides of squash leaves, causing them to curl and wither. Spray with kerosene emulsion diluted with 6 parts of water. It is necessary thoroughly to cover the under side of the leaves; the sprayer, therefore, must be fitted with an upturned nozzle. Burn the vines as soon as the crop is harvested and keep down all weeds. Tobacco sprays may be used.

The stink-bug is very troublesome to squashes. The rusty-black adult emerges from hibernation in spring and lays its eggs on the under side of the leaves. The nymphs suck the sap from the leaves and stalks, causing serious injury. Trap the adults under boards in the spring. Examine the leaves for the smooth shining brownish eggs and destroy them. The young nymphs may be killed with kerosene emulsion.

Curculio. - The adult curculio of the plum and peach is a small snout-beetle that inserts its eggs under the skin of the fruit and then makes a characteristic crescent-shaped cut beneath it. The grub feeds within the fruit and causes it to drop. When full grown, it enters the ground, changes in late summer to the beetle, which finally goes into hibernation in sheltered places. Spray plums just after blossoms fall with arsenate of lead, 6 to $8 \mathrm{lb}$. in 100 gal. of water, and repeat the application in about a week. After the fruit has set, jar the trees daily over a sheet or curculio-catcher and destroy the beetles; this is practically the only procedure for peaches, for they cannot be sprayed.

The quince curculio is somewhat larger than that infesting the plum and differs in its life-history. The grubs leave the fruits in the fall and enter the ground, where they hibernate and transform to adults 
the next May, June, or July, depending on the season. When the adults appear, jar them from the tree on sheets or curculio-catchers and destroy them. To determine when they appear, jar a few trees daily, beginning the latter part of May in New York.

Currant-worm. - In the spring the small green, black-spotted larvæ feed on the foliage of currants and gooseberries, beginning their work on the lower leaves. A second brood occurs in early summer. When worms first appear, spray with $1 \mathrm{lb}$. Paris green or $4 \mathrm{lb}$. arsenate of lead in 100 gal. of water. Ordinarily the poison should be combined with bordeaux (for leaf-spot).

Cut-worms. - Probably the remedy for cut-worms most often practiced in gardens, and which cannot fail to be effective when faithfully carried out, is hand-picking with lanterns at night or digging them out from around the base of the infested plants during the day. Bushels of cut-worms have been gathered in this way, and with profit. When from some cause success does not attend the use of the poisoned baits, to be discussed next, hand-picking is the only other method yet recommended that can be relied upon to check cut-worm depredations.

The best methods yet devised for killing cut-worms in any situation are the poisoned baits, using Paris green or arsenate of lead for the purpose. Poisoned bunches of clover or weeds have been thoroughly tested, even by the wagon-load, over large areas, and nearly all have reported them very effective; lamb's quarters (pigweed), peppergrass, and mullein are among the weeds especially attractive to cutworms. On small areas the making of the baits is done by hand, but they have been prepared on a large scale by spraying the plants in the field, cutting them with a scythe or machine, and pitching them from wagons in small bunches wherever desired. Distributed a few feet apart, between rows of garden plants at nightfall, they have attracted and killed enough cut-worms often to save a large proportion of the crop; if the bunches can be covered with a shingle, they will keep fresher much longer. The fresher the baits, and the more thoroughly the baiting is done, the more cut-worms one can destroy. However, it may sometimes happen that a sufficient quantity of such green succulent plants cannot be obtained early enough in the season in some localities. In this case, and we are not sure but in all cases, the poisoned bran mash can be used to the best advantage. It is easily 
made and applied at any time, is not expensive, and thus far the results show that it is a very attractive and effective bait. A tablespoonful can be quickly dropped around the base of each cabbage or tomato plant; small amounts may be easily scattered along the rows of onions and turnips, or a little dropped on a hill of corn or cucumbers.

The best time to apply these poisoned baits is two or three days before any plants have come up or been set out in the garden. If the ground has been properly prepared, the worms will have had but little to eat for several days and they will thus seize the first opportunity to appease their hunger upon the baits, and wholesale destruction will result. The baits should always be applied at this time wherever cut-worms are expected. But it is not too late usually to save most of a crop after the pests have made their presence known by cutting off some of the plants. Act promptly and use the baits freely.

For mechanical means of protecting from cut-worms, see pp. 186-7.

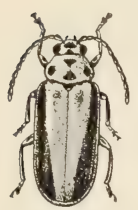

235. Elm-leaf beetle, adult, somewhat enlarged (after Howard).

Elm-leaf beetle. - Generally speaking one thorough and timely spraying is ample to control the elm-leaf beetle (Fig. 235). Use arsenate of lead, $1 \frac{1}{2}$ lb. to 25 gal., and make the application to the under side of the leaves the latter part of May or very early in June in New York. Occasionally, when the beetle is very abundant, due in all probability to no spraying in earlier years, it may be advisable to make a second application, and the same may be true when conditions necessitate the application earlier than when it will be most efficacious. This latter condition is likely to obtain wherever a large number of trees must be treated with inadequate outfit.

Oyster-shell scale. - This is an elongate scale or bark-louse, $\frac{1}{8} \mathrm{in}$. in length, resembling an oyster shell in shape and often incrusting the bark of apple twigs. It hibernates as minute white eggs under the old scales. The eggs hatch during the latter part of May or in June, the date depending on the season. When these young appear, spray with kerosene emulsion, diluted with 6 parts of water, or whale-oil or any good soap, $1 \mathrm{lb}$. in 4 or $5 \mathrm{gal}$. of water. When trees are regularly sprayed with lime-sulfur for San José Scale, this insect is also held in control. 
Pear insects. - The psylla is one of the most serious insects affecting the pear tree. It is a minute, yellowish, flat-bodied, sucking insect often found in the axils of the leaves and fruit early in the season. They develop into minute cicada-like jumping-lice. The young psyllas secrete a large quantity of honey-dew in which a peculiar black fungus grows, giving the bark a characteristic sooty appearance. There may be four broods annually and the trees are often seriously injured. After the blossoms fall, spray with kerosene emulsion, diluted with 6 parts of water, or whale-oil soap, $1 \mathrm{lb}$. in 4 or 5 gal. of water. Repeat the application at intervals of 3 to 7 days until the insects are under control. Tobacco extracts may be tried.

The pear slug is a small, slimy, dark green larva which skeletonizes the leaves in June, and a second brood appears in August. Spray thoroughly with $1 \mathrm{lb}$. Paris green, or $4 \mathrm{lb}$. arsenate of lead, in 100 gal. of water.

Potato insects. - The Colorado potato beetle, or potato-bug, emerges from hibernation in the spring and lays masses of orange eggs on the under side of the leaves. The larvæ are known as "slugs" and "softshells" and cause most of the injury to the vines. Spray with Paris green, $2 \mathrm{lb}$. in $100 \mathrm{gal}$. of water, or arsenite of soda combined with bordeaux mixture. It may sometimes be necessary to use a greater strength of the poison, particularly on the older "slugs."

The small black flea-beetles riddle the leaves with holes and cause the foliage to die. Bordeaux mixture as applied for potato blight protects the plants by making them repellent to the beetles.

Raspberry, blackberry, and dewberry insects. - The greenish, spiny larvæ of the saw-fly feed on the tender leaves in spring. Spray with Paris green or arsenate of lead, or apply hellebore.

The cane-borer is a grub that burrows down through the canes, causing them to die. In laving her eggs, the adult beetle girdles the tip of the cane with a ring of punctures, causing it to wither and droop. In midsummer, cut off and destroy the drooping tips.

Red spider. - Minute reddish mites on the under sides of leaves in greenhouses and sometimes out of doors in dry weather. Syringe off the plants with clear water two or three times a week, taking care not to drench the beds. Red spider and black mite may be treated with sulfocide.

Rose Insects. - The green plant-lice usually work on the buds, and 
the yellow leaf-hoppers feed on the leaves. Spray, whenever necessary, with kerosene emulsion, diluted with 6 parts of water, or whale-oil or any good soap, $1 \mathrm{lb}$. in 5 or 6 gal. of water; or a tobacco extract.

The rose-chafer is often a most pernicious pest on roses, grapes, and other plants. The ungainly, long-legged, grayish beetles occur in sandy regions and often swarm into vineyards and destroy the blossoms and foliage. Spray thoroughly with arsenate of lead, $10 \mathrm{lb}$. in 100 gal. of water. Repeat the application if necessary. (See under Rose on page 395.)

San José scale. - This pernicious scale is nearly circular in outline and about the size of a small pin head, with a raised center. When abundant, it forms a crust on the branches and causes small red spots on the fruit. It multiplies with marvelous rapidity, there being three or four broods annually in New York, and each mother scale may give birth to several hundred young. The young are born alive, and breeding continues until late autumn when all stages are killed by the cold weather except the tiny half-grown black scales, many of which hibernate safely. Spray thoroughly in the fall after the leaves drop, or early in the spring before growth begins, with lime-sulfur wash, or miscible oil 1 gal. in 10 gal. of water. When badly infested, make two applications, one in the fall and another in the spring. In case of large old trees, 25 per cent crude oil emulsion should be applied just as the buds are swelling. Lime-sulfur is now the standard remedy.

In nurseries, after the trees are dug, fumigate with hydrocyanic acid gas, using $1 \mathrm{oz}$. of potassium cyanide for every $100 \mathrm{cu}$. ft. of space. Continue the fumigation from one-half to three-quarters of an hour. Do not fumigate the trees when they are wet, since the presence of moisture renders them liable to injury.

Tent-caterpillar. - The insect hibernates in the egg stage. The eggs are glued in ring-like brownish masses around the smaller twigs, where they may be easily found and destroyed. The caterpillars appear in early spring, devour the tender leaves, and build unsightly nests on the smaller branches. This pest is usually controlled by the treatment recommended for the codlin-moth. Destroy the nests by burning or by wiping out when small. Often a bad pest on apple trees.

Violet gall-fly. - Violets grown under glass are often greatly injured by a very small maggot, which causes the edges of the leaves to curl, 
turn yellowish, and die. The adult is a very minute fly resembling a mosquito. Pick off and destroy infested leaves as soon as discovered. Fumigation is not advised for this insect or for red-spider.

White-fly. - The minute white-flies are common on greenhouse plants and often in summer on plants about gardens near greenhouses. The nymphs are small greenish, scale-like insects found on the under side of the leaves; the adults are minute, white, mealy-winged flies. Spray with kerosene emulsion or whale-oil soap ; or if infesting cucumbers or tomatoes, fumigate over night with hydrocyanic acid gas, using $1 \mathrm{oz}$. of potassium cyanide to each $1000 \mathrm{cu}$. ft. of space. (See page 188.)

White grubs. - The large curved white grubs that are so troublesome in lawns and strawberry fields are the larvæ of the common June beetles. They live in the ground, feeding on the roots of grasses and weeds. Dig out grubs from beneath infested plants. Thorough early fall cultivation of land intended for strawberries will destroy many of the pupæ. In lawns, remove the sod, destroy the grubs, and make new sward, when the infestation is bad.

\section{Treatment for some of the common plant diseases.}

The following advice (mostly adapted from Whetzel and Stewart) covers the most frequent types of fungous disease appearing to the home gardener. Many other kinds, however, will almost certainly attract his attention the first season if he looks closely. The standard remedy is bordeaux mixture; but because this material discolors the foliage the carbonate of copper is sometimes used instead. The treatments here recommended are for New York; but it should not be difficult to apply the dates elsewhere. The gardener must supplement all advice of this character with his own judgment and experience, and take his own risks.

Apple scab. - Usually most evident on the fruit, forming blotches and scabs. Spray with bordeaux, 3-3-50, or lime-sulfur, 1-40; first, just before the blossoms open; second, as the blossoms fall; third, 10 to 14 
days after the blossoms fall. The second spraying seems to be the most important. Always apply before rains, not after.

Asparagus rust. - The most common and destructive disease of asparagus, producing reddish or black pustules on the stems and branches. Late in the fall, burn all affected plants. Fertilize liberally and cultivate thoroughly. During the cutting season, permit no plants to mature and cut all wild asparagus plants in vicinity once a week. Rust may be partially controlled by spraying with bordeaux, $5-5-50$, containing a sticker of resin-sal-soda soap, but it is a difficult and expensive operation and probably not profitable except on large acreage. Begin spraying after cutting as soon as new shoots are 8 to $10 \mathrm{in}$. high and repeat once or twice a week until about September 15. Dusting with sulfur has proved effective in California.

Cabbage and cauliflower diseases. - Black-rot is a bacterial disease; the plants drop their leaves and fail to head. Practice crop rotation; soak seed $15 \mathrm{~min}$. in a solution made by dissolving one corrosive sublimate tablet in a pint of water. Tablets may be bought at drug stores.

Club-root or club-foot is a well-known disease. The parasite lives in the soil. Practice crop rotation. Set only healthy plants. Do not use manure containing cabbage refuse. If necessary to use infested land, apply good stone lime, 2 to 5 tons per acre. Apply at least as early as the autumn before planting; two to four years is better. Lime the seed-bed in same way.

Carnation rust. - This disease may be recognized by the brown, powdery pustules on the stem and leaves. Plant only the varieties least affected by it. Take cuttings only from healthy plants. Spray (in the field, once a week; in the greenhouse, once in two weeks) with copper sulfate, $1 \mathrm{lb}$. to 20 gal. of water. Keep the greenhouse air as dry and cool as is compatible with good growth. Keep the foliage free from moisture. Train the plants so as to secure a free circulation of air among them.

Chestnut. - The bark disease of chestnut has become very serious in southeastern New York, causing the bark to sink and die and killing the tree. Cutting out the diseased places and treating aseptically may be useful in light cases, but badly infected trees are incurable, in the present state of our knowledge. Inspection of nursery stock 
and burning of affected trees is the only procedure now to be recommended. The disease is reported in New England and western New York.

Chrysanthemum leaf-spot. - Spray with bordeaux, 5-5-50, every ten days or often enough to protect new foliage. Ammoniacal copper carbonate may be used, but it is not so effective.

Cucumber diseases. - "Wilt" is a disease caused by bacteria that are distributed chiefly by striped cucumber beetles. Destroy the beetles or drive them away by thorough spraying with bordeaux, 5-5-50. Gather and destroy all wilted leaves and plants. The most that can be expected is that the loss may be slightly reduced.

Downy mildew is a serious fungous disease of the cucumber known among growers as "the blight." The leaves become mottled with yellow, show dead spots, and then dry up. Spray with bordeaux, $5-5-50$. Begin spraying when the plants begin to run, and repeat every 10 to 14 days throughout the season.

Currant diseases. - Leaf-spots and anthracnose are caused by two or three different fungi. The leaves become spotted, turn yellow, and fall prematurely. They may be controlled by three to five sprayings with bordeaux, 5-5-50, but it is doubtful whether the diseases are sufficiently destructive on the average to warrant so much expense.

Gooseberry powdery mildew. - The fruit and leaves are covered with a dirty white growth of fungus. In setting a new plantation, choose a site where the land is well underdrained and where there is a good circulation of air. Cut away drooping branches. Keep the ground underneath free from weeds. Spray with potassium sulfide, $1 \mathrm{oz}$. to 2 gal.; begin when the buds are breaking and repeat every 7 to 10 days until the fruit is gathered. Powdery mildew is very destructive to the European varieties.

Grape black-rot. - Remove all "mummies" that cling to the arms at trimming time. Plow early, turning under all old mummies and diseased leaves. Rake all refuse under the vine into the last furrow and cover with the grape hoe. This cannot be too thoroughly done. The disease is favored by wet weather and weeds or grass in the vineyard. Use surface cultivation and keep down all weeds and grass. Keep the vines well sprouted; if necessary sprout twice. Spray with bordeaux mixture, 4-4-50, until the middle of July, after that with 
ammoniacal copper carbonate. The number of sprayings will vary with the season. Make the first application when the third leaf shows. Infections take place with each rain, and occur throughout the growing season. The foliage should be protected by a coating of the spray before every rain. The new growth especially should be well sprayed.

Hollyhock rust. - Fig. 212. Eradicate the wild mallow (Malva rotundifolia). Remove all hollyhock leaves as soon as they show signs of rust. Spray several times with bordeaux mixture, taking care to cover both sides of leaves.

Lettuce drop or rot. - This is a fungous disease often destructive in greenhouses, discovered by the sudden wilting of the plants. It is completely controlled by steam sterilization of the soil to the depth of two inches or more. If it is not feasible to sterilize the soil, use fresh soil for every crop of lettuce.

Muskmelon diseases. - "Blight" is a very troublesome disease. The leaves show angular dead-brown spots, then dry up and die; the fruit often fails to ripen and lacks flavor. It is caused by the same fungus as is the downy mildew of cucumbers. While bordeaux has proved effective in controlling the downy mildew on cucumbers, it seems to be of little value in lessening the same disease on melons.

"Wilt" is the same as cucumber wilt; treatment same.

Peach diseases. - Brown-rot is difficult to control. Plant resistant varieties. Prune the trees so as to let in sunlight and air. Thin the fruit well. As often as possible pick and destroy all rotten fruits. In the fall destroy all remaining fruits. Spray with self-boiled limesulfur, 8-8-50, to which $2 \mathrm{lb}$. arsenate lead is added to the 50 gals., making first application as calyx is shedding, second 2-3 weeks later, third one month before fruit ripens, but omitting the arsenate.

Leaf-curl is a disease in which the leaves become swollen and distorted in spring and drop during June and July (Fig. 213). Elberta is an especially susceptible variety. Easily and completely controlled by spraying the trees once, before the buds swell, with bordeaux, $5-5-50$, or with the lime-sulfur mixtures used for San José scale.

Black-spot or scab often proves troublesome in wet seasons and particularly in damp or sheltered situations. While this disease attacks the twigs and leaves, it is most conspicuous and injurious on the fruit, where it appears as dark spots or blotches. In severe attacks 
the fruit cracks. In the treatment of this disease it is of prime importance to secure a free circulation of air about the fruit. Accomplish this by avoiding low sites, by pruning, and by removal of windbreaks. Spray as for brown-rot, with lime-sulfur, 8-8-50.

Yellows is a so-called "physiological disease." Cause unknown. Contagious, and sericus in some localities. Known by the premature ripening of the fruit, by red streaks and spots in the flesh, and by the peculiar clusters of sickly, yellowish shoots that appear on the limbs here and there (Fig. 215). Dig out and burn diseased trees as soon as discovered.

Pear diseases. - Fire-blight kills the twigs and branches, on which the leaves suddenly blacken and die but do not fall. It also produces cankers on the trunk and large limbs. Prune out blighted branches as soon as discovered, cutting 6 to 8 in. below the lowest evidences of the disease. Clean out limb and body cankers. Disinfect all large wounds with corrosive sublimate solution, 1 to 1000 , and cover with coat of paint. Avoid forcing a rapid, succulent growth. Plant the varieties least affected.

Pear scab is very similar to apple scab. It is very destructive to some varieties, as, for example, Flemish Beauty and Seckel. Spray three times with lime-sulfur, 1-50, or bordeaux, $3-3-50$, following the general methods employed for apple scab.

Plum and cherry diseases. - Black-knot is a fungous disease. The spores of the fungus are carried from tree to tree by the wind and thus spread the infection. Cut out and burn all knots as soon as discovered. See that the knots are removed from all plum and cherry trees in the neighborhood.

Leaf-spot is a disease in which the leaves become covered with reddish or brown spots and fall prematurely (Fig. 211) ; badly affected trees winterkill. Often, the dead spots drop out, leaving clear-cut holes. Bordeaux, 5-5-50, or lime-sulfur, 1-40. For cherries, four applications: first, just before blossoms open; second, when fruit is free from calyx; third, two weeks later; fourth, two weeks after third. In plums it may be controlled by two or three applications of bordeaux, $3-3-50$, or self-boiled lime-sulfur. Make the first one about ten days after the blossoms fall and the others at intervals of about three weeks. This applies to European varieties. Japan plums should not be sprayed with bordeaux. 
Potato diseases. - There are different kinds of potato blight and rot. The most important are early blight and late blight - both fungous diseases. Early blight affects only the foliage. Late blight kills the foliage and often rots the tubers. Two serious troubles often mistaken for blight are: (1) Tip burn, the browning of the tips and margins of the leaves due to dry weather; and (2) flea-beetle injury, in which the leaves show numerous small holes and then dry up. The loss from blight and flea-beetles is enormous - often, one-fourth to one-half the crop. For blight-rot and flea-beetles spray with bordeaux, $5-5-50$. Begin when the plants are 6 to 8 in. high and repeat every 10 to 14 days during the season, making 5 to 7 applications in all. Use 40 to 100 gal. per acre at each application. Under conditions exceptionally favorable to blight it will pay to spray as often as once a week.

Scab is caused by a fungus that attacks the surface of the tubers. It is carried over on diseased tubers and in the soil. In general, when land becomes badly infested with scab, it is best to plant it with other crops for several years. (See page 190.)

Raspberry diseases. - Anthracnose is very destructive to black raspberries, but not often injurious to the red varieties. It is detected by the circular or elliptical gray scab-like spots on the canes. Avoid taking young plants from diseased plantations. Remove all old canes and badly diseased new ones as soon as the fruit is gathered. Although spraying with bordeaux, $5-5-50$, will control the malady, the treatment may not be profitable. If spraying seems advisable, make the first application when the new canes are 6 to 8 in. high and follow with two more at intervals of 10 to 14 days.

Cane-blight or wilt is a destructive disease affecting both red and black varieties. Fruiting canes suddenly wilt and die. It is caused by a fungus which attacks the cane at some point and kills the bark and wood, thereby causing the parts above to die. No successful treatment is known. In making new settings, use only plants from healthy plantations. Remove the fruiting canes as soon as the fruit is gathered.

Red-rust is often serious on black varieties, but does not affect red ones. It is the same as red rust of blackberry. Dig up and destroy affected plants. 
Rose diseases. - Black leaf-spot is one of the commonest diseases of the rose. It causes the leaves to fall prematurely. Spray with bordeaux, $5-5-50$, beginning as soon as the first spots appear on the leaves. Two or three applications at intervals of ten days will very largely control the disease. Ammoniacal copper carbonate may be used on roses grown under glass. Apply once a week until disease is under control.

For mildew on greenhouse roses, keep the steam pipes painted with a paste made of equal parts lime and sulfur mixed up with water. The mildew is a surface-feeding fungus and is killed by the fumes of the sulfur. Outdoor roses that become infested with the mildew may be dusted with sulfur, or sprayed with a solution of potassium sulfide, $1 \mathrm{oz}$. to 3 gal. water. Spray or dust with the sulfur two or three times at intervals of a week or ten days.

Strawberry leaf-spot. - The most common and serious fungous disease of the strawberry; also called rust and leaf-blight. The leaves show spots which at first are of a deep purple color, but later enlarge and the center becomes gray or nearly white. The.fungus passes the winter in the old diseased leaves that fall to the ground. In setting new plantations, remove all diseased leaves from the plants before they are taken to the field. Soon after growth begins, spray the newly set plants with bordeaux, 5-5-50. Make three or four additional sprayings during the season. The following spring, spray just before blossoming and again 10 to 14 days later. If the bed is to be fruited a second time, mow the plants and burn over the beds as soon as the fruit is gathered. Plant resistant varieties.

Tomato leaf-spot. - The distinguishing character of this disease is that it begins on the lower leaves and works towards the top, killing the foliage as it goes. It is controlled with difficulty because it is carried over winter in the diseased leaves and tops that fall to the ground. When setting out plants, pinch off all the lower leaves that touch the ground; also any leaves that show suspicious-looking dead-spots. The trouble often starts in the seed-bed. Spray plants very thoroughly with bordeaux, 5-5-50, beginning as soon as the plants are set out. Stake and tie up for greater convenience in spraying. Spray under side of the leaves. Spray ever ${ }_{y}$ week or ten days. 


\section{CHAPTER VII}

THE GROWING OF THE ORNAMENTAL PLANTS - THE CLASSES OF PLANTS, AND LISTS

IN choosing the kinds of plants for the main grounds the gardener should carefully distinguish two categories, - those plants to compose the structural masses and design of the place, and those that are to be used for mere ornament. The chief merits to be sought in the former are good foliage, pleasing form and habit, shades of green, and color of winter twigs. The merits of the latter lie chiefly in flowers or colored foliage.

Each of these categories should be again divided. Of plants for the main design, there might be discussion of trees for a windbreak, of trees for shade; of shrubs for screens or heavy plantings, for the lighter side plantings, and for incidental masses about the buildings or on the lawn; and perhaps also of vines for porches and arbors, of evergreens, of hedges, and of the heavier herbaceous masses.

Plants used for mere embellishment or ornamentation may be ranged again into categories for permanent herbaceous borders, for display beds, ribbon edgings, annuals for temporary effects, foliage beds, plants for adding color and emphasis to the shrubbery masses, plants desired to be grown as single specimens or as curiosities, and plants for porch-boxes and window-gardens.

Having now briefly suggested the uses of the plants, we shall proceed to discuss them in reference to the making of home grounds. This chapter contains a brief consideration of 
Planting for immediate effect,

The use of "foliage" trees and shrubs,

Windbreaks and screens,

The making of hedges,

The borders,

The flower-beds,

Aquatic and bog plants,

Rockeries and alpine plants;

and then it runs into nine sub-chapters, as follows:-

1. Plants for carpet-beds, p. 234;

2. The annual plants, p. 241;

3. Hardy herbaceous perennials, p. 260;

4. Bulbs and tubers, p. 281;

5. The shrubbery, p. 290;

6. Climbing plants, p. 307;

7. Trees for lawns and streets, p. 319 ;

8. Coniferous evergreen trees and shrubs, p. 331;

9. Window-gardens, p. 336;

and then, in Chapter VIII, the particular cultures of plants needing special care are briefly discussed.

\section{Planting for immediate effect.}

It is always legitimate, and, in fact, desirable, to plant for immediate effect. One may plant very thickly of rapid-growing trees and shrubs for this purpose. It is a fact, however, that very rapid-growing trees usually lack strong or artistic character. Other and better trees should be planted with them and the featureless kinds be gradually removed. (Page 41.)

The effect of a new place may be greatly heightened by a dexterous use of annuals and other herbaceous stuff in the shrub plantations. Until the shrubbery covers the ground, temporary plants may be grown among them. Subtropical beds 
may give a very desirable temporary finish to places that are pretentious enough to make them seem in keeping.

Very rough, hard, sterile, and stony banks may sometimes be covered with coltsfoot (Tussilago Farfara), sacaline, Rubus cratcegifolius, comfrey, and various wild growths that persist in similar places in the neighborhood.

However much the planter may plan for immediate effects, the beauty of trees and shrubs comes with maturity and age, and this beauty is often delayed, or even obliterated, by shearing and excessive heading-back. At first, bushes are stiff and erect, but when they attain their full character, they usually droop or roll over to meet the sward. Some bushes make mounds of green much sooner than others that may even be closely related. Thus the common yellow-bell (Forsythia virdissima) remains stiff and hard for some years, whereas $\dot{F}$. suspensa makes a rolling heap of green in two or three years. Quick informal effects can also be secured by the use of Hall's Japanese honeysuckle (Lonicera Halliana of nurserymen), an evergreen in the South, and holding its leaves until midwinter or later in the North. It may be used for covering a rock, a pile of rubbish, a stump (Fig. 236), to fill a corner against a foundation, or it may be trained on a porch or arbor. There is a form with yellow-veined leaves. Rosa Wichuraiana and some of the dewberries are useful for covering rough places.

Many vines that are commonly used for porches and arbors may be employed also for the borders of shrub-plantations and for covering rough banks and rocks, quickly giving a finish to the cruder parts of the place. Such vines, among others, are various kinds of clematis, Virginia creeper, actinidia, akebia, trumpet creeper, periploca, bitter-sweet (Solanum Dulcamara), wax-work (Celastrus scandens).

Of course, very good immediate effects may be secured by very close planting (page 222), but the homesteader must not neglect to thin out these plantations when the time comes. 


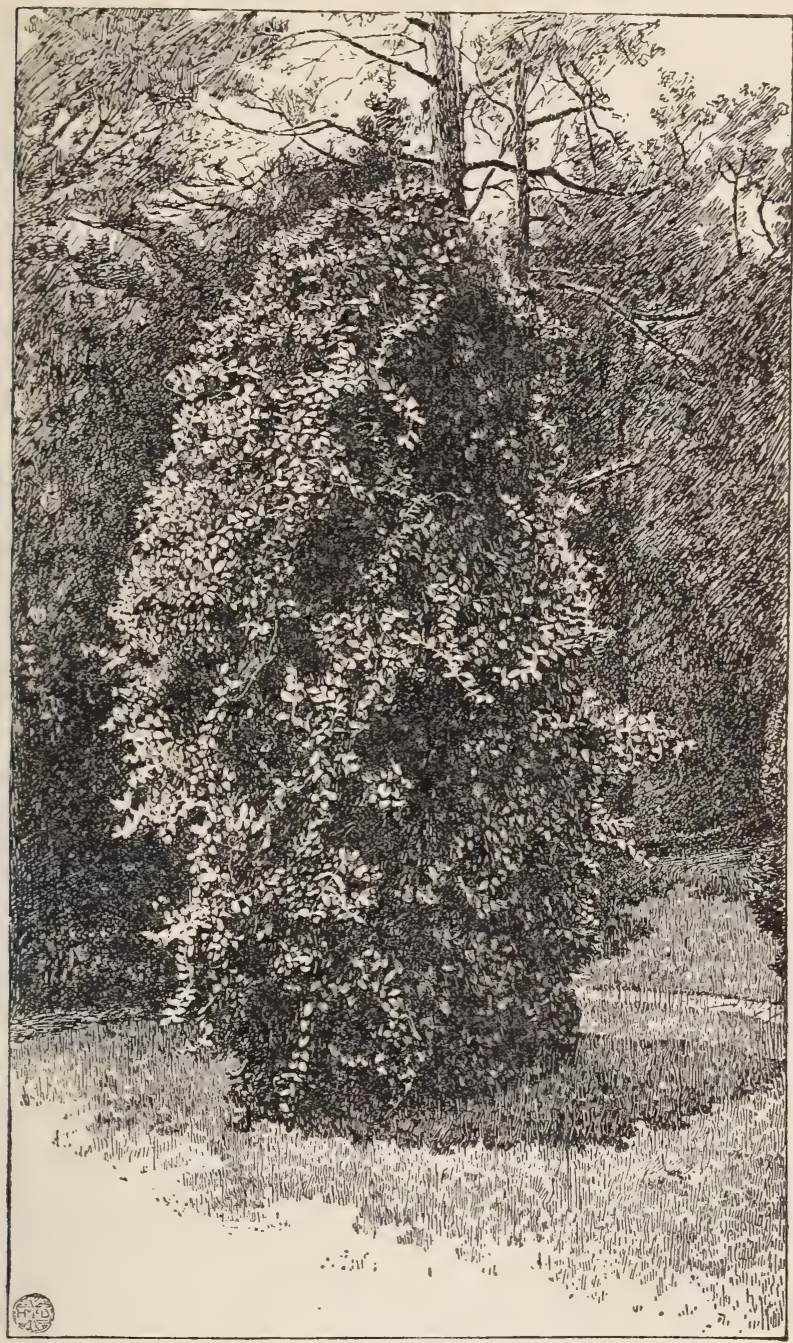

236. Stump covered with Japanese honeysuckle. 
The use of "foliage" trees and shrubs.

There is always a temptation to use too freely of the trees and shrubs that are characterized by abnormal or striking foliage. The subject is discussed in its artistic bearings on pages 40 and 41 .

As a rule, the yellow-leaved, spotted-leaved, variegated, and other abnormal "foliage" plants are less hardy and less reliable than the green-leaved or "natural" forms. They usually require more care, if they are kept in vigorous and seemly condition. Some marked exceptions to this are noted in the lists of trees and shrubs.

There are some plants of striking foliage, however, that are perfectly reliable, but they are usually not of the 'horticultural variety" class, their characteristics being normal to the species. Some of the silver or white-leaved poplars, for example, produce the most striking contrasts of foliage, particularly if set near darker trees, and for this reason they are much desired by many planters. Bolle's poplar (Populus Bolleana of the nurseries) is one of the best of these trees. Its habit is something like that of the Lombardy. The upper surface of the deeply lobed leaves is dark dull green, while the under surface is almost snowy white. Such emphatic trees as this should generally be partially obscured by planting them amongst other trees, so that they appear to mix with the other foliage; or else they should be seen at some distance. Other varieties of the common white poplar or abele are occasionally useful, although most of them sprout badly and may become a nuisance. But the planting of these immodest trees is so likely to be overdone that one scarcely dare recommend them, although, when skillfully used, they may be made to produce most excellent effects. If any reader has a particular fondness for trees of this class (or any others with woolly-white foliage) and if he has only an ordinary city lot or farm-yard to ornament, let him 
reduce his desires to a single tree, and then if that tree is planted in the interior of a group of other trees, no harm can result.

\section{Windbreaks and screens.}

A shelter-belt for the home grounds is often placed at the extreme edge of the home yard, toward the heaviest or prevailing wind. It may be a dense plantation of evergreens. If so, the Norway spruce is one of the best for general purposes in the northeastern states. For a lower belt the arbor vitæ is excellent. Some of the pines, as the Scotch or Austrian, and the native white pine, are also to be advised, particularly if the belt is at some distance from the residence. As a rule, the coarser the tree the farther it should be placed from the house.

The common deciduous trees of the region (as elm, maple, box-elder) may be planted in a row or rows for windbreaks. Good temporary shelter belts are secured by poplars and large willows. On the prairies and far north the laurel willow (Salix laurifolia of the trade) is excellent. Where snow blows very badly, two lines of breaks may be planted three to six rods apart, so that the inclosed lane may catch the drift; this method is employed in prairie regions.

Persons may desire to use the break as a screen to hide undesirable objects. If these objects are $o^{c}$ a permanent character, as a barn or an unkempt property, evergreen trees should be used. For temporary screens, any of the very large-growing herbaceous plants may be employed. Very excellent subjects are sunflowers, the large-growing nicotianas, castor beans, large varieties of Indian corn, and plants of like growth. Excellent screens are sometimes made with vines on a trellis.

Very efficient summer screens may be made with ailanthus, paulownia, basswood, sumac, and other plants that tend to throw up very vigorous shoots from the base. After these plants have been set a year or two, they are cut back nearly to the ground in winter or spring, and strong shoots are thrown 
up with great luxuriance during the summer, giving a dense screen and presenting a semi-tropical effect. For such purposes, the roots should be planted only two or three feet apart. If, after a time, the roots become so crowded that the shoots are weak, some of the plants may be removed. Top-dressing the area every fall with manure will tend to make the ground rich enough to afford a very heavy summer growth. (See Fig. 50.)

\section{The making of hedges.}

Hedges are much less used in this country than in Europe, 'and for several reasons. Our climate is dry, and most hedges do not thrive so well here as there; labor is high-priced, and the trimming is therefore likely to be neglected; our farms are so large that much fencing is required; timber and wire are cheaper than live hedges.

However, hedges are used with good effect about the home grounds. In order to secure a good ornamental hedge, it is necessary to have a thoroughly well-prepared deep soil, to set the plants close, and to shear them at least twice every year. For evergreen hedges the most serviceable plant in general is the arbor vitæ. The plants may be set at distances of 1 to $2 \frac{1}{2}$ feet apart. For coarser hedges, the Norway spruce is used; and for still coarser ones, the Scotch and Austrian pines. In California the staple conifer hedge is made of Monterey cypress. For choice evergreen hedges about the grounds, particularly outside the northern states, some of the retinosporas are very useful. One of the most satisfactory of all coniferous plants for hedges is the common hemlock, which stands shearing well and makes a very soft and pleasing mass. The plants may be set from 2 to 4 feet apart.

Other plants that hold their leaves and are good for hedges are the common box and the privets. Box hedges are the best for very low borders about walks and flower-beds. The dwarf variety can be kept down to a height of 6 inches to a foot for 
any number of years. The larger-growing varieties make excellent hedges 3,4 , and 5 feet high. The ordinary privet or prim holds its leaves well into winter in the North. The socalled Californian privet holds its leaves rather longer and stands better along the seashore. The mahonia makes a low, loose hedge or edging in locations where it will thrive. Pyracantha is also to be recommended where hardy. In the southern states, nothing is better than Citrus trifoliata. This is hardy even farther north than Washington in very favored localities. In the South, Prunus Caroliniana is also used for hedges. Saltbush hedges are frequent in California.

- For hedges of deciduous plants, the most common species are the buckthorn, Japan quince, the European hawthorn and other thorns, tamarix, osage orange, honey locust, and various kinds of roses. Osage orange has been the most used for farm hedges. For home grounds, Berberis. Thunbergii makes an excellent free hedge; also Spircea Thunbergii and other spireas. The common Rosa rugosa makes an attractive free hedge.

Hedges should be trimmed the year after they are set, although they should not be sheared very closely until they reach the desired or permanent height. Thereafter they should be cut into the desired form in spring or fall, or both. If the plants are allowed to grow for a year or two without trimming, they lose their lower leaves and become open and straggly. Osage orange and some other plants are plashed; that is, the plants are set at an angle rather than perpendicularly, and they are wired together obliquely in such a way that they make an impenetrable barrier just above the surface of the ground.

For closely clipped or sheared hedges, the best plants are arbor vitæ, retinospora, hemlock, Norway spruce, privet, buckthorn, box, osage orange, pyracantha, Citrus trifoliata. The pyracantha (Pyracantha coccinea) is an evergreen shrub allied 
to cratægus, of which it is sometimes considered to be a species. It is also sometimes referred to cotoneaster. Although hardy in protected places in the North, it is essentially a bush of the middle and southern latitudes, and of California. It has persistent foliage and red berries. Var. Lalandi has orange-red berries (Plate XIX).

\section{The borders.}

The word "border" is used to designate the heavy or continuous planting about the boundaries of a place, or along the walks and drives, or against the buildings, in distinction from planting on the lawn or in the interior spaces. A border re ceives different designations, depending on the kinds of plants that are grown therein: it may be a shrub-border, a flowerborder, a hardy border for native and other plants, a vineborder, and the like.

There are three rules for the choosing of plants for a hardy border: choose (1) those that you like best, (2) those that are adapted to the climate and soil, (3) those that are in place or in keeping with that part of the grounds.

The earth for the border should be fertile. The whole ground should be plowed or spaded and the plants set irregularly in the space; or the back row may be set in a line. If the border is composed of shrubs, and is large, a horse cultivator may be run in and out between the plants for the first two or three years, since the shrubs will be set 2 to 4 feet apart. Ordinarily, however, the tilling is done with hand tools. After the plants are once established and the border is filled, it is best to dig up as little as possible, for the digging disturbs the roots and breaks the crowns. It is usually best to pull out the weeds and give the border a top-dressing each fall of well-rotted manure. If the ground is not very rich, an application of ashes or some commercial fertilizer may be given from time to time.

The border should be planted so thick as to allow the plants 
to run together, thereby giving one continuous effect. Most shrubs should be set 3 feet apart. Things as large as lilacs may go 4 feet and sometimes even more. Common herbaceous perennials, as bleeding heart, delphiniums, hollyhocks, and the like, should go from 12 to 18 inches. On the front edge of the border is a very excellent place for annual and tender flowering plants. Here, for example, one may make a fringe of asters, geraniums, coleus, or anything else he may choose. (Chap. II.)

Into the heavy borders about the boundaries of the place the autumn leaves will drift and afford an excellent mulch. If these borders are planted with shrubs, the leaves may be left there to decay, and not be raked off in the spring.

The general outline of the border facing the lawn should be more or less wavy or irregular, particularly if it is on the boundary of the place. Alongside a walk or drive the margins may follow the general directions of the walk or drive.

In making borders of perennial flowers the most satisfactory results are secured if a large clump of each kind or variety is grown. The herbaceous border is one of the most flexible parts of grounds, since it has no regular or formal design. Allow ample space for each perennial root, - often as much as three or four square feet, - and then if the space is not filled the first year or two, scatter over the area seeds of poppies, sweet peas, asters, gilias, alyssum, or other annuals. Figures 237-239, from Long ("Popular Gardening," i., 17, 18), suggest methods of making such borders. They are on a scale of ten feet to the inch. The entire surface is tilled, and the irregular diagrams designate the sizes of the clumps. The diagrams containing no names are to be filled with bulbs, annuals, and tender plants, if desired.

It must not be supposed, however, that one cannot have a border unless he has wide marginal spaces about his grounds. It is surprising how many things one can grow in an old fence. Perennials that grow in fence-rows in fields ought also to grow 

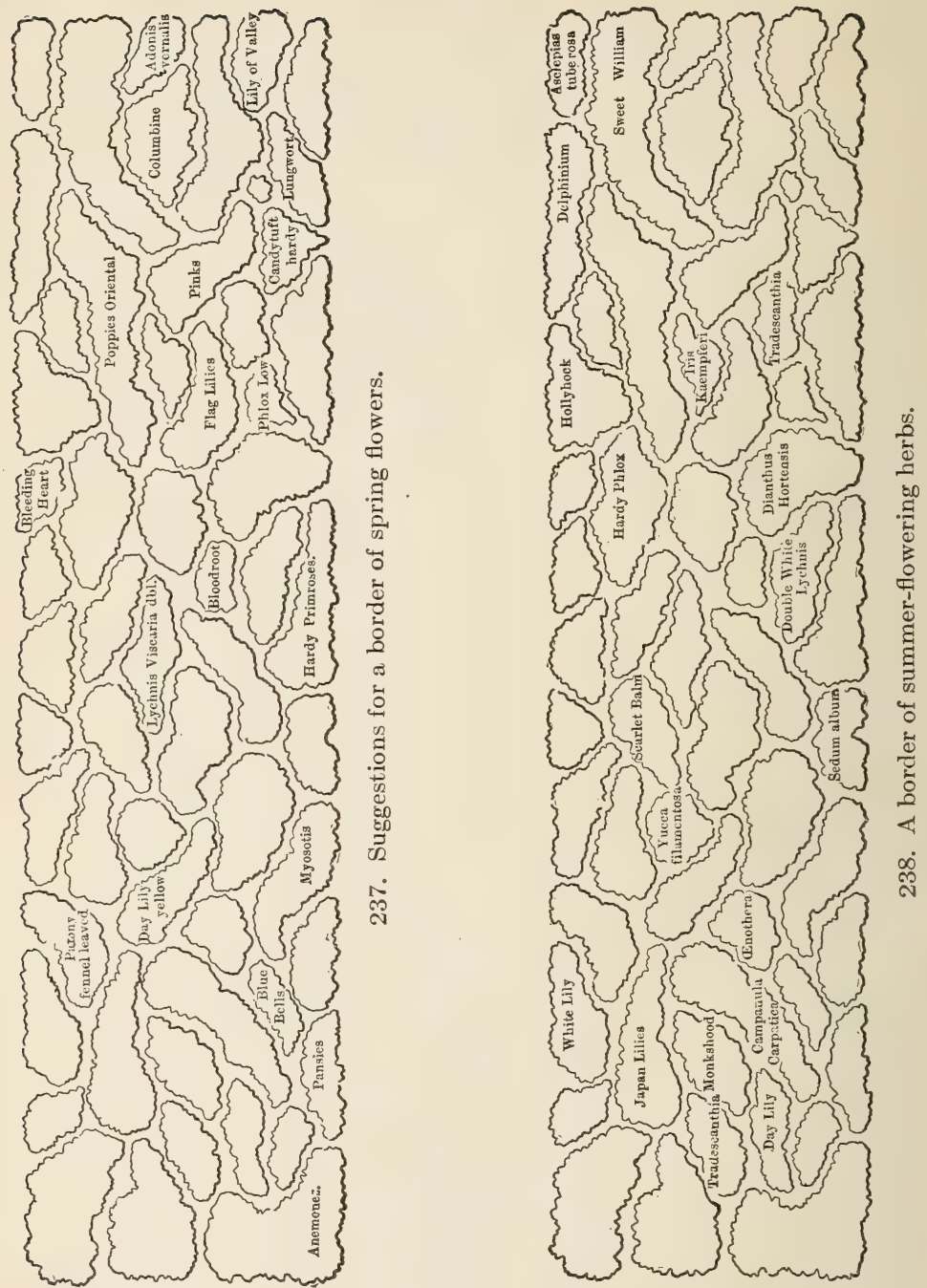
in similar boundaries on the home grounds. Some of the garden annuals will thrive alongside a fence, particularly if the fence does not shut off too much light; and many vines (both perennial and annual) will cover it effectively. Among annuals, the large-seeded, quick-germinating, rapid-growing kinds will do best. Sunflower, sweet pea, morning glory, Japanese hop, zinnia, marigold, amaranths, four o'clock, are some of the kinds that will hold their own. If the effort is made to grow plants in such places, it is important to give them all the advantage possible early in the season, so that they will get well ahead of the grass and weeds. Spade up the ground all you can. Add a little quickacting fertilizer. It is best to start the plants in pots or small boxes, so that they will be in advance of the weeds when they are set out.

\section{The flower-beds.}

We must remember to distinguish two uses of flowers, - their part in a landscape design or picture, and their part in a bed or separate garden for bloom. We now consider the flower-bed proper; and we include in the flower-bed such "foliage" plants as coleus, celosia, croton, and canna, although the

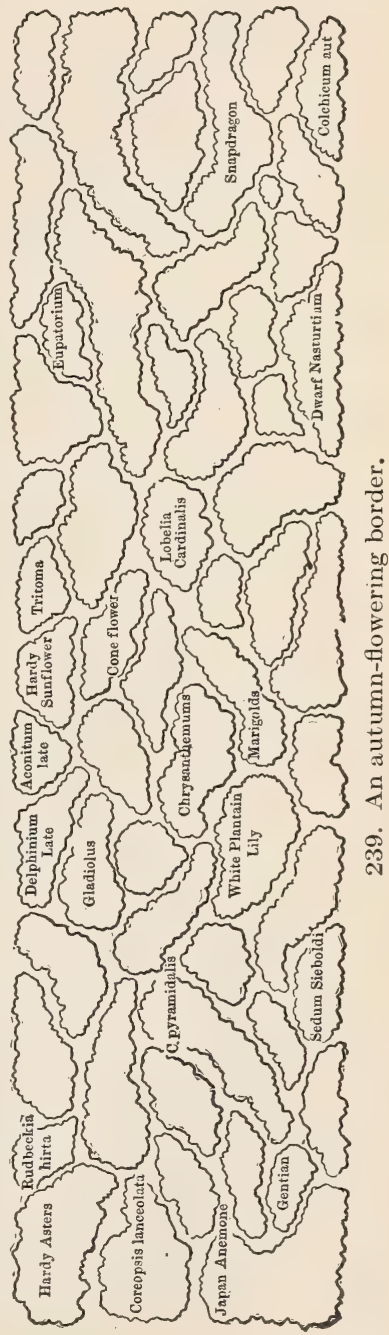


main object of the flower-bed is to produce an abundance of flowers.

In making a flower-bed, see that the ground is well drained; that the subsoil is deep; that the land is in a mellow and friable condition, and that it is fertile. Each fall it may have a mulch of rotted manure or of leafmold, which may be spaded under deeply in the spring; or the land may be spaded and left rough in the fall, which is a good practice when the soil has much clay. Make the flower-beds as broad as possible, so that the roots of the grass running in from either side will not meet beneath the flowers and rob the beds of food and moisture. It is well to add a little commerc al fertilizer each fall or spring.

Although it is well to emphasize making the ground fertile, it must be remembered (as indicated on page 114) that it can easily be made too rich for such plants as we desire to keep within certain stature and for those from which we wish an abundance of bloom in a short season. In over-rich ground, nasturtiums and some other plants not only "run to vine," but the bloom lacks brilliancy. When it is the leaf and vegetation that is wanted, there is little danger of making the ground too rich, although it is possible to make the plant so succulent and sappy that it becomes sprawly or breaks down; and other plants may be crippled and crowded out.

There are various styles of flower-planting. The mixed border, planted with various hardy plants, and extending along either side of the garden-walk, was popular years ago; and, with modifications in position, form, and extent, has been a popular attachment to home grounds during the past few years. To produce the best effects the plants should be set close enough to cover the ground; and the selection should be such as to afford a continuity of bloom.

The mixed flower-bed may contain only tender summerblooming plants, in which case the bed, made up mostly of annuals, does not purport to express the entire season. 
In distinction from the mixed or non-homogeneous flowerbed are the various forms of "bedding," in which plants are massed for the purpose of making a connected and homogeneous bold display of form or color. The bedding may be for the purpose of producing a strong effect of white, of blue, or of red; or of ribbon-like lines and edgings; or of luxurious and tropical expression; or to display boldly the features of a particular plant, as the tulip, the hyacinth, the chrysanthemum.

In ribbon-bedding, flowering or foliage plants are arranged in ribbon-like lines of harmoniously contrasting colors, commonly accompanying walks or drives, but also suitable for marking limits, or for the side borders. In such beds, as well as the others, the tallest plants will be placed at the back, if the bed is to be seen from one side only, and the lowest at the front. If it is to be seen from both sides, then the tallest will stand in the center.

A modification of the ribbon-line, bringing the contrasting colors together into masses forming circles or other patterns, is known as "massing," or "massing in color," and sometimes is spoken of as "carpet-bedding."

Carpet-bedding, however, belongs more properly to a style of bedding in which plants of dense, low, spreading habit chiefly foliage plants, with leaves of different forms and colors - are planted in patterns not unlike carpets or rugs. It is often necessary to keep the plants sheared into limits. Carpetbedding is such a specialized form of plant-growing that we shall treat of it separately (page 234).

Beds containing the large foliage plants, for producing tropical effects, are composed, in the main, of subjects that are allowed to develop naturally. In the lower and more orderly massing, the plants are arranged not only in circles and patterns according to habit and height, but the selection is such that some or all may be kept within proper limits by pinching or 
trimming. Circles or masses composed of flowering plants usually cannot be cut back at the top, so that the habit of the plants must be known before planting; and the plants must be placed in parts of the bed where trimming will not be necessary. They may be clipped at the sides, however, in case the branches or leaves of one mass or line in the pattern grow beyond their proper bounds.

The numbers of good annuals and perennials that may be used in flower-beds are now very large, and one may have a wide choice. Various lists from which one may choose are given at the end of this chapter; but special comment may be made on those most suitable for bedding, and in its modification in ribbon-work and sub-tropical massing.

\section{Bedding effects.}

Bedding is ordinarily a temporary species of planting; that is, the bed is filled anew each year. However, the term may be used to designate a permanent plantation in which the plants are heavily massed so as to give one continuous or emphatic display of form or color. Some of the best permanent bedding masses are made of the various hardy ornamental grasses, as eulalias, arundo, and the like. The color effects in bedding may be secured with flowers or with foliage.

Summer bedding is often made by perennial plants that are carried over from the preceding year, or better, that are propagated for that particular purpose in February and March. Such plants as geranium, coleus, alyssum, scarlet salvia, ageratum, and heliotrope may be used for these beds. It is a common practice to use geranium plants which are in bloom during the winter for bedding out during the summer, but such plants are tall and ungainly in form and have expended the greater part of their energies. It is better to propagate new plants by taking cuttings or slips late in the winter and setting out young fresh vigorous subjects. (Page 30.) 
Some bedding is very temporary in its effect. Especially is this true of spring bedding, in which the subjects are tulips, hyacinths, crocuses, or other early-flowering bulbous plants. In this case, the ground is usually occupied later in the season by other plants. These later plants are commonly annuals, the seeds of which are sown amongst the bulbs as soon as the season is far enough advanced; or the annuals may be started in boxes and the plants transplanted amongst the bulbs as soon as the weather is fit.

Many of the low-growing and compact continuous-flowering annuals are excellent for summer bedding effects. There is a list of some useful material for this purpose on page 249 .

Plants for subtropical effects (Plates IV and V).

The number of plants suitable to produce a semitropical mass or for the center or back of a group, which may be readily grown from seed, is limited. Some of the best kinds are included below.

It will often be worth while to supplement these with others, to be had at the florists, such as caladiums, screw pines, Ficus elastica, araucarias, Musa Ensete, palms, dracenas, crotons, and others. Dahlias and tuberous begonias are also useful. About a pond the papyrus and lotus may be used.

Practically all the plants used for this style of gardening are liable to injury from winds, and therefore the beds should be placed in a protected situation. The palms and some other greenhouse stuff do better if partially shaded.

In the use of such plants, there are opportunities for the exercise of the nicest taste. A gross feeder, as the ricinus, in the midst $o$ a bed of delicate annuals, is quite out of place; and a stately, royal-looking plant among humbler kinds often makes the latter look common, when if headed with a chief of their own rank all would appear to the best advantage.

Some of the plants much used for subtropical bedding, and 
often started for that purpose in a greenhouse or coldframe, are:-
Acalypha.
Amarantus.
Aralia Sieboldii (properly Fatsia Japonica).
Bamboos.
Caladium and colocasia.
Canna.
Coxcomb, particularly the new "foliage" kinds.
Grasses, as eulalias, pampas-grass, pennisetums.
Gunnera.
Maize, the striped form.
Ricinus or castor bean.
Scarlet sage.
Wigandia.

\section{Aquatic and bog plants.}

Some of the most interesting and ornamental of all plants grow in water and in wet places. It is possible to make an aquatic flower-garden, and also to use water and bog plants as a part of the landscape work.

The essential consideration in the growing of aquatics is the making of the pond. It is possible to grow water-lilies in tubs and half barrels; but this does not provide sufficient room, and the plant-food is likely soon to be exhausted and the plants to fail. The small quantity of water is likely also to become foul.

The best ponds are those made by good mason work, for the water does not become muddy by working among the plants. In cement ponds it is best to plant the roots of water-lilies in shallow boxes of earth ( 1 foot deep and 3 or 4 feet square), or to hold the earth in mason-work compartments.

Usually the ponds or tanks are not cement lined. In some soils a simple excavation will hold water, but it is usually 


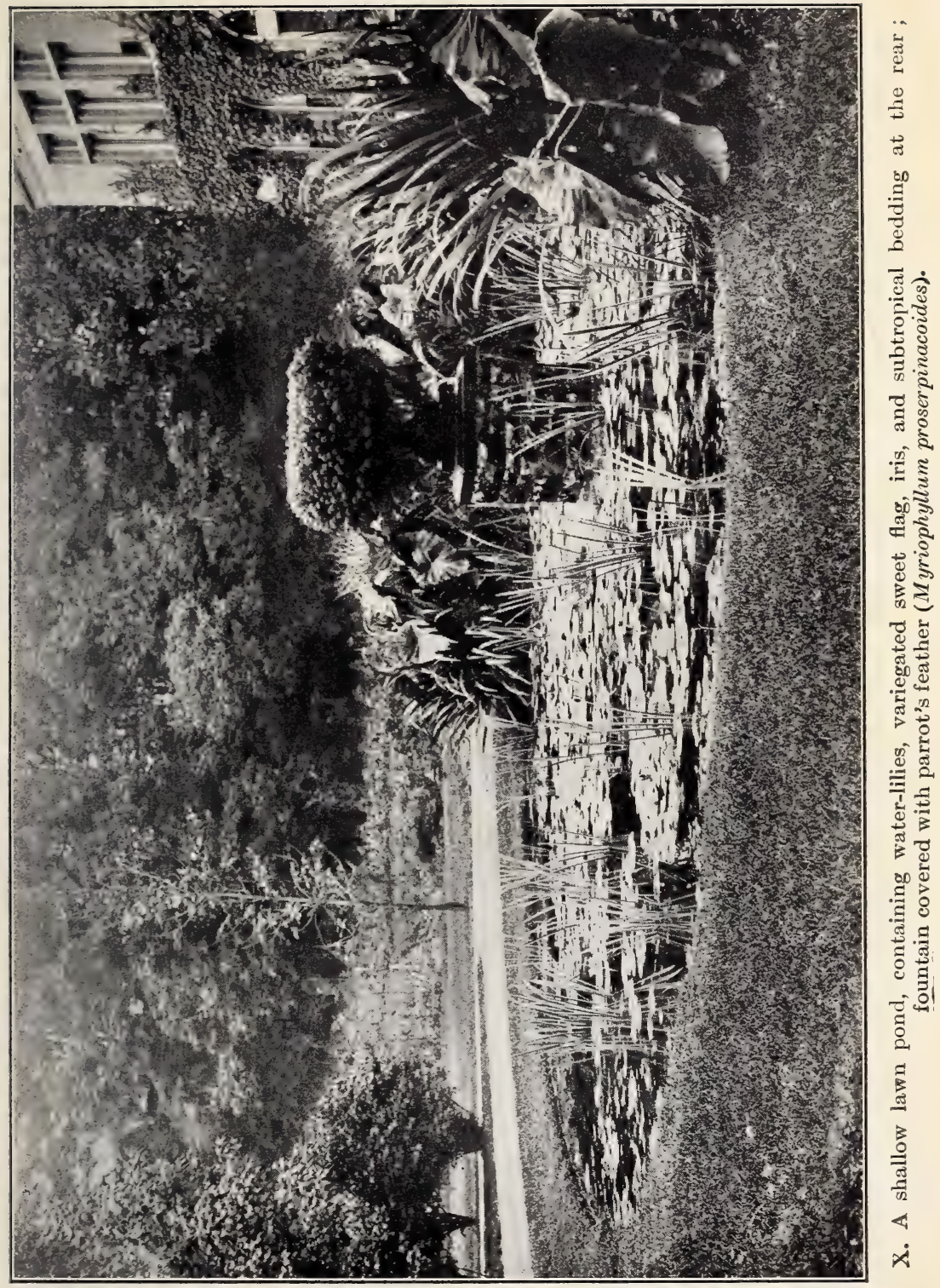



necessary to give the tank some kind of lining. Clay is often used. The bottom and sides of the tank are pounded firm, and then covered with 3 to 6 in. of clay, which has been kneaded in the hands, or pounded and worked in a box. Handfuls or shovelfuls of the material are thrown forcibly upon the earth, the operator being careful not to walk upon the work. The clay is smoothed by means of a spade or maul, and it is then sanded.

The water for the lily pond may be derived from a brook, spring, well, or a city water supply. The plants will thrive in any water that is used for domestic purposes. It is important that the water does not become stagnant and a breeding place for mosquitoes. There should be an outlet in the nature of a stand-pipe, that will control the depth of water. It is not necessary that the water run through the pond or tank rapidly, but only that a slow change take place. Sometimes the water is allowed to enter through a fountain-vase, in which water plants (such as parrot's feather) may be grown (Plate X).

In all ponds, a foot or 15 in. is sufficient depth of water to stand above the crowns of the plants; and the greatest depth of water should not be more than $3 \mathrm{ft}$. for all kinds of waterlilies. Half this depth is often sufficient. The soil should be 1 to $2 \mathrm{ft}$. deep, and very rich. Old cow manure may be mixed with rich loam. For the nympheas or water-lilies, 9 to 12 in. of soil is sufficient. Most of the foreign water-lilies are not hardy, but some of them may be grown with ease if the pond is covered in winter.

Roots of ha:dy water-lilies may be planted as soon as the pond is clear cf frost, but the tender kinds (which are also to be taken up in the fall) should not be planted till it is time to plant out geraniums. Sink the roots into the mud so that they are just buried, and weight them down with a stone or clod. The nelumbium, or so-called Egyptian lotus, should not be transplanted till growth begins to show in the roots in the 
spring. The roots are cleaned of decayed parts and covered with about $3 \mathrm{in}$. of soil. A foot or so of water is sufficient for lotus ponds. The roots of Egyptian lotus must not freeze. The roots of all water-lily-like plants should be frequently divided and renewed.

With hardy aquatics, the water and roots are allowed to remain naturally over winter. In very cold climates, the pond is protected by throwing boards over it and covering with hay, straw, or evergreen boughs. It is well to supply an additional depth of water as a further protection.

As a landscape feature, the pond should have a background, or setting, and its edges should be relieved, at least on sides and back, by plantings of bog plants. In permanent ponds of large size, plantings of willows, osiers, and other shrubbery may set off the area to advantage. Many of the wild marsh and pond plants are excellent for marginal plantings, as sedges, cat-tail, sweet-flag (there is a striped-leaved form), and some of the marsh grasses. Japanese iris makes an excellent effect in such places. For summer planting in or near ponds, caladium, umbrella-plant, and papyrus are good.

If there is a stream, "branch," or "run" through the place, it may often be made one of the most attractive parts of the premises by colonizing bog plants along it.

\section{Rockeries, and alpine plants.}

A rockery is a part of the place in which plants are grown in pockets between rocks. It is a flower-garden conception rather than a landscape feature, and therefore should be at one side or in the rear of the premises. Primarily, the object of using the rocks is to provide better conditions in which certain plants may grow; sometimes the rocks are employed to hold a springy or sloughing bank and the plants are used to cover the rocks; now and then a person wants a rock or a pile of stones in his yard, as another person would want a piece of statuary or a 
sheared evergreen. Sometimes the rocks are natural to the place and cannot well be removed; in this case the planning and planting should be such as to make them part of the picture.

The real rock-garden, however, is a place in which to grow plants. The rocks are secondary. The rocks should not appear to be placed for display. If one is making a collection of rocks, he is pursuing geology rather than gardening.

Yet many of the so-called rock-gardens are mere heaps of stones, placed where it seems to be convenient to pile stones rather than where the stones may improve conditions for the growing of plants.

The plants that will naturally grow in rock pockets are those requiring a continuous supply of root moisture and a cool atmosphere. To place a rockery on a sand bank in the burning sun is therefore entirely out of character.

Rock-garden plants are those of cool woods, of bogs, and particularly of high mountains and alpine regions. It is generally understood that a rock-garden is an alpine-garden, although this is not necessarily so.

In this country alpine-gardening is little known, largely because of our hot dry summers and falls. But if one has a rather cool exposure and an unfailing water supply, he may succeed fairly well with many of the alpines, or at least with the semialpines. Most of the alpines are low and often tufted plants, and bloom in a spring temperature. In our long hot seasons, the alpine-garden may be expected to be dormant during much of the summer, unless other rock-loving plants are colonized in it. Alpine plants are of many kinds. They are specially to be found in the genera arenaria, silene, diapensia, primula, saxifraga, arabis, aubrietia, veronica, campanula, gentiana. They comprise a good number of ferns and many little heaths.

A good rock-garden of any kind does not have the stones piled merely on the surface; they are sunken well into the ground and are so placed that there are deep chambers or channels that 
hold moisture and into which roots may penetrate. The pockets are filled with good fibrous moisture-holding earth, and often a little sphagnum or other moss is added. It must then be arranged so that the pockets never dry out.

Rock-gardens are usually failures, because they violate these very simple elementary principles; but even when the soil conditions and moisture conditions are good, the habits of the rock plants must be learned, and this requires thoughtful experience. Rock-gardens cannot be generally recommended.

\section{Piants for Carpet-Beds}

(By Ernest Walker)

The beauty of the carpet-bed lies largely in its unity, sharp contrast and harmony of color, elegance - often simplicity of design, nicety of execution, and the continued distinctness of outline due to scrupulous care. A generous allowance of greensward on all sides contributes greatly to the general effect, in fact it is indispensable.

Whatever place is chosen for the bed, it should be in a sunny exposure. This, nor any kind of bed, should not be planted near large trees, as their greedy roots will rob the soil not only of its food, but of moisture. The shade also will be a menace. As the plants stand so thick, the soil should be well enriched, and spaded at least a foot deep. In planting, a space of at least six inches must be left between the outer row of plants and the edge of the grass. The very style of the bed requires that lines be straight, the curves uniform, and that they be kept so by the frequent and careful use of the shears. During dry periods watering will be necessary. The beds, however, should not be watered in the hot sunshine. Foliage plants are most in use, and are the ones which will prove the most satisfactory in the hands of the inexperienced, as they submit to severe clipping and are thus more easily managed. 
The following list will be helpful to the beginner. It embraces a number of the plants in common use for carpet-bedding, although not all of them. The usual heights are given in inches. This, of course, in different soils and under different treatment is more or less a variable quantity. The figures in parentheses suggest in inches suitable distances for planting in the row when immediate effects are expected. A verbena in rich soil will in time cover a circle three feet or more in diameter; other plants mentioned spread considerably; but when used in the carpetbed, they must be planted close. One cannot wait for them to grow. The aim is to cover the ground at once. Although planted thick in the row, it will be desirable to leave more room between the rows in case of spreading plants like the verbena. Most of them, however, need little if any more space between the rows than is indicated by the figures given. In the list those plants that bear free clipping are marked with an asterisk $\left({ }^{*}\right)$ :

\section{Lists for carpet-beds.}

The figure immediately following the name of plant indicates its height, the figures in parentheses the distance for planting, in inches.

\section{Low-growing Plants}

A. Foliage Plants.

Crimson. - *Alternanthera amœna spectabilis, 6 (4-6). Alternanthera paronychioides major, 5 (3-6). Alternanthera versicolor, 5 (3-6).

Yellow. - Alternanthera aurea nana, 6 (4-6).

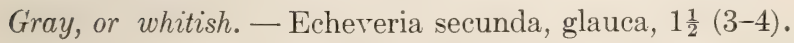

Echeveria metallica, 9 (6-8).

Cineraria maritima, 15 (9-12).

Sempervivum Californicum, $1 \frac{1}{2}(3-4)$.

Thymus argenteus, $6(4-6)$.

Bronze brown. - Oxalis tropæoloides, 3 (3-4). 
Variegated (white and green). -

Geranium Mme. Salleroi, 6 (6-8).

*Sweet alyssum, variegated, 6 (6-9).

B. Flowering Plants.

Scarlet. - Phlox Drummondii, Dwarf, 6 (4-6).

Cuphea platycentra, Cigar Plant, 6 (4-6).

White. - Sweet alyssum, Little Gem, 4 (4-6).

Sweet alyssum, common, 6 (6-8).

Phlox Drummondii, Dwarf, 6 (4-6).

Blue. - Lobelia, Crystal Palace, 6 (4-6).

Ageratum, Dwarf Blue, 6 (6-8).

\section{Plants of Taller Growth}

A. Foliage Plants.

Crimson. - *Coleus Verschaffeltii, 24 (9-12).

*Achyranthes Lindeni, 18 (8-12).

*Achyranthes Gilsoni, 12 (8-12).

*Achyranthes Verschaffeltii, 12 (8-12).

*Acalypha tricolor, 12-18 (12).

Yellow. - *Coleus, Golden Bedder, 24 (9-12).

*Achyranthes, aurea reticulata, 12 (8-12).

Golden feverfew (Pyrethrum parthenifolium aureum), (6-8).

Bronze geranium, $12(9)$.

Silvery white.-Dusty miller (Centaurea gymnocarpa), 12 (8-12)

*Santolina Chamæcyparissus incana, 6-12 (6-8).

Geranium, Mountain of Snow, $12(6-9)$.

Variegated (white and green).-

*Stevia serrata var., 12-18 (8-12).

Phalaris arundinacea var. (grass), 24 (4-8).

Cyperus alternifolius var., 24-30 (8-12).

Bronze. - *Acalypha marginata, 24 (12).

B. Flowering Plants.

Scarlet. - Salvia splendens, 36 (12-18).

Geraniums, 24 (12). 


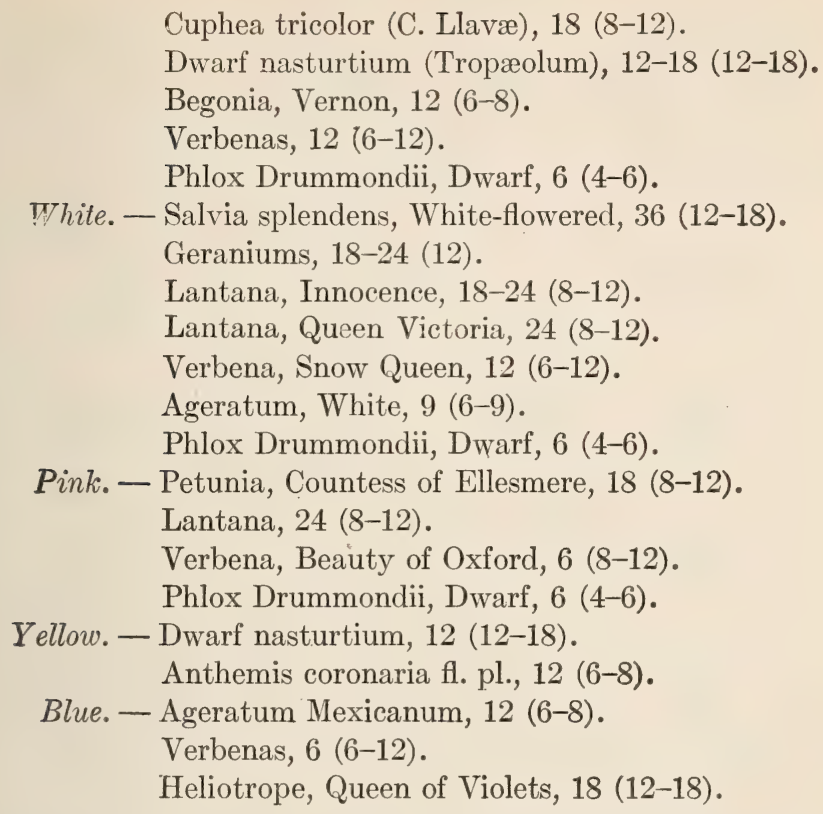

In Fig. 240 are shown a few designs suitable for carpet-beds. They are intended merely to be suggestive, not to be copied precisely. The simple forms and component parts of the more elaborate beds may be arranged into other designs. Likewise the arrangement of plants, which will be mentioned as suitable for making a given pattern, is only one of many possible combinations. The idea is merely to bring out the design distinctly. To accomplish this it is only necessary to use plants of contrasting color or growth. To illustrate how varied are the arrangements that may be used, and how easily different effects are produced with a single design, several different combinations of color for the bed No. 1 will be mentioned:

No. 1. - Arrangement A: Outside, Alternanthera amœena spectabilis; inside, Stevia serrata variegata. B: lobelia, Crystal 

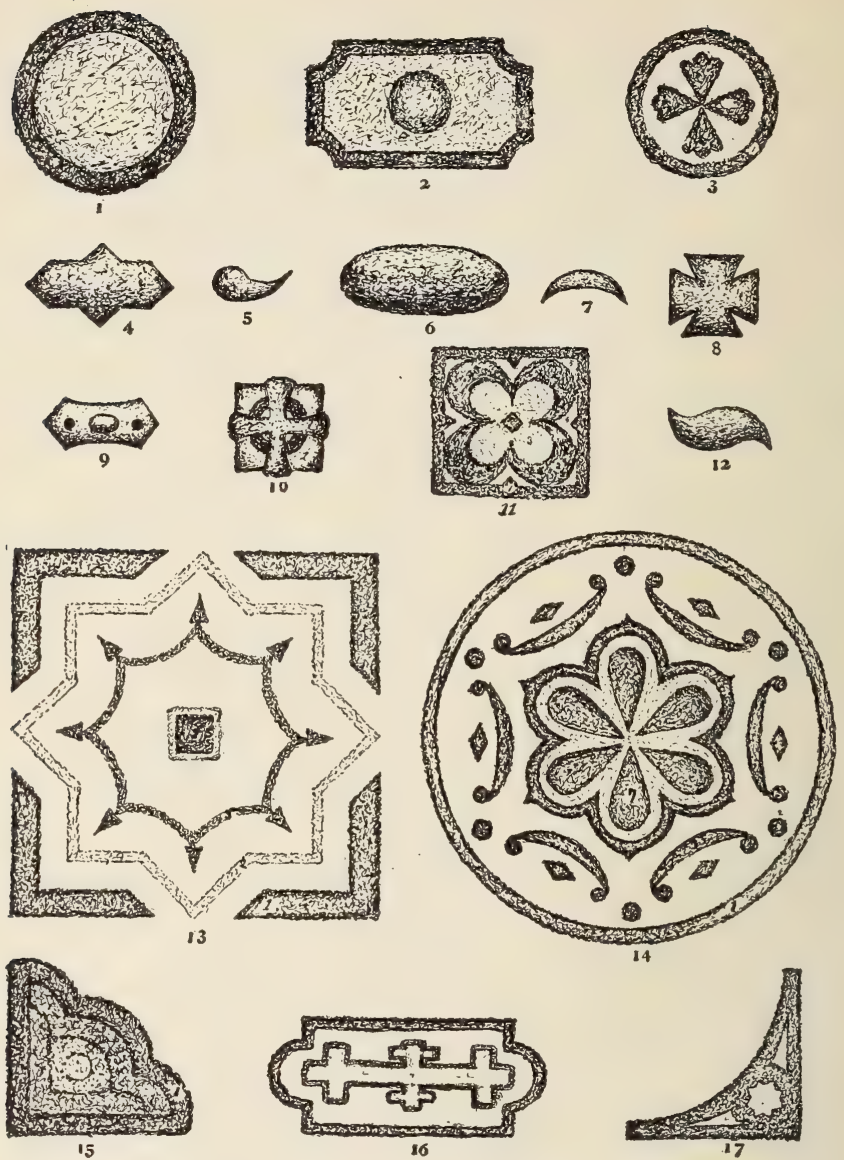

240. Designs for carpet-beds.

Palace; Mme. Salleroi geranium. C: lobelia, Crystal Palace; scarlet dwarf phlox. D: sweet alyssum; petunia, Countess of Ellesmere. E: coleus, Golden Bedder; Coleus Verschaffeltii. F: Achyranthes Lindeni; yellow dwarf nasturtium.

No. 2. - Outside, red alternanthera; middle, dusty miller; center, pink geranium. 
No. 3. - Outside, Alternanthera aurea nana ; middle, Alternanthera amœna spectabilis; center, Anthemis coronaria.

No. $4,5,6,7,8,12$ may each be filled with a single color, or given a border of suitable plants if the planter so chooses.

No. 9. - Ground, Alternanthera aurea nana; center, Acalypha tricolor; black dots, scarlet geranium.

No. 10. - Ground of Centaurea gymnocarpa; circle, Achyranthes Lindeni ; cross, Golden coleus.

No. 11. - Border, Oxalis tropæoloides; center, blue heliotrope, blue ageratum, or Acalypha marginata; cross about the center, Thymus argenteus, or centaurea ; scallop outside the cross,blue lobelia ; corners, inside border, santolina.

Designs 13 and 14 are, in character, somewhat in the style of a parterre; but instead of the intervening spaces in the bed being ordinary walks they are of grass. Such beds are of a useful type, because they may be made large and yet be executed with a comparatively small number of plants. They are especially suitable for the center of an open plot of lawn with definite formal boundaries on all sides, such as walks or drives. Whether they are to be composed of tall-growing or of low-growing plants will depend upon the distance they are to be from the observer. For a moderate-sized plot the following plants might be used:-

No. 13. - Border, red alternanthera; second row, dwarf orange or yellow nasturtium; third row, Achyranthes Gilsoni, or Acalypha tricolor; central square, scarlet geraniums, with a border of Centaurea gymnocarpa; intervening spaces, grass. Instead of the square of geraniums, a vase might be substituted, or a clump of Salvia splendens.

No. 14. - Composite beds like this and the former are always suggestive. They contain various features which may readily be recombined into other patterns. Sometimes it may be convenient to use only portions of the design. The reader should feel that no arrangement is arbitrary, but merely a suggestion that he may use with the utmost freedom, only keeping harmony in view. For No. 14, the following may be an acceptable planting arrangement: Border, Mme. Salleroi geranium; small dots, dwarf scarlet tropeolum; diamonds, blue lobelia ; crescents, Stevia serrata variegata; 
inner border, crimson achyranthes or coleus ; loops, Centaurea gymnocarpa ; wedge-shaped portions, scarlet geranium.

No. 15. - Suitable for a corner. Border, red alternanthera; second row, Alternanthera aurea nana; third row, red alternanthera; center, Echeveria Californica.

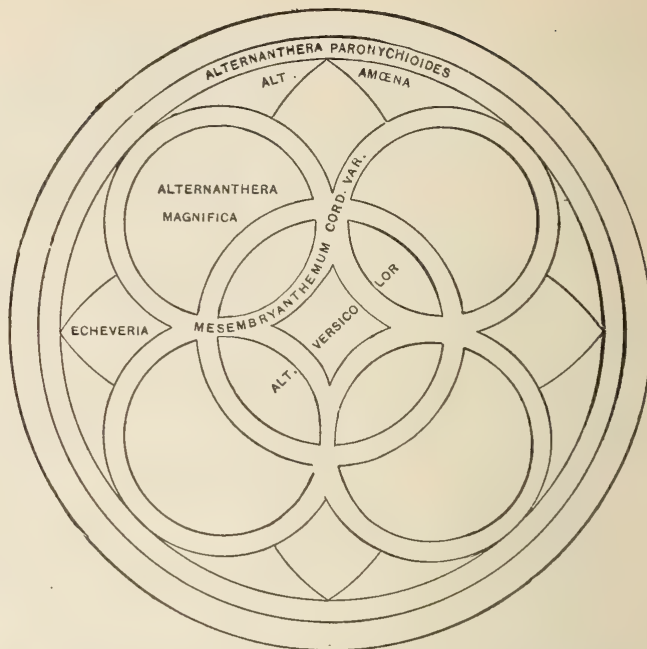

No. 16. - Border, 241. Carpet-bed for a bay or recession in the border crimson alternanplanting. thera (another border of yellow alternanthera might be placed

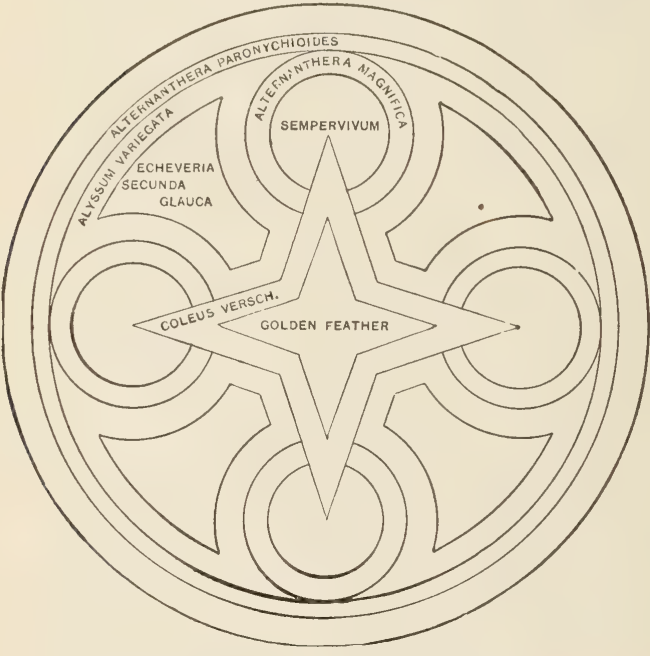

242. Another circular carpet-bed. inside of this); ground, Echeveria secunda glauca; inner border, Oxalis tropæoloides; center, Alternanthera aurea nana. Or, inner border, Echeveria Californica; center, crimson alternanthera.

No. 17. - Another bed intended to fill an angle. Its curved side will also fit it for use with a circular design. Border,dwarf 
blue ageratum ; circle, blue lobelia ; ground (3 parts), crimson alternanthera.

Other carpet or mosaic beds (after Long), with the plants indicated, are shown in Figs. 241, 242.

\section{The Annual Plants}

The annual flowers of the seedsmen are those that give their best bloom in the very year in which the seeds are sown. True annuals are those plants that complete their entire life-cycle in one season. Some of the so-called annual flowers will continue to bloom the second and third years, but the bloom is so poor and sparse after the first season that it does not pay to keep them. Some perennials may be treated as annuals by starting the seeds early; Chinese pink, pansy and snapdragon are examples.

The regular biennials may be treated practically as annuals; that is, seeds may be sown every year, and after the first year, therefore, a seasonal succession of bloom may be had. Of such are adlumia, Canterbury bell; lunaria, ipomopsis, Enothera Lamarckiana; and foxglove, valerian, and some other perennials would better be treated as biennials.

Most annuals will bloom in central New York if the seeds are sown in the open ground when the weather becomes thoroughly settled. But there are some kinds, as the late cosmos and moonflowers, for which the northern season is commonly too short to give good bloom unless they are started very early indoors.

If flowers of any annual are wanted extra early, the seeds should be started under cover. A greenhouse is not necessary for this purpose, although best results are to be expected with such a building. The seed may be sown in boxes, and these boxes then placed in a sheltered position on the warm side of a building. At night they may be covered with boards or matting. In very cold "spells" the boxes should be brought inside. In this simple way seeds may often be started one to three weeks ahead of the time when they can be sown in the 
open garden. Moreover, the plants are likely to receive better care in these boxes, and therefore to grow more rapidly. Of course, if still earlier results are desired, the seed should be sown in the kitchen, hotbed, coldframe, or in a greenhouse. In starting plants ahead of the season, be careful not to use too deep boxes. The gardener's "flat" may be taken as a suggestion. Three inches of earth is sufficient, and in some cases (as when the plants are started late) half this depth is enough.

The difficulty with early sown seedlings is "drawing up," and weakness from crowding and want of light. This is most liable to occur with window-grown plants. Vigorous June-sown plants are better than such weaklings. It must be remembered that very early bloom usually means the shortening of the season at the other end; this may be remedied to some extent by making sowings at different times.

The "hardy" annuals are such as develop readily without the aid of artificial heat. They are commonly sown in May or earlier, directly in the open ground where they are to grow. Florists often sow certain kinds in the fall, and winter the young plants in coldframes. They may also be wintered under a covering of leaves or evergreen boughs. Some of the hardy annuals (as sweet pea) withstand considerable frost. The "half-hardy" and "tender" annuals are alike in that they require more warmth for their germination and growth. The tender kinds are very quickly sensitive to frost. Both these, like the hardy kinds, may be sown in the open ground, but not until the weather has become settled and warm, which for the tender kinds will not commonly be before the first of June; but the tender kinds, at least, are preferably started in the house and transplanted to their outdoor beds. Of course, these terms are wholly relative. What may be a tender annual in Massachusetts may be a hardy annual or even a perennial in Louisiana.

These terms as ordinarily used in this country refer to the northern states, or not farther south than middle Atlantic states. 
Some familiar examples of hardy annuals are sweet alyssum, ageratum, calendula, calliopsis, candytuft, Centaurea Cyanus, clarkia, larkspur, gilia, California poppy, morning-glory, marigold, mignonette, nemophila, pansy, phlox, pinks, poppies, portulaca, zinnia, sweet pea, scabiosa.

Examples of half-hardy annuals are: China aster, alonsoa, balsam, petunia, ricinus, stocks, balloon-vine, martynia, salpiglossis, thunbergia, nasturtium, verbena.

Examples of tender annuals: Amarantus, celosia or coxcomb, cosmos, cotton, Lobelia Erinus, cobea, gourds, ice-plant, sensitive-plant, solanums, torenia, and such things as dahlias, caladiums, and acalypha used for bedding and subtropical effects.

Some annuals do not bear transplanting well; as poppies, bartonia, Venus' looking-glass, the dwarf convolvulus, lupinus, and malope. It is best, therefore, to sow them where they are to grow.

Some kinds (as poppies) do not bloom all summer, more especially not if allowed to produce seed. Of such kinds a second or third sowing at intervals will provide a succession. Preventing the formation of seeds prolongs their life and flowering period.

A few of the annuals thrive in partial shade or where they receive sunshine for half the day; but most of them prefer a sunny situation.

Any good garden soil is suitable for annuals. If not naturally fertile and friable, it should be made so by the application of well-rotted stable-manure or humus. The spading should be at least one foot deep. The upper six inches is then to be given a second turning to pulverize and mix it. After making the surface fine and smooth the soil should be pressed down with a board. The seed may now be sprinkled on the soil in lines or concentric circles, according to the method desired. After covering the seed, the soil should be again pressed down with a 
board. This promotes capillarity, by which the surface of the soil is better supplied with moisture from below. Always mark with a label the kind and position of all seed sown.

If the flowers are to be grown about the edges of the lawn, make sure that the grass roots do not run underneath them and rob them of food and moisture. It is well to run a sharp spade deep into the ground about the edges of the bed every two or three weeks for the purpose of cutting off any grass roots that may have run into the bed. If beds are made in the turf, see that they are $3 \mathrm{ft}$. or more wide, so that the grass roots will not undermine them. Against the shrub borders, this precaution may not be necessary. In fact, it is desirable that the flowers fill all the space between the overhanging branches and the sod.

It is surprising how few of the uncommon or little known annuals really have great merit for general purposes. There is nothing yet to take the place of the old-time groups, such as amaranths, zinnias, calendulas, daturas, balsams, annual pinks, candytufts, bachelor's buttons, wallflowers, larkspurs, petunias, gaillardias, snapdragons, coxcombs, lobelias, coreopsis or calliopsis, California poppies, four-o'clocks, sweet sultans, phloxes, mignonettes, scabiosas, nasturtiums, marigolds, China asters, salpiglossis, nicotianas, pansies, portulacas, castor beans, poppies, sunflowers, verbenas, stocks, alyssums, and such good old running plants as scarlet runners, sweet peas, convolvuluses, ipomeas, tall nasturtiums, balloon vines, cobeas. Of the annual vines of recent introduction, the Japanese hop has at once taken a prominent place for the covering of fences and arbors, although it has no floral beauty to recommend it.

For bold mass-displays of color in the rear parts of the grounds or along the borders, some of the coarser species are desirable. Good plants for such use are: sunflower and castor bean for the back rows; zinnias for bright effects in the scarlets and lilacs; African marigolds for brilliant yellows; nicotianas for whites. Unfortunately, we have no robust-growing annuals with good 
blues. Some of the larkspurs and the browallias are perhaps the nearest approach to them.

For lower-growing and less gross mass-displays, the following are good: California poppies for oranges and yellows; sweet sultans for purples, whites, and pale yellows; petunias for purples, violets, and whites; larkspurs for blues and violets; bachelor's buttons (or cornflowers) for blues; calliopsis and coreopsis and calendulas for yellows; gaillardias for red-yellows and orange-reds; China asters for many colors.

For still less robustness, good mass-displays can be made with the following: alyssums and candytufts for whites; phloxes for whites and various pinks and reds; lobelias and browallias for blues; pinks for whites and various shades of pink; stocks for whites and reds; wallflowers for brown-yellows; verbenas for many colors.

A garden of pleasant annual flowers is not complete that does not contain some of the "everlastings" or immortelles. These "paper flowers" are always interesting to children. They are not so desirable for thə making of "dry bouquets" as for their value as a part of a garden. The colors are bright, the blooms hold long on the plant, and most of the kinds are very easy to grow. My favorite groups are the different kinds of xeranthemums and helichrysums. The globe amaranths, with clover-like heads (sometimes known as bachelor's buttons), are good old favorites. Rhodanthes and acrocliniums are also good and reliable.

The ornamental grasses should not be overlooked. They add a note to the flower-garden and to bouquets that is distinct and can be secured by no other plants. They are easily grown. Some of the good annual grasses are Agrostis nebulosa, the brizas, Bromus brizoformis, the species of eragrostis and pennisetums, and Coix Lachryma as a curiosity. Such good lawn grasses as arundo, pampas-grass, eulalias, and erianthus are perennials and are therefore not included in this discussion. 
Some of the most reliable and easily grown annuals are given in the following lists (under the common trade names).

\section{List of annuals by color of flowers.}

\section{White Flowers}

Ageratum Mexicanum album.

Alyssum, common sweet; compacta.

Centranthus macrosiphon albus.

China asters.

Convolvulus major.

Dianthus, Double White Margaret.

Iberis amara; coronaria, White Rocket.

Ipomœa hederacea.

Lavatera alba.

Malope grandiflora alba.

Matthiola (Stocks), Cut and Come Again; Dresden Perpetual; Giant

Perfection; White Pearl.

Mirabilis longiflora alba.

Nigella.

Phlox, Dwarf Snowball; Leopoldii.

Poppies, Flag of Truce; Shirley; The Mikado.

Zinnia.

Cacalia lutea.

\section{Yellow and Orange Flowers}

Calendula officinalis, common; Meteor; sulphurea; suffruticosa.

Calliopsis bicolor marmorata; cardaminefolia; elegans picta.

Cosmidium Burridgeanum.

Erysimum Perofskianum.

Eschscholtzia Californica.

Hibiscus Africanus; Golden Bowl.

Ipomœa coccinea lutea.

Loasa tricolor.

Tagetes, various kinds.

Thunbergia alata Fryeri; aurantiaca.

Tropæolum, Dwarf, Lady Bird; Tall, Schulzi.

Zinnia. 
Blue and Purple Flowers

Ageratum Mexicanum; Mexicanum, Dwarf.

Asperula setosa azurea.

Brachycome iberidifolia.

Browallia Czerniakowski; elata.

Centaurea Cyanus, Victoria Dwarf Compact; Cyanus minor.

China asters of several varieties.

Convolvulus minor; minor unicaulis.

Gilia achilleæfolia; capitata.

Iberis umbellata; umbellata lilacina.

Kaulfussia amelloides; atroviolacea.

Lobelia Erinus; Erinus, Elegant.

Nigella.

Phlox variabilis atropurpurea.

Salvia farinacea.

Specularia.

Verbena, Black-blue; cærulea; Golden-leaved.

Whitlavia gloxinioides.

Abromia umbellata.

Red and Rose-red Flowers

Alonsoa grandiflora.

Cacalia, Scarlet.

Clarkia elegans rosea.

Convolvulus tricolor roseus.

Dianthus, Half Dwarf Early Margaret; Dwarf Perpetual; Chinensis.

Gaillardia picta.

Ipomœa coccinea; volubilis.

Matthiola annuus; Blood-red Ten Weeks; grandiflora, Dwarf.

Papaver (Poppy) cardinale; Mephisto.

Phaseolus multiflorus.

Phlox, Large-flowering Dwarf; Dwarf Fireball; Black Warrior. Salvia coccinea.

Saponaria.

Tropæolum, Dwarf, Tom Thumb.

Verbena hybrida, Scarlet Defiance.

Zinnia. 
Useful annuals for edgings of beds and walks, and for ribbon-beds.

Ageratum, blue and white.

Alyssum, sweet.

Brachycome.

Calandrinia.

Clarkia.

Collinsias.

Dianthuses or pinks.

Gilia.

Gypsophila muralis.

Iberis or candytufts.
Leptosiphons.

Lobelia Erinus.

Nemophilas.

Nigellas.

Portulaca or rose moss (Fig. 243) Saponaria Calabrica.

Specularia.

Torenia.

Whitlavia.

\section{Annuals that continue to bloom after frost.}

This list is compiled from Bulletin 161, Cornell Experiment Station. Several hundred kinds of annuals were grown at this station (Ithaca, N.Y.) in 1897 and 1898. The notes are given in the original trade names under which the seedsmen supplied the stock.

Abronia umbellata.

Adonis æstivalis ; autumnale.

Argemone grandiflora.

Calendulas.

Callirrhoë.

Carduus benedictus.

Centaurea Cyanus.

Centauridium.

Centranthus macro-

Cerinthe retorta. [siphon.

Cheiranthus Cheiri.

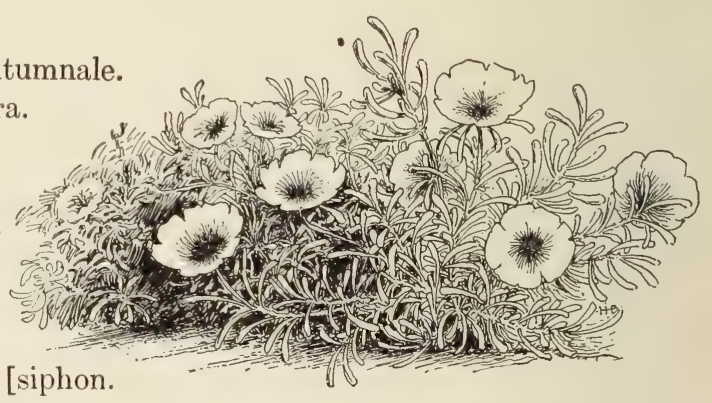

243. Portulaca, or rose moss.

Chrysanthemums.

Convolvulus minor; tricolor.

Dianthus of various kinds.

Elsholtzia cristata. 
Erysimum Perofskianum; Arkansanum.

Eschscholtzias, in several varieties (Fig. 249).

Gaillardia picta.

Gilia achilleæfolia ; capitata ; laciniata ; tricolor.

Iberis affinis.

Lavatera alba.

Matthiolas or stocks.

Enothera rosea ; Lamarckiana ;

Phlox Drummondii. [Drummondii.

Podolepis affinis; chrysantha.

Salvia coccinea; farinacea; Horminum.

Verbenas.

Vicia Gerardi.

Virginian stocks.

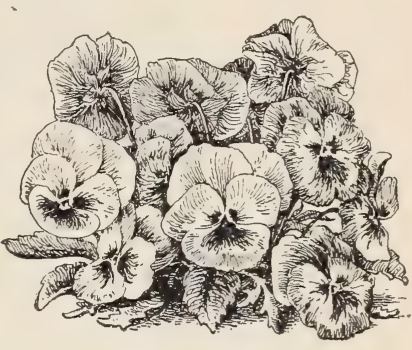

244. Pansies.

Viscaria elegans; oculata; Coeli-rosa.

List of annuals suitable for bedding (that is, for " mass effects" of color).

A list of this kind is necessarily both incomplete and imperfect, because good new varieties are frequently appearing, and the taste of the gardener must be consulted. Any plants may be used, broadly speaking, for bedding; but the following list (given in terms of trade names) suggests some of the best subjects to use when beds of solid, strong color are desired.

Adonis æstivalis; autumnalis.

Ageratum Mexicanum; Mexicanum, Dwarf.

Bartonia aurea.

Cacalia.

Calendula officinalis, in several forms; pluvialis;. Pongei; sulphurea, fl. pl. ; suffruticosa.

Calliopsis bicolor marmorata; cardaminefolia; elegans picta.

Callirrhoë involucrata; pedata; pedata nana.

Centaurea Americana; Cyanus, Victoria Dwarf Compact; Cyanus minor; suaveolens.

China asters.

Chrysanthemum Burridgeanum; carinatum; coronarium; tricolor. 
Convolvulus minor; tricolor.

Cosmidium Burridgeanum.

Delphinium, single; double.

Dianthus, Double White Half Dwarf Margaret; Dwarf Perpetual;

Caryophyllus semperflorens; Chinensis, double; dentosus hybridus; Heddewigii; imperialis; laciniatus, Salmon Queen; plumarius; superbus, dwarf fl. pl.; picotee.

Elsholtzia cristata.

Eschscholtzia Californica; crocea; Mandarin; tenuifolia (Fig. 249). Gaillardia picta ; picta Lorenziana.

Gilia achilleæfolia ; capitata ; laciniata ; linifolia ; nivalis ; tricolor. Godetia Whitneyi ; grandiflora maculata ; rubicunda splendens. Hibiscus Africanus; Golden Bowl.

Iberis affinis ; amara ; coronaria ; umbellata.

Impatiens or balsam.

Lavatera alba ; trimestris.

Linum grandiflorum.

Madia elegans.

Malope grandiflora.

Matricaria eximia plena.

Matthiola or stock, in many forms; Wallflower-leaved; bicornis.

Nigella, or Love-in-a-mist.

Enothera Drummondii ; Lamarckiana ; rosea ; tetraptera.

Papaver or poppy, of many kinds; cardinale; glaucum; umbrosum.

Petunia, bedding kinds.

Phlox Drummondii, in many varieties.

Portulaca (Fig. 243).

Salvia farinacea ; Horminum; splendens.

Schizanthus papilionaceus; pinnatus.

Silene Armeria ; pendula.

Tagetes, or marigold, in many forms; erecta; patula ; signata. Tropæolum, Dwarf.

Verbena auriculæflora; Italica striata; hybrida; cærulea; Goldenleaved.

Viscaria Cœli-rosa; elegans picta; oculata.

Zinnia, Dwarf; elegans alba; Tom Thumb; Haageana; coccinea plena (Fig. 247). 


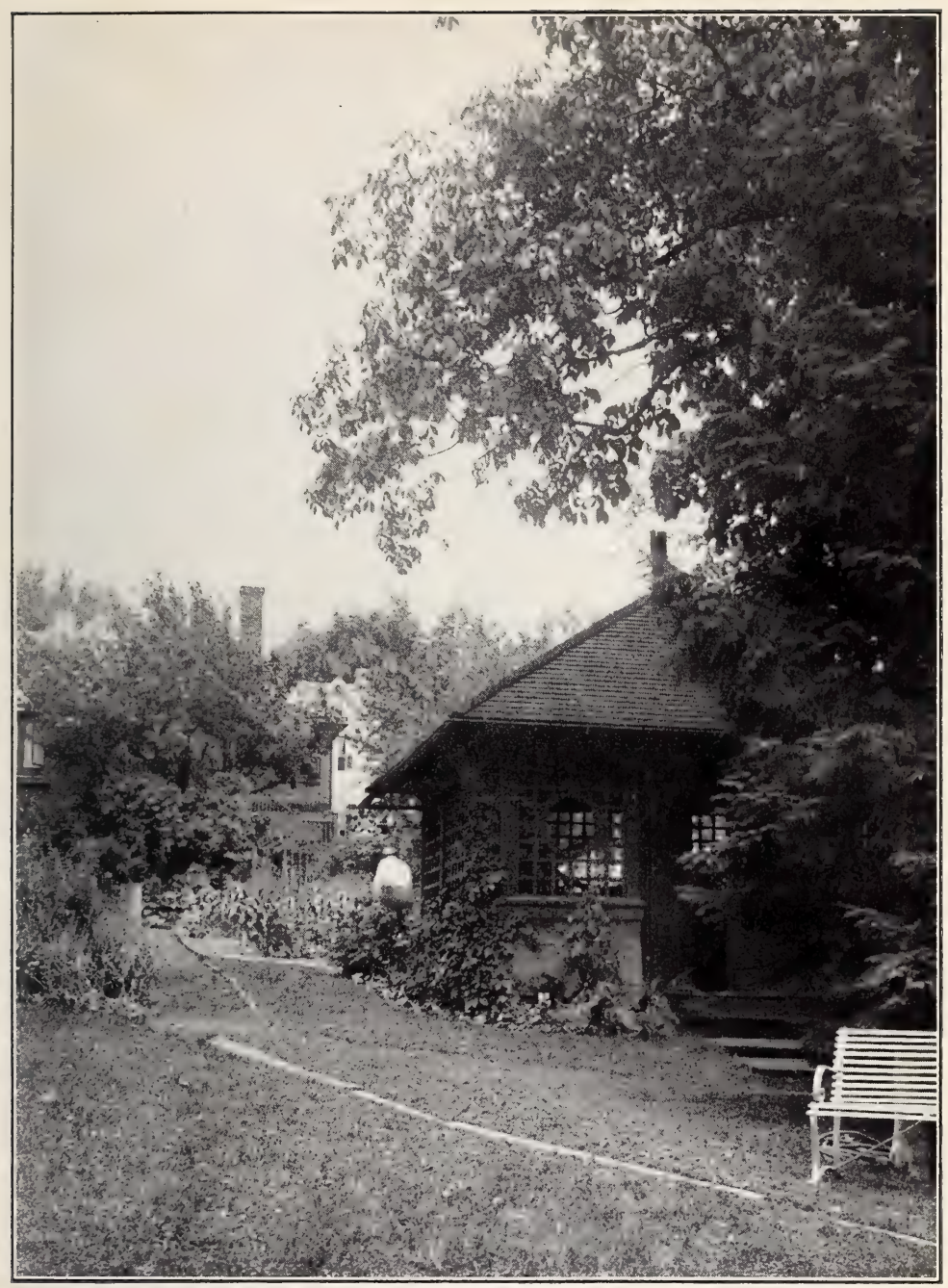

XI. A back yard with summer house, and gardens beyond. 



\section{List of annuals by height.}

It is obviously impossible to make any accurate or definite list of plants in terms of their height, but the beginner may be aided by approximate measurements. The following lists are made from Bulletin 161 of the Cornell Experiment Station, which gives tabular data on many annuals grown at Ithaca, N.Y. Seeds of most of the kinds were sown in the open, rather late. "The soil varied somewhat, but it was light and well tilled, and only moderately rich." Ordinary good care was given the plants. The average height of the plants of each kind at full growth, as they stood on the ground, is given in these lists. Of course, these heights might be less or more with different soils, different treatments, and different climates; but the figures are fairly comparable among themselves.

The measurements are based on the stock supplied by leading seedsmen under the trade names here given. It is not unlikely that some of the discrepancies were due to mixture of seed or to stock being untrue to type; some of it may have been due to soil conditions. The same name may be found in two divisions in some instances, the plants having been grown from different lots of seeds. The lists will indicate to the grower what variations he may expect in any large lot of seeds.

Seedsmen's catalogues should be consulted for what the trade considers to be the proper and normal heights for the different plants.

\section{Plants 6-8 in. high}

Abronia umbellata grandiflora.

Alyssum compactum.

Callirrhoë involucrata.

Godetia, Bijou, Lady Albemarle, and Lady Satin Rose.

Gypsophila muralis.

Kaulfussia amelloides.

Leptosiphon hybridus. 
Linaria Maroccana.

Lobelia Erinus and Erinus Elegant.

Nemophila atomaria, discoidalis, insignis, and rnaculata.

Nolana lanceolata, paradoxa, prostrata, and atriplicifolia.

Podolepis chrysantha and affinis.

Portulaca.

Rhodanthe Manglesii.

Sedum cæruleum.

Silene pendula ruberrima.

Verbena.

Alyssum.

Plants $9-12$ in. high

Asperula setosa azurea.

Brachycome iberidifolia.

Calandrinia umbellata elegans.

Callirrhoë pedata nana.

Centaurea Cyanus Victoria Dwarf Compact.

Centranthus macrosiphon nanus.

Collinsia bicolor, candidissima and multicolor marmorata.

Convolvulus minor and tricolor.

Eschscholtzia crocea.

Gamolepis Tagetes.

Gilia laciniata and linifolia.

Godetia Duchess of Albany, Prince of Wales, Fairy Queen, Brilliant, grandiflora maculata, Whitneyi, Duke of Fife, rubicunda splendens Helipterum corymbiflorum.

Iberis affinis.

Kaulfussia amelloides atroviolacea, and a. kermesina.

Leptosiphon androsaceus and densiflorus.

Linaria bipartita splendida.

Matthiola dwarf Forcing Snowflake, Wallflower-leaved.

Mesembryanthemum crystallinum.

Mimulus cupreus.

Nemophila atomaria oculata and marginata.

Nigella.

Nolana atriplicifolia.

Omphalodes linifolia. 
Enothera rosea and tetraptera.

Phlox, Large-flowering Dwarf and Dwarf Snowball.

Rhodanthe maculata.

Saponaria Calabrica.

Schizanthus pinnatus.

Silene Armeria and pendula.

Specularia.

Viscaria oculata cærulea.

Plants $13-17$ in. high

Abronia umbellata.

Acroclinium album and roseum.

Brachycome iberidifolia alba.

Browallia Czerniakowski and elata.

Cacalia.

Calandrinia grandiflora.

Calendula sulphurea flore pleno.

Chrysanthemum carinatum.

Collomia coccinea.

Convolvulus minor and minor unicaulis.

Dianthus, the Margaret varieties, Dwarf Perpetual, Caryophyllus semperflorens, Chinensis, dentosus hybridus, Heddewigii, imperialis, laciniatus, plumarius, superbus dwarf, picotee, Comtesse de Paris.

Elsholtzia cristata.

Eschscholtzia Californica, Mandarin, maritima and tenuifolia.

Gaillardia picta.

Gilia achilleæfolia alba and nivalis.

Helipterum Sanfordii.

Hieracium, Bearded.

Iberis amara, coronaria Empress, coronaria White Rocket, Sweetscented, umbellata, umbellata carnea, and umbellata lilacina.

Leptosiphon carmineus.

Lupinus nanus, sulphureus.

Malope grandiflora.

Matthiola, Wallflower-leaved and Virginian stock.

Mirabilis alba.

Nigella. 
Enothera Lamarckiana.

Palafoxia Hookeriana.

Papaver, Shirley and glaucum.

Petunia.

Phlox of many kinds.

Salvia Horminum.

Schizanthus papilionaceus.

Statice Thouini and superba.

Tagetes, Pride of the Garden and Dwarf.

Tropæolum, many kinds of dwarf.

Venidium calendulaceum.

Verbena of several kinds.

Viscaria Coli-rosa, elegans picta, oculata, and oculata alba. Whitlavia gloxinioides.

\section{Plants 18-23 in. high}

Adonis æstivalis and autumnalis.

Amarantus atropurpureus.

Calendula officinalis, Meteor, suffruticosa, and pluvialis.

Calliopsis bicolor marmorata.

Callirrhoë pedata.

Centaurea Cyanus minor Blue and suaveolens.

Centranthus macrosiphon.

Chrysanthemum Burridgeanum, carinatum, tricolor Dunnettii.

Cosmidium Burridgeanum.

Delphinium (annual).

Eutoca Wrangeliana.

Gaillardia picta (Fig. 245), Lorenziana.

Gilia achilleæfolia, a. rosea and tricolor.

Helichrysum atrosanguineum.

Ipomœea coccinea.

Linum grandiflorum.

Loasa tricolor.

Lupinus albus, hirsutus and pubescens.

Malope grandiflora alba.

Matricaria eximia plena.

Matthiola, several kinds. 
Enothera Drummondii.

Paparer Ilephisto, cardinale, c. hybridum, c. Danebrog, umbrosum.

Tagetes patula and signata.

Vicia Gerardii.

Whitlavia grandiflora and g. alba.

Xeranthemum album and multiflorum album.

Zinnias of many kinds (all not mentioned in other lists).

\section{Plants 24-30 in. high}

Bartonia aurea.

Calendula officinalis fl. pl., Prince of Orange and Pongei.

Calliopsis elegans picta.

Cardiospermum Halicacabum.

Carduus benedictus.

Centaurea Cyanus minor Emperor William.

Cheiranthus Cheiri.

Chrysanthemum tricolor, t. hybridum and coronarium sulphureum fl. pl.

Clarkia elegans rosea.

Datura cornucopia.

Erysimum Arkansanum and Perofskianum.

Eutoca viscida.

Gilia capitata alba.

Helichrysum bracteatum and macranthum.

Hibiscus Africanus.

Impatiens, all varieties.

Lupinus hirsutus pilosus.

Matthiola Blood-red Ten Weeks, Cut and Come Again, grandiflora, annuus, and others.

Mirabilis Jalapa folio variegata and longiflora alba.

Papaver, American Flag, Mikado and Double.

Perilla laciniata and Nankinensis.

Salvia farinacea.

Tagetes Eldorado, Nugget of Gold, erecta fl. pl.

Xeranthemum annuum and superbissimum fl. pl.

Zinnia elegans alba fl. pl. 


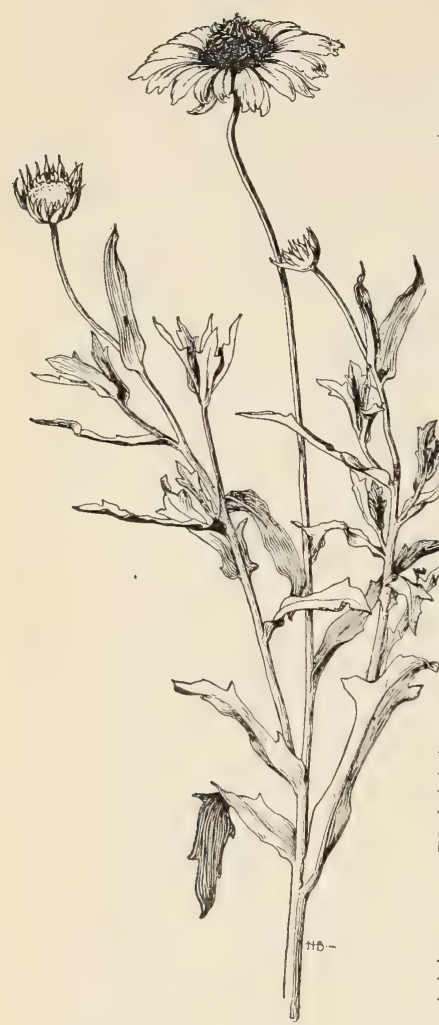

245. Gaillardia, one of the showy garden annuals.

Distances for planting annuals

(or plants treated as annuals).

Only an approximate idea can be given of the distances apart at which annuals should be planted, for not only does the distance depend on the fertility of the land (the stronger the soil the greater the distance), but also on the object the person has in growing the plants, whether to produce a solid 
mass effect or to secure strong specimen plants with large individual bloom. If specimen plants are to be raised, the distances should be liberal.

The distances here given for some of the commoner annuals may be considered to represent average or usual spaces that single plants may occupy under ordinary conditions in flowerbeds, although it would probably be impossible to find any two gardeners or seedsmen who would agree on the details. These are suggestions rather than recommendations. It is always well to set or sow more plants than are wanted, for there is danger of loss from cut-worms and other causes. The general tendency is to let the plants stand too close together at maturity. In case of doubt, place plants described in books and catalogues as very dwarf at six inches, those as medium-sized at twelve inches, very large growers at two feet, and thin them out if they seem to demand it as they grow.

The plants in these lists are thrown into four groups (rather than all placed together with the numbers after them) in order to classify the subject in the beginner's mind.

\section{6 to 9 inches apart}

Ageratum, very dwarf kinds. .

Alyssum.

Asperula setosa.

Cacalia.

Candytuft.

Clarkia, dwarf.

Collinsia.

Gysophila muralis.

Kaulfussia.

Larkspur, dwarf kinds.

Linaria.

Linum grandiflorum.

Lobelia Erinus. Mignonette, dwarf kinds.

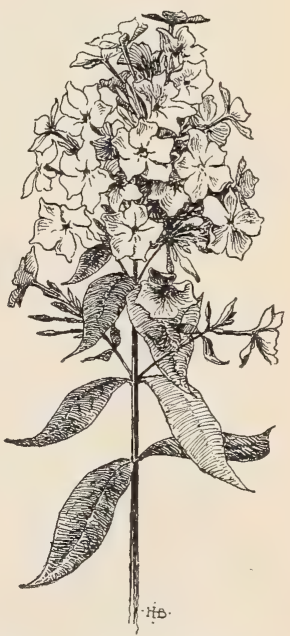

246. Wild phlox $(P$. maculata), one of the parents of the perennial garden phloxes. 


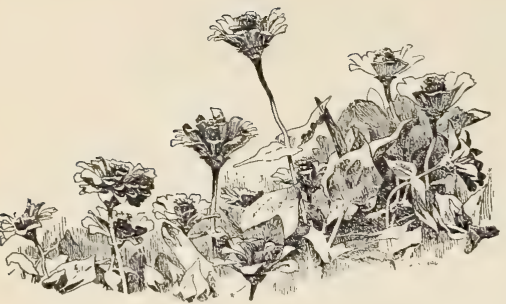

247. Zinnias. Often known as "youth and old age."

Pansy.

Phlox, very dwarf kinds.

Pinks, very dwarf kinds.

Rhodanthe.

Schizopetalon.

Silene Armeria.

Snapdragon, dwarf.

Sweet pea.

Torenia.

10 to 15 inches apart

Those marked (ft.) are examples of plants that may usually stand at twelve inches.

Abronia (ft.).

Acroclinium.

Adlumia.

Adonis autumnalis.

Ageratum, tall kinds.

Alonsoa.

Aster, China, smaller kinds (ft.).

Balsam.

Bartonia.

Browallia.

Calendula.

California poppy (Eschscholtzia).

Calliopsis.

Cardiospermum.

Carnation, flower-garden kinds

Celosia, small kinds.

[ft.).

Centaurea Cyanus.

Centauridium (ft.).

Centranthus (ft.).

Clarkia, tall (ft.).

Convolvulus tricolor (ft.).

Gaillardia, except on strong land.

Gilias.

Glaucium.

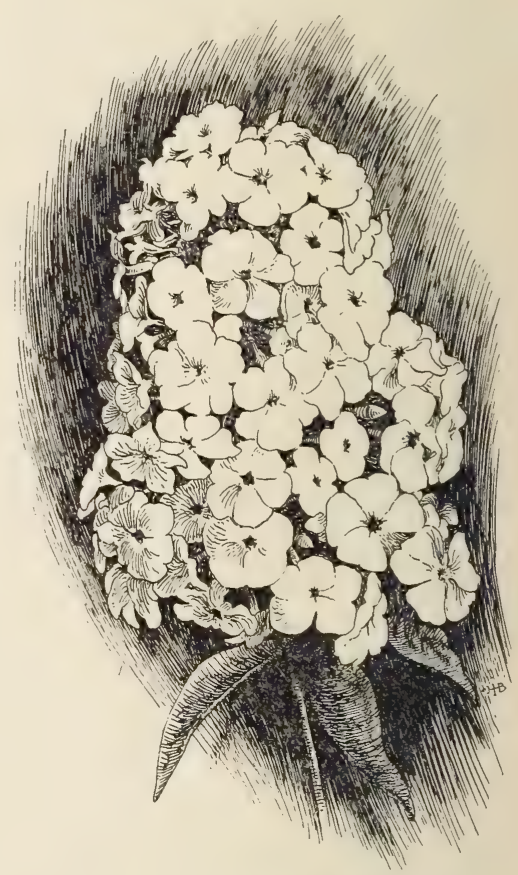

248. Improved perennial phlox.

Godetia (ft.). 
Gomphrena.

Gypsophila elegans.

Helichrysum (ft.).

Hunnemannia.

Jacobæa. [kinds.

Larkspur, tall annual Malope. [varieties. Marigold, intermediate Mignonette, tall kinds. Mesembryanthemum (ice-plant) (ft.).

Morning-glory.

Nasturtium, dwarf.

Nemophila.

Nigella.

Petunia.

Phlox Drummondii.

Pinks.

Poppies (6 to 18 in., according to variety).

Portulaca (ft.).

Salpiglossis (ft.).

Scabiosa (ft.).

Schizanthus.

Snapdragon, tall kinds.

Statice (ft.).

Stock (ft.).

Tagetes, dwarf French.

Thunbergia (ft.).

Verbena.

Whitlavia (ft.). [(ft.).
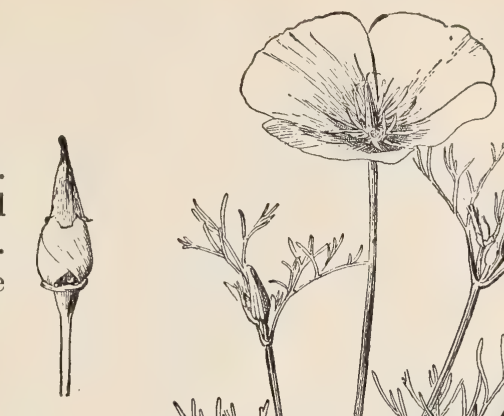
Canterbury bell (up to $3 \mathrm{ft}$.).

Celosia, large kinds (up to 30 in.).

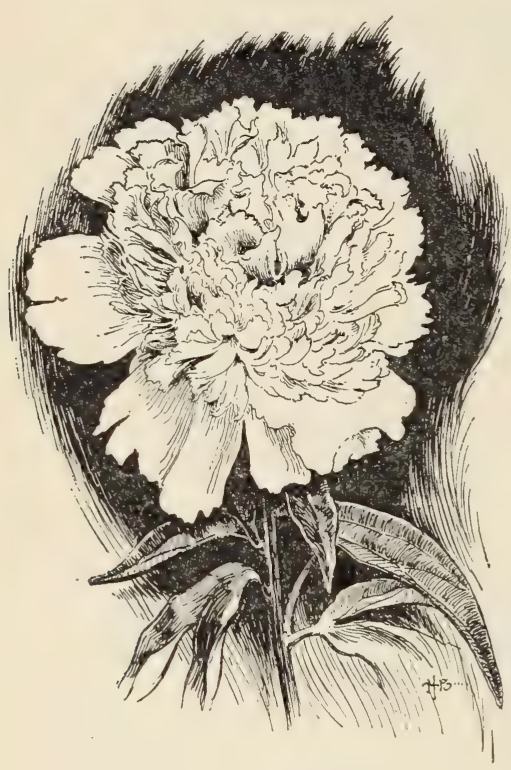

250. A modern peony.
Chrysanthemum, annual.

Cosmos, smaller kinds.

Euphorbia marginata.

Four o'clock (up to 30 in.)

Hop, Japanese. [to 30 in.).

Kochia, or summer cypress (up

Marigold, tall kinds.

Nasturtium, tall, if allowed to spread on the ground.

Nicotiana (up to 30 in.).

Enothera, tall kinds.

Salvia coccinea (splendens grandiflora), about $2 \mathrm{ft}$. Zinnia, tall kinds ( $\mathrm{u}$ ) to $3 \mathrm{ft}$ ).

\section{About 3 fect or more}

Caladium.

Cosmos, tall kinds (2 to $3 \mathrm{ft}$.).

Dahlia.

Datura.

Martynia.

Ricinus or castor bean.

Solanums.

Sunflower, tall kinds.

Wigandia.

\section{Hardy Herbaceous Perennials}

There is a rapidly growing appreciation of perennial herbs, not only as flower-garden and lawn subjects, but as parts of native landscapes. Every locality yields its wild asters, goldenrods, columbines, iris, trilliums, lilies, anemones, pentstemons, mints, sunflowers, or other plants; and many of these also make good subjects for the home grounds.

It is important to remember that some perennial herbs begin to fail after one to three seasons of full bloom. It is a good 
plan to have new plants coming on to take their place; or the old roots may be taken up in the fall and divided, only the fresh and strong parts being planted again.

Perennial herbs are propagated in various ways, - by seeds, and by cuttings of the stems and roots, but mostly by the easy method of division. On the raising of these plants from seeds, William Falconer writes as follows in Dreer's "Garden Book" for 1909:

"Hardy perennials are easily grown from seed. In many cases they are a little slower than annuals, but with intelligent care they are successfully raised, and from seed is an excellent way to get up a big stock of perennials. Many sorts, if sown in spring, bloom the first year from seeds as early as annuals; for instance: gaillardia, Iceland poppies, Chinese larkspur, platycodon, etc. Others do not bloom until the second year.

"The amateur may have more success and less bother growing perennials from seed sown in the open ground than from any other way. Prepare a bed in a nice, warm, sheltered spot in the garden, preferably not very sunny. Let the surface of the bed be raised four or five inches above the general level, and the soil be a mellow fine earth on the surface. Draw shallow rows across the surface of the bed three or four inches apart, and here sow the seeds, keeping the varieties of one kind or nature as much together as practicable, covering the seeds thinly; press the whole surface gently, water moderately, then dust a little fine loose soil over all. If the weather is sunny or windy, shade with papers or a few branches, but remove these in the evening. When the seedlings come up, thin them out to stiffen those that are left, and when they are two or three inches high, they are fit for transplanting into permanent quarters. All this should be done in early spring, say March, April, or May. Again, in July or August perennials are very easily raised out of doors, and much in the same way as above. Or 
they may be sown in early spring indoors, in the window, the hotbed, the coldframe, or the greenhouse, preferably in boxes or pans, as for growing annuals. Some gardeners sow seed right in the coldframe. I have tried both ways, and find the boxes best, as the different varieties of seeds do not come up at the same time, and you can remove them from the close frame to more airy quarters as soon as the seed comes up, whereas, if sown in a frame, you would have to give them all the same treatment. When the seedlings are large enough, I transplant them into other boxes, and put them into a shady part of the garden, but not under the shade of trees, as there they will 'draw' too much. About the fifteenth of September plant them in the garden where they are to bloom, or if the garden is full of summer-flowering plants, put them in beds in the vegetable garden, to be planted out in the early spring, and give them a light covering of straw or manure to keep sudden changes of the weather away from them."

Hardy perennial herbs may be planted in September and October with excellent results; also in spring. See that they are protected with mulch in winter.

\section{Perennial herbs suitable for lawn and "planting" effects.}

Some of the striking plants that are valuable for lawn planting in the North, chosen chiefly on account of their size, foliage, and habit, are mentioned in the following brief list. They may or may not be suitable for flower-gardens. It is impossible to give to this list any degree of completeness; but the names here printed will be suggestive of the kinds of things that may be used. The asterisk $(*)$ denotes native plants.

Yucca, Yucca filamentosa.*

Funkia, Funkia, of several species.

Peltate saxifrage, Saxifraga peltata.*

Rose mallow, Hibiscus Moscheutos.* 
Elecampane, Inula Helenium (Fig. 251).

Wild sunflowers, Helianthus $*$ of different species, especially $H$. orygalis, $H$. giganteus, $H$. grosse-serratus, $H$. strumosus.

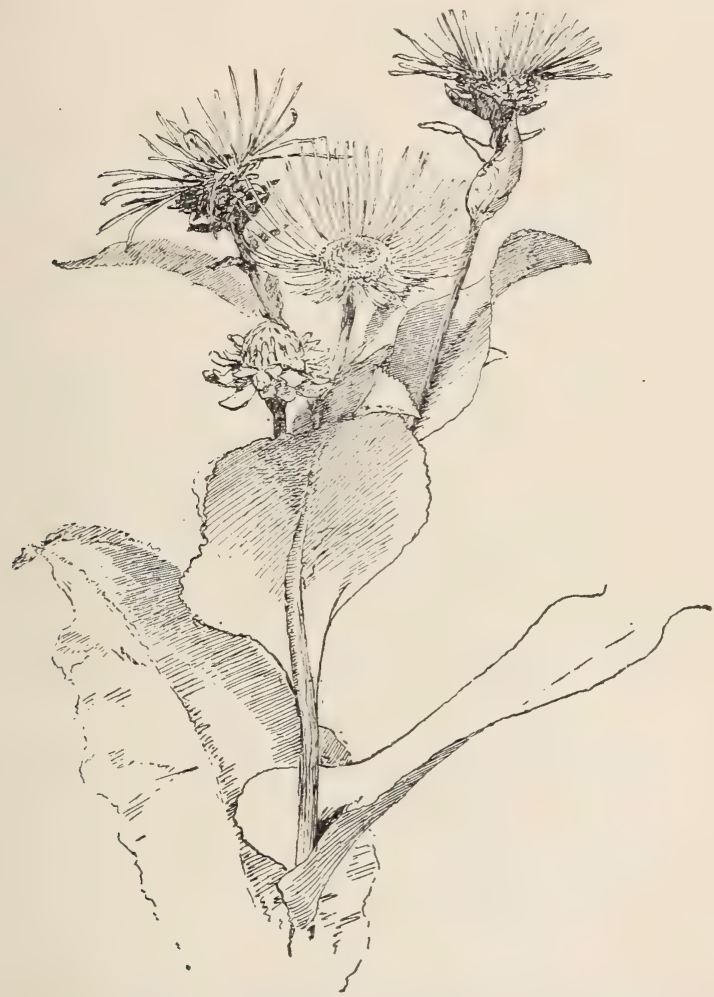

251. Elecampane. Naturalized in old fields and along roadsides.

Compass-plants, Silphium* of several species, especially S. terebin. thinaceum, S. laciniatum, S. perfoliatum.

Sacaline, Polygonum Sachalinense.

Japanese knotweed, Polygonum cuspidatum.

Bocconia, Bocconia cordata.

Wild wormwood, Arterrisia Stelleriana* and others. 
Butterfly-weed, Asclepias tuberosa.*

Wild asters, Aster* of many species, especially A. Nova-Anglice (best), A. lowis, $A$. multiflorus, $A$. spectabilis.

Golden-rods, Solidago* of various species, especially S. speciosa, S. nemoralis, $S$. juncea, $S$. gigantea.

Loose-strife, Lythrum Salicaria.

Flags, Iris of many species, some native.

Japanese wind-flower, Anemone Japonica.

Goat's beard, Aruncus sylvester (Spircea Aruncus).*

Baptisia, Baptisia tinctoria.*

Thermopsis, Thermopsis mollis.*

Wild senna, Cassia Marilandica.*

Wild trefoil, Desmodium Canadense* and others.

Ribbon grass, Phalaris arundinacea* var. picta.

Zebra grass, Eulalia (or Miscanthus) species, and varieties.

Wild panic grass, Panicum virgatum.*

Bambusas (and related things) of several sorts.

Ravenna grass, Erianthus Ravennoe.

Arundo, Arundo Donax, and var. variegata.

Reed, Phragmites communis.*

This and the remaining plants of the list should be planted in the edges of water or in bogs (the list might be greatly extended).

Wild rice, Zizania aquatica.*

Cat-tail, Typha angustifolia* and T. latifolia.*

Lizard's-tail, Saururus cernuцs.*

Peltandra, Peltandra undulata.*

Orontium, Orontium aquaticum.*

Native calla, Calla palustris.*

A brief seasonal flower-garden or border

list of herbaceous perennials.

To facilitate making a selection of perennial herbs for bloom, the plants in the following list are arranged according to their flowering season, beginning with the earliest. The name of the month indicates when they usually begin to bloom. It should be understood that the blooming season of plants is not a fixed 
period, but varies more or less with localities and seasons. These dates are applicable to most of the middle and northern states. Natives to North America are marked with an asterisk $(*)$ This list is by Ernest Walker.

\section{MARCH}

Blue Wind-flower, Anemone blanda. 6 in. March-May. Sky-blue, star-like flowers. Foliage deeply cut. For border and rockwork. Bloodroot, Sanguinaria Canadensis.* 6 in. March-April. Pure white. Glaucous foliage. Partial shade. Border or rock-work.

\section{APRIL}

Mountain Rock-cress, Arabis albida. 6 in. April-June. Flowers pure white; close heads in profusion. Fragrant. For dry places and rock-work.

Purple Rock-cress, Aubrietia deltoidea. 6 in. April-June. Small purple flowers in great profusion.

Daisy, Bellis perennis, 4-6 in. April-July. Flowers white, pink, or red; single or double. The double varieties are the more desirable. Cover the plants in winter with leaves. May be raised from seed, like pansies.

Spring Beauty, Claytonia Virginica.* 6 in. April-May. Clusters of light pink flowers. Partial shade. From six to a dozen should be set together.

Shooting Star, Dodecatheon Meadia** $1 \mathrm{ft}$. April-May. Reddish purple flowers, orange-yellow eye, in clusters. Cool, shady location, Plant several in a place.

Dog's-bane, Doronicum plantagineum var. excelsum. 20 in. April-June. Large, showy flowers; orange-yellow. Bushy plants.

Liver-leaf, Hepatica acutiloba* and triloba** 6 in. April-May. Flowers small but numerous, varying white and pink. Partial shade.

Hardy Candytuft, Iberis sempervirens. 10 in. April-May. Small white flowers in clusters; profuse. Large, spreading, evergreen tufts. Alpine Lamp-flower, Lychnis alpina.* 6 in. April-May. Flowers star-like, in showy heads; pink. For border and rockery. 
Early Forget-me-not, Myosotis dissitiflora. 6 in. April-June. Small clusters of deep sky-blue flowers. Tufted habit.

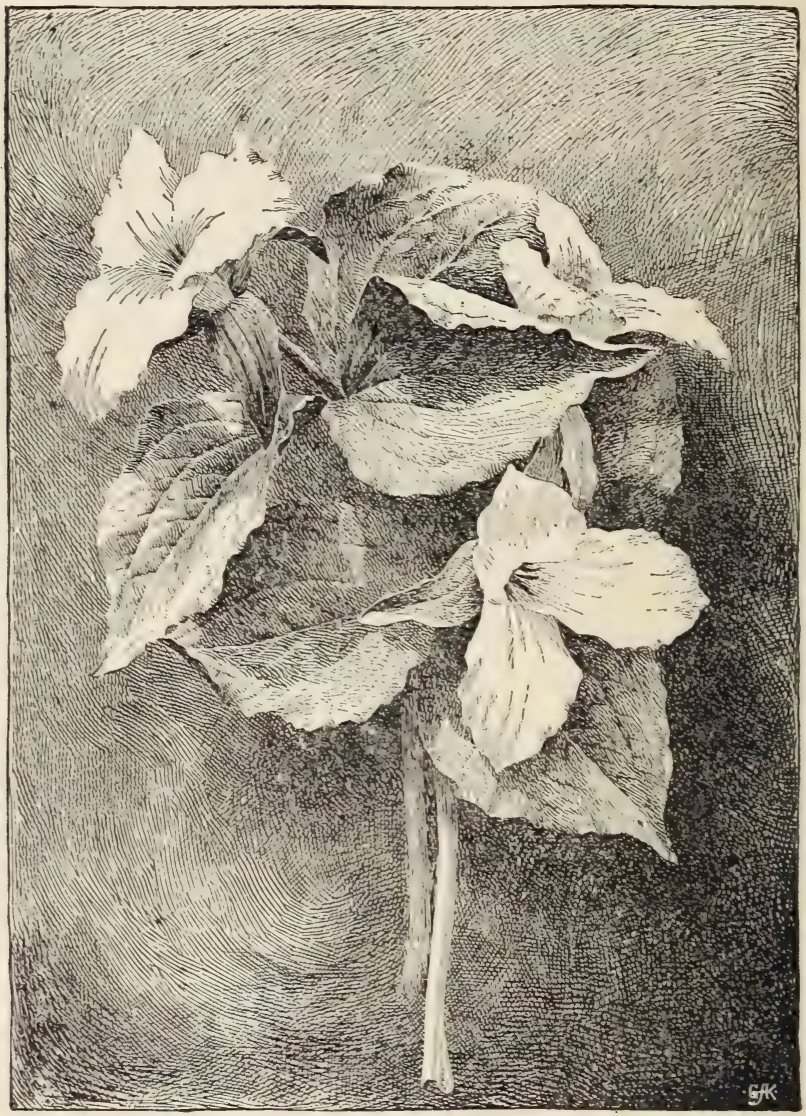

252. The wild Trillium grandiflorum.

Everblooming F., M. pai'stris var. semperflorens. 10 in. Light blue; spreading habit.

Blue-bells, Mertensia Virginıa.* $1 \mathrm{ft}$. April-May. Flowers blue, 
changing to pink; pendent; tubular; not showy, but beautiful. Rich soil. Partial shade.

Tree Peony, Pæonia Moutan. (See May, Pæonia.)

Moss Pink, Phlox subulata* 6 in. April-June. Numerous deep pink, small flowers; creeping habit; evergreen. Suitable for dry places as a covering plant.

Trilliums.* Of several species; always attractive and useful in the border (Fig. 252). They are common in rich woods and copses. Dig the tubers in late summer and plant them directly in the border. The large ones will bloom the following spring. The same may be said of the erythronium, or dog's-tooth violet or adder's tongue, and of very many other early wild flowers.

\section{MAY}

Ajuga reptans. 6 in. May-June. Spikes of purple flowers. Grows well in shady places; spreading. A good cover plant.

Madwort, Alyssum saxatile var. compactum. $1 \mathrm{ft}$. May-June. Flowers fragrant, in clusters, clear golden-yellow. Foliage silvery. Well-drained soil. One of the best yellow flowers.

Columbine, Aquilegia glandulosa and others (Fig. 253). $1 \mathrm{ft}$. May-June. Deep blue sepals; white petals. Aquilegias are old favorites. (See June.) The wild $A$. Canadensis* is desirable.

Lily-of-the-Valley, Convallaria majalis.* 8 in. May-June. Racemes of small white bells; fragrant. Well known. Partial shade. (See page 381.)

Fumitory, Corydalis nobilis. $1 \mathrm{ft}$. May-June. Large clusters of fine yellow flowers. . Bushy, upright habit. Does well in partial shade. Bleeding-Heart, Dicentra spectabilis. $2 \frac{1}{2} \mathrm{ft}$. May-June. Well known. Racemes of heart-shaped, deep pink and white flowers. Will bear partial shade.

Crested Iris, Iris cristata* 6 in. May-June. Flowers blue, fringed with yellow. Leaves sword-shaped.

German Iris, I. Germanica. $12-15$ in. May-June. Numerous varieties and colors. Large flowers, 3-4 on a stem. Broad, glaucous, sword-shaped leaves.

Peony, Proonia officinalis. $2 \mathrm{ft}$. May-June. This is the well-known herbaceous peony. There are numerous varieties and hybrids. 


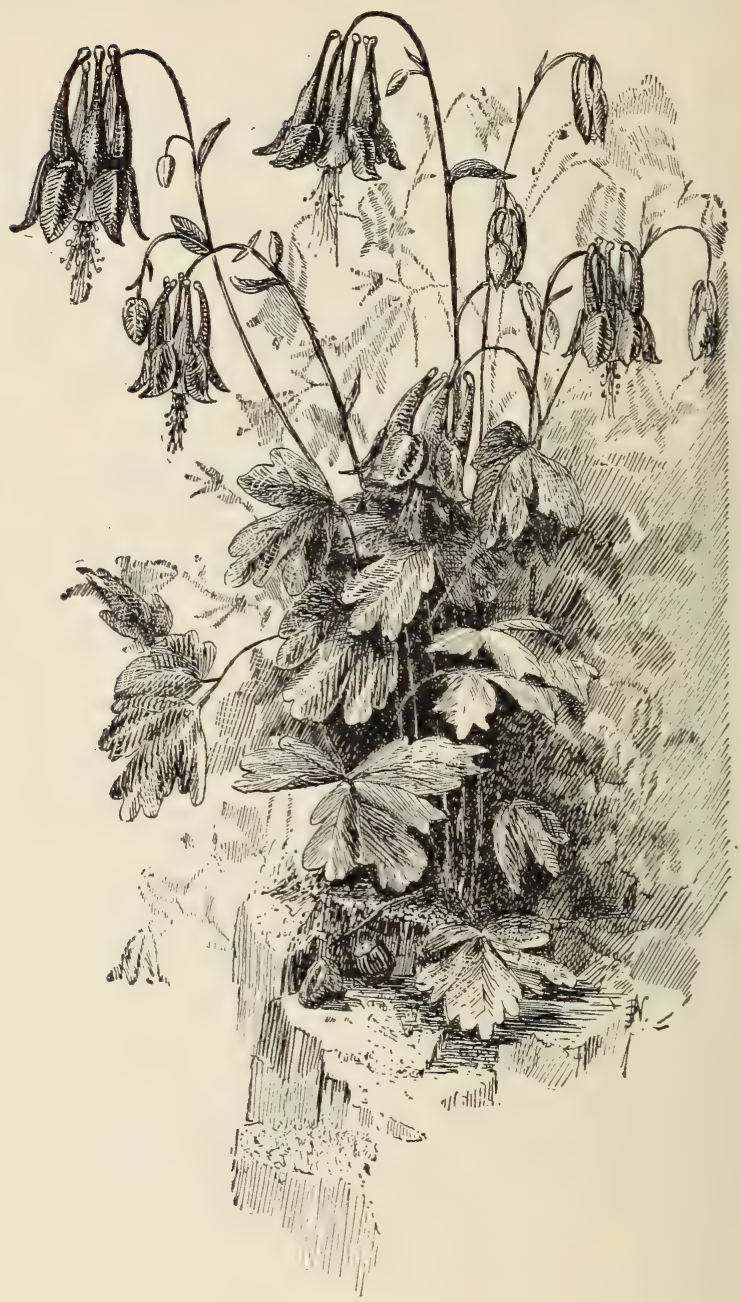

253. One of the columbines. 
Large flowers, 4-6 in. across. Crimson, white, pink, yellowish, etc. Suitable for lawn or the border. Fig. 250.

Tree Peony, P.Moutan. $4 \mathrm{ft}$. April-May. Numerous named varieties.

Flowers as above, excepting yellow. Branched, dense, shrubby habit.

Meadow Sage, Salvia pratensis. $2 \frac{1}{2}$ f . May-June, August. Spikes of deep blue flowers. Branching from the ground.

\section{JUNE}

Achillea Ptarmica, fl. pl., var. "The Pearl." $\frac{1}{2} \mathrm{ft}$. June-August. Small double white flowers, in few-flowered clusters. Rich soil. Wind-flower, Anemone Pennsylvanica.* 18 in. June-September. White flowers on long stems. Erect habit. Does well in the shade. St. Bruno's Lily, Paradisea Liliastrum: 18 in. June-July. Bell-like, white flowers in handsome spikes.

Golden-spurred Columbine, Aquilegia chrysantha.* $3 \mathrm{ft}$. June-August. Golden flowers with slender spurs; fragrant.

Rocky Mountain Columbine, A. corulea** 1 ft. June-August. Flowers with white petals and deep blue sepals, 2-3 in. in diameter. (See May.)

Woodruff, Asperula odorata. 6 in. June-July. Small white flowers. Herbage fragrant when wilted. Does well in shade; spreading habit. Used for flavoring drinks, scenting and protecting garments. Astilbe Japonica (incorrectly called Spiræa). $2 \mathrm{ft}$. June-July. Small white flowers in a feathery inflorescence. Compact habit.

Poppy Mallow, Callirrhoë involucrata.* 10 in. June-October. Large crimson flowers, with white centers. Trailing habit. For border and rockery.

Carpathian Harebell, Campanula Carpatica (Fig. 254). 8 in. JuneSeptember. Flowers deep blue. Tufted habit. For border or rockery. Good for cutting.

C. glomerata var. Dahurica. $2 \mathrm{ft}$. June-August. Deep purple flowers in terminal clusters. Branching from the ground. Erect habit.

Canterbury Bell, C. Medium. An old favorite. It is biennial, but blooms the first season if sown early.

Corydalis lutea. $1 \mathrm{ft}$. June-September. Flowers yellow, in terminal clusters. Loose branching habit. Glaucous foliage. 
Scotch Pink, Dianthus plumarius. 10 in. June-July. White and pink-ringed flowers on slender stems. Densely tufted habit.

Fringed Pink, D. superbus. 18 in. July-August. Fringed flowers. Lilac tint.

Gas Plant, Dictamnus Fraxinella. $3 \mathrm{ft}$. June. Flowers purple,

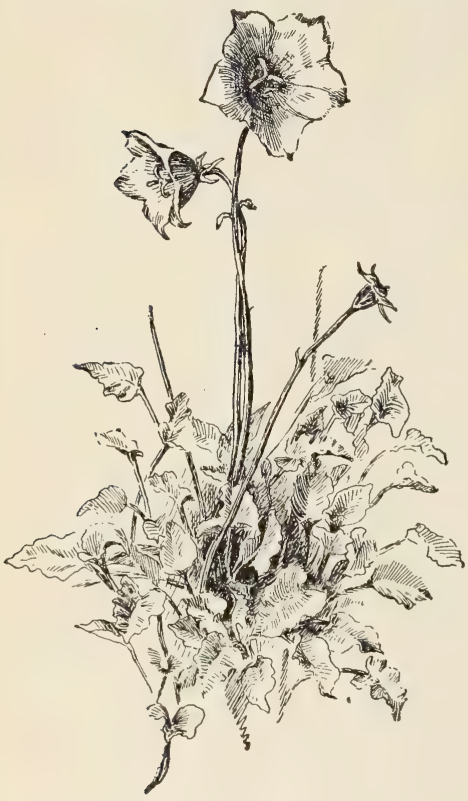

254. Campanula Carpatica. showy, fragrant; in long spikes. Regular habit. Var.alba. White. Gaillardia aristata.* $2 \mathrm{ft}$. JuneOctober. Showy orange and maroon flowers on long stems. Good for cutting. Hybrid gaillardias offer quite a variety of brilliant colors.

Heuchera sanguinea.* 18 in. JuneSeptember. Flowers in open panicles, scarlet, on clustered stems from a tufted mass of pretty foliage.

Japan Iris, Iris lavigata (I. Kampferi). 2-3 ft. June-July. Large flowers of various colors, in variety. Green, sword-likeleaves. Dense tufted habit. Prefers a moist situation.

Blazing Star, Liatris spicata** $2 \mathrm{ft}$. June-August. Spikes of fine, small purple flowers. Slender foliage. Unbranched, erect stems. Will grow in the poorest soil. Iceland Poppy, Papaver nudicaule.* $1 \mathrm{ft}$. June-October. Bright yellow flowers. A close, dense habit. Erect, naked stems. The varieties Album, white, and Miniatum, deep orange, are also desirable.

Oriental Poppy, $P$. orientale. $2-4 \mathrm{ft}$. June. Flowers $6-8$ in. across ; deep scarlet, with a purple spot at the base of each petal. There are other varieties of pink, orange, and crimson shades.

Pentstemon barbatus var. Torreyi.* 3-4 ft. June-September. Crimson flowers in long spikes. Branching from the base. Erect habit. 
• 


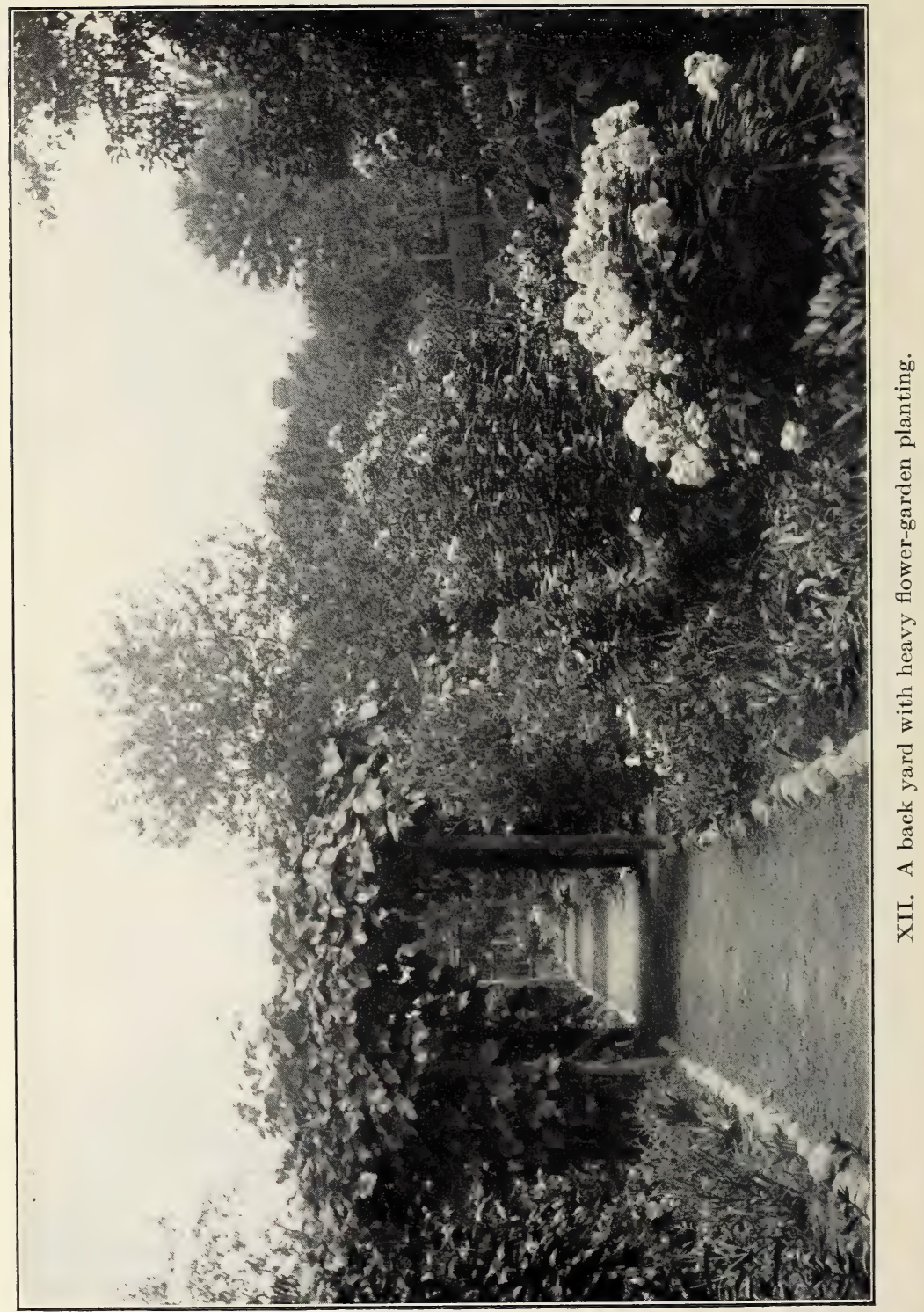


Perennial Phlox, Phlox paniculata* and hybrids with P. maculata.* 2-3 ft. June. A great variety of colors in selfs and variegated forms. Flowers borne in large, flat panicles. (Figs. 246, 248.)

Rudbeckia maxima.* 5-6 ft. August. Large flowers ; cone-like center and long, drooping, yellow petals.

Dropwort, Ulmaria Filipendula. $3 \mathrm{ft}$. June-July. White flowers in compact clusters. Tufted foliage, dark green and handsomely cut. Erect stems. (Often referred to Spiræa.)

Adam's Needle, Yucca filamentosa.* 4-5ft. June-July. Waxen white, pendulous, liliaceous flowers in a great thyrsus. Leaves long, narrow, dark green, with marginal filaments. For the lawn, and for massing in large grounds.

\section{JULY}

Hollyhock, Althoe rnsea. 5-8 ft. Summer and fall. Flowers white, crimson, and yellow, lavender and purple. Stately plants of spirelike habit; useful for the back of the border, or beds and groups. The newer double varieties have flowers as fine as a camellia. The plant is nearly biennial, but in rich, well-drained soil and with winter protection it becomes perennial. Easily grown from seed, blooming the second year. Seeds may be sown in August in frames and carried over winter in the same place. The first year's bloom is usually the best. (See paga 376.)

Yellow Chamomile, Anthemis tinctoria. $12-38$ in. July-November. Flowers bright yellow, 1-2 in. in diameter. Useful for cutting. Dense, bushy habit.

Delphinium Chinense. $3 \mathrm{ft}$. July-September. Variable colors; from deep blue to lavender and white. Fine for the border.

D. formosum. $4 \mathrm{ft}$. July-September. Fine spikes of rich blue flowers. One of the finest blue flowers cultivated.

Funkia lancifolia. (See under August.)

Helianthus multiflorus, * var. $f$. $p l$. 4 ft. July-September. Large double flowers, of a fine golden color. Erect habit. An excellent flower.

Lychnis Viscaria var. flore pleno. 12-15 in. July-August. Double, deep rose-red flowers in spikes. For groups and masses.

Monarda didyma.* $2 \mathrm{ft}$. July-October. Showy scarlet flowers in terminal heads. 
Pentstemon grandiflorus.* 2 ft. July-August. Leafy spikes of showy purple flowers.

$P$. lovigatus var. Digitalis.* $3 \mathrm{ft}$. July-August. Pure white flowers in spikes, with purple throats.

Platycodon grandiflorum (Campanula grandiflora). $3 \mathrm{ft}$. JulySeptember. Deep blue, bell-shaped flowers. Dense, fine, erect habit.

$P$. Mariesi. $1 \mathrm{ft}$. July-September. Flowers larger; deep violetblue. Heavier foliage.

\section{August}

Day Lily, Funkia subcordata. 18 in. August-October. Trumpet, lily-like, pure-white flowers in clusters, borne upon a stalk from the midst of a group of heart-shaped green leaves.

$F$. lancifolia var. albo-marginata. July-August. Lavender flowers. Lance-like leaves margined with white.

Flame Flower, Kniphofia aloides (Tritoma Uvaria). $3 \mathrm{ft}$. AugustSeptember. Bright orange-scarlet flowers, in close, dense spikes, at the summit of several scape-like stems. Leaves slender, forming a large tuft. For lawn and borders. Hardy only when covered with litter or straw in winter.

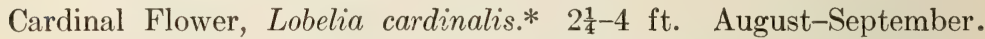
Flowers intense cardinal-red, of unrivaled brilliancy. Tall spikes. Stems clustered; erect.

Giant Daisy, Chrysanthemum (or Pyrethrum) uliginosum. 3-5 ft. July-October. Flowers white, with golden centers. About 2 in. across. A stout, upright, bushy plant. Useful for cutting.

Golden Glow, Rudbeckia laciniata* 6-7 ft. August-September. Large double golden-yellow flowers in great profusion. Bushy habit. Cut off when done flowering. Leaves appear at the base and a new crop of flowers, on stems about $1 \mathrm{ft}$. high, appear in October.

Goldenrod, Solidago rigida.* 3-5 ft. August-October. Flowers large for this genus, in close, short racemes in a corymbose-paniculate cluster. Fine, deep yellow. Erect habit. One of the best of the goldenrods. 


\section{SEPTEMBER}

Japanese Wind-flower, Anemone Japonica. $2 \mathrm{ft}$. August-October. Flowers large, bright red. One of the best autumn flowers. A. Japonica var. alba. Flowers pure white, with yellow centers. Fine for cutting.

\section{OCTOBER}

Hardy Chrysanthemums. The Chinese and Japanese Chrysanthemums, so well known, are hardy in light, well-drained soils, if well protected with litter or leaves during the winter, and in such situations will stand without protection south of Indianapolis. Chrysanthemums are gross feeders, and should have a rich soil. (See page 365.)

But there is a race of hardier or border chrysanthemums that is again coming into favor, and it is sure to give much satisfaction to those who desire flowers in latest fall. These chrysanthemums are much like the "artemisias" of our mother's gardens, although improved in size, form, and in range of color.

\section{One hundred extra-hardy perennial herbs.}

The following list of 100 "best hardy perennials" is adapted from a report of the Central Experimental Farm, Ottawa, Ontario. These plants are chosen from over 1000 species and varieties that have been on trial at that place. Those considered to be the best twenty-five for Canada are marked by a dagger $(\dagger)$; and those native to North America by an asterisk (*).

Achillea Ptarmica flore pleno. - Height, 1 foot; in bloom fourth week of June; flowers, small, pure white, double, and borne in clusters; blooming freely throughout the summer. $\dagger$ Aconitum autumnale. - Height, 3 to 4 feet; September; flowers, bluish purple, borne in loose panicles. Aconitum Napellus. - Height, 3 to 4 feet; July; flowers, deep blue, borne on a large terminal spike; desirable for the rear of the border. Adonis vernalis. - Height, 6 to 9 inches; first week of May; flowers, large, lemon-yellow, borne singly from the ends of the stems. 
Agrostemma (Lychnis) Coronaria var. atropurpurea. - Height, 1 to 2 feet; fourth week of June; flowers, medium size, bright crimson, borne singly from the sides and ends of the stems; a very showy plant with silvery foliage, and continues to bloom throughout the summer.

Anemone patens.* - Height 6 to 9 inches; fourth week of April; flowers, large, and deep purple.

Anthemis tinctoria var. Kelwayi. - Height, 1 to 2 feet; fourth week of June; flowers, large, deep yellow, borne singly on long stems; it continues to bloom profusely throughout the summer; is very showy and valuable for cutting. $\dagger$

Aquilegia Canadensis.* - Height, 1 to $1 \frac{1}{2}$ feet; third week of May; flowers, medium size, red and yellow.

Aquilegia chrysantha.* - Height, 3 to 4 feet; fourth week of June; flowers, large, bright lemon-yellow, with long slender spurs; much later than other columbines. $\dagger$

Aquilegia ccrulea.* - Height, 1 to $1 \frac{1}{2}$ feet; fourth week of May; flowers, large, deep blue with white center and long spurs. $\dagger$ Aquilegia glandulosa. - Height, 1 foot; third week of May; flowers, large, deep blue with white center and short spurs.

Aquilegia oxysepala. - Height, 1 foot; second week in May; flowers, large, deep purplish blue with blue and yellow centers; a very desirable early species.

Aquilegia Stuarti. - Height 9 to 12 inches; third week of May ; flowers, large, deep blue with white center; one of the hest.

Arabis alpina. - Height, 6 inches; first week in May ; flowers, small, pure white, in clusters.

Arnebia echioides. - Height, 9 inches; third week of May; flowers, yellow, borne in clusters with petals spotted with purple. One of the most charming of early flowering plants.

Asclepias tuberosa.* - Height, $1 \frac{1}{2}$ to 2 feet; third week of July. Flowers, bright orange, borne in clusters. Very showy. Aster alpinus.*-Height, 9 inches ; first week of June ; flowers, large, bright purple, borne on long stems from the base of the plant; the earliest flowering of all the asters.

Aster Amellus var. Bessarabicus. - Height, 1 to $1 \frac{1}{2}$ feet; July to September; flowers, large, deep purple, singly on long stems; very fine. $\dagger$ 


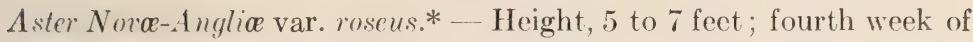
August ; flowers, bright pink, borne profusely in large terminal clusters; very showy.

Boltonia asteroides.* - Height, 4 to 5 feet; September; flowers, smaller than the next, pale pink, borne very profusely in large panicles; much later than the next species.

Boltonia latisquama.*-Height, 4 feet; first week of August; flowers, large, white, somewhat resembling asters, and borne very profusely in large panicles.

Campanula Carpatica. - Height, 6 to 9 inches; first week of July; flowers, medium size, deep blue, borne profusely in loose panicles; continues in bloom throughout the summer. A white variety of this is also good.

Campanula Grossekii. - Height, 3 feet; first week of July; flowers, large, deep blue, borne on a long spike.

Campanula persicifolia. - Height, 3 feet; flowers, large, blue, borne in a raceme with long flower stems. There are also white and double varieties which are good.

Clematis recta. - Height, 4 feet; fourth week of June; flowers, small, pure white, borne profusely in dense clusters. This is a very compact bushy species and desirable for the rear of the border. Clematis Jackmani with large deep purple flowers and Clematis Vitalba with small white flowers, are excellent climbing sorts.

Convallaria majalis* (Lily-of-the-valley).- Height, 6 to 9 inches ; latter part of May.

Coreopsis delphinifolia.* - Height, 2 to 3 feet; first week of July; flowers, large, yellow, with dark centers and borne singly with long stems.

Coreopsis grandiflora.* - Height, 2 to 3 feet; fourth week of June; flowers, large, deep yellow, borne singly on long stems, blooming profusely throughout the summer.

Coreopsis lanceolata.* - Height, 2 feet; fourth week of June; flowers large though slightly smaller than the last, and borne on long stems, blooming throughout the season. $\dagger$

Delphinium Cashmerianum. - Height, $1 \frac{1}{2}$ feet; first week of July; flowers, pale to bright blue, in large open heads. $\dagger$

Dianthus plumarius flore pleno.- Height, 9 inches; second week of 
June; flowers, large, white or pink, very sweet scented, and two or three borne on a stem. A variety called Mrs. Simkins is especially desirable, being very double, white and deliciously perfumed, almost equaling a carnation. It blooms the fourth week of June.

Dicentra spectabilis (Bleeding Heart). - Height, 3 feet; second week of May; flowers, heart-shaped, red and white in pendulous racemes. Dictamnus albus. - Height, $1 \frac{1}{2}$ to 2 feet; second week of June; flowers, white with an aromatic fragrance, and borne in large terminal racemes. A well-known variety has purple flowers with darker markings.

Doronicum Caucasicum. - Height, 1 foot; second week of May ; flowers, large, yellow, and borne singly.

Doronicum plantagineum var. excelsum. - Height, 2 feet; third week of May; flowers, large and deep yellow. $\dagger$

Epimedium rubrum. - Height, 1 foot; second week of May; flowers, small, bright crimson and white, borne in a loose panicle. A very dainty and beautiful little plant.

Erigeron speciosus.* - Height, $1 \frac{1}{2}$ feet; second week of July ; flowers, large, violet-blue, with yellow centers, and borne in large clusters on long stems.

Funkia subcordata (grandiflora). - Height, $1 \frac{1}{2}$ feet; August; flowers, large and white, borne in racemes. The best funkia grown at Ottawa; both leaves and flowers are handsome.

Gaillardia aristata var. grandiflora.* - Height, $1 \frac{1}{2}$ feet; third week of June; flowers, large, yellow, with deep orange centers, and borne singly on long stems. The named varieties, Superba and Perfection, are more highly colored and are of great merit. These all continue blooming profusely until late in the autumn. $\dagger$

Gypsophila paniculata (Infant's breath).-Height, 2 feet; second week of July; flowers, small, white, borne profusely in large open panicles.

Helenium autumnale.*-Height, 6 to 7 feet; second week of July; flowers, large, deep yellow, borne in large heads; very ornamental in late summer.

Helianthus doronicoides.* - Height, 6 to 7 feet; second week of August; flowers, large, bright yellow, and borne singly; continues blooming for several weeks. 
Helianthus multiflorus.*-Height, 4 feet; flowers, large, double, bright yellow, and borne singly; a very striking late-flowering perennial.

Heuchera sanguinea.* - Height, 1 to $1 \frac{1}{2}$ feet; first week of June; flowers, small, bright, scarlet, borne in open panicles; continues blooming throughout the summer.

Hemerocallis Dumortierii. - Height, $1 \frac{1}{2}$ feet; second week of June; flowers, large, orange-yellow, with a brownish tinge on the outside, and three or four on a stem. $\dagger$

Hemerocallis flava. - Height, 2 to 3 feet; latter part of June; flowers, bright orange-yellow and fragrant. $\dagger$

Hemerocallis minor. - Height, 1 to $1 \frac{1}{2}$ feet; second week of July; flowers, medium size and yellow; blooms later than the two preceding species and has a smaller flower and narrower foliage.

Hibiscus Moscheutos.* - Height, 5 feet; third week of August; flowers, very large, varying in color from white to deep pink. A variety called "Crimson Eye" is very good. This plant makes a fine show in late summer.

Hypericum Ascyron (or pyramidatum).* - Height, 3 feet; fourth week of July; flowers, large, yellow, and borne singly.

Iberis sempervirens. - Height, 6 to 12 inches; third week of May; flowers, pure white, fragrant, and borne in dense flat clusters. $\dagger$

Iris Chamœiris. - Height, 6 inches; fourth week of May; flowers, bright yellow with brown markings.

Iris flavescens. - Height, $1 \frac{1}{2}$ to 2 feet; first week of June; flowers, lemon-yellow with brown markings.

Iris Florentina. - Height, 2 feet; first week of June; flowers, very large, pale blue or lavender, sweet scented. $\dagger$

Iris Germanica. - Height, 2 to 3 feet; first week of June; flowers, very large, of elegant form; color, deep lilac and bright purple, sweet scented. There is a large number of choice varieties of this iris. $\dagger$

Iris loevigata (Kampferi). - Height, $1 \frac{1}{2}$ to 2 feet; first week of July; flowers, purple and modified colors, very large and distinct in color and shape. $\dagger$

Iris pumila. - Height, 4 to 6 inches; third week of May; flowers, deep purple. There are several varieties. 
Iris Sibirica. - Height, 3 to 4 feet; fourth week of May; flowers, deep blue, borne on long stems in clusters of two or three. This species has many varieties.

Iris variegata. - Height, 1 to $1 \frac{1}{2}$ feet; first week of June; flowers, . yellow and brown, veined with various shades of brown.

Litium auratum. - Height, 3 to 5 feet; July ; flowers, very large, white, with a yellow central band on each petal, and thickly spotted with purple and red. The most showy of all lilies and a splendid flower. This has proved hardy at the Central Experimental Farm, although it has been reported tender in some localities. $\dagger$

Lilium Canadense.* - Height, 2 to 3 feet; latter part of May; flowers, yellow to pale red with reddish spots, pendulous.

Lilium elegans. - Height, 6 inches; first week of July; flowers, pale red; several varieties are better than the type.

Lilium speciosum. - Height, 2 to 3 feet; July; flowers, large, white, tinged and spotted with deep pink and red. Hardier than Litium auratum and almost as fine. There are several fine varieties. $\dagger$

Lilium superbum.* - Height, 4 to 6 feet; first week of July; flowers, very numerous, orange red, thickly spotted with dark brown. An admirable lily for the rear of the border. $\dagger$

Litium tenuifolium. - Height, $1 \frac{1}{2}$ to 2 feet; third week of June; flowers, pendulous and bright scarlet. One of the most graceful of all lilies.

Lilium tigrinum. - Height, 2 to 4 feet; flowers, large, deep orange, spotted thickly with purplish black.

Linum perenne. - Height, $1 \frac{1}{2}$ feet; first week of June; flowers, large deep blue, borne in loose panicles, continuing throughout the summer. Lobelia cardinalis.* - Height, 2 to 3 feet; August; flowers, bright scarlet, borne in terminal racemes; very showy.

Lychnis Chalcedonica flore pleno. - Height, 2 to 3 feet; first week of July ; flowers, bright crimson, double, and borne in terminal racemes. Lysimachia clethroides. - Height, 3 feet; fourth week of July ; flowers, white, borne in long spikes. A very striking late-flowering perennial. Myosotis alpestris. - Height, 6 inches; third week of May; flowers, small, bright blue with a yellowish eye. A very profuse bloomer. Enothera Missouriensis.*_-Height, 1 foot ; fourth week of June; flowers, very large, rich yellow, and borne singly, throughout the summer. 
Paonia officinalis. - Height, 2 to 4 feet; early part of July. The double-flowered varieties are the best, and can be obtained in several colors and shades. $\dagger$

Papaver nudicaule.* - Height, 1 foot; second week of May; flowers, medium size, orange, white, or yellow, almost continuously until late autumn. $\dagger$

Papaver orientale. - Height, 2 to 3 feet; first week of June; flowers, very large, scarlet, and variously marked, according to variety, there being many forms.

Pentstemon barbatus var. Torreyi.* - Height, 2 to 3 feet; first week of July ; flowers, deep red, borne in long spikes, very ornamental.

Phlox amœna.* - Height, 6 inches; second week of May; flowers, medium size, bright pink, in compact clusters.

Phlox decussata* (the garden perennial hybrids).- Height, 1 to 3 feet; third week of July; flowers, of many beautiful shades and colors, are found in the large number of named varieties of this phlox, which continues to bloom until late in the autumn. $\dagger$

Phlox reptans.* - Height, 4 inches; fourth week of May; flowers, medium size, purple, and borne in small clusters.

Phlox subulata* (setacea). - Height, 6 inches; third week of May; flowers, medium size, deep pink, and borne in small clusters.

Platycodon grandiflor m. - Height, $1 \frac{1}{2}$ to 2 feet; second week of July ; flowers, very large, deep blue, borne singly or in twos. $\dagger$

Platycodon grandiflorum var. album. - A white-flowered variety of the above and makes a fine contrast to it when they are grown together. It blooms a few days earlier than the species.

Platycodon Mariesii. - Height, 1 foot; second week of July; flowers, large and deep blue.

Polemonium cæruleum.* - Height, 2 feet; second week of June; flowers, deep blue, borne in terminal spikes.

Polemonium reptans.* - Height, 6 inches; third week of May ; flowers, medium in size, blue, and borne profusely in loose clusters.

Polemonium Richardsoni.* - Height, 6 inches; third week of May; flowers, medium in size, blue, borne profusely in pendulous panicles.

Potentilla hybrida var. versicolor. - Height, 1 foot; fourth week of June; flowers, large, deep orange and yellow, semi-double. 
Primula cortusoides. - Height, 9 inches ; third week of May ; flowers, small, deep rose, in compact heads.

Pyrethrum (or Chrysanthemum) uliginosum. - Height, 4 feet; September; flowers, large, white with yellow centers, and borne singly on long stems.

Rudbeckia laciniata* (Golden Glow).-Height, 5 to 6 feet; August; flowers, large, lemon-yellow, double, and borne on long stems. One of the best of lately introduced perennials. $\dagger$

Rudbeckia maxima.* - Height, 5 to 6 feet; July and August; flowers, large, with a long cone-shaped center and bright yellow rays, and borne singly. The whole plant is very striking.

Scabiosa Caucascia. - Height, $1 \frac{1}{2}$ feet; first week of July; flowers, large, light blue, and borne singly on long stems, very freely throughout remainder of the summer.

Solidago Canadensis* (Golden-rod). - Height, 3 to 5 feet; first week of August; flowers, small, golden yellow, and borne in dense panicles.

Spircea (properly Aruncus) astilboides. - Height, 2 feet; fourth week of June; flowers, small, white, very numerous, and borne in many branched panicles. Both foliage and flowers are ornamental.

Spircea (or Ulmaria) Filipendula. - Height, 2 to 3 feet; third week of June; flowers, pure white, borne profusely in loose panicles. The foliage of this species is also very good. There is a double flowered variety which is very effective. $\dagger$

Spircea (Ulmaria) purpurea var. elegans. - Height, 2 to 3 feet; first week of July; flowers, whitish with crimson anthers, borne very profusely in panicles.

Spircea Ulmaria (Ulmaria pentapetala). - Height, 3 to 4 feet; second week of July ; flowers, very numerous, dull white, borne in large compound heads, having a soft, feathery appearance.

Spirca venusta (Ulmaria rubra var. venusta). - Height, 4 feet; second week of July; flowers, small, bright pink, borne profusely in large panicles. $\dagger$

Statice latifolia. - Height, $1 \frac{1}{2}$ feet; first week of July ; flowers, small, blue, borne very profusely in loose panicles. Very effective in the border.

Thalictrum aquilegifolium. - Height, 4 to 5 feet; fourth week of 
June; flowers, small, white to purplish, very numerous and borne in large panicles.

Trollius Europous. - Height, $1 \frac{1}{2}$ to 2 feet; fourth week of May; flowers, large, bright yellow, continuing a long time.

\section{Bulbs AND Tubers}

(See the particular culture of the different kinds in Chapter VIII; and instructions for forcing on $p .345$.

It is customary to write of bulbs and tubers together, because the tops and flowers of all the bulbous and tuberous plants spring from large reservoirs of stored food, giving rise to similar methods of culture and of storage.

Structurally, the bulb is very different from the tuber, however. A bulb is practically a large dormant bud, the scales representing the leaves, and the embryo stem lying in the center. Bulbs are condensed plants in storage. The tuber, on the other hand, is a solid body, with buds arising from it. Some tubers represent thickened stems, as the Irish potato, and some thickened roots, as probably the sweet-potato, and some both stem and root, as the turnip, parsnip, and beet. Some tubers are very bulb-like in appearance, as the corms of crocus and gladiolus.

Using the word "bulb" in the gardener's sense to include all these plants as a cultural group, we may throw them into two classes: the hardy kinds, to be planted in fall; and the tender kinds, to be planted in spring.

Fall-planted bulbs.

The fall-planted bulbs are of two groups: the "Holland bulbs" or early spring bloomers, as crocus, tulip (Fig. 255), hyacinth (Fig. 262), narcissus (Fig. 260), squill (Fig. 256), snowdrop; the summer bloomers, as lilies (Figs. 258, 259). The treatments of the two groups are so similar that they may be discussed together. 


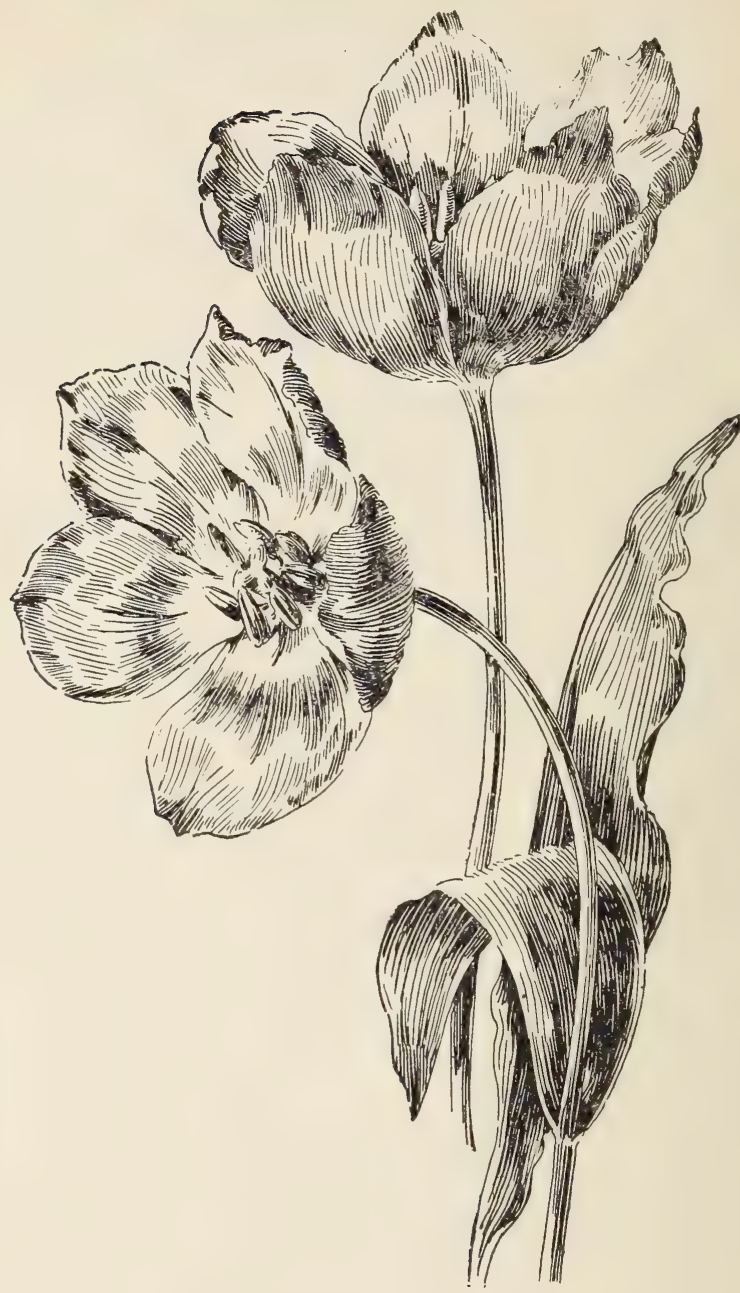

255. Tulips, the warmest of spring flowers. 
All these bulbs may be planted as soon as they are mature; but in practice they are kept till late September or October before they are put into the ground, as nothing is gained by earlier planting, and, moreover, the ground is usually not ready to receive them until some other crop is removed.

These bulbs are planted in the fall (1) because they keep better in the ground than when stored;

(2) because they will take root in fall and winter

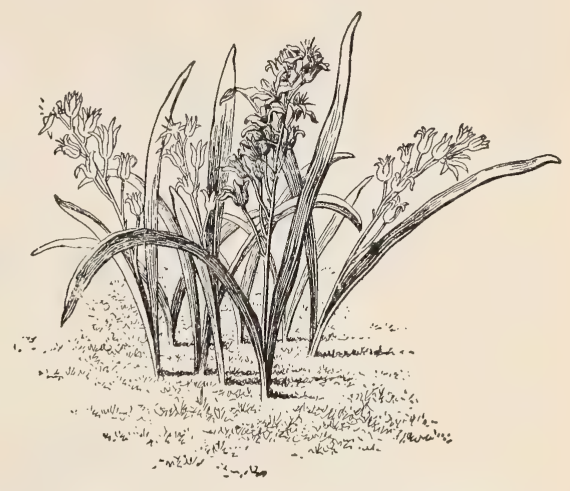

256. One of the squills.-Scilla bifolia. and be ready for the first warmth of spring; (3) and because it is usually impossible to get on the ground early enough in spring to plant them with much hope of success for that season.

The bulbs lie dormant until spring, so far as outward appearances go; they are mulched to insure that they will not start in warm weather of fall or winter, and to protect the ground from heaving.

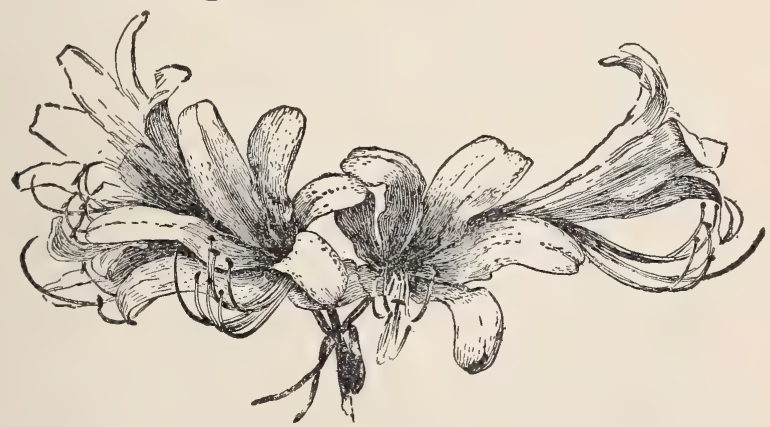

257. A purple-flowered Amaryllis. - Lycoris squamigera, but known as Amaryllis Hallii. 
To secure good bulbs and of the desired varieties, the order should be placed in spring or early summer. For flower-garden effects, the large and mature bulbs should be secured; for colonizing in shrubbery or on the lawn, the smaller sizes may be sufficient. Insist that your bulbs shall be first class, for there is wide difference in the quality; even with the best of treatment, good results cannot be secured from poor bulbs.

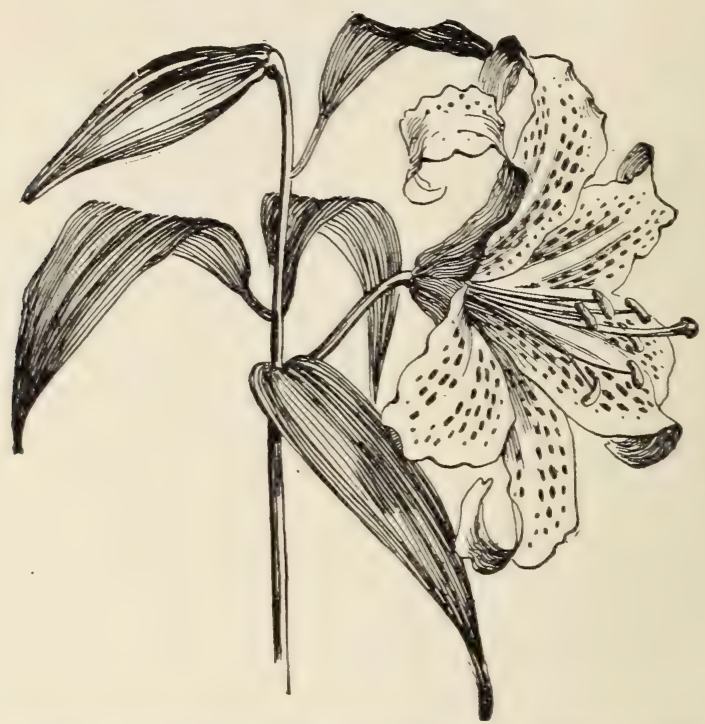

258. The Japanese gold-banded lily. - Litium auratum.

It is not generally known that there are autumn-flowering bulbs. Several species of crocus bloom in the fall, $C$. sativus (the saffron crocus) and $C$. speciosus being the ones generally recommended. The colchicums are excellent autumn-blooming bulbs and should be more generally planted. C. autumnale, rosy purple, is the usual species. These autumn-blooming bulbs are planted in August or early September and treated in 
general the same as other similar bulbs. The colchicums usually remain in the ground several years in good condition.

All kinds of bulbs are partial to a deep, rich, water-free soil. This is no small part of their successful culture. The spot should be well drained, either naturally or artificially. In flattish and rather moist lands the beds may be made above the surface, some 18 inches high, and bordered with grass. A layer of rough stones a foot deep is sometimes used in the bottom of ordinary beds for drainage, and with good results, when other methods are not convenient, and when there is fear that the bed may become too wet. If the place is likely to be rather wet, place a large handful of sand where the bulb is to go and set the bulb on it. This will keep the water from standing around the bulb. Very good results may be had in heavy soil by this method.

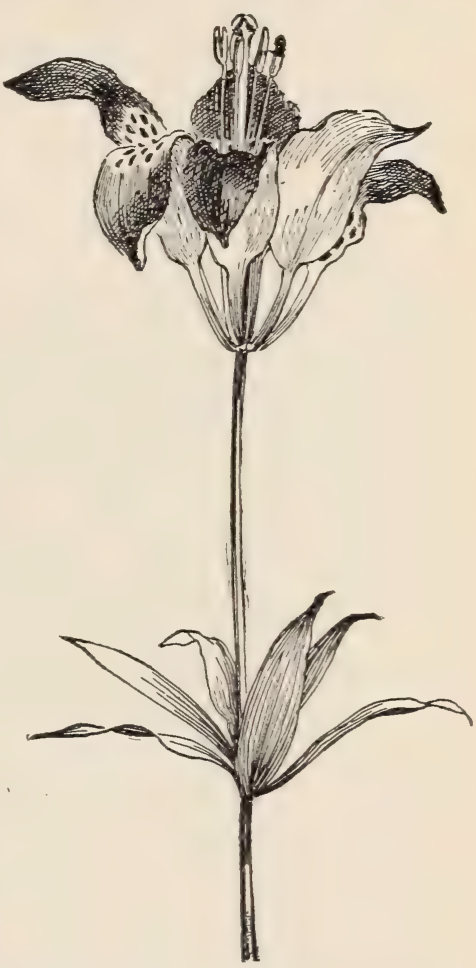

259. One of the common wild lilies. Lilium Philadelphicum.

The soil for bulbs should be well enriched with old manure. Fresh manure should never be allowed close about the bulb. The addition of leafmold and a little sand also improves the texture of heavy soils. For lilies the leafmold may be omitted. Let the spading be at least a foot deep. Eighteen inches will be none too deep for lilies. To make a bulb bed, throw 
out the top earth to the depth of 6 inches. Put into the bottom of the bed about 2 inches of well-rotted manure and spade it into the soil. Throw back half of the top soil, level it off nicely, set the bulbs firmly on this bed, and then cover them with the remainder of the earth; in this way one will have the bulbs from 3 to 4 inches below the surface, and they will all be of

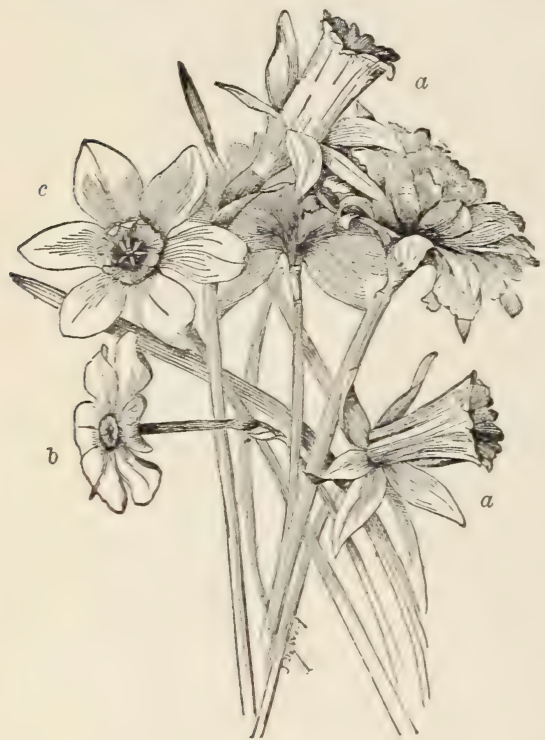

260. Common species of narcissus. a a. Narcissus Pseudo-Narcissus or daffodil; b. Jonquil ; c. N. Poeticus. uniform depth and will give uniform results if the bulbs themselves are well graded. The "design" bed may be worked out easily in this way, for all the bulbs are fully exposed after they are placed, and they are all covered at once.

Of course, it is not necessary that the home gardener go to the trouble of removing the earth and replacing it if he merely wants good blooms; but if he wants a good bed as a whole, or a mass effect, he should take this pains. In the shrubberies and on the lawn he may "stick them in" here and there, seeing that the top of the bulb is 3 to 6 inches beneath the surface, the depth depending on the size of the bulb (the bigger and stronger the bulb, the deeper it may go) and on the nature of the soil (they may go deeper in sand than in hard clay).

As the time of severe winter freezing approaches, the bed should receive a mulch of leaves, manure or litter, to the depth 
of 4 inches or more, according to the latitude and the kind of material. If leaves are used, 3 inches will be enough, because the leaves lie close together and may smother out the frost that is in the ground and let the bulbs start. It will be well to let the mulch extend 1 foot or more beyond the margins of the bed. When cold weather is past, half of the mulch should be removed. The remainder may be left on till there is no longer danger of frost. On removing the last of the mulch, lightly work over the surface among the bulbs with a thrust-hoe.

If the weather happens to be very bright during the blooming season, the duration of the flowers may be prolonged by light shading - as with muslin, or slats placed above the beds. If planted where they have partial shade from surrounding trees or shrubbery, the beds will not need attention of this kind.

Lilies may remain undisturbed for years. Crocuses and tulips may stand two years, but hyacinths should be taken up each year and replanted; tulips also will be better

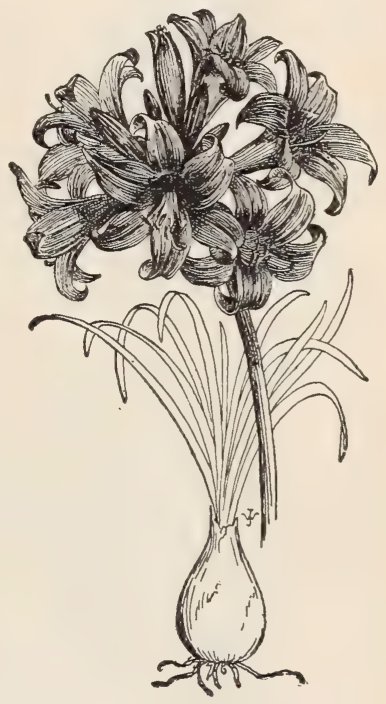

261. The Belladonna lily. Amaryllis Belladonna. for the same treatment. Narcissus may remain for some years, or until they show signs of running out.

Bulbs that are to be taken up should be left in the ground till the foliage turns yellow, or dies down naturally. This gives the bulbs a chance to ripen. Cutting off the foliage and digging too early is a not uncommon and serious mistake. Bulbs that have been planted in places that are wanted for summer bedding plants may be dug with the foliage on and 
heeled-in under a tree, or along a fence, to stand till ripened. The plant should be injured as little as possible, as the foliage of this year makes the flowers of the next. When the foliage has turned yellow or died down, the bulbs - after cleaning, and

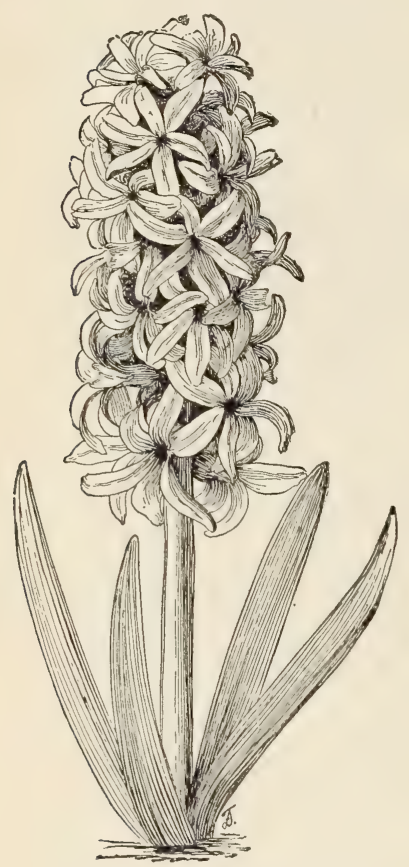

262. The common Dutch hyacinth. curing them for a few hours in the sun - may be stored in the cellar or other cool, dry place, to await fall planting. Bulbs that are lifted prematurely in this way should be planted permanently in the borders, for they will not make good flower-garden subjects the following year. In fact, it is usually best to buy fresh, strong bulbs each year of tulips, hyacinths, and crocuses if the best results are desired, using the old bulbs for shrubberies and mixed borders.

Crocuses and squills are often planted in the lawn. It is not to be expected that they will last more than two to three years, however, even if care is taken not to cut the tops closely when the lawn is cut. The narcissus (including daffodils and jonquils) will remain in good condition for years in grassy parts of the place, if the tops are allowed to mature.

\section{List of outdoor fall-planted bulbs for the North.}

Crocus.

Hyacinth.

Tulip.
Narcissus (including daffodil and jonquil). Scilla, or squill. Snowdrop (Galanthus). 
Snowflake (Leucoium).

Chionodoxa.

Hardy alliums.

Bulbocodium.

Camassia.

Lily-of-the-valley.

Winter aconite (Eranthis hyemalis).

Dog-tooth violets (Erythronium).

Crown imperial (Fritillaria Imperialis).

Fritillary (Fritillaria Meleagris).

Trilliums.

Lilies.

Peonies, tuberous anemones, tuberous buttercups, iris, bleeding heart, and the like, may be planted in autumn and are often classed with fall-planted bulbs.

\section{Winter bulbs (p. 345).}

Some of these bulbs may be made to bloom in the greenhouse, window-garden, or living room in winter. Hyacinths are particularly useful for this purpose, because the bloom is less affected by cloudy weather than that of tulips and crocuses. Some kinds of narcissus also "force" well, particularly the daffodil; and the Paper-white and "Chinese sacred lily" are practically the only common bulbs from which the home gardener may expect good bloom before Christmas. The method of handling bulbs for winter bloom is described under Window-gardening (on p. 345).

\section{Summer bulbs.}

There is nothing special to be said of the culture of the socalled summer-blooming and spring-planted bulbs, as a class. They are tender, and are therefore planted after cold weather is past. For early bloom, they may be started indoors. Of course, any list of spring-planted bulbs is relative to the climate, 
for what may be planted in spring in New York perhaps may be planted in the fall in Georgia.

The common "summer bulbs" are:-

Gladiolus
Tuberose
Dahlia
Canna
Arum

Calla

Calochortus

Alstremeria

Amaryllis

Colocasia

\section{The Shrubbery}

(Exclusive of coniferous evergreens and climbing plants.)

The common hardy shrubs or bushes may be planted in fall or spring. In the northernmost parts of the country and in Canada spring planting is usually safer, although on welldrained ground and when thoroughly mulched the plants may even there do well if planted as soon as the leaves drop in fall. If the shrubs are purchased in spring, they are likely to have come from "cellared stock"; that is, the nurserymen dig much of their stock in fall and store it in cellars built for the purpose. While stock that is properly cellared is perfectly reliable, that which has been allowed to get too dry or which has been otherwise improperly handled comes on very slowly in the spring, makes a poor growth the first year, and much of it may die.

In the planting of any kind of trees or shrubs, it is well to remember that nursery-grown specimens generally transplant more readily and thrive better than trees taken from the wild; and this is particularly true if the stock was transplanted in the nursery. Trees that transplant with difficulty, as the papaw or asimina, and some nut trees, may be prepared for removal by cutting some of their roots - and especially the tap-root, if they have such - a year or two in advance.

It is ordinarily best to plow or spade the entire area in which the shrubs are to be set. For a year or two the ground should 


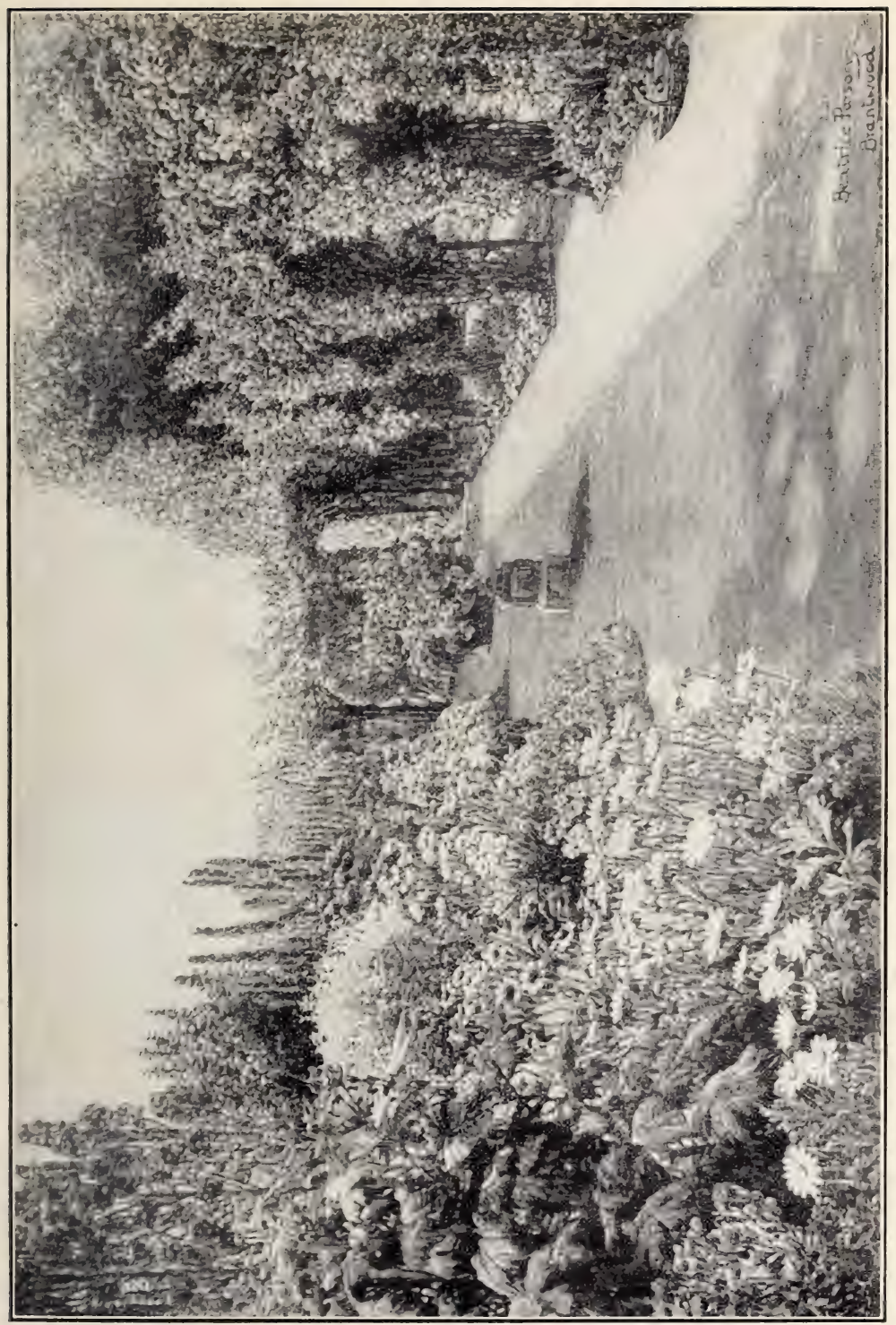

$\therefore$ 믈

¿

ว

$-\approx 0$

ก 2

$\stackrel{\Xi}{0} \approx$

:

๘

$=$

की

눈

2.

을

$\Xi \div$

茨

㱐

를

든

들

$\approx \cong$

娄

ฮิ

$\frac{5}{20}-$

들

$\overline{\overline{0}} \overline{\mathrm{i}}$

.

$\frac{\delta}{0} \equiv$

$\geqslant$

$\check{\check{c}} \geqslant$

B.

ข

$\div$ ․

o.

อ

를

$\tilde{\sigma} \leqq \frac{\vec{b}}{\mathrm{~b} 0}$

$\div=$

$\stackrel{0}{\Xi}$

ఏ气

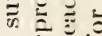

-

$\overleftrightarrow{\Xi}$

¿

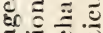

ป

오쵸

$E$

$\Xi$ 

be tilled between the shrubs, either by horse tools or by hoes and rakes. If the place looks bare, seeds of quick-growing flowers may be scattered about the edges of the mass, or herbaceous perennials may be used.

The larger shrubs, as lilacs and syringas, may be set about 4 feet apart; but the smaller ones should be set about 2 feet apart if it is desired to secure an immediate effect. If after a few years the mass becomes too crowded, some of the specimens may be removed (p. 76).

Throw the shrubs into an irregular plantation, not in rows, and make the inner edge of the mass more or less undulating and broken.

It is a good practice to mulch the plantation each fall with light manure, leafmold, or other material. Even though the shrubs are perfectly hardy, this mulch greatly improves the land and promotes growth. After the shrub borders have become two or three years old, the drifting leaves of fall will be caught therein and will be held as a mulch (p. 82).

When the shrubs are first planted, they are headed back one half or more (Fig. 45); but after they are established they are not to be sheared, but allowed to take their own way, and after a few years the outermost ones will droop and meet the greensward (pp. 25, 26).

Many rapid-growing trees may be utilized as shrubs by cutting them off near the ground every year, or every other year, and allowing young shoots to grow. Basswood, black ash, some of the maples, tulip tree, mulberry, ailanthus, paulownia, magnolias, Acer campestre, and others may be treated in this way (Fig. 50).

Nearly all shrubs bloom in spring or early summer. If kinds blooming late in summer or in fall are desired, they may be looked for in baccharis, caryopteris, cephalanthus, clethra, hamamelis, hibiscus, hydrangea, hypericum, lespedeza, rhus (R. Cotinus), Sambucus Canadensis in midsummer, tamarisk. 
Plants that bloom in very early spring (not mentioning such as birches, alders, and hazels) may be found in amelanchier, cydonia, daphne, dirca, forsythia, cercis (in tree list), benzoin, lonicera ( $L$. fragrantissima), salix ( $S$. discolor and other pussy willows), shepherdia.

Shrubs bearing conspicuous berries, pods, and the like, that persist in fall or winter may be found in the genera berberis (particularly B. Thunbergii), colutea, corylus, cratægus, euonymus, ilex, physocarpus, ostrya, ptelea, pyracantha (Plate XIX) pyrus, rhodotypos, rosa ( $R$. rugosa), staphylea, symphoricarpus, viburnum, xanthoceras.

\section{List of shrubbery plants for the North.}

The following list of shrubs (of course not complete) comprises a selection with particular reference to southern Michigan and central New York, where the mercury sometimes falls to fifteen degrees below zero. Application is also made to Canada by designating species that have been found to be hardy at Ottawa.

The list is arranged alphabetically by the names of the genera.

The asterisk $\left({ }^{*}\right)$ denotes that the plant is native to North America.

The double dagger (†) indicates species that are recommended by the Central Experimental Farms, Ottawa, Ontario.

It is often difficult to determine whether a group should be listed among shrubs or trees. Sometimes the plant is not quite a tree and is yet something more than a shrub or bush; sometimes the plant may be distinctly a tree in its southern range and a shrub in its northern range; sometimes the same genus or group contains both shrubs and trees. In the following genera there are doubtful cases: æsculus, alnus, amelanchier, betula, caragana, castanea, cornus ( $C$. florida), cratægus, elæagnus, prunus, robinia. 
Dwarf buckeye, Esculus parviflora (Pavia macrostachya).*

Attractive in habit, foliage, and flower; produces a large foliage mass.

Alder.

Several bushy species of alder are good lawn or border subjects, particularly in wet places or along streams, as $A$. viridis, ${ }^{*} A$. rugosa, ${ }^{*} A$. incana, ${ }^{*}$ and others.

June-berry, Amelanchier Canadensis* and others.

Flowers profusely in spring before the leaves appear; some of them become small trees.

Azalea, Azalea viscosa* and A. nudiflora.*

Require partial shade, and a woodsy soil.

Japanese azalea, A. mollis (or A. Sinensis).

Showy red and yellow or orange flowers; hardy north.

Groundsel tree, "white myrtle," Baccharis halimifolia.*

Native on the Atlantic seashore, but grows well when planted inland; valuable for its white fluffy "bloom" (pappus) in latest fall; 4-10 ft.

Spice-bush, Benzoin odoriferum (Lindera Benzoin).*

Very early-blooming bush of wet places, the yellow, clustered, small flowers preceding the leaves; $6-10 \mathrm{ft}$.

Barberry, Berberis vulgaris.

Common barberry; $4-6 \mathrm{ft}$. The purple-leaved form (var. purpurea $\ddagger$ ) is popular.

Thunberg's barberry, B. Thunbergii. $\ddagger$

One of the best of lawn and border shrubs, with compact and attractive habit, deep red autumn foliage and bright scarlet berries in profusion in fall and winter; excellent for low hedges; $2-4 \mathrm{ft}$.

Mahonia, B. Aquifolium.*†

Evergreen; needs some protection in exposed places; $1-3 \mathrm{ft}$.

Dwarf birch, Betula pumila.*

Desirable for low places; $3-10 \mathrm{ft}$.

Box, Buxus sempervirens.

An evergreen shrub, useful for hedges and edgings in cities; several varieties, some of them very dwarf. See page 220.

Carolina allspice, sweet-scented shrub, Calycanthus floridus.*

Dull purple, very fragrant flowers; $3-8 \mathrm{ft}$. 
Siberian pea-tree, Caragana arborescens. $\ddagger$

Flowers pea-like, yellow, in May; very hardy; 10-15 feet.

Small pea-tree, C. pygmoea.

Very small, 1-3 ft, but sometimes grafted on $C$. arborescens.

Shrubby pea-tree, $C$. frutescens. $\ddagger$

Flowers larger than those of $C$. arborescens; $3-10 \mathrm{ft}$.

Large-flowered pea-tree, $C$. grandiflora. $\ddagger$

Larger-flowered than the last, which it resembles; $4 \mathrm{ft}$.

Blue spirea, Caryopteris Mastacanthus.

Flowers bright blue, in late summer and fall; $2-4 \mathrm{ft}$., but is likely to die to ground in winter.

Chinquapin or dwarf chestnut, Castanea pumila.*

Becomes a small tree, but usually bushy.

Ceanothus, Ceanothus Americanus.*

A very small native shrub, desirable for dry places under trees; $2-3 \mathrm{ft}$. There are many good European garden forms of ceanothus, but not hardy in the northern states.

Button-bush, Cephalanthus occidentalis.*

Blossoms in July and August; desirable for water-courses and other low places; $4-10 \mathrm{ft}$.

Fringe tree, Chionanthus Virginica.*

Shrub as large as lilac, or becoming tree-like, with fringe-like white flowers in spring.

White alder, Clethra alnifolia.*

A very fine, hardy shrub, producing very fragrant flowers in July and August; should be better known; 4-10 ft.

Bladder senna, Colutea arborescens.

Pea-like yellowish flowers in June, and big inflated pods; 8-12 ft.

European osier, Cornus alba (known also as C. Sibirica and C. Tatarica).

Branches deep red ; 4-8 ft.; the variegated-form $\ddagger$ has leaves edged white.

Bailey's osier, C. Baileyi.*

Probably the finest of the native osiers for color of twigs and foliage; $5-8 \mathrm{ft}$. 
Red-twigged osier, C. stolonifera.*

The red twigs are very showy in winter; 5 to $8 \mathrm{ft}$; some bushes are brighter in color than others.

Flowering dogwood, C. florida.*

Very showy tree or big shrub, desirable for borders of groups and belts. A red-flowered variety is on the market.

Cornelian Cherry, C. Mas.

Becoming a small tree, 15-20 ft.; flowers numerous in bunches, yellows before the leaves; fruit, cherry-like, edible, red.

Hazel or filbert, Corylus maxima var. purpurea.

A well-known purple-leaved shrub, usually catalogued as C. Avellana purpurea. The eastern American species (C.Americana* and C.rostrata*) are also interesting.

Cotoneaster.

Several species of cotoneaster are suitable for cultivation in the middle and southern latitudes. They are allied to cratægus. Some are evergreen. Some kinds bear handsome persistent fruits. Some are hardy North.

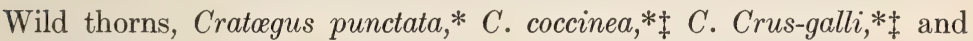
others.

The native thorn apples or hawthorns, of numerous species, are amongst our best large shrubs for planting and should be much better known; $6-20 \mathrm{ft}$.

Japanese quince, Cydonia (or Pyrus) Japonica.

An old favorite blooming in earliest spring, in advance of the leaves; not hardy at Lansing, Mich. ; 4-5ft.

Maule's Japanese quince, C. Maulei. $\ddagger$

Bright red; iruit handsome; hardier than C. Japonica; 1-3 ft.

Daphne, Daphne Mezereum.

Produces rose-purple or white flowers in abundance in earliest spring before the leaves appear. Should be planted on the edges of groups; leaves deciduous; $1-4 \mathrm{ft}$.

\section{Garland flower, D. Cneorum. $\ddagger$}

Pink flowers in very early spring and again in autumn; leaves evergreen; $1-1 \frac{1}{2} \mathrm{ft}$. 
Deutzia, Deutzia scabra (or crenata) and varieties.

Standard shrubs; the variety "Pride of Rochester," with pinkish flowers, is perhaps the best form for the North; $4-6 \mathrm{ft}$. Of this and the next there are forms with ornamental foliage.

Small deutzia, D. gracilis.

Very close little bush, with pure white flowers; $2-3 \mathrm{ft}$.

Lemoine's deutzia, D. Lemoinei.

A hybrid, very desirable; 1-3 ft.

Weigela, Diervilla Japonica and other species.

Free bloomers, very fine, in many colors, 4-6 ft.; the forms known as candida, $\ddagger$ rosea, $\ddagger$ and Sieboldii variegata, $\ddagger$ are hardy and good.

Leatherwood, Dirca palustris.*

If well grown, the leatherwood makes a very neat plant; blossoms appear before the leaves, but not showy; 4-6 ft.

Russian olive, oleaster, Elocagnus angustifolia.f

Foliage silvery white; very hardy; becoming a small tree, 15-20 ft.

Wolf-willow, $E$. argentea.*‡

Large and silvery leaves; suckers badly; 8-12 ft.

Goumi, E. longipes (sometimes called E. edulis).

Attractive spreading bush, with handsome edible cranberry-like berries; $5-6 \mathrm{ft}$.

Burning-bush, Euonymus atropurpureus.*

Very attractive in fruit ; 8-12 ft., or even becoming tree-like.

Several other species are in cultivation, some of them evergreen. In the North, success may be expected with $E$. Europaus (sometimes a small tree), $E$. alatus, E. Bungeanus, E. latifolius, and perhaps others.

Exochorda, Exochorda grandiflora.

A large and very showy shrub, producing a profusion of apple-like white flowers in early spring; 6-12 ft; allied to the spireas.

Forsythia, Forsythia viridissima.

Blossoms yellow, appearing before the leaves; requires protection in many places North; 6-10 ft.

Drooping forsythia, $F$. suspensa.

Makes an attractive mass on a bank or border; 6-12 ft. 
Dyer's weed, Genista tinctoria. $\ddagger$

Yellow pea-like flowers in June; 1-3 ft.

Silver-bell tree, Halesia tetraptera.*

Bell-shaped white flowers in May; 8-10 ft.

Witch hazel, Hamamelis Virginiana*

Blossoms in October and November; unique and desirable if well grown; 8-12 ft.

Althea, Rose of Sharon, Hibiscus Syriacus (Althra frutex).

In many forms, purple, red, and white, and perhaps the best of late summerblooming shrubs; $8-12 \mathrm{ft}$.

Hydrangea, Hydrangea paniculata, var. grandiflora. $\ddagger$

One of the best and most showy small flowering shrubs; 4-10 ft.

Downy hydrangea, $H$. radiata.*

Attractive in both foliage and flower.

Oak-leaved hydrangea, $H$. quercifolia.*

This is especially valuable for its luxuriant foliage; even if killed to the ground in winter, it is still worth cultivating for its strong shoots.

The greenhouse hydrangea ( $H$. hortensis in many forms) may be used as an outdoor subject in the South.

St. John's wort, Hypericum Kalmianum, $* \ddagger H$. prolificum, $*$ and $H$. Moserianum.

Small undershrubs, producing bright yellow flowers in profusion in July and August; $2-4 \mathrm{ft}$.

\section{Winter-berry, Ilex verticillata.*ł}

Produces showy red berries, that persist through the winter; should be massed in rather low ground; flowers imperfect; 6-8 ft.

The evergreen hollies are not suitable for cultivation in the North; but in the warmer latitudes, the American holly (Ilex opaca), English holly ( $I$. Aquifolium), and Japanese holly (I.crenata) may be grown. There are several native species.

\section{Mountain laurel, Kalmia latifolia*}

One of the best shrubs in cultivation, evergreen, 5-10 ft., or even becoming a small tree south; usually profits by partial shade; thrives in a peaty or loamy rather loose soil, and said to be averse to limestone and clay; extensively transferred from the wild for landscape effects in large private places; should thrive as far north as it grows wild. 
Kerria, corchorus, Kerria Japonica.

A bramble-like shrub, producing attractive yellow single or double flowers from July until September; twigs very green in winter. There is a variegated-leaved form. Good for banks and borders; 2-3 ft.

Sand myrtle, Leiophyllum buxifolium.*

Evergreen, more or less procumbent; $2-3 \mathrm{ft}$.

Lespedeza, Lespedeza bicolor $\ddagger$

Reddish or purple small flowers in late summer and fall; 4-8 ft.

Lespedeza, L. Sieboldii (Desmodium penduliflorum). $\ddagger$

Rose-purple large flowers in fall; killed to the ground in winter, but it blooms the following year; 4-5 ft.

Lespedeza, L. Japonica (Desmodium Japonicum).

Flowers white, later than those of $L$. Sieboldii; springs up from the root.

Privet, Ligustrum vulgare, L. ovalifolium (L. Californicum), and $L$. Amurense $\ddagger$

Much used for low hedges and borders; 4-12 ft.; several other species.

Tartarian honeysuckle, Lonicera Tatarica. $\ddagger$

One of the most chaste and comely of shrubs; $6-10 \mathrm{ft}$.; pink-flowered; several varieties.

Regel's honeysuckle, L. spinosa (L. Alberti).‡

Blooms a little later than above, pink; $2-4 \mathrm{ft}$.

Fragrant honeysuckle, L. fragrantissima.

Flowers exceedingly fragrant, preceding leaves; $2-6 \mathrm{ft}$.; one of the earliest things to bloom in spring.

There are other upright honeysuckles, all interesting.

Mock-orange (Syringa incorrectly), Philadelphus coronarius. $\ddagger$

In many forms and much prized; $6-12 \mathrm{ft}$.

Other species are in cultivation, but the garden nomenclature is confused. The forms known as $P$. speciosus, $P$. grandiflorus, and var. speciosissimus $\ddagger$ are good; also the species $P$. pubescens,* P. Gordonianus,* and $P$. microphyllus,* the last being dwarf, with small white very fragrant flowers.

Nine-bark, Physocarpus opulifolius (Spircea opulifolia).*

A good vigorous hardy bush, with clusters of interesting pods following the flowers; the var. aurea $\ddagger$ is one of the best yellow-leaved shrubs; $6-10 \mathrm{ft}$. 
Andromeda, Pieris floribunda.*

A small ericaceous evergreen; should have some protection from the winter sun; for this purpose, it may be planted on the north side of a clump of trees; $2-6 \mathrm{ft}$.

Shrubby cinquefoil, Potentilla fruticosa.*‡

Foliage ashy; flowers yellow, in June; $2-4 \mathrm{ft}$.

Sand cherry, Prunus pumila* and P. Besseyi.*

The sand cherry of sandy shores grows 5-8 ft; ; the western sand cherry $(P$. Besseyi) is more spreading and is grown for its fruit. The European dwarf cherry $(P$. fruticos $a)$ is $2-4 \mathrm{ft}$., with white flowers in umbels.

Flowering almond, P. Japonica.

In its double-flowered form, familiar for its early bloom; $3-5 \mathrm{ft}$; often grafted on other stocks, which are liable to sprout and become troublesome.

Hop-tree, Ptelea trifoliata.*

Very interesting when bearing its roundish winged fruits; $8-10 \mathrm{ft}$., but becoming larger and tree-like.

Buckthorn, Rhamnus cathartica.

Much used for hedges; 8-12 ft.

Alpine buckthorn, $R$. alpina.

Foliage attractive; $5-6 \mathrm{ft}$.

Rhododendron, Rhododendron Catawbiense* and garden varieties (p. 391).

Hardy in well-adapted locations, $3-8 \mathrm{ft}$., and higher in its native regions.

Great laurel, $R$. maximum.*

A fine species for mass planting, native as far north as southern Canada. Extensively transplanted from the wild.

White kerria, Rhodotypos kerrioides.

White flowers in May and blackish fruit ; 3-5 ft.

Smoke-tree (Fringe-tree erroneously), Rhus Cotinus.

One of the best shrubs for massing; two colors are grown; the billowy "bloom," holding late in the season, is composed of flower stems rather than flowers; size of large lilac bushes.

Dwarf sumac, $R$. copallina.*

Attractive in foliage, and especially conspicuous in autumn from the brilliant red of its leaves; 3-5 ft., sometimes much taller. 
Sumac, smooth and hairy, R. glabra* and R. typhina.*

Useful for the borders of large groups and belts. They may be cut down every year and allowed to sprout (as in Fig. 50). The young tops are handsomest. $R$. glabra is the finer species for this purpose. They usually grow 10-15 ft. tall.

Osbeck's sumac, $R$. semialata var. Osbeckii.

Strong bush, 10-20 ft., with leaf-rachis strongly winged, the foliage pinnately compound.

Flowering, or fragrant currant, Ribes aureum.*‡

Well known and popular, for its sweet-scented yellow flowers in May; 5$8 \mathrm{ft}$.

Red-flowering currant, $R$. sanguineum.*

Flowers red and attractive; 5-6 ft. R. Gordonianum, recommendable, is a hybrid between $R$. sanguineum and $R$. aureum.

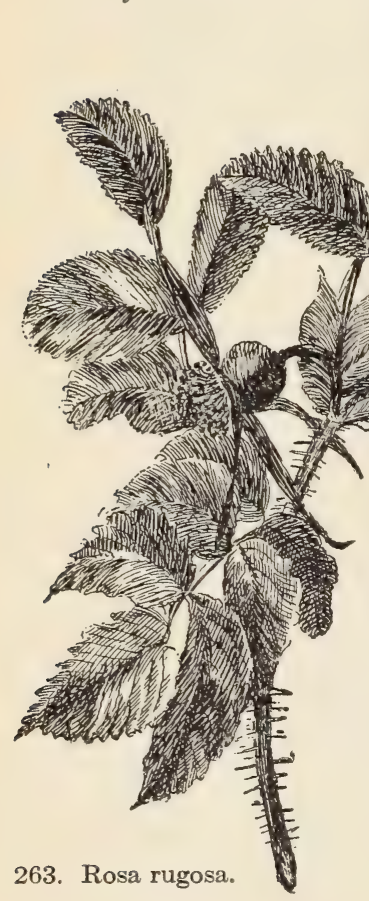

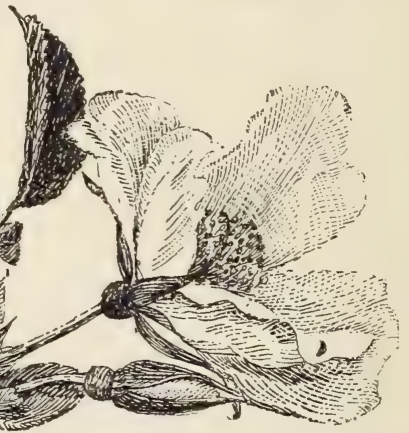
semi-double, and which do not require high culture, are to be preferred. It is not intended to include here the common garden roses; see Chapter VIII for these. It is much to be desired that the wild roses receive more attention from planters. Attention has been too exclusively taken by the highly improved garden roses.

Japanese rose, Rosa rugosa. $\ddagger$

Most excellent for lawn planting, as the foliage is thick and not attacked by insects (Fig. 263); white and pink flowered forms; $4-6 \mathrm{ft}$.

Wild swamp rose, $R$. Carolina.* 
Wild dwarf rose, $R$. humilis* ( $R$. lucida of Michigan).

This and cther wild dwarf roses, 3-6 ft., may be useful in landscape work.

Say's Rose, $R$. acicularis var. Sayi.*

Excellent for lawns; 4-5 ft.

Red-leaved rose, $R$. ferruginea (R. rubrifolia). +

Excellent foliage; flowers single, pink; 5-6 ft.

Japanese bramble, Rubus cratogifolius.

Valuable for holding banks; spreads rapidly; very red in winter; $3-4 \mathrm{ft}$.

Flowering raspberry, mulberry (erroneously), $R$. odoratus.*

Attractive when well grown and divided frequently to keep it fresh; there is a whitish form; $3-4 \mathrm{ft}$.

Japanese wineberry, $R$. phœnicolasius.

Attractive foliage and red hairy canes; fruit edible; 3-5 ft.

Kilmarnock willow, Salix Caproa, var. pendula.

A small weeping plant grafted on a tall trunk; usually more curious than ornamental.

Rosemary willow, S. rosmarinifolia $\ddagger$ of nurserymen ( $R$. incana properly).

6-10 ft.

Shining willow, S. lucida.*

Very desirable for the edges of water; 6-12 ft.

Long-leaved willow, S. interior.*

Our narrowest-leaved native willow; useful for banks; liable to spread too rapidly; $8-12 \mathrm{ft}$.

Fountain willow, S. purpurea.

Attractive foliage and appearance, particularly if cut back now and then to secure new wood; excellent for holding springy banks; $10-20 \mathrm{ft}$.

Pussy willow, S. discolor.*

Attractive when massed at some distance from the residence; $10-15 \mathrm{ft}$.

Laurel-leaved willow, $S$. pentandra (S. laurifotia of cultivators) $\ddagger$

See under Trees, p. 329.

Many of the native willows might well be cultivated. 
Elders, Sambucus pubens* and S. Canadensis.*

The former, the common "red elder," is ornamental both in flower and fruit. S. Canadensis is desirable for its profusion of fragrant flowers appearing in July; the former is 6-7 ft. high and the latter 8-10 ft.

Golden-leaved elder, S. nigra var. foliis aureis, $\ddagger$ and also the cut-leaved elder, are desirable forms of the European species; $5-15 \mathrm{ft}$.

Buffalo-berry, Shepherdia argentea.*

Silvery foliage; attractive and edible berries; $10-15 \mathrm{ft}$., often tree-like.

Shepherdia, S. Canadensis.*

Spreading bush, 3-8 ft., with attractive foliage and fruit.

Early spirea, Spircea arguta. $\ddagger$

One of the earliest bloomers among the spireas; $2-4 \mathrm{ft}$.

Three-lobed spirea, bridal wreath, S. Van Houttei. $\ddagger$

One of the most showy early-flowering shrubs; excellent for massing; blooms a little later than the above; $3-6 \mathrm{ft}$.

Sorbus-leaved spirea, S. sorbifolia (Sorbaria sorbifolia) +\$

Desirable for its late blooming, - late June and early July; 4-5 ft.

Plum-leaved spirea, S. prunifolia.

Fortune's spirea, S. Japonica (S. callosa), $\ddagger 2$ to $4 \mathrm{ft}$.

Thunberg's spirea, S. Thunbergii.

Neat and attractive in habit; useful for border-hedges; $3-5 \mathrm{ft}$.

St. Peter's Wreath, S. hypericifolia; 4-5 ft.

Round-leaved spirea, $S$. bracteata. $\ddagger$

Follows Van Houttei; 3-6 ft.

Douglas' spirea, S. Douglasii.*

Blossoms late, - in July; 4-8 ft.

Hard-hack, S. tomentosa.*

Much like the last, but less showy; 3-4 ft.

Willow-leaved spirea, S. salicifolia.*†

Blooms late; 4-5 ft.

Bladder-nut, Staphylea trifolia.*

Well-known rather coarse native shrub; 6-12 ft. 
Colchican bladder-nut, S. Colchica.

Good early flowering shrub; 6-12 ft.

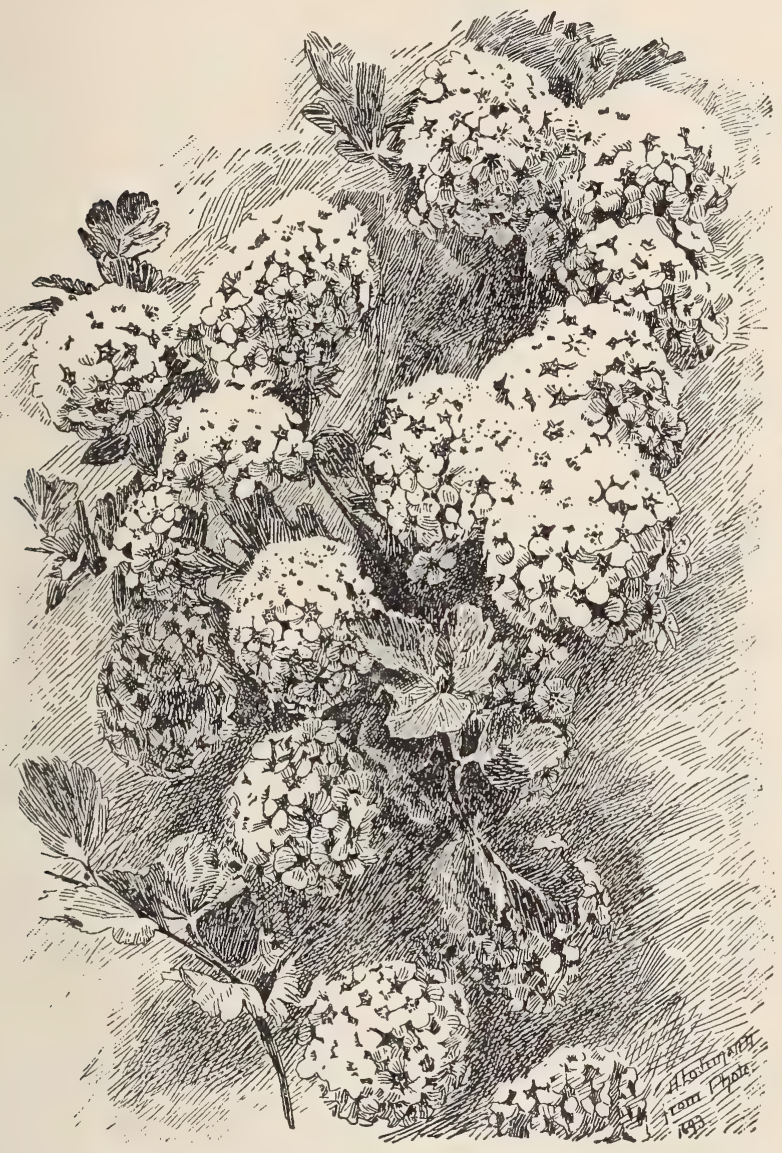

264. A spirea, one of the most serviceable flowering shrubs.

Styrax, Styrax Japonica.

One of the most graceful of flowering shrubs, producing fragrant flowers in early summer; 8-10 ft. or more. 
Snow-berry, Symphoricarpos racemosus.* $\ddagger$

Cultivated for its snow-white berries, that hang in autumn and early winter; $3-5 \mathrm{ft}$.

Indian currant, S. vulgaris.*

Foliage delicate; berries red; valuable for shady places and against walls; 4-5 ft.

Common lilac, Syringa vulgaris. $\ddagger$ (The name syringa is commonly mis applied to the species of Philadelphus.)

The standard spring-blooming shrub in the North; 8-15 ft.; many forms. Josika lilac, S. Josikœa.

Blooming about a week later than S. vulgaris; 8-10 ft.

Persian lilac, S. Persica.

More spreading and open bush than S. vulgaris; $6-10 \mathrm{ft}$.

Japanese lilac, S. Japonica $\ddagger$

Blooms about one month later than common lilac; 15-20 ft.

Rouen lilac, S. Chinensis (or Rothomagensis). $\ddagger$

Blooms with the common lilac; flowers more highly colored than those of S. Persica; $5-12 \mathrm{ft}$.

Chinese lilacs, S. oblata $\ddagger$ and S. villosa. $\ddagger$

The former 10-15 ft. and blooming with common lilac; the latter 4-6 ft., and blooming few days later.

Tamarisk, Tamarix of several species, particularly (for the North)

T. Chinensis, T. Africana (probably the garden forms under this name are all $T$. parviflora), and $T$. hispida (T. Kashgarica).

All odd shrubs or small trees with very fine foliage, and minute pink flowers in profusion.

Common snowball, Viburnum Opulus.* $\ddagger$

The cultivated snowball $\ddagger$ is a native of the Old World; but the species grows wild in this country (known as High-bush Cranberry), $\ddagger$ and is worthy of cultivation; 6-10 ft.

Japanese snowball, V. tomentosum (catalogued as V. plicatum). 6-10 ft.

Wayfaring tree, V. Lantana. $\ddagger$

Fruit ornamental; 8-12 ft., or more. 
Plum-leaved haw, $V$. prunifolium.* $*$

Leaves smooth and glossy; $8-15 \mathrm{ft}$.

Sweet viburnum or sheep-berry, $V$. Lentago.*

Tall coarse bush, or becoming a small tree.

Arrow-wood, $V$. dentatum.*

Usually 5-8 ft., but becoming taller.

Dockmackie, $V$. acerifolium.*

Maple-like foliage; $4-5 \mathrm{ft}$.

Withe-rod, lilac viburnum, $V$. cassinoides.*

2-5 ft.

Other native and exotic viburnums are desirable.

Xanthoceras, Xanthoceras sorbifolia.

Allied to the buckeyes; hardy in parts of New England; 8-10 ft.; handsome.

Prickly ash, Zanthoxylum Americanum.*

Shrubs for the South.

Many of the shrubs in the preceding catalogue are also well adapted to the southeastern states. The following brief list includes some of the most recommendable kinds for the region south of Washington, although some of them are hardy farther North. The asterisk (*) denotes that the plant is native to this country.

The crape myrtle (Lagerstrœmia Indica) is to the South what the lilac is to the North, a standard dooryard shrub; produces handsome red (or blush or white) flowers all summer; 8-12 feet.

Reliable deciduous shrubs for the South are: althea, Hibiscus Syriacus, in many forms; Hibiscus Rosa-Sinensis; Azalea calendulacea,* mollis, and the Ghent azalea (A. Pontica); blue spirea, Caryopteris Mastacanthus; European forms of ceanothus; French mulberry, Callicarpa Americana*; calycanthus*; flowering willow, Chilopsis linearis*; fringe, Chionanthus Vir- 
ginica*; white alder, Clethra alnifolia*; corchorus, Kerria Japonica; deutzias, of several kinds; goumi, Eloxagnus longipes; pearl bush, Exochorda grandiflora; Japan quince, Cydonia Japonica; golden-bell, Forsythia viridissima; broom, Spartium junceum; hydrangeas, including $H$. Otaksa, grown under cover in the North; Jasminum nudiflorum; bush honeysuckles; mock orange, Philadelphus coronarius and grandiflorus*; pomegranate; white kerria, Rhodotypos kerrioides; smoke tree, Rhus Cotinus; rose locust, Robinia hispida*; spireas of several kinds; Stuartia pentagyna*; snowberry, Symphoricarpos racemosus*; lilacs of many kinds; viburnums of several species, including the European and Japanese snowballs; weigelas of the various kinds; chaste-tree, Vitex Agnus-Castus; Thunberg's barberry; red pepper, Capsicum frutescens; Plumbago Capensis; poinsettia.

A large number of broad-leaved evergreen shrubs thrive in the South, such as: fetter bush, Andromeda floribunda*; some of the palms, as palmettoes* and chamærops; cycas and zamia* far South; Abelia grandiflora; strawberry tree, Arbutus Unedo; ardisias and aucubas, both grown under glass in the North; azaleas and rhododendrons (not only $R$. Catawbiense, ${ }^{*}$ but $R$. maximum, ${ }^{*} R$. Ponticum, and the garden forms); Kalmia latifolia*; Berberis Japonica and mahonia*; box ; Cleyera Japonica; cotoneasters and pyracantha; eleagnus of the types grown under glass in the North; gardenias; euonymus*; hollies*; anise-tree, Illicium anisatum; cherry laurels, Prunus or Laurocerasus of several species; mock orange (of the South), Prunus Carotiniana, * useful for hedges; true laurel or bay-tree, Laurus nobilis; privets of several species; Citrus trifoliata, specially desirable for hedges; oleanders; magnolias*; myrtle, Myrtus communis; Osmanthus (Olea) fragrans, a greenhouse shrub North; Osmanthus Aquifolium*; butcher's broom, Ruscus aculeatus; phillyreas*; Pittosporum Tobira; shrubby yuccas *; Viburnum Tinus and others; and the camellia in many forms. 



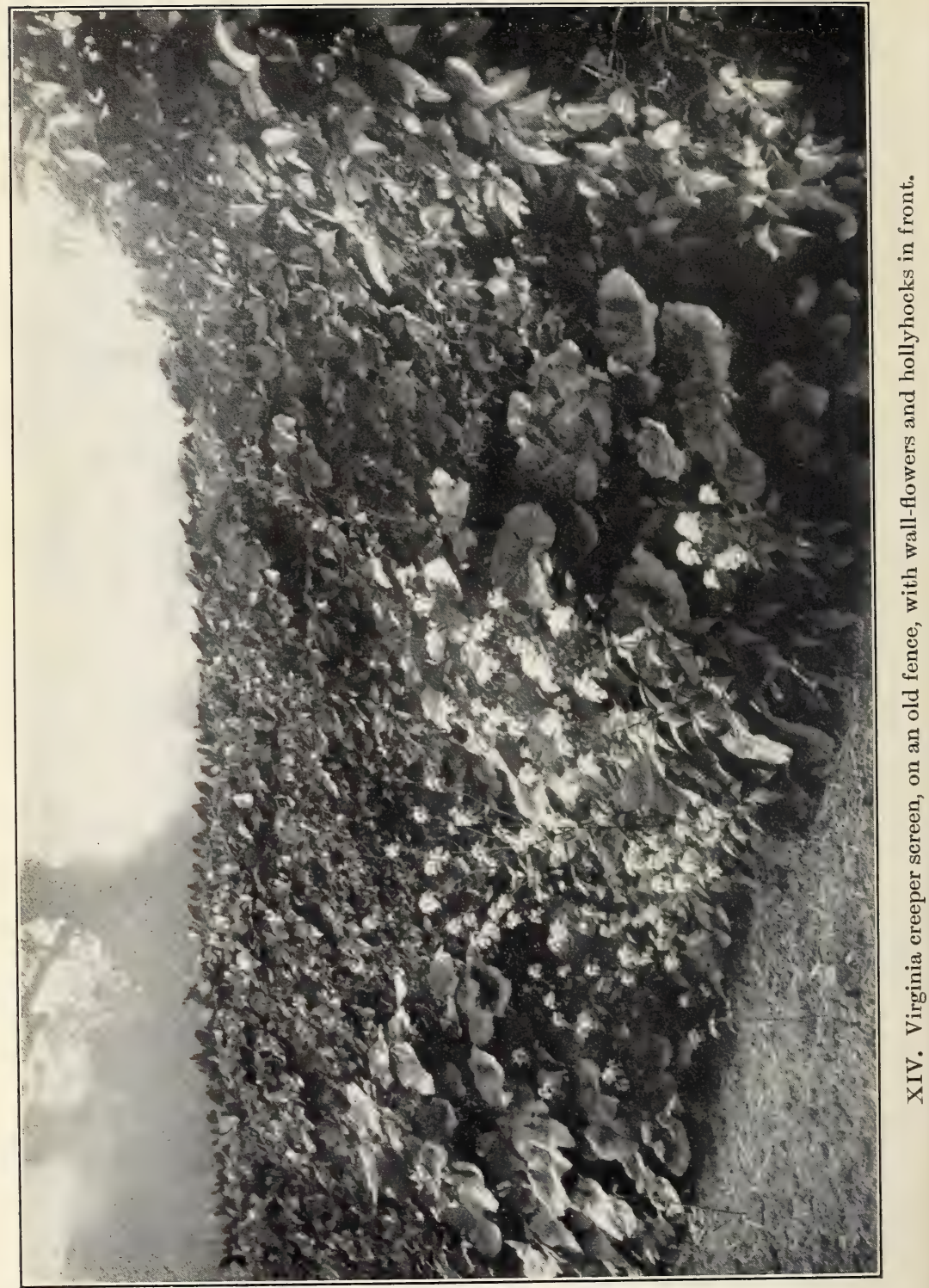




\section{Chimbing Plants}

Vines do not differ particularly in their culture from other herbs and shrubs, except as they require that supports be provided; and, as they overtop other plants, they demand little room on the ground, and they may therefore be grown in narrow or unused spaces along fences and walls.

In respect to the modes of climbing, vines may be thrown into three groups, - those that twine about the support; those that climb by means of special organs, as tendrils, roots, leafstalks; those that neither twine nor have special organs but that scramble over the support, as the climbing roses and the brambles. One must recognize the mode of climbing before undertaking the cultivation of any vine.

Vines may also be grouped into annuals, both tender (as morning-glory) and hardy (as sweet pea); biennials, as adlumia, which are treated practically as annuals, being sown each year for bloom the next year; herbaceous perennials, the tops dying each fall down to a persisting root, as cinnamon vine and madeira vine; woody perennials (shrubs), the tops remaining alive, as Virginia creeper, grape, and wistaria.

There is scarcely a garden in which climbing plants may not be used to advantage. Sometimes it may be to conceal obtrusive objects, again to relieve the monotony of rigid lines. They may also be used to run over the ground and to conceal its nakedness where other plants could not succeed. The shrubby kinds are often useful about the borders of clumps of trees and shrubbery, to slope the foliage down to the grass, and to soften or erase lines in the landscape.

In the South and in California, great use is made of vines, not only on fences but on houses and arbors. In warm countries, vines give character to bungalows, pergolas, and other individual forms of architecture.

If it is desired that the vines climb high, the soil should be 
fertile; but high climbing in annual plants (as in sweet peas) may be at the expense of bloom.

The use of vines for screens and pillar decorations has increased in recent years until now they may be seen in nearly all grounds. The tendency has been towards using the hardy vines, of which the ampelopsis, or Virginia creeper, is one of the most common. This is a very rapid grower, and lends itself to training more readily than many others. The Japan ampelopsis (A. tricuspidata or Veitchii) is a good clinging vine, growing very rapidly when once established, and brilliantly colored after the first fall frosts. It clings closer than the other, but is not so hardy. Either of these may be grown from cuttings or division of the plants.

Two recommendable woody twiners of recent distribution are the actinidia and the akebia, both from Japan. They are perfectly hardy, and are rapid growers. The former has large thick glossy leaves, not affected by insects or disease, growing thickly along the stem and branches, making a perfect thatch. It blooms in June. The flowers, which are white with a purple center, are borne in clusters, followed by round or longish edible fruits. The akebia has very neat-cut foliage, quaint purple flowers, and often bears ornamental fruit.

Of the tender vines, the nasturtiums and ipomeas and morning-glories are the most common in the North, while the adlumia, balloon vine, passion vine, gourds, and others, are frequently used. One of the best of recent introduction is the annual hop, especially the variegated variety. This is a very rapid-growing vine, seeding itself each year, and needing little care. The climbing geraniums (Pelargonium peltatum and its derivatives) are much used in California. All the tender vines should be planted after danger of frost is past.

So many good vines are now on the market that one may grow a wide variety for many uses. The home gardener should keep his eyes open for the wild vines of his neighborhood and 
add the best of them to his collection. Most of these natives are worthy of cultivation. Even the poison ivy makes a very satisfactory cover for rough and inaccessible places in the wild, and its autumn color is very attractive; but of course its cultivation cannot be recommended.

Vines that cling closely to walls of buildings are Virginia creeper (one form does not cling well), Boston or Japanese ivy (Ampelopsis tricuspidata; also A. Lowii, with smaller foliage), English ivy, euonymus (E.radicans and the var. variegata), and Ficus repens far south; others that cling less closely are trumpet creeper, and climbing hydrangea (Schizophragma hydrangeoides).

Vines for trailing, or covering the ground, are periwinkle (Vinca), herniaria, moneywort (Lysimachia nummularia), ground-ivy (Nepeta Glechoma), Rosa Wichuraiana, species of native greenbrier or smilax (not the so-called smilax of florists), Rubus laciniatus, dewberries, and also others that usually are not classed as vines. In the South, Japanese honeysuckle and Cherokee rose perform this function extensively. In California, species of mesembryanthemum (herbaceous) are extensively used as ground covers on banks. Page 86 .

For quickly covering brush and rough places, the many kinds of gourds may be used; also pumpkins and squashes, watermelons, Cucumis foetidissima, wild cucumbers (Echinocystis lobata and Sicyos angulata), nasturtiums, and other vigorous annuals. Many of the woody perennials may be used for such purposes, but usually these places are only temporary.

For arbors, strong woody vines are desired. Grapes are excellent; in the South the muscadine and scuppernong grapes are adaptable to this purpose (Plate XV). Actinidia and wistaria are also used. Akebia, dutchman's pipe, trumpet creeper, clematis, honeysuckles, may be suggested. Roses are much used in warm climates.

For covering porches, the standard vine in the North is Vir- 
ginia creeper. Grapes are admirable, particularly some of the wild ones. Japan honeysuckle is much used; and it has the advantage of holding its foliage well into the winter, or even all winter southward. Actinidia, akebia, wistaria, roses, dutchman's pipe, and clematis are to be recommended; the largeflowered clematises, however, are more valuable for their bloom than for their foliage ( $C$. paniculata, and the native species are better for covering porches).

The annual vines are mostly used as flower-garden subjects, as the sweet pea, morning-glories, mina, moonflowers, cypress vine, nasturtiums, cobea, scarlet runner. Several species of convolvulus, closely allied to the common morning-glory, have now enriched our lists. For baskets and vases the maurandia and the different kinds of thunbergias are excellent.

The moonflowers are very popular in the South, where the seasons are long enough to allow them to develop to perfection. In the North they must be started early (it is a good plan to soak or notch the seeds) and be given a warm exposure and good soil (see in Chap. VIII).

In the following lists, the plants native to the United States or Canada are marked by an asterisk $(*)$.

Annual herbaceous climbers.

(Grown each year from seed.)

a. Tendril-climbers

Adlumia (biennial).*

Balloon Vine (Cardiospermum).*

Cobea.

Gourds.

Nasturtiums (Tropcolum).

Canary-bird Flower (Tropæolum peregrinum).

Sweet pea (Fig. 265).

Wild cucumber.*

Maurandia. 
Gourds or gourd-like plants, as, Coccinia Indica; Cucumis of several interesting species, as C. erinaceus, grossulariaformis, odoratissimus; dipper or bottle gourd (Lagenaria); vegetable sponge, dish-cloth gourd, rag gourd (Luffa); balsam apple, balsam pear (Momordica); snake gourd (Trichosanthes); bryonopsis ; Abobra viridiflora.

All the above except sweet pea are quickly cut down by frost.

b. Twiners

Beans, Flowering.

Cypress vine.

Dolichos Lablab, and others.

Hop, Japanese.

Ipomœa Quamoclit (cypress vine) and others.

Moonflower, several species.

Morning-glory.

Mina lobata.

Thunbergia.

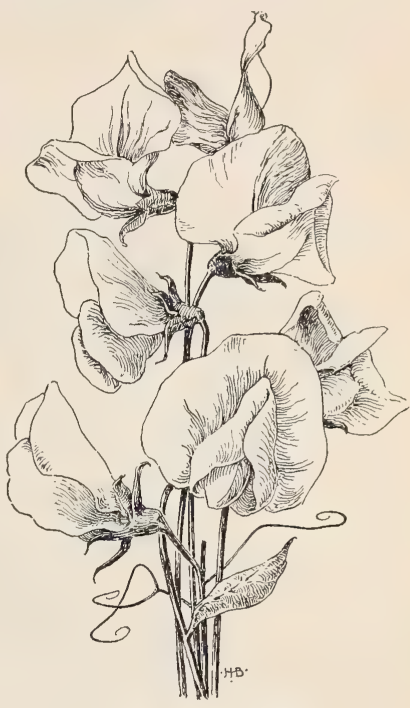

265. Sweet pea.

Mikania scandens.*

Butterfly pea, Centrosema Virginiana.*

Scarlet runner, Phaseolus multiflorus (perennial South).

Velvet or banana bean, Mucuna pruriens var. utilis (for the South).

\section{Perennial herbaceous climbers.}

(The tops dying down in fall, but the root living over winter and sending up a new top.)

\section{a. Tendril-climbers or root-climbers}

Everlasting pea, Lathyrus latifolius.

Clematis of various species, as C. aromatica, Davidiana, heracleafolia (C. tubulosa), are more or less climbing. Most of the clematises are shrubs. 
May-pop, Passiflora incarnata.*

Not reliable north of Virginia.

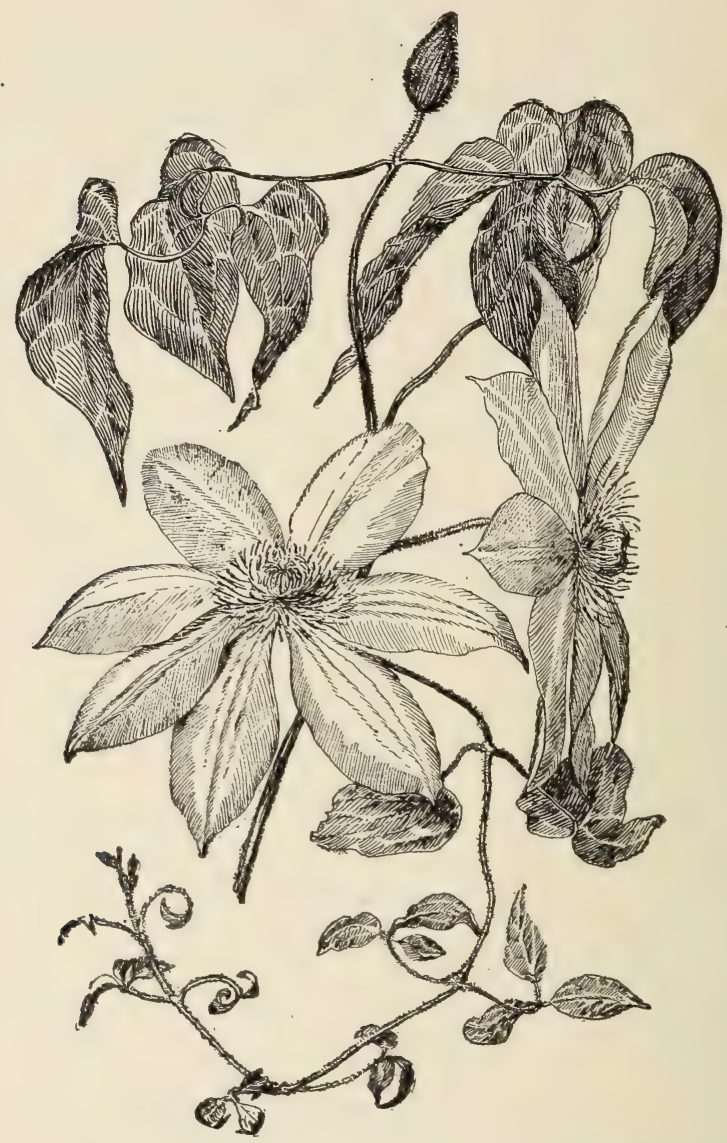

266. Clematis Henryi. One-third natural size.

Wild Gourd, Cucurbita fœtidissima (Cucumis perennius).*

Excellent strong rugged vine for covering piles on the ground. 
Mexican rose, mountain rose, Antigonon leptopus.

Root tuberous; a rampant grower, with pink bloom; outdoors South, and a conservatory plant North. .

Kenilworth ivy, Linaria Cymbalaria.

A very graceful little perennial vine, re-sowing itself even where not hardy; favorite for baskets.

\section{b. Herbaceous twiners}

Hop, Humulus Lupulus.*

Produces the hops of commerce, but should be in common use as an ornamental plant.

Chinese yam, cinnamon vine, Dioscorea divaricata (D. Batatas).

Climbs high, but does not produce as much foliage as some other vines.

Wild yam, D. villosa.*

Smaller than the preceding; otherwise fully as good.

Ground-nut, Apios tuberosa.*

A bean-like vine, producing many chocolate-brown flowers in August and September.

Scarlet runner and White Dutch runner beans, Phaseolus multiflorus.

Perennial in warm countries; annual in the North.

Moonflowers, Ipomaa, various species.

Some are perennials far South, but annual North.

Hardy moonflower, Ipomcea pandurata.*

A weed where it grows wild, but an excellent vine for some purposes.

Wild morning-glory, Rutland beauty, Convolvulus Sepium,* and California rose, C. Japonicus.

The former, white and pink, is common in swales. The latter, in double or semi-double form, is often run wild.

Madeira vine, mignonette vine, Boussingaultia baselloides.

Root a large, tough, irregular tuber.

Mikania, climbing hempweed, Mikania scandens.*

A good compositous twiner, inhabiting moist lands. 


\section{Woody perennial climbers.}

(Climbing shrubs, the tops not dying down in fall except in climates in which they are not hardy.)

\section{a. Tendril-climbers, root-climbers, scramblers, and trailers}

Virginia creeper, Ampelopsis quinquefolia**

The best vine for covering buildings in the colder climates. Plants should be selected from vines of known habit, as some individuals cling much better than others. Var. hirsuta,* strongly clinging, is recommended by the experimental station at Ottawa, Canada. Var. Engelmanni* has small and neat foliage.

Japanese iry, Boston iry, A. tricuspidata (A. Veitchii).

Handsomer than the Virginia creeper, and clings closer, but is often injured by winter in exposed places, especially when young; in northern regions, tops should be protected for first year or two.

Variegated ivy, A. heterophylla var. elegans (Cissus variegata).

Handsome delicate hardy grape-like vines with mostly three-lobed blotched leaves and bluish berries.

Garden clematis, Clematis of various species and varieties.

Plants of robust and attractive habit, and gorgeous blooms; many garden forms. C. Jackmani, and its rarieties, is one of the best. C. Henryi (Fig. 266 ) is excellent for white flowers. Clematises bloom in July and August.

Wild clematis, $C$. Virginiana.*

Very attractive for arbors and for corering rude objects. The pistillate plants bear curious woolly balls of fruit.

Wild clematis, C. verticillaris.*

Less vigorous grower than the last, but excellent.

Japanese clematis, $C$. paniculata.

The best late-blooming woody vine, producing enormous masses of white flowers in late summer and early fall.

Trumpet creeper, Tecoma radicans.*

One of the best of all free-flowering shrubs; climbs by means of roots; flowers very large, orange-scarlet.

Chinese trumpet creeper, T. grandiflora (Bignonia grandiflora).

Flowers orange-red; sometimes scarcely climbing. 
Bignonia, Bignonia capreolata.*

A good strong evergreen vine, but often a nuisance in fields in the South.

Frost grape, Vitis cordifolia.*

One of the finest of all vines. It is a very tall grower, producing thick, heavy, dark leaves. Its foliage often reminds one of that of the moon-seed. Does not grow readily from cuttings.

Summer and river-bank grapes, $V$. bicolor,* and $V$. vulpina (riparia).*

The common wild grapes of the Northern states.

Muscadine, scuppernong, $V$. rotundifolia.*

Much used for arbors in the Southern states (Plate XV).

Ivy, Hedera Helix.

The European ivy does not endure the bright sun of our winter; on the north side of a building it often does well; the best of vines for covering buildings, where it succeeds; hardy in favorable localities as far north as southern Ontario; many forms.

Greenbrier, Smilax rotundifolia* and S. hispida.*

Unique for the covering of small arbors and summer-houses.

Euonymus, Euonymus radicans.

A very close-clinging root-climber, excellent for low walls; evergreen; the variegated variety is good.

Climbing fig, Ficus repens.

Used in greenhouses North, but is hardy far South.

Matrimony vine, boxthorn, Lycium Chinense.

Flowering all summer; flowers rose-pink and buff, axillary, star-like, succeeded by scarlet berries in the fall; stems prostrate, or scrambling; an oldfashioned vine on porches.

\section{Bitter-sweet, Solanum Dulcamara.}

A common scrambling or semi-twining vine along roadsides, with brilliant red poisonous berries; top dies down or nearly so.

Periwinkles, Vinca minor and $V$. major.

The former is the familiar trailing evergreen myrtle, with blue flowers in early spring; in its variegated form the latter is much used for hanging baskets and vases. 
Climbing hydrangea, Schizophragma hydrangeoides.

Clings to walls by rootlets, producing white flowers in midsummer.

Passion-flower, species of Passiflora and Tacsonia.

Used in the South and in California.

Actinidia, Actinidia arguta.

\section{b. Woody twiners}

Very strong grower, with beautiful thick foliage that is not attacked by insects or fungi; one of the best vines for arbors.

Akebia, Akebia quinata.

Very handsome and odd Japanese vine; a strong grower, and worthy general planting.

Honeysuckles, woodbine, Lonicera of many kinds.

Japanese honeysuckle, L. Halliana (a form of L. Japonica).

10-20 ft.; flowers, white and buff, fragrant mainly in spring and fall; leaves small, evergreen; stems prostrate and rooting, or twining and climbing. Trellises, or for covering rocks and bare places; extensively run wild in the South. Var. aurea reticulata is similar to the type, but with handsome golden appearance.

Belgian Honeysuckle, L. Periclymenum var. Belgica.

6-10 ft.; monthly; flowers in clusters, rosy red, buff within; makes a large, rounded bush.

Coral or trumpet honeysuckle, L. sempervirens.*

6-15 ft.; June; scattering scarlet flowers through the summer; with no support makes a large rounded bush; for trellises, fences, or a hedge; it is one of the list of hardy trees and shrubs recommended for Canada by the Experiment Station at Ottawa.

Honeysuckle, L. Caprifolium, with cup-like connate leaves.

Good native climbing honeysuckles are L. flava,* Sullivanti,* hirsuta,* dioica,* and Douglasi.*

Wistaria, Wistaria Sinensis and W. speciosa.*

The Chinese species, Sinensis, is a superb plant; flowers blue-purple; there is a white-flowered variety.

Japanese wistaria, W. multijuga.

Flowers smaller and later than the Chinese, in looser racemes. 
Dutchman's pipe, Aristolochia macrophylla (A. Sipho).*

A robust grower, possessing enormous leaves. Useful for covering verandas and arbors.

Wax-work or false bitter-sweet, Celastrus scandens.*

Very ornamental in fruit; flowers imperfect.

Japanese celastrus, $C$. orbiculatus ( $C$. articulatus of the trade).

$C$. articulatus and $C$. scandens are in the list of 100 trees and shrubs recommended by the Experiment Station at Ottawa for Canada.

Moonseed, Menispermum Canadense.*

A small but very attractive twiner, useful for thickets and small arbors.

Bokhara climbing polygonum, Polygonum Baldschuanicum.

Hardy North, although the young growth may be killed; flowers numerous, minute, whitish; interesting, but does not make a heavy cover.

Kudzu vine, Pueraria Thunbergiana (Dolichos Japonicus).

Makes very long growths from a tuberous root; shrubby South, but dies to the ground in the North.

Silk vine, Periploca Groca.

Purplish flowers in axillary clusters; long, narrow, shining leaves; rapid growing.

Potato vine, Solanum jasminoides.

A good evergreen vine South, particularly the var. grandiflorum.

Yellow jasmine, Gelsemium sempervirens.*

A good native evergreen vine for the South, with fragrant yellow flowers.

Malayan jasmine, Trachelospermum (or Rhynchospermum) jasminoides.

A good evergreen vine for the South and in California.

Climbing asparagus, Asparagus plumosus.

Popular as an outdoor vine far South and in California.

Jasmines, Jasminum of several species.

The best known in gardens are $J$. nudiflorum, yellow in earliest spring, $J$. officinale, the jessamine of poetry, with white flowers, and'J. Sambac, the Arabian jasmine (and related species) with white flowers and unbranched leaves; these are not hardy without much protection north of Washington or Philadelphia, and J. Sambac only far South. 
Bougainvillea, Bougainvilloea glabra and B. spectabilis.

The magenta-flowered variety, sometimes seen in conservatories in the North, is a popular outdoor vine in the South and is profusely used in southern California. The red-flowered form is less seen, but is preferable in color.

Wire-vine (polygonum of florists), Muehlenbeckia complexa.

Abundantly used on buildings and chimneys in southern California.

\section{Climbing roses.}

The roses do not twine nor possess any special climbing organs; therefore they must be provided with a.trellis or woven-wire

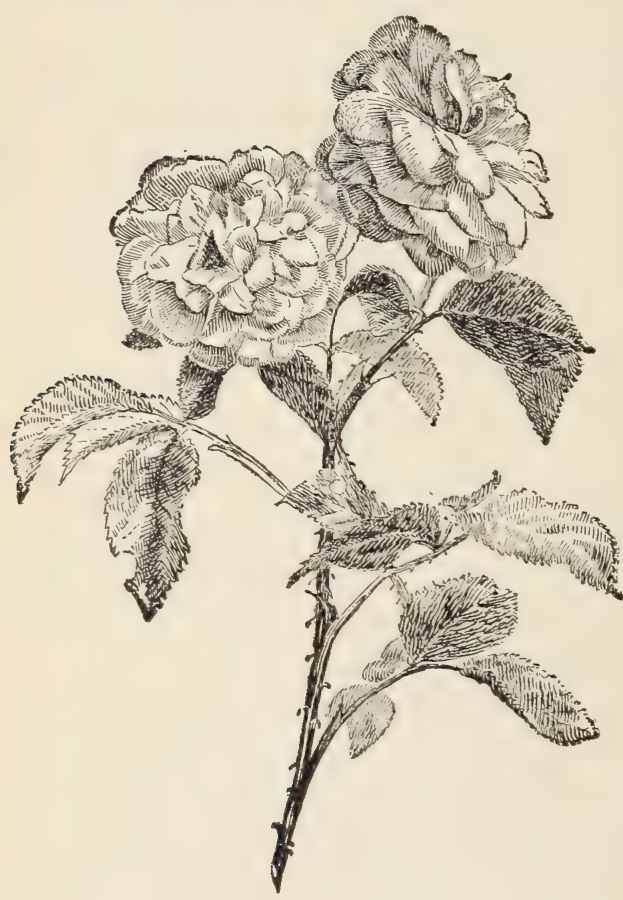

267. Climbing rose, Jules Margottin. fence. Some of the roses classed as climbing are such as only need good support, Fig. 267. For culture of roses,seeChapterVIII.

The most popular climbing or pillar rose at present is Crimson Rambler, but while it makes a great display of flowers, it is not the best climbing rose. Probably the best of the real climbing roses for this country, bloom, foliage, and habit all considered, are the derivatives of the native prairie rose, Rosa setigera (native as far north as Ontario and Wisconsin). Baltimore Belle and Queen of the Prairie belong to this class. 



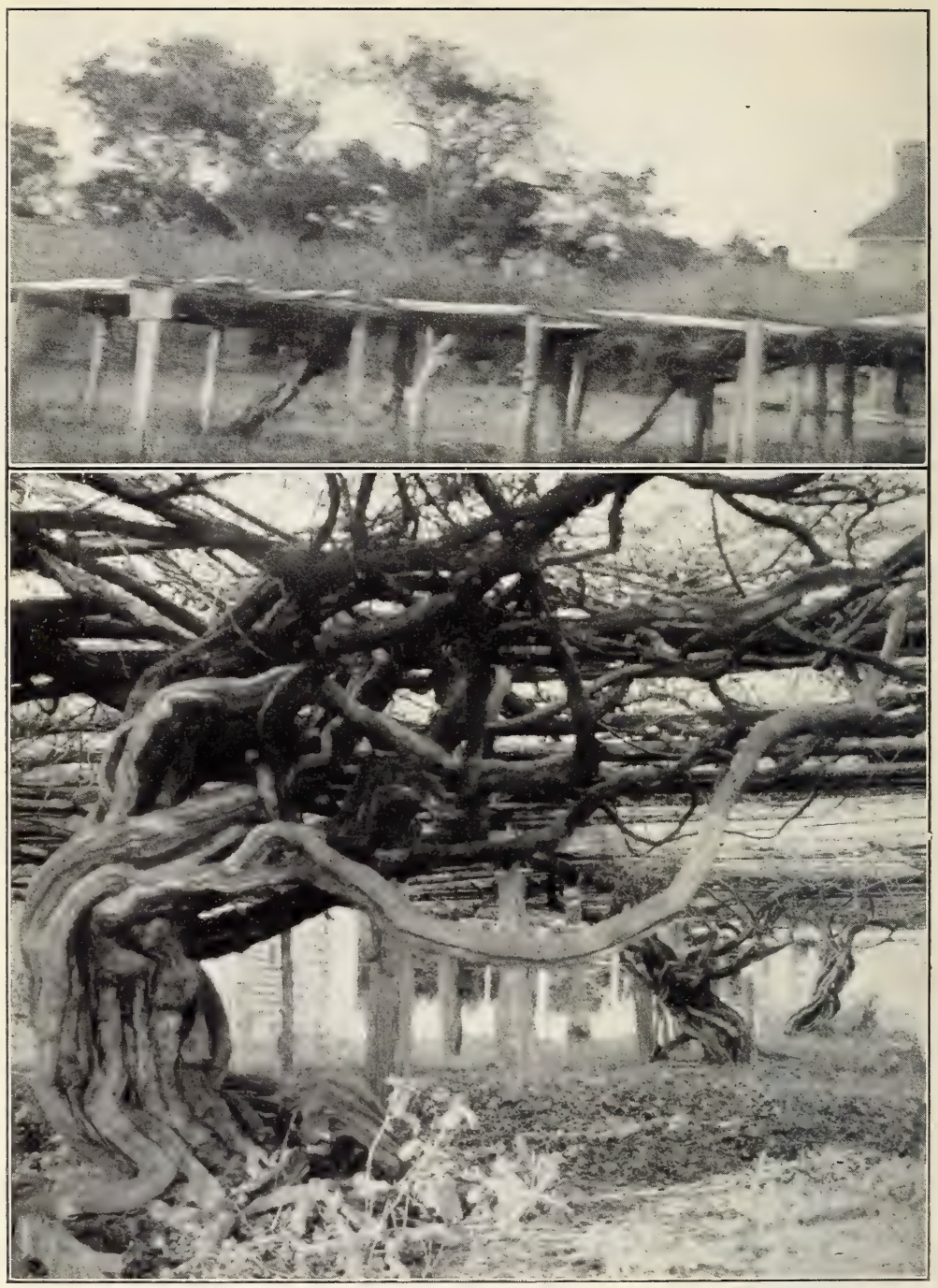

XV. Scuppernong grape, the arbor vine of the South. This plate shows the noted scuppernongs on Roanoke Island, of which the origin is unknown, but which were of great size more than one hundred years ago. 
The climbing polyantha roses (hybrids of Rosa multiflora and other species) include the class of "rambler" roses that has now come to be large, including not only the Crimson Rambler, but forms of other colors, single and semi-double, and various climbing habits; a very valuable and hardy class of roses, particularly for trellises.

The Memorial rose ( $R$. Wichuraiana) is a trailing, half-evergreen, white-flowered species, very useful for covering banks and rocks. Derivatives of this species of many kinds are now available, and are valuable.

The Ayrshire roses ( $R$. arvensis var. capreolata) are profuse but rather slender growers, hardy North, bearing double white or pink flowers.

The Cherokee rose (R. lovigata or $R$. Sinica) is extensively naturalized in the South, and much prized for its large white bloom and shining foliage; not hardy in the North.

The Banksia rose (R. Banksioe) is a strong climbirg rose for the South and California with yellow or white lowers in clusters. A larger-flowered form (R. Fortuneana) is a hybrid of this and the Cherokee rose.

The climbing tea and noisette roses, forms of $R$. Chinensis and $R$. Noisettiana, are useful in the open in the South.

\section{Trees for Lawns and Streets}

A single tree may give character to an entire home property; and a place of any size that does not have at least one good tree usually lacks any dominating landscape note.

Likewise, a street that is devoid of good trees cannot be the best residential section; and a park that lacks well-grown trees is either immature or barren.

Although the list of good and hardy lawn and street trees is rather extensive, the number of kinds generally planted and recognized is small. Since most home places can have but few trees, and since they require so many years to mature, it is 
natural that the home-maker should hesitate about experimenting, or trying kinds that he does not himself know. So the homemaker in the North plants maples, elms, and a white birch, and in the South a magnolia and China-berry. Yet there are numbers of trees as useful as these, the planting of which might give our premises and streets a much richer expression.

It is much to be desired that some of the trees with "strong" and rugged characters be introduced into the larger grounds; such, for example, as the hickories and oaks. These may often transplant with difficulty, but the effort to secure them is worth the expenditure. Good trees of oaks, and others supposed to be difficult to transplant, may now be had of the leading nurserymen. The pin oak (Quercus palustris) is one of the best street trees and is now largely planted.

It is at least possible to introduce a variety of trees into a city or village, by devoting one street or a series of blocks to a single kind of tree, - one street being known by its lindens, one by its plane-trees, one by its oaks, one by its hickories, one by its native birches, beech, coffee-tree, sassafras, gum or liquidambar, tulip tree, and the like. There is every reason why a city, particularly a small city or a village, should become to some extent an artistic expression of its natural region.

The home-maker is fortunate if his area already possesses well-grown large trees. It may even be desirable to place the residence with reference to such trees (Plate VI); and the planning of the grounds should accept them as fixed points to which to work. The operator will take every care to preserve and safeguard sufficient of the standing trees to give the place singularity and character.

The care of the tree should include not only the protecting of it from enemies and accidents, but also the maintaining of its characteristic features. For example, the natural rough bark should be maintained against the raids of tree-scrapers; and the grading should not be allowed to disguise the natural bulge 
of the tree at the base, for a tree that is covered a foot or two above the natural line is not only in danger of being killed, but it looks like a post.

The best shade trees are usually those that are native to the particular region, since they are hardy and adapted to the soil and other conditions. Elms, maples, basswoods, and the like are nearly always reliable. In regions in which there are serious insect enemies or fungous diseases, the trees that are most likely to be attacked may be omitted. For instance, in parts of the East the chestnut bark-disease is a very great menace; and it is a good plan in such places to plant other trees than chestnuts.

A good shade tree is one that has a heavy foliage and dense head, and that is not commonly attacked by repelling insects and diseases. Trees for shade should ordinarily be given sufficient room that they may develop into full size and symmetrical heads. Trees may be planted as close as 10 or 15 feet apart for temporary effect; but as soon as they begin to crowd they should be thinned, so that they develop their full characteristics as trees.

Trees may be planted in fall or spring. Fall is desirable, except for the extreme North, if the land is well drained and prepared and if the trees may be got in early; but under usual conditions, spring planting is safer, if the stock has been wintered well (see discussion under Shrubs, p. 290). Planting and pruning are discussed on pp. 124 and 139.

If one desires trees with conspicuous bloom, they should be found among the magnolias, tulip trees, kolreuteria, catalpas, chestnuts, horse-chestnut and buckeyes, cladrastis, black or yellow locust, wild black cherry, and less conspicuously in the lindens; and also in such half-trees or big shrubs as cercis, cytisus, flowering dogwood, double-flowered and other forms of apples, crab-apples, cherries, plums, peaches, hawthorn or cratægus, amelanchier, mountain ash. 
Among drooping or weeping trees the best may be found in the willows (Salix Babylonica and others), maples (Wier's), birch, mulberry, beech, ash, elm, cherry, poplar, mountain ash.

Purple-leaved varieties occur in the beech, maple, elm, oak, birch, and others.

Yellow-leaved and tricolors occur in the maple, oak, poplar, elm, beech, and other species.

Cut-leaved forms are found in birch, beech, maple, alder, oak, basswood, and others.

\section{List of hardy deciduous trees for the North.}

(The genera are arranged alphabetically. Natives are marked by *; good species for shade trees by $\dagger$; those recommended by the Experiment Station at Ottawa, Ontario, by $\ddagger$.)

In a number of the genera, the plants may be shrubby rather than arboreus in some regions (see the Shrub list), as in acer (A. Ginnala, A. spicatum), æsculus, betula (B. pumila), carpinus, castanea (C. pumila), catalpa (C. ovata), cercis, magnolia (M. glauca particularly), ostrya, prunus, pyrus, salix, sorbus.

Norway maple, Acer platanoides. $\dagger$

One of the finest medium-sized trees for single lawn specimens; there are several horticultural varieties. Var. Schwedlerił is one of the best of purpleleaved trees. The Norway maple droops too much and is too low-headed for roadside planting.

Black sugar maple, A. nigrum.*†

Darker and softer in aspect than the ordinary sugar maple.

Sugar maple, A. saccharum.*†‡

This and the last are among the very best roadside trees.

Silver maple, A. saccharinum (A. dasycarpum).*†

Desirable for water-courses and for grouping; succeeds on both wet and dry lands.

Wier's cut-leaved silver maple, A. saccharinum var. Wieri.†‡

Light and graceful; especially desirable for pleasure grounds. 
Red, soft, or swamp maple, 1. rubrum.*

Valuable for its spring and autumn colors, and for variety in grouping.

Sycamore maple, A. Pseudo-platanus.

A slow grower, to be used mostly as single specimens. Several horticultural varieties.

English maple, A. campestre.

A good medium-sized tree of slow growth, not hardy on our northern borders; see under Shrubs (p. 291).

Japan maple, A. palmatum (A. polymorphum).

In many forms, useful for small lawn specimens; does not grow above $10-20 \mathrm{ft}$.

Siberian maple, A. Ginnala. $\ddagger$

Attractive as a lawn specimen when grown as a bush; the autumn color is very bright; small tree or big shrub.

Mountain maple, A. spicatum.*

Very bright in autumn.

Box-elder, Acer Negundo (Negundo aceroides or fraxinifolium).*†

Very hardy and rapid growing; much used in the West as a windbreak, but not strong in ornamental features.

Horse chestnut, Esculus Hippocastanum. $\dagger$

Useful for single specimens and roadsides; many forms.

Buckeye, A. octandra (E. flava).*†

Ohio buckeye, $E$. glabra.*

Red buckeye, A. carnea (E. rubicunda).

Ailanthus, Ailanthus glandulosa.

A rapid grower, with large pinnate leaves; the staminate plant possesses a disagreeable odor when it flowers; suckers badly; most useful as a shrub; see the same under Shrubs (also Fig. 50).

Alder, Alnus glutinosa.

The var. imperialis $\ddagger$ is one of the best cut-leaved small trees.

European birch, Betula alba.

Cut-leaved weeping birch, B. alba var. laciniata pendula. $\neq$

American white birch, $B$. populifolia.*

Paper, or canoe birch, B. papyrifera.* 
Cherry birch, B. lenta.*

Well-grown specimens resemble the sweet cherry; both this and the yellow birch $\left(B\right.$. lutea* $\left.^{*}\right)$ make attractive light-leaved trees; they are not appreciated.

Hornbeam or blue beech, Carpinus Americana.*

Chestnut, Castanea sativa† and C.Americana.*† Showy catalpa, Catalpa speciosa. $\dagger \ddagger$

Very dark, soft-foliaged tree of small to medium size; showy in flower; for northern regions should be raised from northern-grown seed.

Smaller catalpa, $C$. bignonioides. $\dagger$

Less showy than the last, blooming a week or two later ; less hardy.

Japanese catalpa, C. ovata (C. Kampferi) +

In northern sections often remains practically a bush.

Nettle-tree, Celtis occidentalis.*

Katsura-tree, Cercidiphyllum Japonicum.

A small or medium-sized tree of very attractive foliage and habit.

Red-bud, or Judas-tree, Cercis Canadensis.*

Produces a profusion of rose-purple pea-like flowers before the leaves appear; foliage also attractive.

Yellow-wood, or virgilia, Cladrastis tinctoria.*

One of the finest hardy flowering trees.

Beech, Fagus ferruginea * ${ }^{*}$

Specimens which are symmetrically developed are among our best lawn trees; picturesque in winter.

European beech, F. sylvatica. $\dagger$

Many cultural forms, the purple-leaved being everywhere known. There are excellent tricolored varieties and weeping forms.

Black ash, Fraxinus nigra ( $F$. sambucifolia).*†

One of the best of the light-leaved trees; does well on dry soils, although native to swamps; not appreciated.

White ash, F. Americana.*†

European ash, F. excelsior.†

There is a good weeping form of this.

Maiden-hair tree, Ginkgo biloba (Salisburia adiantifolia). $\ddagger$

Very odd and striking; to be used for single specimens or avenues. 
Honey locust, Gleditschia triacanthos.*†

Tree of striking habit, with big branching thorns and very large pods; there is also a thornless form.

Kentucky coffee-tree, Gymnocladus Canadensis.*

Light and graceful; unique in winter.

Bitternut, Hicoria minima (or Carya amara).*

Much like black ash in aspect; not appreciated.

Hickory, H. ovata, (or Carya alba), ${ }^{* \ddagger}$ and others.

Pecan, H. Pecan.*ं

Hardy in places as far north as New Jersey, and reporteu still farther.

Butternut, Juglans cinerea.*

Walnut, $J$. nigra.*

Varnish-tree, Kølreuteria paniculata.

A medium-sized tree of good character, producing a profusion of goldenyellow flowers in July; should be better known.

European larch, Larix decidua (L. Europœea). $\ddagger$

American larch or tamarack, L. Americana**

Gum-tree, sweet gum, Liquidambar styraciflua.*ं

A good tree, reaching as far north as Connecticut, and hardy in parts of western New York although not growing large; foliage maple-like; a characteristic tree of the South.

Tulip tree or whitewood, Liriodendron Tulipifera.*†

Unique in foliage and flower and deserving to be more planted.

Cucumber tree, Magnolia acuminata. $* \dagger$

Native in the Northern states; excellent.

White bay-tree, $M$. glauca.*

Very attractive small tree, native along the coast to Massachusetts; where not hardy, the young growth each year is good.

Of the foreign magnolias hardy in the North, two species and one group of hybrids are prominent: M. stellata (or M. Halleana) and $M$. Yulan (or $M$. conspicua), both white-flowered, the former very early and having 9-18 petals and the latter (which is a larger tree) having 6-9 petals; M. Soulangeana, a hybrid group including the forms known as Lennei, nigra, Norbertiana, speciosa, grandis. All these magnolias are deciduous and bloom before the leaves appear. 
Mulberry, Morus rubra.*

White mulberry, $M$. alba.

Russian mulberry, $M$. alba var. Tatarica.

Teas' weeping mulberry is a form of the Russian.

Pepperidge or gum-tree, Nyssa sylvatica.*

One of the oddest and most picturesque of our native trees; especially attractive in winter; foliage brilliant red in autumn; most suitable for low lands.

Iron-wood, hop hornbeam, Ostrya Virginica.*

A good small tree, with hop-like fruits.

Sourwood, sorrel-tree, Oxydendrum arboreum.*

Interesting small tree native from Pennsylvania in the high land south, and should be reliable where it grows wild.

Plane or buttonwood, Platanus occidentalis.* $†$

Young or middle-aged trees are soft and pleasant in aspect, but they soon become thin and ragged below; unique in winter.

European plane-tree, $P$. orientalis. $\dagger$

Much used for street planting, but less picturesque than the American; several forms.

Aspen, Populus tremuloides.*

Very valuable when well grown; too much neglected (Fig. 33). Most of the poplars are suitable for pleasure grounds, and as nurses for slower growing and more emphatic trees (p. 41).

Large-toothed aspen, $P$. grandidentata.*

Unique in summer color; heavier in aspect than the above; old trees become ragged.

Weeping poplar, $P$. grandidentata, var. pendula.

An odd, small tree, suitable for small places, but, like all weeping trees, likely to be planted too freely.

Cottonwood, P. deltoides ( $P$. monilifera).*

The staminate specimens, only, should be planted if possible, as the cotton of the seed-pods is disagreeable when carried by winds; var. aurea $\ddagger$ is one of the good golden-leaved trees.

Balm of Gilead, P. balsamifera* and var. candicans.*

Desirable for remote groups or belts. Foliage not pleasant in color. 
Lombardy poplar, P. nigra, var. Italica.

Desirable for certain purposes, but used too indiscriminately (p. 41); it is likely to be short-lived in northern climates.

White poplar, abele, $P$. alba.

Sprouts badly; several forms.

Bolle's poplar, P. alba, var. Bolleana.

Habit much like the Lombardy; leaves curiously lobed, very white beneath, making a pleasant contrast (p. 218).

Certinensis poplar, $P$. laurifolia ( $P$. Certinensis).

A very hardy Siberian species, much like $P$. deltoides, useful for severe climates.

Wild black cherry, Prunus serotina.*

European bird cherry, P. Padus.

A small tree much like the choke cherry, but a freer grower, with larger flowers, and racemes which appear about a week later.

Choke cherry, P. Virginiana.*

Very showy while in flower.

Purple plum, P. cerasifera var. atropurpurea (var. Pissardi).

One of our most reliable purple-leaved trees.

Rose-bud cherry, $P$. pendula ( $P$. subhirtella).

A tree of drooping habit and beautiful rose-pink flowers preceding the leaves.

Japanese flowering cherry, P. Pseudo-Cerasus. North.

In many forms, the famous flowering cherries of Japan, but not reliable

There are ornamental-flowered peaches and cherries, more curious and interesting than useful.

Wild crab, Pyrus coronaria* and P. Ioensis.*

Very showy while in flower, blooming after apple blossoms have fallen; old specimens become picturesque in form. P. Ioensis flore pleno $\ddagger$ (Bechtel's Crab) is a handsome double form.

Siberian crab, P. baccata. $\ddagger$

Excellent small tree, both in flower and fruit. 
Flowering crab, $P$. floribunda. forms.

Pretty both in flower and fruit; a large shrub or small tree; various Hall's crab, P. Halliana (P. Parkmani).

One of the best of the flowering crabs, particularly the double form.

Various forms of double-flowering apple are on the market.

Swamp white oak, Quercus bicolor.*†

A desirable tree, usually neglected; very picturesque in winter.

Bur oak, Q. macrocarpa.*†

Chestnut oak, Q. Prinus, *† and especially the closely related $Q$. Muhlenbergii (or Q. acuminata).*†

White oak, Q. alba.*†

Shingle oak, Q. imbricaria.*†

Scarlet oak, Q. coccinea.*†

This and the next two are glossy-leaved, and are desirable for bright planting.

Black oak, Q. velutina (Q. tinctoria).*†

Red oak, Q. rubra.*††

Pin oak, Q. palustris.*†

Excellent for avenues; transplants well.

Willow oak, Q. Phellos.*

English oak, Q. Robur.

Many forms represented by two types, probably good species, $Q$. pedunculata (with stalked acorns) and $Q$. sessiliflora (with stalkless acorns). Some of the forms are reliable in the Northern states.

The oaks are slow growers and usually transplant with difficulty. Natural specimens are most valuable. A large well-grown oak is one of the grandest of trees.

Locust, Robinia Pseudacacia.*†

Attractive in flower; handsome as single specimens when young; many forms; used also for hedges.

Peach-leaved willow, Salix amygdaloides.*

Very handsome small tree, deserving more attention. This and the next valuable in low places or along water-courses.

Black willow, S. nigra.* 
Weeping willow, S. Babylonica.

To be planted sparingly, preferably near water; the sort known as the Wisconsin weeping willow appears to be much hardier than the common type; many forms.

White willow, S. alba, and various varieties, one of which is the Golden willow.

Tree willows are most valuable, as a rule, when used for temporary plantations or as nurses for better trees (p. 42).

Laurel-leaved willow, S. laurifolia. $\$$

A small tree used in cold regions for shelter-belts; also a good ornamental tree. See also under Shrubs (p. 301).

Sassafras, Sassafras officinalis.*†

Suitable in the borders of groups or for single specimens; peculiar in winter; too much neglected.

Rowan or European mountain ash, Sorbus Aucuparia (Pyrus Aucuparia) $\ddagger$

Service-tree, $S$. domestica.

Fruit handsomer than that of the mountain ash and more persistent; small tree.

Oak-leaved mountain ash, S. hybrida (S. quercifolia).

Small tree, deserving to be better known.

Bald cypress, Taxodium distichum.*

Not entirely hardy at Lansing, Mich.; often becomes scraggly after fifteen or twenty years, but a good tree; many cultural forms.

American linden or basswood, Titia Americana.*†

Very valuable for single trees on large lawns, or for roadsides.

European linden, T. vulgaris and T. platyphyllos (T. Europoa of nurserymen is probably usually the latter). $\dagger$

Has the general character of the American basswood.

European silver linden, T. tomentosa and varieties. $\dagger$

Very handsome; leaves silvery white beneath; among others is a weeping variety.

American elm, Ulmus Americana.* $\dagger$

One of the most graceful and variable of trees; useful for many purposes and a standard street tree. 
Cork elm, U. racemosa.*

Softer in aspect than the last, and more picturesque in winter, having prominent ridges of bark on its branches; slow grower.

Red or slippery elm, U. fulva.*

Occasionally useful in a group or shelter-belt; a stiff grower.

English elm, U. campestris, and Scotch or wych elm, U. scabra (U. mantana).

Often planted, but are inferior to $U$. Americana for street planting, although useful in collections. These have many horticultural forms.

\section{Non-coniferous trees for the South.}

Among deciduous trees for the region of Washington and south may be mentioned: Acer, the American and European species as for the North; Catalpa bignonioides and especially C. speciosa; celtis; cercis, both American and Japanese; flowering dogwood, profusely native; white ash; ginkgo; kœlreuteria; sweet gum (liquidambar); American linden; tulip tree; magnolias much as for the North; China-berry (Melia Azedarach); Texas umbrella-tree (var. umbraculiformis of the preceding); mulberries; oxydendrum; paulownia; oriental plane-tree; native oaks of the regions; Robinia Pseudacacia; weeping willow; Sophora Japonica; Sterculia platanifolia; American elm.

Broad-leaved evergreens of real tree size useful for the South may be found among the cherry laurels, magnolias, and oaks. Among the cherry laurels are: Portugal laurel (Prunus Lusitanica), English cherry laurel in several forms (P. Laurocerasus), and the "mock-orange" or "wild orange" (P. Caroliniana). In magnolia, the splendid $M$. grandiflora is everywhere used. In oaks, the live-oak (Quercus Virginiana, known also as $Q$. virens and $Q$. sempervirens) is the universal species. The cork oak (Q. Suber) is also recommended. 


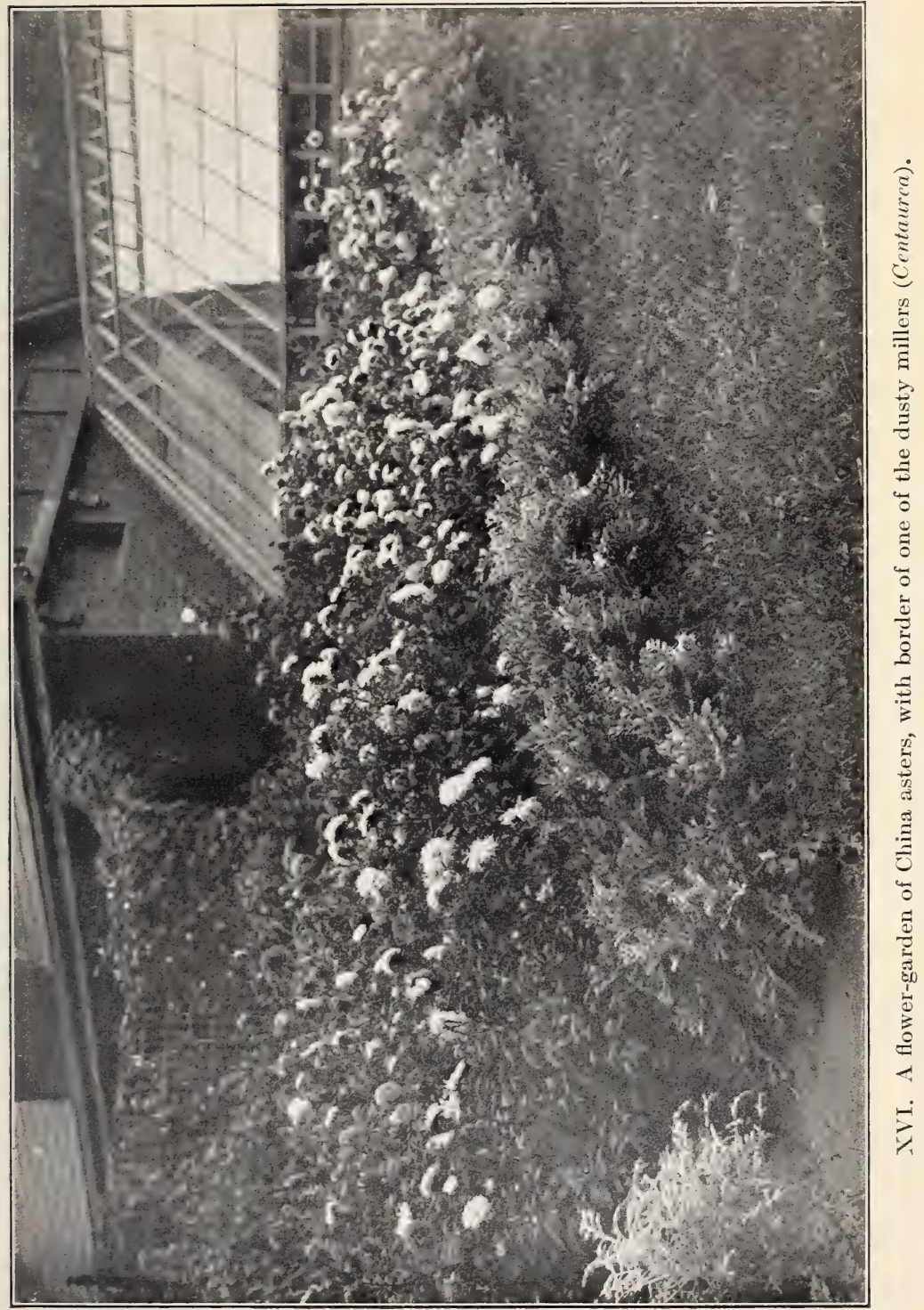





\section{Coniferous Evergreen Shrubs and Trees}

In this country the word "evergreen" is understood to mean coniferous trees with persistent leaves, as pines, spruces, firs, cedars, junipers, arborvitæ, retinosporas, and the like. These trees have always been favorites with plant lovers, as they have very distinctive forms and other characteristics. Many of them are of the easiest culture.

It is a common notion that, since spruces and other conifers grow so symmetrically, they will not stand pruning; but this is an error. They may be pruned with as good effect as other trees, and if they tend to grow too tall, the leader may be stopped without fear. A new leader will arise, but in the meantime the upward growth of the tree will be somewhat checked, and the effect will be to make the tree dense. The tips of the branches may also be headed in with the same effect. The beauty of an evergreen lies in its natural form; therefore, it should not be sheared into unusual shapes, but a gentle trimming back, as suggested, will tend to prevent the Norway spruce and others from growing open and ragged. After the tree attains some age, 4 or 5 in. may be taken off the ends of the main branches every year or two (in spring before growth begins) with good results. This slight trimming is ordinarily done with Waters's long-handled pruning shears.

There is much difference of opinion as to the proper time for the transplanting of evergreens, which means that there is more than one season in which they may be moved. It is ordinarily unsafe to transplant them in the fall in northern climates or bleak situations, since the evaporation from the foliage during the winter is likely to injure the plant. The best results are usually secured in spring or summer planting. In spring they may be moved rather late, just as new growth is beginning. Some persons also plant them in August or early September, as the roots secure a hold on the soil before winter. In the 
Southern states transplanting may be done at most times of the year, but late fall and early spring are usually advised.

In transplanting conifers, it is very important that the roots be not exposed to the sun. They should be moistened and covered with burlaps or other material. The holes should be ready to receive them. If the trees are large, or if it has been necessary to trim in the roots, the top should be cut when the tree is set.

Large evergreens (those $10 \mathrm{ft}$. and more high) are usually best transplanted late in winter, at a time when a large ball of earth may be moved with them. A trench is dug around the tree, it being deepened a little day by day so that the frost can work into the earth and hold it in shape. When the ball is thoroughly frozen, it is hoisted on to a stone-boat or truck (Fig. 148 ) and moved to its new position.

Perhaps the handsomest of all the native conifers of the northeastern United States is the ordinary hemlock, or hemlock spruce (the one so much used for lumber); but it is usually difficult to move. Transplanted trees from nurseries are usually safest. If the trees are taken from the wild, they should be selected from open and sunny places.

For neat and compact effects near porches and along walks, the dwarf retinosporas are very useful.

Most of the pines and spruces are too coarse for planting very close to the residence. They are better at some distance removed, where they serve as a background to other planting. If they are wanted for individual specimens, they should be given plenty of room, so that the limbs will not be crowded and the tree become misshapen. Whatever else is done to the spruces and firs, the lower limbs should not be trimmed up, at least not until the tree has become so old that the lowest branches die. Some species hold their branches much longer than others. The oriental spruce (Picea orientalis) is one of the best in this respect. The occasional slight heading-in, that has been men- 
tioned, will tend to preserve the lower limbs, and it will not be marked enough to alter the form of the tree.

The number of excellent coniferous evergreens now offered in the American trade is large. They are slow of growth and require much room if good specimens are to be obtained; but if the space can be had and the proper exposure secured, no trees add greater dignity and distinction to an estate. Reliable comments on the rarer conifers may be found in the catalogues of the best nurserymen.

\section{List of shrubby conifers.}

The following list contains the most usual of the shrub-like cuniferous evergreens, with asterisks $\left(^{*}\right)$ to mark those native to this country. The double dagger $(\ddagger)$ in this and the succeeding list marks those species that are found to be hardy at Ottawa, Ontario, and are recommended by the Central Experimental Farm of Canada.

Dwarf arborvitæ, Thuja occidentalis.*

There are many dwarf and compact varieties of arborvitæ, most of which are excellent for small places. The most desirable for general purposes, and also the largest, is the so-called Siberian. Other very desirable forms are those sold as globosa, ericoides, compacta, $\ddagger$ Hovey, $\ddagger$ Ellwangeriana, $\$$ pyramidalis, $\ddagger$ Wareana (or Sibirica), $\ddagger$ and aurea Douglasii. $\neq$

Japanese arborvitæ or retinospora, Chamccyparis of various species.

Retinosporas $\ddagger$ under names as follows: Cupressus ericoides, $2 \mathrm{ft}$., with fine soft delicate green foliage that assumes a purplish tinge in winter; $C$. pisifera, one of the best, with a pendulous habit and bright green foliage; C. pisifera var. filifera, with drooping branches and thread-like pendulous branches; C. pisifera var. plumosa, more compact than $P$. pisifera and feathery; var. aurea of the last, "one of the most beautiful golden-leaved evergreen shrubs in cultivation."

Juniper, Juniperus communis,* and garden varieties.

The juniper is a partially trailing plant, of loose habit, suitable for banks and rocky places. There are upright and very formal varieties of it, the best being those sold as var. Hibernica (fastigiata), $\ddagger$ "Irish juniper," and var. Suecica, "Swedish juniper." 
Northern juniper, J. Sabina, var. prostrata.*

One of the best of the low, diffuse conifers; var. tamariscifolia, $\$ 1-2 \mathrm{ft}$.

Chinese and Japanese junipers in many forms, J. Chinensis. Dwarf Norway spruce, Picea excelsa, dwarf forms.

Several very dwarf sorts of the Norway spruce are in cultivation, some of which are to be recommended.

Dwarf pine, Pinus montana, var. pumilio.

Mugho pine, P. montana var. Mughus.

There are other desirable dwarf pines.

Wild yew, Taxus Canadensis.*

Common in woods; a wide-spreading plant known as "ground hemlock"; 3-4 ft.

\section{Arboreous conifers.}

The evergreen conifers that one is likely to plant may be roughly classed as pines; spruces and firs; cedars and junipers; arborvitæ; yews.

White Pine, Pinus Strobus.* $\ddagger$

The best native species for general planting; retains its bright green color in winter.

Austrian pine, P. Austriaca $\ddagger$

Hardy, coarse, and rugged; suitable only for large areas; foliage very dark.

Scotch pine, $P$. sylvestris.

Not so coarse as Austrian pine, with a lighter and bluer foliage.

Red pine, $P$. resinosa.*†

Valuable in groups and belts; usually called "Norway pine"; rather heavy in expression.

Bull pine, $P$. ponderosa.*

A strong majestic tree, deserving to be better known in large grounds; native westward.

Cembrian pine, P. Cembra.

A very fine slow-growing tree; one of the few standard pines suitable for small places. 
Scrub pine, P. divaricata (P. Banksiana).*

A small tree, more odd and picturesque than beautiful, but desirable in certain places.

Mugho pine, $P$. montana var. Mughus. $\ddagger$

Usually more a bush than a tree (2 to $12 \mathrm{ft}$.), although it mav attain a height of 20-30 ft.; mentioned under Shrubs (p. 334).

Norway spruce, Picea excelsa.ł

The most commonly planted spruce; loses much of its peculiar beauty when thirty to fifty years of age; several dwarf and weeping forms.

White spruce, $P$. alba.*‡

One of the finest of the spruces; a more compact grower than the last, and not so coarse; grows slowly.

Oriental spruce, $P$. orientalis.

Especially valuable from its habit of holding its lowest limbs; grows slowly; needs some shelter.

Colorado blue spruce, $P$. pungens. $* \ddagger$

In color the finest of the conifers; grows slowly; seedlings vary much in blueness.

Alcock's spruce, P. Alcockiana †

Excellent; foliage has silvery under surfaces.

Hemlock spruce, Tsuga Canadensis.*

The common lumber hemlock, but excellent for hedges and as a lawn tree; young trees may need partial protection from sun.

White fir, Abies concolor.*†

Probably the best of the native firs for the northeastern region; leaves broad, glaucous.

Nordmann's fir, A. Nordmanniana.

Excellent in every way; leaves shining above and lighter beneath.

Balsam fir, A. balsamea.*

Loses most of its beauty in fifteen or twenty years.

Douglas fir, Pseudotsuga Douglasii.* $\ddagger$

Majestic tree of the northern Pacific slope, hardy in the east when grown from seeds from far north or high mountains. 
Red cedar, Juniperus Virginiana.*

A common tree, North and South; several horticultural varieties. Arborvitæ (white cedar, erroneously), Thuja occidentalis.*

Becomes unattractive after ten or fifteen years on poor soils; the horticultural varieties are excellent; see p. 333, and Hedges, p. 220.

Japanese yew, Taxus cuspidata.

Hardy small tree.

Conifers for the South.

Evergreen conifers, trees and bushes, for regions south of Washington: Abies Fraseri and A. Picea (A. pectinata); Norway spruce; true cedars, Cedrus Atlantica and Deodara; cypress, Cupressus Goveniana, majestica, sempervirens; Chamocyparis Lawsoniana; practically all junipers, including the native cedar (Juniperus Virginiana); practically all arborvitæ, including the oriental or biota group; retinosporas (forms of chamæcyparis and thuja of several kinds); Carolina hemlock, Tsuga Caroliniana; English yew, Taxus baccata; Libocedrus decurrens; cephalotaxus and podocarpus; cryptomeria; Bhotan pine, Pinus excelsa; and the native pines of the regions.

\section{Window-Gardens}

Although the making of window-gardens may not be properly a part of the planting and ornamenting of the home grounds, yet the appearance of the residence has a marked effect on the attractiveness or unattractiveness of the premises; and there is no better place than this in which to discuss the subject. Furthermore, window-gardening is closely associated with various forms of temporary plant protection about the residence (Fig. 268).

Window-gardens are of two types: the window-box and porch-box type, in which the plants are grown outside the window and which is a summer or warm-weather effort; the inte- 
rior or true window-garden, made for the enjoyment of the family in its internal relations, and which is chiefly a winter or coldweather effort.

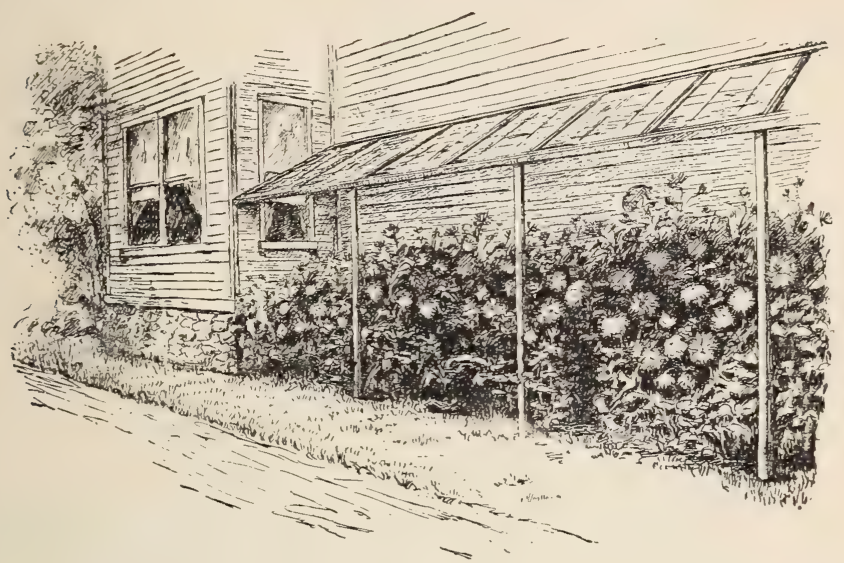

268. A protection for chrysanthemums. Very good plants can be grown under a temporary shed cover. The roof may be of glass, oiled paper, or even of wood. Such a shed cover will afford a very effective and handy protection for many plants (p. 366).

The window-box for outside effect.

Handsomely finished boxes, ornamental tiling, and bracket work of wood and iron suitable for fitting out windows for the growing of plants, are on the market; but such, while desirable, are by no means necessary. A stout pine box of a length corresponding to the width of the window, about 10 inches wide and 6 deep, answers quite as well as a finer box, since it will likely be some distance above the street, and its sides, moreover, are soon covered by the vines. A zinc tray of a size to fit into the wooden box may be ordered of the tinsmith. It will tend to keep the soil from drying out so rapidly, but it is not a necessity. A few small holes in the bottom will provide for drainage; but with carefulness in watering these are not necessary, 
since the box by its exposed position will dry out readily during summer weather, unless the position is a shaded one. In the latter case provision for good drainage is always advisable.

Since there is more or less cramping of roots, it will be necessary to make the soil richer than would be required were the plants to grow in the garden. The most desirable soil is one that does not pack hard like clay, nor contract much when dry, but remains porcus and springy. Such a soil is found in the potting earth used by florists, and it may be obtained from them at 50 cents to $\$ 1$ a barrel. Often the nature of the soil will be such as to make it desirable to have at hand a barrel of sharp sand for mixing with it, to make it more porous and prevent baking. A good filling for a deep box is a layer of clinkers or other drainage in the bottom, a layer of pasture sod, a layer of old cow manure, and fill with fertile garden earth.

Some window-gardeners pot the plants and then set them in the window-box, filling the spaces between the pots with moist moss. Others plant them directly in the earth. The former method, as a general rule, is to be preferred in the winter window-garden; the latter in the summer.

The plants most valuable for outside boxes are those of drooping habit, such as lobelias, tropeolums, othonna, Kenilworth ivy, verbena (Fig. 269), sweet alyssum, and petunia. Such plants may occupy the front row, while back of them may be the erect-growing plants, as geraniums, heliotropes, begonias (Plate XX).

For shady situations the main dependence is on plants of graceful form or handsome foliage; while for the sunny window the selection may be of blooming plants. Of the plants mentioned below for these two positions, those marked with an asterisk (*) are of climbing habit, and may be trained up about the sides of the window.

Just what plants will be most suitable depends on the exposure. For the shady side of the street, the more delicate kinds of 


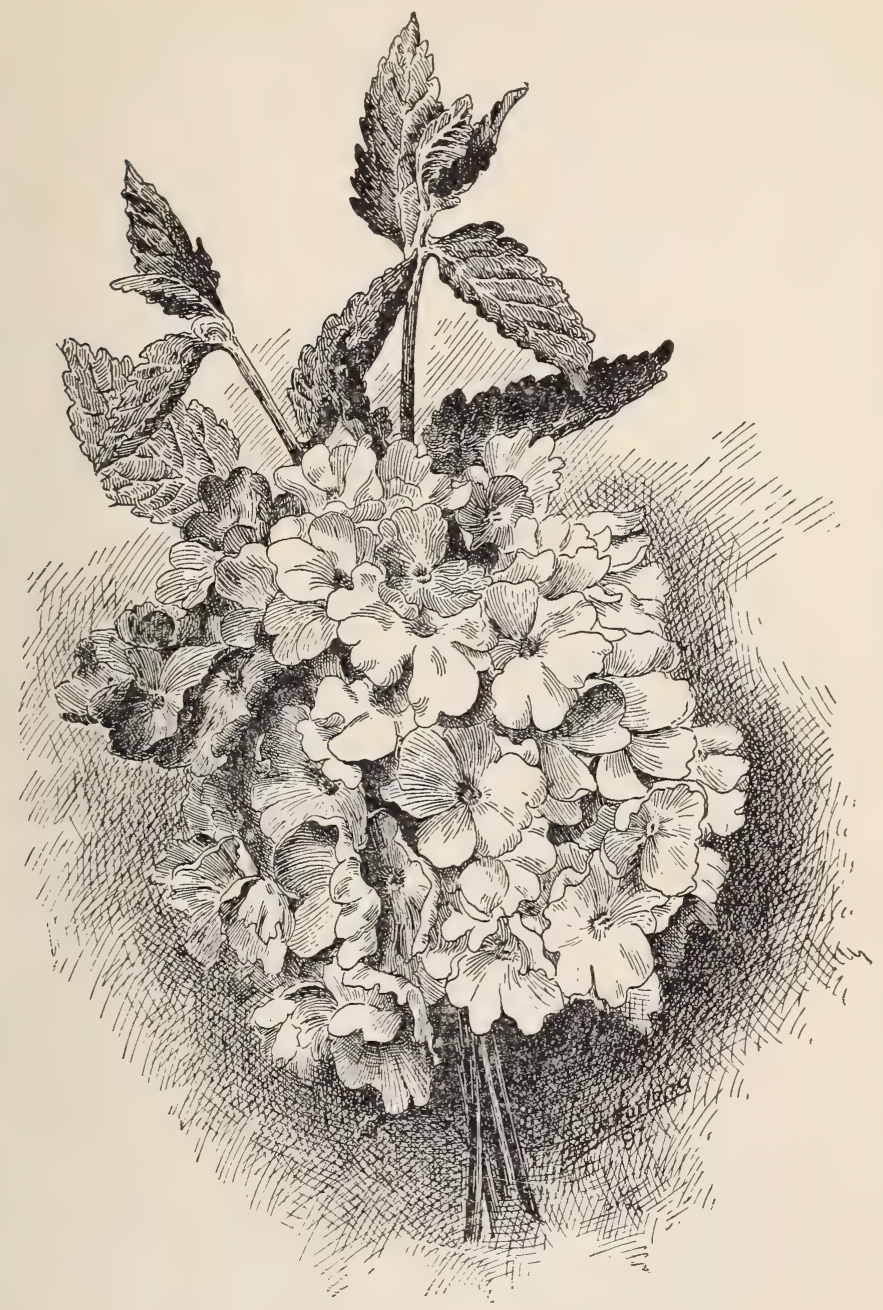

269. Bouquet of verbenas. 
plants may be used. For full exposure to the sun, it will be necessary to choose the more vigorous-growing kinds. In the latter position, suitable plants for drooping would be: tropeolums, ${ }^{*}$ passifloras, * the single petunias, sweet alyssum, lobelias, verbenas, mesembryanthemums. For erect-growing plants: geraniums, heliotropes, phlox. If the position is a shaded one, the drooping plants might be of the following: tradescantia, Kenilworth ivy, senecio* or parlor ivy, sedums, moneywort,* vinca, smilax, ${ }^{*}$ lygodium* or climbing fern. Erect-growing plants would be dracenas, palms, ferns, coleus, centaurea, spotted calla, and others.

After the plants have filled the earth with roots, it will be desirable to give the surface among them a very light sprinkling of bone-dust or a thicker coating of rotted manure from time to time during the summer; or instead of this, a watering with weak liquid manure about once a week. This is not necessary, however, until the growth shows that the roots have about exhausted the soil.

In the fall the box may be placed on the inside of the window. In this case it will be desirable to thin out the foliage somewhat, shorten in some of the vines, and perhaps remove some of the plants. It will also be desirable to give a fresh coating of rich soil. Increased care will be necessary, also, in watering, since the plants will have less light than previously, and, moreover, there may be no provision for drainage.

Porch-boxes may be made in the same general plan. Since the plants are likely to be injured in porch-boxes, and since these boxes should have some architectural effect, it is well to use abundantly of rather heavy greenery, such as swordfern (the common form of Nephrolepis exaltata) or the Boston fern, Asparagus Sprengeri, wandering jew, the large drooping vinca (perhaps the variegated form), aspidistra. With these or similar things constituting the body of the box planting, the flowering plants may be added to heighten the effect. 


\section{The inside window-garden, or "house plants."}

The winter window-garden may consist simply of a jardinière, or a few choice pot-plants on a stand at the window, or of a considerable collection with more or less elaborate arrangements. for their accommodation in the way of box, brackets, shelves, and stands. Expensive arrangements are by no means necessary, nor is a large collection. The plants and flowers themselves are the main consideration, and a small collection well cared for is better than a large one unless it can be easily accommodated and kept in good condition.

The box will be seen near at hand, and so it may be more or less ornamental in character. The sides may be covered with ornamental tile held in place by molding; or a light latticework of wood surrounding the box is pretty. But a neatly made and strong box of about the dimensions mentioned on page 337 , with a strip of molding at the top and bottom, answers just as well; and if painted green, or some neutral shade, only the plants will be seen or thought of. Brackets, jardinières, and stands may be purchased of any of the larger florists.

The box may consist of merely the wooden receptacle; but a preferable arrangement is to make it about eight inches deep instead of six, then have the tinsmith make a zinc tray to fit the box. This is provided with a false wooden bottom, with cracks for drainage, two inches above the real bottom of the tray. The plants will then have a vacant space below them into which drainage water may pass. Such a box may be thoroughly watered as the plants require without danger of the water running on the carpet. Of course, a faucet should be provided at some suitable point on a level with the bottom of the tray, to permit of its being drained every day or so if the water tends to accumulate. It would not do to allow the water to remain long; especially should it never rise to the false bottom, as then the soil would be kept too wet. 
The window for plants should have a southern, southeastern, or eastern exposure. Plants need all the light they can get in the winter, especially those that are expected to bloom. The window should be tight-fitting. Shutters and a curtain will be an advantage in cold weather.

Plants like a certain uniformity in conditions. It is very trying on them, and often fatal to success, to have them snug and warm one night and pinched in a temperature only a few degrees above freezing the next. Some plants will live in spite of it, but they cannot be expected to prosper. Those whose rooms are heated with steam, hot water, or hot air will have to guard against keeping rooms too warm fully as much as keeping them too cool. Rooms in brick dwellings that have been warm all day, if shut up and made snug in the evening, will often keep warm over night without heat except in the coldest weather. Rooms in frame dwellings exposed on all sides soon cool down. It is difficult to grow plants in rooms lighted by gas. Most living-rooms have air too dry for plants. In such cases the bowwindow may be set off from the room by glass doors; one then has a miniature conservatory. A pan of water on the stove or on the register and damp moss among the pots, will help to afford plants the necessary humidity.

The foliage will need cleansing from time to time to frec it from dust. A bath tub provided with a ready outlet for the water is an excellent place for this purpose. The plants may be turned on their sides and supported on a small box above the bottom of the tub. Then they may be freely syringed without danger of making the soil too wet. It is usually advisable not to wet the flowers, however, especially the white waxen kinds, like hyacinths. The foliage of rex begonias should be cleansed with a piece of dry or only slightly moist cotton. But if the leaves can be quickly dried off by placing them in the open air on mild days, or moderately near the stove, the foliage may be syringed. 
Some persons attach the box to the window, or support it on brackets attached below the window-sill; but a preferable arrangement is to support the box on a low and light stand of suitable height provided with rollers. It may then be drawn back from the window, turned around from time to time to give the plants light on all sides, or turned with the attractive side in as may be desired.

Often the plants are set directly in the soil; but if they are kept in pots they may be rearranged, and changed about to give those which need it more light. Larger plants that are to stand on shelves or brackets may be in porous earthenware pots; but the smaller ones that are to fill the window-box may be placed in heavy paper pots. The sides of these are flexible, and the plants in them therefore may be crowded close together with great economy in space. When pots are spaced, damp sphagnum or other moss among them will hold them in place, keep the soil from drying out too rapidly, and at the same time give off moisture, so grateful to the foliage.

In addition to the stand, or box, a bracket for one or more pots on either side of the window, about one-third or half-way up, will be desirable. The bracket should turn on a basal hinge or pivot, to admit of swinging it forward or backward. These bracket plants usually suffer for moisture, and are rather difficult to manage.

Florists now usually grow plants suitable for window-gardens and winter flowering, and any intelligent florist, if asked, will take pleasure in making out a suitable collection. The plants should be ordered early in the fall; the florist will then not be so crowded for time and can give the matter better attention.

Most of the plants suitable for the winter window-garden belong to the groups that florists grow in their medium and cool houses. The former are given a night temperature of about $60^{\circ}$, the latter about $50^{\circ}$. In each case the temperature is 10 to $15^{\circ}$ higher for the daytime. Five degrees of variation below 
these temperatures will be allowable without any injurious effects; even more may be borne, but not without more or less check to the plants. In bright, sunny weather the day temperature may be higher than in cloudy and dark weather.

Plants for an average night temperature of $60^{\circ}$ (trade names).

Upright flowering plants. - Abutilons, browallias, calceolaria "Lix coln Park," begonias, bouvardias, euphorbias, scarlet sage, richardia or calla, heliotropes, fuchsias, Chinese hibiscus, jasmines, single petunias, swainsona, billbergia, freesias, geraniums, cupheas.

Upright foliage plants. - Muehlenbeckia, Cycas revoluta, Draccena fragans and others, palms, cannas, Farfugium grande, achyranthes, ferns, araucarias, epiphyllums, pandanus or "screw pine," Pilea arborea, Ficus elastica, Grevillea robusta.

Climbing plants. - Asparagus tenuissimus, A. plumosus, Cobøa scandens, smilax, Japanese hop, Madeira vine (Boussingaultia), Senecio mikanioides and $S$. macroglossus (parlor ivies). See also list below.

Low-growing, trailing, or drooping plants. - These may be used for baskets and edgings. Flowering kinds are: Sweet alyssum, lobelia, Fuchsia procumbens, mesembryanthemum, Oxalis pendula, O. floribunda and others, Russelia juncea, Mahernia odorata or honey-bell.

Foliage plants of drooping habit. - Vincas; Saxifraga sarmentosa, Kenilworth ivy, tradescantia or wandering jew, Festuca glauca,* othonna, Isolepsis gracilis,* English ivy, Selaginella denticulata, and others. Some of these plants flower quite freely, but the flowers are small and of secondary consideration. Those with an asterisk (*) droop but slightly.

Plants for an average night temperature of $50^{\circ}$.

Upright flowering plants. - Azaleas, cyclamens, carnations, chrysanthemums, geraniums, Chinese primroses, stevias, marguerite or Paris daisy, single petunias, Anthemis coronaria, camellias, ardisia (berries), cinerarias, violets, hyacinths, narcissus, tulips, the Easter lily when in bloom, and others.

Upright foliage plants. - Pittosporums, palms, aucuba, euonymus (golden and silvery variegated), araucarias, pandanus, dusty millers. 
Climbing plants. - English ivy, maurandia, senecio or parlor ivy, lygodium (climbing fern).

Drooping or trailing plants. - Flowering kinds are: Sweet alyssum, Mahernia odorata, Russelia and ivy geranium.

\section{Bulbs in the window-garden.}

Bulbs flowering through the winter add to the list of house plants a charming variety. The labor, time, and skill required is much less than for growing many of the larger plants more commonly used for winter decorations (for instructions on growing bulbs out-of-doors, see p. 281; also the entries in Chapter VIII).

Hyacinths, narcissus, tulips, and crocus, and others can be made to flower in the winter without difficulty. Secure the bulbs so as to be able to pot them by the middle or last of October, or if earlier all the better. The soil should be rich sandy loam, if possible; if not, the best that can be got, to which about one-fourth the bulk of sand is added and mixed thoroughly.

If ordinary flower-pots are to be used, place in the bottom a few pieces of broken pots, charcoal, or small stones for drainage, then fill the pot with dirt so that when the bulbs are set on the dirt the top of the bulb is even with the rim of the pot. Fill around it with soil, leaving just the tip of the bulb showing above the earth. If the soil is heavy, a good plan is to sprinkle a small handful of sand under the bulb to carry off the water, as is done in the beds outdoors. If one does not have pots, he may use boxes. Starch boxes are a good size to use, as they are not heavy to handle; and excellent flowers are sometimes secured from bulbs planted in old tomato-cans. If boxes or cans are used, care must be taken to have holes in the bottoms to let the water run out. A large hyacinth bulb will do well in a 5 -inch pot. The same size pot will do for three or four narcissuses or eight to twelve crocuses.

After the bulbs are planted in the pots or other receptacles, 
they should be placed in a cool place, either in a cold pit or cellar, or on the shady side of a building, or, better yet, plunged or buried up to the rim of the pot in a shady border. This is done to force the roots to grow while the top stands still, as only the bulbs with good roots will give good flowers. When the weather gets so cold that a crust is frozen on the soil, the pots should be covered with a little straw, and as the weather gets colder more straw must be used. In six to eight weeks after planting the bulbs, they should have made roots enough to grow the plant, and they may be taken up and placed in a cool room for a week or so, after which, if they have started into growth, they may be taken into a warmer room where they can have plenty of light. They will grow very rapidly now and will want much water, and after the flowers begin to show, the pots may stand in a saucer of water all the time. When just coming into bloom the plants may have full sunlight part of the time to help bring out the color of the flowers.

Hyacinths, tulips, and narcissus all require similar treatment. When well rooted, which will be in six or eight weeks, they are brought out and given a temperature of some $55^{\circ}$ to $60^{\circ}$ till the flowers appear, when they should be kept in a cooler temperature, say $50^{\circ}$. The single Roman hyacinth is an excellent house plant. The flowers are small, but they are graceful and are well adapted to cutting. It is early.

The Easter lily is managed the same way, except to hasten its flowers it should be kept at not lower than $60^{\circ}$ at night. Warmer will be better. Lily bulbs may be covered an inch or more deep in the pots.

Freesias may be potted six or more in a pot of mellow soil, and then started into growth at once. At first they may be given a night temperature of $50^{\circ}$; and $55^{\circ}$ to $60^{\circ}$ when they have begun to grow.

Small bulbs, as snowdrop and crocus, are planted several or a dozen in a pot and buried, or treated like hyacinths; but 
they are very sensitive to heat, and require to be given the light only when they have started to grow, without any forcing. Forty to $45^{\circ}$ will be as warm as they ever need be kept.

\section{Watering house plants.}

It is impossible to give rules for the watering of plants. Conditions that hold with one grower are different from those of another. Advice must be general. Give one good watering at the time of potting, after which no water should be given until the plants really need it. If, on tapping the pot, it gives out a clear ring, it is an indication that water is needed. In the case of a soft-wooded plant, just before the leaves begin to show signs of wilt is the time for watering. When plants are taken up from the ground, or have their roots cut back in repotting, gardeners rely, after the first copious watering, on syringing the tops two or three times each day, until a new root-growth has started, watering at the roots only when absolutely necessary. Flants that have been potted into larger pots will grow without the extra attention of syringing, but those from the borders that have had their roots mutilated or shortened, should be placed in a cool, shady spot and be syringed often. One soon becomes familiar with the wants of individual plants, and can judge closely as to need of water. All soft-wooded plants with a large leaf-surface need more water than hard-wooded plants, and a plant in luxuriant growth of any kind more than one that' has been cut back or become defoliated. When plants are grown in living-rooms, moisture must be supplied from some source, and if no arrangement has been made for securing moist air, the plants should be syringed often.

All plant-growers should learn to withhold water when plants are "resting" or not in active growth. Thus camellias, azaleas, rex begonias, palms, and many other things are usually not in their growing period in fall and midwinter, and they 
should then have only sufficient water to keep them in condition. When growth begins, apply water; and increase the water as the growth becomes more rapid.

\section{Hanging baskets.}

To have a good hanging basket, it is necessary that some careful provision be made to prevent too rapid drying out of the earth. It is customary, therefore, to line the pot or basket with moss. Open wire baskets, like a horse muzzle, are often lined with moss and used for the growing of plants. Prepare the earth by mixing some well-decayed leafmold with rich garden loam, thereby making an earth that will retain moisture. Hang the basket in a light place, but still not in direct sunlight; and, if possible, avoid putting it where it will be exposed to drying wind. In order to water the basket, it is often advisable to sink it into a pail or tub of water.

Various plants are well adapted to hanging baskets. Among the drooping or vine-like kinds are the strawberry geranium, Kenilworth ivy, maurandia, German ivy, canary-bird flower, Asparagus Sprengeri, ivy geranium, trailing fuchsia, wandering jew, and othonna. Among the erect-growing plants that produce flowers, Lobelia Erinus, sweet alyssum, petunias, oxalis, and various geraniums are to be recommended. Among foliage plants such things as coleus, dusty miller, begonia, and some geraniums are adaptable.

\section{Aquarium.}

A pleasant adjunct to a window-garden, living room, or conservatory, is a large glass globe or glass box containing water, in which plants and animals are living and growing. A solid glass tank or globe is better than a box with glass sides, because it does not leak, but the box must be used if one wants a large aquarium. For most persons it is better to buy the aquarium box than to attempt to make it. Five points are important in 
making and keeping an aquarium: (1) The equilibrium between plant and animal life must be secured and maintained; (2) the aquarium must be open on top to the air or well ventilated; (3) the temperature should be kept between $40^{\circ}$ and $50^{\circ}$ for ordinary animals and plants (do not place in full sun in a hot window); (4) it is well to choose such animals for the aquarium as are adapted to life in still water; (5) the water must be kept fresh, either by the proper balance of plant and animal life or by changing the water frequently, or by both.

The aquatic plants of the neighborhood may be kept in the aquarium, - such things as myriophyllums, charas, eel-grass, duckmeats or lemnas, cabomba or fish grass, arrow-leafs or sagittaria, and the like; also the parrot's feather, to be bought of florists (a species of myriophyllum). Of animals, there are fishes (particularly minnows), water insects, tadpoles, clams, snails. If the proper balance is maintained between plant and animal life, it will not be necessary to change the water so frequently. 


\section{CHAPTER VIII}

THE GROWING OF THE ORNAMENTAL PLANTS - INSTRUCTIONS ON PARTICULAR KINDS

In the preceding chapter advice is given that applies to groups or classes of plants, and many lists are inserted to guide the grower in his choice or at least to suggest to him the kinds of things that may be grown for certain purposes or conditions. It now remains to give instructions on the growing of particular kinds or species of plants.

It is impossible to include instructions on any great number of plants in a book like this. It is assumed that the user of this book already knows how to grow the familiar or easily handled plants; if he does not, a book is not likely to help him very much. In this chapter all such things as the common annuals and perennials and shrubs and trees are omitted. If the reader is in doubt about any of these, or desires information concerning them, he will have to consult the catalogues of responsible seedsmen and nurserymen or cyclopedic works, or go to some competent person for advice.

In this chapter are brought together instructions on the growing of such plants commonly found about home grounds and in window-gardens as seem to demand somewhat special or particular treatment or about which the novice is likely to ask; and of course these instructions must be brief.

It may be repeated here (p. 115) that a person cannot expect to grow a plant satisfactorily until he learns the natural time of the plant to grow and to bloom. Many persons handle their begonias, cacti, and azaleas as if they should be 


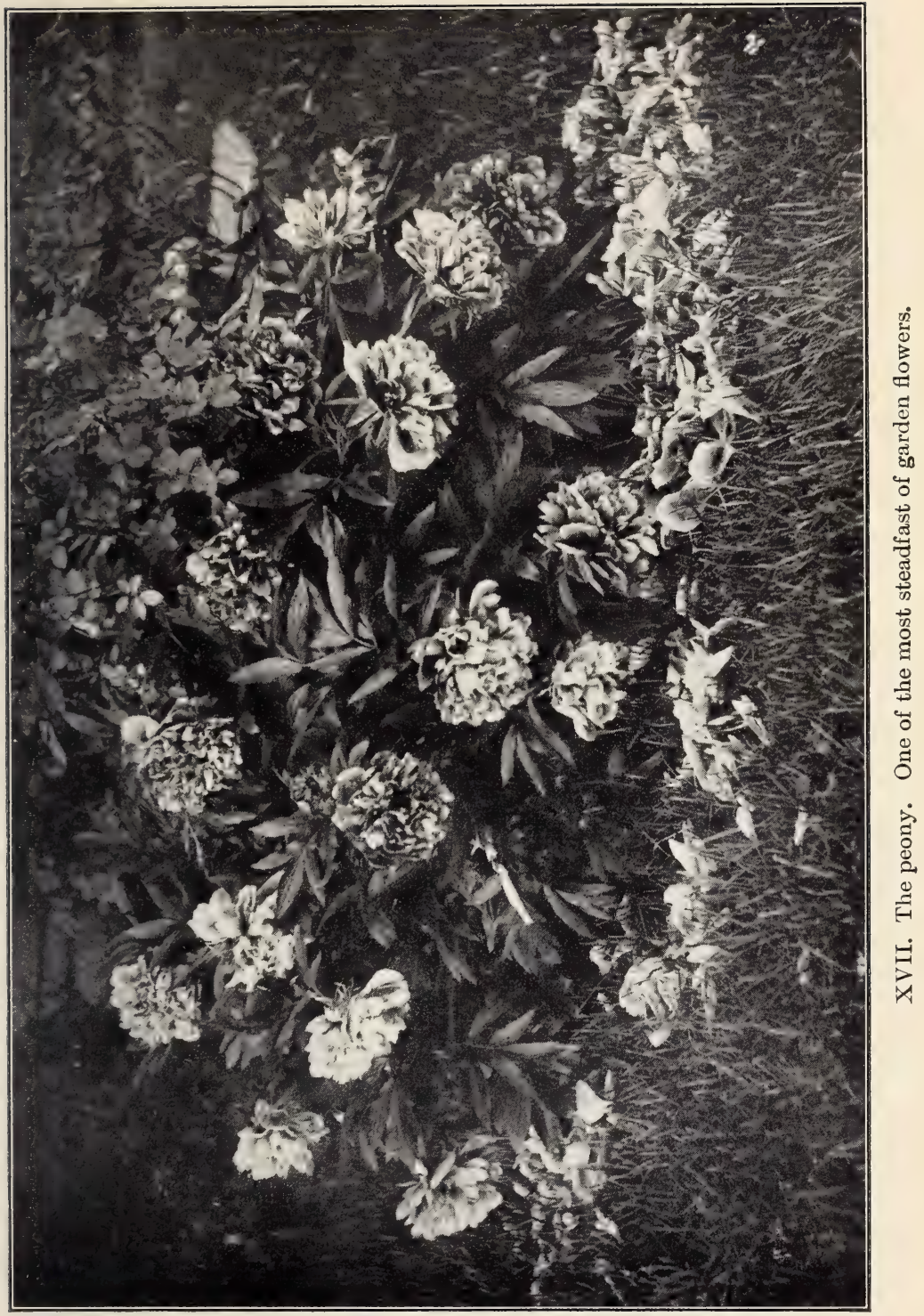



active the whole year round. The key to the situation is water: at what part of the year to withhold and at what part to apply is one of the very first things to learn (pp. 100, 175, 347).

Abutilons, or flowering maples as they are often called, make good house plants and bedding plants. Nearly all house gardeners have at least one plant.

Common abutilons may be grown from seed or from cuttings of young wood. If the former, the seed should be sown in February or Narch in a temperature of not less than $60^{\circ}$. The seedlings should be potted when about four to six leaves have grown, in a rich sandy soil. Frequent pottings should be made to insure a rapid growth, making plants large enough to flower by fall. Or the seedlings may be planted out in the border when danger of frost is over, and taken up in the fall before frost; these plants will bloom all winter. About one half of the newer growth should be cut off when they are taken up, as they are very liable to spindle up when grown in the house. When grown from cuttings, young wood should be used, which, after being well rooted, may be treated in the same way as the seedlings.

The varieties with variegated leaves have been improved until the foliage effects are equal to the flowers of some varieties; and these are a great addition to the conservatory or window garden. The staple spotted-leaved type is A. Thompsoni. A compact form, now much used for bedding and other outdoor work, is Savitzii, which is a horticultural variety, not a distinct species. The old-fashioned greenleaved $A$. striatum, from which $A$. Thompsoni has probably sprung, is one of the best. A. megapotamicum or vexillarium is a trailing or drooping red-and-yellow-flowered species that is excellent for baskets, although not now much seen. It propagates readily from seed. There is a form with spotted leaves.

Abutilons are most satisfactory for house plants when they are not much more than a year old. They need no special treatment.

Agapanthus, or African lily (Agapanthus umbellatus and several varieties). - A tuberous-rooted, well-known conservatory or window plant, blooming in summer. Excellent for porch and yard decoration. 
It lends itself to many conditions and proves satisfactory a large part of the year, the leaves forming a green arch over the pot, covering it entirely in a well-grown specimen. The flowers are borne in a large cluster on stems growing 2-3 ft. high, as many as two or three hundred bright blue flowers often forming on a single plant. A large, well-grown plant throws up a number of flower-stalks through the early season.

The one essential to free growth is an abundance of water and an occasional application of manure water. Propagation is effected by division of the offsets, which may be broken from the main plant in early spring. After flowering, gradually lessen the quantity of water until they are placed in winter quarters, which should be a position free from frost and moderately dry. The agapanthus, being a heavy feeder, should be grown in strong loam to which is added well-rotted manure and a little sand. When dormant, the roots will withstand a little frost.

Alstremeria. - The alstremerias (of several species) belong to the amaryllis family, being tube-ous-rooted plants, having leafy stems terminating in a cluster of ten to fifty small lily-shaped flowers of rich colors in summer.

Most of the alstremerias should be given pot culture, as they are easily grown and are not hardy in the open in the North. The culture is nearly that of the amaryllis, - a good, fibrous loam with a little sand, potting the tubers in early spring or late fall. Start the plants slowly, giving only enough water to cause root growth; but after growth has become established, a quantity of water may be given. After flowering they may be treated as are amaryllis or agapanthus. The roots may be divided, and the old and weak parts shaken out. The plants grow 1-3 ft. high. The flowers often have odd colors.

Amaryllis. - The popular name of a variety of house or conservatory tender bulbs, but properly applied only to the Belladonna lily. Most of them are hippeastrums, but the culture of all is similar. They are satisfactory house plants for spring and summer bloom. One dificulty with their culture is the habit of the flower-stalk starting into growth before the leaves grow. This is caused in most cases by stimulating root growth before the bulb has had sufficient rest. 
The bulbs should be dormant four or five months in a dry place with a temperature of about $50^{\circ}$. When wanted to be brought into flower, the bulbs, if to be repotted, should have all the dirt shaken off and potted in soil composed of fibrous loam and leafmold, to which should be added a little sand. If the loam is heavy, place the pot in a warm situation; a spent hotbed is a good place. Water as needed, and as the flowers derelop liquid manure may be given. If large clumps are well established in 8- or 10 -inch pots, they may be top-dressed with new soil containing rotted manure, and as growth increases liquid manure may be given twice a week until the flowers open. After flowering, gradually withhold water until the leaves die, or plunge the pots in the open, in a sunny place. The most popular species for window-gardens is $A$. Johnsoni (properly a hippeastrum), with red flowers. Figs. 257, 261.

Bulbs receired from dealers should ba placed in pots not much broader than the bulb, and the neck of the bulb should not be covered. Keep rather dry until active growth begins. The ripened bulbs, in fall, may be stored as potatoes, and then brought out in spring as rapidly as any of them show signs of growth.

Anemone. - The wind-flowers are hardy perennials, of easy culture, one group (the Anemone coronariu, fulgens, and hortensis forms) being treated as bulbs. These tuberous-rooted plants should be planted late in September or early in October, in a well-enriched sheltered border, setting the tubers 3 in. deep and 4-6 in. apart. The surface of the border should be mulched with leaves or strany manure through the severe winter weather, uncorering the soil in March. The flowers mill appear in April or May, and in June or July the tubers should be taken up and placed in dry sand until the following fall. These plants are not as well known as they should be. The range of color is very wide. The flowers are often $2 \mathrm{in}$. across, and are lasting. The tubers may be planted in pots, bringing them into the conservatory or house at intervals through the winter, where they make an excellent showing when in bloom.

The Japanese anemone is a wholly different plant from the above. There are white-flowered and red-flowered varieties. The best known is A. Japonica var. alba, or Honorine Jobert. This species blooms 
from August to November, and is at that season the finest of burder plants. The pure white flowers, with lemon-colored stamens, are held well up on stalks 2-3 ft. high. The flower-stems are long and excellent for cutting. This species may be propagated by division of the plants or by seed. The former method should be employed in the spring; the latter, as soon as the seeds are ripe in the fall. Sow the seed in boxes in a warm, sheltered situation in the border or under glass. The seed should be covered lightly with soil containing a quantity of sand and not allowed to become dry. A well-enriched, sheltered position in a border should be given.

The littie wild wind-flowers are easily colonized in a hardy border.

Aralia, A. Sicboldii (properly Fatsia Japonica and F. papyrifera), as it is sometimes called, and the variety iariegata, with large, palmlike leaves, are grown for their tropical appearance.

Sow in February, in shallow trays and light soil, in a temperature of $65^{\circ}$. Continue the temperature. When two or three leaves have formed, transplant into other trays 1 in. apart. sprinkle them with a fine rose or spray; and do not allow them to suffer for water. Later transfer them to small pots and repot them as they grow. Plant out in beds after the weather has become warm aid settled. Half-hardy perennials in the North, becoming $3 \mathrm{ft}$. or more high; a shrub in the south and in California. Used often in subtropical work.

Araucaria, or Norfolk Island pine, is now sold in pots by florists as a window plant. There are several species. The greenhouse specimens are the juvenile state of plants that become large trees in their native regions; therefore, it is not to be expected that they will keep shapely and within bounds indefinitely.

The common species (A. excelsa) makes a symmetrical evergrecn subject. It keeps well in a cool window, or on the reranda in the summer. Protect it from rirect sunlight, and give plenty of room. If the plant begins to fail, return it to the florist for recuperation, or procure a new plant.

Auricula. - A half-harty peremial of the primrose trilne (Primula A uricula), very popular in Europe, but little grown in America on account of the hot, dry summers. 
In this country auriculas are usually propagated by seed, as for cineraria; but special varieties are perpetuated by offsets. Seeds sown in February or March should give blooining plants for the next February or March. Keep the plants cool and moist, and away from the direct sun during the summer. Gardeners usually grow them in frames. In the fall, they are potted into 3-in. or 4-in. pots, and made to bloom either in frames as for violets or in a cool conservatory or greenhouse. In April, after blooming has ceased, repot the plants and treat as the previous year. As with most annual-blooming perennials, best results are to be expected with year-old or two-year-old plants. Auriculas grow 6-8 in. high. Colors white and many shades of red and blue.

Azaleas are excellent outdoor and greenhouse shrubs, and are sometimes seen in windows. They are less grown in this country than in Europe, largely because of our hot, dry summers and severe winters.

There are two common types or classes of azaleas: the hardy or Ghent azaleas, and the Indian azaleas. The latter are the familiar large-flowered azaleas of conservatories and window-gardens.

Ghent azaleas thrive in the open along the seacoast as far north as southern New England. They require a sandy peaty soil, but are treated as other shrubs are. The large flower-buds are liable to injury from the warm suns of late winter and early spring, and to avoid this injury the plants are often protected by covers or shades of brush. In the interior country, little attempt is made to flower azaleas permanently in the open, although they may be grown if carefully tended and well protected.

Both Ghent and Indian azaleas are excellent pot-plants for bloom in late winter and spring. The plants are imported in great numbers from Europe in fall, and it is better to buy these plants than to attempt to propagate them. Pot them up in large-sized pots, keep them cool and backward for a time until they are established, then take them into a conservatory temperature in which carnations and roses thrive. They should be potted in a soil of half peat or well-decayed mold and half rich loam; add a little sand. Pot firmly, and be sure to provide sufficient drainage. Keep off red spider by syringing.

After blooming, the plants may be thinned by pruning out the 
straggling growths, and repotted. Set them in a frame or in a semishaded place during summer, and see that they make a good growth. The wood should be well ripened in the fall. After cold weather sets in, keep the Indian or evergreen kinds half dormant by setting them in a cool, dull-lighted cellar or pit, bringing them in when wanted for bloom. The Ghent or deciduous kinds may be touched with frost without injury; and they may be kept in a cellar until wanted.

Begonias are familiar tender bedding and house plants. Next to the 'geranium, begonias are probably the most popular for house culture of the entire plant list. The ease of culture, great variety of kinds, profusion of bloom or richness of foliage, together with their adaptability to shade, make them very desirable.

Begonias may be divided into three sections: the fibrous-rooted class, which contains the winter-flowering, branching kinds; the rex forms, or beefsteak geraniums, having large ornamental leaves; the tuberous-rooted, those that bloom through the summer, the tuber rest. ing in the winter.

The fibrous-rooted kinds may be propagated by seed or cuttings, the latter being the usual method. Cuttings of half-ripened wood root easily, making a rapid growth, the plants flowering in a few months.

The rex type, having no branches, is propagated from the leaves. The large mature leaves are used. The leaf may be cut into sections, having at the base a union of two ribs. These pieces of leaves may be inserted in the sand as any other cutting. Or a whole leaf may be used, cutting through the ribs at intervals and laying the leaf flat on the propagating bench or other warm, moist place. In a short time young plants having roots of their own will form. These may be potted when large enough to handle, and will soon make good plants (Fig 125).

Rex begonias usually grow little during winter, and they should therefore be kept fairly dry and no effort made to push them. Be sure that the pots are well drained, so that the soil does not become sour. New plants - those a year or so old - are usually most satisfactory. Keep them away from direct sunlight. An insidious disease of rex begonia leaves has recently made its appearance. The best treatment yet known is to propagate fresh plants, throwing away the old stock and the dirt in which it is grown. 
The tuberous-rooted begonias make excellent bedding plants for those who learn their simple but imperative requirements. They are also good pot subjects for summer.

The amateur would better not attempt to grow the tuberous begonias from seed. He should purchase good two-year tubers. These should be able to run for two or three years before they are so old or so much spent that they give unsatisfactory results.

In the North, the tubers are started indoors, for bedding, in February or early March in a rather warm temperature. They will fill a five-inch pot before they are ready to be turned out into the ground. They should not be planted out till the weather is thoroughly settled, for they will not stand frost or unfavorable climatic conditions.

The plants should be given a soil that holds moisture, but is yet well drained. They will not do well in water-logged ground. They should have partial shade; near the north side of a building is a good place for them. Too much watering makes them soft and they tend to break down. Keep the foliage dry, particularly in sunny weather; the watering should be done from underneath.

After blooming, lift the bulbs, dry them off, and keep over winter in a cool place. They may be packed in shallow boxes in dry earth or sand.

Florists sometimes divide the tubers just after growth starts in the spring, so that a good eye may be got with each'plant; but the amateur would better use the entire tuber, unless he desires to increase or multiply some particular plant.

If the house gardener desires to raise tuberous begonias from seed, he must be prepared to exercise much patience. The seeds, like those of all begonias, are very small, and should be sown with great care. Start the seeds in late winter. Simply sprinkle them on the surface of the soil, which should be a mixture of leafmold and sand, with the addition of a small quantity of fibrous loam. Watering should be done by setting the pot or box in which the seeds are sown in water, allowing the moisture to ascend through the soil. When the soil has become completely saturated, set the box in a shady situation, covering it with glass or some other object until the tiny seedlings appear. Never allow the soil to become dry. The seedlings should be transplanted, as soon as they can be handled, into boxes or pots containing the 
same mixture of soil, setting each plant down to the seed-leaf. They will need three or four transplantings before they reach the blooming stage, and at each one after the first, the proportion of fibrous loam may be increased until the soil is composed of one-third each of loam, sand, and leafmold. The addition of a little well-rotted manure may be made at the last transplanting.

Cactus. - Various kinds of cactus are often seen in small collections of house plants, to which they add interest and oddity, being different from other plants.

Most cacti are easy to grow, requiring little care and enduring the heat and dryness of a living room much better than most other plants. Their requirements are ample drainage and open soil. Cactus growers usually make a soil by mixing pulverized plaster or lime refuse with garden loam, using about two-thirds of the loam. The very fine parts, or dust, of the plaster, are blown out, else the soil is likely to cement. They may be rested at any season by simply setting them away in a dry place for two or three months, and bringing them into heat and light when they are wanted. As new growth advances they should have water occasionally, and when in bloom, they should be watered freely. Withhold water gradually after blooming until they are to be rested.

Some of the most common species in cultivation are the phyllocactus species, often called the night-blooming cereus. These are not the true night-blooming cereuses, which have angular or cylindrical stems, covered with bristles, while these have flat, leaf-like branches; the flowers of these, however, are very much like the cereus, opening at evening and closing before morning, and as the phyllocacti may be grown with greater ease, blooming on smaller and younger plants, they are to be recommended.

The true night-blooming cereuses are species of the genus Cereus. The commonest one is $C$. nycticalus, but $C$. grandiflorus, $C$. triangularis and others are occasionally seen. These plants all have long rod-like stems which are cylindrical or angular. These stems often reach a height of 10 to $30 \mathrm{ft}$., and they need support. They should be trained along a pillar or tied to a stake. They are uninteresting leafless things during a large part of the year; but in midsummer, after they are three or more years old, they throw out their 
great tubular flowers, which open at nightfall and wither and die when the light strikes them next morning. They are very easily grown, either in pots or planted in the natural soil in the conservatory. The only special care they need is good drainage at the roots, so that the soil will not become soggy.

The epiphyllum, or lobster cactus, or crab cactus, is one of the best of the family, easy of culture. It bears bright-colored blossoms at the end of each joint. When in flower, which will be in the winter months, it requires a richer soil than the other cacti. A suitable soil is made of two-thirds fibrous loam and one third leafmold; usually it is best to add sand or pulverized brick. In fall and early winter, keep rather dry, giving more water as the plant comes into bloom.

Opuntias, or prickly pears, are often grown as border plants through the summer. In fact, all the family may be planted out, and if a number of kinds are set in a bed together, they make a striking addition to the garden. Be very careful not to bruise the plants. It is better to plunge them in the pots than to turn them out of the pots.

Caladium. - Tuberous-rooted, tender perennial plants used for conservatory decoration, and also for subtropical and bold effects in the lawn (Plate IV). The plants commonly known under this name are really colocasias.

The roots should be dormant in the winter, being kept in a warm cellar or under a greenhouse bench, where they are not liable to frost or dampness. The roots are usually covered with earth, but they are kept dry. Early in spring the roots are put into boxes or pots and are started into growth, so that by the time settled weather comes they will be 1 or 2 feet high and ready to set directly into soil.

When set out of doors, they should be protected from strong winds, and from the full glare of direct sunlight. The soil should be rich and deep, and the plants should have an abundance of water. They do well about ponds (see Plate $\mathbf{X}$ ).

Caladiums are most excellent plants for striking effects, especially against a house, high shrubbery, or other background. If they are planted by themselves, they should be in clumps rather than scattered as single specimens, as the effect is better. See that they get a good start before they are planted in the open ground. As soon as killed 
down by frost, dig them, dry the roots of superfluous moisture, and store till wanted in late winter or spring.

Calceolaria. - The calceolarias are small greenhouse herbs sometimes used in the window-garden. They are not very satisfactory plants for window treatment, however, since they suffer from dry atmosphere and from sudden changes of temperature.

The calceolarias are grown from seeds. If the seeds are sown in early summer and the young plants are transplanted as they need, flowering specimens may be had for the late fall and early winter. In the growing of the young plants, always aroid exposing them to direct sunlight; but they should be given a place that has an abundance of screened or tempered light. A new crop of plants should be raised each year.

There is a race of shrubby calceolarias, but it is little known in this country. One or two species are annuals adaptable to cultivation in the open garden, and their little ladyslipper-like flowers are attractive. However, they are of secondary importance as annual garden flowers.

Calla (properly Richardia), Egyptian lily. - The calla is one of the most satisfactory of winter house-plants, lending itself to various conditions.

The requirements of the calla are rich soil and an abundance of water, with the roots confined in as small a space as possible. If a too large pot is used, the growth of foliage will be rery rank, at the expense of the flowers; but by using a smaller-sized pot and applying liquid manure, the flowers will be produced freely. A 6-inch pot will be large enough for all but an exceptionally large bulb or tuber. If desired, a number of tubers may be grown together in a larger pot. The soil should be very rich but fibrous - at least one third well-rotted manure will be none too much, mixed with equal parts of fibrous loam and sharp sand. The tubers should be planted firmly and the pots set in a cool place to make roots. After the roots have partially filled the pot, the plant may be brought into heat and given a sunny position and an abundance of water. An occasional sponging or washing of the leaves will free them from dust. No other treatment will be required until the flowers appear, when liquid manure may be given. 
The plant will thrive all the better at this time if the pot is placed in a saucer of water. In fact, the calla will grow well in an aquarium.

The calla may be grown through the entire year, but it will prove more satisfactory, both in leaf and flower, if rested through part of the summer. This may be done by laying the pots on their sides in a dry shady place under shrubbery, or if in the open slightly covered with straw or other litter to keep the roots from becoming extremely dry. In September or October they may be shaken out, cleaning off all the old soil, and repotted, as already mentioned. The offsets may be taken off and set in small pots and given a year's growth, resting them the second year and having them in flower that winter.

The spotted calla has variegated foliage and is a good plant for mixed collections. This blooms in the spring, which will lengthen the season of calla bloom. The treatment of this is similar to that of the common calla.

Camellias are half-hardy woody plants, blooming in late winter and spring. Years ago camellias were very popular, but they have been crowded out by the informal flowers of recent times. Their time will come again.

During the blooming season keep them cool - say not over $50^{\circ}$ at night and a little higher by day. When blooming is done they begin to grow; then give them more heat and plenty of water. See that they are well ripened by winter with large plump flower-buds. If they are neglected or kept too dry during their growing season (in summer) they will drop their buds in fall. The soil for camellias should be fibrous and fertile, compounded of rotted sod, leafmold, old cow manure, and sufficient sand for good drainage. Always screen them from direct sunlight. Do not try to force them in early winter, after the growth has ceased. Their summer quarters may be in a protected place in the open air.

Camellias are propagated by cuttings in winter, which should give blooming plants in two years.

Cannas are among the most ornamental and important plants used in decorative gardening. They make fine herbaceous hedges, groups, 
masses, and - when desirable - good center plants for beds. They are much used for subtropical effects (see Plate V).

Cannas grow 3 to 10 feet or more high. Formerly they were valued chiefly for their foliage, but since the introduction, in 1884, of the Crozy Dwarf French type with its showy flowers, cannas are grown as much for their bloom as for their foliage effects. The flowers of these new kinds are as large as those of gladioli, and are of various shades of yellow and red, with banded and spotted forms. These flowering kinds grow about 3 feet high. The older forms are taller. In both sections there are green-leaved and dark coppery-red-leaved varieties.

The canna may be grown from seed and had in bloom the first year by sowing in February or March, in boxes or pots placed in hotbeds or a warm house, first soaking the seeds in warm water for a short time or filing a small notch through the coat of each seed (avoiding the round germinating point). It requires two years to raise strong plants of the old-fashioned tall cannas from seed. Sow in light, sandy soil, where the earth may be kept at $70^{\circ}$ till after germination. After the plants have got well up, transplant them to about 3 or 4 inches apart, or place in pots 3 inches wide, in good rich soil. They may now be kept at $60^{\circ}$.

The majority of cannas, however, are grown from pieces of the roots (rhizomes), each piece having a bud. The roots may be divided at any time in the winter, and if early flowers and foliage are wanted, the pieces may be planted in a hotbed or warmhouse in early April, started into growth, and planted out where wanted as soon as the ground has warmed and all danger of frost is over. A hardening of the plants, by learing the sash off the hotbeds, or setting the plants in shallow boxes and placing the boxes in a sheltered position through May, not forgetting a liberal supply of water, will fit the plants to take kindly to the final planting out.

Plant out roots or started plants when there is no longer danger of frost. For mass effects, the plants may stand twelve to eighteen inches apart; for individual bloom twenty to twenty-four inches or more. Some gardeners plant them not closer than twenty to twenty-four inches for mass beds, if the soil is good and the plants strong. Give them a warm sunny place. 
The old (foliage) sorts may be left out late to ripen up the fleshy root-stocks. Cut the tops off immediately after frost. The roots are safe in the ground as long as it does not freeze. Dig, and dry or "cure" for a few days, then winter them like potatoes in the cellar. It is a common mistake to dig canna roots too early.

The French sorts are commonly thought to keep best if kept growing somewhat during the winter; but if managed right, they may be carried over like the others. Immediately after frost, cut off the tops next the ground. Cover the stumps with a little soil and leave the roots in the ground till well ripened. Clean them after digging, and cure or dry them for a week or more in the open air and sun, taking them indoors at night. Then place them away from frost in a cool, dry place.

Carnations are now among the most popular florists' flowers; but it is not generally known that they may be easily grown in the outdoor garden. They are of two types, the outdoor or garden varieties, and the indoor or forcing kinds. Normally, the carnation is a hardy perennial, but the garden kinds, or marguerites, are usually treated as annuals. The forcing kinds are flowered but once, new plants being grown each year from cuttings.

Marguerite carnations bloom the year the seed is sown, and with a slight protection will bloom freely the second year. They make attractive house plants if potted in the fall. The seeds of these carnations should be sown in boxes in March and the young plants set out as early as possible, pinching out the center of the plant to make them branch freely. Give the same space as for garden pinks.

The winter-flowering carnations have become prime favorites with all flower lovers, and a collection of winter house-plants seems incomplete without them.

Carnations grow readily from cuttings made of the suckers that form around the base of the stem, the side shoots of the flowering stem, or the main shoots before they show flower-buds. The cuttings from the base make the best plants in most cases. These cuttings may be taken from a plant at any time through the fall or winter, rooted in sand and potted up, to be held in pots until the planting out time in the spring, usually in April, or any time when the ground is ready to 
handle. Care should be taken to pinch out the tops of the young plants while growing in the pot, and later while in the ground, causing them to grow stocky and send out new growths along the stem. The young plants should be grown cool, a temperature of $45^{\circ}$ suiting them well. Attention should be given to spraying the cuttings each day while in the house to keep down the red spider, which is very partial to the carnation.

In the summer, the plants are grown in the field, and not in pots, being transplanted from the cutting-box. The soil in which they are to be planted should be moderately rich and loose. Clean cultivation should be given throughout the summer. Frequently pinch out the tops.

The plants are taken up in September and potted firmly, and well watered; then set in a cool, partially shaded situation until root growth has started, and watering the plant as it shows need of water.

The usual living-room conditions as to moisture and heat are not such as the carnation demands, and care must be taken to overcome the dryness by spraying the foliage and setting the plant in a position not exposed to the direct heat of a stove or the sun. In commercial houses, it is not often necessary to spray established plants. Pick off most or all of the side buds, in order to add to the size of the leading flowers. After all is said, it is probably advisable in most cases to purchase the plants when in bloom from a florist, and after blooming either throw them away or store them for planting out in the spring, when they will bloom throughout the summer.

If conditions are right, the rust should not be very troublesome, if the start was made with clean stock. Keep all rusted leaves picked off.

Century plants or agaves are popular plants for the window-garden or conservatory, requiring little care and growing slowly, thus needing repotting only at long intervals. When the plants have outgrown their usefulness as house-plants, they are still valuable as porch decorations, for plunging in rock-work, or about rustic nooks. The stripedleaved variety is the most desirable, but the normal type, with its bluegray leaves, is highly ornamental.

There are a number of dwarf species of agave that are not so common, although they may be grown with ease. Such plants add novelty 
to a collection, and may be used through the summer as noted above or plunged with cactus in a bed of tropical plants. All succeed well in loam and sand in equal parts, with a little leafmold in the case of the small varieties.

The more common species are propagated by suckers from around the base of the established plants. A few kinds having no suckers must be grown from seed.

As to watering, they demand no special care. Agaves will not stand frost to any extent.

When the head throws up its great stem and blooms, it may exhaust itself and die; but this may be far short of a century. Some species bloom more than once.

Chrysanthemums are of many kinds, some being annual flowergarden plants, some perennial border subjects, and one form is the universal florists' plant. In chrysanthemums are now included the pyrethrums.

The annual chrysanthemums must not be confounded with the wellknown fall-flowering kinds, as they will prove a disappointment if one expects large flowers of all colors and shapes. The annuals are mostly coarse-growing plants, with an abundance of bloom and a rank smell. The flowers are single in most cases, and not very lasting. They are useful for massing and also for cut-flowers. They are among the easiest of hardy annuals to grow. The stoniest part of the garden will usually suit them. Colors white and shades of yellow, the flowers daisy-like ; 1-3 ft.

Amongst perennial kinds, Chrysanthemum frutescens is the wellknown Paris daisy or marguerite, one of the most popular of the genus. This makes a good pot-plant for the window-garden, blooming throughout the winter and spring months. It is usually propagated by cuttings, which, if taken in spring, will give large blooming plants for the next winter. Gradually transfer to larger pots or boxes, until the plants finally stand in 6-inch or 8-inch pots or in small soap boxes. There is a fine yellow-flowered variety. The marguerite daisy is much grown out-of-doors in California.

The hardy perennial kinds are small-flowered, late-blooming plants, known to many old people as "artemisias." They have been 
improved of late years, and they are very satisfactory plants of easy culture. The plants should be renewed from seed every year or two.

In variety of form and color, and in size of bloom, the florists' chrysanthemum is one of the most wonderful of plants. It is a late autumn flower, and it needs little artificial heat to bring it to perfection. The great blooms of the exhibitions are produced by growing only one flower to a plant and by feeding the plant heavily. It is hardly possible for the amateur to grow such specimen flowers as the professional florist or gardener does; neither is it necessary. A well-grown plant with fourteen to twenty flowers is far more satisfactory as a window-plant than a long, stiff stem with only one immense flower at the apex. The culture is simple, much more so than that of many of the plants commonly grown for house decoration. Although the season of bloom is short, the satisfaction of having a fall display of flowers before the geraniums, begonias, and other house-plants have recovered from their removal from out of doors, repays all efforts. Very good plants can be grown under a temporary shed cover, as shown in Fig. 268. The roof need not necessarily be of glass. Under such a corer, also, potted plants, in bloom, may be set for protection when the weather becomes too cold.

Cuttings taken in March or April, planted out in the border in May, well tended through the summer and lifted before frost in September, will bloom in October or November. The ground in which the plants are to bloom should be moderately rich and moist. The plants may be tied to stakes. When the buds show, all but the center one of eash cluster on the leading shoots should be picked off, as also the small lateral branches. A thrifty bushy plant thus treated will usuallyhave flowers large enough to show the character of the variety, also numbers enough to make a fine display.

After blooming, the plants are lifted from the border. As to the receptacle into which to put them, it need not be a flower-pot. A pail or soap-box, with holes bored for drainage, will suit the plant just as well, and by covering the box with cloth or paper the difference will not be noticed.

If cuttings are not to be had, young plants may be bought of the florists and treated in the manner described. Buy them in midsummer or earlier. 
It is best not to attempt to flower the same plant two seasons. After the plant has bloomed, the top may be cut down, and the box set in a cellar and kept moderately dry. In February or March, bring the plant to the sitting-room window and let the shoots start from the root. These shoots are taken for cuttings to grow plants for the fall bloom.

Cineraria is a tender greenhouse subject, but it may be grown as a house-plant, although the conditions necessary to the best results are difficult to secure outside a glasshouse.

The conditions for cinerarias are a cool temperature, frequent repotting, and guarding against the attacks of the greenfly. Perhaps the last is the most difficult, and with one having no facilities for fumigating, it will be almost impossible to prevent the difficulty. A living room usually has too dry air for cinerarias.

The seed, which is very minute, should be sown in August or September to have plants in bloom in January or February. Sow the seed on the surface of fine soil and water very lightly to settle the seeds into the soil. A piece of glass or a damp cloth may be spread over the pot or box in which the seeds are sown, to remain until the seeds are up. Always keep the soil damp, but not wet. When the seedlings are large enough to repot, they should be potted singly in 2- or 3-inch pots. Before the plants have become pot-bound, they should again be repotted into larger pots, until they are in at least 6-inch pots in which to bloom.

In all this time, they should be grown cool and, if not possible to fumigate them with tobacco, the pots should stand on tobacco stems, which should be moist at all times. The general practice, in order to have bushy plants, is to pinch out the center when the flower-buds show, causing the lateral branches to start, which they are slow to do if the central stem is allowed to grow. Plants bloom but once.

Clematis. - One of the best of woody climbing vines, the common C. Flammula, Virginiana, paniculata and others being used frequently to cover division walls or fences, growing year after year without any care and producing quantities of flowers. C. paniculata is now planted very extensively. The panicles of star-shaped flowers entirely cover 
the vine and have a pleasant fragrance. It is one of the bast of all fall-flowering vines, and hardy north; clings well to a chicken-wire trellis.

The large-flowered section, of "which Jackmani is perhaps the best known, is very popular for pillar or porch climbers. The flowers of this section are large and showy, running from pure white, through blue, to scarlet. Of this class, a serviceable purple is Jackmani; white, Henryi (Fig. 266); blue, Ramona; crimson, Madame E. André.

A deep, mellow, fertile soil, naturally moist, will suit the requirements of clematis. In dry times apply water freely, particularly for the large-flowered kinds. Also provide trellis or other support as soon as they begin to run. Clematis usually blooms on the wood of the season: therefore prune in winter or early spring, in order to secure strong new flowering shoots. The large-flowered kinds should be cut back to the ground each year; some other kinds may be similarly treated unless they are wanted for permanent bowers.

The clematis root disease is the depredation of a nematode or eelworm. It is seldom troublesome in ground that thoroughly freezes, and this may be the reason why it so often fails when planted against buildings.

Coleus. - The commonest "foliage plant" in window-gardens. It was used very exterssively at one time in ornamental bedding and ribbon borders, but owing to its being tender has lost in favor, and its place is largely taken by other plants.

Coleus is grown with the greatest ease from cuttings or slips. Take cuttings only from vigorous and healthy plants. It may also be grown from seed, although the types have not become fixed, and a large number of differently marked plants may be had from the same packet. This would not be a drawback in the window-garden, unless a uniform effect is desired; in fact, the best results are often secured from seeds. Sow the seed in gentle heat in March.

Grow new plants each year, and throw the old ones away.

Crocus (see Bulbs, p. 281). - Crocus is one of the best of spring bulbs, easily grown and giving good satisfaction either in the border or scattered through the lawn. They are also forced for winter (see 
p. 345). They are so cheap and lasting that they may be used in quantity. A border of crocuses along the edges of walks, little clumps of them in the lawn, or masses in a bed, give the first touch of color as the spring opens.

A sandy soil suits the crocus admirably. Plant in the fall, in the open, 3 to 4 inches deep. When they show signs of failing, take up the bulbs and reset them. They tend to rise out of the ground, because the new bulb or corm forms on the top of the old one. They run out on lawns in two or three years. If best results are desired, it is well to renew the bed occasionally by buying new bulbs. Crocus beds may be filled later in the season with quick-growing annuals. It is important that only the best flowering bulbs be secured.

They may be forced with ease, planted in pots or shallow boxes, put away in a cool place and brought into the house at any time through the winter. A low temperature will bring them into bloom in perfection in about four weeks from the time they are brought in. They can be had in the window-garden in this way, opening in the sunshine.

Croton. - Under this name many varieties and so-called species of Codiæum are grown for conservatory decoration, and latterly for foliage bedding in the open. The colors and shapes of the leaves are very various and attractive. The crotons make good window-garden subjects, although they are very liable to the attack of the mealy bug.

The plants should be given an abundance of light in order to bring out their fine colors; but it is usually advisable to screen them from the direct rays of the sun when they are grown under glass. If the red spider or the mealy bug attack them, they may be syringed with tobacco water. Plants that are propagated indoors in winter may be massed in beds out of doors in summer, where they make very striking effects. Give them strong deep soil, and be sure that they are syringed frequently enough on the underside of the leaves to keep down the red spider. If the plants have been gradually subjected to strong light before they are taken out of doors, they will stand the full sunlight and will develop their rich colors to perfection. In the fall they may be taken up, cut back, and used for window-garden or conservatory subjects.

Crotons are shrubs or small trees, and they may be transferred into 
large pots or tubs and grown into large tree-like specimens. Old and scraggly specimens should be thrown away.

Crotons are propagated readily by cuttings of half-ripened wood any time in winter or spring.

Cyclamen. - A tender greenhouse tuberous plant, sometimes seen in the window-garden. The Persian cyclamen is best for the housegardener to grow.

Cyclamens may be grown from seed sown in April or September in soil containing a large proportion of sand and leafmold. If sown in September, they should be wintered in a coolhouse. In May they should be potted into larger pots and placed in a shaded frame, and by July will have become large enough for their flowering pot, which should be either 5 -inch or 6 -inch. They should be brought into the house before danger of frost, and grown cool until through flowering. A temperature of $55^{\circ}$ suits them while in flower. After flowering, they will need a rest for a short time, but should not become very dry, or the bulb will be injured. When they start into growth, they should have the old soil shaken off and be potted into smaller pots. At no time should more than half the tuber be under the soil.

April-sown plants should be similarly treated. Cyclamens should bloom in about fifteen months from seed. The seed germinates very slowly.

Tubers large enough to flower the first year may be purchased from the seedsmen at moderate prices; and unless one has facilities for growing the seedlings for a year, purchase of the tubers will give the best satisfaction. Secure new tubers, for old ones are not so good.

The soil best suited to the cyclamen is one containing two parts leafmold, one part each of sand and loam.

Dahlia is an old farorite which, on account of its formal flowers, has been in disfavor for a few years, although it has always held a place in the rural districts. Now, however, with the advent of the cactus and semi-cactus types (or loose-flowered forms), and the improvement of the singles, it again has taken a front rank among late summer flowers, coming in just in advance of the chrysanthemum.

The single varieties may be grown from seed, but the double sorts 


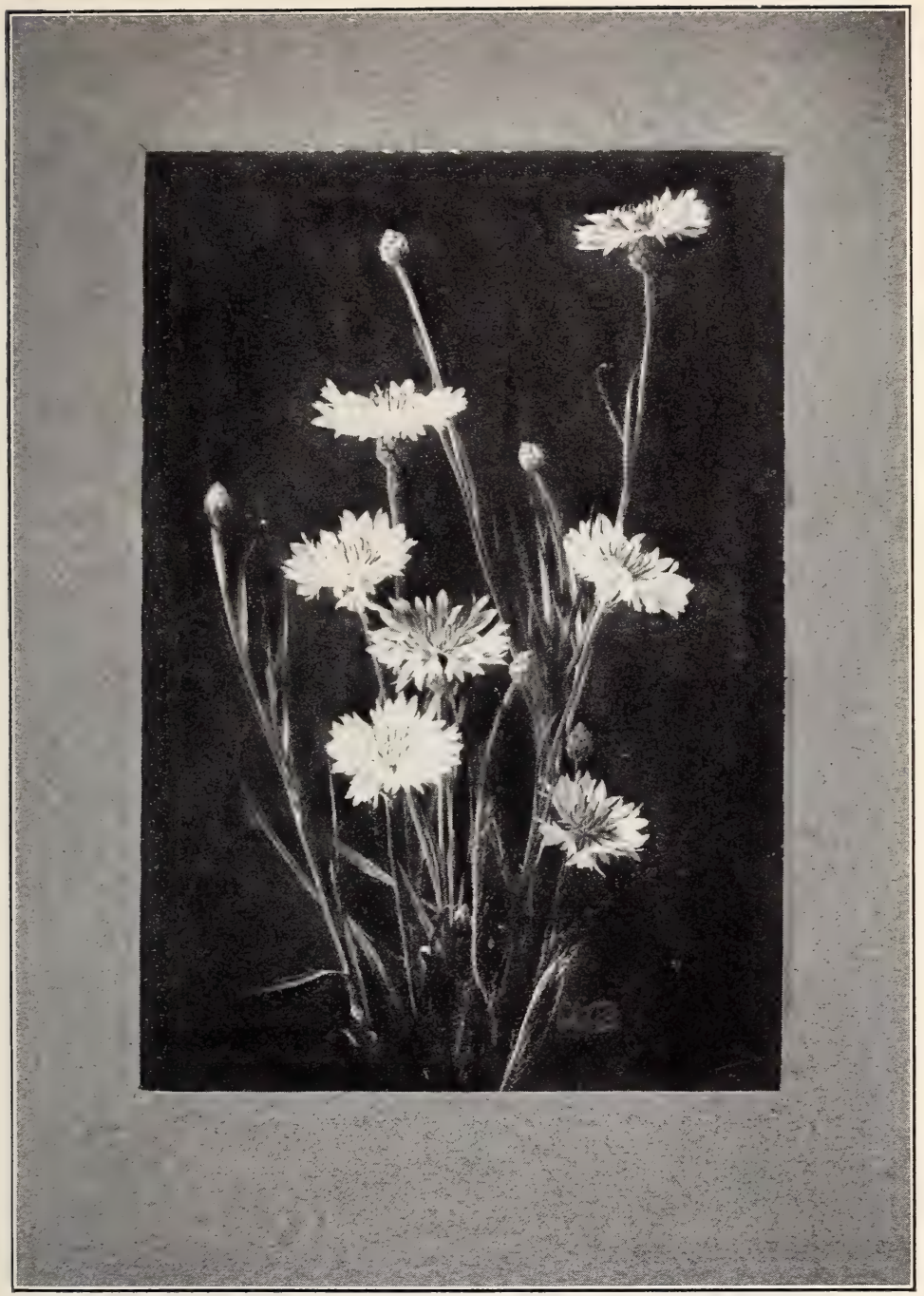

XVIII. Cornflower or bachelor's button. Centaurea Cyanus. 

should be grown from cuttings of young stems or from division of the roots. If cuttings are to be made, it will be necessary to start the roots early, either in a hotbed or house. When the growths have reached 4 or 5 inches, they may be cut from the plant and rooted in sand. Care should be taken to cut just below a joint, as a cutting made between two joints will not form tubers. The most rapid method of propagation of named varieties is to grow from cuttings in this way.

In growing the plants from roots, the best plan is to place the whole root in gentle heat, covering slightly. When the young growth has started, the roots may be taken up, divided, and planted out 3 to 4 feet apart. This plan will insure a plant from each piece of root, whereas if the roots are divided while dormant, there is danger of not having a bud at the end of each piece, in which case no growth will start; the roots are sometimes cut into pieces while dormant, however, but one should be sure that a piece of old stem with bud is on each piece.

One objection to the old dahlia was its lateness of bloom. But by starting the roots early in a frame, or in boxes that are covered at night, the plants may be had in flower several weeks earlier than usual. They may be started in April, or at least three weeks in advance of planting time. Little water will be required till they start. When they begin shooting up, the plants should have the full sun, and air, on all mild days. They will then make a slow, sturdy growth. All forcing should be avoided. These plants, set out when there is no longer danger of frost, and well watered before completely covering the roots, will grow right on, and often begin blooming in July.

Dormant roots may be set out in May. The roots, unless small, should be divided before planting, as a single strong root is usually better than a whole clump. The roots of all but the Dwarf should be set about 3 feet apart, in rows. In poor soils none but the first class will need stakes.

The dahlia flourishes best in a deep, loose, moist soil; very good results can be had on sandy soil, provided plant-food and moisture are furnished. Clay should be avoided. If the ground is too strong, they will probably bloom too late for the northern latitudes. .

If the plants are to be grown without stakes, the center of each plant should be pinched out after making two or three joints. By doing this 
the lateral bracches will start near the ground and be stiff enough to withstand the winds. In most home gardens the plants are allowed to reach their full height, and are tied to stakes if necessary. The tall kinds reach a height of 5 to $8 \mathrm{ft}$.

Dahlias are very susceptible to frost. After the first frost, lift the roots, let them dry in the sun, shake off the dirt, trim off tops and broken parts; and store them in a cellar, as for potatoes. They may be placed in barrels of sand, if the open cellar is not usable. Cannas may be stored in the same place.

The tree dahlia ( $D$. excelsa, but cultivated as $D$. arborea) is grown more or less far South and in California. It has not been much improved.

Ferns. - The native ferns transplant easily to the garden, and they make an attractive addition to the side of a house, or as an admixture in a hardy border. The ostrich, cinnamon, and royal ferns are the best subjects. Give all outdoor ferns a place that is protected from winds, otherwise they will shrivel and perhaps die. Screen them from the hot sun, or give them the shady side of the building. See that the soil is uniformly moist, and that it does not get too hot. Mulch with leafmold in the fall. It is not difficult to colonize many of the native ferns in shady and protected places where trees do not sap all the strength from the ground.

Probably the one fern grown most extensively as a house-plant is the small-leaved maidenhair fern (or Adiantum gracillimum). This and other species are among the finest of house plants, when sufficient moisture can be given. They make fine specimens as well as serving the purpose of greenery for cut flowers. Other species often grown for house plants are A. cuneatum and A. Capillus-Veneris. All these do well in a mixture of fibrous sod, loam, and sand, with ample drainage material. They may be divided if an increase is wanted.

Another fern for house culture is Nephrolepsis exaltata. This is no doubt the most easily grown of the list, flourishing in a sittingroom. A variety of $N$. exaltata, called the Boston fern, is a decided addition to this group, having a drooping habit, covering the pot and making a fine stand or bracket plant; and there are now several other forms of it suitable for the best window-gardens. 
Several species of pteris, especially $P$. serrulata, are valuable house ferns, but require a warmer place than those mentioned above. They will also thrive better in a shady or ill-lighted corner.

Perfect drainage and care in watering have more to do with the successful growing of ferns than any special mixture of soils. If the drainage material in the bottom of the pot or box is sufficient, there is little danger of overwatering; but water-logged soil is always to be avoided. Do not use clay soils. Ferns need protection from the direct sunshine, and also a moist atmosphere. They thrive well in a close glass box, or window-garden, if the conditions can be kept equable.

Freesia. - One of the best and most easily handled tender winterflowering bulbs; height 12 or 15 inches. The white form (Freesia refracta alba) is the best.

The white or yellowish bell-shaped flowers of freesia are produced on slender stalks just above the foliage, to the number of six to eight in a cluster. They are very fragrant, and last for a considerable time when picked. The bulbs are small, and look as though they could not produce a growth of foliage and flowers, but even the smallest mature bulb will prove satisfactory. Several bulbs should be planted together in a pot, box, or pan, in October, if wanted for the holidays, or later if wanted at Easter. The plants bloom from ten to twelve weeks from planting, under ordinary care.

No special treatment is required; keep the plants cool and moist through the growing season. The soil should contain a little sand mixed with fibrous loam, and the pot should be well drained. After flowering, gradually withhold water and the tops will die down, after which the roots may be shaken out and rested until time to plant in fall. Care should be taken to keep them perfectly dry.

The bulbs increase rapidly from offsets. Plants may also be grown from seed, which should be sown as soon as ripe, giving blooming plants the second or third year.

Fuchsia. - Well-known window or greenhouse shrub, treated as an herbaceous subject; many interesting forms; late winter, spring and summer. 
Fuchsia is readily grown from cuttings. Soft green wood should be used for cuttings, and it will root in about three weeks, when the cuttings should be potted. Take care not to have them pot-bound while in growth, but do not overpot when bloom is wanted. Given warmth and good soil, they will make fine plants in three months or less. In well-protected, partially shady places they may be planted out, growing into miniature bushes by fall.

Plants may be kept on from year to year; and if the branches are well cut back after blooming, abundant new bloom will come. But it is usually best to make new plants each year from cuttings, since young plants commonly bloom most profusely and demand less care. Fuchsias are amongst the best of window subjects.

Geranium. - What are commonly known as geraniums are, strictly speaking, pelargoniums. (See Pelargonium.)

The true geraniums are mostly hardy perennials, and therefore should not be confounded with the tender pelargoniums. Geraniums are worthy a place in a border. They may be transplanted early in the spring, setting them $2 \mathrm{ft}$. apart. Height 10 to $12 \mathrm{in}$. The common wild cranesbill (Geranium maculatum) improves under cultivation, and is an attractive plant when it stands in front of taller foliage.

Gladiolus. - Of summer and fall-blooming bulbous plants, gladiolus is probably the most widely popular. The colors range from scarlet and purple, to white, rose, and pure yellow. The plants are of slender, erect habit, growing from 2 to 3 feet high.

Gladioli dislike a heavy clay soil. A light loam or sandy soil suits them best. No fresh manure should be added to the soil the year in which they are grown. They should have a new place every year, if possible, and always an open sunny situation.

The corms may be covered 2 inches deep in heavy soils, and 4 to 6 in light soils. They may stand 8 to 10 inches apart, or half this distance for mass effects. For a succession, they may be planted at short intervals, the earliest planting being of smaller corms in the early spring as soon as the soil is dry enough to work; later the larger are to be planted - the last setting being not later than the Fourth of July. 
This last planting will afford fine late flowers. The plants should be supported by inconspicuous stakes.

The successive plantings may be in the same bed among those set earlier, or they may ba grouped in unoccupied nooks, or portions of the border. The plants may stand as close as 6 inches from each other. The earlier planting may be a foot apart to admit of later settings between.

Late in the fall, after frosts and before freezing, the corms are to be dug, cleaned, and dried in the sun and air for a few hours and then stored away in boxes about $2 \frac{1}{2}$ inches deep in a cool, dark, and dry place. The tops should be left on, at least till completely shriveled.

The varieties are perpetuated and multiplied by the little corms that appear about the base of the large new corm which is formed each year. These small corms may be taken off in the spring and sown thickly in drills. Many of them will make flowering plants by the second season. They are treated like the large corms, in the fall.

Gladioli are easily grown from seed also, but this method cannot be depended on to perpetuate desirable varieties, which can be reproduced only by the cormels. Some of the best flowers may be crosspollinated, or allowed to form səad in the usual manner; the seed sown thickly in drills, and shaded till the plantlets appear, then carefully cultivated, will afford a crop of small corms in the fall. These may be stored for the winter, like the other young corms, and, like them, many will flower the second season, affording a great variety and quite likely some new and striking kinds. Those that do not flower should be reserved for further trial. They often prove finer than those first to flower.

Early-flowering varieties of gladioli may be forced for late winter or spring bloom.

For bouquets, cut the spike when the lower flowers open ; keep in fresh water, cut off the end of the stem frequently, and the other flowers will expand.

Gloxinia. - Choice greenhouse tuberous-rooted, spring and summerblooming perennials, sometimes seen in window-gardens, but really not adapted to them, although some skillful house-gardeners grow them successfully. 
Gloxinias must have a uniform moist and warm atmosphere and protection from the sun. They will not stand abuse or varying conditions. Propagated often by leaf-cuttings, which should give flowering plants in one year. From the leaf, inserted half its length in the soil (or sometimes only the petiole inserted) a tuber arises. This tuber, after resting until midwinter or later, is planted, and flowering plants soon arise.

Gloxinias also grow readily from seeds, which may be germinated in a temperature of about $70^{\circ}$. Flowering plants may be had in August if seeds are sown in late winter, say in early February. This is the usual method. After the bloom is past, the tuber is partially dried off and kept dormant till the following season. It will usually show signs of activity in February or March, when it may be shaken out of the old earth and a little water may then be applied and the amount increased till the plant is in bloom. The same tubers may be bloomed several times.

Success in the growing of gloxinias is largely a matter of proper watering. Keep the dormant tuber just dry enough to prevent shriveling, never trying to force it ahead of its time. Avoid wetting the leaves. Protect from direct sunlight. Protect from draughts on the plants.

Grevillea. - The "she oak," very graceful greenhous plant, suitable also for house culture. The plants grow freely from seed, and until they become too large are as decorative as ferns. Grevillıas are really trees, and are valuable in greenhouses and rooms only in their young state. They withstand much abuse. They are now very popular as jardiniere subjects. Seeds sown in spring will give handsome plants by the next winter. Discard the plants as soon as they become ragged.

Hollyhocks. - These old garden favorites have been neglected of late years, primarily because the hollyhock rust has been so prevalent, destroying the plants or making them unsightly (see pp. 183, 210).

Their culture is very simple. The seed is usually sown in July or August, and the plants set where wanted the following spring. They will bloom the same year in which they are transplanted - the year 
following the seed-sowing. New plants should be set every two years, as the old crowns are likely to rot or die after the first flowering, or at least to become weak. (See page 271.)

Hyacinths (see Bulbs, p. 281) are popular spring-flowering bulbs. Hyacinths are hardy, but they are often used as window or greenhouse plants. They are easy to grow and very satisfactory (Fig. 262).

For winter flowering, the bulbs should be procured early in the fall, potted in October in soil composed of loam, leafmold, and sand. If ordinary flower-pots are used, put in the bottom a few pieces of broken pots, charcoal, or small stones for drainage; then fill the pot with dirt, so that when the bulb is planted, the top will be on a level with the rim of the pot. Fill in around the bulb with soil, leaving just the tip showing. These pots of bulbs should be placed in a cold pit, cellar or on the shady side of a building. In all cases, plunge the pot in some cool material (as cinders). Before the weather becomes cold enough to freeze a crust on the ground, the pots should have a protection of straw or leaves to keep the bulbs from severe freezing. In about six to eight weeks the bulbs should have made roots enough to grow the plant, and the pots may be placed, in a cool room for a short time. When the plants have started into growth, they may be placed in a warmer situation. Watering should be carefully attended to from this time, and when the plant is in bloom, the pot may be set in a saucer or other shallow dish containing water. After flowering, the bulbs may be ripened by gradually withholding water until the leaves die. They may then be planted out in the border, where they will bloom each spring for a number of years, but will never prove satisfactory for forcing again.

The open-ground culture of hyacinths is the same as for tulips and other Holland bulbs.

The hyacinth is the most popular of the Dutch bulbs for growing in vases of water. The narcissus may be grown in water, and do just as well, but it is not as attractive in glasses as the hyacinth. Glasses for hyacinths may be had of florists who deal in supplies, and in various shapes and colors. The usual form is tall and narrow, with a cup-like mouth to receive the bulb. They are filled with water, so that it will just reach the base of the bulb when placed in position in the cup or shoulder 
above. The vessels of dark-colored glass are preferable to those of clear glass, as roots prefer darkness. When the glasses have been filled, they are set away in a cool, dark place, where roots will form, as in potted bulbs. Results are usually secured earlier in water than in soil. To keep the water sweet, a few lumps of charcoal may be put in the glass. As the water evaporates, add fresh; add enough so that it runs over, and thereby renews that in the glass. Do not disturb the roots by taking out the bulb.

Iris includes many handsome perennials, of which the blue flag is familiar to every old-fashioned garden. They are favorites every where, for their brilliant spring and summer bloom; and they are easy to grow.

Most irises thrive best in a rather moist soil, and some of them may be colonized in the water in margins of ponds.

Gardeners usually divide them into two sections - the tuberousrooted or rhizomatous, and the bulbous. A third division - the fibrous-rooted - is sometimes made.

The common and most serviceable species belong to the tuberousrooted section. Here is the beautiful and varied Japanese iris, Iris lavigata (or I. Kampferi), which is among the most deserving of all hardy perennials. Most of these irises need no special care. They are propagated by division of the rootstocks. Plant the pieces one foot apart if a mass effect is desired. When the plants begin to fail, dig them up, divide the roots, discard the old parts, and grow a new stock, as before. The Japanese iris needs much water and a very rich soil. Readily grown from seeds, giving bloom the second year. I. Susiana, of this section, is one of the oddest of irises, but it is not quite hardy in the North.

Of the bulbous section, most species are not hardy far North. The bulbs should be taken up and replanted every two or three years. The Persian and Spanish irises belong here. The bulbs give rise to but a single stem.

Lily. - Under this name are included bulbous plants of many kinds, not all of them being true lilies. It has been said of this family oi plants that it has no "poor relations," each of them being perfect in itself. Many of the choicest kinds are comparatively unknown, al- 
though easy to cultivate. In fact, all of the lilies may be grown with comparative ease in regions where the given species are hardy.

A light, fertile, well-drained soil, mellow to the depth of at least one foot, a handful of sand under each bulb if the soil is inclined to be stiff, and planting so that the crown of the bulb will be at least 4 inches below the surface, are the general requirements. One exception to the depth of planting is Lilium auratum, or golden-banded lily. This should be planted deeper - from 8 to 12 inches below the surface - as the new buibs form over the old one and soon bring the bulbs to the surface if they are not planted deep. Deep working of the ground is always desirable; 18 inches, or even 2 feet, will be none too deep. L. candiaum and L. testaceum should be planted in August or September, if possible; but usually lilies are planted in October and November.

For all lilies it is safer to provide good winter protection in the form of a mulch of leaves or manure, and extending beyond the horders of the planting. This should be 5 inches to a foot deep, according to the latitude or locality.

While most lilies profit by partial shade (except $L$. candidum), they should never be planted near or under trees. The shade or protection of tall-growing herbaceous plants is sufficient. In fact, the best results, both as to growth and effect, may be secured by planting amongst low shrubbery or border plants.

Most kinds are the better for remaining undisturbed for a number of years; but if they are to be taken up and divided, or moved to other quarters, they should not be allowed to become dry. The small bulbs, or offsets, may be planted in the border, and if protected, will grow to flowering size in two or three years. In taking up bulbs for division it is best to do so soon after the tops die after blooming. At least this should be done early in the fall, not later than October, giving the plants a chance to become established before freezing weather.

As pot-plants some kinds of lilies are very satisfactory, especially those that may be forced into bloom through the winter. The best knds for this purpose are L. Harrisii (Easter lily), L. longiflorum, and $L$, candiaum. Others may be forced with success, but these are the ones most generally used. The winter culture for forcing is practically the same as for hyacinths in pots. 
Some of the best kinds of lilies are mentioned below:-

L. candidum (Annunciation lily). White; 3 to 4 feet high; it makes an autumn growth, and should, therefore, be planted in August; set the bulbs from 4 to 6 inches deep.

L. speciosum (L. lancifolium), var. procox. White, tinged with pink; bears several flowers on a stem about 3 feet high.

L. speciosum, var. rubrum. Rose color, spotted with red.

L. Brownii. Flowers white inside, chocolate-colored outside ; the stems grow about 3 feet high, bearing from 2 to 4 tubular flowers; not difficult to manage with good protection and drainage; the bulbs are impatient of being kept long out of the ground; after planting, they should not be disturbed as long as they flower well. L. maculatum (L. Hansoni). Dark yellow; stems 3-4 feet high, each producing 6 to 12 flowers.

L. testaceum (L. excelsum, L. Isabellinum). Rich buff color, with delicate spots; plants about 3 to 5 feet high, with 3 to a dozen flowers on a stem; plant the bulbs in September.

L. longiflorum. White; large tubular flowers, 2 to 8 on a stem; height, about $2 \frac{1}{2}$ feet.

L. Batemannice (a form of L. elegans). Apricot yellow; 6 to 12 flowers on stems 3 to 4 feet high.

L. auratum (Japanese gold-banded lily). Immense white flowers banded with yellow and dotted with red or purple, from 3 to 12 on a stem; height, 3 to 4 feet; the bulbs need thorough protection, good drainage, and should be planted 10 or 12 inches deep (Fig. 258).

L. tigrinum (Tiger lily). An old favorite, with many drooping bright red spotted flowers; var. splendens is specially good; 3 to $5 \mathrm{ft}$.

L. tenuifolium. Rich scarlet flowers nodding in a raceme or panicle; $1 \frac{1}{2}$ to $2 \mathrm{ft}$.

L. Maximouiczii (L. Leichtlinii). Flowers clear yellow, with small, dark spots, 10 to 12 on a stem; height, 4 feet.

L. monadelphum. Yellow tubular-shaped flowers in clusters of 6 to a dozen or more; stems $2 \frac{1}{2}$ feet tall.

L. elegans (L. Thunbergianum), var. Alice Wilson. Lemon-yellow; stems 2 feet high, bearing 2 to 8 flowers.

L. elegans, var. fulgens atrosanguineum. Dark crimson; height, 1 foot 
Lily-of-the-valley. - A perfectly hardy little perennial, bearing racemes of small, white, bell-shaped flowers in early spring; and also much forced by florists.

For ordinary cultivation, sods or mats of roots may be dug from any place in which the plant is colonized. Usually it thrives best in partial shade; and the leaves make an attractive mat on the north side of a building, or other shady place, in which grass will not grow. The plants will take care of themselves year after year. Better results may be expected from good commercial roots. The "pips" may be planted any time from November on, from 3 to 6 inches apart.

For forcing indoors, imported roots or "pips" are used, as the plants are grown for this particular purpose in parts of Europe. These roots may be planted in pots, and treated as recommended for winter-flowering bulbs (p. 345). Florists force them in greater heat, however, often giving them a bottom heat of $80^{\circ}$ or $90^{\circ}$; but skill and experience are required in order to attain uniformly good results in this case.

Mignonette. - Probably no flower is more generally grown for its fragrance than the mignonette. It is a half-hardy annual, thriving either in the open or under glass.

The mignonette needs a cool soil, only moderately rich, shade part of the day, and careful attention to cutting the flower-stalks before the seeds are ripe. If a sowing be made in late April, followed by a second sowing in early July, the season may be extended until severe frosts. There are few flowers that will prove as disappointing if the simple treatment it needs is omitted. Height, 1 to 2 feet.

It may be sown in pots late in summer and be had in the house in winter.

Moon-flowers are species of the morning-glory family that open their flowers at night. A well-grown plant trained over a porch trellis, or allowed to grow at random over a low tree or shrub, is a striking object when in full flower at dusk or through a moonlit evening. In the Southern states (where it is much grown) the moon-flower is a perennial, but even when well protected does not survive the winters in the North.

Cuttings usually give best results in the Northern states, as the 
seasons are not long enough for seed plants to give good bloom. Cuttings may be made before danger of frost and wintered in the house, or the plants may be grown from seed sown in January or February. Seeds should be scalded or filed just before sowing.

The true moon-flower is Ipomaea Bona-Nox, white-flowered; but there are other kinds that go under this name. This grows 20 to 30 feet where the seasons are long enough.

Narcissus (see Bulbs, p. 281). - Daffodils, jonquils, and the poet's narcissus all belong to this group, and many of them are perfectly hardy. The polyanthus section, which includes the Paper-white narcissus and sacred lily or Chinese joss-flower, are not hardy except with unusually good protection, and are, therefore, most suitable for growing indoors.

It is common to allow the hardy sorts to take care of themselves when once planted. This they will do, but much more satisfactory results will be had by lifting and dividing the clumps every three or four years. A single bulb in a few years forms a large clump. In this condition the bulbs are not properly nourished, and consequently do not flower well. Lifting is preferably done in August or September, when the foliage has died down and the bulbs are ripe.

The narcissi are well suited to partially shaded places, and will grow and please wherever good taste may place them. They should be freely used, as they are fragrant, bright of color, and easily managed growing among shrubbery, trees, and in places where other flowers would refuse to grow. They should be planted in clumps or masses, in September or October, setting the bulbs 5 to 8 inches apart, according to size, and 3 or 4 inches deep.

Several species and numberless varieties, both double and single, are grown. A few good types only can be mentioned (Fig. 260):-

Daffodils, or Trumpet narcissus (Narcissus Pseudo-Narcissus and derivatives).

Single-flowered, Yellow. - Golden Spur, Trumpet Major, Van Sion. White. - Albicans.

White and Yellow. - Empress, Horsefieldi.

Double-flowering, Yellow. - Incomparable fl. pl., Van Sion. White. - Alba plena odorata. 
Poet's narcissus ( $N$. poeticus). Flowers white, with yellow cups edged crimson. Very fragrant.

Jonquils ( $N$. Jonquilla). These have very fragrant yellow flowers, both double and single, and are old garden favorites.

Polyanthus narcissus ( $N$. Tazetta). These include paper-white, Chinese sacred lily (var. orientalis), and others.

Primrose Peerless (N. biflorus).

Narcissi may be forced into flower through the winter, as described on p. 345. A popular kind for winter bloom is the so-called Chinese sacred lily. This grows in water without any soil whatever.

1 Secure a bowl or glass dish, about three times the size of the bulb; put some pretty stones in the bottom; set in the bulb and build up around it with stones so as to hold it stiff when the leaves have grown; tuck two or three small pieces of charcoal among the stones to keep the water sweet, then fill up the dish with water and add a little every few days, as it evaporates. Set the dish in a warm, light place. In about six weeks the fragrant, fine white flowers will fill the room with perfume. The Paper-white, closely allied to this, is also forced, and is one of the few good bulbs that may be bloomed before Christmas. The Van Sions, single and double (a form of daffodil), are also much forced.

Oleander. - An old favorite shrub for the window-garden, and much planted in the open far South.

While there are many named varieties of the oleander, but two are often seen in general cultivation. These are the common red and white varieties. Both these, as well as the named varieties, are of easy management and well adapted to home culture, growing in pots or tubs for several years without special care. Well-grown specimens are very effective as porch or lawn plants, or may be used to good advantage in mixed beds of tall-growing plants, plunging the pot or tub to the rim in the soil. The plants should be cut back after flowering. They should be rested in any out-of-the-way place through the winter. When brought out in the spring, they should be given sun and air in order to make a sturdy growth.

Propagation is effected by using well-ripened wood for cuttings, placed in a close frame; or the slips may be rooted in a bottle or can of water, care being taken to supply water as evaporation takes place. 
After being rooted, they may be potted, using soil with a large proportion of sand. Well-established plants may be repotted in good loam and well-rotted manure. They should bloom the second year.

Oxalis. - A number of hardy species of oxalis are excellent plants for rock-work and edging. The greenhouse species are very showy, growing without extra care, and blooming freely through the late winter and spring months and some of them make excellent windowgardening subjects.

The house species are mostly increased by bulbs, a few by division of the root. O. violacea is one of the commonest of house-plants. Give a sunny window, for the flowers open only in sun or very bright light. The bulbous (tuberous) kinds are treated much as recommended for Bulbs (p. 281), except that the bulbs must not freeze. The tubers are started in August or September for winter bloom. It is best to use deep pots, or the tubers will throw themselves out. The crown should be near the surface. After flowering, the bulbs are dried off and kept until new bloom is wanted.

The "Bermuda buttercup" is $O$. lutea and $O$. flava of gardens (properly O.cernua); it is a Cape of Good Hope species. Its culture is not peculiar.

Palms. - No more graceful plants for room decoration can be found than well-grown specimens of some species of palms. Most florists' palms are well adapted for this purpose when small, and as the growth is usually very slow, a plant may be used for many years.

Palm plants thrive best in partial shade. One of the frequent causes of failure in the culture of the palm is the overpotting and subsequent overwatering. A palm should not be repotted until the mass of roots fills the soil and preferably when it is active; then a pot only a size larger should be used. Use ample drainage in the bottom to carry off excess of water: Although the plants need a moist soil, water standing at the roots proves injurious. Withhold free use of water when the plants are partially dormant (page 347).

A soil composed of well-rotted sod, leafmold, and a little sand will meet the requirements.

Under ordinary living-room conditions, palms are subject to much 
abuse. Water is allowed to stand in the jardiniere, the plant is kept in dark corners and hallways, the air is dry, and scale is allowed to infest the leaves. If the plant begins to fail, the housewife is likely to repot it or to give it more water, both of which may be wrong. The addition of bone-meal or other fertilizer may be better than repotting. Keep the plant in good light (but not in direct sunlight) as much as possible. Sponge the leaves to remove dust and scale, using soapsuds. When a new leaf begins to appear, add bone-meal to make it grow vigorously.

Among the best palms for house culture are arecas, Cocos Weddelliana, latania, kentia, howea, caryota, chamærops, and phœnix. Cycas may also be regarded as a palm.

The date palm may be grown from seed of the common commercial date. Seed of the other varieties may be purchased from leading seedsmen; but, as the seed germinates only under favorable conditions, and the palm is a very slow-growing plant while young, the best plan is to purchase the plants from a dealer when wanted. When the plants become weak or diseased, take them to a florist for treatment and recuperation, or purchase new ones. Sometimes the florist places two or three small palms in one pot, making a very satisfactory table piece for two or three years.

It is well to set the palms out of doors in the summer, plunging the pots nearly or quite to the rim. Turn or lift the pots occasionally so that the roots will not strike through into the earth. Choose a partially shaded place, where the hot sun will not strike them directly and where the wind will not injure"them.

Pandanus, or screw pine. - The screw pines are stiff-leaved sawedged plants often grown in window-gardens and used for porch decoration.

The Pandanus utilis and P. Veitchii (the latter striped-leaved or white-leaved) are exceedingly ornamental, and are well adapted to house culture. The singular habit of growth, bright glossy leaves, and the ability to withstand the dust and shade of a dwelling room, make them a desirable addition to the house collection.

They are propagated by the offsets or young plants that grow around the base of the trunk; or they may be increased by seed. If by the 
former method, the offsets should be cut off and set in sand, at a temperature of $65^{\circ}$ or $70^{\circ}$. The cuttings root slowly and the plants for a time make very slow growth. The general cultural treatment is that of palms. Give abundance of water in summer.

Pansy (Fig. 244) is without doubt the most popular hardy spring flower in cultivation. The strains of seed are many, each containing great possibilities.

The culture is simple and the results are sure. Seed sown in August or September, in boxes or a frame, will make plants large enough to reset in November (three or four inches apart) and bloom the following March; or they may be left until March in open seed-beds before setting out. Also, if they are sown very thinly in the frames, they may remain undisturbed through the winter, blooming very early the following spring. The frames should be protected by mats, boards, or other covering through the severe cold, and as the sun gains strength, care should be taken to keep them from heaving by alternate thawing and freezing. Seed sown in boxes in January or February will make fine blooming plants by April, taking the place of those blooming earlier.

The pansy is generally mentioned with plants suitable for partial shade, but it also thrives in other localities, especially where the sun is not very hot nor the weather very dry. The requisites for satisfactory pansy culture are fertile, moist, cool soil, protection from the noonday sun, and attention to keeping plants from going to seed. As the ground becomes warm, a mulch of leafmold or other light material should be spread over the bed to retain moisture and exclude heat. Spring and fall gire the best bloom. In hot summer weather the flowers become small.

Pelargonium. - To this genus belong the plants known as geraniums - the most satisfactory of house-plants, and extensively used as bedding plants. No plants will give better returns in leaf and flower; and these features, added to the ease of propagation, make them general favorites. The common geranium is one of the few plants that can be bloomed at any time of the year.

There are several main groups of pelargoniums, as the common "fish geraniums" (from the odor of the foliage), the "show" or Lady 
Washington pelargoniums, the ivy geraniums, the thin-leaved bedders (as Madame Salleroi), and the "rose" geraniums.

Cuttings of partially ripened wood of all pelargoniums root very easily, grow to blooming size in a short time, and, cither planted out or grown in a pot, make fine decorations. The common or fish geraniums are much more satisfactory when not more than a year old. Take cuttings from the old plants at least once a year. In four or five months the young plants begin to bloom. Plants may be taken up from the garden and potted, but they rarely give as much satisfaction as young, vigorous subjects; new plants should be grown every year. Repot frequently until they are in 4- to 5-inch pots; then let them bloom.

The show pelargoniums have but one period of bloom, usually in April, but they make up in size and coloring. This section is more difficult to manage as house-plants than the common geranium, needing more direct light to keep it stocky, and being troubled by insects. Still, all the trouble taken to grow the plants will be well repaid by the handsome blossoms. Take cuttings in late spring, after flowering, and blooming plants may be had the following year. Good results are sometimes secured by keeping these plants two or three years. Cut back after each blooming season.

For house culture the geraniums need a fertile, fibrous loam, with the addition of a little sand; good drainage is also an essential.

Peony. - The herbaceous peony has long had a place in the garden; it has now been much improved and constitutes one of the very best plants known to cultivation. It is perfectly hardy, and free from the many diseases and insects that attack so many plants. It continues to bloom year after year without renewal, if the soil is well prepared and fertile. Fig. 250.

Inasmuch as the peony is such a strong grower and produces so many enormous flowers, it must have a soil that can supply abundant plant-food and moisture. The old-fashioned single and sami-double comparatively small-flowered kinds will give goor results in any ordinary ground, but the newer highly improved sorts must be given better treatment. This is one of the plants that profit by a very rich soil. The place should be very deeply plowed or else trenched; and if the 
land is in sod or is not in good heart, the preparation should begin the season before the peonies are planted. A deep moist loam suits them best; and as the plants grow and bloom, add bone meal and top-dress with manure. When making their growth and when in bloom, they should not be allowed to want for water.

In purchasing peony roots, be careful to secure only well-grown and selected stock. Cheap stock, job lots, and odds and ends are likely to be very disappointing.

The plants may be set in fall or spring, the latter being preferable in the North. Cover the crown bud 2 or 3 inches, being careful not to injure it. If the best blooms are desired, give plenty of room, as much as $3 \times 4$ feet. Peonies grow 2 to 3 feet or even more in height. Strong roots of some varieties will give bloom the first year; considerable bloom will come the second year; but the full bloom on most varieties should not be expected before the third year. The flowers may be brightened and their duration prolonged by partial shade while in bloom.

If old plants become weak, or if they drop their buds, dig them up and see whether the roots are not more or less dead and decayed; divide to fresh parts and replant in well-enriched ground; or purchase new plants.

Peonies are propagated by division of the roots in early fall, one good strong eye being left to each piece.

The peony has merit for its foliage as well as for its bloom, particularly when the soil is rich and the growth luxuriant. This value of the plant is commonly overlooked. The peony deserves its popularity.

Phlox. - Garden phloxes are of two kinds, the annual and perennial. Both are most valuable.

Excepting the petunia, no plant will give the profusion of bloom with as little care as the annual phlox (Phlox Drummondii). For clear and brilliant colors, the many varieties of this are certainly unrivaled. The dwarf kinds are the more desirable for ribbon-beds, as they are not so "leggy." There are whites, pinks, reds, and variegated of the most dazzling brilliancy. The dwarfs grow ten inches high, and bloom continuously. Set them 8 inches apart in good soil. Seed may be 
sown in the open ground in May, or for early plants, in the hotbed in March. They may be sown close in the fall if sown very late, so that the seeds will not start till spring.

The perennial phlox of the gardens has been developed from the native species, Phlox paniculata and $P$. maculata. The garden forms are often collectively known under the name of $P$. decussata. In recent years the perennial phlox has been much improved, and it now constitutes one of the best of all flower-garden subjects. It grows three feet tall, and bears a profusion of fine flowers in heavy trusses in midsummer to fall. Figs. 246, 248.

Perennial phlox is of easy culture. The important point is that the plants begin to fail of best bloom about the third year, and they are likely to become diseased; and new plantings should be made if the strongest flowers are desired. The plants may be taken up in fall, the roots divided and cleaned of dead and weak parts, and the pieces replanted. Usually, however, the beginner will secure more satisfaction in purchasing new cutting-grown plants. This phlox propagates readily by seed, and if one does not care to perpetuate the particular variety, he will find much satisfaction in raising seedlings. Some varieties "come true" from seed with fair regularity. Seedlings should bloom the second year.

Fertile garden soil of any kind should raise good perennial phlox. See that the plants do not want for water or plant-food at blooming time. Liquid manure will often help to keep them going. If they are likely to suffer for water when in bloom, wet the ground well every evening.

If the leading shoots are pinched off early in the season, and again in midsummer, the bloom will be later, perhaps in September rather than in July.

Primulas, or primroses, are of various kinds, some being border plants, but mostly known in this country as greenhouse and windowgarden subjects. One of them is the auricula (p. 354). The true or English cowslip is one of the hardy border plants; also the plants commonly known as polyanthus.

Common hardy primulas (or polyanthus and related forms) grow 6 to 10 inches high, sending up trusses of yellow and red flowers in 
early spring. Propagated by division, or by seed sown a year before the plants are wanted. Give them rather moist soil.

The primula of the winter-garden is mostly the $P$. Sinensis (Chinese Primrose), grown very extensively by florists as a Christmas plant. With the exception of the full double varieties, it is usually grown from seed. There is a popular single form known as P. stellata. The seed of Chinese primulas sown in March or April will make large flowering plants by November or December, if the young plants are shifted to larger pots as needed. The seed should be sown on the flat surface of the soil, composed of equal parts loam, leafmold, and sand. The seed should be pressed down lightly and the soil watered carefully to prevent the seed from being washed into the soil. Very fine sphagnum moss may be sifted over the seed, or the box set in a moist place, where the soil will remain wet until the seeds germinate. When the plants are large enough, they should be potted separately or pricked out into shallow boxes. Frequent pottings or transplantings should be given until September, when they should be in the pots in which they are to bloom. The two essentials to successful growth through the hot summer are shade and moisture. Height, 6 to 8 inches. Bloom in winter and spring.

At present the "baby Primrose" (Primula Forbesi) is popular. It is treated in essentially the same way as the Sinensis. The obconica ( $P$. obconica) in several forms is a popular florist's plant, but is not much used in window-gardens. The hairs poison the hands of some persons. Culture practically as for $P$. Sinensis.

All primulas are impatient of a dry atmosphere and fluctuating conditions.

Rhododendrons are broad-leaved evergreen shrubs that are admirably adapted to producing strong planting effects. Some of them are hardy in the Northern states.

Rhododendrons require a fibrous or peaty soil and protection from bleak winds and bright suns in summer and winter. A northern or somewhat shady exposure, to break the force of the midday sun, is advisable; but they should not be planted where large trees will sap the fertility and moisture from the ground. They protect each other if grown in masses, and also produce better planting effects. 


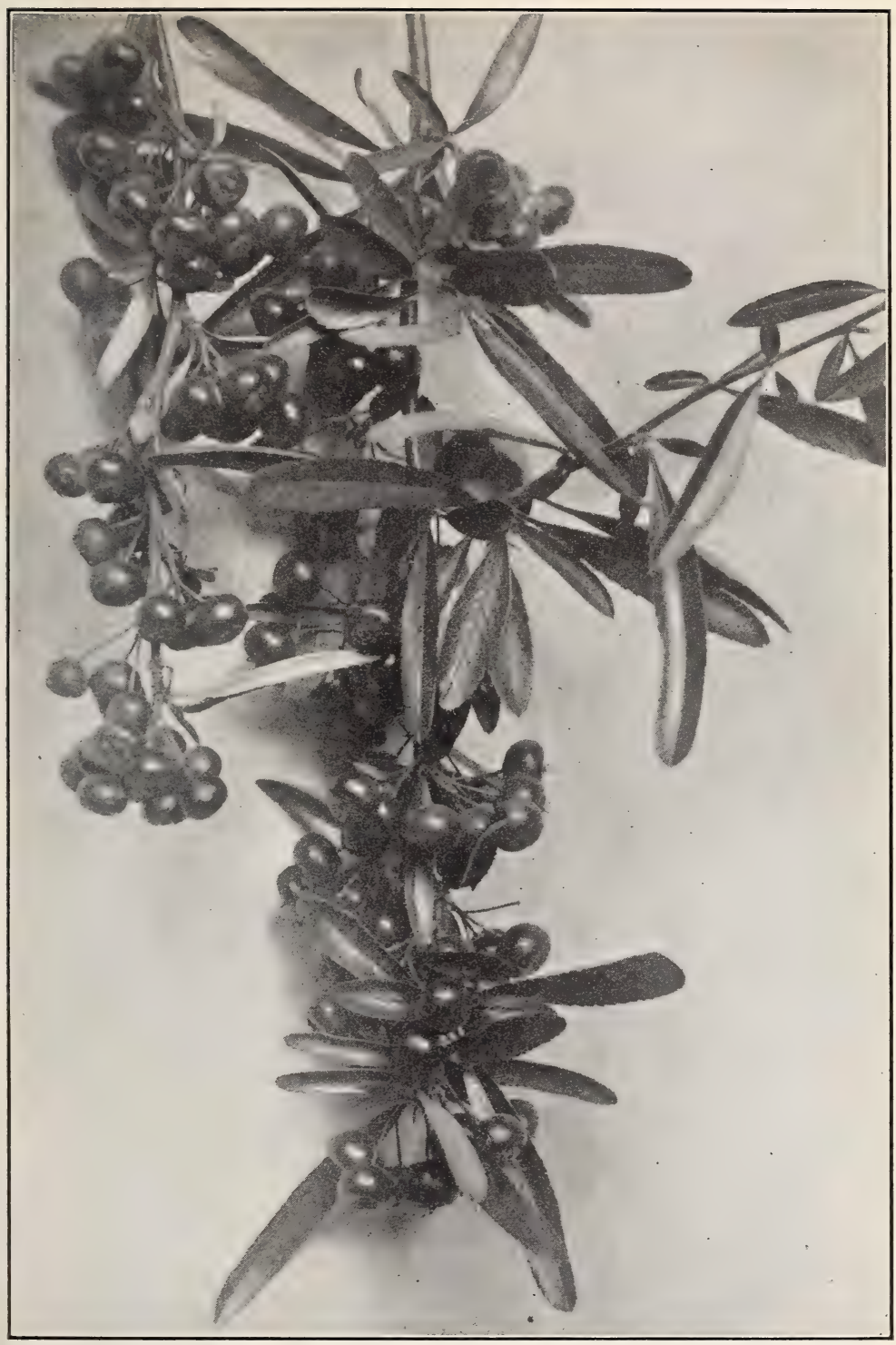

XIX. Pyracantha in fruit. One of the best ornamental-fruited plants for the middle and milder latitudes. 

They require a deep, fibrous earth, and it is supposed that they do not thrive in limestone soils or where wood ashes are freely used. While rhododendrons will sometimes succeed without any special preparation of the ground, it is advisable to take particular pains in this regard. It is well to dig a hole 2 or 3 feet deep, and fill it with earth compounded of leafmold, well-rotted sod, and peat. The moisture supply should be never failing, for they suffer from drought. They should be mulched summer and winter. Plant in spring.

The hardy garden forms are derivatives of Rhododendron Catawbiense, of the southern Appalachian Mountains. The Pontica and other forms are not hardy in the North.

The "great laurel" of the northern United States (p. 299) is Rhododendron maximum. This has been extensively colonized in large grounds by being removed from the wild in carload lots. When the native conditions are imitated, it makes unusually good mass planting. Like all rhododendrons it is impatient of drought, hard soil, and full exposure to midday sun. This species is valued for its foliage and habit more than for its bloom. The wild form of $R$. Catawbiense is also transferred to grounds in large quantities.

Rose. - No home property is complete without roses. There are so many kinds and classes that varieties may be found for almost any purpose, from climbing or pillar subjects (p. 31S) to highly fragrant teas, great hybrid perpetuals, free-blooming bedders, and good foliage subjects for the shrubbery. There is no flower in the growing of which one so quickly develops the temper and taste of the connoisseur.

Roses are essentially flower-garden subjects rather than lawn subjects, since flowers are their chief beauty. Yet the foliage of many of the highly developed roses is good and attractive when the plants are well grown. To secure the best results with roses, they should be placed in a bed by themselves, where they can he tilled and pruned and well taken care of, as other flower-garden plants are. The ordinary garden roses should rarely be grown in mixed borders of shrubbery. It is usually most satisfactory also to make beds of one variety rather than to mix them with several varieties.

If it is desired to have roses in mixed shrubbery borders, then the single and informal types should be chosen. The best of all these is 
Rosa rugosa. This has not only attractive flowers through the greater part of the season, but it also has very interesting foliage and a striking habit. The great profusion of bristles and spines gives it an individual and strong character. Even without the flowers, it is valuable to add character and cast to a foliage mass. The foliage is not attacked by insects or fungi, but remains green and glossy throughout the year. The fruit is also very large and showy, and persists on bushes well through the winter. Some of the wild roses are also very excellent for mixing into foliage masses, but, as a rule, their foliage characteristics are rather weak, and they are liable to be attacked by thrips.

There are so many classes of roses that the intending planter is likely to be confused unless he knows what they are. Different classes require different treatment. Some of them, as the teas and hybrid perpetuals (the latter also known as remontants), bloom from new canes; while the rugosa, the Austrian, Harrison's yellow, sweet briers, and some others are bushes and do not renew themselves each year from the crown or bases of the canes.

The outdoor roses may be divided into two great groups so far as their blooming habit is involved: (1) The continuous or intermittent bloomers, as the hybrid perpetuals (blooming chiefly in June), bourbons, tea, rugosa, the teas and hybrid teas being the most continuous in bloom; (2) those that bloom once only, in summer, as Austrian, Ayrshire, sweet briers, prairie, Cherokee, Banksian, provence, most moss roses, damask, multiflora, polyantha, and memorial (Wichuraiana). "Perpetual" or recurrent-blooming races have been developed in the Ayrshire, moss, polyantha, and others.

While roses delight in a sunny exposure, nevertheless our dry atmosphere and hot summers are sometimes trying on the flowers, as are severe wintry winds on the plants. While, therefore, it is never advisable to plant roses near large trees, or where they will be overshadowed by buildings or surrounding shrubbery, some shade during the heat of the day will be a benefit. The best position is an eastern or northern slope, and where fences or other objects will break the force of strong winds, in those sections where such prevail.

Roses should be carefully taken up every four or five years, tops and roots cut in, and then reset, either in a new place or in the old, after enriching the soil with a fresh supply of manure, and deeply spading 
it over. In Holland, roses are allowed to stand about eight years. They are then taken out and their places filled with young plants.

\section{Soil and planting for roses.}

The best soil for roses is a deep and rich clay loam. If it is mor or less of a fibrous character irom the presence of grass roots, as is the case with newly plowed sod ground, so much the better. While such is desirable, any ordinary soil will answer, provided it is well manured. Cow manure is strong and lasting, and has no heating effect. It will cause no damage, even if not rotted. Horse manure, however, should be well rotted before mixing it with the soil. The manure may be mixed in the soil at the rate of one part in four. If well rotted, however, more will not do any damage, as the soil can scarcely be made too rich, especially for the everblooming (hybrid tea) roses. Care should be taken to mix the manure thoroughly with the earth, and not to plant the roses against the manure.

In planting, care must be taken to avoid exposing the roots to the drying of sun and air. If dormant field-grown plants have been purchased, all broken and bruised roots will need to be cut off smoothly and squarely. The tops also will need cutting back. The cut should always be made just above a bud, preferably on the outer side of the cane. Strong-growing sorts may be cut back one-fourth or one-half, according as they have good or bad roots. Weaker-growing kinds, as most of the everblooming roses, should be cut back most severely. In both cases it is well to remove the weak growth first. Plants set out from pots will usually not need cutting back.

Hardy roses, especially the strong field-grown plants, should be set in the early fall if practicable. It is desirable to get them out just as soon as they have shed their foliage. If not then, they may be planted in the early spring. At that season it is advisable to plant them as early as the ground is dry enough, and before the buds have started to grow. Dormant pot-plants may also be set out early, but they should be perfectly inactive. Setting them out early in this condition is preferable to waiting till they are in foliage and full bloom, as is so often required by buyers. Growing pot-plants may be planted any time in spring after danger of frost is past, or even during the summer, if they are watered and shaded for a few days. 
Open-ground plants should be set about as deep as they stood previously, excepting budded or grafted plants, which should be set so that the union of the stock and graft will be 2 to 4 inches below the surface of the ground. Plants from pots may also be set an inch deeper than they stood in the pots. The soil should be in a friable condition. Roses should have the soil compact immediately about their roots; but we should distinguish between planting roses and setting fence posts. The dryer the soil the more firmly it may be pressed.

As a general statement, it may be said that roses on their own roots will prove more satisfactory for the general run of planters than budded stock. On own-rooted stock, the suckers or shoots from below the surface of the soil will be of the same kind, whereas with budded roses there is danger of the stock (usually Manetti or dog rose) starting into growth and, not being discovered, outgrowing the bud, taking possession, and finally killing out the weaker growth. Still, if the plants are set deep enough to prevent adventitious buds of the stock from starting and the grower is alert, this difficulty is reduced to a minimum. There is no question but that finer roses may be grown than from plants on their own roots, withstanding the heat of the American summer, if the grower takes the proper precautions.

\section{Pruning roses.}

In pruning roses, determine whether they bloom on canes arising each year from the ground or near the ground, or whether they make perennial tops; also form a clear idea whether an abundance of flowers is wanted for garden effects, or whether large specimen blooms are desired.

If one is pruning the hybrid perpetual or remontant roses (which are now the common garden roses), he cuts back all very vigorous canes perhaps one-half their length immediately after the June bloom is past in order to produce new, strong shoots for fall flowering, and also to make good bottoms for the next year's bloom. Very severe summer pruning, however, is likely to produce too much leafy growth. In the fall, all canes may be shortened to 3 feet, four or five of the best canes being left to each plant. In spring, these canes are again cut back to fresh wood, leaving perhaps four or five good buds on 
each cane; from these buds the flowering canes of the year are to come. If it is desired to secure fewer blooms, but of the best size and quality, fewer canes may be left and only two or three new shoots be allowed to spring from each one the next spring.

The rule in trimming all cane-bearing roses is, cut back weak growing kinds severely; strong growers moderately.

Climbing and pillar roses need only the weak branches and the tips shortened in. Other hardy kinds will usually need cutting back about one-fourth or one-third, according to the vigor of the branches, either in the spring or fall.

The everblooming or hybrid tea roses will need to have all dead wood removed at the time of uncovering them in spring. Some pruning during the summer is also useful in encouraging growth and flowers. The stronger branches that have flowered may be cut back onehalf or more.

The sweet briers, Austrian and rugosas may be kept in bush form; but the trunks may be cut out at the ground every two or three years, new shoots having been allowed to come up in the meantime. All rampant growths should be cut back or taken out.

\section{Insects and diseases of roses (see pp. 205, 213).}

Most of the summer insects that trouble the rose are best treated by a forceful spray of clear water. This should be done early in the day and again at evening. Those having city water or good spray pumps will find this an easy method of keeping rose pests in check. Those without these facilities may use whale-oil soap, fir-tree oil, good soap suds, the tobacco preparations, or Persian insect powder.

The rose-bug or chafer should be hand-picked or knocked off early in the morning into a pan of coal oil. The leaf-roller must be crushed.

The mildews are controlled by the various sulfur sprays.

\section{Winter protection of roses.}

All garden roses should be well mulched with leaves or coarse manure in the fall. Mounding earth about the root also affords excellent protection. Bending over the tops and covering with grass or evergreen boughs is also to be recommended for such kinds as are suspected to be injured by winter; the boughs are preferable because they do not attract mice. 
North of the Ohio River all the everblooming roses, even if they will endure the winter unprotected, will be better for protection. This may be slight southward, but should be thorough northward. The soil, location, and surroundings often determine the extent of protection. If the situation is not so favorable, more protection will be necessary. Along the Ohio, a heap of stable manure, or light soil that does not become packed and water-logged, placed about the base of the plants, will carry over many of the tea roses. The tops are killed back; but the plants sprout from the base of the old branches in the spring. Bon Silene, Etoile de Lyon, Perle des Jardins, Mme. Camille, and others are readily wintered there in this way.

About Chicago (American Florist, x., No. 358, p. 929, 1895) beds have been successfully protected by bending down the tops, fastening them, and then placing over and among the plants a layer of dead leaves to the depth of a foot. The leaves must be dry, and the soil also, before applying them; this is very essential. After the leaves, a layer of lawn-clippings, highest at the middle, and 4 or 5 inches thick, placed over the leaves, holds them in place and sheds water. This protection carries over the hardiest sorts of everblooming roses, including the teas. The tops are killed back when not bent down, but this protection saves the roots and crowns; when bent down, the tops went through without damage. Even the climbing rose Gloire de Dijon was carried through the winter of 1894-1895 at Chicago without the slightest injury to the branches.

Strong plants of the everblooming or hybrid tea roses can now be had at very reasonable rates, and rather than go to the trouble of protecting them in the fall, many persons buy such as they need for bedding purposes each spring. If the soil of the beds is well enriched, the plants make a rapid and luxuriant growth, blooming freely throughout the summer.

If one desires to go to the trouble, he may protect these and also the tea roses even in the northern states by mounding earth about the plants and then building a little shed or house about them (or inverting a large box over them) and packing about the plants with leaves or straw. Some persons make boxes that can be knocked down in the spring and stored. The roof should shed water. This method is better than tying the plants up in straw and burlaps. Some of the hybrid teas do not need so much protection as this, even in central New York. 


\section{Varieties of roses.}

The selection of kinds should be mads in reference to the locality and purpose for which the roses are wanted. For bedding roses, those that are of free-blooming habit, even though the individual flowers are not large, are the ones that should be chosen. For permanent beds, the so-called hybrid perpetual or remontant roses, blooming principally in June, will be found to be hardy at the North. But if one can give them proper protection during the winter, then the Bengal, tea, bourbon, and hybrid teas or everblooming roses, may be selected.

In sections where the temperature does not fall below $20^{\circ}$ above zero, any of the monthly roses will live without protection. At the South the remontants and other deciduous roses do not do as well as farther North. The tender climbers - Noisettes, climbing teas, bengals, and others - are excellent for pillars, arbors, and verandas at the South, but are fit only for the conservatory in those parts of the country where there is severe freezing. For the open air at the North we have to depend for climbing roses mainly on the prairie climbers, and the ramblers (polyanthas), with their recent pink and white varieties. The trailing Rosa Wichuraiana is also a useful addition as an excellent hardy rose for banks.

For the northern states a choice small list is as follows: hybrid perpetuals, Mrs. John Laing, Wilder, Ulrich Bruner, Frau Karl Druschki, Paul Neyron; dwarf polyanthas, Clothilde Soupert, Madame Norbert Levavasseur (Baby Rambler), Mlle. Cecile Bruner; hybrid teas, Grus an Teplitz, La France, Caroline Testout, Kaiserin Victoria, Killarney; teas, Pink Maman Cochet, White Maman Cochet.

The following classified lists embrace some of the varieties of recognized merit for various purposes. There are many others, but it is desirable to limit the list to a few good kinds. The intending planter should consult recent catalogues.

Free-blooming monthly roses for bedding. - These are recommended not for the individual beauty of the flower - although some are very fine - but because of their suitability for the purpose indicated. If to be carried over winter in the open ground, they need to be protected north of Washington. In beds, pegging down the branches will be found desirable. Those starred $\left(^{*}\right)$ have proved hardy in southern Indiana without protection, although they are more satisfactory with 
it. (The name of the class to which the variety belongs is indicated by the initial letter or letters of the class name: C., China; T., Tea; H. T., Hybrid Tea; B., Bourbon; Pol., Polyantha; N., Noisette; H. P., Hybrid Perpetual; Pr., Prairie Climber) :-

Red -

Sanguinea, C.

Agrippina, C.

Marion Dingee, $\mathrm{T}$.

*Meteor, H. T.

Blush -

*Cels, C.

Mme. Joseph Schwartz, T.

* Souvenir de la Malmaison, B.

Mignonette, Pol.

\section{Yellow-}

*Isabella Sprunt, T.

Mosella (Yellow Soupert), Pol.
Pink -

*Hermosa, B.

Souvenir d'un Ami, T.

Pink Soupert, Pol.

*Gen. Tartas, T.

White -

*Clothilde Soupert, Pol.

*Sombreuil, B.

Snowflake, T.

Pacquerette, Pol.

Yellow-continued.

La Pactole, $\mathrm{T}$.

Marie van Houtte, $\mathrm{T}$.

Free-blooming monthly roses for summer cutting and beds. - These are somewhat less desirable for purely bedding purposes than the preceding; but they afford finer flowers and are useful for their fine buds. Those starred (*) are hardy in southern Indiana without protection:-

Red -

*Meteor.

*Dinsmore, H. P.

*Pierre Guillot, H. T.

Papa Gontier, T.

White -

- The Bride, T.

Senator McNaughton, T.

*Marie Guillot, T.

*Mme. Bavay, T.

Kaiserin Augusta Victoria, H. T.

Yellow -

Perle des Jardins, $\mathrm{T}$.

Mme. Welch, T.
Light Pink -

*La France, H. T.

Countess de Labarthe, $\mathrm{T}$.

*Appoline, B.

Dark Pink -

*American Beauty, H. T.

*Duchess of Albany, H. T.

Mme. C. Testout, H. T.

Adam, T.

*Marie Ducher, T.

Yellow-continued.

Sunset, T.

Marie van Houtte, $\mathrm{T}$. 
Hybrid perpetual, or remontant, roses. - These do not flower as freely as the groups previously mentioned; but the individual flowers are very large and unequaled by any other roses. They flower chiefly in June. Those named are among the finest sorts, and some of them flower more or less continuously:-

Red -

Alfred Colomb.

Earl of Dufferin.

Glorie de Margottin.

Anna de Diesbach.

Ulrich Brunner.
Pink-

Mrs. John Laing.

Paul Neyron.

Queen of Queens.

Magna Charta.

Baroness Rothschild.

White -

Margaret Dickson. Merveille de Lyon.

Hardy climbing, or pillar roses. - These bloom but once during the season. They come after the June roses, however, - a good season and at that time are masses of flowers. They require only slight pruning.

White -

Baltimore Belle, Pr.

Washington, $\mathrm{N}$.

Rosa Wichuraiana (trailing).

Crimson -

Crimson Rambler, Pol.
Pink -

Queen of the Prairies, Pr.

Tennessee Belle, Pr.

Climbing Jules Margotten, H. P.

Yellow-

Yellow Rambler, Pol.

Tender climbing, or pillar roses. For conservatories, and the South as far north as Tennessee. - Those with an asterisk (*) are halfhardy north of the Ohio River, or about as hardy as the hybrid teas. These need no pruning except a slight shortening-in of the shoots and a thinning out of the weak growth.

\section{Yellow -}

Maréchal Niel, N.

Solfaterre, N.

* Gloire de Dijon, T.

Yellow Banksia (Banksiana).
White -

*Aimée Vibert, $\mathrm{N}$.

Bennett's Seedling (Ayrshire).

White Banksia (Banksiana).

Red -

*Reine Marie Henriette, T. James Sprunt, C. 


\section{Roses in winter (by C. E. Hunn).}

Although the growing of roses under glass must be left chiefly to florists, advice may be useful to those who have conservatories:-

When growing forcing roses for winter flowers, florists usually provide raised beds, in the best-lighted houses they have. The bottom of the bed or bench is left with cracks between the boards for drainage; the cracks are covered with inverted strips of sod, and the bench is then covered with 4 or 5 inches of fresh, fibrous loam. This is made from rotted sods, with decayed manure incorporated at the rate of about one part in four. Sod from any drained pasture-land makes good soil. The plants are set on the bed in the spring or early summer, from 12 to 18 inches apart, and are grown there all summer.

During the winter they are kept at a temperature of $58^{\circ}$ to $60^{\circ}$ at night, and from $5^{\circ}$ to $10^{\circ}$ warmer during the day. The heating pipes are often run under the benches, not because the rose likes bottom heat, but to economize space and to assist in drying out the beds in case of their becoming too wet. The greatest care is required in watering, in guarding the temperature, and in rentilation. Draughts result in checks to the growth and in mildewed foliage.

Dryness of the air, especially from fire heat, is followed by the appearance of the minute red spider on the leaves. The aphis, or green plant louse, appears under all conditions, and must be kept down by the use of some of the tobacco preparations (several of which are on the market).

For the red spider, the chief means of control is syringing with either clear or soapy water. If the plants are intelligently ventilated and giren, at all times, as much fresh air as possible, the red spider is less likely to appear. For mildew, which is easily recognized by its white, powdery appearance on the foliage, accompanied with more or less distortion of the leaves, the remedy is sulfur in some form or other. The flowers of sulfur may be dusted thinly orer the foliage; enough merely slightly to whiten the foliage is sufficient. It may be dusted on from the hand in a broadcast way, or applied with a powder-bellows, which is a better and less wasteful method. Again, a paint composed of sulfur and linseed oil may be applied to a part of one of the steam or hot-water heating pipes. The fumes arising from this are not 
agreeable to breathe, but fatal to mildew. Again, a little sulfur may be sprinkled here and there on the cooler parts of the greenhouse flue. Under no circumstances, however, ignite any sulfur in a greenhouse. The vapor of burning sulfur is death to plants.

Propagation of house roses. - The writer has known women who could root roses with the greatest ease. They would simply break off a branch of the rose, insert it in the flower-bed, cover it with a belljar, and in a few weeks they would have a strong plant. Again they would resort to layering; in which case a branch, notched halfway through on the lower side, was bent to the ground and pegged down so that the notched part was covered with a few inches of soil. The layered spot was watered from time to time. After three or four weeks roots were sent forth from the notch and the branch or buds began to grow, when it was known that the layer had formed roots.

Several years ago a friend took a cheese-box, filled it with sharp sand to the brim, supported it in a tub of water so that the lower halfinch of the box was immersed. The sand was packed down, sprinkled, and single-joint rose cuttings, with a bud and a leaf near the top, were inserted almost their whole length in the sand. This was in July, a hot month, when it is usually difficult to root any kind of cutting: moreover, the box stood on a southern slope, facing the hot sun, without a particle of shade. The only attention given the box was to keep the water high enough in the tub to touch the bottom of the cheesebox. In about three weeks he took out three or four dozen of as nicely rooted cuttings as could have been grown in a greenhouse.

The "saucer system," in which cuttings are inserted in wet sand contained in a saucer an inch or two deep, to be exposed at all times to the full sunshine, is of a similar nature. The essentials are, to give the cuttings the "full sun" and to keep the sand saturated with water.

Whatever method is used, if cuttings are to be transplanted after rooting, it is important to pot them off in small pots as soon as they have a cluster of roots one-half inch or an inch long. Leaving them too long in the sand weakens the cutting.

Smilax of the florists is closely allied to asparagus (it is Asparagus medeoloides of the botanists). While it cannot be recommended for 
house culture, the ease with which it may be grown and the uses to which the festoons of leaves may be put entitle it to a place in the conservatory or greenhouse.

Seed sown in pots or boxes in January or February, the plants shifted as needed until planted on the bench in August, will grow fine strings of green by the holidays. The temperature should be rather high. The plants should be set on low benches, giving as much room as possible overhead. Green-colored strings should be used for the vines to climb on, the vines frequently syringed to keep down the red spider, which is very destructive to this plant, and liquid manure given as the vines grow. The soil should contain a good proportion of sand and be enriched with well-rotted manure.

After the first strings are cut, a second growth fully as good as the first may be had by cleaning up the plants and top-dressing the soil with rotted manure. Sometimes the old roots are kept three or four years. Slightly shading the house through August will add to the color of the leaves. The odor from a vine of smilax thickly covered with the small flowers is very agreeable.

Stocks. - The Ten-weeks and the biennial or Brompton stocks (species of Matthiola) are found in nearly all old-fashioned gardens. Most gardens are thought to be incomplete without them, and the use of the biennial flowering species as house-plants is increasing.

The Ten-weeks stock is usually grown from seed sown in hotbeds or boxes in March. The seedlings are transplanted several times previous to being planted out in early May. At each transplanting the soil should be made a little richer. The double flowers will be more numerous when the soil is rich.

The biennial species (or Brompton stocks) should be sown the season previous to that in which flowers are wanted, the plants wintered over in a cool house, and grown in the following spring. They may be planted out through the summer and lifted into pots in August or September for winter flowering. These may be increased by cuttings taken from the side shoots; but the sowing of seed is a surer method, and unless an extra fine variety is to be saved, it would be the best one to pursue. Height, 10 to 15 inches. 
Sweet pea. - A hardy, tendril-climbing annual, universally prized as an outdoor garden plant; also forced to some extent by florists. ( )n any oceasion the sweet pea is in place. A bouquet of shaded colors, with a few sprays of galium or the perennial gypsophila, makes one of the choicest of table decorations.

Deep, mellow soil, early planting, and heavy mulching suit them admirably. It is easy to make soils too rich in nitrogen for sweet peas; in such case, they will run to vine at the expense of flowers.

Sow the seeds as soon as the ground is fit to work in the spring, making a drill 5 inches deep. Sow thickly and cover with 2 inches of earth. When the plants have made 2 or 3 inches' growth above the earth, fill the drill nearly full, leaving a slight depression in which water may be caught. After the soil is thoroughly soaked with water, a good mulch will hold the moisture. To have the ground ready in early spring, it is a good plan to trench the ground in the fall. The top of the soil then dries out very quickly in spring and is left in good physical condition.

In the middle and soüthern states the seed may be planted in fall, particularly in lighter soils.

Frequent syringing with clear water will keep off the red spider that often destroys the foliage, and attention to picking the seed pods will lengthen the season of bloom. If the finest flowers are wanted, do not let the plants stand less than 8 to 12 inches apart.

A succession of sowings may be made at intervals through May and June, and a fair fall crop secured if care is taken to water and mulch; but the best results will be secured with the very early planting. When the plants are watered, apply enough to soak the soil, and do not water frequently.

Swainsona. - This plant has been called the winter sweet pea, but the flowers are not fragrant. It makes a very desirable house plant, blooming through the late winter and early spring months. The blossoms, which resemble those of the pea, are borne in long racemes. The foliage is finely cut, resembling small locust leaves, and adds to the beauty of the plant, the whole effect being exceedingly graceful. Swainsona may be grown from seed or cuttings. Cuttings taken in late 
winter should make blooming plants in summer; these plants may be used for winter bloom, but it is better to raise new plants. Some gardeners cut back old plants to secure new blooming wood; this is desirable if the plants grow more or less permanently in the greenhouse border, but for pots new plants should be grown.

The common swainsona is white-flowered; but there is a good rosecolored variety.

Tuberose (properly tuber-ose, not tube-rose, from its specific name, Polianthes tuberosa). - This plant, with its tall spikes of waxen and fragrant white flowers, is well known in the middle latitudes, but usually requires more heat and a longer season than are commonly present in the most northern states.

The tuberose is a strong feeder, and loves warmth, plenty of water while growing, and a deep, rich, and well-drained soil. The bulbs may be set in the garden or border the last of May or in June, coviering them about 1 inch deep. Preparatory to planting, the old dead roots at the base of the bulb should be cut away and the pips or young bulbs about the sides removed. After keeping them till their scars are dried over, these pips may be planted 5 or 6 inches apart in drills, and with good soil and cultivation they will make blooming bulbs for the following year.

Before planting the large bulbs, it may be well to examine the points, to determine whether they are likely to bloom. The tuberose blooms but once. If there is a hard, woody piece of old stem in the midst of the dry scales at the apex of the bulb, it has bloomed, and is of no value except for producing pips. Likewise if, instead of a solid core, there is a brownish, dry carity extending from the tip down into the middle of the bulb, the heart has rotted or dried up, and the bulb is worthless as far as blooming is concerned.

Bulbs of blooming size set in the border in June flower toward the close of September. They may be made to flower three or four weeks sooner by starting them early in some warm place, where they may be given a temperature of about $60^{\circ}$ to $70^{\circ}$. Prepare the bulbs as above, and place them with their tips just above the surface in about 3- or 4-inch pots, in light sandy soil. Water them thoroughly, afterwards sparingly, till the leaves have made considerable growth. 



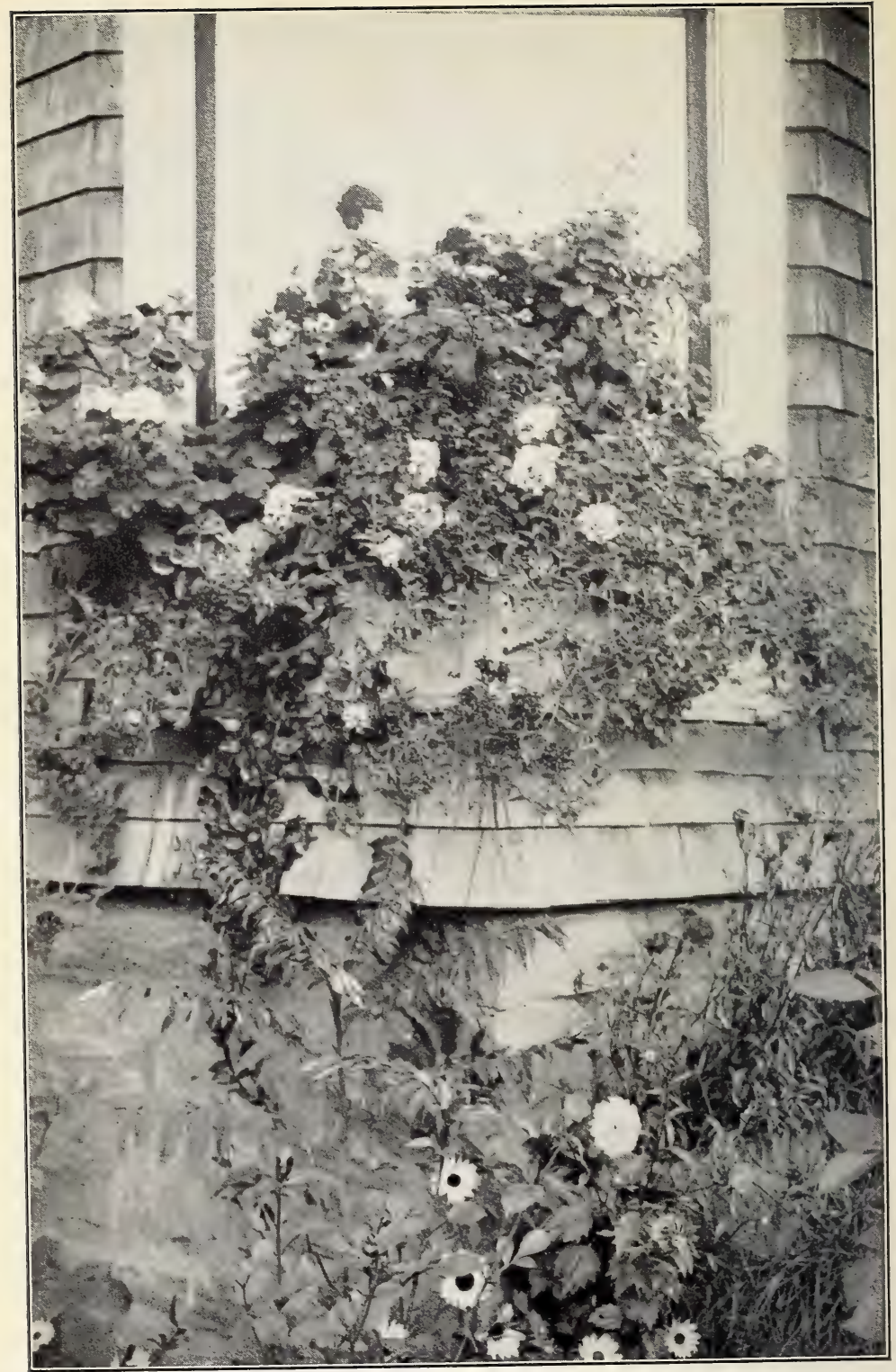

XX. A simple but effective window-box, containing geraniums, petunias, verbenas, heliotrope, and vines. 
These plants may be turned out into the open ground the last of May or in June, and will probably flower in early September.

In the northern states, if planted in the border they will not start into growth until the ground has become thoroughly warm, - usually after the middle of June, - making the season before frost too short for their perfect growth and flower. If any danger of fall frost is feared, they may be lifted into pots or boxes and taken into the house, when they will bloom without a check. As with other bulbs, a sandy soil will suit.

Just before frost dig up the bulbs, cut off the tops to within 2 inches of the apex of the bulb. They may then be placed in shallow boxes and left out in the sun and air for a week or more, to cure. Each evening, if the nights are cold, they should be removed to some room where the temperature will not fall below $40^{\circ}$. When the outer scales have become dry, the remaining soil may be shaken off and the bulbs stored away in shallow boxes for the winter. They keep best in a temperature of $45^{\circ}$ to $50^{\circ}$. It should never fall below $40^{\circ}$.

The Dwarf Pearl, originating in 1870, has long been popular, and is still so with many. But others have come to prefer the old, tall kind, the flowers of which, even if not so large, are perfect in form and seem to open better.

Tulips are undoubtedly the most prized of all early spring bulbs. They are hardy and easy to grow. They also bloom well in winter in a sunny climate. The garden bed will last several years if well cared for, but most satisfactory bloom is secured if the old bulbs are taken up every two or three years and replanted, all the inferior ones being cast aside. When the stock begins to run out, buy anew. The old stock, if not entirely spent, may be planted in the shrubbery or perennial borders.

September is the best time for planting tulips, but as the beds are usually occupied at this time, planting is commonly postponed till October or November. For garden culture the single early tulips are the best. There are excellent early double-flowered varieties. Some prefer the double, as their flowers last longer. Late tulips are gorgeous, but occupy the beds too long in the spring. While tulips are hardy, they are benefited by a winter mulch. 
In working out design patterns, the utmost care should be used to have the lines and curves uniform, which is only to be secured by marking out the design, and careful planting. Formal planting is, however, by no means necessary for pleasing effects. Borders, lines, and masses of single colors, or groups of mixed colors which harmonize, are always in order and pleasing. Clear colors are preferable to neutral tints. As varieties vary in height and season of blooming, only named varieties should be ordered if uniform bedding effects are desired. See pp. 286 and 345 ; Fig. 255.

Violet. - While the culture of violets as house-plants rarely proves successful, there is no reason why a good supply may not be had elsewhere through the greater part of the winter and the spring months.

A sheltered location being selected, young plants from runners may be set in August or September. Have the ground fertile and well drained. These plants will make fine crowns by December, and often will bloom before weather sufficiently cold to freeze them.

To have flowers through the winter, it will be necessary to afford some protection. This may best be accomplished by building a frame of boards large enough to cover the plants, making the frame in the same way as for a hotbed, 4 to 6 inches higher at the back than the front. Cover the frame with sash or boards, and as the weather becomes severe, mats or straw should be placed over and around the frame to protect the plants from freezing. Whenever the weather will permit, the covering should be removed and air admitted, but no harm will come if the frames are not disturbed for several weeks. Much sunlight and a high temperature through the middle of winter are to be avoided, for if the plants are stimulated, a shorter period of bloom will result. In April the frame may be removed, the plants yielding the later part of the crop without protection.

Violets belong with the "cool" plants of florists. When well hardened off, considerable frost does not harm them. They should always be kept stocky. Start a new lot from runner-plants each year. They thrive in a temperature of $55^{\circ}$ to $65^{\circ}$. Pages 190, 206.

Wax-plant. - The wax-plant, or hoya, is one of the commonest of window-garden plants, and yet it is one that house-gardeners usually 
have difficulty in flowering. However, it is one of the easiest plants to manage if a person understands its nature.

It is naturally a summer-blooming plant, and should rest in winter. In the winter, keep it just alive in a cool and rather dry place. If the temperature does not go above $50^{\circ}$ Fahr., so much the better; neither should it go much lower. In late winter or spring, the plant is brought out to warm temperature, given water, and started into growth. The old flower-stems should not be cut off, since new flowers come from them as well as from the new wood. When it is brought out to be started into growth, it may be repotted, sometimes into a size larger pot, but always with more or less fresh earth. The plant should increase in value each year. In conservatories, it is sometimes planted out in the ground and allowed to run over a wall, in which case it will reach a height of many feet. 


\section{CHAPTER IX}

\section{THE GROWING OF THE FRUIT PLANTS}

Fruits should be counted a regular part of the home premises. There are few residence plots so small that fruits of some kind cannot be grown. If there is no opportunity for planting the orchard fruits by themselves at regular intervals, there are still boundaries to the place, and along these boundaries and scattered in the border masses, apples, pears, and other fruits may be planted.

It is not to be expected that fruits will thrive as well in these places as in well-tilled orchards, but something can be done, and the results are often very satisfactory. Along a back fence or walk, one may plant a row or two of currants, gooseberries, or blackberries, or he may make a trellis of grapes. If there are no trees near the front or back of the border, the fruit plants may be placed close together in the row and the greatest development of the tops may be allowed to take place laterally. If one has a back yard fifty feet on a side, there will be opportunity, in three borders, for six to eight fruit trees, and bush-fruits between, without encroaching greatly on the lawn. In such cases, the trees are planted just inside the boundary line.

A suggestion for the arrangement of a fruit garden of one acre is given in Fig. 270. Such a plan allows of continuous cultivation in one direction and facilitates spraying, pruning, and harvesting; and the intermediate spaces may be used for the growing of annual crops, at least for a few years. 


\section{Dwarf fruit-trees.}

For very small areas, and for the growing of the finest dessert fruits, dwarf trees may be grown of apples and pears. The 10 RODS.

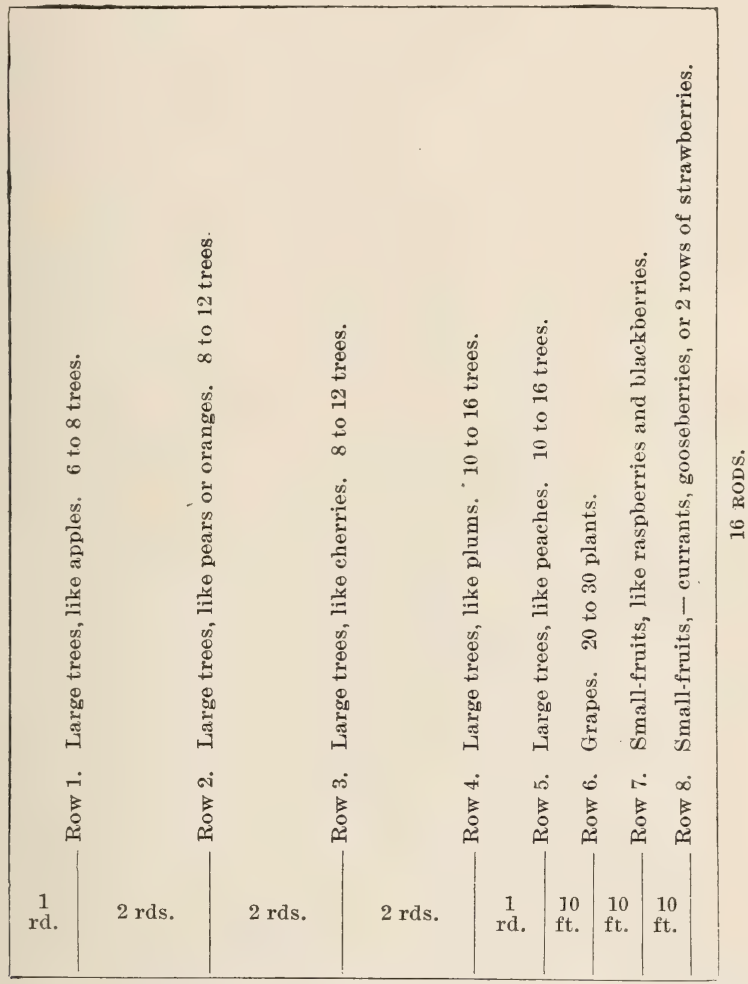

270. Plan for a fruit-garden of one acre. From "Principles of Fruit-growing." apple is dwarfed when it is worked on certain small and slowgrowing types of apple trees, as the paradise and doucin stocks. The paradise is the better, if one desires a very small and productive tree or bush. The doucin makes only a half-dwarf. 
The pear is dwarfed when it is grown on the root of quince. Dwarf pears may be planted as close as ten feet apart each way, although more room should be given them if possible. Paradise dwarfs (apples) may be planted eight or ten feet each way, and doucin twice that distance. All dwarfs should be kept small by vigorous annual heading-in. If the tree is making good growth, say one to three feet, a half to two-thirds of the growth may be taken off in winter. A dwarf apple or pear tree should be kept within a height of twelve or fifteen feet, and it should not attain this stature in less than ten or twelve years. A dwarf apple tree, in full bearing, should average from two pecks to a bushel of first quality apples, and a dwarf pear should do somewhat more than this.

If one grows dwarf fruit trees, he should expect to give them extra attention in pruning and cultivating. Only in very exceptional instances can the dwarf fruits be expected to equal the free-growing standards in commercial results. This is particularly true of dwarf apples, which are practically home-garden plants in this country. This being the case, only the choice dessert fruits should be attempted on paradise and doucin roots. For home gardens the paradise will probably give more satisfaction than the doucin.

If the tree is taken young, it may be trained along a wall or on an espalier trellis; and in such conditions the fruits should be of extra quality if the varieties are choice. Plate XXII shows the training of a dwarf pear on a wall. This tree has been many years in good bearing. In most parts of the country a southern wall exposure is likely to force the bloom so early as to invite danger from spring frosts.

Age and size of trees.

For ordinary planting, it is desirable to choose trees two years from bud or graft, except in case of the peach, which should be one year old. Many growers find strong one-year trees prefer- 
able. A goorl size is about five-eighths of an inch in diameter just above the collar, and five feet in height, and if they have been well grown, trees of this size will give as good results as those seven-eighths of an inch, or more, in diameter, and six or seven feet high. Buy first-class trees of reliable dealers. It rarely pays to try to save a few cents on a tree, for quality is likely to be sacrificed.

If properly packed, trees can be shipped long distances and may do as well as those grown in a home nursery, but it will generally be best to secure the trees as near home as possible, provided the quality of the trees and the price are satisfactory. When a large number is to be purchased, it will be better to send the order direct to some reliable nursery, or to select the trees in person, than to rely on tree peddlers.

\section{Pruning (see p. 139).}

Having planted the trees, they should be carefully pruned. As a rule, trees with low heads are desirable. Peaches and dwarf pears should have the lower branches from 12 to 24 inches above ground, and sweet cherries and standard pears generally not over 30 inches; plums, sour cherries, and apples may be somewhat higher, but if properly handled, when started 3 feet from the ground, the tops will not be in the way of the cultivation of the orchard.

For all except the peach in the northern states, a pyramidal form will be desirable. To secure this, four or five side branches with three or four buds each, should be allowed to grow and the center shoot should be cut off at a height of 10 to 12 inches. After growth has started, the trees should be occasionally examined and all surplus shoots removed, thus throwing the full vigor of the plant into those that remain. As a rule three or four shoots on each branch may be left to advantage. The following spring the shoots should be cut back one-half and about half of the branches removed. Care should be taken to 
avoid crotches, and if any of the branches cross, so that they are likely to rub, one or the other should be cut out. This cuttingback and trimming-out should be continued for two or three years, and in the case of dwarf pear trees regular heading-back each year should be continued. Although an occasional heading-back will be of advantage to the trees, apple, plum, and cherry trees that have been properly pruned while young will not require so much attention after they come into bearing.

Heavy pruning of the top tends to the production of wood; therefore the severe pruning of orchard trees, following three or four years of neglect, sets the trees into heavy wood-bearing, and makes them more vigorous. Such treatment generally tends away from fruit-bearing. This heavy pruning is usually necessary in neglected orchards, however, to bring trees back into shape and to revitalize them; but the best pruning-treatment of an orchard is to prune it a little every year. It should be so pruned that the tops of the trees will be open, that no two limbs will interfere with each other, and so that the fruit itself will not be so abundant as to overload the tree.

In general, it is best to prune orchard trees late in winter or early in spring. It is sometimes better, however, to leave peaches and other tender fruits until after the buds have swollen, or even after the flowers have fallen, in order that one may determine how much they have been injured by the winter. Grape vines should be pruned in winter or not later (in New York) than the first of March. If pruned later than this, they may bleed. The above remarks will apply to other trees as well as to fruits.

\section{Thinning the fruit.}

If the best size and quality of fruit are desired, care must be taken to see that the plant does not overbear.

Thinning of fruit has four general uses: to cause the remaining fruit to grow larger; to increase the chances of annual crops; 
to save the vitality of the tree; to enable one to combat insects and diseases by destroying the injured fruit.

The thinning is nearly always performed soon after the fruit is thoroughly set. It is then possible to determine which of the fruits are likely to persist. Peaches are usually thinned when they are the size of one's thumb. If thinned before this time, they are so small that it is difficult to pick them off; and it is not so easy to see the work of the curculio and thereby to select the injured fruits. Similar remarks apply to other fruits. The general tendency is, even with those who thin their fruits, not to thin enough. It is usually safer to take off what would seem to be too many than not to take off enough. The remaining specimens are better. Varieties that tend to overbear profit very greatly by thinning. This is notably the case with many Japanese plums, which, if not thinned, are very inferior.

Thinning may also be accomplished by pruning. Cutting off the fruit-buds will have the effect of removing the fruit. In the case of tender fruits, as peaches, however, it may not be advisable to thin very heavily by means of pruning, since the fruit may be still further thinned by the remaining days of winter, by late spring frost, or by the leaf-curl or other disease. However, the proper pruning of a peach tree in winter is, in part, a thinning of the fruit. The peach is borne on the wood of the previous season's growth. The best fruits are to be expected on the strongest and heaviest growth. It is the practice of peach-growers to remove all the weak and immature wood from the inside of the tree. This has the effect of thinning out the inferior fruit and allowing the energy of the tree to be expended on the remainder.

Apples are rarely thinned; but, in many cases, thinning can be done with profit. 


\section{Washing and scrubbing the trees.}

The washing of orchard trees is an old practice. It usually results in making a tree more vigorous. One reason is that it destroys insects and fungi that lodge underneath the bark; but probably the chief reason is that it softens the bark and allows the trunk to expand. It is possible, also, that the potash from the soap or lye eventually passes into the ground and affords some plant-food. Trees are ordinarily washed with soap suds or with a lye solution. The material is usually applied with an old broom or a stiff brush. The scrubbing of the tree is perhaps nearly or quite as beneficial as the application of the wash itself.

It is customary to wash trees late in spring or early in summer, and again in the fall, with the idea that such washing destroys the eggs and the young of borers. It no doubt will destroy borers if they are just getting a start, but it will not keep away the insects that lay the eggs, and will not destroy the borers that have found their way beneath the bark. It is perhaps quite as well to wash the trees very early in the spring, when they are starting into growth.

It is an old practice to wash trees with strong lye when they are affected with the oyster-shell bark louse. The modern method of treating these pests, however, is to spray with some kerosene or oil compound when the young growth is starting, for at that time the young insects are migrating to the new wood and they are very* easily destroyed (p. 204).

The whitewashing of the trunks of trees tends also to relieve them of insects and fungi; and it is probable that in hot and dry regions the white covering affords protection from climate.

\section{Gathering and keeping fruit (see p. 158).}

Nearly all fruits should be gathered as soon as they will readily part from the stems on which they are borne. With many perishable fruits the proper time for gathering will be deter- 
mined largely by the distance they are to be shipped. With the exception of winter varieties of apples and pears and a few kinds of grapes, it is best to dispose of fruit soon after it is gathered, unless it is kept for family use.

If for winter use, the fruit should at once be placed in the cellar or fruit house in which it is to be stored, and there kept as near the freezing point as possible. There will be less danger of shriveling if the fruit is placed at once in closed barrels or other tight packages, but if proper ventilation is provided, it may be kept in bins with little loss. Even though no ice is used, it will be possible to maintain a fairly low temperature by opening the windows at night when the outside atmosphere is colder than that inside the building, and closing them during the day as the outer air becomes warmer.

Fruit should be handled with great care at all times, for if the cells become broken by rough handling, the keeping qualities will be greatly injured. The illustrations (Figs. 187-189) show three types of fruit storage houses.

Apples and winter pears may be packed in sand or leaves in the cellar (in boxes) and thereby be kept from shriveling.

Almond. - The almond tree is seldom seen in the eastern states, but now and then one will be found in a yard and not bearing. The failure to bear may be due to frost injury or lack of pollination.

The almond is about as hardy as the peach, but it blooms so early in the spring that it is little grown east of the Pacific slope. It is an interesting ornamental tree, and its early bloom is a merit when the fruit is not desired. The almonds commonly sold by nurserymen in the east are hard-shell varieties, and the nuts are not good enough for commerce. The almond fruit is a drupe, like the peach, but the flesh is thin and hard and the pit is the "almond" of commerce. Culture as for peach.

The "flowering almonds" are bushes of different species from the fruit-bearing tree (p. 299). They are usually grafted on plum, and the stock is likely to throw up suckers and cause trouble. 
Apples thrive over a wider range of territory and under more varied conditions than any other tree fruit. This means that they are easy to grow. In fact they are so easy to grow that they are usually neglected.

Apples do best on a strong, sandy loam soil, or a light clay loam. While a soil very rich in organic matter is not desirable, good results cannot be secured unless it contains a fair amount of vegetable matter. A clover sod is particularly desirable for this as well as for other fruits.

For a commercial orchard, most varieties should be from 35 to 40 feet apart; but the slow-growing and long-lived sorts may be at 40 feet, and, halfway between in both directions, some of the shortlived, early-bearing varieties may be placed, to be removed after they begin to crowd. In home grounds the trees may be placed somewhat closer than 35 to 40 feet, especially if they are planted on the boundaries, so that the limbs may project freely in one direction.

It is ordinarily advisable, especially in the humid climates east of the Great Lakes, to have the body of the tree $3 \frac{1}{2}$ to $4 \frac{1}{2}$ feet long. The limbs should be trimmed up to this point when the tree is set. From three to five main branches may be left to form the framework of the top. These should be shortened back one-fourth or one-half when the tree is set. (Figs. 142-145) Subsequent pruning should keep the top of the tree open and maintain it in more or less symmetrical form. West of the Great Lakes, particularly on the plains and in the semi-arid regions, the top may be started much nearer the ground.

In orchard conditions, the trees should be kept in clean culture, especially for the first few years; but this is not always possible in home yards. In lieu of tillage, the sward may be mulched each fall with stable manure, and commercial fertilizer may be applied each fall or spring. If fruit is wanted rather than foliage and shade, care should be taken not to make ground too rich, but to keep it in such condition that the tree is making a fairly rigorous growth, with good strong foliage, but is not overgrowing. An apple tree in full bearing is usually in good condition if the twigs grow 10 to 18 inches each season.

Apple trees should begin to bear when three to five years planted, and at ten years should be bearing good crops. With good treatment, they should continue to bear for thirty or more years in the northeastern states. 


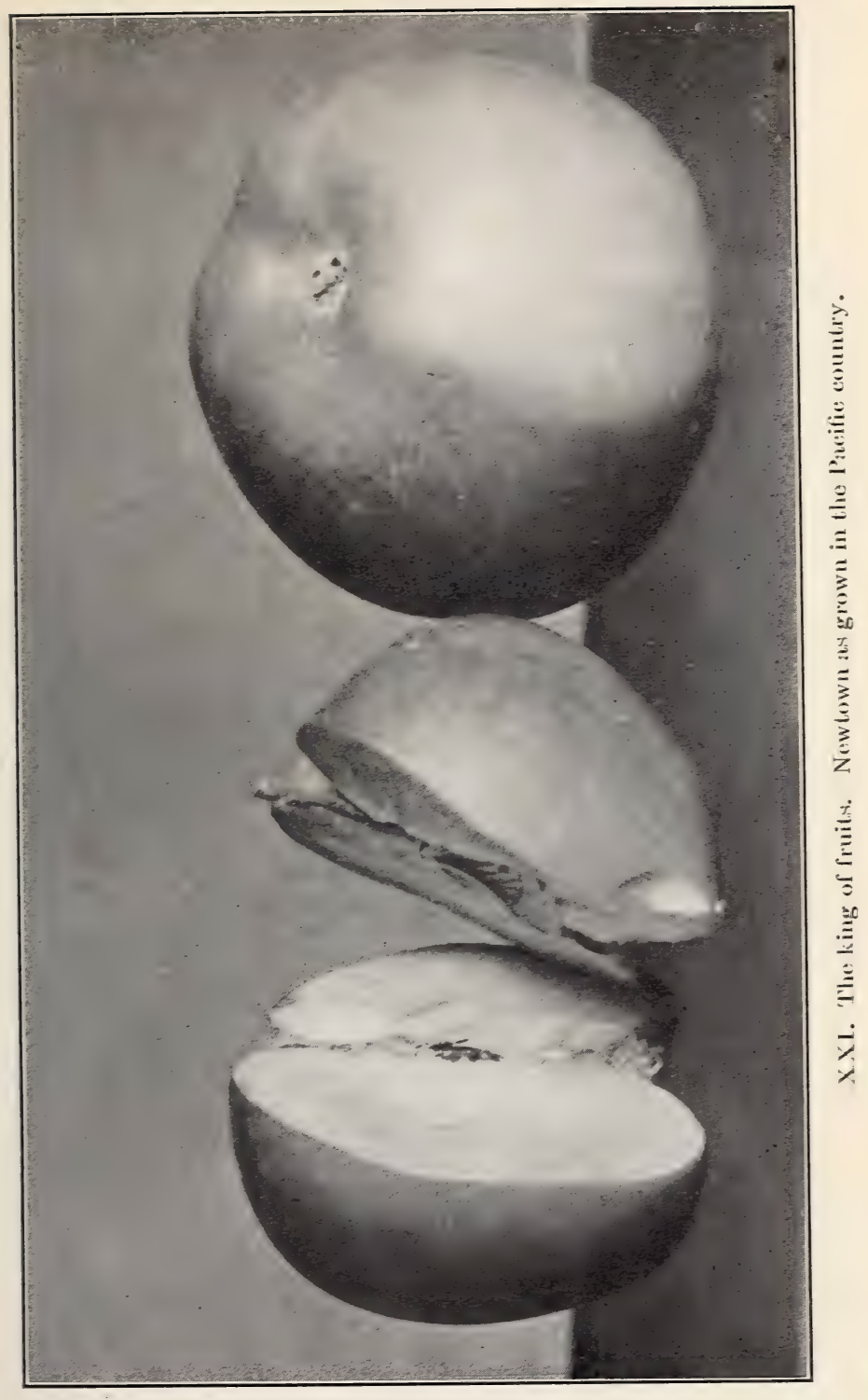





\section{Insects and diseases of the apple (see p. 198).}

Among the insects most commonly found on the apple tree are the codlin-moth, canker-worm, and tent-caterpillar. The codlin-moth lays its egg on the fruit soon after the blossoms fall, and the larvæ, on hatching, eat their way inside. A thorough spraying of the trees with arsenites (p. 201) within a week after the blossoms fall will do much toward destroying them; and a second application, in about three weeks, will be essential. The canker-worm (Fig. 217) and tent-caterpillars feed on the leaves,and can also be destroyed by means of arsenites. To be effective against the former, however, the applications must be made soon after they hatch, and very thoroughly.

A close watch should be kept for borers. Whenever the bark appears to be dead or sunken in patches, remove it and search for the cause. A borer will usually be found underneath the bark. About the base of the tree the most serious injury occurs from borers, since the insect which enters there bores into the hard wood. His presence can be determined by the chips that are cast from his burrows. If the trees are well cultivated and in a thrifty growing condition, the injury will be greatly reduced. It will be well to wash the trunks and larger branches with soft soap, thinned with water so that it can be applied with a brush or broom, during the spring. The addition of an ounce of Paris green in each five gallons of the wash will be of value. The only real remedy, however, is to dig the borers out.

The most troublesome disease of the apple is the apple-scab, which disfigures the fruit as well as lessens its size. It also often does much harm to the foliage, and thus checks the growth of the trees (Fig. 214). The Baldwin, Fameuse, Northern Spy and Red Canada are particularly subject to this disease, and it is much more troublesome in moist seasons than when the weather is dry. The use of fungicides will do much to lessen the injury from this disease.

\section{Varieties of apple.}

The selection of varieties of apples for home use is, to a large extent, a personal matter; and no one may say what to plant. A variety that is successfully grown in one section may prove disappointing in another. One should study the locality in which he wishes to 
plant and choose those rarieties which are the most successfully grown there,-choosing from amongst the successful kinds those which he likes best and which seem best to meet the purposes for which he is to grow them.

For the northern and eastern states, the following varieties will generally be found valuable:-

Early. - Yellow Transparent, Early Harvest, Early Strawberry, Primate, Dyer, Summer Rose, Early Joe, Red Astrachan, Golden Sweet, Oldenburg, * Summer Pearmain, Williams (Favorite), Chenango, Bough (Sweet), Summer Queen, Gravenstein,* Jefferis, Porter, Maiden Blush.

Autumn. - Bailey (Sweet), Fameuse,* Jersey Sweet, Fall Pippin, Wealthy,* Mother, Twenty Ounce, Magnate.

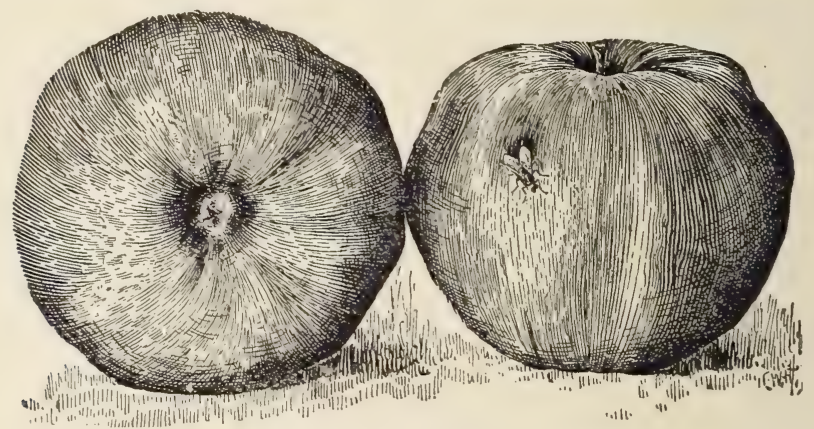

271. The Jonathan.

Winter. - Jonathan* (Fig. 271), Hubbardston,* Grimes,* Tompkins King,* Wagener* (Fig. 272), Baldwin,* Yellow Bellfower, Tolman (Sweet), Northern Spy, * Red Canada,* Roxbury, McIntosh,* Yellow Newtown (Plate XXI), Golden Russet, Belmont, Melon, Lady, Rambo, York Imperial, Pomme Gris, Esopus (Spitzenburgh), Swaar, Peck (Pleasant), Rhode Island Greening, Sutton, Delicious, Stayman Winesap, Westfield (Seek-no-further).

* The varieties marked with an asterisk (*) are particularly valuable for market purposes as well as for home use; the others are chiefly desirable for home use. 
For the South and Southwest the varieties named in the following list are of value:-

Early. - Red June, Yellow Transparent, Red Astrachan, Summer Queen, Benoni, Oldenburg, Gravenstein, Maiden Blush, Earlyripe,* Wiiliams,* Early Cooper,* Horse.

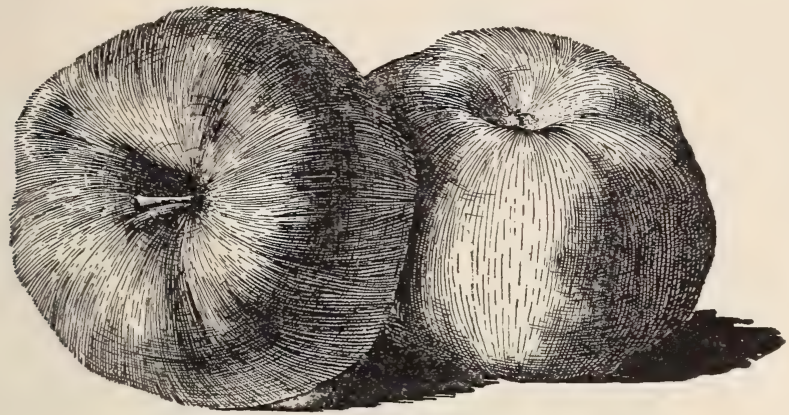

272. The Wagener.

Autumn. - Haas, Late Strawberry, Oconee, Rambo, Peck (Peck Pleasant), Carter Blue, Bonum,* Smokehouse,* Hoover.

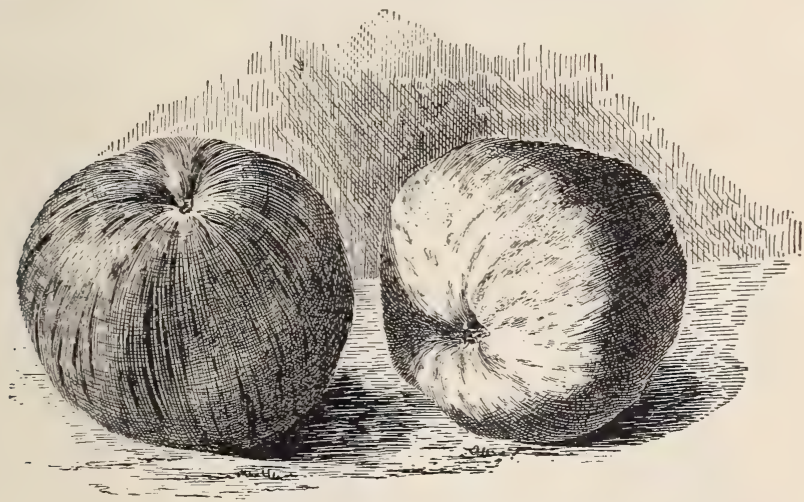

273. Pewaukee Apple.

Winter. - Shockley, Rome Beauty,* Smith Cider, Grimes, Buckingham, Jonathan, *Winesap, Kinnard, York Imperial, Gilpin (Romanite), * Ibid. 
Ralls (Genet), Limbertwig, Royal Lumbertwig, Stayman Winesap,* Milam, Virginia Beauty,* Terry,* Ingram.*

In the Northwest only such varieties as are extremely hardy will be satisfactory, and among those likely to succeed we may mention:-

Early. - Yellow Transparent, Tetofski, Oldenburg.*

Autumn. - Fameuse, Longfield, Wealthy, McMahan,* McIntosh,* Shiawassee.

Winter. - Wolf River,* Hibernal, Northwestern (Greening), Pewaukee (Fig. 273), Switzer, Golden Russet, Patten (Greening).*

Apricot. - This fruit is not often seen in home gardens in the East, although it deserves to be better known. When grown at all, it is likely to be trained on walls, after the English custom.

In the latitude of New York, the apricot has proved as hardy as the peach. Given the right conditions as to soil and exposure, it will yield abundant crops, ripening its fruits about three weeks in advance of early peaches.

The apricot usually thrives best on strong land; but otherwise the treatment given the peach suits it very well. The soil should be rather dry; especially should the subsoil be such that no water may stand around the roots. The exposure should be to the north or west to retard the blooming period, as the one great drawback to the successful fruiting is the early blooming and subsequent freezing of the flowers or the small fruits.

The two serious difficulties in the growing of apricots are the ravages of the curculio, and the danger to the flowers from the spring frosts. It is usually almost impossible to secure fruits from one or two isolated apricot trees, because the curculios will take them all. It is possible, also, that some of the varieties need cross-pollination.

Among the best kinds of apricots are Montgamet, Jackson, Royal, St. Ambroise, Early Golden, Harris, Roman (Fig. 274) and Moorpark. In the East, apricots are commonly worked on plums, but they also thrive on the peach.

The introduction of the Russian varieties, a few years ago, added to

* The varieties marked with an asterisk (*) are particularly valuable for market purposes as well as for home use; the others are chiefly desirable for home use. 
the list sereral desirable kinds that have proved hardier and a little later in blooming than the old kinds. The fruits of the Russian varieties, while not as large as the other varieties, fully equal many of them in flavor, and they are very productive. They bear more profusely and with less care than the old-fashioned and larger kinds.

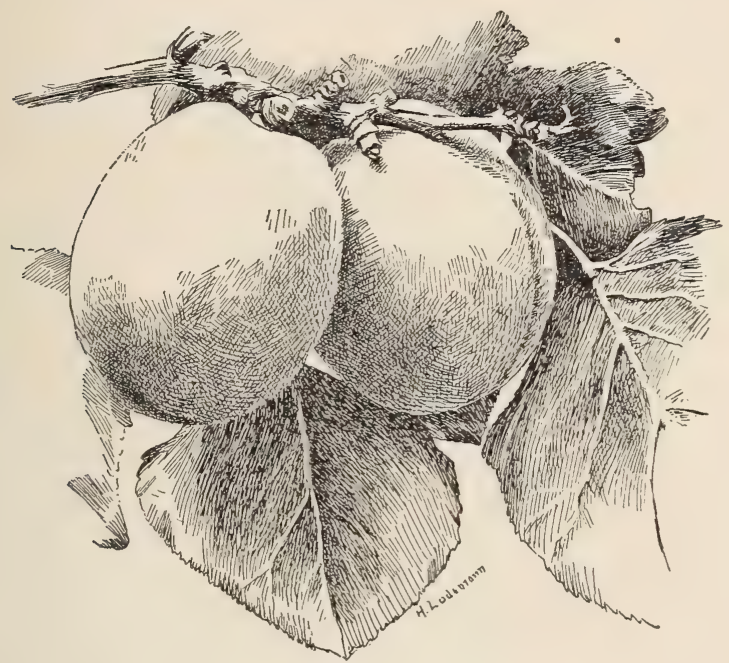

274. Roman Apricot.

Blackberry. - In a general way, the planting and care of a blackberry plantation is the same as required by raspberries. From the fact that they ripen later in the season, when droughts are most common, even greater attention should be given to placing them in land that is retentive of moisture, and to providing an efficient mulch, which can generally best be secured with a cultivator. The smaller-growing kinds (as Early Harvest and Wilson) may be planted $4 \times 7 \mathrm{ft}$., the rankgrowing varieties (as Snyder) $6 \times 8 \mathrm{ft}$. Thorough cultivation throughout the season will help in a material degree to hold the moisture necessary to perfect a good crop. The soil should be cultivated very shallow, however, so as not to disturb the roots, as the breaking of the roots starts a large number of suckers that have to be cut out and destroyed. 
While hill culture (as recommended above) is desirable for the garden, commercial growers generally use continuous rows.

Blackberries, like dewberries and raspberries, bear but one crop on the cane. That is, canes which spring up this year bear next year. From 3 to 6 canes are sufficient to be left in each hill. The superfluous ones are thinned out soon after they start from the ground. The old canes should be cut out soon after fruiting, and burned. The new shoots should be pinched back at the height of 2 or $3 \mathrm{ft}$. if the plants are to support themselves. If to be fastened to wires, they may be allowed to grow throughout the season and be cut back when tied to the wires in winter or early spring.

Blackberry plants are sometimes laid down in cold climates, - the tops being bent over and held to the ground by earth or sods thrown on their tips (Fig. 155).

The most troublesome disease of the blackberry is orange rust (conspicuous on the under sides of the leaves), which often proves very destructive, particularly to Kittatinny and a few other sorts. There is no remedy, and on the first appearance of the disease the infected plants should be dug up and burned (p. 212).

\section{Varieties of blackberries.}

Many of the better varieties of blackberries are lacking in hardiness, and cannot be grown except in the more favorable localities. Snyder and Taylor are most generally successful, although Wilson and Early Harvest are often grown on a large scale for market, and do well with winter protection. Eldorado is much like Snyder, that seems hardy and productive. Erie, Minnewaski, Kittatinny, and Early King are in many sections large and valuable sorts.

Cherry. - Of cherries there are two common types, the sweet cherries and the sour cherries. The sweet cherries are larger and tallergrowing trees. They comprise the varieties known as the hearts, bigarreaus, and dukes. The sour cherries (Fig. 275) include the various kinds of morellos and pie cherries, and these usually ripen after the sweet cherries.

The sour cherries make low, round-headed trees. The fruits are extensively used for canning. Sour cherries thrive well on clay loams. 
The sour cherry should be planted 18 by $18 \mathrm{ft}$. apart, in well-prepared, under-drained soil. The trees may be slightly trimmed back each year, keeping the head low and bushy.

The sweet cherries have proved disappointing in many instances from the rotting of the fruit. This may never be entirely avoided, but good cultivation, soil not too rich in nitrogen, attention to spraying, and picking the fruit when dry, will lessen the loss very much. In years of severe rotting the fruit should be picked before it becomes fully ripe, placed in a cool, airy room and allowed to color. It will be

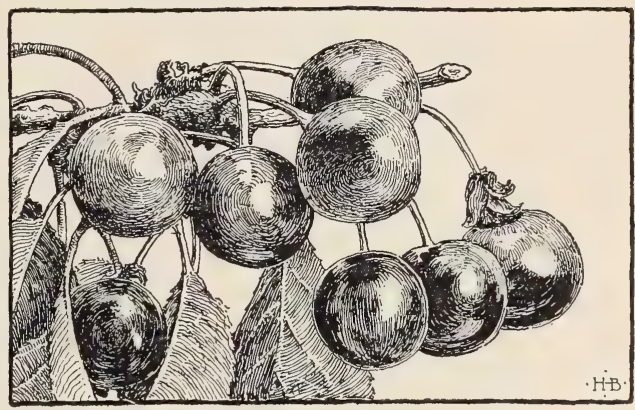

275. Sour or pie cherries. nearly as well flavored as if left on the tree; and, as the fungus usually attacks only the ripe fruit, a considerable part of the crop may be saved. Set the trees 25 or $30 \mathrm{ft}$. apart. Only very well-drained land should be devoted to sweet cherries, preferably one of a somewhat gravelly nature.

Leaf-blight is readily controlled by timely spraying with bordeaux mixture (see bottom p. 211). The curculio or fruit worm may be controlled by jarring, as for plums, or by spraying (p. 202). The jarring process is seldom employed with cherries for the curculio, inasmuch as the poison spray seems, for some reason, to be particularly effective on these fruits.

\section{Varieties of cherry.}

Of the sour varieties, May Duke (Fig. 36), Pichmond, Dyehouse, Montmorency, Ostheim, Hortense (Fig. 34), Late Kentish, Suda, and Morello (English Morello) (Fig. 35) are the most valuable. The following sweet varieties are of value where they sucreed: Rockport, (Yellow) Spanish, Elton, (Governor) Wood, Coe, Windsor, (Black) Tartarian, and Downer. 
Cranberry. - The growing of cranberries in artificial bogs is an American industry. The common large cranberry of markets is also a peculiarly American fruit, since it is unknown in other countries except as the fruit is shipped there.

Cranberries are grown in bogs, which may be flooded. The whole area is kept under water during the winter time, largely to prevent the plants from winter injury by the heaving and freezing and thawing of the bogs. Flooding is also employed at intervals for the purpose of drowning out insects, mitigating drought, and protecting against frost and fires. The ordinary practice is to choose a bog which has a creek running through it, or through which some creek or ditch may be diverted. At the lower side of the bog flood-gates are provided, so that when the gates are shut, the water backs up and floods the area. It is best that the bog be comparatively flat, so that the water will be of approximately equal depth over the whole area. At the shallowest places the water should stand about a foot above the plants. The water is usually let on the bog early in December and kept on until April or early May. No flooding is done during the rest of the year unless there is some particular occasion therefor.

All the wild and turfy growth should be taken off the bog before the vines are set. This is done either by digging it off and removing it bodily, or by drowning it out by means of a year's flooding. The former method is generally considered to be the better. After the turfy growth is removed, the bog is smoothed, and covered 2 or 3 in. deep with clean sand. The vines are now set, the lower ends of them being shoved through the sand into the richer earth. In order to prevent a too rapid and tangled growth of vine, it is customary to resand the bog every three or four years to a depth of one-fourth or one-half inch. When sanding is not practicable, the vines may be mown off when they become too luxuriant.

The plants for setting are merely cuttings or branches of the vines. These cuttings may be 5 to 10 inches long. They are inserted into the ground in a hole made by a crowbar or stick. They are usually planted at distances of 12 to 18 inches each way, and the vines are allowed to cover the entire ground as with a mat. In three years a good crop should be secured, if the weeds and wild growth are kept down. A crop ranges between 50 to 100 barrels per acre. 
Currant. - As the currant is one of the hardiest and most productive of fruits in the North, so is it often neglected, the patch allowed to become foul with grass, never thinned or trimmed, the worms eating the leaves until, in the course of time, the plants weaken and die. Along the fence is no place to plant currants, or, indeed, any other fruit; plant out in the open, at least 5 feet from anything that will interfere with cultivation.

To fruit crop will respond more readily to good care than the currant. Clean cultivation and a liberal use of manure or fertilizers will certainly be followed by well-paying crops. One- or two-year-old plants may be set, 4 by 6 feet. Trim the bush by cutting off most of the suckers below the surface of the ground. The currant should have cool moist soil. If the season is dry, a mulch of straw or leaves will assist the plants to establish themselves.

Currants are easily propagated by mature cuttings of the new or previous year's canes.

The red and white currants bear mostly on two-year-old or older wood. A succession of young shoots should be allowed to grow to take the place of the old bearing wood. Cut out the canes as they grow older. The partial shade afforded by a young orchard suits the currant well, and if the ground is in good condition, no bad results will follow to the orchard, provided the currants are removed before the trees need the entire feeding space.

A currant patch should continue in good bearing for 10 to 20 years, if properly handled. One very important point is to keep the old, weak canes cut out, and a succession of two to four new ones coming from the root each year.

To combat the currant worm, spray thoroughly with Paris green to kill the first brood, just as soon as holes can be seen in the lower leaves - usually before the plants are in bloom. For the second brood, if it appear, spray with white hellebore (p. 203). For borers, cut out and burn the affected canes.

\section{Varieties of currants.}

In most sections the Red Dutch will be found to be the most satis-factory variety, as the plants are much less injured by borers than are Cherry (Plate XXIII), Fay, and Versailles, which are larger and better 
varieties, and are to be preferred in sections where the borers are not troublesome. Victoria is a valuable market sort where borers are numerous, as it is little injured by them. The same is also true of (Prince) Albert, which is little attacked by currant worms and is particularly valuable as a late sort. White Dutch and White Grape are valuable light-colored varieties, and (Black) Naples as a variety for jelly. London (London Market) is also proving to be satisfactory in some sections.

Dewberry. - The dewberry may be called an early trailing black-

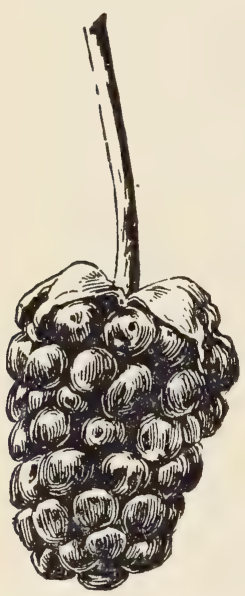

276. Lucretia dewberry. berry. The culture is very simple. Support should be given to the canes, as they are very slender and rank growers. A wire trellis or largemeshed fence-wire answers admirably; or (and this is the better general method) they may be tied to stakes. The fruits are large and showy, which, combined with their earliness, makes them desirable; but they are usually deficient in flavor. The Lucretia (Fig. 276) is the leading variety.

Lay the canes on the ground in winter. In the spring tie all the canes from each plant to a stake. After fruiting, cut the old canes and burn them (as for blackberries). In the meantime, the young canes (for next year's fruiting) are growing. These may be tied up as they grow, to be out of the way of the cultivator. Dewberries are one to two weeks earlier than blackberries.

Fig. - The fig is little grown in the East except as a curiosity, but on the Pacific coast it has gained considerable prominence as an orchard fruit. Figs will stand considerable frost, and seedling or inferior varieties grow out-of-doors without protection as far north as Virginia. Many of the varieties fruit on young sprouts, and, inasmuch as the roots will stand considerable cold, these varieties will often give a few figs in the northern states. Figs have been fruited in the open ground in Michigan. In regions having ten degrees of frost, the fig should be laid down in winter. For this purpose the plants are pruned to branch from the ground, and the soft tops are bent to the surface and covered 
with earth. In commercial cultivation, fig trees grow large, and they stand 18 to 25 feet apart; but in gardens where they are to be bent over, they are to be kept as bushes.

Adriatic is the most commonly grown white fig. Among the other varieties are California Black or Mission Fig, Brown Ischia, Brown Turkey, White Ischia, and Celeste (Celestial).

Gooseberry. - The gooseberry differs little from the currant in its requirements as to soil, pruning, and general care. The plants should be set 3 to 4 feet apart; rows 5 to 7 feet apart. Select a rich, rather moist soil. The tops need no winter protection. If mildew and worms are to be kept in check, spraying must be begun with the very first sign of trouble and be thoroughly done (pp. 203, 209).

The propagation of the gooseberry is similar to that of the currant, although the practice of earthing up a whole plant, causing every branch thus covered to throw out roots, is prac-

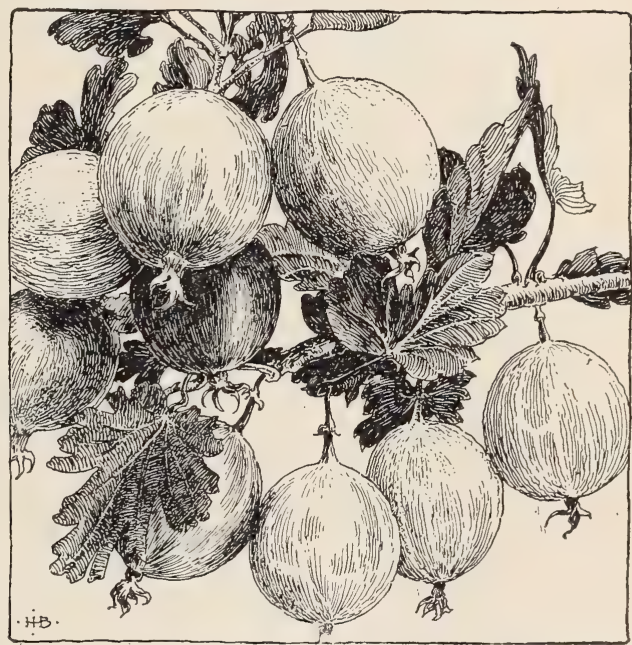

277. One of the English-American gooseberries. ticed with the European varieties. The rooted branches are cut off the following spring and planted in nursery rows or sometimes directly in the field. In order to succeed with this method, the plant should have been cut back to the ground so that all the shoots are yearling.

Since the advent of the practice of spraying with fungicides to prevent mildew, the culture of the gooseberry has increased. There is now no reason why, with a little care, good crops of many of the best English varieties may not be grown. 
A large part of the gooseberry crop is picked green for culinary purposes. Several of the English varieties and their derivatives have proved of value, having larger fruits than the natives (Fig. 277).

\section{Varieties of gooseberries.}

For ordinary use the Downing can generally be recommended. It is hardy, productive, of fair size, and greenish white in color. Houghton is even more hardy and productive, but the fruit is rather 'small and of a dark red color. Among the varieties of European origin that can be successfully grown, if the mildew can be prevented, are Industry, Triumph, Keepsake, Lancashire Lad, and Golden Prolific. Among other varieties that are promising are Champion, Columbus, Chautauqua, and Josselyn (Red Jacket).

Grape. - One of the surest of fruit crops is the grape, a crop each year being reasonably certain after the third year from the time of setting the vines; and the good amateur kinds are numerous.

The grape does well on any soil that is under good cultivation and well drained. A soil with considerable clay is better under these circumstances than a light, sandy loam. The exposure should be to the sun; and the place should admit of cultivation on all sides.

For planting, 1- or 2-year-old vines should be used, being set either in the fall or early spring. At planting, the vine is cut back to 3 or 4 eyes, and the roots are well shortened in. The hole in which the plant is to be set should be large enough to allow a full spreading of the roots. If the season should be dry, a mulch of coarse litter may be spread around the vine. If all the buds start, the strongest one or two may be allowed to grow. The canes arising from these buds should be staked and allowed to grow through the season; or in large plantations the first-year canes may be allowed to lie on the ground.

The second year one cane should be cut back to the same number of eyes as the first year. After growth begins in the spring, two of the strongest buds should be allowed to remain. These two canes now arising may be grown to a single stake through the second summer, or they may be spread horizontally on a trellis. These are the canes that form the permanent arms or parts of the vine. From them start the upright shoots which, in succeeding years, are to bear the fruits. 
In order to understand the pruning of grapes, the operator must fully grasp this principle: Fruit is borne on wood of the present season, which arises from wood of the previous season. To illustrate: A growing shoot, or cane, of 1909 makes buds. In 1910 a shoot arises from each bud; and near the base of these shoots the grapes are borne ( 1 to 4 clusters on each). While every bud on the 1909 shoot may produce shoots or canes in 1910, only the strongest of these new canes will bear fruit. The skilled grape-grower can tell by the looks of his cane (as he prunes it in winter) which buds will give rise to the grape-producing wood the following season. The larger and stronger buds usually give best results; but if the cane itself is very big and stout, or if it is very weak and slender, he does not expect good results from any of its buds. A hard, well-ripened cane the diameter of a man's little finger is the ideal size.

Another principle to be mastered is this: A vine should bear only a limited number of clusters, - say from 30 to 80. A shoot bears clusters near its base; beyond these clusters the shoot grows on into a long, leafy cane. An average of two clusters may be reckoned to a shoot. If the vine is strong enough to bear 60 clusters, 30 good buds must be left at the pruning (which is done from December to late February).

The essential operation of pruning a grape vine, therefore, is each year to cut back a limited number of good canes to a few buds, and to cut off entirely all the remaining canes or wood of the previous season's growth. If a cane is cut back to 2 or 3 buds, the stub-like part which remains is called a spur. Present systems, however, cut each cane back to 8 or 10 buds (on strong varieties), and 3 or 4 canes are left, 一 all radiating from near the head or trunk of the vine. The top of the vine does not grow bigger from year to year, after it has once covered the trellis, but is cut back to practically the same number of buds each year. Since these buds are on new wood, it is evident that they are each year farther and farther removed from the head of the vine. In order to obviate this difficulty, new canes are taken out each year or two from near the head of the vine, and the 2-year-or 3-year-old wood is cut away.

The training of grapes is a different matter. A dozen different systems of training may be practiced on the same trellis and from the 
same style of pruning, - for training is only the disposition or ar rangement of the parts.

On arbors, it is best to carry one permanent arm or trunk from each root over the framework to the peak. Each year the canes are cut

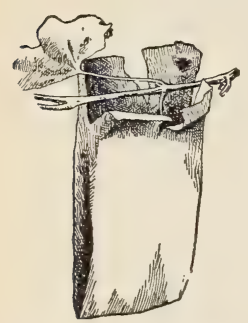
back to short spurs (of 2 or 3 buds) a'ong the sides of this trunk.

Grapes are set from 6 to 8 feet apart in rows which are 8 to 10 feet apart. A trellis made of 2 or 3 wires is the best support. Slat trellises catch too much wind and blow down. Avoid stimulating manures. In very cold climates, the vines may be taken off the trellis in early winter and laid on the ground and lightly covered with 278. Bag ready to earth. Along the boundaries of
be applied.

home lots, where grapes are often planted, little is to be expected in the way of fruit because the ground is not well tilled.

The grape is subject to many insects and diseases, some of which are very destructive. The black-rot is the most usual trouble. See p. 209.

To produce bunches of high quality and free from

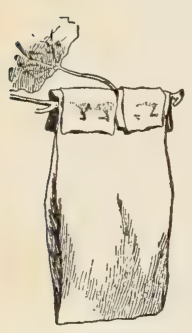
rot and frost injury, grapes are sometimes bagged. When the grapes are 279. The second about half grown, the bunch is covered with a grocer's manila bag. The bags

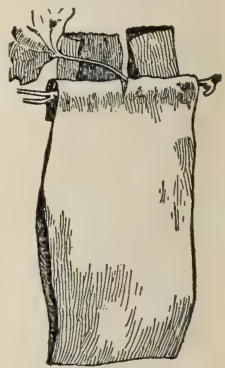
remain until the fruit is ripe. The grapes usually mature earlier in the bags. The top of the bag is split, and the flaps are secured over the branch with a pin; Figs. $278,279,280$ explain the operation.

In all the above discussion, the so-called native 280. The bagging complete. grapes alone are considered. In California, the European or vinifera types are grown, the requirements of which are radically different from those of the eastern kinds.

\section{Varieties of grapes.}

Under nearly all conditions, the Concord will be a raluable black variety, although Worden, which is a few days earlier, may be pre- 

ferred by many. Noore (Moore Early) has been our best very early black variaty, but is likely to be superseded by Campbell, which is a stronger vine, more productive, bunches larger, fruit of better quality, and of superior keeping qualities, making it valuable for shipping purposes. Catawba, Delaware, and Brighton are among the best rad varieties, although Agawam and Salem are much used. Winchell (Green Mountain) is the best early white variety, and in most sections Niagara, a late white sort, does well. Diamond (Moore Diamond) is a white grape of better quality than Niagara.

\section{Grapes under glass (S. W. Fletcher).}

The European grapes rarely thrive out of doors in eastern America. Grape houses are necessary, with or without artificial heat. Fruit for home use may be grown very satisfactorily in a cold grapery (without artificial heat). A simple lean-to against the south side of a building or wall is cheap and serviceable. When a separate building is desired, an even-span house running north and south is preferable. There is no advantage in having a curved roof, except as a matter of looks. A compost of four parts rotted turf to one of manure is laid on a sloping cement bottom outside the house, making a border 12 feet wide and 2 feet deep. The cement may be replaced with rubble on well-drained soils, but it is a poor makeshift. Every three years the upper 6 inches of the border should be renewed with manure. The border inside the house is prepared likewise. Two-year-old potted vines are planted about 4 feet apart in a single row. Part of the roots go through a crevice in the wall to the outer border and part remain inside; or all may go outside if the house is desired for other purposes. One strong cane is trained to a wire trellis hanging at least 18 inches from the glass, and is cut back to 3 feet the first year, 6 the second, and 9 the third. Do not be in a hurry to get a long cane. Pruning is on the spur system, as recommended for arbors on p. 430. The vines are usually laid on the ground for winter and covered with leaves or wrapped with cloth.

As soon as the buds swell in early spring, tie the vines to the trellis and start out one shoot from each spur, rubbing off all others. After the berries begin to color, however, it is better to leave all further growth to shade the fruit. Pinch back each of these laterals two 
joints beyond the second bunch. To keep down red spider and thrips, the foliage should be sprayed with water every bright morning except during the blooming season. At least one-third of the berries should be thinned from each bunch; do not be afraid of taking out too many. Water the inside border frequently all through the summer, and the outside occasionally if the season is dry. Mildew may appear in July. The best preventives are to syringe faithfully, admit air freely, and sprinkle sulfur on the ground.

Fruit may be kept fresh on the vines in a warm (or artificially heated) grapery until late December; in a coldhouse it must be picked before frost. After the fruit is off, ventilate from top and bottom and withhold water, so as thoroughly to ripen the wood. Along in November the canes are pruned, covered with straw or wrapped with mats and laid down till spring. Black Hamburg is superior to all other varieties for a cold grapery; Bowood Muscat, Muscat of Alexandria, and Chasselas Musque may be added in the warmhouse. Good vines will live and bear almost indefinitely.

Mulberry. - Both for fruit and ornament the mulberry should be more generally planted. Even if the fruit is not to the taste, the tree is naturally open-centered and round-headed, and is an interesting subject; some of the varieties have finely cut leaves. The fruits are in great demand by the birds, and after they begin to ripen the strawberry beds and cherry trees are freer from robins and other fruiteating birds. For this reason alone they are a valuable tree for the fruit-grower. Trees may be purchased cheaper than one can propagate them.

If planted in orchard form, place them 25 to 30 feet apart. About the borders of a place they can go closer. The Russian varieties are often planted for windbreaks, for they are very hardy and thrive under the greatest neglect; and for this purpose they may be planted 8 to 20 feet apart. The Russians make excellent screens. They stand clipping well. The fruit of the Russians varies in quality, as the trees are usually directly from seed; but now and then a tree bears excellent fruit.

New American, Trowbridge, and Thorburn are leading kinds of fruit-bearing mulberries for the North. The true Downing is not 
hardy in the northern states; but New American is often sold under this name. Mulberries thrive in any good soil, and need no special treatment.

Nuts. - The nut trees demand too much room for most homeground fruit plantations, although they are also useful for windbreaks and shade. The hickories, all American, make excellent lawn trees, and should be better known. The filberts and cobnuts, small trees or bushes, are not successfully grown in this country except in very special cases.

The commercial nut-growing in the United States and Canada is chiefly of almonds (p. 415), walnuts, and pecans, with some attempt at chestnuts. Of these the chestnut is the most adaptable for home places in the northeastern section.

Of chestnuts there are three types in cultivation: the European, the Japanese, and the American. The American, or native chestnuts, of which there are several improved varieties, are the hardiest and most reliable, and the nuts are the sweetest, but they are also the smallest. The Japanese varieties are usually injured by the winter in central New York. The European varieties are somewhat hardier, and some of the varieties will thrive in the northern states. Chestnuts are very easily grown, although the bark disease (p. 208) now threatens them. They usually bear better when two or more trees are planted near each uther. Sprouts in old chestnut clearings are often allowed to remain, and sometimes they are grafted to the improved varieties. The young trees may be grafted in the spring by the whip-graft or cleftgraft method; but the cions should be perfectly dormant, and the operation should be very carefully done. Even with the best workmanship, a considerable percentage of the grafts are likely to fail or to break off after two or three years. The most popular single variety of chestnut is the Paragon, which bears large and excellent nuts when the tree is very young. When the home ground is large enough, two or three of these trees should be planted near the borders.

Orange. - Oranges are grown extensively in Florida, in places along the Gulf, and in many parts of California, but in the most favored sections there is occasionally some injury from cold or frost to the trees or fruit. 
The soil preferred for oranges in California is a rich, deep alluvium, avoiding hard-pan or adobe subsoils. Stagnant water in the subsoil is a fatal defect. Although they can be grown near the ocean at a lower level, an elevation of 600 to 1200 feet is generally desirable. While southern California is particularly adapted to orange culture, the fruit is successfully raised along the foot-hills of the San Joaquin and Sacramento valleys and in other parts of the state.

In Florida, pine lands with a clay subsoil are generally preferred for oranges, but if properly handled, good results can be obtained from hammock land. As elevated spots cannot be secured, a timber belt surrounding the orchard or along the north and west sides is desirable.

The distance for the large-growing kinds of orange in the orchard is from 25 to 30 feet each way, but the half-dwarf kinds, such as Bahia or Washington Navel, may be as close as 20 feet each way, although 25 feet will be desirable. If the roots are sacked, the trees should be placed in the hole without removing the covering, and the soil should then be packed about them; but if they are puddled, a mound should be made in the bottom of the hole. In the center an opening should be made into which the tap-root can be inserted. After the soil has been firmly packed about it, the other roots should be spread out and the hole filled with good soil, packing it carefully. Care should be taken that the roots are not exposed in handling the trees, and if the weather is hot and dry, the tops should be shaded. Water may often be used with good results in settling the soil about the roots.

When transplanted, the tops should be cut back in proportion to the amount of roots lost in digging the trees. The head is usually started with the branches about 2 feet from the ground. Each year while the trees are small, the strong shoots should be cut back to preserve a symmetrical form and the weak and surplus shoots should be removed.

The cultivation of orange orchards should be the same as recommended for other fruits, except that as they grow in hot, dry climates, it should be even more thorough, that the evaporation of moisture from the soil may be reduced to a minimum. California growers have found that by frequent shallow cultivation they can reduce the amount 
of water that must be applied by irrigation, and that frequent tillage and a little water will give better results than little or no cultivation and a large amount of water. The amount of water required will also depend on the season and the character of the soil. Thus on strong soils and after a heavy rainfall no irrigation will be required, while sandy soils will need irrigating as often as once in three or four weeks from May to October. As a general rule, two or three irrigations in a season will be ample. When used at all, water should be applied in sufficient quantities to wet down to the roots of the trees. Frequent scanty waterings may do much harm. The water is usually applied in furrows, and for young trees there should be one on either side of each row, but as the roots extend the number should be increased, until when five or six years old the entire orchard should be irrigated from furrows 4 or 5 feet apart. In Florida, irrigation is not practiced.

Cover-cropping in winter is now common in Florida and California, some of the leguminous crops being used.

\section{Varieties of the orange.}

Among the best varieties are: Bahia, commonly known as Washington Navel, Thompson Improved, Maltese Blood, Mediterranean Sweet, Paper Rind St. Michael, and Valencia. Homosassa, Magnum Bonum, Nonpareil, Boone, Parson Brown, Pineapple, and Hart are favorites in Florida. The tangerines and mandarins, or the "kidglove " oranges, have a thin rind that is easily detached from the rather dry pulp. Orange trees are frequently injured by various scale insects, but for several of the most troublesome kinds, insect parasites have been found that keep them partially or wholly in check, and for others the trees are sprayed, or fumigated with hydrocyanic acid gas.

Peach. - Given the proper exposure, peaches may be fruited in many sections where now it is thought impossible to have a crop. It is usually the practice of the amateur to set peach trees in the shelter of some building, exposed on the south or east to the sun, and "in a pocket" as regards winds. This should be reversed, except in the close vicinity of large bodies of water. The fruit-buds of peaches will stand very cold weather when perfectly dormant, often as low as $12^{\circ}$ 
or $18^{\circ}$ below zero in New York; but if the buds once become swollen, comparatively light freezing will destroy the crop. Therefore, if the trees be set on elevations where a constant air drainage may be obtained, sheltered, if at all, on the south and east from the warming influence of the sun, the buds will remain dormant until the ground becomes warm, and the chances of a failure will be lessened. This advice applies mostly to interior sections.

A well-drained, sandy loam or gravelly soil suits the peach better than a heavy soil; but if the heavier soil is well drained, good crops may be secured.

Peaches are short-lived at best, and one should be satisfied with three or four crops from each tree. They bear young, usually a partial crop the third year. If a crop may be had every other year until the trees are eight or ten years old, they will have well repaid the effort of cultivation. But they often bear twice this long. Young trees may be set every four or five years to replace older ones, thus having trees at a bearing age at all times on a small place. Trees should be set 14 to 18 feet apart each way.

Peach trees are always bought when they are one year old, that is, one year from the bud. For example, the bud is inserted in the fall of 1909. It remains dormant until the spring of 1910 , when it pushes into vigorous growth; and in the fall of 1910 the tree is ready for sale. Peach trees that are more than a year old are scarcely worth the buying. It is a common practice, when setting peach trees, to prune them back to a whip, leaving a stub bearing not more than one bud where each branch is cut off.

The three great enemies of the peach are the borer, the yellows, and the curculio.

The borer is best handled by digging it out every spring and fall. Trees attacked by the borer have an exudation of gum about the crown. If the borers are dug out twice a year, they will not get sufficient start to make the operation very laborious. It is the only sure way (p. 200).

The yellows is a communicable disease, the cause of which is not definitely known. It shows itself in the fruit ripening prematurely, with distinct red spots which extend through the flesh, and later by the throwing out of fine, branching, twiggy tufts along the main 
branches (Fig. 215). The only treatment is to pull out the trees and burn them. Other trees may be set in the same places.

The curculio must be captured by jarring on sheets (see Plum).

\section{Varieties of the peach.}

For home use it is advisable to provide varieties that will ripen in succession, but for market purposes, in most, sections, the medium and late kinds should be most extensively planted. Although there are many varieties that have a local reputation, but are not commonly found in the nurseries, the following kinds are well known, and can be generally grown with success: Alexander, Hale Early, Rivers, St. John, Bishop, Connett (Southern Early), Carmais, Crawford (Early and Late), Oldmixon, Lewis, Champion, Sneed, Greensboro, Kalamazoo, Stump, Elberta, Ede (Capt. Ede), Stevens (Stevens' Rareripe), Crosby, Gold Drop, Reeves, Chairs, Smock, Salway, and Levy (Henrietta).

Pear. - No fruit plantation should be considered complete without trees of various kinds of pears, ripening fruits from early in August till winter. The late varieties are generally good keepers, and extend the season into February, thus supplying fruit for six or seven months.

As the pear grows to perfection on quince, the dwarf tree is peculiarly adapted to planting on small home grounds, and is often used as a

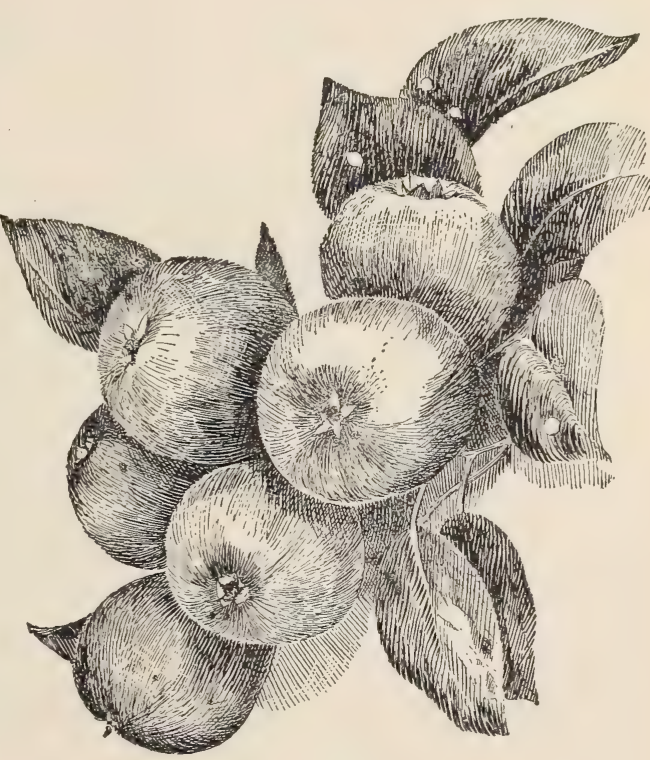

281. Seckel pear. 
boundary plant, or to serve the purpose of a screen. These dwarf trees should be set deep -4 to 6 inches below the union - to prevent

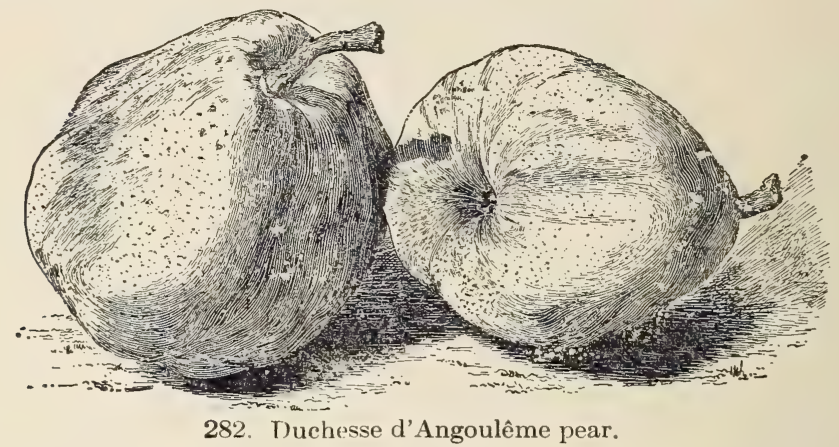

the stock from growing. Dwarf trees may be set as near together as 10 to 16 feet (p. 410), while the standard or tall-growing pears should be set 18 to 25 feet apart. Trees are planted when two or three years old.

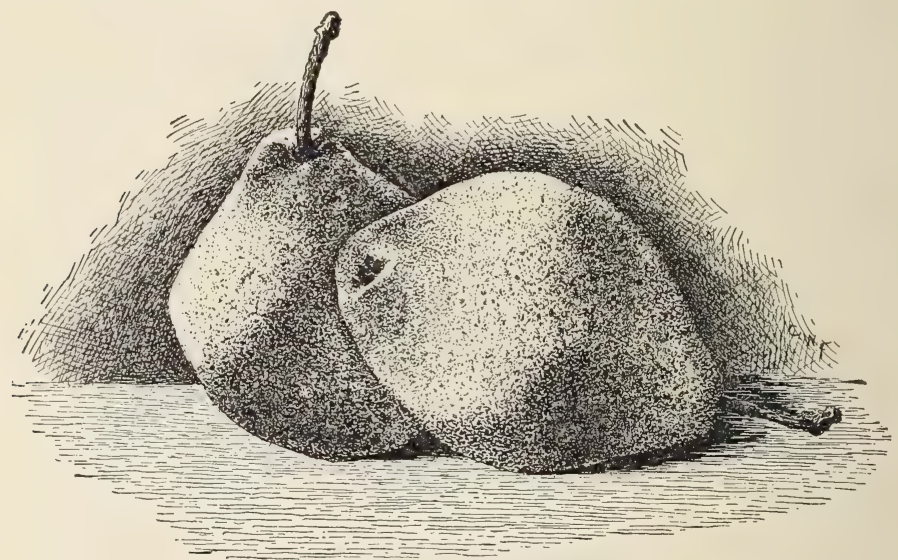

283. The Kieffer pear.

The pear thrives on clay soil, if well under-drained, and for this reason may succeed in places where other fruits might fail. A good, steady growth should be maintained, but the use of nitrogenous 
manures should be avoided, as they tend to make a rank growth and invite attacks of pear blight, which is the worst enemy of the pear (p. 211).

\section{Varieties of the pear.}

As a selection to supply a succession of varieties throughout the season, the following list is recommended:-

Early. - Summer Doyenne, Bloodgood, Clapp, Osband, Elizabeth (Manning's Elizabeth).

Autumn. - Bartlett, Boussock, Flemish (Flemish Beauty), Buffum, Howell, Seckel (Fig. 281), Louise Bonne, Angoulême (Duchesse d'Angoulême) (Fig. 282), Sheldon.

Winter. - Anjou, Clairgeau, Lawrence, Kieffer (Figs. 283, 284), Winter Nelis, and Easter Beurre.

For ordinary market purposes the following have been proved valuable: Bartlett, Howell, Anjou, Clairgeau, and Lawrence. In the central and southern states, Kieffer is grown successfully. For home use this variety is not to be recommended in the North, because of its poor quality and smaller size.

For growing as dwarfs, Angoulême (Duchesse d'Angoulême), Louise Bonne,

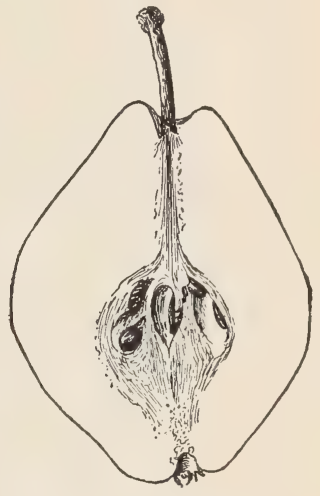

284. Kieffer pear. Anjou, Clairgeau, and Lawrence are most popular, but many other varieties thrive on the quince.

Plum. - Of plums there are three general or common types: first, the common Domestica or European plum, which gives rise to all the older varieties, like Lombard, Bradshaw, Green Gage, the Prunes, the Egg plums, the Damsons, and the like; second, the Japanese plums, which have become popular within the last twenty years, and which are adapted to a wider range of country than the Domesticas; third, the native plums of several species or types, which are adapted to the plains, the middle and southern states, and some kinds to the cold North. 
Wherever the Domestica and Japanese plums can be grown, the native plums are not destined to become popular; but many of the natives are much hardier than others, and are therefore adapted to regions in which the Domestica and Japanese are not safe. Others of them are well adapted to the middle and southern states. The Domestica and Japanese plums are considerably hardier than peaches, but not so hardy as the apple. The northern limit of their general cultivation is the southern peninsula of Michigan, central and southern Ontario, central New York, and central New England.

Plums thrive on a great variety of soils, but they do better, as a rule, on those that are rather heavy and have a considerable content of clay. In fact, many of the varieties will thrive on clay as hard as that in which pears will grow. On the other hand, they often thrive well in light, and even almost sandy soils.

The trees are set when they are two and three years from the bud. It is preferable to have plum trees on stocks of the same species, but it is not always possible to secure them at the nurseries. In the South, plums are worked mostly on peach roots, and these make excellent trees where the climate is not too severe, and especially on the lighter lands on which they are planted in the South. In the North the larger part of the plum stocks are grown on the Myrobalan plum roots. This Myrobalan is an Old World species of plum, of smaller growth than the Domestica. This stock, therefore, tends to dwarf the tree, and it is also likely to throw up sprouts from the roots.

Plum trees are set 12 to 18 feet apart. Many growers like to set them 8 feet apart in rows, and have the rows from 16 to 20 feet apart.

Plums are pruned much the same as apples and pears. That is, the top is thinned out from year to year, and all superfluous branches and broken or diseased wood are removed. If the soil is very strong and the trees are close together, it may be well to head them in a little each year, especially those varieties which grow very strong and robust.

\section{Pests and diseases (pp. 202, 211).}

There are four leading difficulties in the growing of plums - leafblight, fruit-rot, black-knot, and curculio.

The leaf-blight usually appears about midsummer, the leaves becoming spotted and dropping off. The remedy is to spray thoroughly 
with bordeaux mixture, beginning soon after the fruits have set, and before the trouble begins to show.

The fruit-rot may be prevented by the same means - that is, by spraying with bordeaux mixture. It is usually best to begin just after the fruits are well set. A very important consideration in the checking of this disease is to thin the fruit so that it does not hang in clusters. If one fruit touches another, the rot spreads from fruit to fruit in spite of the spraying. Some varieties, as Lombard and Abundance, are specially susceptible to this injury.

The black-knot is best kept in check by cutting out the knots whenever they can be seen, and burning them. As soon as the leaves drop, the orchard should be gone over and all knots taken out. Orchards that are thoroughly sprayed with bordeaux mixture for the leafblight and fruit-rot fungus are less liable to attacks of black-knot.

The curculio, or the insect which is the parent of the worms in the fruit, is the inveterate enemy of the plum and other stone fruits. The mature beetle lays the eggs in the fruits when they are very small, usually beginning its work about as soon as the flowers fall. These eggs soon hatch, and the little maggot bores into the fruit. Those fruits that are attacked whilst very young ordinarily fall from the tree, but those attacked when they are half or more grown, may adhere to the tree, but remain wormy and gummy at the picking time. The mature beetles are sluggish in the mornings, and are easily jarred from the trees. Taking advantage of this fact, the fruit-grower may jar them on sheets; or, in large orchards, into a large canvas hopper, which is wheeled from tree to tree upon a wheelbarrow-like frame, and under the apex of which is a tin can into which the insects roll. There is a slit or opening in one side of the hopper, which allows the tree to stand nearly in the middle of the canvas. The operator then gives the tree two or three sharp jars with a padded pole or mallet. The edges of the hopper are then quickly shaken with the hands and the insects roll down into the tin receptacle. In this receptacle there is kerosene oil, or it may be emptied from time to time. Just how long this machine is to be run in the orchard will depend entirely on circumstances. It is advisable to use the catcher soon after the blossoms fall, for the purpose of finding out how, abundant the insects are. If a few insects are caught from each tree, there is indication that there are enough of the 
pests to make serious trouble. If after a few days the insects seem to have disappeared, it will not be necessary to continue the hunt. In some years, especially in those succeeding a very heavy crop, it may be necessary to run the curculio-catcher every morning for four or five weeks; but, as a rule, it will not be necessary to use it oftener than two or three times a week during that season; and sometimes the season may be shortened by one half. The insects fall most readily when the weather is cool, and it is best, therefore, to get through the whole orchard, if possible, before noon. On cloudy days, however, the insects may be caught all day. A smart man can attend to 300 or 400 iullbearing trees in six hours if the ground has been well rolled or firmed, as it should be before the bugging operation begins. The same treatment applies to the saving of peaches and rarely, also, of sour cherries.

\section{Varieties of the plum.}

The following varieties of European origin will be found desirable for growing in the northern and eastern states: Bradshaw, Imperial Gage, Lombard, McLaughlin, Pond, Quackenbos, Copper, Jefferson, Italian Prune (Fellenberg), Shropshire, Golden Drop (Cou Golden Drop), Bavay or Reine Claude, Grand Duke, Monarch.

Several of the Japanese varieties are also well adapted to growing in these sections, as well as in the states farther south. The trees are generally hardy, but they bloom early, and are likely to be injured by late frosts in some localities. Among the better kinds are the Red June, Abundance, Chabot, Burbank, and Satsuma.

Few of the above sorts are hardy in the Northwest, and growers there have to rely on varieties of native species. Among these are: Forest Garden, Wyant, De Soto, Rollingstone, Weaver, Quaker, and Hawkeye. Farther south still other classes of plums have been introduced, among them being Wildgoose, Clinton, Moreman, Miner, and Golden Beauty. And still farther south, Transparent, Texas Belle (Paris Belle), Newman, Lone Star, and El Paso are grown.

Quince. - Although not largely grown, quinces generally find a ready sale, and they are desirable for home use. The trees are usually planted about 12 feet each way, and may be trained either in a shrub or tree form, but it will generally be best to grow them with a short trunk. 
They succeed best on a deep, moist, and fertile soil. They require much the same care as the pear. The insects and diseases by whirh they are attacked are also the same as for that fruit. Blight is particularly bad. The fruit is borne on short shoots of the same season, and strong heading-in of the growth in winter removes a good part of the buds from which the shoots arise. The Orange is the most common variety, but Champion, Meech (Fig. 285), and Rea are sometimes grown.

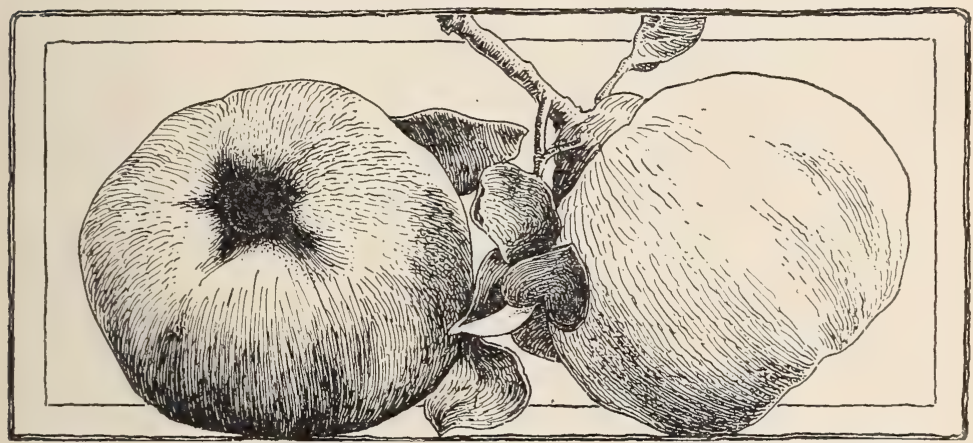

285. Meech Quince (Meech's Prolific).

Raspberry. - Both the red and black raspberries are essentials of a good garden. A few plants of each will produce a supply of berries for a family through six or eight weeks, provided both early and late varieties are planted.

A cool situation, soil that will hold moisture without being wet, and thorough preparation of the ground, are the conditions necessary to success. The blackcap raspberries should be set 3 to 4 feet apart, the rows 6 or 7 feet; the red varieties 3 feet apart, the rows 5 feet apart. Spring setting is usually preferable.

The shoots of raspberries sent up one season fruit and die the following year, as in blackberries and dewberries.

Most of the blackcap varieties naturally throw out side branches the first season, and with such it is a good plan to pinch back the new canes as soon as they have reached a height of 2 to 3 feet, according to the full height of the variety. This will hasten the throwing out of 
side shoots, upon which fruit will be borne the following year. As soon as severe freezing weather is over in the spring, these side shoots should be cut back 9 to 12 inches, according to the strength of the canes and the number of side branches upon them.

The same method of pruning is advisable with red varieties like Cuthbert, which naturally branch freely. Other sorts, like King, Hansell, Marlboro, Turner, and Thwack, that seldom branch, should not be pinched back in summer, as, even though this might induce them to send out shoots, the branches will be weak, and if they survive the winter, will produce less fruit than would the strong buds upon the main canes had they not been forced into growth.

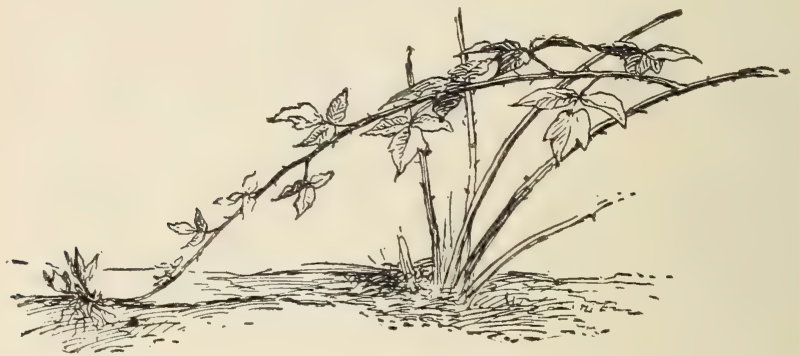

286. A rooting tip of the black raspberry.

As soon as the crop has been gathered, and the old canes are dead, they should be remored, and at the same time all of the surplus new shoots should be cut away. From four to five good canes will be sufficient for each hill, while in rows the number may be from two to three in each foot.

Pruned in this way, nearly all varieties will have stems sufficiently large to support themselves, but as there will be more or less breaking down and injury to the fruit from the bending over of the canes, many growers prefer to support them by means of stakes or trellises. Stakes may be set in each hill, or for matted rows stout stakes 3 feet high are driven at intervals of 40 feet and a No. 10 galvanized wire is stretched along the row, to which the canes are tied. It would be a saving of labor if a wire is stretched either side of the row, as then no tying will be required. 



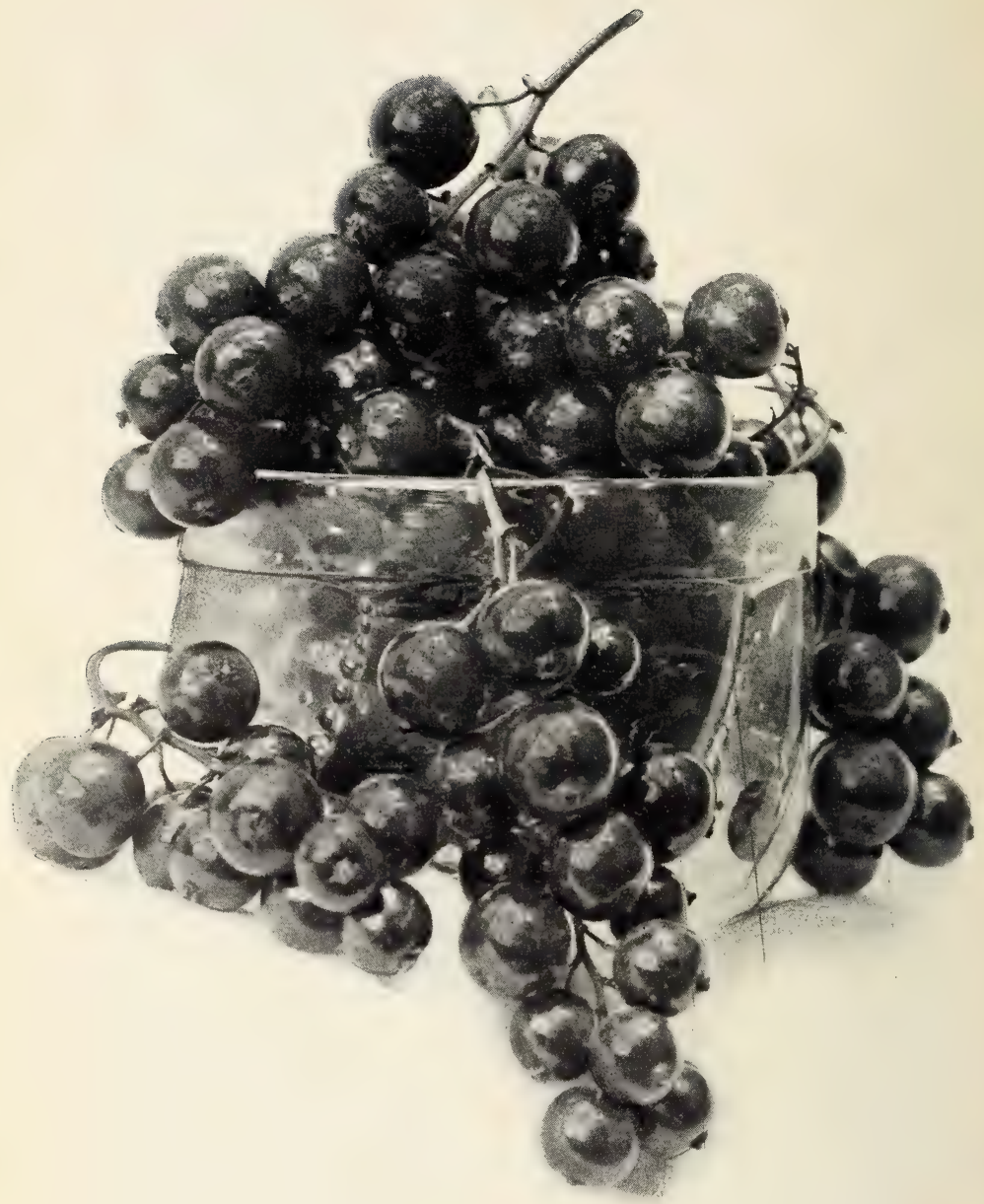

XXIII. Cherry currant. 
If it is desired to secure new plants, the ends of the branches of the black varieties should be covered with soil about the middle of August, when the tips are seen to divide into several slender shoots, and to take root (Fig. 286); these can be taken up and planted the following spring. While the suckers that spring from the roots of red varieties (Fig. 287) may be used in propagating them, it will be better to use plants grown from root-cuttings, as they will have much better roots.

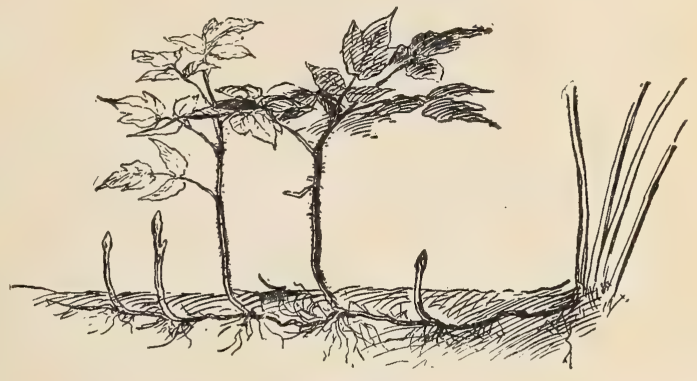

287. Sprouting habit of red raspberry.

Raspberries may be bent over to the ground so that the snow will protect them, in severe climates.

For red rust, pull out the plant, root and branch, and burn it. Short rotations - fruiting the plants only two or three years - and burning the old canes and trimmings, will do much to keep raspberry plantations healthy. Spraying will have some effect in combating anthracnose.

\section{Varieties of raspberries.}

Of the black sorts the following will be found desirable: Palmer, Conrath, Kansas, and Eureka, which ripen in the order named. In some sections the Gregg is still valuable, but it is somewhat lacking in hardiness. Ohio is a favorite variety for evaporating. Of the purplecap varieties, Shaffer and Columbian generally succeed. Among the red varieties none are more universally successful than Cuthbert. King is a promising early variety, and Loudon is a valuable late kind. Many growers find Marlboro and Turner well worthy of cultivation, although rather local in their adaptations; while for home use, Golden Queen, a yellow Cuthbert, is much liked.

Strawberry. - Every one may grow strawberries, yet the saying that strawberries will grow on any soil is misleading, although true. Some 
varieties of strawberries will grow on certain soils better than other varieties. What these varieties are can be determined only by an actual test, but it is a safe rule to choose such varieties as prove good in many localities.

As to the methods of culture, so much depends on the size of the plot, the purpose for which the fruit is wanted, and the extent of care one is willing to give, that no set rule can be given for a garden in which but few plants are grown and extra care can be given. The grower must always be sure that his varieties will "fertilize"; that is, that he has sufficient pollen-bearing kinds to insure a crop.

With the highest culture, good results can be obtained from the hill system of growing strawberries. For this the plants may be set in rows 3 feet apart and 1 foot in the row, or if it be worked both ways, they may be from 2 to $2 \frac{1}{2}$ feet each way. In the small garden, where a horse cannot be used, the plants are frequently

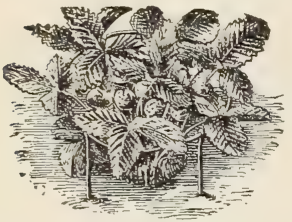

288. Strawberry plant supported by a wire rack. set 1 foot each way, arranging them in beds of three to five rows, with walks 2 feet wide between them. As fast as runners form, they should be removed, so that the entire vigor of the plant will be exerted in strengthening the crown. When extra fine specimen berries are desired, the plant may be held above the ground by a wire frame, as shown in Fig. 288.

Or strawberries may be grown by the narrow matted-row system, in which the runners, before rooting, should be turned along the rows at a distance of 4 to 6 inches from the parent plant. These runners should be the first ones made by the plant and should not be allowed to root themselves, but "set in." This is not a difficult operation; and if the runners are separated from the parent plant as soon as they become well established, the drain on that plant is not great. All other runners should be cut off as they start. The row should be about 12 inches wide at fruiting time (Fig. 289). Each plant should have sufficient feeding ground, full sunlight, and a firm hold in the soil. This matted-row system is perhaps as good a method, either in a private garden or field culture, as could be practiced. With a little care in hoeing, weeding, and cutting off runners, the beds seem to produce as large crops the second year as the first. 
The old way of growing a crop was to set the plants 10 to 12 inches apart, in rows 3 feet apart, and allow them to run and root at will, the results being a mass of small, crowded plants, each striving to obtain plant-food and none of them succeeding in getting enough. The last, or outside runners, having but the tips of their roots in the ground, are moved by the wind, heaved by the frost, or have the exposed roots dried out by the wind and sun.

Ground rich in potash produces the firmest and best flavored berries. Excessive use of stable manure, usually rich in nitrogen, should be avoided, as tending to make too rank growth of foliage and berries of a soft texture.

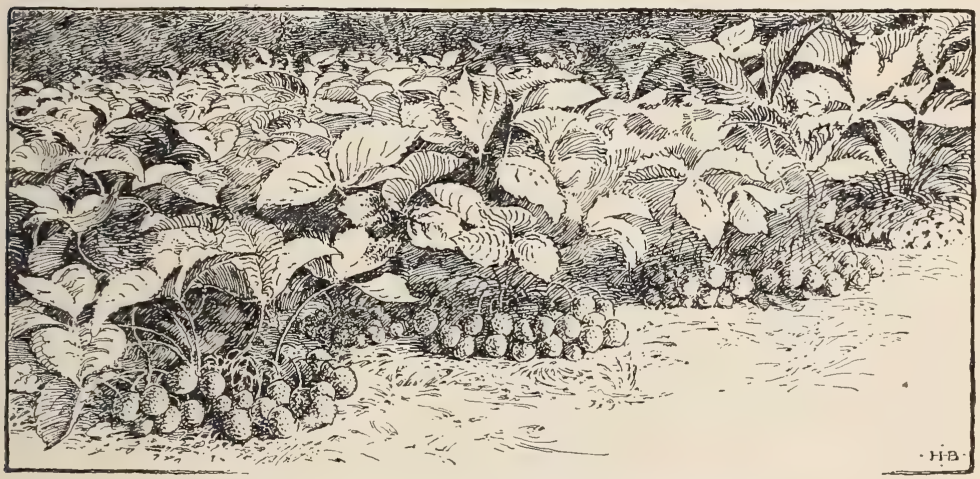

289. A narrow matted row of strawberries.

For most purposes, strawberries should be set as early in the spring as the ground can be worked. The planting can be done with a trowel, spade, or dibble, taking care to spread the roots out as much as possible and to press the soil firmly about them, holding the plant so that the bud will be just above the surface. If the season is late and the weather is hot and dry, some or all of the older leaves should be removed. If water is used, it should be poured about the roots before the hole is filled and as soon as it has soaked away the remaining soil should be packed about the plants. During the first season the blossom stalks should be removed as soon as they appear, and the runners should be restricted to a space about 1 foot wide. Some persons prefer still 
further to reduce the number of plants, and after layering from three to four plants between those originally set, to remove all others.

Strawberries are often set in August or September, but this is advisable only for small patches or when the soil is in the best possible condition and the highest culture is given. For garden culture, it may pay to secure potted plants (Fig. 290). These are sold by many nurserymen, and they may be obtained by plunging pots beneath the runners as soon as the fruiting season is passed. In August, the plant should fill the pot (which should be 3 -inch or 4 -inch) and the plant is ready for setting in the plantation. Such plants should bear a good crop the following spring.

During the first season strawberries should be frequently worked,

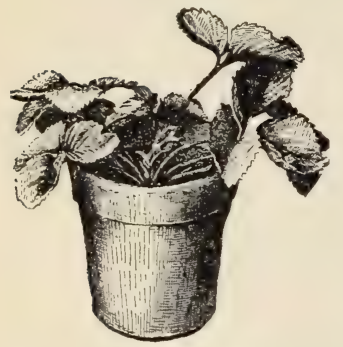

290. A potted strawberry plant. rather deep at first, but as the weather becomes warm and the roots fill the ground, tillage should be restricted to a depth of not more than 2 inches. The weeds should never be allowed to get a start, and if the season is dry, cultivation should be so frequent that the surface soil should at all times be loose and open, forming a dust mulch to conserve the moisture. If the fall is moist and the plantation free from weeds, there will be little occasion for cultivation after the first of September, until just before the ground freezes up, when a thorough cultivation should be given. In addition to the horse cultivation, the hoe should be used whenever necessary to loosen the soil about the plants and to destroy weeds that may start in the row.

After the ground has frozen, it will be advisable to mulch the plants by covering the space between the rows with some waste material to the depth of about 2 inches. Directly over the plants a covering of 1 inch will generålly suffice. The material used should be free from the seeds of grass and weeds, and should be such as will remain upon the beds without blowing off and that will not pack down too closely upon the plants. Marsh hay makes an ideal mulch, but where it cannot be secured, straw will answer. Corn fodder makes a clean but rather coarse mulch, and where they can be held in place by some other 
material, forest leaves do well as a mulch between the rows. In the spring the straw should be removed from over the plants and allowed to remain between the rows as a mulch, or all of it may be removed and the soil worked with a cultivator.

A large crop should be produced the second season; many persons think it best to renew the plantation each year, but if the plants are healthy and the ground free from grass and weeds, the plantation can often be retained for a second crop. It will be well to plow the soil away from the rows so as to leave but a narrow strip, and along this the old plants should be cut out so as to leave the new plants about 1 foot apart. If this is done in July, the rows should fill up by winter, so as to be in about the same condition as a new bed.

\section{Insects and diseases of the strawberry.}

The insect most commonly troublesome to the strawberry grower is the common June-bug, or May-beetle, the larvæ of which are often very common in land that has been in sod. Two years should elapse before sod land is used for this crop.

Cut-worms are often troublesome, but plowing the land the fall previous to setting the plants will destroy many of them. They can be poisoned by sprinkling about the field clover or other green plants that have been soaked in Paris green water (p. 203).

The most common fungous disease of the strawberry is leaf-blight or " rust," which frequently causes much injury to the foliage, and may result in the loss of the crop. Varieties least subject to the disease should be chosen for planting, and on suitable soils and well cared for, there need be little loss from this disease if the plantation is frequently renewed. The rust and mildew may be held in check by bordeaux mixture. It is usually sufficient to spray after the blooming season (or at any time the first year the plants are set), in order to secure healthy foliage for the next year (p. 213).

\section{Varieties of strawberries.}

For most parts of the country, Haverland, Warfield, Bubach, and Gandy afford a succession and are all hardy and productive varieties. The first three are imperfect-flowered varieties, and some such perfect- 
flowering kinds as Lowett or Bederwood should be provided to fertilize them. Among other varieties that do well in most sections are Brandywine, Greenville, Clyde, and Woolverton. Parker Earle is very late, and is valuable for either home use or market, upon strong, moist soils, where it can have the best of care. Belt (William Belt) and Marshall have large, showy fruits, and do well on strong soil.

Excelsior or Michel might be added as very early; Aroma is grown very extensively in some sections; also Tennessee (Tennessee Prolific) is a very promising new sort from Tennessee. 


\section{CHAPTER X}

THE GROWING OF THE VEGETABLE PLANTS

A Vegetable garden is admittedly a part of any home place that has a good rear area. A purchased vegetable is never the same as one taken from a man's own soil and representing his own effort and solicitude.

It is essential to any satisfaction in vegetable-growing that the soil be rich and thoroughly subdued and fined. The plantation should also be so arranged that the tilling can be done with

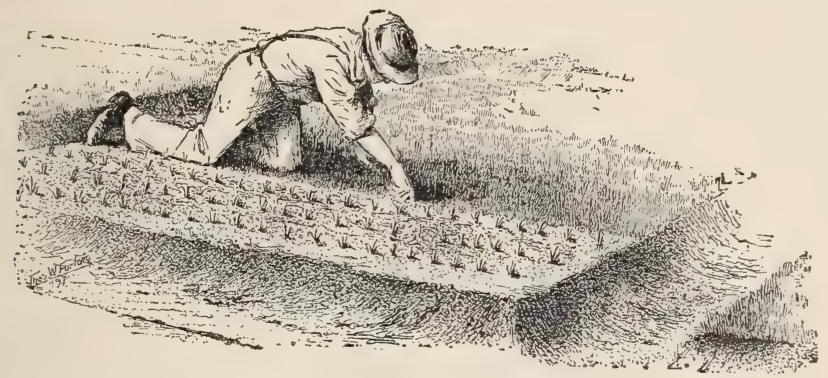

291. Cultivating the backache.

wheel tools, and, where the space will allow it, with horse tools. The old-time garden bed (Fig. 291) consumes time and labor, wastes moisture, and is more trouble and expense than it is worth.

The rows of vegetables should be as long and continuous as possible, to allow of tillage with wheel tools. If it is not desired to grow a full row of any one vegetable, the line may be made up of several species, one following the other, care being taken to place together such kinds as have similar requirements; one long row, for example, might contain all the parsnips, carrots, and salsify. One or two long rows containing a dozen kinds of 
vegetables are usually preferable to a dozen short rows, each with one kind of vegetable.

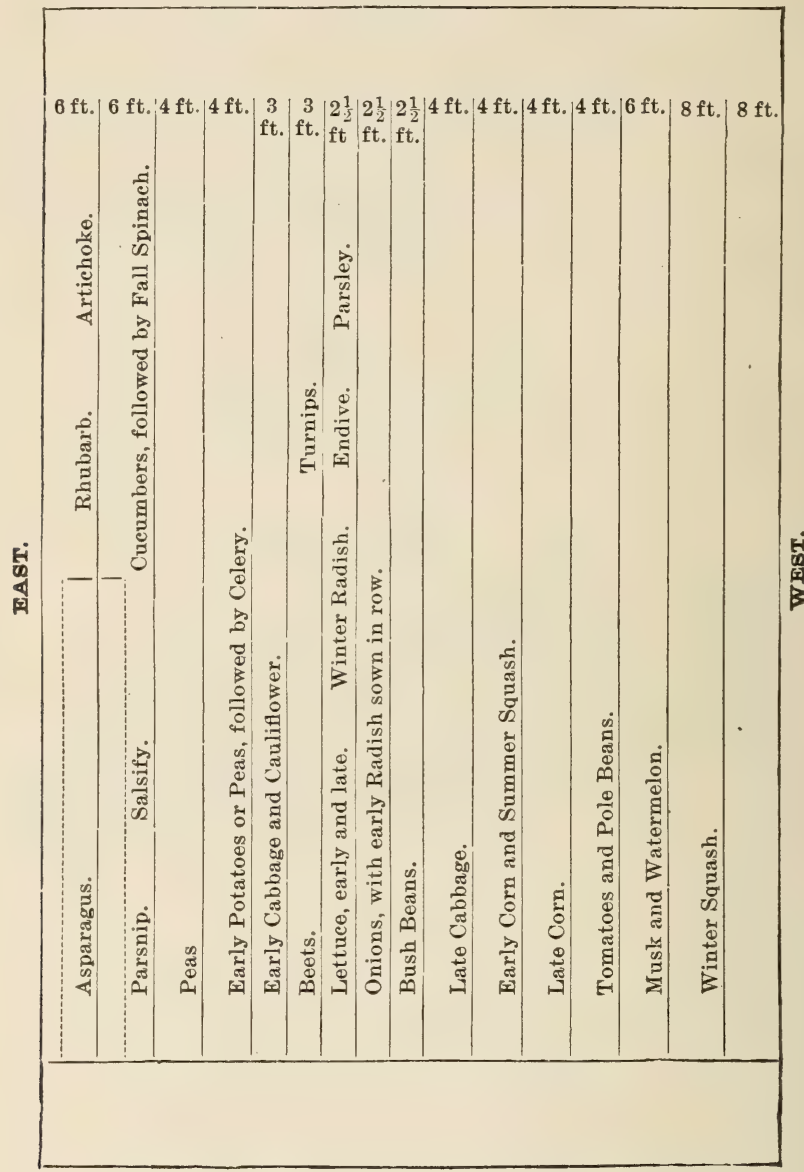

292. Tracy's plan for a kitchen-garden.

It is well to place the permanent vegetables, as rhubarb and asparagus, at one side, where they will not interfere with the 
plowing or tilling. The annual vegetables should be grown on different parts of the area in succeeding years, thus practicing something like a rotation of crops. If radish or cabbage maggots or club-root become thoroughly established in the plantation, omit for a year or more the vegetables on which they live.

A suggestive arrangement for a kitchengarden is given in Fig. 292. In Fig. 293 is a plan of a fenced garden, in which gates are provided at the ends to allow the turning of a horse and cultivator (Webb Donnell, in American Gardening). Figure 294 shows a garden with continuous rows, but with two breaks running across the area, dividing the plantation into blocks. The area is surrounded with a windbreak, and the frames and permanent plants are at one side.
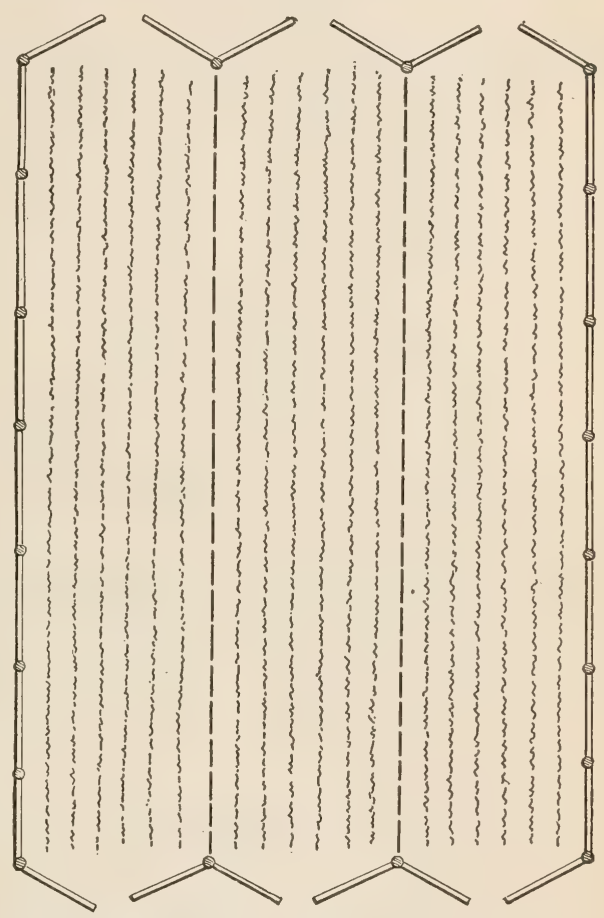

It is by no means necessary that the vegetable-garden contain only kitchen-garden products. Flowers may be dropped in here and there wherever a vacant corner occurs or a plant dies. Such informal and mixed gardens usually have a personal character that adds greatly to their interest, and, therefore, to their value. One is generally impressed with 
this informal character of the home-gardens in many European countries, a type of planting that arises from the necessity of making the most of every inch of land. It was the writer's pleasure to look over the fence of a Bavarian peasant's garden and to see, on a space about 40 feet by 100 feet in area, a

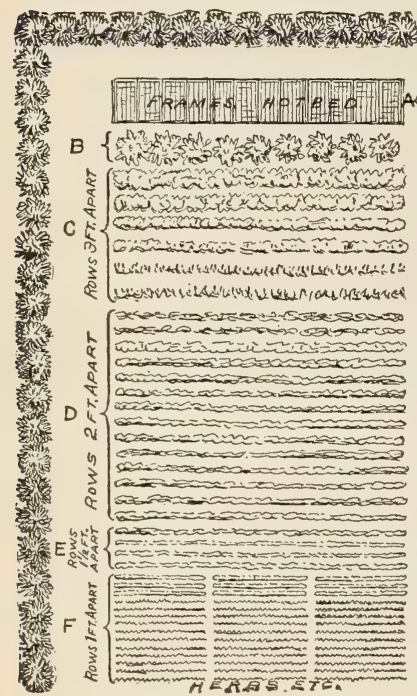

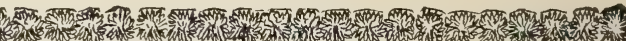 NORTH}
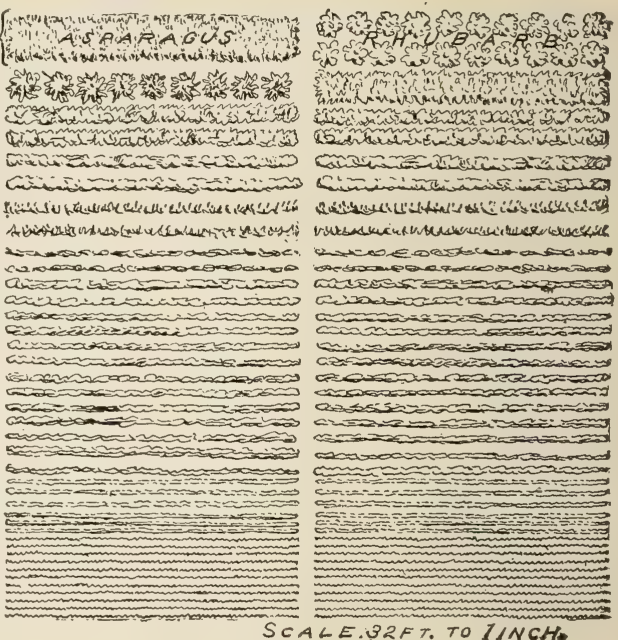

294. A family kitchen-garden.

delightful medley of onions, pole beans, peonies, celery, balsams, gooseberries, coleus, cabbages, sunflowers, beets, poppies, cucumbers, morning-glories, kohl-rabi, verbenas, bush beans, pinks, stocks, currants, wormwood, parsley, carrots, kale, perennial phlox, nasturtiums, feverfew, lettuce, lilies !

\section{Vegetables for six (by C. E. Hunn).}

A home vegetable-garden for a family of six would require, exclusive of potatoes, a space not over 100 by 150 feet. Beginning at one side of the garden and running the rows the 
short way (having each row 100 feet long) sowings may be made, as soon as the ground is in condition to work, of the following:

Fifty feet each of parsnips and salsify.

One hundred feet of onions, 25 feet of which may be potato or set onions, the remainder black-seed for summer and fall use.

Fifty feet of early beets ; 50 feet of lettuce, with which radish may be sown to break the soil and be harvested before the lettuce needs the room.

One hundred feet of early cabbage, the plants for which should be from a frame or purchased. Set the plants 18 inches to 2 feet apart.

One hundred feet of early cauiiflower; culture same as for cabbage.

Four hundred and fifty feet of peas, sown as follows :-

100 feet of extra early.

100 feet of intermediate.

100 feet of late.
100 feet of extra early, sown late.

50 feet of dwarf varieties.

If trellis or brush is not to be used, frequent sowings of the dwarfs will maintain a supply.

After the soil has become warm and all danger of frost has passed, the tender vegetables be planted as follows:

Corn in five rows 3 feet apart, three rows to be early and intermediate and two rows late.

One hundred feet of string beans, early to late varieties.

Vines as follows :-

10 hills of cucumbers, $6 \times 6$ feet. 20 hills of muskmelon, $6 \times 6$ feet.
6 hills of early squash, $6 \times 6$ feet. 10 hills of Hubbard, $6 \times 6$ feet.

One hundred feet of okra.

Twenty eggplants. One hundred feet (25 plants) tomatoes.

Six large clumps of rhubarb.

An asparagus bed 25 feet long and 3 feet wide.

Late cabbage, cauliflower, and celery are to occupy the space made vacant by removing early crops of early and intermediate peas and string beans.

A border on one side or end will hold all herbs, such as parsley, thyme, sage, hyssop, mints. 


\section{The classes of vegetables.}

Before attempting to grow particular vegetables, it will help the beginner to an understanding of the subject if he recognizes certain cultural groups or classes, and what their main requirements are.

\section{Root-crops - Beet, carrot, parsnip, salsify.}

The root-crops are cool-weather plants; that is, they may be sown very early, even before light frosts disappear; and the winter kinds grow very late in the fall, or may be left in the ground till most other crops are harvested. They are not often transplanted.

Loose and deep soil, free from clods, is required to grow straight and well-developed roots. The land must also be perfectly drained, not only to remove superfluous moisture, but to provide a deep and friable soil. Subsoiling is useful in hard lands. A large admixture of sand is generally desirable, provided the soil is not likely to overheat in sunny weather.

To keep roots fresh in the cellar, pack them in barrels, boxes, or bins of sand which is just naturally moist, allowing each root to come wholly or partly in contact with the sand. The best material in which to pack them is sphagnum moss, the same that nurserymen use in packing trees for shipment, and which may be obtained in bogs in many parts of the country. In either sand or sphagnum, the roots will not shrivel; but if the cellar is warm, they may start to grow. Roots can also be buried, after the manner of potatoes. Page 158.

Alliaceous group - Onion, leek, garlic.

A group of very hardy cool-weather plants, demanding unusually careful preparation of the surface soil to receive the seeds and to set the young plants going. They withstand frost and cool weather, and may be sown very early. Seeds are 
sown directly where the plants are to stand. For early onions, however, the special practice has recently arisen of transplanting from seedbeds.

\section{Brassicaceous group - Cabbage, kale, cauliflower.}

These are cool-weather crops, all of them withstanding considerable frost. The cabbages and kales are often started in fall in the middle and southern latitudes, and are harvested before hot weather arrives.

In the northern states, these plants will all do best when started early in hotbed, frame, or greenhouse, - from the last of February to April - and transplanted to the open ground May first to June first, partly because their season of growth may be long and partly to enable them to escape the heat of midsummer. Still, some persons are successful in growing late cabbage, kale, and cauliflower, by sowing the seeds in hills and in the open ground where the plants are to mature. It is best to transplant the young plantlets twice, first from the seed-bed to boxes, or frames, about the time the second set of true leaves appears, placing the plants 24 inches apart each way, and transplanting again to the open ground in rows 4 to 5 feet apart, with plants 2 to 4 feet apart in the row. If the plants are started under cover, they should be hardened off by exposure to light and air during the warmer hours of several days preceding the final transplanting.

The most serious enemy of cabbage-like plants is the rootmaggot. See discussion of this insect on pp. 187, 201.

The cabbage-worm (larva of the white butterfly shown in

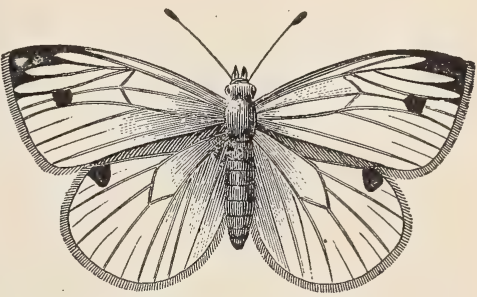

295. The white butterfly that lays the eggs for the cabbage-worm.

Fig. 295) can be dispatched with pyrethrum or kerosene 
emulsion. It must be treated very early, before the worm gets far into the head (p. 200).

The club-root or stump-root is a fungous disease for which there is no good remedy. Use new land if the disease is present (p.208).

\section{Solanaceous group - Tomato, egg-plant, red pepper.}

These are warm-weather plants, very impatient of frost. They are all natives of southern zones, and have not yet become so far acclimatized in the North as not to need the benefit of our longest seasons.

Plants should be started early, under glass. They should be "pricked off," when the second leaves appear, 3 or 4 inches apart, into flats or boxes. These boxes should be kept in a coldframe, to which an abundance of light and air is admitted on warm, sunny days, in order to harden them off. After all danger of frost is past, and the garden soil is well warmed, the plants may be finally transplanted.

If the ground is too rich, these plants are likely to grow too late in the northern seasons.

Cucurbitaceous group - Cucumber, melon, squash, pumpkin.

All the members of this group are very tender to frost, and they must not be planted till the season is thoroughly open and settled. The plants are not transplanted, unless they are transferred from boxes or pots.

Seeds must be planted somewhat shallow from early spring to midsummer. For the earliest cucumbers and melons, seeds are planted in frames. That is, each hill is inclosed by a portable box frame about 3 feet square and usually having a movable sash cover. The cover is raised or removed in warm days, and the frame bodily taken away when all danger of frost is past. In field culture, seeds are planted an inch deep, four to six in a hill, with hills 4 by 6 feet apart, these distances 
being varied slightly, according to location and variety. Good cucumbers are sometimes grown in hills surrounding a barrel in which manure is placed to be leached out by successive waterings.

The omnipresent enemies of all the cucurbitaceous crops are the little cucumber beetle and the large black "stink bug." Ashes, lime, or tobacco dust occasionally seem to show some efficiency in preventing the ravages of these insects, but the only reasonably sure immunity is in the use of covers over the hills (Fig. 229) and in hand-picking (p. 202). Covers may also be made by stretching mosquito netting over arcs of barrel hoops or bent wires. If by some such means the plants are kept insect-free till they outgrow the protection, they will usually escape serious damage from insects thereafter. It is well to plant trap or decoy hills of cucumbers, squashes, or melons in advance of the regular planting, on which the bugs may be harvested.

Leguminous crops - Peas and beans.

Two cultural groups are included in the legumes, - the bean group (including all field, garden, and kidney beans, and the cowpea) comprising warm-weather plants; the pea group (including field and garden pea, the Windsor or Broad bean) comprising cool-weather plants. The former are quickly susceptible to frost and should be planted only after the weather is settled. The latter are among the earliest vegetables to be planted. The leguminous crops are not transplanted, the seed being placed where the plants are to grow.

Salad plants and pot-herbs ("greens").

These plants are all grown for their tender, fresh, succulent leaves, and therefore every reasonable effort should be made to secure quick and continuous foliage growth. It is manifestly expedient that they be grown in warm, mellow ground, well cultivated and copiously watered. Such small plants as cress, 
corn salad, and parsley may be grown in small beds, or even in boxes or pots; but in a garden where space is not too scant, they may. be more conveniently managed in rows, like peas or beets. Nearly all the salad plants may be sown in the spring, and from time to time throughout the summer for succession. The group is culturally not homogeneous, inasmuch as some of the plants need special treatment; but most of them are cool-weather subjects.

\section{Sweet-herbs.}

The herb garden should find a place on all amateurs' grounds. Sweet-herbs may sometimes be made profitable by disposing of the surplus to the green grocer and the druggist. The latter will often buy all that the housewife wishes to dispose of, as the general supply of medicinal herbs is grown by specialists, and goes into the hands of the wholesaler and is often old when received by the local dealer.

The seedsmen's catalogues mention upwards of forty different herbs, medicinal and culinary. The majority of them are perennial, and will grow for many years if well taken care of. However, it is better to resow them every three or four years. Beds 4 feet square of each of the herbs will supply an ordinary family.

The perennial sweet-herbs may be propagated by division, although they are usually grown from seeds. The second year - and sometimes even the first year - the plants are strong enough for cutting. The common perennial sweet-herbs are: Sage, lavender, peppermint, spearmint, hyssop, thyme, marjoram, balm, catnip, rosemary, horehound, fennel, lovage, winter savory, tansy, wormwood, costmary.

The commoner annual species (or those that are treated as annuals) are: Anise, sweet basil, summer savory, coriander, pennyroyal, caraway (biennial), clary (biennial), dill (biennial), sweet marjoram (biennial). 
The culture of the leading vegetables.

Having now obtained a view of the layout of the vegetablegarden and a good conception of the leading cultural groups, we may proceed with a discussion of the different kinds of vegetables themselves. Good experience is better than book advice; but the person who consults a book is the one who lacks experience. Any printed directions are necessarily imperfect, and they may not be adaptable to the particular conditions under which the amateur works; but they ought to set him in the right direction so that he may more easily find his way. Seedsmen's catalogues often contain much useful and reliable advice of this kind.

Asparagus. - The best of all early spring vegetables; a hardy herbaceous perennial, grown for the soft edible shoots that spring from the crown.

The culture of asparagus has been simplified in the past few years, and at present the knowledge required successfully to plant and grow a good supply need not be that of a professional. The old method of excavating to the depth of 3 feet or more, throwing in from 4 to 6 inches of broken stone or bricks for drainage, then filling to within 16 to 18 inches of the surface with well-rotted manure, with 6 inches of soil upon which to set the roots, has given place to the simple practice of plowing or digging a trench from 14 to 16 inches deep, spreading well-rotted manure in the bottom to the depth of 3 or 4 inches; when well trodden down covering the manure with 3 or 4 inches of good garden soil, then setting the plants, with the roots well spread out, covering carefully with soil to the level of the garden, and firming the soil with the feet. This will leave the crowns of the plants from 4 to 5 inches below the surface.

In stubborn, heavy soil the best method to pursue in making a permanent bed is to throw out all the dirt from the trench and replace with good, fibrous loam.

In setting, 1-year-old plants will prove more satisfactory than older ones, being less liable to suffer from injury to the root system than those that have made a larger growth. Two years after setting the 
crop may be cut somewhat, but not sooner if a lasting bed is desired, as the effort to replace the stalks has a tendency to weaken the plant

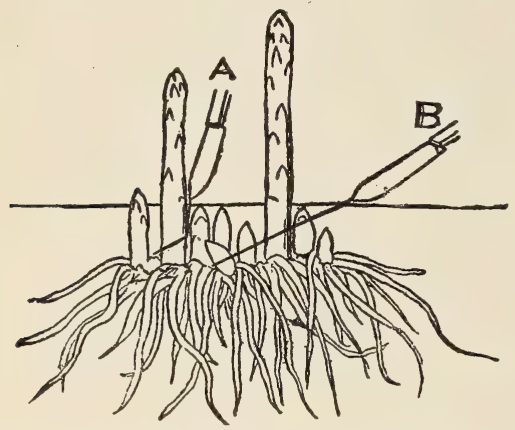

296. Good $(A)$ and poor $(B)$ modes of inserting the knife to cut asparagus. Some careful growers pull or break the shoots rather than cut them. unless the roots are well established. The cutting should cease in June or early July, or the roots may be much weakened. In cutting, care should be taken to insert the knife vertically, so that adjoining crowns will not be injured (Fig. 296).

The yearly treatment of an asparagus bed consists of cleaning off tops and weeds in the fall and adding a dressing of well-rotted manure to the depth of 3 or 4 inches, this manure to be lightly forked into the bed the following spring; or the tops may be allowed to stand for winter protection and the mulch left off. A top-dressing of nitrate of soda, at the rate of 200 pounds per acre, is often beneficial as a spring stimulant, particularly in the case of an old bed. Good results will also follow an application of bone meal or superphosphate at the rate of some 300 to 500 pounds per acre. The practice of sowing salt on an asparagus bed is almost universal; yet beds that have never received a pound of salt are found to be as productive as those having received an annual dressing. Nevertheless, a salt dressing is recommended. Two rows of asparagus 25 feet long and 3 feet apart should supply a large family with an abundance throughout the season, and if well taken care of, will last a number of years.

Conover Colossal is the variety most generally grown, and is perhaps the most satisfactory sort. Palmetto, a variety originating at the South, is also very popular.

Artichoke. - The artichoke of literature is a tall, coarse perennial of the thistle tribe, producing edible flower-heads. Cardoon is a related plant. 
The fleshy scales of the head and the soft "bottom" of the head are the parts used. The young suckers or shoots may also be tied together and blanched, using them like asparagus or Swiss chard. But few of these plants would be needed for a family, as they produce a number of flower-heads to a plant and a quantity of suckers. The plants should be set from 2 to 3 feet apart in the row, the rows being 3 feet apart. This regetable is not quite hardy in the North, but a corering of leaves or barnyard litter to the depth of a foot will protect it well. The plant is perennial, but the best yield comes from young plants. If the heads are allowed to ripen, they reduce the vitality of the plant. Artichokes have never become so popular in this country as to have produced a long list of varieties. Large Green Globe is most commonly offered by seedsmen. Edible heads should be secured the second year from seed. Seedlings are likely to vary greatly, and if one is fond of artichokes, he would do better to propagate by suckers from the best plants.

These plants make no mean decorative subjects, either massed or in a mixed border, and from the rarity of their culture are always objects of interest.

Artichoke, Jerusalem, is a wholly different plant from the above, although it is commonly known as "artichoke" in this country. It is a species of sunflower that produces potato-like tubers. These tubers may be used in lieu of potatoes. They are very palatable to hogs; and when the plant becomes a weed, - as it often does, - it may be exterminated by turning the hogs into the field. Hardy, and will grow anywhere.

Bean. - Every garden grows beans of one kind or another. Under this general name, many kinds of plants are cultivated. They are all tender, and the seeds, therefore, should not be planted until the weather is thoroughly settled; and the soil should be warm and loose. They are all annuals in northern countries, or treated as such.

The bean plants may be classified in various ways. In respect to stature, they may be thrown into three general categories; viz. the pole or climbing beans, the bush beans, and the strict-growing or upright beans (as the Broad or Windsor bean). 
In respect to their uses, beans again may be divided into three categories; viz. those used as string or snap beans, the entire pod being eaten; those that are used as shell beans, the full-size but immature beans being shelled from the pod and cooked; dry beans, or those eaten in their dry or winter condition. The same variety of bean may be used for all of these three purposes at different stages of its development; but as a matter of fact, there are varieties better for one purpose than the other.

Again, beans may be classified in respect to their species. Those species that are best known are as follows: (1) Common bean, or Phaseolus vulgaris, of which there are both tall and bush forms. All the common snap and string beans belong here, as also the Speckled Cranberry types of pole beans, and the common field beans. (2) The Lima beans, or Phaseolus lunatus. The larger part of these are pole beans, but lately dwarf or bush varieties have appeared. (3) The Scarlet Runner, Phaseolus multiflorus, of which the Scarlet Runner and White Dutch Runner are familiar examples. The. Scarlet Runner is usually grown as an ornamental vine, and it is perennial in warm countries, but the seeds are edible as shelled beans. The White Dutch Runner is oftener cultivated for food. (4) The Yard-Long, or Asparagus bean, Dolichos sesquipedalis, which produces long and weak vines and very long, slender pods. The green pods are eaten, and also the shelled beans. The French Yard-Long is the only variety of this type that is commonly known in this country. This type of bean is popular in the Orient. (5) The Broad beans, of which the Windsor is the common type. These are much grown in the Old World for stock feed, and they are sometimes used for human food. They grow to one strict, central, stiff stalk, to a height of 2 to 4 or 5 feet, and they are very unlike other kinds of beans in appearance. In this country, they are very little grown on account of our hot and dry summers. In Canada they are somewhat raised, and are sometimes used in the making of silage. (6) The cowpea, which is really a bean (species of Vigna), much grown in the South for hay and green-manuring, is also a very good table vegetable and one that is destined to increase in popularity for domestic use.

The culture of the bean, while of the easiest, often proves a failure as far as the first crop is concerned, from planting the seed before the 
ground has become warm and ciry. No vegetable seed will decay quicker than beans, and the delay caused by waiting for the soil to become warm and free from excessive moisture will be more than made up by the rapidity of growth when finally they are planted. Beans will grow on most any land, but the best results may be secured by having the soil well enriched and in good physical condition.

From the 5th to the 10th of May in the latitude of central New York, it will be safe to plant beans for an early crop. The beans may be dropped 2 inches deep in shallow drills, the seeds to lie 3 inches apart. Cover to the surface of the soil, and if the ground be dry, firm it with the foot or the back of the hoe. For the bush varieties, allow 2 feet between the drill-rows, but for the dwarf Limas $2 \frac{1}{2}$ feet is better. Pole Limas are usually planted in hills 2 to 3 feet apart in the rows. Dwarf Limas may be sown thinly in drills.

A large number of the varieties of both the green-podded and the wax-podded beans are used almost exclusively as snap beans, to be eaten with the pod while tender. The various strains of the Black Wax are the most popular string beans. The pole or running beans are used either green or dried, and the Limas, both tall and dwarf, are well known for their superior flavor either as shelled or dry beans. The old-fashioned Cranberry or Horticultural Lima type (a pole form of Phaseolus vulgaris) is probably the best shell bean, but the trouble of poling makes it unpopular. Dwarf Limas are much more desirable for small gardens than the pole varieties, as they may be planted much closer, the bother of procuring poles or twine is avoided, and the garden will have a more sightly appearance. Both the dwarf Limas and pole Limas require a longer season in which to mature than the bush beans, and only one planting is usually made.

The ordinary bush beans may be planted at intervals of two weeks from the first planting until the 10th of August. Each planting may be made on ground previously occupied by some early-maturing crop. Thus, the first to third plantings may be on ground from which has been harvested a crop of spinach, early radish, or lettuce; after that, on ground where early peas have been grown; and the later sowings where beets or early potatoes have grown. String beans for canning are usually taken from the last crop. 
One quart of seed will plant 100 feet of drill of the bush beans; or 1 quart of Limas will plant 100 hills.

Limas are the richest of beans, but they often fail to mature in the northern states. The land should not be very strong in nitrogen (or stable manure), else the plants will run too much to vine and be too late. Choose a fertile sandy or gravelly soil with warm exposure, use some soluble commercial fertilizer to start them off, and give them the best of culture. Aim to have the pods set before the droughts of midsummer come. Good trellises for beans are made by wool twine stretched between two horizontal wires, one of which is drawn a foot above the ground and the other 6 or 7 feet high.

Bean plants are not troubled by insects to any extent, but they are sometimes attacked by blight. When this occurs, do not plant the same ground to beans again for a year or two.

Beet. - This vegetable is grown for its thick root, and for its

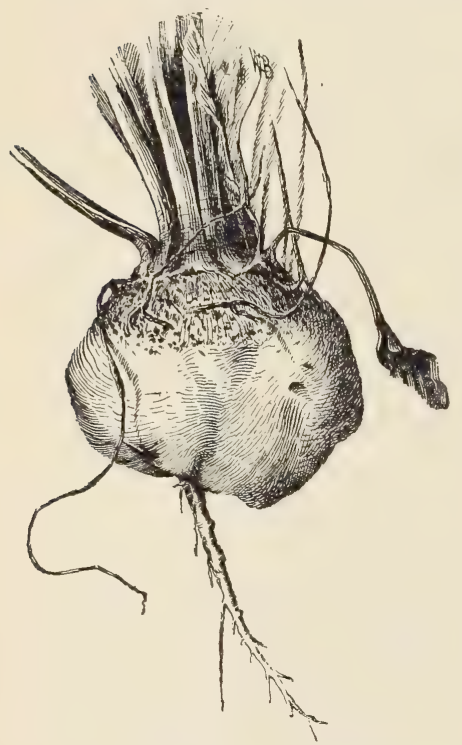

297. Bastian turnip beet. herbage (used as "greens"); and ornamental-leaved varieties are sometimes planted in flower-gardens.

Being one of the hardiest of spring vegetables, the seed may be sown as early in the spring as the ground can be worked. A light, sandy soil is the best on which to grow beets to perfection, but any well-tilled garden land will raise satisfactory crops. On heavy ground the turnip beet gives the best results, as the growth is nearly all at or above the surface. The long varieties, having tapering roots running deep into the soil, are liable to be misshapen unless the physical condition of the soil is such that the roots meet with little obstruction. A succession of sowings should be made, at intervals of two to three weeks, until late summer, as 
the beets are much more desirable in their young stage than when they have become old and woody. The mangel-wurzel and the sugarbeet are usually grown as a field crop, and will not enter into the calculations of the home garden.

In order to hasten the seasun of the extra-early crop of beets, the seeds may be sown in boxes or in the soil of a hotbed in February or March, transplanting the small plants to the open ground at the time the first sowing of seed is made. As the flat or turnip-rooted varieties grow at the surface of the ground, the seed may be sown thickly, and as the more adranced roots are large enough to use they may be pulled, learing room for the later ones to develop, thus growing a large quantity in a small area and having a long season of small beets from one sowing.

For winter use the late July-sown seed will give the best roots, growing through the cool months of the fall to a medium size and remaining firm without being tough or stringy. These may bə dug after light frosts and before any severe cold weather, and stored in barrels or boxes in the cellar, using enough dry dirt to fill spaces between the roots and cover them to the depth of 6 inches. These roots, thus packed in a cool cellar, will be fit to use through the entire winter months. When it can be had, florists' or sphagnum moss is an excellent medium in which to pack roots for winter.

The early round or turnip varieties (Fig. 297) are best for early and summer use. The long blood beets may be used for storing, but these require a longer season of growth.

Broccoli is almost identical with the cauliflower, except that it usually requires a longer season and matures in the fall. It is grown more generally in Europe than in this country. The special merit of broccoli is its adaptability for late summer planting and its rapid growth in the late season. It is said that a large proportion of broccoli is used in the manufacture of pickles. The culture is the same as for cauliflower, - deep, moist soil well enriched, cool weather, and the destruction of the cabbage worm.

Brussels sprouts. - The plant is grown for the buttons or sprouts (miniature cabbage heads) that grow thickly along the stem (Fig. 298). 
It should be more generally known, as it is one of the choicest of

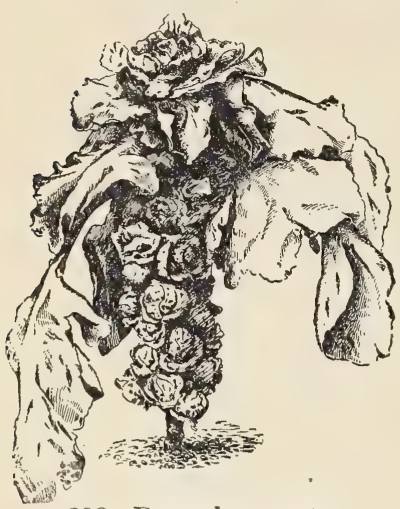

298. Brussels sprouts. the cabbage family, and may be had. at its best after the season for cauliflower has passed. It is the better for being touched by the fall frosts. The buttons should be cut off rather than broken. The very small hard "sprouts" or buttons are the best. The culture is essentially the same as for late cabbage or broccoli. One ounce will sow 100 feet of drill, or make upward of 2000 plants. Set plants in field 2 to 3 feet apart, or dwarf varieties closer. They require the entire season in which to grow.

Cabbage. - The cabbage is now so extensively grown as a field crop, from which the market is supplied, and the plants require so much room that many home-gardeners incline to give up its culture; but the early varieties, at least, should be grown at home.

For an early crop in the North, the plants must be started either in February or early March, or the previous September and wintered over in coldframes. This latter method was once a common practice by gardeners near large cities, but the building of greenhouses to replace the many hotbeds of the market-gardener has changed the practice in many localities, and now most of the early cabbages in the North are grown from seed sown in January, February, or March. The plants are hardened off in March and early April and planted out as early as possible. The private grower, or one with a small garden, may often procure his early plants from the market-gardener much cheaper than he can grow them, as usually only a limited number of early cabbage plants are wanted; but for the midseason and main crop, the seed may be sown in May or June in a seed-bed, setting the plants in July.

The seed-bed should be made mellow and rich. A good border will do. The seed is sown preferably in rows, thus allowing thinning of the plants and the pulling of any weeds that germinate. The young plants 
will well repay attention to watering and thinning. The rows should ba 3 or 4 inches apart. When the plants are large enough to transplant, they may be planted where early vegetables have bəən grown. Set the plants from 18 to 24 inches apart in the row, the rows being 3 feet apart for thə medium-growing kinds. One ounce of seed will furnish about 2000 plants.

All cabbages require deep and rich soil, and one that holds moisture well. Regular cultivation should ba given so that moisture may be saved and the growth be continuous.

For early planting, the number of varieties is limited to three or four. For an intermediate crop the list is more extended, and the late varieties are very numerous. The early list is headed by the Jersey Wakefield, a variety that heads very quickly, and, although not one of the solid kinds, is ganerally grown. The Early York and Winnigstadt are good varieties to follow it. The latter especially is solid and of very good quality. For the midseason, the Succession and All Season are of the best, and for the winter supply the Drumhead, Danish Ball, and Flat Dutch types are leaders. One of the best of the cabbages for table use is seldom seen in the garden - the Savoy cabbage. It is a type with netted leaves, making a large, low-growing head, the center of which is very solid and of excellent flavor, especially late in the fall, when the heads have had a slight touch of frost. Savoy should be grown in every private garden.

The best remedy for the cabbage worm is to kill the first brood on the very young plants with Paris green. After the plants begin to head, pyrethrum, kerosene emulsion, or salt water may be used. On a small area, hand-picking may be recommended (p. 200).

The maggot is the most serious cabbage pest. After studying the seventy odd remedies proposed, Slingerland concludes that six are efficient and practicable: growing the young plants in closely covered frames; tarred paper cards placed snugly about the base of the plants to keep the fly away; rubbing the eggs from the base of the plant; hand-picking of the maggots; treating the plants with emulsion of carbolic acid; treating them with carbon bisulfide. The insecticidal materials are injected or poured into the soil about the base of the plant (pp. 187, 201).

The club-root, which causes the roots to become greatly thickened 
and distorted, is difficult to manage if cabbages or allied plants are grown continuously on land in which diseased plants have been raised. Changing the location of the cabbage or cauliflower patch is the best procedure. If very different crops, as corn, potatoes, peas, tomatoes, are grown on the land, the disease will be starved out in two or three years (p. 208).

There are many ways of storing cabbages for winter and spring use, none of which are uniformly successful. The general subject is dis-

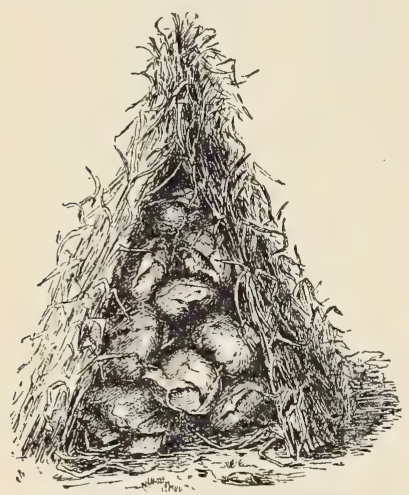

299. A method of storing cabbages. cussed on p. 158. On this point T. Greiner writes as follows: "I have heretofore piled a lot of cabbages cut from the stump in a conical heap in the field, and covered them with clusters of the outer leaves cut off with a piece of the stump. The leaves are carefully placed over the heap in shingle fashion, so as to shed water. Cabbages thus piled and covered may be left out until real winter weather sets in. But I find that slugs and earthworms frequently infest the cabbages thus stored, and do a good deal of damage. It might be well to place a solid floor of lime or salt upon the ground, and then pack the cabbages upon this. If to be left out after severe freezing has set in, one should put additional covering, such as straw, corn-stalks or marsh hay, over the whole heap." Mr. Burpee's little book, 'Cabbage and Cauliflower for Profit,' written by J. M. Lupton, a prominent cabbagegrower, suggests the following plan for early winter sales: "Take the cabbages up with the roots on, and store in well-ventilated cellars, where they will keep till mid-winter. Or stack them in some sheltered position about the barn, placing one above the other in tiers, with the roots inside, and covering deeply with seaweed; or if this cannot be obtained, something like cornstalks may be used to keep them from the weather as much as possible (Fig. 299). When thus stored, they may be obtained any time during the winter when prices are favorable. 
Carrot. - While essentially a farm crop in this country, the carrot is nevertheless a most acceptable garden vegetable. It is hardy and easily grown. The extraearly varieties may be forced in a hotbed, or seed may be sown as soon as the ground is fit to work in the spring. The stump-rooted, or half-long varieties (Fig. 300), are sown for the general garden crop.

Well-enriched, mellow loam, deeply dug or plowed, is best suited to the requirements of carrots. The seed for the main crop may be sown as late as July 1 . Sow thickly, thinning to 3 to 4 inches in the row. The rows, if in a garden that is hand-worked, may be 12 inches apart. If the cultivation is performed with a horse, the rows should be from 2 to 3 feet apart. One ounce will sow 100 feet of drill.

Cauliflower. - This is the choicest of all vegetables of the cabbage group, and its culture is much the most difficult. While the special requirements are few, they must be fully met if good results are to be expected.

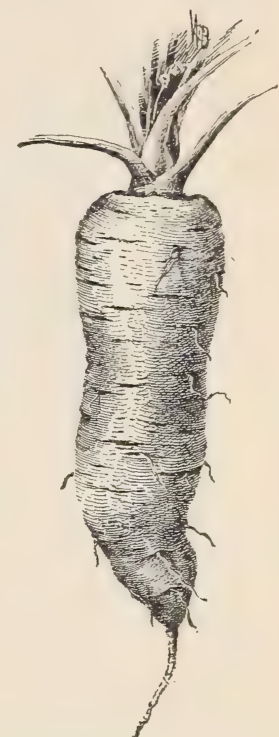

300. A half-long carrot.

The general culture of cauliflower is much like that of cabbage, except that the cauliflower, being more tender, should be more thoroughly hardened off before setting out, the heads must be protected from hot suns, the plants must never suffer for moisture, and the greatest care must be taken to secure only highly bred seeds.

It is essential that the plants be set out as carly as possible, as the warm weather of June causes them to make imperfect heads unless the soil is filled with moisture. No garden crop will so well repay the cost and time of thorough irrigation, either by running the water between the rows or applying it directly to the plants. When it is impossible to furnish water and there is danger of losing the soil moisture, it is a good plan to mulch heavily with straw or some other substance. This mulch, if put on just after a heavy rain, will hold the moisture for a long time. Cauliflower prospers best in a cool climate. 
When the heads begin to form, the outside leaves may be brought together and tied above the head, excluding the direct sunshine and

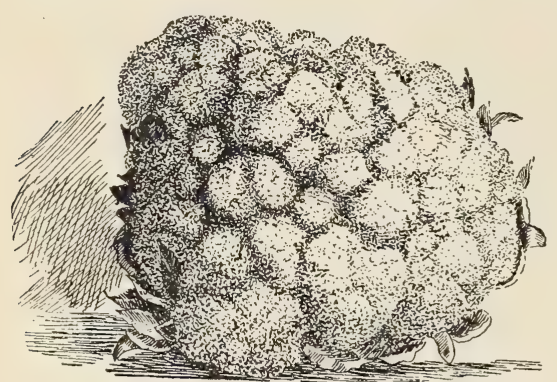

301. Cauliflower head with leaves trimmed off. keeping the head white and tender. Fig. 301 shows a good head.

No vegetable will respond more quickly to good culture and well-manured soil than the cauliflower, and none will prove such an utter failure when neglected. It is imperative that care be taken to destroy all the cabbage worms before the leaves are tied in, as after that it will be impossible to see or reach them. From 1000 to 1500 plants may be grown from 1 ounce of seed. Good cauliflower seed is very expensive.

For winter crop, seeds may be started in June or July, as for late cabbage.

Erfurt, Snowball, and Paris are popular early varieties. Nonpareil and Algiers are good late kinds.

Celeriac. - A form of the celery plant in which the tuberous root is the edible part (Fig. 302). The tuber has the celery flavor in a pronounced degree, and is used for flavoring soups and for celery salad. It may be served raw, sliced in vinegar and oil, or boiled.

The culture is the same as given for celery, except that no earthing or blanching is required. About an equal number of plants are obtained from the same weight of seed as from celery seed. Celeriac is extensively used abroad, but, unfortunately, little known in America.

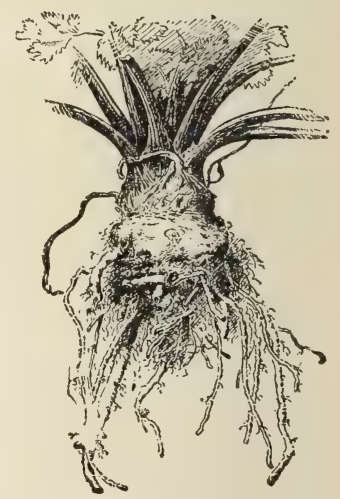

302. Celeriac or turniprooted celery.

Celery. - Although celery has now become a staple vegetable with all 
clisses of pcople, the home-gardener is likely not to attempt its culture; yet it is not difficult to raise in small quantities in most any good garden land. While the commercial celery is largely grown on reclaimed swamp lands, such areas are not at all essential to its cultivation.

The self-blanching varieties have simplified the culture of celery so that the amateur, as well as the expert, may have a good supply at least six months of the year. The so-called new culture, which consists of setting the plants close together and causing them to shade each other, can be recommended for the garden when a supply of well-rotted manure is to had, and when any amount of water is available. This method is as follows: Fork or spade into the soil a large quantity of manure to the depth of 10 to 12 inches; pulverize the soil until the ground for the depth of 4 to 6 inches is in very fine condition. Then set the plants in rows 10 inches apart and the plants but 5 or 6 inches apart in the rows. It will be seen that plants set as close as this wil! soon fill the soil with a mass of roots and must have large amoints of plant-food, as well as a large quantity of water; and the making of such a bed can be recommended only to those who can supply these needs.

The common practice in home gardens is to plow or dig a shallow trench, setting the plants in the bottom and hoeing in the soil as the plants grow. The distance apart of the rows and plants will depend on the varieties. For the dwarf varieties, such as White Plume, Golden Self-blanching, and others of this type, the rows may be as close as 3 feet and the plants 6 inches in the rows. For the large-growing varieties, as Kaiamazoo, Giant Pascal, and, in fact, most of the late varieties, the rows may be $4 \frac{1}{2}$ to 5 feet apart and the plants 7 or 8 inches in the row.

The seed for an early crop should be sown in February or early in March in shallow boxes, which may be placed in a hotbed or sunny window, or sown directly in the soil of a hotbed. Cover the seeds thinly and press the soil firmly over them. When the seedling plants are about 1 inch high, they should be transplanted to other boxes or hotbeds, setting the plants 1 inch apart in rows 3 inches apart. At this transplanting, as with the following ones, the tall leaves should be cut or pinched off, leaving only the upright growth, as with the ut- 
most care it is almost impossible to prevent the outside leafstalks from wilting down and dying. The roots should also be trimmed back at each transplanting in order to increase the feeding roots. The plants should be set as deep as possible, care being taken, however, not to allow the heart of the plant to be covered up. The varieties usually grown for an early crop are the so-called salf-blanching varieties. They may be made fit for the table with much less labor than the late crop, the shade required to blanch the stalks being much less. When only a few short rows are grown in a private garden, screens of lath may be made by driving stakes on each side of the row and tacking lath on, leaving spaces of an inch or more for the light to enter; or each head may be wrapped in paper, or a tile drain pipe may be set over the plant. In fact, any material that will exclude the light will render the stalks white and brittle.

The seed for the main or fall crop should be sown in April or early May in a seed-bed prepared by forking short well-rotted manure into a fine soil, sowing the seed thinly in rows 8 or 10 inches apart, covering the seed lightly and firming over the seed with the feet, hoe, or back of a spade. This seed-bed should be kept moist at all times until the seed germinates, either by close attention to watering or by a lath screen. The use of a piece of cloth laid directly on the soil, and the bed wet through the cloth, is often recommended, and if the cloth is always wet and taken off the bed as soon as the seed sprouts, it may be used. After the young plants hare grown to the height of 1 or 2 inches they must be thinned out, leaving the plants so that they do not touch each other, and transplanting those thinned - if wanted - to other ground prepared in the same manner as the seed-bed. All these plants may be sheared or cut back to induce stockiness.

An ounce of seed will furnish about three thousand plants.

If in a private garden, the ground on which the fall crop is usually set will likely be'that from which a crop of some early vegetable has been taken. This land should be again well enriched with fine, wellrotted manure, to which may be added a liberal quantity of wood ashes. If the manure or ashes is not easily obtained, a small amount may be used by plowing or digging out a furrow 8 or 12 inches deep, scattering the manure and ashes in the bottom of the trench and filling it up almost level with the surface. The plants should be set about 
the middle of July, preferably just before a rain. The plant bed should have a thorough soaking shortly before the plants are lifted, and each plant be trimmed, both top and root, before satting. The plants should be set from 5 to 6 inches apart in the rows and the earth well firmed around each one.

The after-cultivation consists in thorough tillage until the time of "handling" or earthing up the plants. This process of handling is accomplished by drawing up the earth with one

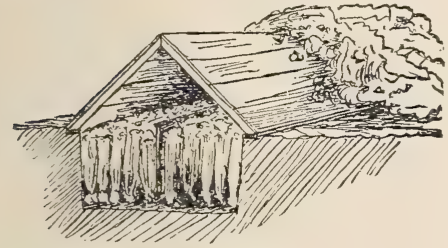

304. A celery pit. hand while holding the plant with the

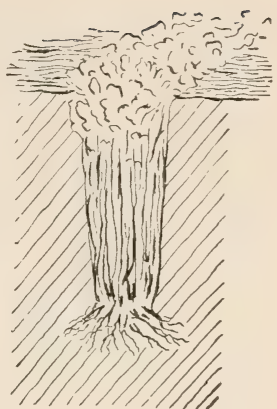

303. Storing celery in a trench in the field. (See p. 515.) other, packing the soil well around the stalks. This process may be continued until only the leaves are to be seen. For the private grower, it is much easier to blanch the celery with boards or paper, or if the celery is not wanted until winter, the plants may be dug up, packed closely in boxes, covering the roots with soil, and placed in a dark, cool cellar, where the stalks will blanch themselves. In this way celery may be stored in boxes in the house cellar. Put earth in the bottom of a deep box, and plant the celery in it.

Celery is sometimes stored in trenches in the open (Fig. 303), the roots being transplanted to such places in late fall. The plants are set close together and the trenches are covered with boards. A wider trench oi pit may be made (Fig. 304) and covered with a shed roof.

Chard, or Swiss chard, is a development of the beet species characterized by large succulent leaistalks instead of enlarged roots

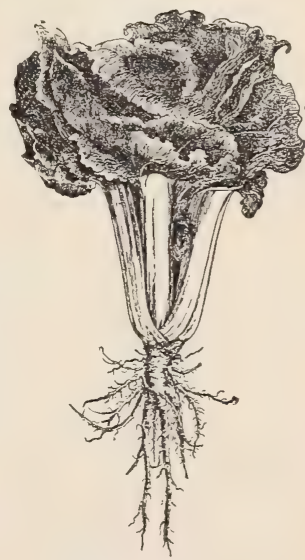

305. Swiss chard. 
(Fig. 305). The leaves are very tender and make "greens" much like young beets. They are cultivated exactly like beets. Only one variety is offered by most seedsmen in this country, though in France and Germany several varieties are grown.

Chicory is grown for two purposes, - for the roots and for the herbage. "Barbe de capucin" is a salad made from young shoots of chicory.

The Magdeburg chicory is the variety usually spoken of, it being the one most extensively grown. The roots of this, after being ground and roasted, are used either as a substitute or an adulterant for coffee.

The Witloof, a form of chicory, is used as a salad, or boiled and served in the same manner as cauliflower. The plants should be thinned to 6 inches. In the latter part of summer they should be banked up like celery, and the leaves used after becoming white and tender. This and the common wild chicory are often dug in the fall, the leaves cut off, the roots packed in sand in a cellar and watered until a new growth of leaves starts. These leaves grow rapidly and are very tender, making a fine salad vegetable. One packet of seed of the Witloof will furnish plants enough for a large family.

Chervil. - The chervil is grown in two forms, - for the leaves, and for the tuberous roots.

The curled chervil is a good addition to the list of garnishing and seasoning vegetables. Sow seeds and cultivate the same as parsley.

The tuberous chervil resembles a short carrot or parnsip. It is much esteemed in France and Germany. The tubers have somewhat the flavor of a sweet potato, perhaps a little sweeter. They are perfectly hardy, and, like the parsnip, the better for frosts. The seed may be sown in September or October, as it does not keep well; or as soon as the ground is fit to work in the spring, it being slow to germinate after the weather becomes hot and dry. One packet of seed will give all the plants necessary for a family.

Collards. - This is a name given to a kind of kale, used when young as greens; also to young cabbages used in the same way. 


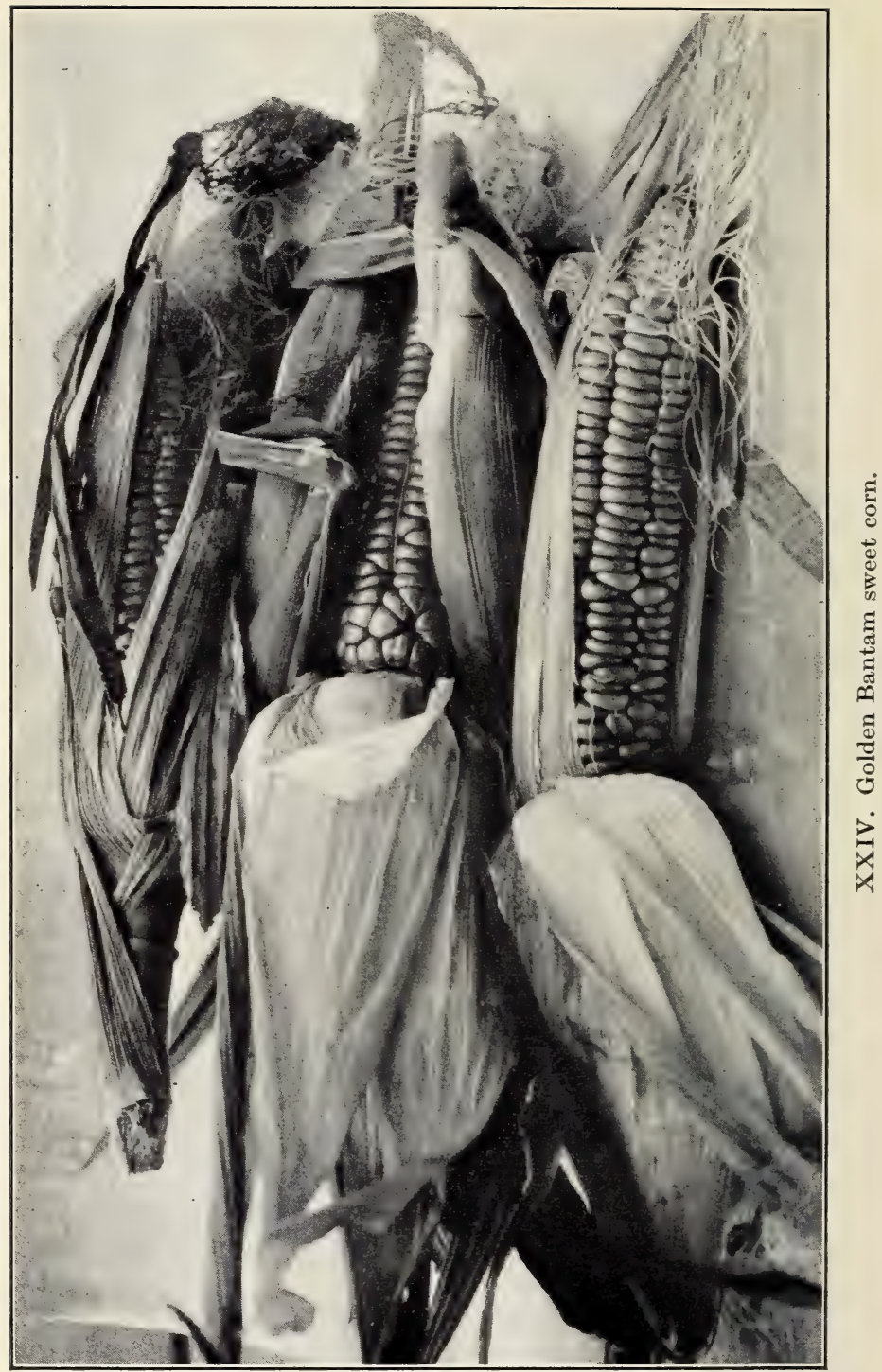


The seed of any eariy cabbage may be sown thickly in rows 18 inches apart, from early spring to late fall. The plants are cut off when 6 or 8 inches high and boiled as are other greens.

The kale, or Georgia collards, is grown in the South, where cabbages fail to head. It grows to the height of 2 to 6 feet, furnishing a large quantity of leaves. The young leaves and tufts that arise as the old leaves are pulled off make excellent greens.

Cives. - A small perennial of the onion family, used for flavoring.

It is propagated by division of the root. It may be planted in a permanent place in the border, and, being completely hardy, will remain for years. The leaves are the parts used, as the roots are very rank in flavor. The leaves may be cut frequently, as they readily grow again.

Corn salad. - This is one of the earliest spring salad vegetables, coming into condition with spinach, and needing the same culture.

Sown in the fall, and covered with straw or hay when cold weather sets in, it will start into rapid growth when the covering is removed in March or April. Or the seed may be sown in early spring, and plants will be fit to use in six or eight weeks. One packet of seed will suffice for a small family.

Corn, sweet or sugar. - This is the characteristic American table vegetable, and one that every home-gardener expects to grow. Too often, however, only one planting of one kind is made. The ears come to edible maturity almost simultaneously, and a short season is the result.

The first planting of sweet corn should be made from May 1 to 10 , planting early, intermediate, and late varieties at the same time, then at intervals of two weeks until the middle of July, when the late varieties should be planted, thus having a succession from the first crop until October.

The soil for corn should be fertile and "quick." The coarser manure left from the preparation of the ground for small crops may be used to good advantage. Corn for the garden is better pianted in drills, the drills 3 feet apart, dropping the seed from 10 to 12 inches apart in the drills. One quart of seed will plant 200 hills. 
For extra early, Marblehead, Adams, Vermont, Minnesota, and Early Corey are favorites. A most excellent extra early yellow sweet corn, with kernels looking like small field corn, is Golden Bantam; the ears are small and would probably not attract the market buyer, but for home use the variety is unexcelled (Plate XXIV). For later crop, Crosby, Hickox, Shoe Peg, and Stowell Evergreen are now popular.

Cress. - Two very unlike species of plants are grown under the name of cress, - the upland-cress and the water-cress. There are still other species, but not much known in this country.

The upland cress, or the true pepper grass, may be grown on any garden soil. Sow early in the spring. It makes a rapid growth and can be cut in from four to five weeks. Succession of sowings must be made, as it runs quickly to seed. The curled variety is the one usually grown, as the leaves may be used for garnishing as well as for salads. One packet of seed will be sufficient for each sowing. Any good soil will do. Sow thickly in drills 12 to 18 inches apart. In summer it runs to seed quickly, so that it is usually grown in spring and fall.

The water-cress is more exacting in its culture, and can be successfully grown only in moist places, such as edges of shallow slow-running creeks, open drains, or beds excavated near such streams. A few plants for private use may be grown in a frame, provided a retentive soil is used and attention given to watering the bed often. Watercress may be propagated from pieces of the stem, used as cuttings. If one is fond of water-cress, it is well to colonize it in some clean creek or pool. It will take care of itself year by year. Seeds may also be used for propagating it.

Cucumber. - The custom of putting down cucumber pickles in the home kitchen is probably passing out; but both the pickling and the slicing cucumbers, especially the latter, are still an essential part of a good home garden. A stale or wilted cucumber is a very poor article of food.

For early use, the cucumber is usually started in a hotbed or coldframe by sowing the seed on pieces of sod 4 to 6 inches square, turned grass side down. Three or four seeds are placed on or pushed 
into each piece of sod and covered with 1 to 2 inches of fine soil. The soil should be well watered and the glass or cloth placed over the frame. The roots will run through the sod. When the plants are large enough to set out, a flat trowel or a shingle may be slipped under the sod and the plants moved to the hill without check. In place of sod, old quart berry-boxes are good; after setting in the hill the roots may force their way through the cracks in the baskets. The baskets also decay rapidly. Flower-pots may be used. These plants from the frames may be set out when danger of frost is over, usually by the 10th of May, and should make a very rapid growth, yielding good-sized fruits in two months. The hills should be made rich by forking in a quantity of wellrotted manure, and given a slight elevation above the garden - not high enough to allow the wind to dry the soil, but slightly raised so that water will not stand around the roots.

The main crop is grown from seed planted directly in the open, and the plants are grown under level culture.

One ounce of seed will plant fifty hills of

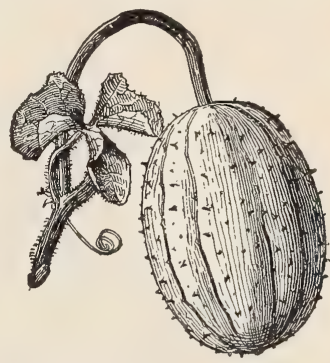
cucumbers. The hills may be 4 to 5 feet 306 . West Indian gherkin apart each way. (Cucumis Anguria).

The White Spine is the leading general-purpose variety. For very early or pickling sorts, the Chicago, Russian, and other picklings are good.

The striped beetle is an inveterate pest on cucumbers and squashes (see page 201).

The name gherkin is applied to small pickling cucumbers. The West India gherkin is a wholly distinct species, but is grown like cucumbers. (Fig. 306.)

Dandelion. - Under domestication the dandelion has been developed until quite unrecognizable to the casual observer. The plants attain a large size and the leaves are much more tender.

Sow in spring in well-manured soil, either in drills or in hills 1 foot apart. A cutting of leaves may be had in September or October, and some of the stools may stand until spring. The delicacy of the 
leaves may be improved by blanching them, either by the use of boards or earth. One trade packet of seed will supply a sufficient number for a family. The whole plant is destroyed when the crop of leaves is taken.

The seed may be selected from the best field-grown plants, but it is better to buy the French seed of the seedsmen.

Egg-plant. - The egg-plant or guinea squash has never become a popular home-garden product in the North. In the South it is better known.

Unless one has a greenhouse or a very warm hotbed, the growing of egg-plants in the North should be left to the professional gardener, as the young plants are very tender, and should be grown without a

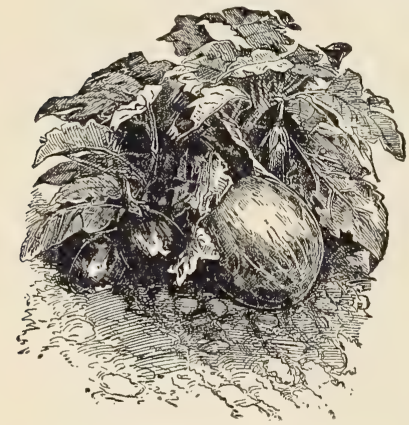

307. Black Pekin egg-plant. check. The seed should be sown in the hotbed or the greenhouse about April 10, keeping a temperature of $65^{\circ}$ to $70^{\circ}$. When the seedlings have made three rough leaves, they may be pricked out into shallow boxes, or, still better, into 3 -inch pots. The pots or boxes should be plunged to the rim in soil in a hotbed or coldframe so situated that protection may be given on chilly nights. The 10th of June is early enough to plant them out in central New York.

The soil in which egg-plants are to grow cannot well be made too "quick," as they have only a short season in which to develop their fruits. The plants are usually set 3 feet apart each way. A dozen plants are sufficient for the needs of a large family, as each plant should yield from two to six large fruits. The fruits are fit to eat at all stages of growth, from those the size of a large egg to their largest development. One ounce of seed will furnish 600 to 800 plants.

The New York Improved Purple is the standard variety. Black Pekin (Fig. 307) is good. For early, or for a short-season climate, the Early Dwarf Purple is excellent. 
Endive. - One of the best fall salad vegetables, being far superior to lettuce at that time and as easily grown.

For fall use, the seed may be sown from June to August, and as the plants become fit to eat about the same time from sowing as lettuce does, a succession may be had until cold weather. The plants will need protection from the severe fall frosts, and this may be given by carefully lifting the plants and transplanting to a frame, where sash or cloth may be used to cover them in freezing weather.

The leaves, which con-

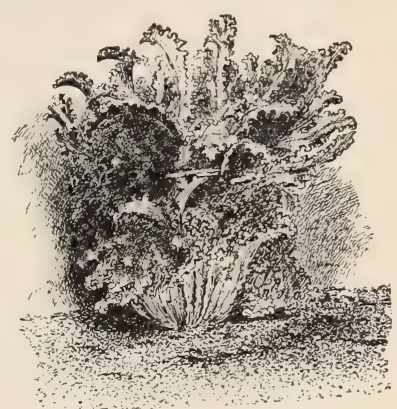

308. Endive tied up. stitute practically the whole plant, are blanched before being used, either by tying together with some soft material (Fig. 308) or by standing boards on each side of the row, allowing the top of the boards to meet over the conter of the row. Tie the leaves only when they are dry.

The rows should be $1 \frac{1}{2}$ or 2 feet apart, the plants 1 foot apart in the rows. One ounce of seed will sow 150 feet of drill.

Garlic. - An onion-like plant, the bulbs of which are used for flavoring.

Garlic is little known in this country except amongst those of foreign birth. It is multiplied the same as multiplier onions - the bulb is broken apart and each bulbule or "clove" makes a new compound bulb in a few weeks. Hardy; plant in early spring, or in the South in the fall. Plant 2 to 3 inches apart in the row.

Horseradish. - Widely used as an appetizer, and 309. A good horseradish root. 
the fragments of roots being left in the soil to grow for further use. This method results in having nothing but tough, stringy roots, very unlike the product of a properly planted and well-cared-for bed. A good horseradish root should be straight and shapely (Fig. 309).

The best horseradish is secured from sets planted in the spring at the time of setting early cabbage, and dug as late the same fall as the weather will permit. It becomes, therefore, an annual crop. The roots for planting are small pieces, from 4 to 6 inches long, obtained when trimming the roots dug in the fall. These pieces may be packed in sand and stored until wanted the following spring.

In planting, the roots should be set with the upper end 3 inches below the surface of the ground, using a dibber or sharp-pointed stick in making the holes. The crop may be planted between rows of earlysown beets, lettuce, or other crop, and giren full possession of the ground when these crops are harrested. When the ground is inclined to be stiff or the subsoil is near the surface, the roots may be set in a slanting position. In fact, many gardeners practice this method of planting. thinking that the roots make a better growth and are more uniform in size.

Kale. - Under this name, a great variety of cabbage-tribe plants is grown, some of them reaching a height of sereral feet. Usually, howerer, the name is applied to a low-growing, spreading plant, extensively used for winter and spring greens.

The culture given to late cabbage is suitable. At the approach of serere freezing weather a slight protection is given in the Torth. The leares remain green through the winter and may be gathered from under the snow at a time when material for greens is searcc. Some of the kales are very ornamental because of their blue and purple curled foliage. The Scotch Curled is the most popular variety. Let the plants stand 18 to 30 inches apart. Young cabbage plants are sometimes used as kale. Collards and borecole are kinds of kale. Sea-kale is a wholly different regetable (which see).

Kales are extensirely grown at Norfolk, Ta., and southward, and shipped North in winter, the plants being started in late summer or in fall. 
Kohlrabi is little known in the United States. It looks like a leafy turnip growing above ground.

If used when small ( 2 to 3 inches in diameter), and rot allowed to become hard and tough, it is of superior quality. It should be more generally grown. The cuiture is very simple. A succession of sowings should be made from early spring until the middle of summer, in drills 18 inches to 2 feet apart, thinning the young plants to 6 or 8 inches in the rows. It matures as quickly as turnips. One ounce of seed to 100 feet of drill.

Leek. - The leek is little grown in this country except by persons of foreign extraction. The plant is one of the onion family, and is used mostly as flavoring for soups. Well-grown leeks have a very agreeable and not very strong onion flavor.

Leek is of the easiest culture, and is usually grown as a second crop, to follow beets, early peas, and other early stuff. The seed should be sown in a seed-bed in April or early May and the seedlings planted out in the garden in July, in rows 2 feet apart, the plants being 6 inches apart in the rows. The plants should be set deep if the neck or lower part of the leaves is to be used in a blanched condition. The soil may be drawn towards the plants in hoeing, to further the blanching. Being very hardy, the plants may be dug in late fall, and stored the same as celery, in trenches or in a cool root-cellar. One ounce of seed to 100 feet of drill.

Lettuce is the most extensively grown salad vegetable. It is now in demand, and is procurable, every month in the year. The winter and early spring crops are grown in forcing-houses and coldframes, but a supply from the garden may be had from April to November, by the use of a cheap frame in which to grow the first and last crops, relying on a succession of sowings for the intermediate supply.

Seed for the first crop may be sown in a coldframe in March, growing the crop thick and having many plants which are small and tender; or, by thinning out to the distance of 3 inches and allowing the plants to make a larger growth, the plants pulled up may be set in the open ground for the next crop.

Sowings should be made in the garden from April to October, at 
short intervals. A moist location should be chosen for the July and August sowings. The early and late sowings should be of some loosegrowing variety, as they are in edible condition sooner than the cabbage or heading varieties.

The cabbage varieties are far superior to the loose-growing kinds for salads. To be grown to perfection, they should have very rich soil, frequent cultivation, and an occasional stimulant, such as liquid manure or nitrate of soda.

The cos lettuce is an upright-growing type much esteemed in Europe, but less grown here. The leaves of the full-grown plants are tied together, thus blanching the center, making it a desirable salad or garnishing variety. It thrives best in summer.

One ounce of seed will grow 3000 plants or sow 100 feet of drill. In the garden, plants may stand 6 inches apart in the rows, and the rows may be as close together as the system of tillage will allow.

Mushroom. - Sooner or later, the novice wants to grow mushrooms. While it is easy to describe the conditions under which they may be grown, it does not follow that a crop may be predicted with any certainty.

Latterly, careful studies have been made of the growing of mushrooms from spores and of the principles involved in the making of spawn, with the hope of reducing the whole subject of mushroom growing to a rational basis. A good idea of this work may be had by reading Duggar's contribution on the subject in Bulletin 85 of the Bureau of Plant Industry, United States Department of Agriculture. In this place, however, we may confine ourselves to the customary horticultural practice.

The following paragraphs are from "Farmers' Bulletin," No. 53 (by William Falconer), of the U. S. Dept. of Agriculture (March, 1897) :-

Mushrooms are a winter crop, coming in from September till April or May - that is, the work of preparing the manure begins in September and ends in February, and the packing of the crop begins in October or November and ends in May. Under extraordinary conditions the season may begin earlier and last longer, and, in fact, it may continue all summer. 
Mushrooms can be grown almost anywhere out of doors, and also indoors where there is a dry bottom in which to set the beds, where a uniform and moderate temperature can be maintained, and where the beds can be protected from wet overhead, and from winds, drought, and direct sunshine. Among the most desirable places in which to grow mushrooms are barns, cellars, closed tunnels, sheds, pits, greenhouses, and regular mushroom houses. Total darkness is not imperative, for mushrooms grow well in open light if shaded from sunshine. The temperature and moisture are more apt to be equable in dark places than in open, light ones, and it is largely for this reason that mushroom houses are kept dark.

The best fertilizer for mushrooms, so far as the writer's experience goes, is fresh horse manure. Get together a lot of this material (short and strawy) that has been well trampled and wetted in the stable. Throw it into a heap, wet it well if it is at all dry, and let it heat. When it begins to steam, turn it over, shake it well so as to mix thoroughly and evenly, and then tramp it down solid. After this let it stand till it again gets quite warm; then turn, shake, trample as before, and add water freely if it is getting dry. Repeat this turning, moistening, and trampling as often as it is needful to keep the manure from " burning." If it gets intensely hot, spread it out to cool, after which again throw it together. After being turned in this way several times, and the heat in it is not apt to rise above $130^{\circ} \mathrm{F}$., it should be ready to make up in the beds. By adding to the manure at the second or third turning onefourth or one-fifth of its bulk of loam, the tendency to intense heating is lessened and its usefulness not at all impaired. Some growers prefer short manure exclusively, that is, the horse droppings, while others like a good deal of straw mixed in with this. The writer's experience, however, is that, if properly prepared, it matters little which is used.

Ordinarily the beds are only 8 to 10 inches deep; that is, they are faced with 10-inch-wide hemlock boards, and are only the depth of this board. In such beds put a layer of fresh, moist, hot manure, and trample it down firm until it constitutes half the depth of the bed; then fill up with the prepared manure, which should be rather cool $\left(100^{\circ}\right.$ to $115^{\circ} \mathrm{F}$.) when used, and pack all firmly. If desired, the beds can be made up entirely of the prepared manure. Shelf beds are usually 9 inches deep; that is, the shelf is bottomed with 1 -inch boards 
and faced with 10 -inch wide boards. This allows about 8 inches for manure, and 1 inch rising to 2 inches of loam on top. In filling the shelf beds the bottom half may be of fresh, moist or wettish, hot manure, packed down solid, and the top half of rather cool prepared manure, or it may be made up of all prepared manure. As the shelf beds cannot be trodden and cannot be beaten very firm with the back of the fork, a brick is used in addition to the fork.

The beds should be spawned after the heat in them has fallen below $100^{\circ} \mathrm{F}$. The writer considers $90^{\circ} \mathrm{F}$. about the best temperature for spawning. If the beds have been covered with hay, straw, litter, or mats, these should be removed. Break each brick into twelve or fifteen pieces. The rows should be, say, 1 foot apart, the first one being 6 inches from the edge, and the pieces should be 9 inches apart in the row. Commencing with the first row, lift up each piece, raise 2 to 3 inches of the manure with the hand, and into this hole place the piece, covering over tightly with the manure. When the entire bed is spawned, pack the surface all over. It is well to cover the beds again with straw, hay, or mats, to keep the surface equally moist. The flake spawn is planted in the same way as the brick spawn, only not quite so deep.

At the end of eight or nine days the mulching should be removed and the beds covered with a layer of good loam 2 inches thick, so that the mushrooms can come up in and through it. This gives them a firm hold, and to a large extent improves their quality and texture. Any fair loam will do. That from an ordinary field, wayside, or garden is generally used, and it answers admirably. There exists an idea that garden soil surfeited with old manure is unfit for mushroom beds because it is apt to produce spurious fungi. This, however, is not the case. In fact, it is the earth most commonly used. For molding the beds the loam should be rather fine, free, and mellow, so that it can be easily and evenly spread and compacted firmly into the manure.

If an even atmospheric temperature of from $55^{\circ}$ to $60^{\circ} \mathrm{F}$. can be maintained, and the house or cellar containing the mushroom beds is kept close and free from drafts, the beds may be left uncovered, and should be watered if they become dry. But no matter where the beds are situated, it is well to lay some loose hay or straw or some old matting or carpet over them to keep them moist. The covering, however, 
should be removed just as soon as the young mushrooms begin to appear above ground. If the atmosphere is dry, the pathways and walls should be sprinkled with water. The mulching should also be sprinkled, but not enough to cause the water to soak into the bed. However, if the bed should get dry, do not hesitate to water it.

Mustard. - Almost all the mustards are good for greens, though white mustard is usually best. Chinese mustard is also valuable.

Seed should be sown in drills, 3 to $3 \frac{1}{2}$ feet apart, and covered with a half inch of soil. The ease with which they may be grown, and the abundance of herbage which they yield, mark their special utility. Sow very early for spring greens, and in late summer or early September for fall greens.

Muskmelon. - The most delicious of all garden vegetables eaten from the hand, and of simple cultivation; but like many another plant that is easy to grow it often fails completely. The season and soil must be warm and the growth continuous.

The natural soil for melons is a light, sandy loam, well enriched with rotted manure, although good crops may be grown on land naturally heavy if the hills are specially prepared. When only heary soil is available, the earth where the seeds are to be planted should be thoroughly pulverized and mixed with fine, well-rotted manure. A sprinkling of leafmold or chip-dirt will help to lighten it. On this hill from ten to fifteen seeds may be sown, thinning to four or five vines when danger of insects is over.

The season may be advanced and the damage from insects lessened by starting the plants in hotbeds. This may be done by using fresh sod, cut into 6-inch pieces, placing them grass-side down in the hotbed, sowing eight to ten seeds on each piece, and covering with 2 inches of light soil. When all danger of frost is over, and the ground has become warm, these sods may be carefully lifted and set in the prepared hills. The plants usually grow without check, and fruit from two to four weeks ahead of those from seed planted directly in the hill. Old quart berryboxes are excellent to plant seeds in, as, when they are set in the ground, they very quickly decay, causing no restriction to the roots.

Netted Gem, Hackensack, Emerald Gem, Montreal, Osage, and the 
Nutmeg melon are popular varieties. One ounce of seed will plant about fifty hills.

Okra. - A plant of the cotton family, from the green pods of which is made the well-known gumbo soup of the South, where the plant is more extensively grown than in the North. The pods are also used in their green state for stews, and are dried and used in winter, when they are nutritious, and form no little part of the diet in certain sections of the country.

The seeds are very sensitive to cold and moisture, and should not be sown until the ground has become warm - the last week in May or the first of June being early enough in New York. The seed should be sown in a drill 1 inch deep, the plants thinned to stand 12 inches in the row. Give the same culture as for corn. One ounce will sow 40 feet of drill. Dwarf varieties are best for the North. Green Density and Velvet are leading varieties.

Onion. - A few onions, of one kind or another, give character to every good kitchen-garden. They are grown from seeds (" black seed ") for the main crop. They are also grown from sets (which are very small onions, arrested in their development); from "tops". (which are bulblets produced in the place of flowers); and from multipliers or potato onions, which are compound bulbs.

The extremely early crop of onions is grown from sets, and the late or fall crop is grown from seed sown in April or early May. The sets may be saved from the crop harvested the previous fall, saving no bulbs measuring over three-fourths of an inch in diameter, or, better, they may be purchased from the seedsman. These sets should be planted as early as possible in the spring, preferably on land that has been manured and trenched in the fall. Plant in rows 12 inches apart, the sets being 2 or 3 inches in the row. Push the sets well down into the ground and cover with soil, firming them with the feet or a roller. In cultivating, the soil should be thrown towards the tops, as the white stems are usually sought as an indication of mildness. The crop will be in condition to use in three to four weeks, and may be made to last until small seed onions are to be had. Tops or multipliers may also be used for the early crop. 
In growing onions from soed, it is only necessary to say that the seed should be in the ground very early in order that the bulbs make their growth before the extreme hot weather of August, when, for want of moisture and because of the heat, the bulbs will ripen up while small. Early in April, in New York, if the ground is in condition, the seed should be sown thickly in drills from 12 to 16 inches apart, and the ground above the seeds well firmed. Good cultivation and constant weeding is the price of a good crop of onions. In cultivating and hoeing, the soil should be kept away from the rows, not covering the growing bulbs, but allowing them to spread over the surface of the ground. When the crop is ready to be harvested, the bulbs may be pulled or cultivated up, left to dry in double rows for several days, the tops and roots taken off, and the bulbs stored in a dry place. Later in the season they may be allowed to freeze, covering with chaff or straw to hold them frozen, and kept until early spring; but this method is usually

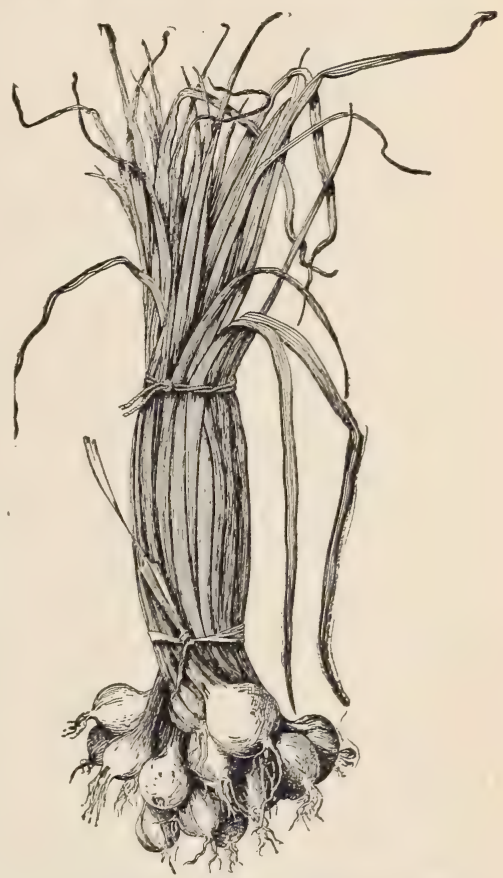

310. Bunch onions, grown from seed. unsafe with beginners, and always so in a changeable climate. Onion seed should always be fresh when sown - praferably of the last year's crop. One ounce of onion seed will sow 100 feet of drill.

One of the recent methods of securing extra large and also early bulbs from seed is to sow the seed in a hotbed in February or early March, and transplant to the open ground in April. A bunch of onions, for eating from hand, is shown in Fig. 310.

The Danvers, Prizetaker, Globe, and Wethersfield are favorite varieties, with the addition of White Queen or Barletta for pickling. 
Parsley. - This is the most universal of, garnishes. It is used also as a flavoring in soups.

The seed is slow to germinate, and often the second or third sowing is made, thinking the first is a failure; but usually after what would

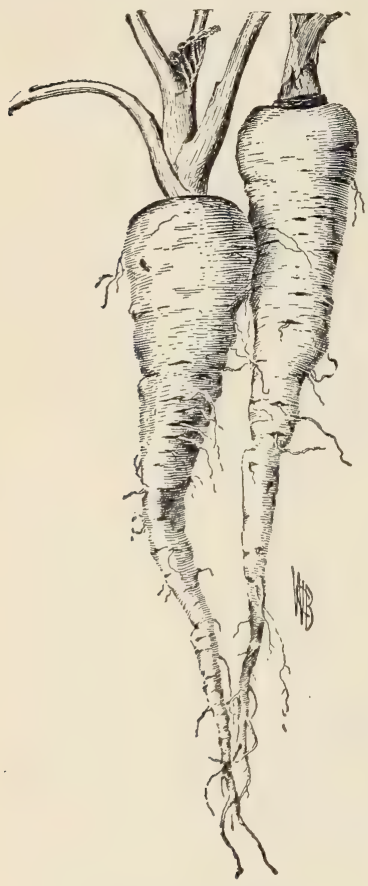

311. The Student parsnip, a leading variety. seem a long time the young plants will be seen. When sown in the open ground, it should be thinned to stand 3 or 4 inches in the row, the rows being 10 to 12 inches apart. A few plants in a border will give a supply for a large family, and with a little protection will live over winter.

Roots may be lifted in the fall, put into boxes or old cans, and grown in a sunny window for winter use. The Curled parsley is the form commonly used.

Parsnip. - A standard winter and spring vegetable, of the easiest culture in deep soil (Fig. 311).

Parsnips are the better for the winter's freeze, although they are of good quality if taken up after the fall frosts and packed in soil, sand, or moss in the cellar.

The seed, which must be not over one year old, should be sown as early as possible in well-prepared soil, firmed with the feet or roller. As the seed germinates rather slowly, the ground often becomes crusted or baked over the seeds, in which case it should be broken and fined with a garden rake. This operation often means the success of the crop. Radish or cabbage seeds may be sown with the parsnip seed to mark the row and break the crust. One ounce of seed will sow 200 feet of drill. Thin to 6 inches apart in the row.

Pea. - Perhaps no vegetable is planted in greater expectancy than the pea. It is one of the earliest seeds to go into the ground, and the planting fever is impatient. 
There is great difference in quality between the smooth and the wrinkled peas. The first are a little the earliest to be planted and to become fit for use, and on that account should be planted in a small way; but the wrinkled sorts are much superior in quality.

The early crop of peas may be forwarded by sprouting the seeds indoors. Soil may be made too rich or strong for peas.

For the kitchen-garden the dwarf and half-dwarf varieties are the best, as the tall kinds will need brush or wire to support them, causing considerable trouble and labor and not being as neat in appearance. The dwarf varieties should be planted four rows in a block, each row being only 6 or 8 inches apart. The peas on the two center rows may be picked from the outside. Leave a space of 2 feet and plant the same.

The tall varieties yield a larger crop than the dwarfs, but as the rows must be made from 3 to 5 feet apart, the dwarf ones, which are planted only 6 to 8 inches apart, will give as large a yield on the same area. Always plant double rows of the tall varieties; that is, two rows from 4 to 6 inches apart, with the brush or wire between, the double rows being from 3 to 5 feet apart, according to varieties.

At the time of the first planting only the smooth varieties should be sown, but by the middle of April in New York the ground will be warm and dry enough for wrinkled sorts. Succession crops should be sown that will come to maturity one after the other, extending the season six or eight weeks. If a further supply is wanted, the early quick-maturing varieties may be sown in August, usually giving a fair crop of peas in September and early October. In the hot weather of midsummer they do not thrive so well. One quart of seed will plant about 100 feet of drill.

Pepper. - The garden pepper is not the pepper of commerce; it is more properly known as red

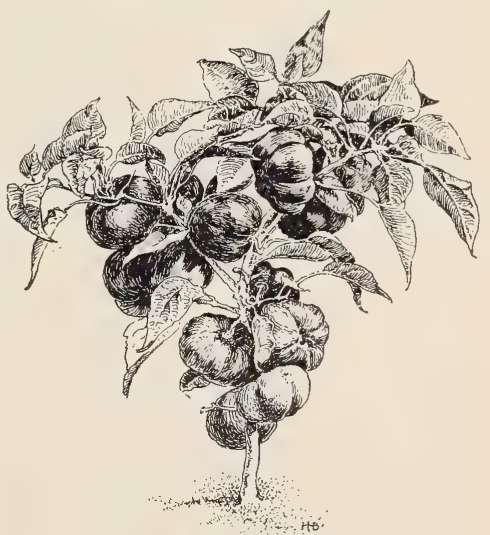

312. One of the bell peppers. 
pepper (though the pods are not always red), chilli, and capsicum. The pods are much used in the South, and most Northern households now employ them to some extent.

Peppers are tender while young, although they will endure a heavy frost in the fall. Their culture is that recommended for egg-plants. A small seedsman's packet of seed will be sufficient for a large number of plants, say two hundred. The large bell peppers (Fig. 312) are the mildest, and are used for making "stuffed peppers " and other dishes. The small, hot peppers are used for seasoning and sauces.

Potato. - The potato is rather more a field crop than a home-garden product; yet the home-gardener often desires to grow a small early lot.

The common practice of growing potatoes on elevated ridges or hills is wrong, unless the soil is so wet that this practice is necessary to insure proper drainage (but in this case the land is not adapted to the growing of potatoes), or unless it is necessary, in a particular place, to secure a very early crop. If the land is elevated into ridges or hills, there is great loss of moisture by means of evaporation. During the last cultivating the potatoes may be hilled up slightly in order to cover the tubers; but the hills should not be made in the beginning for the main crop if land and conditions are right.

Land for potatoes should be rather loamy in character, and ought to have a liberal supply of potash, either naturally or supplied in the drill, by means of an application of sulfate of potash. See that the land is deeply plowed or spaded, so that the roots can penetrate deeper. Plant the potatoes 3 or 4 inches below the natural surface of the ground. It is ordinarily best to drop the pieces in drills. A continuous drill or row may be made by dropping one piece every 6 inches, but it is usually thought best to drop two pieces about erery 12 to 18 inches. The drills are far enough apart to allow good cultivation. If horse cultivation is used, the drills should be at least 3 feet apart.

Small potatoes are considered not to be so good as large ones for planting. One reason is because too many sprouts arise from each one, and these sprouts are likely to crowd each other. The same is true of the tip end or seed end of the tuber. Even when the tip is cut off, the eyes are so numerous that one secures many weak shoots rather than two or three strong ones. It is ordinarily best to cut the potatoes 



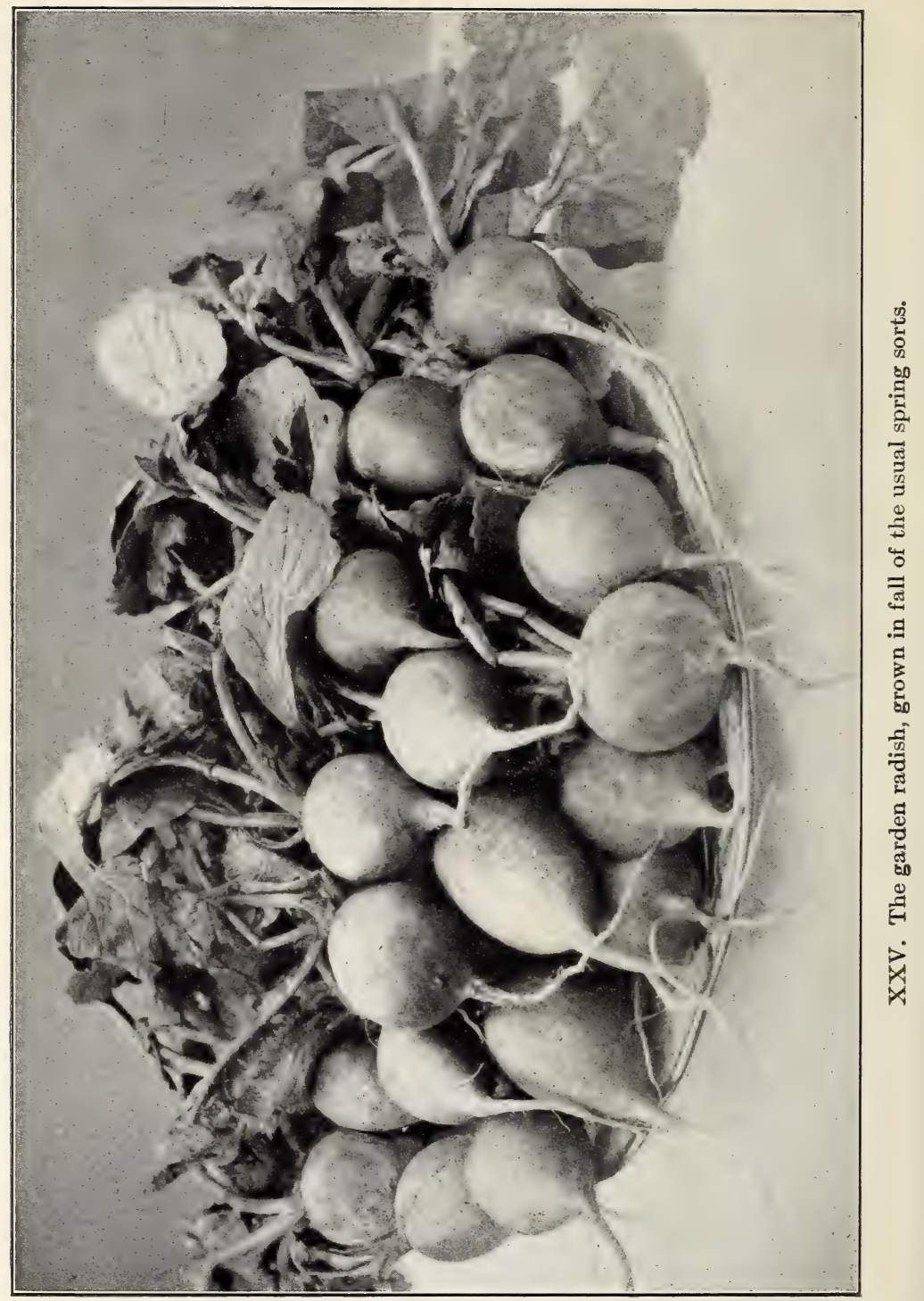


to two or three eyes, leaving as much tuber as possible with each piece. From 7 to 10 bushels of potatoes are required to plant an acre.

For a very early crop in the garden, tubers are sometimes sprouted in the cellar. When the sprouts are 4 to 6 inches high, the tubers are carefully planted. It is essential that the sprouts are not broken in the handling. In this practice, also, the tubers are first cut into large pieces, so that they will not dry out too much.

The staple remedy for the potato bug is Paris green, 2 pounds or more of poison to 150 to 200 gallons of water, with a little lime (see page 193). For the blight, spray with bordeaux mixture, and spray thoroughly. Bordeaux mixture will also keep away the flea beetle to a large extent.

Radish (Plate XXV). - In all parts of the country the radish is popular as a side-dish, being used as an appetizer and for its decorative character. It is a poor product, however, if misshapen, wormy, or tough.

Radishes should be grown quickly in order to have them at their best. They become tough and woody if grown slowly or allowed to stay in the ground too long. A light soil, well enriched, will grow most of the early varieties to table size in three to five weeks. To have a supply through the early months, sowings should be made every two weeks. For spring use, the French Breakfast is still a standard variety (Fig. 313).

For summer, the large white or gray varieties are best. The winter varieties may be sown in September, harvested before severe frosts, and stored in sand in a cool cellar. When they are to be used, if thrown into cold water for a short time they will regain their crispness.

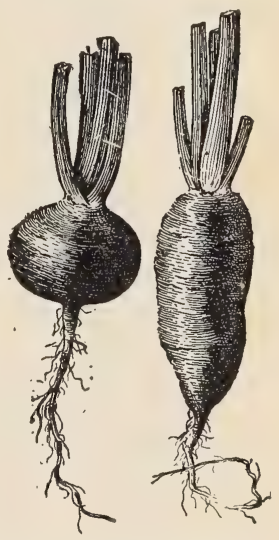

313. French Breakfast and olive-shaped radishes.

Sow radishes thickly in drills, 12 to 18 inches apart. Thin as needed.

Rhubarb, or Pie plant. - A strong perennial herb, to be grown in a bed or row by itself at one end or side of the garden. It is a heavy feeder (Fig. 190). 
Rhubarb is usually propagated by division of the fleshy roots, small pieces of which will grow if separated from the old established roots and planted in rich mellow soil. Poor soil should be made rich by spading out at least 3 feet of the surface, filling with well-rotted manure to within 1 foot of the level, throwing in the top soil and setting the roots with the crowns 4 inches below the surface, firming them with the feet. The stalks should not be cut for use until the second year. See that the plant does not want for water when it is making its heavy leaf growth. In fall, coarse manure should be thrown over the crowns, to be forked or spaded in lightly when spring opens.

In growing seedling rhubarb, the seed may be sown in a coldframe in March or April, protected from freezing, and in two months the plants will be ready to set in rows, 12 inches

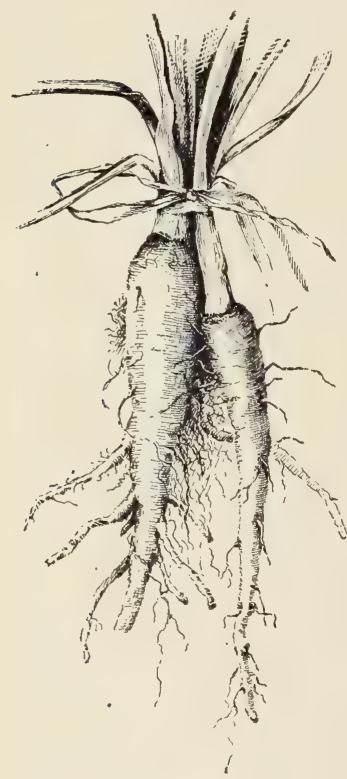

314. Salsify, or oyster plant. apart. Give the plants good cultivation, and the following spring they may be set in a permanent place. At this time the plants should be set in well-prepared ground, at a distance each way of 4 to 5 feet, and treated as those set with pieces of roots.

If given good care and well manured, the plants will live for years and yield abundantly. Two dozen good roots will supply a large family.

Salsify, or Vegetable oyster (Fig. 314). Salsify is one of the best of winter and early spring vegetables, and should be grown in every garden. It may be cooked in several different ways, to bring out the oyster flavor.

The seed should be sown as early in the spring as possible. Handle the same as parsnips in every way. The roots, like parsnips, are the better for the winter freeze, but part of the crop should be dug in the fall, and stored in soil or moss in a cellar for winter use. 
Sea-kale is a strong-rooted perennial, the shoots of which are very highly prized as a delicacy when blanched.

Seed should be sown in a hotbed early in the spring, plants transplanted to the garden when from 2 to 3 inches high, and given good cultivation through the season, being covered with litter on the approach of winter. The young stalks are blanched early the following spring by covering with large pots or boxes, or by banking with sand or other clean material. The Dwarf Green Scotch, Dwarf Brown, and Siberian are among the leading varieties. Sea-kale is eaten much as asparagus is. It is highly prized by those who know it.

Sea-kale is also propagated by cuttings of the roots 4 or 5 inches long, planted directly in the soil in spring. The plant being perennial, the early shoots may be bleached year after year.

Sorrel of the European garden sorts may be sown in spring, in drills 16 inches apart in beds, or 3 to $3 \frac{1}{2}$ feet apart in rows. After the plants are well established they should be thinned to 10 to 12 inches apart in the rows. They are perennial, and may be kept growing in the same place for several years. Broad-leaved French is the most popular variety.

Spearmint is prized by many persons as a seasoning, particularly for the Thanksgiving and holiday cookery.

It is a perennial and perfectly hardy, and will live in the open garden year after year. If a supply of the fresh herbage is wanted in winter, remove sods of it to the house six weeks before wanted. Place the sods in boxes, and treat as for house plants. The plants should have been frosted and become perfectly dormant before removal.

Spinach. - The most extensively grown of all "greens," being in season in earliest spring, and in fall and winter.

The earliest spinach that finds its way to market is produced from seed sown in September or October, often protected by frames or other means through the severe winter, and cut soon after growth starts in early spring. Even as far north as New York spinach may stand over winter without protection.

Spinach is forced by placing sash over the frames in February and 
March, protecting the young leaves from severe freezing by mats of straw thrown over the frames.

Seed may be sown in early spring for a succession; later in the season seed of the New Zealand summer spinach may be sown, and this will grow through the heat of the summer and yield a fine quality of leaves. The seed of this kind, being very hard, should be scalded and allowed to soak a few hours before sowing. This seed is usually sown in hills about 3 feet apart, sowing four to six seed in each hill.

The spring and winter spinach. should be sown in drills 12 to 14 inches apart, one ounce being sufficient for 100 feet of drill. Remember that common spinach is a cool-weather (fall and spring) crop.

Squash. -- The summer squashes rarely fail of a crop if they once escape the scourge of the striped beetle (p. 201). The late varieties

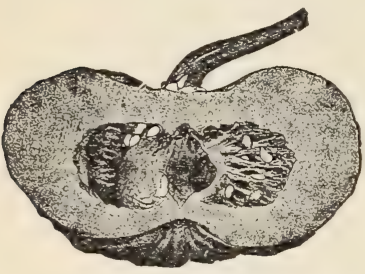

315. One of the so-called Japanese type of squash (Cucurbita moschata). are not so certain; they must secure a strong start, and be on "quick" fertile warm land in order to make a crop before the cool nights of fall (Fig. 315).

The time of planting, method of preparing the hills, and after-culture are the same as for cucumbers and melons, except that for the early bush varieties the hills should be 4 or 5 feet apart, and for the later running varieties from 6 to 8 feet apart. From eight to ten seeds should be planted in each hill, thinning to four plants after danger from bugs is over. Of the early squashes, one ounce of seed will plant fifty hills; of the later varieties, one ounce will plant but eighteen to twenty hills. For winter use, varieties of the Hubbard type are best. For summer use, the Crooknecks and Scallop squashes are popular. In growing winter squashes in a Northern climate, it is essential that the plants start off quickly and vigorously: a little chemical fertilizer will help.

Pumpkins are grown the same as squashes.

Sweet-potato is rarely grown north of Philadelphia; in the South it is a universal garden crop. 
Sweet-potatoes are grown from sprouts planted on ridges or hills, not by planting the tubers, as with the common or Irish potato. The method of obtaining these sprouts is as follows: In April, tubers of sweet-potatoes are planted in a partially spent hotbed by using the whole tuber (or if a large one, by cutting it in two through the long way), covering the tubers with 2 inches of light, well-firmed soil. The sash should be put on the frames and only enough ventilation given to keep the potatoes from decaying. In ten or twelve days the young sprouts should begin to appear, and the bed should be watered if dry. The sprouts when pulled from the tuber will be found to have rootlets at the lower end and along the stems. These sprouts should be about 3 to 5 inches long by the time the ground is warm enough to plant them out on their ridges.

The ridges or hills should be prepared by plowing out a furrow 4 to 6 inches deep. Scatter manure in the furrow and plow back the soil so as to raise the center at least 6 inches above the level of the soil. On this ridge the plants are set, placing the plants well in to the leaves and about 12 to 18 inches apart in the rows, the rows being from 3 to 4 feet apart.

The after-cultivation consists in stirring the soil between the ridges; and as the vines begin to run they should be lifted frequently to prevent rooting at the joints. When the tips of the vines have been touched by frost the crop may be harvested, the tubers left to dry a few days, and stored in a dry, warm place.

To keep sweet potatoes, store in layers in barrels or boxes in dry sand, and keep them in a dry room See that all bruised or chilled potatoes are thrown out.

Tomato. - The tomato is an inhabitant of practically every home garden, and everybody understands its culture (Fig. 316).

The early fruits are very easily grown by starting the plants in a greenhouse, hotbed, or in shallow boxes placed in windows. A pinch of seed sown in March will give all the early plants a large family can use. When the plants have reached the height of 2 or 3 inches, they should be transplanted into 3-inch flower-pots, old berry boxes, or other receptacles, and allowed to grow slowly and stocky until time to set them out, which is from May 15 on (in New York). 
They should be set in rows 4 or 5 feet apart, the plants being the same distance in the rows.

Some support should be given to keep the fruits off the ground and to hasten the ripening. A trellis of chicken-wire makes an excellent support, as does the light lath fencing that may be bought or made at home. Stout stakes, with wire strung the length of the rows, afford

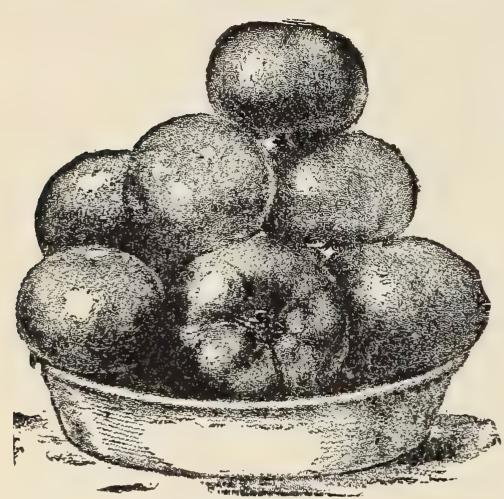

316. A good form or type of tomato.

an excellent support. A very showy method is that of a frame made like an inverted $V$, which allows the fruits to hang free; with a little attention to trimming,

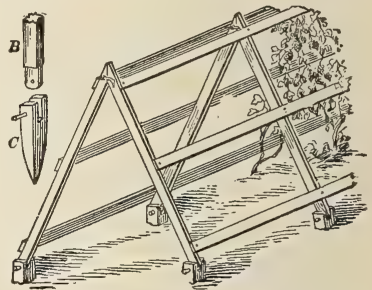

317. A tomato trellis.

the light reaches the fruits and ripens them perfectly (Fig. 317). This support is made by leaning together two lath frames.

The late fruits may be picked green and ripened on a shelf in the sun; or they will ripen if placed in a drawer.

One ounce of seed will be enough for from twelve to fifteen hundred plants. A little fertilizer in the hill will start the plants off quickly. The rot is less serious when the vines are kept off the ground and the rampant suckers are cut out. Varieties pass out and new ones come into notice, so that a list is of small permanent value.

Turnips and Rutabagas are little grown in home gardens; and yet a finer quality of vegetable than most persons know could be secured if these plants were raised on one's own soil and brought fresh to the table. They are usually a fall crop, from seed sown in July and early August, although some kitchen-gardens have them from spring-sown seed. The culture is easy. 
Turnips should be grown in drills, like beets, for the early crop. The young plants will stand light frosts. Choose a rainy day for planting, if practicable. Cover the seed very lightly. Thin the young plants to 5 to 7 inches in the row. Sow every two weeks if a constant supply is desired, as turnips rapidly become hard and woody in warm summer weather. For the fall and winter crop in the North,

"On the fourteenth day of July,
Sow your turnips, wet or dry."

In many parts of the northern and middle states tradition fixes the 25th of July as the proper time for sowing flat turnips for winter use. In the middle states, turnips are sometimes sown as late as the end of August. Prepare a piece of very mellow ground, and sow the seed thinly and evenly broadcast. In spite of the old rhyme, a gentle shower will then be acceptable. These turnips are pulled after frost, the tops removed, and the roots stored in cellars or pits.

For the early crop, Purple-top Strap-leaf, Early White Flat Dutch, and Early Purple-top Milan are the favorite varieties. Yellow-fleshed sorts like Golden Ball are very fine for early table use, when well grown, but most eaters prefer white turnips in spring, although they occasionally patronize the yellow varieties in the fall. Yellow Globe is the favorite yellow fall turnip, though some persons grow yellow rutabagas and call them turnips. For late crop of white turnips, the same varieties chosen for spring sowing are also desirable.

Rutabagas are distinguished from turnips by their smooth, bluish foliage, long root, and yellow flesh. They are richer than turnips; they require the same treatment, exæept that the season of growth is longer. Fall-sown or summer-sown bagas should have a month the start of flat turnips.

Except the maggot (see cabbage maggot, p. 201), there are no serious insects or diseases peculiar to turnips and bagas.

Watermelon. - The watermelon is shipped everywhere in such enormous quantities, and it covers so much space in the garden, that home-gardeners in the North seldom grow it. When one has room, it should be added to the kitchen-garden.

The culture is essentially that for muskmelons (which see), except that most varieties require a warmer place and longer period of growth. 
Give the hills a distance of 6 to 10 feet apart. Choose a warm, "quick" soil and sunny exposure. It is essential, in the North, that the plants grow rapidly and come into bloom early. One ounce of seed will plant thirty hills.

There are several white or yellow-fleshed varieties, but aside from their oddity of appearance they have little value. A good watermelon has a solid, bright red flesh, preferably with black seeds, and a strong protecting rind. Kolb Gem, Jones, Boss, Cuban Queen, and Dixie are among the best varieties. There are early varieties that will ripen in the Northern season, and make a much better melon than those secured on the market.

The so-called "citron," with hard white flesh, used in making preserves, is a form of watermelon. 


\section{CHAPTER XI}

\section{SEASONAL REMINDERS}

THE author assumes that a person who is intelligent enough to make a garden, does not need an arbitrary calendar of operations. Too exact advice is misleading and unpractical. Most of the older gardening books were arranged wholly on the calendar method - giving specific directions for each month in the year. We have now accumulated sufficient fact and experience, however, to enable us to state principles; and these principles can be applied anywhere, - when supplemented by good judgment, - whereas mere rules are arbitrary and generally useless for any other condition than that for which they were specifically made. The regions of gardening experience have expanded enormously within the past fifty and seventyfive years. Seasons and conditions vary so much in different years and different places that no hard and fast advice can be given for the performing of gardening operations, yet brief hints for the proper work of the various months may be useful as suggestions and reminders.

The Monthly Reminders are compiled from files of the "American Garden" of some years back, when the author had editorial charge of that magazine. The advice for the North (pages 504 to 516) was written by T. Greiner, La Salle, N.Y. well known as a gardener and author. That for the South (pages 516 to 526) was made by H. W. Smith, Baton Rouge, La., for the first nine months, and it was extended for "GardenMaking" to the months of October, November, and December by F. H. Burnette, Horticulturist of the Louisiana Experiment Station. 


\section{KITCHEN-GARDEN PLANTING TABLE}

\section{A Guide to the Proper Times for Sowing of Various Seeds in Order to obtain Confinuous Succession of Crops}

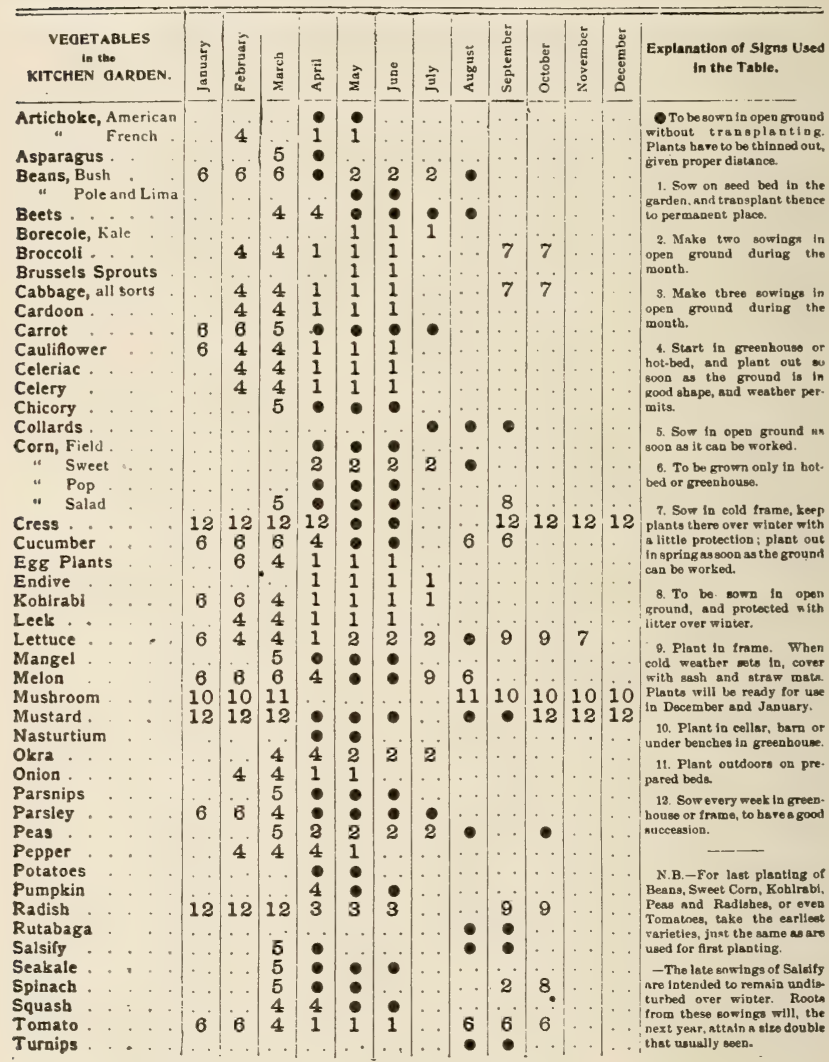




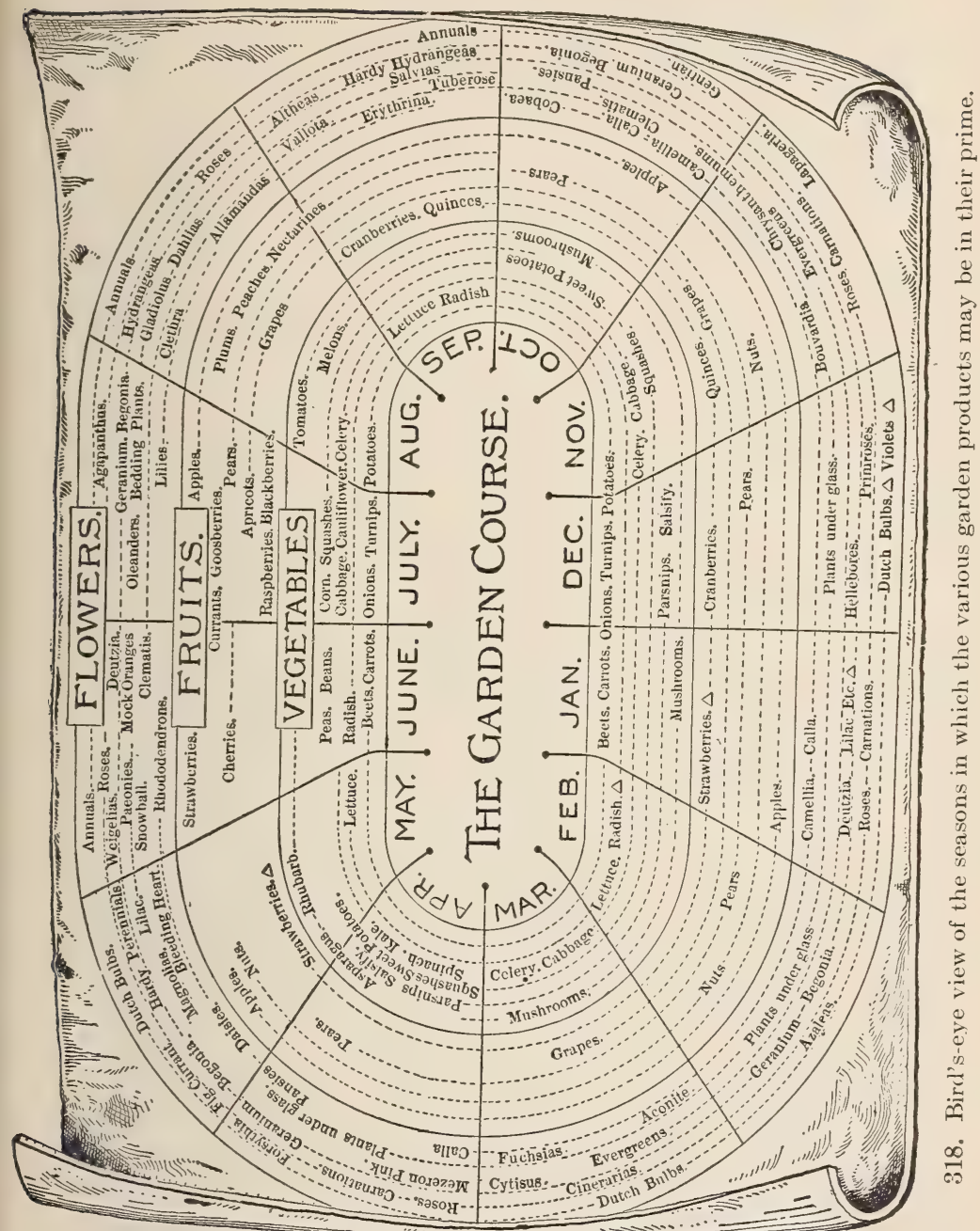




\section{SUGGESTIONS AND REMINDERS.-I. FOR THE NORTH}

\section{JANUARY}

Cabbage plants in frames need free airing whenever the temperature is abore the freezing point, or so long as the soil of the bed is not frozen. Snow, in that case, should be remored soon after its fall. As long as the soil is frozen the snow can safely be left on for a number of days. Cabbage, cauliflower, and lettuce seed should be sown at intervals to secure plants for extra-early sales or setting. A month later they will be ready to transfer to boxes, which should go to the coldframe and be given protection by mats or shutters.

Coldframes must be well rentilated on warm, sunny days; leave the sashes off as long as is possible without injury to the plants. Keep the soil in a friable condition, and look carefully to any possible places where water can stand and freeze. If the frames seem too cold, bank up around them with coarse manure.

Hotbeds. - Look up and repair the sashes. Save the horse-manure from day to day, rejecting dry litter, and piling up the droppings and urine-soaked bedding in thin layers to prevent violent heating.

Lettuce in frames treat as advised for cabbage plants.

Pruning should now be considered. Perhaps it is best to prune fruit-trees in March or April, but grapes and currants and gooseberries may be pruned now. January and February are good months in which to prune peach trees. Thin out the peach trees well, taking care to remove all the dead wood. If you have much pruning to do in apple, pear, or plum orchards, you will save time by utilizing the warm days now. Study well the different methods of pruning. Never let an itinerant pruner touch your trees until you are satisfied that he understands his business.

Tools should now be inspected and repaired, and any new ones that are needed made or ordered.

\section{FEBRUARY}

Cabbage. - Sow seed of Jersey Wakefield in flats filled with light loamy soil, the last week of this month. Sow thinly, corer lightly, and place the boxes in a gentle hotbed or any warm, sunny situation. When the plants are strong, transplant them into flats $1 \frac{1}{2}$ in. apart 
each way. As growth begins, gradually expose them to the open air on all favorable occasions. Late in March remove them to a coldframe, and properly harden them off before setting them in the open ground. '

Celery. - We urgently advise every one who has a garden, large or small, to make a trial of the new celery-culture. You need, first, good plants. Get some seed of White Plume or Golden Self-blanching, and sow it thickly in flats filled with fine loam. Cover by sifting a thin layer of sand or fine soil over it, and firm well. Keep in a moderately warm place, watering as needed, until plants appear. If you have a number of flats, they may be placed on top of one another. At the first sign of plant-growth, bring the flats gradually to the light. When the plants are $1 \frac{1}{2}$ or $2 \mathrm{in}$. high, transplant them into other flats, setting them in rows $2 \frac{1}{2}$ in. apart, the plants half an inch apart in the rows. Then set the flats in a coldframe until the plants are large enough to plant out in the open ground.

Hotbeds for raising early plants should be made this month. Always break the manure up fine and tread it down well. Be sure to put enough in the center of beds, so that there will be no sagging. Fresh manure of hard-worked and well-fed horses, free from dry litter, is best. An addition of leaves used for bedding will serve to produce a more moderate but more lasting heat. Sheep-manure may also be added to the horse-manure, should there be a scant supply of the latter on hand.

Onions. - We urgently advise giving the new onion-culture a trial. For seed, buy a packet or an ounce of Prizetaker, Spanish King, White Victoria, or some other large kind of globe onion. Sow the seed in flats, in a hotbed, or in a greenhouse late in the month, and transplant the onions to the open ground as soon as the latter is in working condition. Set the plants in rows $1 \mathrm{ft}$. apart and about $3 \mathrm{in}$. apart in the row.

Plums. - Make a thorough inspection of all plum and cherry trees, wild and cultivated, for plum-knot. Cut and burn all the knots found. Remove all "mummy" plums, for they spread the fruit-rot.

Rhubarb. - Give the plants in the garden a heavy dressing of fine old compost. If you wish a few early stalks, place kegs or boxes over some of the plants, and heap over them some heating horse-manure. 


\section{MARCH}

Beets. - A few seeds may be sown in the hotbed.

Cabbage, cauliflower, and celery seeds may be sown for the early crop.

Egg-plants. - Seeds should be sown. Take care that the young plants are never stunted.

Grafting may be done in favorable weather. Cherries and plums must be grafted early. Use liquid grafting-wax in cold weather.

Hotbeds may be made at any time, but do not grow impatient about the work, for there will be cold weather yet. Clean, fresh manure is necessary, and a layer $2 \mathrm{ft}$. thick should be tramped hard. When once started and the seeds sown, do not let the beds get too hot. Give them air on fine days and give the seedlings plenty of water. Use two thermometers - one to test the atmosphere and the other the heat of the soil.

Lettuce should be sown in the hotbed for an early crop.

Onion seed for the new onion-culture may be sown at the close of the month.

Peas. - Sow now, if the ground can be worked.

Peppers may be sown late in the month.

Potatoes kept for seed must not be allowed to sprout. Keep them in a temperature near freezing point. Rub off the sprouts from potatoes kept for eating, and pick out all decayed specimens.

Spinach. - Sow some seeds for an early crop.

Tomato seeds may be sown in the hotbeds.

\section{APRIL}

Artichokes. - Sow the seeds for next year's crop. A deep, rich, sandy loam is best. Fork in a dressing of well-rotted manure around the old plants.

Asparagus. - Spade in some good manure in the bed, and give the soil a thorough working before the crowns start. Sow seeds in the open ground for young plants for a new bed.

Beans. - Limas may be started on sods in a hotbed or a coldframe towards the last of the month.

Beets. - The ground should be prepared and the seed sown for beets for cattle as soon as the weather will permit. Put them in before 
planting corn. They will stand considerable cold weather, and should be planted early to get a start of the weeds.

Blackberries should be pruned, the brush drawn off, piled, and burned. If it is necessary to stake them, try a wire trellis, the same as for grapes, putting on one wire $2 \frac{1}{2} \mathrm{ft}$. high. The young plants should be dug before the buds start.

Cabbage seed may be sown in the open ground, in coldframes, or in pans or boxes in the house. Early varieties should be started at once. Cabbages like a rich and heavy loam, with good drainage. Give them all the manure you can get.

Cauliflower seeds may be sown toward the last of the month. They should never have a check from the time the seed is sown until harvested.

Carrot. - Sow the seed of early sorts, like Early Forcing, as soon as the ground can be worked.

Celery. - Plan to grow celery by the new method. Plenty of manure and moisture are required to do this. Sow the seed in light, rich soil in the house, hotbed, coldframe, or open ground. Transplant the plants once before setting them in the field. Page 505.

Cress. - Sow early and every two or three weeks. Watercress should be sown in damp soil or in streams. The outer edges of a hotbed may also be utilized. Cress is often a profitable crop when rightly handled.

Cucumber seeds may be sown on sods in the hotbed.

Egg-plant. - Sow in the hotbed, and transplant when 2 in. high to other beds or pots. They must have good care, for a check in their growth means all the difference between profit and loss.

Lettuce. - Sow the seeds in the hotbed, and in the open ground as soon as it can be worked. Plants sown a month ago should be transplanted.

Leek. - Sow the seeds in the open ground in drills 6 in. apart and $1 \mathrm{in.} \mathrm{deep,} \mathrm{and} \mathrm{when} \mathrm{large} \mathrm{enough,} \mathrm{thin} \mathrm{to} 1 \mathrm{in}$. in the row.

Muskmelon. - Plant seeds in sods in the hotbed.

Parsnip. - Dig the roots before they grow and become soft and pithy. Seeds may be sown as soon as the ground is dry enough to work.

Parsley. - Soak the seeds in warm water for a few hours, and sow in the open ground. 
Peas. - Sow the seeds as soon as the ground can be worked. They will stand considerable cold and transplanting also. Time may be gained by sowing some seeds in moist sand in a box in the cellar and transplanting when well sprouted. Plant deep in light, dry soil; cover an inch at first, and draw in the earth as the vines grow.

Potatoes. - Plant early on rich soil free from blight and scab. For a very early crop, the potatoes may be sprouted before planting.

Peppers. - Sow the seeds in the hotbed or in the boxes in the house.

Radish seeds may be sown in the open ground or in the hotbed and the crop harvested from there. The small, round varieties are best for this purpose.

Strawberries. - Give a good, thorough cultivation between the rows and then remove the mulch from the plants, placing it in the rows, where it will help to keep the weeds down.

Salsify. - Sow the seeds as soon as the ground can be worked. Give the same care and cultivation as for carrots or parsnips.

Spinach seeds must be sown early, and then every two weeks for a succession. Thin out and use the plants before they send up flowerstalks.

Squashes. - Hubbards and summer squashes may be started on sods in the hotbed.

Tomato. - Sow in the hotbed or in shallow boxes in the house. Try some of the yellow varieties; they are the finest flavored of any.

\section{MAY}

Beans. - The bush sorts may be planted in the open ground, and limas in pots or sods in a coldframe or spent hotbed. Limas require a long season to mature, and should be started early.

Beets. - Sow for a succession. Transplant those started under glass.

Cabbages always do best on a freshly turned sod, and should be set before the land has had time to dry after plowing. The secret of success in getting a large yield of cabbage is to start with rich land and put on all the manure obtainable. Clean out the hog yard for this purpose.

Cucumbers. - Sow in the open ground toward the last of the month. A few may be started as advised for lima beans. 
Lettuce. - Sow for a succession, and thin to 4 in. in the rows.

Melons. - Plant in the open ground toward the end of the month. It is useless to plant melons and other cucurbitaceous plants until settled weather has arrived.

Onions. - Finish planting and transplanting, and keep all weeds down, both in the seed-bed and the open field.

Peas. - Sow for a succession.

Squashes. - Plant as advised for melons and cucumbers. They require a rich, well-manured soil.

Strawberries. - Remove the blossoms from newly set plants. Mulch with salt hay or marsh hay or clean straw or leaves those that are to bear. Mulching conserves moisture, keeps the berries clean, and prevents weeds from growing.

Sweet corn. - Plant early and late varieties, and by making two or three plantings of each, at intervals, a succession may be kept up all summer and fall. Sweet corn is delicious, and one can hardly have too much of it.

Tomatoes. - Set some early plants by the middle of the month or earlier, if the ground is warm, and the season early and fair. They may be protected from the cold by covering with hay, straw, cloth, or paper, or even with earth. The main crop should not be set until the 20 th or 25 th, or until all danger of frost is over. However, tomatoes will stand more chilly weather than is ordinarily supposed.

\section{JUNE}

Asparagus. - Cease cutting and allow the shoots to grow. Keep the weeds down and the soil well stirred. An application of a quick commercial fertilizer or of liquid manure will be beneficial.

Beans. - Sow the wax sorts for succession. As soon as a crop is off, pull out the vines and plant the ground to late cabbage, turnips, or sweet corn.

Beets. - Transplant in rows 1 to $3 \mathrm{ft}$. apart and 6 in. in the row. Cut off most of the top, water thoroughly, and they will soon start.

Cabbage and cauliflower. - Set plants for the late crop. Rich, newly turned sod and a heavy dressing of well-rotted manure go a long way toward assuring a good crop. 
Celery. - Set the main crop, and try the new method of setting the plants 7 in. apart each way, if you have rich land and can irrigate, but not unless these conditions are present. Page 505.

Cucumbers may yet be planted, if done early in the month.

Currants. - Spray with Paris green for the currant worm until the fruit sets. Hellebore is good, but it is difficult to get it of good strength; use it for all late spraying.

Lettuce. - Sow for succession in a moist, cool, and partially shaded spot. The seed does not germinate well in hot weather.

Lima beans should be hoed frequently, and started on the poles if they are contrary.

Melons. - Cultivate often and watch for the bugs. A screen of closely woven wire or mosquito netting may be used to cover the vines, or tobacco dust sifted on thickly.

Onions. - Keep free from weeds and stir the ground frequently and especially after every rain.

Squashes. - Keep the ground well cultivated and look out for bugs. (See Melons.) Layer the vines and cover the joints with fresh soil, to prevent death of the vines from the attacks of the borer.

Strawberries. - Plow up the old bed that has borne two crops, as it will usually not pay to keep it. Set the ground to late cabbage or some other crop. The young bed that has borne the first crop should have a thorough cultivation and the plow run close to the rows to narrow them to the required width. Pull up or hoe out all weeds and keep the ground clean the rest of the season. This applies with equal force to the newly set bed. A bed can be set late next month from young runners. Pinch off the end after the first joint, and allow it to root on a sod or in a small pot set level with the surface.

Tomatoes. - For an early crop train to a trellis, pinch off all side shoots, and allow all the strength to go to the main stalk. They may also be trained to poles, the same as lima beans, and can be set closer if grown in this way. Spray with the bordeaux mixture for the blight, keep the foliage thinned and the vines off the ground.

Turnips. - Sow for an early fall crop. 


\section{JULY}

Beans. - Sow the wax sorts for a succession.

Beets. - Sow Early Egyptian or Eclipse for young beets next fall.

Blackberries. - Head back the young canes to $3 \mathrm{ft}$., and the laterals also when they get longer. They may be pinched with the thumbnail and finger in a small patch, but this soon makes the fingers sore, and when there are many bushes to go over, it is better to use a pair of shears or a sharp sickle.

Cabbage. - Set plants for the late crop.

Corn. - Plant sweet corn for succession and late use.

Cucumbers. - It is late to plant, but they may be put in for pickles if done before the Fourth. Cultivate those which are up, and keep an eye open for bugs.

Currants. - Cover a few bushes with muslin or burlap before the fruit ripens, and you can eat currants in August. Use hellebore, rather than Paris green, for the last brood of currant worms, and apply it as soon as the worms appear. There is little danger in using it, even if the currants are ripe.

Lettuce seed does not germinate well in hot weather. Sow in a moist, shaded position for a succession.

Lima beans. - Hoe them frequently, and give assistance to get on the poles.

Melons. - Watch for bugs, and apply tobacco dust freely around the plants. Keep them well cultivated. A light application of bone meal will pay.

Peaches, pears, and plums should be thinned to secure fine fruit and to help sustain the vigor of the tree. Ripening the seed is what draws on the tree's vitality, and if the number of seeds can be reduced onehalf or two-thirds, part of the strength required to ripen them will go into perfecting the fruit and seeds left, and add greatly to the fine appearance, flavor, and quality of the edible portion.

Radishes. - Sow the early kinds for a succession, and toward the end of the month the winter sorts may be put in.

Raspberries. - Pinch back the canes to $2 \frac{1}{2} \mathrm{ft}$., the same way as given for blackberries.

Squashes. - Keep the ground well stirred, and use tobacco dust 
freely for bugs and beetles. Cover the joints with fresh soil, to guard against injury by the vine-borer.

\section{AUGUST}

Beets. - A last sowing of the early table sorts may be made for a succession.

Cabbage. - Harvest the early crop, and give good cultivation to the main crop. Keep down the bugs and worms.

Celery. - The latest crop may yet be set. Earlier set plants should be handled as they attain sufficient size. Common drain tiles are excellent for blanching if one has them, and must be put on when the plants are about half grown. Hoe frequently to keep the plants growing.

Onions. - Harvest as soon as the bulbs are well formed. Let them lie on the ground until cured, then draw to the barn floor or some other airy place and spread thinly. Market when you can get a good price, and the sooner the better.

Tomatoes may be hastened in coloring by being picked just as they begin to color and placed in single layers in a coldframe or hotbed, where they can be covered with sash.

\section{SEPTEMBER}

In many parts of the North it is not too late to sow rye, or peas, or corn, to afford winter protection for orchards. As a rule, very late fall plowing for orchards is not advisable. Now is a good time to trim up the fence-rows and to burn the brush piles, in order to destroy the breeding places of rabbits, insects, and weeds. Cuttings of gooseberries and currants may be taken. Use only the wood of the current year's growth, making the cuttings about a foot long. Strip off the leaves, if they have not already fallen, tie the cuttings in large bundles, and bury them in a cold cellar, or in a sandy, well-drained knoll; or if the cutting-bed is well prepared and well drained, they may be planted immediately, the bed being well mulched upon the approach of winter. September and October are good months in which to set orchards, provided the ground is well prepared and well drained, and is not too much exposed to sweeping winds. Wet lands should never 
be set in the fall; and such lands, however, are not fit for orchards. Strawberries may still be set; also bush fruits.

Seeds of various flowers may now be sown for winter bloom, if one has a conservatory or good window. Petunias, phloxes, and many annuals make good window plants. Quicker results are secured, however, if border plants of petunias and some other things are dug up just before frost and placed in pots or boxes. Keep them cool and shaded for a couple of weeks, cut down the tops, and they will send up a vigorous and floriferous growth. Winter roses should now be in place in the beds or in pots.

There will be odd days when one can go to the woods and fields and collect roots of wild herbs and shrubs for planting in the yard or along the unused borders of the garden.

\section{OCTOBER}

Asparagus. - Old plantations should now be cleaned off, and the tops removed at once. This is a good time to apply manure to the beds. For young plantations, which may be started now as well as in spring, select a warm soil and sunny exposure, and give each plant plenty of room. We like to set them in rows $5 \mathrm{ft}$. apart and at least $2 \mathrm{ft}$. apart in the rows.

Cabbages. - The heads that will winter best are those just fully formed, not the over-ripe ones. For family use, bury an empty barrel in a well-drained spot, and fill it with good heads. Place a lot of dry leaves on top, and cover the barrel so that it will shed rain. Or, pile some cabbages in a corner of the barn floor and cover them with enough straw to prevent solid freezing. Pages 159, 470.

Cabbage-plants, started from seed last month, should be pricked out in cold-frames, putting about 600 to the ordinary sash and setting them quite deep.

Chicory. - Dig what is wanted for salad, and store it in sand in a dry cellar.

Endive. - Blanch by gathering up the leaves and tying them lightly at the tips.

General garden management. - The only planting that can be done in open ground at this time is restricted to rhubarb, asparagus, and 
perhaps onion-sets. Begin to think about next year's planting, and to make arrangements for the manure that will be needed. Often you can purchase it now to good advantage, and haul it while the roads are yet good. Clean up and plow the ground when the crops are harvested.

Lettuce. - Plants to be wintered over should be set in frames like cabbage-plants.

Onions. - Plant sets of Extra Early Pearl, or some other hardy kind, in the same fashion as in early spring. They are likely to winter well, and will give an early crop of fine bunching onions. For the North, fall sowing of onion-seed cannot be recommended.

Parsley. - Lift some plants and set them in a coldframe 4 or 5 in. apart, or in a box filled with good soil, and place in a light cellar or under a shed.

Pears. - Pick the winter sorts just before there is danger from freezing. Put them in a cool, dark place, where they will neither mold nor shrivel. To hasten ripening, they may be brought into a warm room as wanted.

Rhubarb. - If plants are to be set or replanted this fall, enrich the ground with a superabundance of fine old stable-manure, and give each plant a few feet of space each way. In order to have fresh pieplant in winter, dig up some of the roots and plant them in good soil in a barrel placed in the cellar.

Sweet-potatoes. - Dig them when ripe after the first frost. Cut off the vines, and turn the potatoes out with a potato-fork or plow. Handle them carefully to prevent bruising. Only sound, well-ripened roots are in proper condition to be wintered over.

\section{NOVEMBER.}

Asparagus. - Manure before winter sets in.

Beets. - They keep best in pits. Some may be kept in the cellar for use during winter, but cover them with sand or sods to prevent shriveling.

Blackberries. - Cut away the old wood and mulch the roots. Tender sorts should be laid down and lightly covered with soil at the tips. 
Carrots. - Treat as advised for beets.

Celery. - Dig up the stalks, leaving the roots on, and stand them close together in a narrow trench, tops just even with the ground-level. Gradually cover them with boards, earth, and manure. Another way is to set them upright upon the floor of a damp cellar or root-house, keeping the roots moist and the tops dry. Celery can stand some frost, but not exposure to less than $22^{\circ} \mathrm{F}$. The stalks intended for use before Christmas may in most localities be left outdoors, to be used as wanted. Should cold weather set in early, they will need covering in some way. Page 475.

Orchard management. - Young trees should have a mound of earth raised around the stem as a support and protection against mice, etc. Small and lately planted trees may have stakes set beside them, and be tied to the stakes with a broad band. Apple and pear trees may yet be planted. Trim superfluous or unhealthy wood out of the old orchards.

Spinach. - Cover the beds lightly with leaves or litter before winter sets in.

Strawberries. - Soon it will be time to mulch the beds. Provide marsh hay, or other coarse litter, free from weed-seeds, and when the ground has frozen an inch or so, spread it all over the surface thinly and evenly.

\section{DECEMBER}

Cabbages. - Plants in coldframes should be aired freely and kept cool. Heads intended for winter and spring use, if not yet taken in or protected from severe freezing, must now be cared for. Do not cover them too deeply, nor store them in too warm a place.

Carrots. - Store them in cellars or pits. If in cellars, keep the roots covered with sand or sod, to prevent wilting.

General garden management. - Begin now to make your plans for next season's work. Carefully study up the matter of rotation, also that of feeding your crops in the most effective and economical manner. Repair frames, sashes, and tools. Clear up the garden and premises. Underdrain where needed. Beds for early vegetables should be thrown up in high, narrow ridges, with deep furrows between. This will enable you to plant them several days or weeks earlier than otherwise. 
Kale. - In very exposed or northern locations cover it lightly with coarse litter.

Onions. - For winter storage select only well-ripened, perfectly dry bulbs. Store them in a dry, airy place, not in the cellar. They may be spread out thinly on the floor, away from the walls, allowed to freeze solid, and then covered several feet deep with hay or straw.

Parsnips. - Take up some roots for winter use and store them in sand in the cellar.

Strawberry-beds should be given their winter covering of marsh hay, etc., as soon as the ground is frozen solid.

\section{SUGGESTIONS AND REMINDERS. - II. FOR THE SOUTH}

\section{JANUARY}

Annuals. - All kinds of hardy annuals and perennials, such as alyssum, snapdragon, foxglove, hollyhock, phlox, poppy, pansy, lobelia, candytuft, sweet pea, Chinese pink, sweet william, larkspur, foliage cinerarias, centaurea, mignonette, and many others of the same class may be sown. Most of them should be sown thinly and where they are intended to flower, as they transplant poorly in this latitude.

Cannas, caladiums, perennial phloxes, chrysanthemums, and verbenas may be taken up, divided, and replanted.

Roses may be planted in quantities. Let the ground intended for them have a thorough dressing of manure. Occasionally a plant may be taken up and divided. The hybrid varieties may now be layered. This is done as follows: Select a shoot and bend it flat upon the ground; hold it in both hands, having a distance of about 6 in. between them; keep the left hand firm, and with the right give the shoot a sharp twist; now cover it with $4 \mathrm{in}$. of earth and tie the free end to an upright stake.

Asparagus beds should be liberally manured. New beds should now be made. Set the plants 6 in. deep. Sow seed now.

Beets and all hardy vegetables (carrots, parsnips, turnips, rutabagas, kohlrabi, spinach, lettuce, herbs, etc.) may now be sown, planted, or transplanted. 
Cabbage plants should be set out on heavily manured ground. Sow seed of Early Summer for a later supply.

Fruits.- If possible, all planting and transplanting of fruit-trees and grape-vines should be finished this month. Pruning should be completed as soon as possible, and preparation made to protect the blossoms of tender fruits next month. Set out strawberry-plants, and during dry weather run the cultivator through all old beds that are at all weedy. It is a good plan, where practicable, to mulch the beds. Here, pine-straw can be had plentifully for the purpose. Examine peach trees for borers. Raspberries and blackberries should be pruned now if the work is not already done. Cuttings of Le Conte pears, Marianna plums, grape-vines, and pomegranates should be put in at once if they have heretofore been forgotten. Root-grafting should be progressing rapidly; this is the best time for this important work.

Onion seeds. - Sow at once, and plant sets as soon as possible.

Peas. - Sow early and late varieties. The late varieties succeed best if sown at this season.

Seasonable work. - This is a good month to obtain canes for staking peas, tomatoes, and beans, hauling manure, making repairs, and examining tools, etc. As the fall crop is harvested, the land should be prepared for another crop. Tile-draining is now is order. Prepare frames to cover with canvas for use next month.

Sweet-potatoes. - A few may be bedded in a frame from which to obtain "draws" for setting out about March 15.

Tomatoes, egg-plants, and peppers. - Sow now on a slight hotbed. When the plants come up, all the air possible should be given during the day. They can be raised without heat, but at this season this plan would better be attempted only by the skillful.

\section{FEBRUARY}

Asters, cannas, dahlias, heliotropes, lobelias, petunias, pyrethrums, ricinus, salvias, and verbenas are best sown in a coldframe, where they can have some protection from heávy rain.

Cannas should be transplanted now.

Chrysanthemums must be planted in well-manured ground in a position where water can be readily supplied to them. 
Dahlias may be taken up and divided as soon as they begin growth. Gladiolus and tuberose bulbs should be planted now. It is a good plan to extend the planting through March and April.

Pansies. - Plant them out in the beds where they are to flower.

Routine work. - Sodding should now proceed rapidly. If sods cannot be obtained, the ground may be planted with Bermuda grass. Plant small pieces of the grass a foot apart and water them if the weather is dry, and they will grow rapidly. Hedges should be cleared up and put in good shape. All planting of trees and shrubs should be finished this month. All pruning of trees must be done early in the month. Young roses cannot be set too early in February. They thrive best when planted in fall. Roll the drives and repair them when necessary. The lawn will now require constant care, and the mower should be used before the grass becomes $1 \frac{1}{2}$ in. high.

Bush-beans may be planted February 14. On alluvial land it is best to plant them on slight rises as a protection against the rains which sometimes occur toward the end of the month. If frost should threaten just as the beans begin to peep out, cover them an inch deep with the plow or hand cultivator. Sow Early Mohawk first, and at the end of the month sow Early Valentine; a week later sow the wax varieties.

Cabbage. - Sow early varieties, such as Early Summer, Early Drumhead, and Early Flat Dutch. Etampes, Extra Early Express, and Winnigstadt sown for small heads in the order named have done very well in southern Louisiana. The earlier sown plants should be transplanted as often as convenient. Should worms cause trouble, dust the plants with a mixture of one part of pyrethrum powder to six of fine dust.

Carrots, celery, beets, endive, kohlrabi, onion sets, parsley, parsnips, radishes and purple-top turnips must now be sown.

Corn. - Plant Extra Early Adams, Yellow Canada, Stowell Evergreen, and White Flint toward the middle of the month. Sow again a week later, and again after another week. If the first two sowings fail, the last one will give the early crop.

Cucumbers. - Sow and protect with small boxes during cold days and nights, or sow in pots or on sods. Protect the seedlings with sashes or canvas, and plant them out late. 
Lettuce. - Sow seeds and transplant the plants on hand. This crop requires a soil well supplied with plant-food.

Melons. - Plant seeds in the same manner as advised for cucumbers.

Okra. - Sow seeds on sods and set out the plants next month.

Peas. - Sow seeds of a number of varieties.

Peppers and egg-plants, if not sown last month, should be sown now. Sow them under glazed sashes and keep close. When the plants appear, give some air, and increase it according to the weather. If a large number of plants is required, the sowing may be delayed until next month. Should flea-beetles trouble you, use plenty of bordeaux on egg-plants.

Potatoes, Irish. - The main crop should be planted as early as possible. Standard varieties are Early Rose, Peerless, and Burbank.

Strawberries. - Run the cultivator through them at least once every three weeks; if they are to be mulched, collect the necessary material. Strawberries planted in February seldom yield much of a crop.

Sweet-potatoes, can now be bedded and protected with canvas, or a row or two of whole tubers may be planted for "draws" and vines.

Tomatoes in frames should be given all the air and light possible and plenty of room ' if protected with canvas, do not allow the plants to crowd.

\section{MARCH}

Beans. - Sow all varieties for a fall crop. As soon as the plants appear, the cultivator must-be run through the crop, and kept going as often as necessary.

Corn. - Continue to plant; and we recommend harrowing the patch as soon as the young corn appears. It is generally planted in hills 3 or $4 \mathrm{ft}$. apart, but better results will be obtained by planting in drills and leaving one stalk every 12 in.

Cucumbers. - Sow in hills $4 \mathrm{ft}$. apart, using a liberal quantity of seed to each hill. When the plants come up, thin them to about six in the hill. When the plants begin to get rough leaves, pull out one or two more from each hill. Striped cucumber-beetles are sometimes very numerous, and in order to get a stand of plants it is necessary to 
go through the patch early every morning and sprinkle all the hills with air-slaked lime.

Egg-plants. - Toward the end of the month the plants growing in frames may be transplanted to their fruiting quarters. Seed may be sown outside after March 15; sooner if a warm and sheltered spot is selected.

Lettuce. - Sow in drills, and when the plants are large enough, thin to a foot apart. If transplanted at this season, they often go to seed.

Okra. - A sowing may be made now, but the main planting would best be deferred until after March 15 . Sow in drills $3 \mathrm{ft}$. apart and thin the plants to $18 \mathrm{in}$. apart in the drills.

Peas. - Early varieties may be sown; it is now too late to sow tallgrowing kinds.

Peppers. - Treat as advised for egg-plants.

Potatoes, Irish. - It is not too late to plant them, but the sooner they are planted the better. The crop planted in February should be harrowed as soon as the shoots begin to come up, and when the rows can be fairly seen, the cultivator must be set to work to keep down weeds and grass.

Squashes. - Plant seed in hills $6 \mathrm{ft}$. apart. The directions for planting melons may be followed. The same remarks apply to pumpkins and other vegetables of this kind.

Sweet-potatoes. - If slips or vines are at hand, they may be planted late in the month for the earliest tubers. The whole potatoes may be planted on a ridge to yield vines for later planting.

Strawberries. - The mulching of beds or rows should be no longer delayed, if clean and plentiful fruit is wanted.

Tomatoes. - About March 15 the frame plants may go to their fruiting quarters. It is necessary to use some judgment in this matter, as they may be killed or injured by an April frost. Seed may be sown in the open ground for plants for late fruiting. Set the plants $4 \mathrm{ft}$. apart each way.

\section{APRIL}

Alternantheras should go out now.

Annuals of all kinds may still be sown where they are to flower, as they transplant with difficulty at this season. 
Coleuses. - Plant out in the beds now. Cuttings root readily, simply requiring to be stuck in.

Beans of all kinds can be planted, limas especially.

Beets. - Make another sowing.

Cabbage plants obtained from spring sowings should be set out as soon as fit. The ground requires to be very rich to carry this crop.

Cucumbers. - These can be sown anywhere now.

Corn. - Make a sowing to yield roasting ears to come in after that sown last month.

Okra. - Sow in drills 3 or $4 \mathrm{ft}$. apart.

Peas. - Make a sowing of early varieties for the last time.

Squash (bush) and pumpkin may now be planted.

Tomatoes should be got out to their fruiting quarters as early in the month as possible. Let them be set at least $4 \mathrm{ft}$. apart each way.

\section{MAY}

Beans. - Plant a few more bush and pole beans.

Celery may now be started. The bed or box needs plenty of water, and should be shaded from sun.

Lettuce requires careful handling to encourage it to germinate. It is best sown in a box and kept shaded and moist.

Melons, cucumbers, squashes, and pumpkins may be sown.

Radishes. - Sow the yellow and white summer varieties.

Remarks. - It is a constant struggle with weeds throughout this month, and the cultivator and plow are ever going. As the land becomes vacant, sow corn or plant sweet-potatoes - draws or vines. Sow some late Italian cauliflower. Let the orchard have constant and thorough cultivation, and remove all unnecessary growth from the trees as soon as they appear. Be always on the lookout for borers. Keep the strawberries as free of grass and coco, or knob-grass, as possible.

\section{JUNE}

Beans. - All kinds may now be sown.

Cauliflower. - Sow the Italian kinds.

Corn. - Make a planting at the beginning of the month and again at the end. 
Cucumbers. - Plant a few more hills. The plants at this season must be given plenty of water.

Endive. - Sow, and attend to the tying up of the plants that are of sufficient size.

Melons. - Sow for a succession a few more water and muskmelons. Okra may still be sown.

Radishes. - Sow the summer varieties now.

Squashes and pumpkins may yet be sown.

Sweet-potato vines may now be set out in quantities.

Tomatoes. - About the middle of the month sow for the fall crop.

JULY

Beans. - Bush and pole beans may be planted towards the end of the month.

Cabbage and cauliflower may now be sown, but the main sowing should be deferred until next month.

Carrots. - A sowing should be made.

Celery. - Sow and transplant what plants there may be on hand. Cucumbers. - These may be sown now for pickling.

Endive. - Transplant and sow.

Grapes should be kept well tied to trellis, and unnecessary growth removed, so that the wood may have the chance of becoming thoroughly ripened. If the cultivator and plow are not used judiciously, a second growth will be started, which is not desirable.

Lettuce. - The seed requires to be sprouted before being sown, and if the sowing is done on a dry day the drills should be watered.

Radishes. - Sow the summer kinds.

Strawberries. - Keep the beds clean of weeds and grass.

Tomatoes. - Make a sowing early in the month, or, what is much better, take cuttings from plants still in bearing.

Turnips. - Sow a few after a shower towards the end of the month.

Remarks. - Much cannot be done this month, as the weather is hot and dry, but the opportunity should not be lost for killing weeds and preparing for the planting season, which is now rapidly drawing near. 


\section{AUGUST}

Artichokes. - Seed of the Green Globe may be sown now and large plants obtained by spring. The seed-bed requires to be shaded.

Bush beans, beets, pole beans, carrots, celery, endive, kohlrabi, lettuce, mustard, Black Spanish and Rose China radishes, parsley, turnips, rutabagas, and salad plants of all kinds may now be sown. The seed should be sown on small ridges, adaptable to the kind of plants, for level culture is not successful in the vegetable garden in this section.

Broccoli should be more grown, for it is hardier than the cauliflower. Many cannot tell the difference between the two. Sow now.

Cabbages must be sown by the middle of the month. Make the ground very rich and shade the seed-bed, keeping it moist during the whole of the time.

Cauliflower should also be sown.

Potatoes, Irish, should be planted by the middle of the month, if possible. Plant only those that have sprouted, and instead of planting on top of the ridge set in the furrow and cover $2 \mathrm{in}$. deep; as the potatoes grow, work more soil down to them.

Salsify. - Sow now or early next month.

Shallots. - Plant them now.

Squash. - Bush kinds may be planted now at any time.

Sweet-potatoes. - Vines may still be set out, with prospects of harvesting a fair crop.

Tomatoes. - If short of plants, cut off good-sized limbs from bearing plants and plant them deep. Keep them moist, and they will root in a few days. Do this just before it rains.

\section{SEPTEMBER}

Annuals of the hardy class may be sown this month: the following list will assist in making a selection: Calliopsis, candytuft, calendulas, vanterbury bells, columbine, corn-flower, daisies, forget-me-nots, gaillardia, godetia, larkspur, Limnanthes Douglasii, mignonette, pansies, Phlox Drummondii, primroses, poppies of all kinds, Saponaria Calabrica, Silene pendula, sweet williams, and sweet peas.

Rulbs. - Study the catalogues and make out your wants, for it is nearing planting time. 
Lilies. - If success is required of the St. Joseph's or Virgin lily (L. candidum), it must be planted right away.

Perennials and biennials should be sown early this month. They have two good growing months ahead of them yet to make considerable progress. The seed-bed will require shade during the middle of the day until the young plants come up; frequent weedings will be required, as coco has not yet quit growing, and winter weeds are now putting in an appearance.

Remarks. - All plants used for salad purposes may be sown this month. The ground between the rows of growing crops should be kept in a fine, friable condition. Vegetable seeds of all kinds should always be sown on slight ridges on all but very sandy soils. If the seed is sown on a level bed, as practiced at the North, the ground will become as hard as a turnpike road should a heavy rain occur; and should this shower come along before the plants are up, a crust a quarter of an inch deep will be formed, and the plants will never see daylight. Sown on a ridge they come all right, as the water gradually drains away, leaving the top of the ridge loose and soft.

\section{OCTOBER}

All spring flower seeds should be sown in boxes or trays in the conservatory, and all spring bulbs should be planted. The hyacinth, narcissus, tulip and anemone, ranunculus and various lily bulbs, will bloom in good season planted at this time. The bedding plants should be carefully watched, so that any attack of aphis may be treated immediately. Sweet peas may be planted the first of this month, although they are commonly sown in September. A rich spot should be selected for them. This is the time to make the new lawn. The soil should be thoroughly stirred and well pulverized, mixing in a good dressing of commercial fertilizer, or, if one prefers it, a mixture which may be made at home, consisting of cotton-seed meal, acid phosphate, and sulfate of potash, at the rate of $1000 \mathrm{lb}$., $300 \mathrm{lb}$., and $100 \mathrm{lb}$. respectively, per acre. A rich, well-rotted compost, as a top dressing, would also be highly beneficial. Roses pruned late in September or early this month will produce fine winter blooms.

In the garden this is a busy month; some of the winter vegetables 
are growing, and others should be sown. The bud artichokes should be separated and set fully $3 \mathrm{ft}$. apart. Onions may still be sown in the early part of the month, and shallots should be divided and set. Some beans may be risked, and English peas sown for winter crop. A few cauliflowers may be tried and cucumbers planted in pots for the hotbeds next month. The following vegetables should be sown: Carrots, corn salad, chervil, Brussels sprouts, broccoli, beets, endive, kohlrabi, kale, lettuce, leeks, mustard, parsley, parsnip, radish, roquette, spinach, Swiss chard, salsify. Some cabbage and a few cauliflowers should be added to the list. Turnips should be sown for succession every two weeks until April or May. The celery should be kept growing and banking up commenced.

This is an excellent time to plant the new strawberry bed. Make the bed rich with well-rotted manure and select good, healthy sets. The Michel's Early and Cloud are probably the most popular varieties for general planting, and should be set in alternating rows.

\section{NOVEMBER}

Flower seeds and bulbs may be planted this month 'of the same varieties as in October. Cuttings of all the herbaceous plants should be made and potted, for use in the house and for the borders next season. The coldframes should also be put in order. Some of the bulbs for winter forcing should be selected and potted. One of the best Louisiana gardeners recommends the following treatment: Select good, strong bulbs and plant them in rich, light soil, in 5-in. pots, covering them about half an inch. Water well and bury the pots 6 or $8 \mathrm{in}$. deep in the ground, leaving them there about five weeks, when the bulbs will be found to be well rooted. From this time gradually expose to the light, and they will soon put forth blooms.

The same vegetables may be sown as for October, and the late cabbage seed planted. The Flat Dutch and Drumhead strains are prime favorites. New sowings of peas, turnips, mustard, and radishes should be made, and the hotbeds prepared and set out to cucumbers. Too much care cannot be taken that the manure should be in the best condition possible, so that a good supply of heat may be depended upon. The cucumbers planted last month will be ready now for setting in the hotbeds, and a winter crop forced. 
Orchard and vineyard planting. - This is the time to prepare land. That on which a late crop of cowpeas has grown is well suited for the purpose, and should be plowed deeply and well worked over. Towards the last of the month it should be cultivated again, in order to be ready for the trees next month.

\section{DECEMBER}

Lawns and yards need watching this month, and attention should be paid to the old leaves and fall rubbish, which makes the yard look untidy. A good place for the leaves is the compost heap. Hedges should be put in shape and the surface drains kept open. Shrubs and roses should be pruned for an early supply of flowers. The Camellia Japonicas are now in bloom, and care should be taken that the small branches are not torn off, instead of being cut properly. Many of these most beautiful of southern ornamental trees have been ruined by careless plucking of flowers.

Garden and orchard. - Many of the fall vegetables may be sown this month and others sown for a succession. Peas, spinach, roquette, radishes, lettuce, endive, and some Early York cabbage should also be sown. In the old spent hotbeds, tomatoes, peppers, and egg-plants may be started; there will not be enough heat to hurry them, and good, strong stocky plants will be secured if care is taken. Irish potatoes may be risked, should there be a favorable time for planting during the latter part of the month. Usually they are planted in January. The chances are about equal should they be planted late this month. Nuts of all kinds, both for budding and otherwise, should be planted. Some of the best Louisiana pecans are said to come true from seed, and may be sown where they are intended to grow. 


\section{INDEX}

The flowering annuals, being mostly in alphabetical lists (pp. 243-260), are not indexed here.

Abelia grandiflora, 306 .

abies species, 335,336 .

Abobra viridiflora, 311 .

abutilons, 351 .

acacia, rose, 300 .

acalypha, 230 .

acer, species, $322,323,330$.

Achillea Ptarmica, 269, 273.

achyranthes, 236,344 .

aconites, 273.

actinidia, 216, 308, 316.

adiantums, 372 .

adlumia, 310 .

Adonis vernalis, 273 .

æsculus species, 293, 323.

African lily, 351.

agapanthus, 351 .

agave, 364 .

Agrostemma Coronaria, 274.

Agrostis nebulosa, 245.

ailanthus, shoots of, 56 .

Ajuga reptans, 267.

akebia, 216, 308, 316.

alder, 293, 323.

alliums, 289.

almond, 415.

alpine plants, 232 .

alstremeria, 352 .

alternanthera, 235, 237, 239.

Althæa frutex, 297.

Althæa rosea, 271.

Alyssum saxatile, 267.

amarantus, 230.

amaryllis, 352 .

Amelanchier Canadensis, 293.

ammoniacal carbonate of copper, 197. ampelopsis species, 308, 309, 314.

andromeda, 299, 306.

anemone, 264, 265, 269, 273, 274, 353.

anise, 460 .

anise-tree, 306.

annuals for bedding, 249 .

annuals that bloom after frost, 248 . annuals by color, 246 .

annuals, cultivation of, 241 .

annuals listed by height, 251 .

annuals for ribbon-beds, 248 .

annuals, distances apart, 256.

Anthemis coronaria, 344.

Anthemis Kelwayi, 274.

Anthemis tinctoria, 271.

Antigonon leptopus, 313.

aphis, 198, 200.

Apios tuberosa, 313.

apple, culture of, 416 .

apple-maggot, 199.

apple-scab, 207, 417.

apricot, culture of, 420 .

aquarium, 348.

aquatic plants, 230.

aquilegias, 267, 269, 274.

Arabis albida, 265.

Arabis alpina, 274.

Aralia Sieboldii, 230, 354.

araucaria, 344, 354.

arborvitæ, 221, 333, 336.

Arbutus Unedo, 306.

architect's garden, 12.

ardisia, 306.

aristolochia, 317.

Arnebia echioides, 274.

arsenate of lead formula, 193.

artemisias, 273, 365.

Artemisia Stelleriana, 263.

artichoke, 462, 463.

Aruncus sylvester, 264.

Arundo Donax, 46, 264.

Asclepias tuberosa, 264, 274.

ashes, 111.

ash, mountain, 329 .

ash trees, 324,330 .

asparagus, 461.

asparagus beetle, 199 .

Asparagus medeoloides, 401.

Asparagus plumosus and tenuissimus: 317,344 . 
asparagus rust, 208.

Asparagus Sprengeri, 340.

aspen, 326.

asperula, 269.

aspidistra, 340 .

asters, native, 264, 274, 275.

Astilbe Japonica, 269.

Aubrietia deltoidea, 265.

aucuba, 344.

auricula, 354 .

azalea, culture of, 355 .

azalea species, 293, 305, 306.

Baccharis halimifolia, 291, 293.

Bacterium tumefaciens, 180.

balm, 460 .

bamboos, 230, 264.

Baptisia tinctoria, 264.

basil, 460 .

baskets, hanging, 348 .

basswood, 329 .

bay-tree, 306 .

bean, 459,463 .

bedding, 228 .

beech, 324 .

beet, 456,466 .

begonias, 356 .

belladonna lily, 287,352 .

Bellis perennis, 265.

Benzoin odoriferum, 293.

Berberis Aquifolium, 293.

Berberis Japonica, 306.

Berberis Thunbergii, 52, 221, 292, 293, 306.

Berberis vulgaris, 51, 293.

Bermuda buttercup, 384.

Bermuda-grass, 80.

betula species, 293, 323, 324.

bignonia species, 314, 315 .

billbergia, 344 .

biota, 336 .

birds, 16.

bitternut, 325 .

bitter-sweet, 315 .

bitter-sweet, false, 317.

blackberries, laying down, 138.

blackberry, culture of, 420 .

blackberry, disease of, 212 .

blackberry insects, 205 .

black-rot, 209.

bladder nut, 302, 303. bleeding-heart, 267, 276.

blister-mite, 199.

blood as fertilizer, 112.

bloodroot, 265 .

blue beech, 324 .

blue-grass, 78 .

Bocconia cordata, 263.

bog plants, 230.

bolting trees, 149 .

boltonias, 275 .

boneblack, 113 .

bone, ground, 113.

bordeaux mixture, 196.

borders, making, 74, 222 .

borers, 199, 417.

bougainvillea, 318 .

Boussingaultia baselloides, 313, 344.

bouvardia, 344 .

box, 293, 306.

box-elder, 323 .

boxthorn, 315 .

bridge-grafting, 148 .

Bridgeman, mentioned, 2.

broccoli, 467.

Bromus brizæformis, 245.

brooks, treatment of, 24, 58, 65, 232

broom, 306.

brussels sprouts, 467.

buckthorn, 221, 299.

budding, 151.

bud-moth, 200.

buffalo berry, 302 .

Buist, mentioned, 2.

bulbocodium, 289 .

bulbs, culture of, 281.

bulbs in window-garden, 345 .

burdock, ornamental, 3 .

Burnette, F. H., quoted, 501.

burning bush, 296.

button-bush, 294.

buttercups, tuberous, 289 .

butternut, 325 .

buttonwood, 326 .

Buxus sempervirens, 293.

cabbage, culture, 457,468 .

cabbage, storing, $159,470,513,515$.

cabbage diseases, 208, 469 .

cabbage insects, $200,457,469$.

cabbage maggots, 187, 201, 469.

cactus, 358 . 
caladium, 230, 359.

calceolaria, 360 .

calendars, 501.

calla, 360 .

Calla palustris, 264.

Callicarpa Americana, 305.

callirrhoë, 269.

Calycanthus floridus, 293, 305.

camassia, 289.

camellias, 306, 361.

campanulas, 269, 272, 275.

candytuft, perennial, 265, 277.

canker-worm, 201, 417.

cannas, 361 .

capsicum, 491.

Capsicum frutescens, 306.

caragana species, 294.

caraway, 460.

carbolic acid emulsion, 194.

carbonate of copper, 197.

cardinal flower, 272.

cardiospermum, 310.

carex for ground cover, 86 .

carnation rust, 208.

carnations, 363.

carpet-bedding, mentioned, 7, 30, 227. carpet-beds described, 234.

Carpinus Americana, 324.

carrot, 456, 471.

carya species, 325 .

Caryopteris Mastacanthus, 291,294,305.

caryota, 385.

case-bearers, 201.

Cassia Marilandica, 264.

castanea species, 294,324 .

catalpa species, $324,330$.

catnip, 460.

cats, 16.

cat-tail, 232, 264.

cauliflower, 457, 471.

cauliflower diseases, 208.

cauliflower insects, 200.

ceanothus, 294, 305.

cedar, 336.

cedrus species, 336 .

Celastrus scandens, 216.

celastrus species, 317 .

celeriac, 472 .

celery, 473.

cellared stock, 290.

cellars, 158, 475.
Celtis occidentalis, 324, 330.

Centrosema Virginiana, 311.

century plants, 38,364 .

cephalanthus, 291, 294.

cephalotaxus, 336.

Cercidiphyllum Japonicum, 324.

Cercis Canadensis, 324, 330.

cereus, 358.

chafer, rose, 206.

chamæcyparis species, 333, 336.

chamærops, 306, 385.

chamomile, 271.

chard, 475 .

cherry, culture, 422 .

cherry diseases, 211.

cherry, ornamental, 327.

cherry trees, shapes of, $43,44$.

chervil, 476.

chestnut, culture of, 433 .

chestnut disease, 208, 321 .

chickens in gardens, 178 .

chickory, 476.

Chilopsis linearis, 305.

China-berry, 330.

Chinese sacred lily, 289, 383.

chinquapin, 294.

Chionanthus Virginica, 294, 305.

chionodoxa, 289.

chrysanthemums, 365 .

chrysanthemums, hardy, 273.

chrysanthemum disease, 209.

Chrysanthemum frutescens, 365 .

chrysanthemum protection, 337.

Chrysanthemum uliginosum, 272, 280.

cineraria, 367.

Cineraria maritima, 235.

cinnamon vine, 313 .

cinquefoil, 299.

Citrus trifoliata, 221, 306.

cives, 477.

Cladrastis tinctoria, 324 .

clary, 460.

Claytonia Virginica, 265.

clematis, 216, 275, 310, 311, 314, 367 ,

Clethra alnifolia, 294, 306.

Cleyera Japonica, 306.

climbing plants, 307.

clothes-post, 55.

club-root, 208, 469.

Cobbett, mentioned, 2.

cobnuts, 433. 
Cobœa scandens, 344.

Coccinea Indica, 311.

Cocos Weddelliana, 385.

Codiæum, 369.

Codlin-moth, 201, 417.

Coffee tree, 325.

Coix Lachryma, 245.

colchicum, 284.

coldframes, 164.

cold storage, 160 .

coleus, 368 .

collards, 476.

colocasia, 230, 359.

coltsfoot for banks, 216.

columbines, 267, 269, 274.

Colutea arborescens, 294.

comfrey, 216.

compass plant, 263.

conifers, discussion on, 331 .

conservation of moisture, 97.

Convallaria majalis, 267, 275.

Convolvulus Japonicus and Sepium, 313.

corchorus, 298, 306.

coreopsis species, 275.

coriander, 460.

corn, sweet, 477.

corn salad, 477.

Cornus Baileyi, 46.

Cornus Mas, 51.

cornus species, 292, 294, 295.

corrosive sublimate for scab, 190.

Corydalis lutea, 269.

Corydalis nobilis, 267.

corylus species, 295.

costmary, 460.

cotoneaster, 222, 295, 365.

cottonwood, 326.

cowpea, 464.

coxcomb for bedding, 230 .

crab cactus, 359 .

crab trees, 327 .

cranberry, 423.

crape myrtle, 305 .

cratægus species, 295.

cress, 478 .

crocus, 368 .

crocus, fall blooming, 284.

Crosby, quoted, 198.

croton, 369.

crown-galls, 180. crown imperial, 289.

cryptomeria, 336.

cucumber, $458,478$.

cucumber diseases, 209.

cucumber insects, 201.

Cucumis Anguria, 479.

Cucumis fœtidissima (perennius), 309, 312.

Cucumis species, 311.

cucurbit insects, 201.

cultivating, 92.

cultivators, 95 .

Cuphea, 236, 344.

cupressus species, 333,336 .

curbing, 69.

curculio, 202, 441.

currant, 425.

currant, flowering, 300 .

currant, Indian, 304.

currant diseases, 209.

currant-worm, 203.

cuttings, 118.

cut-worms, 186, 203, 449.

cycas, $344,385$.

cyclamen, 370 .

Cydonia Japonica, 52, 295, 306.

Cydonia Maulei, 52, 295.

Cypress, bald, 329.

daffodil, 382.

dahlia, 370 .

Dahlia arborea or excelsa, 372.

daisy, 265.

dandelion, 479.

daphnes, 53, 295.

day-lily, 38.

delphiniums, 271, 275.

Desmodium Canadense, 264.

desmodium species, 298.

Deutzia gracilis, 53 .

deutzia species, 296, 306.

dewberry, culture of, 426 .

dewberry for banks, 216 .

dewberry insects, 205.

dianthus, 270, 275.

dibbers, 123, 124.

Dicentra spectabilis, 267, 276.

Dictamnus Fraxinella, 270.

diervillas, 296.

dill, 460.

dioscorea species, 313 . 
Dirca palustris, 296.

diseases of plants, 207.

ditching, 88.

dockmackie, 305.

Dodecatheon Meadia, 265.

dogs and gardens, 178 .

dog-tooth violet, 289 .

dogwoods, 294, 295, 330.

Dolichos Japonicus, 317.

dolichos, species, 464.

Donnell, Webb, quoted, 453.

doronicum, 265, 276.

doucin stocks, 409.

Dracæna fragrans, 344.

drainage of land, 88.

drainage of walks, 69 .

drives and walks, 67 .

dry bouquets, 245 .

Duggar, on mushrooms, 484.

dutchman's pipe, 317 .

dwarf fruit-trees, 409.

Easter lily, 346.

echeveria, 235.

Echinocystis lobata, 309.

egg-plant, 458, 480.

Egyptian lily, 360.

elæagnus species, 51, 296, 306.

elecampane, 263.

elm, 329, 330.

elm-leaf beetle, 204 .

emulsion, carbolic acid, 194; kerosene, 194.

endive, 481.

enemies of plants, 178.

enriching the land, 110.

Epimedium rubrum, 276.

epiphyllum, 344, 359.

Erianthus Ravennæ, 264.

Erigeron speciosus, 276.

Eulalia, 230, 264.

Euonymus, climbing, 309, 315.

Euonymus species, 296, 306.

Euphorbia, 344.

evergreens, discussion on, 331.

everlastings, 245 .

exochorda, 296, 306.

fagus species, 324 .

Falconer, Wm., quoted, 34, 261, 484.

Farfugium grande, 344 .
Fatsia Japonica and F. papyrifera, 230, 354.

fennel, 460 .

ferns, 372 .

fertilizing land, 110.

Fessenden, mentioned, 2.

Festuca glauca, 344.

fetter bush, 306.

Ficus elastica, 229, 344.

Ficus repens, 315 .

fig, 426.

filberts, 295, 433.

fir, 335.

flame flower, 272.

Fletcher, S. W., quoted, 431.

flower-garden in landscape, 27, 34, 225.

foliage in landscapes, 37, 218.

forcing-hill, 161.

forcing plants, 161.

forget-me-nots, 266.

formal gardens, 12.

formalin for scab, 190.

formal trees, 40 .

formulas for fungicides, 196; insecticides, 193.

Forsythia suspensa, 53, 216, 296 ; viridissima, $53,216,296,306$.

frames, 164.

fraxinus species, 324 .

freesia, 373.

fringe tree, 294, 305.

fritillary, 289.

fruit-buds, 141.

fruits, culture of, 408 .

fuchsia, 344,373 .

fumigating, 188.

fumitory, 267.

fungi and insects, 178.

fungicides, 196.

funkia, 38, 262, 271, 272, 276.

gaillardia, perennial, 270, 276 .

gardenia, 306.

Gardiner Hepburn, mentioned, 2.

garlic, 456, 481.

gas plant, 270.

gathering fruit, 414 .

Gelsemium sempervirens, 317.

Genista tinctoria, 297.

geranium, 374, 386.

gherkin, 479. 
ginkgo, 324, 330.

girdled trees, 144 .

gladiolus, 374 .

Gleditschia tricanthos, 325 .

gloxinia, 375 .

Goff device, 187.

goldenglow, 272, 280.

golden-rods, 264, 272, 280.

gooseberry, 427.

gooseberry disease, 209.

goumi, 296, 306.

gourds, ornamental, 310,312 .

grading, 61.

grafting, 151.

grafting-wax, 145.

grape, culture of, 428 .

grape diseases; 209.

grapery, 431.

grapes for ornament, 315.

grasses, ornamental, 245.

grass for lawns, 78 .

greenbrier, 315 .

greens, 459.

Greiver, T., quoted, 501.

Grevillea robusta, 344,376 .

ground-ivy, 309.

ground-nut, 313.

grub, white, 207, 449.

guards for trees, 143.

gum tree, $325,326$.

gunnera, 230,

gutters, 69 .

Gymnocladus Canadensis, 325.

Gypsophila paniculata, 276.

Halesia tetraptera, 52, 297.

Hamamelis Virginiana, 297.

handling the land, 87.

handling the plants, 115.

hand-box, 163.

hand tools, 101.

hand-weeders, 106.

hanging baskets, 348 .

harebells, 269 .

harrows, 94.

hazels, 295.

Hedera Helix, 315.

hedges, 220.

heeling-in, 135.

Helenium autumnale, 276.

helianthus species, 263, 271, 276. hellebore for insects, 193.

hemerocallis species, 277.

hemlock, 221, 335, 336.

Henderson, mentioned, 2.

hepaticas, 265.

herbaceous perennials, 260 .

Heuchera sanguinea, 270, 277.

Hibiscus Moscheutos, 262, 277.

Hibiscus Rosa-Sinensis, 305.

Hibiscus Syriacus, 297, 305.

hickories, 325, 433.

Hicks, Edward, quoted, 132.

hicoria species, 325 .

hippeastrum, 353.

hitching to trees, 144.

hoes, 101.

hollies, 297, 306.

hollyhock, 271, 376.

hollyhock rust, 210.

honey locust, 325 .

honeysuckles, 298, 306, 316.

Hop, 311, 313.

hop-tree, 299.

horehound, 460 .

hornbeam, 324, 326.

horseradish, 481.

hotbeds, 168.

house plants, 341 .

howea, 385.

hoya, 406.

Humulus Lupulus, 313.

Hunn, C. E., quoted, 454.

hyacinth, 377.

hydrangea, 291, 297, 306.

hydrocyanic acid gas, 189 .

hypericum species, 297.

hyssop, 460.

Iberis sempervirens, 265, 277.

ilex species, 297.

Illicium anisatum, 306.

immediate effect, 215 .

immortelles, 245.

inarching, 148.

Indian currant, 304.

insecticides, 193.

insects, remedies for, 198 .

insects and fungi, 178.

Inula Helenium, 263.

Ipomœa pandurata, 313.

Ipomœa Quamoclit, 311. 
iris, 264, 267, 270, 277, 278, 378.

iron-wood, 326.

Isolepis gracilis, 344 .

ivy, Boston, Japanese, 314.

ivy, parlor, 340 (see Senecio).

ivy, true, 315.

jasmines, 317, 344.

jasminum species, 306, 317.

Jerusalem artichoke, 463.

jessamine, 317 .

jonquil, 383.

Judas tree, 324.

juglans species, 325 .

June-grass, 78.

juniper species, 333, 334.

kainit, 163.

kale, 457, 482.

Kalmia latifolia, 297.

katsura-tree, 324 .

keeping fruit, 158, 414.

Kenilworth ivy, 313, 340, 344.

kentia, 385.

kerosene emulsion, 194.

kerria, 298, 306.

kitchen-garden, 454.

Kniphofia aloides, 272.

Kœlreuteria paniculata, 325, 330.

kudzu vine, 317.

labels, 154.

lady-birds, 199.

lagenaria, 311.

Lagerstromia Indica, 305.

land, handling, 87.

larch, 325 .

larix species, 325 .

latania, 385.

Lathyrus latifolius, 311.

laurel, cherry, 306, 330 .

laurel, great, 299, 391 .

laurel, mountain, 297.

laurel, true, 306.

Laurus nobilis, 306.

lavender, 460.

lawn, making, 77.

lawns, treatment, 82.

leaf cuttings, 120.

leatherwood, 296.

leek, 456, 483.
Leiophyllum buxifolium, 298.

lespedeza species, 298 .

lettuce, 483 .

lettuce disease, 210.

Liatris spicata, 270.

Libocedrus decurrens, 336.

ligustrum species, 298.

lilac species, 304 .

liliums, 278, 284, 378, 285.

lily-of-the-valley, 86, 267, 275, 381.

lima beans, 464 .

lime and sulfur wash, 195, 539 .

Linaria Cymbalaria, 313.

linden, 329, 330.

Lindera Benzoin, 293.

Linum perenne, 278.

Liquidambar styraciflua, 325, 330.

Liriodendron Tulipifera, 325.

live-oak, 330 .

liver of sulfur, 197.

liver-leaf, 265.

lizard's tail, 264.

Lobelia cardinalis, $272,278$.

lobster cactus, 359 .

locust, 328.

locust, honey, 221, 325.

Lombardy poplar, 40.

Long, E. A., quoted, 223.

Lonicera Halliana, 53, 216.

lonicera species, $298,316$.

loose-strife, 264.

lotus, 230 .

lovage, 460.

luffa, 311 .

Lychnis alpina, 265.

Lychnis Chalcedonica, 278.

Lychnis Coronaria, 274.

Lychnis Viscaria, 271.

Lycium Chinense, 315.

lycoris, 283.

Lysimachia clethroides, 278.

Lysimachia nummularia, 86, 309.

Lythrum Salicaria, 264.

madeira vine, 313,344 .

maggots of cabbage, 187, 201.

magnolias, 306, 325, 330 .

Mahernia odorata, 344, 345 .

mahonia, 293, 306.

maidenhair tree, 324 .

maize, striped, 230. 
mallow, rose, 262.

M'Mahon, mentioned, 2.

manure for hotbeds, 169 .

maples, 322, 323, 330.

marguerite carnations, 363.

marguerite chrysanthemum, 365.

marjoram, 460.

markers, 108.

marshplants, 230.

Mathews, Schuyler, picture by, 31 . matrimony vine, 315 .

mats, making, 176.

matthiolas, 402.

Melia Azederach, 330.

melon, 458, 487, 499.

melon disease, 210.

melon insects, 201.

Menispermum Canadense, 317.

Mertensia Virginica, 266.

Mesembryanthemum, 309, 344.

mice injury, 144.

mignonette, 381.

mignonette vine, 313 .

mikania, 313.

miscanthus, 264.

miscible oils, 194.

$[306,330$.

mock orange, 298, 306 ; of South, 221,

mite, black or spotted, 205 .

moisture, saving, 97.

moles, 178.

Momordica, 311.

Monarda didyma, 271.

moneywort, 86, 309, 340 (see lysimachia).

Monterey cypress, 220.

monthly advice, 501 .

moon-flower, 313, 381.

moonseed, 317.

morning-glory, perennial, 313.

morus species, 326 .

mounding-up trees, 136.

mountain ash, 329.

mountain laurel, 297.

moving large trees, 130 .

muck, 111.

Mucune utilis, 311.

Muehlenbeckia, 318, 344.

mulberry, 326, 330, 432 .

mulberry, French, 305.

mulching plants, 136.

muriate of potash, 111, 113.
Musa Ensete, 229.

mushrooms, 484.

muskmelon, 487.

muskmelon disease, 210.

mustard, 487.

myosotis, 266, 278.

myriophyllum, 231, 349.

myrtle, running, 86, 315 .

myrtle, true, 306 .

Myrtus communis, 306.

narcissus, 382 .

negundo, 323.

Nepeta Glechoma, 309.

Nephrolepis exaltata, $340,372$.

Nettle tree, 324 .

Nicotiana, 38.

night-blooming cereus, 358 .

nine-bark, 298.

nitrate of soda, 112, 113.

nitrogen, 112.

nozzles, 192.

nuts, 433.

Nyssa sylvatica, 326.

oaks, $328,330$.

odd plants, 40 .

Enothera Missouriensis, 278.

oil insecticides, 194.

okra, 488.

old-fashioned gardens, 32, 34 .

Olea fragrans, 306.

oleander, 306, 383.

oleaster, 296.

onion, $456,488$.

opuntia, 359.

orange, culture of, 433.

Orontium aquaticum, 264.

osage orange, 221.

osiers, 294, 295.

Osmanthus fragrans, 306.

Ostrya Virginica, 326.

oxalis, 384 .

oxalis for window-gardens, 344.

Oxalis tropæoloides, 235.

Oxydendrum arboreum, 326, 330.

oyster plant, 494.

oyster-shell scale, 204.

pæonia: see peony.

palmettoes, 306 . 
palms, 306, 384.

palms for South, 306 .

pampas-grass, 230.

pandanus, 344, 385.

Panicum virgatum, 264.

pansy, culture of, 386 .

papavers, 270,279 .

paper-white narcissus, 289, 383.

papyrus, 232.

Paradisea Liliastrum, 269.

paradise stocks, 409.

paris green formula, 193.

parrot's feather, 231, 349 .

parsley, 490.

parsnip, 456, 490.

Passiflora incarnata, 312.

passiflora species, 316 .

paulownia, 330 .

pavia, 293.

pea, 459,490 .

peach, culture of, 435 .

peach diseases, 210.

pear, culture of, 437.

pear diseases, 211.

pear insects, 205.

pea-trees, 294.

pecan, 325, 433.

pelargonium, 386 .

Pelargonium peltatum, 308.

Peltandra undulata, 264. pennisetum, 230, plate $\mathbf{v}$.

pennyroyal, 460.

pentstemon, 270, 272, 279.

peony, $267,269,279,387$.

peppermint, 460 .

pepperidge, 326 .

pepper, red, 458, 490.

perennials, cultivation of, 260 .

Periploca Græca, 216, 317.

periwinkle, 86, 309, 315.

Phalaris arundinacea, 264.

Phaseolus multiflorus, 311, 313, 464. phaseolus species, 464 .

Philadelphus coronarius and grandi-

florus, 51 .

philadelphus species, 298, 306.

phillyreas, 306.

phlox, culture of, 388 .

phlox, perennial, 271, 279.

Phlox subulata, 267, 279.

phœnix, 385. phosphoric acid, 112, 113.

photographing landscapes, 12.

Phragmites communis, 264.

physocarpus, 298.

picea species, 334, 335.

picture in landscape, 12, 58 .

pie plant, 493.

Pieris floribunda, 299, 306 (Andromeda).

Pilea arborea, 344.

pine, $334,335,336$.

pinks, 270.

pinus species, 334, 335, 336.

Pittosporum, 306, 344.

plane-tree, $326,330$.

plan of grounds, 8 .

plant diseases, 207.

plant-lice, 198.

platanus species, 326 .

platycodon grandiflorum, 272, 279.

plows, 93.

Plumbago Capensis, 306.

plum, culture of, 439 .

plum, diseases, $211,440$.

plum, ornamental, 327.

Poa compressa, 78; pratensis, 78; trivialis, 79 .

podocarpus, 336 .

poinsettia, 306 .

polemoniums, 279.

Polianthes tuberosa, 404.

polyanthus, 389 .

polygonums, $263,317$.

pomegranate, 306 .

poplar, 41, 218, 326, 327.

poppy, Iceland, 270, 279.

Populus Bolleana, 218, 327.

populus species, 326,327 .

Populus tremuloides, 42.

potash salts, 111, 113.

potassium sulfide, 197.

potato, culture, 492 .

potato diseases, 212.

potato insects, 205.

potato scab, 190, 212.

potato vine, 317 .

Potentilla fruticosa, 299.

Potentilla hybrida, 279 .

pot-herbs, 459.

prickly ash, 305 .

Primula Auricula, 354. 
Primula cortusoides, 280.

primulas, 389 .

privets, 298, 306.

propagating, 116, 118.

protecting in winter, 135.

Pruning, 139, 142, 149, 411. pruning at transplanting, 129 .

Prunus Caroliniana, 221, 306, 330.

Prunus Laurocerasius, 306.

prunus species, 299, 327.

Pseudotsuga Douglasii, 335.

psylla, 205.

Ptelea trifoliata, 299.

pteris, 373.

Pueraria Thunbergiana, 317.

pumpkin, 458, 496.

pumps, 183, 185.

pyracantha, 221, 292, 306.

pyrethrum, 272, 280.

pyrus, species, 327.

quercus species, $320,328,330$.

quince, culture of, 442 .

rabbit injury, 144.

radish, 493.

railroad-worm, 199.

rainfall, saving, 97.

raspberry, culture of, 443.

raspberry diseases, 212.

raspberry insects, 205.

ravenna grass, 264.

records of plantation, 154.

red-bud, 324.

red pepper, 458, 490 .

red spider, 205.

red-top, 79.

removing large trees, 130.

repairing trees, 145 .

retinosporas, 220, 221, 333, 336.

rhamnus species, 299.

rhododendron, 390.

rhododendron species, 299, 306.

Rhodotypos kerrioides, 299, 306.

rhubarb, 493.

rhubarb, forcing, 162.

rhubarb for ornament, 39.

Rhus Cotinus, 291, 299, 306.

rhus species, 299, 300.

Rhynchospermum jasminoides, 317 .

Ribes aureum, 53.
Ribes sanguineum, 53.

ribes species, 300 .

richardia, 360 .

ricinus, 230.

rill "improved," 24.

Roberts, mentioned, 87, 93.

robinia species, $300,306,328$.

rockeries, 232.

rollers, 108.

root-crops, 456 .

root cuttings, 118.

root-galls, 180 .

Rosa rugosa, 37, 221, 292, 300.

rosa species, $300,301,318$.

Rosa Wichuraiana, 216, 309.

rose acacia, 300 .

rose, culture of, 391 .

rose diseases, 213.

rose insects, 205.

rosemary, 460.

roses, climbing, 318.

roses in landscapes, 37 .

rows, to make straight, 127.

Rubus cratægifolius, $35,206,301$.

Rubus fruticosus, 53 .

Rubus laciniatus, 53, 309.

Rubus odoratus, 45, 46, 301.

Rubus phœnicolasius, 53, 301.

Rudbeckia laciniata, 272, 280.

Rudbeckia maxima, 271, 280.

Ruscus aculeatus, 306.

Russelia juncea, 344.

rutabaga, 498.

rye-grass, 80 .

sacaline, 216, 263.

sage, 460 .

salad plants, 459 .

Salisburia adiantifolia, 324 .

Salix laurifolia, 219, 301, 329 .

salix species, 301, 328, 329 .

salsify, 456, 494 .

salvia, perennial, 37 .

Salvia pratensis, 269.

Sambucus species, 291, 302.

Sanguinaria Canadensis, 265.

San José scale, 206.

Santolina Chamæcyparissus, 236.

sassafras, 329.

Saururus cernuus, 264.

saving of moisture, 97 . 
savory, 460.

Saxifraga peltata, 262.

Saxifraga sarmentosa, 344 .

Sayers, mentioned, 2.

Scabiosa Caucasica, 280.

scab on potatoes, 190 .

scale, San José, 206.

scarifiers, 105.

Schenley park, 34.

Schizophragma hydrangeoides, 309, 316.

school-grounds, 11.

scilla, 283, 289.

screens for wind, 219.

screen to protect against insects, 186 .

screw pine, 344, 385.

scrubbing trees, 414.

scuppernong, 315 .

sea-kale, 495.

sedges for bogs, 232.

sedum, 340 .

seed-beds, 117.

seedlings, transplanting, 122.

seed-sowing, 116.

Selaginella denticulata, 344 .

sempervivum, 235.

Senecio macroglossus and mikanioides,

$340,344$.

senna, wild, 264.

service-tree, 329.

shearing, 140.

shelter-belts, 219.

she-oak, 376.

shepherdia species, 302 .

shrubs, list of, 292.

shrubs, pruning, 140.

shrubs for the South, 305.

Sicyos angrulata, 309.

silk vine, :17.

Simonds, O. C., quoted, 69.

Slingerland, quoted, 198.

smilax (florists'), 340, 401.

smilax species, 315 .

Smith, H. W., quoted, 501.

Swith and Townsend, quoted, 180.

snıoke-tree, 299, 306.

snowball, 304, 306.

snow-berry, 304, 306.

snowdrop, 281, 288.

snowflake, 289.

st ap insecticides, 194.
Socrates, 2.

sod-cutter, 73.

sodding, 84 .

soil, handling, 87.

soil mulch, 98.

Solanum Dulcamara, 216, 315.

Solanum jasminoides, 317.

solidagos, 264, 272, 280.

Sophora Japonica, 330.

Sorbus species, 329 .

sorrel, 495.

sorrel-tree, 326.

sourwood, 326.

South Carolina, rock, 112.

sowing the seeds, 116.

sparrows, poisoning, 18.

Spartium junceum, 306.

spearmint, 460, 495.

spider, red, 205.

spinach, 495.

Spiræa Aruncus, 264, 280.

spireas, 221, 264, 280, 298, 302, 306.

spraying, 190.

spring beauty, 265 .

spruce, 221, 334, 335.

spuds, 107.

squash, 458, 496.

squash insects, 201, 459.

squill, $283,288$.

stake labels, 155.

staphylea species, 302, 303.

Statice latifolia, 280.

stem cuttings, 118.

Sterculia platanifolia, 330 .

stevia, 344 .

Stewart, quoted, 207.

stink-bug, 202, 459.

St. John's wort, 297.

stocks, 402.

storing of fruits and vegetables, 158, 414,475 .

strawberry, culture of, 445 .

strawberry disease, $213,449$.

strawberry tree, 306.

streams, treatment of, $24,58,65$, 232.

street trees, repairing, 145.

strychnine for sparrows, 18 .

Stuartia pentagyna, 306.

styrax, 303.

subsoiling, 90. 
subtropical gardening, mentioned, 7, 229.

sulfate of potash, 111, 113 .

sulfide of potassium, 197.

sulfur as fungicide, 197.

sumac, 299, 300.

sunflowers, wild, 263, 271.

sunken fence, 66 .

surgery, 142.

swainsona, 344, 403.

sweet-flag, 232.

sweet gum, 325, 330.

sweet-herbs, 460 .

sweet pea, culture of, 403 .

sweet potato, 496 .

Swiss chard, 475.

symphoricarpos species, 304, 306.

Symphoricarpus vulgaris, 53.

syringa, 298, 304.

syringe, 183.

tacsonia, 316.

tallies, 156.

tamarack, 325 .

tamarisk (tamarix), 221, 291, 304.

tankage, 112.

tanks for aquatics, 230.

tansy, 460.

Tarryer, tools, 103.

Taxodium distichum, 329.

taxus species, $334,336$.

Taylor, A. D., quoted, 145.

tecoma species, 314 .

tennis-screen, 55.

tent-caterpillar, 206, 417.

terracas, 62.

Thalictrum aquilegifolium, 280.

Thermopsis, mollis, 264.

thinning fruit, 412.

three guardsmen, 25.

Thuja occidentalis, 333, 336.

thyme, 460.

Thymus argenteus, 235.

tilia species, 329 .

tilling, 92 .

tobacco insecticide, 194.

tomato, 458, 497.

tomato disease, 213.

Townsend and Smith, quoted, 180.

Trachelospermum jasminoides, 317 .

Tracy's garden plan, 452. tradescantia, 340.

transplanting young plants, 122 ; old plants, 124.

tree guards, 143.

Trees, lists and discussion, 319, 331 .

trees, moving large, 130.

tree surgery, 142.

trenching, 89, 90.

trichosanthes, 311 .

trilliums, 267.

trimming, 140.

Tritoma Usaria, 272.

Trollis Europæus, 281.

Tropæolium peregrinum, 310.

trowels, 106.

trumpet creeper, 216, 314.

tsuga species, 335, 336.

tuberose, 404.

tubers, culture of, 281.

tub-plants, transplanting, 125.

tulips, culture of, 405 .

tulip tree, $325,330$.

turnip, 498.

Tussilago Farfara, 216.

typhas, 264.

Ulmaria Filipendula, 271, 280.

ulmus species, $329,330$.

umbrella plant, 232 .

umbrella tree, 330 .

varnish-tree, 325 .

vegetables, culture of, 451 .

vegetable oyster, 494 .

viburnum species, 304, 305, 306.

vigna, 464.

vinca major, 315 .

Vinca minor, 86, 315, 340 (see periwinkle, myrtle).

vines, 307.

violet, culture of 406 .

violet insect, 206.

violets, fumigating, 190 .

virgilia, 324.

Virginia creeper, 216, 308, 309, 314.

Vitex Agnus-Castus, 306.

vitis species, 315 .

Walker, E., quoted, 234, 265.

walks and drives, 67.

walnut, 325,433 . 
wandering jew, 340, 344.

washing trees, 414.

water cress, 478 .

watering hotbeds, 175 .

watering house plants, 347 .

watering land, 100.

water-lilies, 230.

watermelon, 499.

wax for grafting, 145.

wax-plant, 406.

wax-work, 317.

weeders, 95, 106.

weed-spuds, 107.

weeping trees, 40 .

weigela, kinds, 296, 306.

well about a tree, 66 .

wheel-hoes, 96.

Whetzel, quoted, 207.

white-fly, 207.

white grub, 207, 449.

white hellebore, 193.

wigandia, 230.

willows, 41, 219.

willow, species of, $301,328,329$.

windbreaks, 219.

wind-flowers, 264, 265, 269, 273, 274,

353. window-boxes, 337.

window-gardens, 336.

winter aconite, 289.

winter protection, 135.

wires, injury by, 149.

wire-vine, 318.

wistaria, 316.

witch hazel, 297.

witloof, 476.

wood ashes, 111.

woodbine, 316.

woodruff, 269.

wormwood, 460 .

wormwood, wild, 263.

Xanthoceras, 305.

Yams, ornamental, 313.

yellows, 211.

yew, 334, 336.

Yucca filamentosa, 262, 271.

Yuccas, shrubby, 306.

zamia, 306.

Zanthoxylum Americanum, 305.

zebra grass, 264.

Zizania aquatica, 264.

\section{ADDENDUM}

FolLowing are the recent formulas and advice for lime-sulfur preparations, comprising the concentrated and the self-boiled (continued, in this edition, from p. 195). These formulas are likely to be modified somewhat by further studies.

The home-made lime-sulfur is prepared as follows (J. P. Stewart's formula) : $50 \mathrm{lb}$. best stone lime (90-95\% calcium oxide); $100 \mathrm{lb}$. sulfur (powdered commercial, 99 $\frac{1}{2} \%$ pure); water to make 50 to 55 gal. total product at finish. Put 10 gal. of water in kettle and start fire. Place lime in kettle. After slaking is well started, add the dry sulfur and mix thoroughly, adding water enough to maintain a thin paste, which requires about, 5 gallons. After slaking and mixing are completed, add water to make about 50 gallons, bring to a boil, and stir until the sulfury scum practically disappears; then add water to make about 60 gallons and boil down to 50 or 55 gallons. The material 
should be kept well stirred, especially during the early stages of the process. The boiling should continue until the sulfur granules are evidently dissolved, generally 40 to 60 minutes. Pour or strain the clear liquid into a barrel or other storage vessel that can be completely filled or corked, and cut off air contact with a thin layer of paraffin oil, or any other heavy oil, to prevent formation of crystals.

To test the concentration of the commercial and the home-made solutions, secure a Beaumé hydrometer at the drug store, with a range of 25 to 35 degrees. In testing the solution, pour some of the clear reddish liquid into any deep receptacle, deeper than the lydrometer is long, and when full gently drop the instrument into the solution and wait until it comes to rest. Then read on the hydrometer the degree of concentration, which will be the one just at the surface of the liquid. When the degree of concentration of the solution is known, the proper dilution may be obtained by referring to the following figures:

Degree on $\mathrm{Hy}$ DROMETER
Gallons of Water to One Gallon of the Lime-sulfur

\begin{tabular}{c|c|c|c|c}
\hline & $\begin{array}{c}\text { For San José, } \\
\text { Dormant Trees }\end{array}$ & $\begin{array}{c}\text { For Blister Mite, } \\
\text { Dormant Trees }\end{array}$ & $\begin{array}{c}\text { Leaf-curl, Dor- } \\
\text { mant Trees }\end{array}$ & $\begin{array}{c}\text { Summer Spray of } \\
\text { Apple, Pear, } \\
\text { Cherry }\end{array}$ \\
\cline { 2 - 4 } 25 & $5 \frac{1}{2}$ & $7 \frac{1}{2}$ & 11 & 31 \\
26 & $5 \frac{3}{4}$ & $7 \frac{3}{4}$ & 12 & $32 \frac{1}{2}$ \\
27 & 6 & $8 \frac{1}{4}$ & $12 \frac{1}{2}$ & $33 \frac{1}{2}$ \\
28 & $6 \frac{1}{2}$ & $8 \frac{3}{4}$ & 13 & 35 \\
29 & $6 \frac{3}{4}$ & 9 & $13 \frac{1}{2}$ & 36 \\
30 & 7 & $9 \frac{1}{2}$ & 14 & $37 \frac{1}{2}$ \\
31 & $7 \frac{1}{2}$ & 10 & $14 \frac{1}{2}$ & 39 \\
32 & $7 \frac{3}{4}$ & $10 \frac{1}{2}$ & 15 & 40 \\
33 & 8 & 11 & $15 \frac{1}{2}$ & 41 \\
34 & $8 \frac{1}{2}$ & $11 \frac{1}{2}$ & 16 & $42 \frac{1}{2}$ \\
35 & 9 & 12 & $16 \frac{1}{2}$ & $43 \frac{1}{2}$ \\
\hline
\end{tabular}

The usual or average strength of these concentrated lime-sulfurs is about $32^{\circ}$; for dormant trees, a 1-10 dilution is usual, and for trees 
in foliage a 1-40 to 1-50 solution. It is safer, however, to use the hydrometer and make a more careful dilution.

Self-boiled lime-sulfur (Scott's). - This is not a water-boiled solution, as might be inferred from the name, but a mechanical mixture resulting from the heating and bubbling of the slaking lime, with but little sulfur in solution; it is therefore specially adapted to spraying of peaches and plums in foliage, for it causes no injury. It is prepared by placing in a barrel $8 \mathrm{lb}$. best stone lime to which is added a small quantity of cold water to start the slaking. Eight pounds of sulfur worked through a sieve to break up the lumps is then added slowly to the slaking lime, which is kept from burning by the addition of just enough cold water so as not to drown it. The slaking mixture must be stirred constantly. Just as soon as the slaking is completed (which should be in 5 to 15 minutes) fill the barrel with cold water (50 gal.). The mixture is strained into the sprayer tank through a sieve of 20 meshes to the inch. It must be agitated constantly while being applied, as it settles rapidly. Arsenate of lead may be added to this mixture, as to bordeaux. 

THE following pages contain advertisements of a few Macmillan books by the same author 



\title{
Cyclopedia of American Agriculture
}

\author{
Edited By L. H. BAILEY
}

Director of the College of Agriculture and Professor of Rural Economy, Cornell University.

With I0o full-page plates and more than 2000 illus. trations in the text; four volumes; the set, \$20.00 net; half morocco, $\$ 32.00$ net; carriage extra

Volume I - Farms Volume III - Animals

Volume II - Crops Volume IV - The Farm and the Community

"Indispensable to public and reference libraries ... readily comprehensible to any person of average education." - The Nation.

"The completest existing thesaurus of up-to-date facts and opinions on modern agricultural methods. It is safe to say that many years must pass before it can be surpassed in comprehensiveness, accuracy, practical value, and mechanical excellence. It ought to be in every library in the country." - Record-Herald, Chicago.

\section{Cyclopedia of American Horticulture}

\section{Edited By L. H. BAILEY}

With over 2800 original engravings; four volumes; the set, \$20.00 net; half morocco, \$32.00 net; carriage extra

"This really monumental performance will take rank as a standard in its class. Illustrations and text are admirable. ... Our own conviction is that while the future may bring forth amplified editions of the work, it will probably never be superseded. Recognizing its importance, the publishers have given it faultless form. The typography leaves nothing to be desired, the paper is calculated to stand wear and tear, and the work is at once handsomely and attractively bound." - Ner" York Daily Tribune.

PUBLISHED BY

\section{THE MACMILLAN COMPANY}

64-66 Fifth Avenue, New York 


\section{BOOKS ON AGRICULTURE}

On Selection of Land, etc.

Thomas F. Hunt's How to Choose a Farm

E. W. Hilgard's Soils : Their Formation and Relations to Climate and

$\$ 75$ net Plant Growth

Isaac P. Roberts's The Farmstead

On Tillage, etc.

F. H. King's The Soil

Isaac P. Roberts's The Fertility of the Land

Elwood Mead's Irrigation Institutions • .

F. H. King's Irrigation and Drainage $\quad$.

William E. Smythe's The Conquest of Arid America

Edward B. Voorhees's Fertilizers .

Edward B. Voorhees's Forage Crops

H. Snyder's Chemistry of Plant and Animal Life

H. Snyder's Soil and Fertilizers. Third edition

L. H. Bailey's Principles of Agriculture

W. C. Welborn's Elements of Agriculture, Southern and Western .

J. F. Duggar's Agriculture for Southern Schools

G. F. Warren's Elements of Agriculture

T. L. Lyon and E. O. Fippin's The Principles of Soil Management .

Hilgard \& Osterhout's Agriculture for Schools on the Pacific Slope

J. A. Widtsoe's Dry Farming

\section{On Garden-Making}

L. H. Bailey's Manual of Gardening

L. H. Bailey's Vegetable-Gardening

L. H. Bailey's Horticulturist's Rule Book

L. H. Bailey's Forcing Book

A. French's How to Grow Vegetables

On Fruit-Growing, etc.

L. H. Bailey's Nursery Book

L. H. Bailey's Fruit-Growing

L. H. Bailey's The Pruning Book

F. W. Card's Bush Fruits

J. T. Bealby's Fruit Ranching in British Columbia

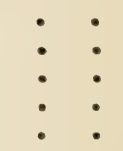

200 net

I 50 net

75 net

I 25 net

I 75 net

I 50 net
I 50 net

I 25 net

I 50 net

I 50 net

I 25 net

I 50 net

I 25 net

I 25 net

I 25 net

75 net

75 net

I Io net

I 75 net

I oo net

I 50 net

\section{On the Care of Live Stock}

D. E. Lyon's How to Keep Bees for Profit . Nelson S. Mayo's The Diseases of Animals W. H. Jordan's The Feeding of Animals . I. P. Roberts's The Horse

George C. Watson's Farm Poultry

C. S. Valentine's How to Keep Hens for Profit .

O. Kellner's The Scientific Feeding of Animals (trans.)

M. H. Reynolds's Veterinary Studies for Agricultural Students

I 50 net

I 50 net

I 50 net

I 50 net

I $50 \mathrm{ne}$. 


\section{BOOKS ON AGRICULTURE-Continued}

\section{On Dairy Work}

Henry H. Wing's Milk and its Products . . . . . . . \$I 50 net

C. M. Aikman's Milk

Harry Snyder's Dairy Chemistry

W. D. Frost's Laboratory Guide in Elementary Bacteriology .

I 25 net

I oo net

I 60 net

I. P. Sheldon's The Farm and the Dairy . • • • • • •

I $\infty$ net

Chr. Barthel's Methods Used in the Examination of Milk and Dairy Products

On Plant Diseases, etc.

George Massee's Plant Diseases

E. C. Lodeman's The Spraying of Plants

H. M. Ward's Disease in Plants (English)

A. S. Packard's A Text-book on Entomology

$\geq 90 \mathrm{ne}^{2}$

\section{On Production of New Plants}

L. H. Bailey's Plant-Breeding • • • • • • • • . I 25 net

L. H. Bailey's The Survival of the Unlike . • . • • . . 200 net

L. H. Bailey's The Evolution of Our Native Fruits . • • . . 2 oo net

W. S. Harwood's New Creations in Plant Life • • • • • $~ I 75$ net

\section{On Economics and Organization}

J. McLennan's Manual of Practical Farming . . . • . . I 50 net

L. H. Bailey's The State and the Farmer • • • • • • . I 25 net

Henry C. Taylor's Agricultural Economics . • • • . . I 25 net

I. P. Roberts's The Farmer's Business Handbook • • • • . I 25 net

George T. Fairchild's Rural Wealth and Welfare . • • • • I 25 net

S. E. Sparling's Business Organization . . . • • • . I 25 net

In the Citizen's Library. Includes a chapter on Farming

Kate V. St. Maur's A Self-supporting Home

Kate V. St Maur's The Farth's Bounty

G. F. Warren and K. C I ivermore's Exercises in Farm

H. N. Ogden's Rural Hygiene . . . . . . • . . I 50 net

\section{On Everything Agricultural}

L. H. Bailey's Cyclopedia of American Agriculture:

Vol. I. Farms, Climates, and Soils. Vol. III. Farm Animals.

Vol. II. Farm Crops.

Vol. IV. The Farm and the Commun.ts

Complete in four royal 8 vo volumes, with over 2000 illustrations.

Price of sets : cloth, $\$ 20$ net; half-morocco, $\$ 32$ net.

For further information as to any of the above, address the publisher. 


\section{OF INTEREST TO ANY GARDENER}

\section{A Woman's Hardy Garden}

By HELENA R. ELY Illustrated Cloth I 2 mo \$I.75 nei

"Mrs. Ely gives copious details of the cost of plants, the exact dates of planting, the number of plants required in a given space for beauty of effect and advantage to free growth, the protection needed from sun and frost, the precautions to take against injury from insects, the satisfaction to be expected from different varieties of plants in the matter of luxuriant bloom and length of time for blossoming, and much information to be appreciated only by those who have raised a healthy garden by the slow teachings of personal experience." - New York 'Times.

\section{Another Hardy Garden Book}

By HELENA R. ELY Illustrated Cloth I 2 mo \$I.75 net

"The great value of 'Another Hardy Garden Book' lies in the fact that it deals with the conditions of soil and climate to be found in this part of the country, it narrates actual experiences in a garden not so far beyond the average city dweller as to discourage him, and it gives just the advice and information needed by the amateur gardener of moderate means and limited responsibilities." - Philadelphia Ledger.

\section{A Self-Supporting Home}

BY KATE V. SAINT MAUR

Illustrated Cloth. I2mo \$I.75 net

"An interesting narrative and a very handy and practical guide to life in the country on the basis of a small income. The common-sense practicality which gives the book its value, is attributable to the fact that these are actual experiences described here." - The Richmond Times-Despatch.

\section{The Earth's Bounty}

BY KATE V. SAINT MAUR

Illustrated Cloth I2mo \$I.75 net

“After reading Mrs. Saint Maur's clever book one feels a longing for the healthful simplicity of the country life and the rewards that it holds out to human thrift and industry. The book is full of practical, accurate business information which should make it invaluable to any one anxious to try farming for profit." - Philadelphia Ledger.

\section{A Book of Vegetables and Garden Herbs} BY ALLEN FRENCH

Illustrated Cloth I2mo \$I.75 net

PUBLISHED BY

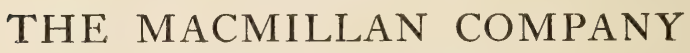

64-66 Fifth Avenue, New York 



$$
\text { - }
$$







\section{LIBRARY OF CONGRESS}

||||||||||||||||||||||||||||||||||||||||||

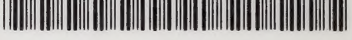

0000926?645 